\title{
Die Begegnung mit Fremden und das Geschichtsbewusstsein
}

Herausgegeben von

Judith Becker und Bettina Braun

Vandenhoeck $\&$ Ruprecht

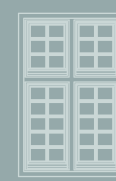

筆

眐

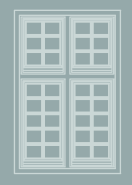

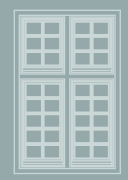
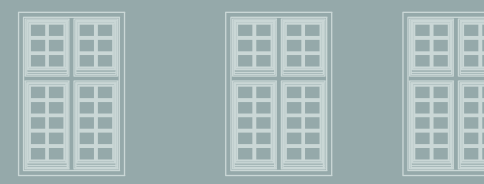

\section{垔五}
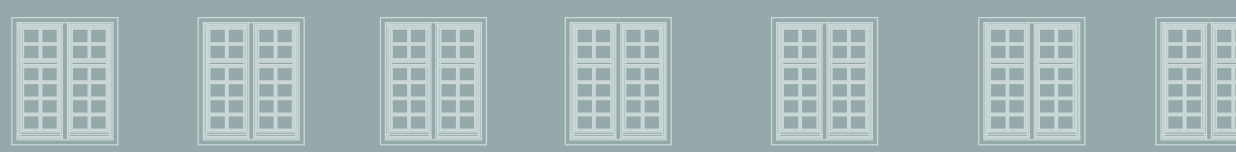

\section{塸}
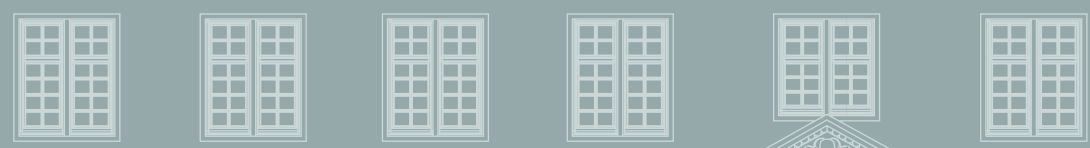

垔吾
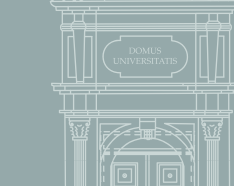


\section{VGR}

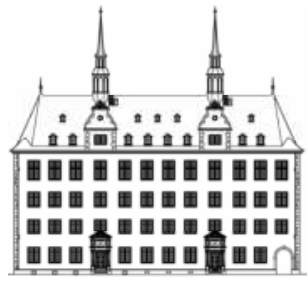




\title{
Veröffentlichungen des Instituts für Europäische Geschichte Mainz
}

\author{
Abteilung für Abendländische Religionsgeschichte \\ Abteilung für Universalgeschichte \\ Herausgegeben von Irene Dingel und Johannes Paulmann
}

Beiheft 88

Vandenhoeck \& Ruprecht 


\section{Die Begegnung mit Fremden und das Geschichtsbewusstsein}

Herausgegeben von

Judith Becker und Bettina Braun

Vandenhoeck \& Ruprecht 
Mit 12 Abbildungen

Bibliografische Information der Deutschen Nationalbibliothek

Die Deutsche Nationalbibliothek verzeichnet diese Publikation in der Deutschen Nationalbibliografie; detaillierte bibliografische Daten sind im Internet über http://dnb.d-nb.de abrufbar.

ISBN (Print) 978-3-525-10112-4

ISBN (OA) 978-3-666-10112-0

https://doi.org/10.13109/9783666101120

(c) 2012, Vandenhoeck \& Ruprecht GmbH \& Co. KG, Göttingen / Vandenhoeck \& Ruprecht LLC, Bristol, CT, U.S.A.

www.v-r.de

Dieses Material steht unter der Creative-Commons-Lizenz Namensnennung - Nicht kommerziell - Keine Bearbeitungen 4.0 International. Um eine Kopie dieser Lizenz zu sehen, besuchen Sie http://creativecommons.org/licenses/by-nc-nd/4.0/.

Satz: Vanessa Brabsche

Gesamtherstellung: $\oplus$ Hubert \& Co, Göttingen 


\section{Inhalt}

Judith Becker/Bettina Braun

Die Begegnung mit Fremden und das Geschichtsbewusstsein -

Einleitung

\section{GRUNDSATZREFERATE}

Rudolf Stichweh

Die Begegnung mit Fremden und die Selbstbeobachtung von

Gesellschaften

Theo Sundermeier

Die Begegnung mit dem Fremden.

Plädoyer für eine Hermeneutik des Vertrauens

Walter Jaeschke

Vom ruhigen Ufer der Selbstsucht zur Selbsterkenntnis des Geistes. Hegel über die konstitutive Funktion des Fremden für die Entstehung von Geschichtsbewusstsein

\section{Der Fremde IM EIGENEN LAND}

Maret Keller

Geschichte und aktueller Status der indigenen Andenbevölkerung in den Chroniken Martín de Murúas (1616) und Felipe Guaman Poma de Ayalas (1615)

Anja Bröchler

Bilder/Schreiben/Geschichte: Tlatelolcos zukünftige Vergangenheit.

Indigene Geschichtsschreibung über die Eroberung Mexikos im

16. Jahrhundert

Perry Johansson

Recovering History in China. War, Sinology, Sources

Eno Blankson Ikpe

Those Obnoxious Cultures. European Encounters with

Ibibio People of Eastern Nigeria 1850-1960 


\section{FREMD IM ANDEREN LAND}

Viviane Rosen-Prest

Willkommene Fremde? Zwei Jahrhunderte Geschichtsschreibung über Hugenotten im deutschen Refuge (17.-19. Jahrhundert)

Carsten Schliwski

Joseph ha-Kohen (1496-1577) als Historiograph im Exil

Kerstin Armborst-Weihs

Westjüdische Wahrnehmungen jüdischer Lebenswelten im Osten

Judith Becker

Die Christianisierung fremder Völker - ein Zeichen für die nahende Endzeit?

\section{Rezeptionen von ERfahrungen mit Fremden}

Felix Wiedemann

Zwischen Völkerflut und Heroismus. Zur Repräsentation der Beduinen in kulturhistorischen Deutungen des Vorderen Orients um 1900

Jeffrey Jaynes

African Christians - Christians Visiting Africa.

The Early Modern Narrative Cosmographies from Breydenbach to al-hassan Ibn Muhammad al-Wazzan (Leo Africanus)

Simon Mills

The Chaplains to the English Levant Company. Exploration and Biblical Scholarship in Seventeenth- and Eighteenth-Century England

Dominik Collet

Fremde Dinge. Die Exotika früher Museen und das europäische

Geschichtsbewusstsein

Wolfgang Reinhard

Schlusskommentar

Autorenverzeichnis .................................................................... 295

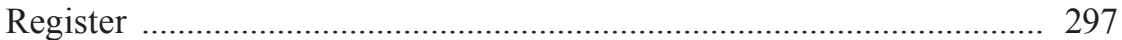




\section{Judith Becker/Bettina Braun}

\section{Die Begegnung mit Fremden und das Geschichtsbewusstsein - Einleitung}

Die zunächst vielleicht einfach nur skurril anmutende Sentenz »Fremd ist der Fremde nur in der Fremde « von Karl Valentin legt - wie so häufig bei Valentin - bei genauerem Hinsehen erhebliche Tiefendimensionen offen und führt mitten in das Thema des vorliegenden Sammelbandes und der ihm vorausgegangenen Tagung ${ }^{1}$. Sie macht deutlich, dass es sich bei Fremdheit nicht um die Eigenschaft eines Gegenstandes oder einer Person handelt - denn dann wäre der/das Fremde ja immer fremd -, sondern dass Fremdheit jeweils zugeschrieben wird. Eine Zuschreibung wiederum setzt einen Kontakt, eine Beziehung voraus. Alteritätstheoretiker sprechen deshalb vom »grundsätzlich relationalen Charakter von Fremdheit « ${ }^{2}$. Etwas völlig Unbekanntes kann also nicht fremd sein.

Dass der Fremde laut Karl Valentin nur »in der Fremde« fremd sei, verweist wiederum auf den Aspekt der Mobilität. Jemand kommt »in die Fremde« ein Ausdruck, der charakteristischerweise in unserer globalisierten Gegenwart zusehends verschwindet - und wird wegen seiner Hautfarbe, Kleidung, Sprache, Religion oder Umgangsformen als fremd wahrgenommen, weil er als nicht vertraut erscheint. Diese Fremdheit wird im Unterschied zur sozialen Fremdheit (= Nichtzugehörigkeit) als kulturelle Fremdheit bezeichnet ${ }^{3}$. Die zitierte Sentenz erlaubt allerdings auch die Deutung, dass die Heimat zur Fremde werden kann, dann nämlich, wenn jemand, der sich bisher zugehörig fühlte, plötzlich ausgegrenzt wird ${ }^{4}$. Fremdheit muss also nicht notwendigerweise im Zusammenhang von Migration auftreten. Bemerkenswert ist, dass Fremdheit unter diesem Aspekt auch im Laufe eines Lebens auftreten kann, ohne dass sich äußere Umstände wesentlich verändern.

1 Der vorliegende Sammelband enthält die für den Druck überarbeiteten Vorträge einer Tagung, die vom 22.-24. Juli 2010 im Institut für Europäische Geschichte in Mainz stattfand. Den Referentinnen und Referenten sei an dieser Stelle herzlich gedankt, dass sie die knappe Abgabefrist akzeptiert und ihre Beiträge rechtzeitig abgeliefert haben.

2 Herfried MünkleR/Bernd Ladwig, Dimensionen der Fremdheit, in: Dies. (Hg.), Furcht und Faszination. Facetten der Fremdheit, Berlin 1997, S. 11-44, hier S. 14.

3 Vgl. dies., Vorwort, in: Ebd., S. 7-9, hier S. 8.

4 In diesem Sinne dürfte vielen Juden Deutschland in den 1930er Jahren zunehmend zur Fremde geworden sein. 
Die soziale Dimension der Fremdheit, die bei Valentin anklingt, ist in der klassischen Definition des Fremden von Georg Simmel als des Wandernden, »der heute kommt und morgen bleibt $\ll^{5}$, indes kaum präsent. Hier steht eindeutig Fremdheit als Resultat eines Wanderungsprozesses im Vordergrund. Dabei konnte der Fremde, wie ihn sich die klassischen Soziologen vorstellten, sowohl der Fremde sein, der gerade erst angekommen war - diesen Fremden hatte Alfred Schütz vor allem im Blick ${ }^{6}$ - oder er konnte sich in der Fremde niedergelassen haben, wie der Händler, der »morgen« geblieben war und von dem Georg Simmel sprach. In jedem Fall stellte sich für die Fremden früher oder später die Frage nach Inklusion oder Exklusion in Bezug auf die fremde Gesellschaft. Denn die einzelnen Kulturen wurden zumeist als relativ klar voneinander abgegrenzt gedacht, sodass multiple Identitäten kaum vorstellbar waren. Das dürfte auch daran liegen, dass der Fremde für die Soziologen der ersten Hälfte des 20. Jahrhunderts vor allem der national Fremde war?

Der Fremde, wie ihn die klassische Soziologie beschrieben hat, ist ein universaler Typus: Wohl jede Sprache verfügt über einen oder mehrere Begriffe für den Fremden; Gesellschaften bilden ihre eigene Identität in Abgrenzung von Fremden ${ }^{8}$. Allerdings, und darauf hat Rudolf Stichweh wiederholt hingewiesen, ändert sich dies möglicherweise gerade. Die im Entstehen begriffene Weltgesellschaft könnte die erste sein, für die es keine Fremden in dem beschriebenen Sinne mehr gibt, da es kein Außen, keine Fremde mehr gibt, aus der sie kommen könnten. Für die Analyse historischer Epochen hingegen ist selbstverständlich davon auszugehen, dass es Fremde gab, die aus der Fremde in die Fremde kamen. Dabei konnte die Fremdheit national oder ethnisch begründet sein, zumindest ebenso häufig jedoch auch religiös, vielfach kamen mehrere Differenzerfahrungen zusammen.

Die Begegnung mit Fremden, die Verarbeitung dieser Erfahrung in Reiseberichten und Belletristik, die praktische Politik der Inklusion und Exklusion von Fremden, der Umgang mit Fremden in Kolonialismus und Imperialismus sind in den letzten Jahren von verschiedenen Wissenschaften vielfach behandelt worden, und zwar sowohl in zahlreichen Einzelstudien als auch durch

5 Georg Simmel, Exkurs über den Fremden, in: Ders., Soziologie. Untersuchungen über die Formen der Vergesellschaftung, Berlin 1908, S. 509-512; jetzt auch in: Peter-Ulrich MerzBenz/Gerhard Wagner (Hg.), Der Fremde als sozialer Typus. Klassische soziologische Texte zu einem aktuellen Phänomen, Konstanz 2002, S. 47-53, hier S. 47.

6 Alfred Schüтz, Der Fremde. Ein sozialpsychologischer Versuch, in: Ders., Gesammelte Aufsätze, Bd. 2: Studien zur soziologischen Theorie, Den Haag 1972, S. 53-69 [engl. Original zuerst 1944]; jetzt auch in Merz-Benz/Wagner, Der Fremde als sozialer Typus, S. 73-92.

7 Rudolf Stichweн, Die klassische Soziologe des Fremden und die Genese der Disziplin Soziologie, in: Ders., Der Fremde. Studien zu Soziologie und Sozialgeschichte, Frankfurt a.M. 2010, S. 9-24, hier S. 9.

8 Ders., Die Semantik des Fremden in der Genese der europäischen Welt, in: Ebd., S. 75-83, hier S. 75. 
Versuche theoretischer Konzeptualisierung und Systematisierung9 ${ }^{9}$ Dieser kaum mehr zu überblickenden Fülle von Untersuchungen soll hier nicht einfach eine weitere hinzugefügt werden, obwohl natürlich noch viele Bereiche der Erforschung harren. Im Fokus des Sammelbandes steht vielmehr eine ganz spezifische Fragestellung, nämlich diejenige nach dem Zusammenhang zwischen der Begegnung mit Fremden und dem Geschichtsbewusstsein. Dass hier eine Interdependenz zu vermuten ist, wird von den - zumeist ja synchron arbeitenden - Soziologen, die sich mit Fremden beschäftigt haben, nur vage angedeutet. Aus der Annahme, dass die Fremden zumeist einen ziemlich radikalen Bruch mit ihrer Vergangenheit vollzogen haben, wird der Schluss gezogen, dass für die Fremden die Gegenwart kein Ort der Bindung gewesen sei, sie vielmehr allein die Zukunft im Blick gehabt hätten ${ }^{10}$. Das Leben in der Fremde führe also dazu, dass diese Menschen ihre Verankerung in der Zeit anders interpretierten als zuvor. Diese Beobachtung leuchtet zunächst ein, ist aber kaum je explizit untersucht worden. Der vorliegende Sammelband möchte hierzu einen ersten Beitrag leisten.

Geschichtsbewusstsein wird dabei als die Trias von Vergangenheitsdeutung, Gegenwartsverständnis und Zukunftsperspektiven verstanden ${ }^{11}$, die in ihren Grundzügen bereits auf Augustin zurückgeht. Auf dieser Grundlage kann nach der Verortung der Menschen in der Zeit gefragt werden. Zudem beinhaltet Geschichtsbewusstsein immer auch eine persönliche Komponente: Das Geschichtsbewusstsein eines Menschen ist in seiner Lebensgeschichte verankert ${ }^{12}$, das einer Gruppe in deren Geschichte bzw. ihrer Überzeugung von und Meinung zu ihrer Geschichte. Hans-Jürgen Pandel teilt das Geschichtsbewusstsein auf in Zeitbewusstsein, Wirklichkeitsbewusstsein und Historizitätsbewusstsein sowie die sozialen Kategorien Identitätsbewusstsein, politisches Bewusstsein, ökonomisch-soziales Bewusstsein und

9 Ein Spezialfall der Begegnung mit Fremden sind die Begegnungen unter kolonialen Vorzeichen. Daher haben sich auch die Postcolonial Studies ausgiebig mit der Frage der Definition von Fremdheit und ihrer Bedeutung für Identitätskonstruktionen beschäftigt. Hervorzuheben sind die Konzepte der Hybridität bzw. der »Contactzones« (vgl. Homi K. BHABHA, Die Verortung der Kultur, Tübingen 2007 u. Mary Louise PRATT, Imperial Eyes. Travel Writing and Transculturation, London u.a. 1992) sowie selbstverständlich die grundlegenden Fragestellungen, in: Edward W. SAID, Orientalismus, Frankfurt a.M. 2009, S. 9-39, 231-258 u. Frantz FAnON, Schwarze Haut, weiße Masken, Frankfurt a.M. 1985. Vgl. aus soziologischer und kulturtheoretischer Perspektive Johann P. Arnason, Civilizations in Dispute. Historical Questions and Theoretical Traditions, Leiden 2003.

10 Stichwen, Die klassische Soziologie, S. 18.

11 Karl-Ernst Jeismann, Geschichtsbewußtsein - Theorie, in: Klaus Bergmann u.a. (Hg.), Handbuch der Geschichtsdidaktik, Seelze-Velber ${ }^{5} 1997$, S. 42-44.

12 Jörn Rüsen stellt daher die Forderung nach der Erforschung der Subjektivität auf, vgl. Jörn RüsEn, Einleitung, in: Ders. (Hg.), Geschichtsbewußtsein. Psychologische Grundlagen, Entwicklungskonzepte, empirische Befunde, Köln u.a. 2001, S. 1-13. 
moralisches Bewusstsein ${ }^{13}$. Geschichtsbewusstsein ist, so Pandels Schlussfolgerung, »nicht nur eine formale Orientierung in der historischen Zeit, sondern eine sozial-politische Orientierung über sich wandelnde gesellschaftliche Verhältnisse $«^{14}$. Das Geschichtsbewusstsein ist auf die Lebenswelt bezogen und in ihr begründet. Auch dies legt seine Veränderung durch die Begegnung mit Fremden, durch Fremdheitserfahrungen nahe. In der Begegnung mit Fremden wird die eigene Identität, werden die eigenen Wertbindungen infrage gestellt ${ }^{15}$. Diese aber stehen in unmittelbarem Zusammenhang mit dem Geschichtsbewusstsein, das wesentlich über eine einfache Zeitdeutung hinausgeht ${ }^{16}$.

Dabei ist einschränkend zu betonen: Das Geschichtsbewusstsein gibt es nicht. Das eine Geschichtsbewusstsein gibt es nicht für eine Gruppe und selbst für einen Menschen nicht. Dieselbe Person kann je nach Perspektive sehr unterschiedliche Arten von Geschichtsbewusstsein ausbilden. So kann - zumindest in der Neuzeit - ein Mensch sich in der politischen oder sozialen Geschichte ganz anders verorten, als wenn er nach seinem Geschichtsverständnis unter religiös-weltanschaulicher Perspektive gefragt wird. Diese grundlegende Unterscheidung muss berücksichtigt werden.

Dieser Sammelband benutzt also einen relativ weiten Begriff von Geschichtsbewusstsein ${ }^{17}$. Geschichtsbewusstsein wird individuell ausgebildet und muss nicht unbedingt explizit ausgearbeitet vorliegen - für die histo-

13 Vgl. Hans-Jürgen Pandel, Geschichtlichkeit und Gesellschaftlichkeit im Geschichtsbewußtsein. Zusammenfassendes Resümee empirischer Untersuchungen, in: Bodo von BorriEs u.a. (Hg.), Geschichtsbewusstsein empirisch, Pfaffenweiler 1991, S. 1-23, sowie ders., Dimensionen des Geschichtsbewusstseins. Ein Versuch, seine Struktur für Empirie und Pragmatik diskutierbar zu machen, in: Geschichtsdidaktik 12 (1987), S. 130-142.

14 Ebd.

15 Dies ist insbesondere von den Postcolonial Studies betont worden, vgl. Dipesh Chakrabarty, Provincializing Europe. Postcolonial thought and historical difference, Princeton u.a. 2000; Homi K. BнавнA thematisiert die Beziehung zwischen kulturellen Wertbindungen und Verortung der Menschen in Zeit und Raum, vgl. z.B. BнавнA, Die Verortung der Kultur, S. 1-28 u. 207-253. In anderen Untersuchungen zur Identitätsbildung findet sich auch ein impliziter Zusammenhang zum Geschichtsbewusstsein, vgl. z.B. Charles TAYLOR, Quellen des Selbst. Die Entstehung der neuzeitlichen Identität, Frankfurt a.M. 1994, bes. S. 55-58. Zur Bedeutung der Fremdheit für die Identitätsbildung vgl. z.B. Bernard WALDENFELs, Grundmotive einer Phänomenologie des Fremden, Frankfurt a.M. 2006. Zur historisch orientierten Werteforschung vgl. Hans JoAs, Die Entstehung der Werte, Frankfurt a.M. 1999.

16 Vgl. zur historischen Analyse der Beziehung von Werten und Geschichtsbewusstsein auch Kerstin Armborst-Weins / Judith Becker, Wertewandel und Geschichtsbewusstsein - Überlegungen zur historischen Untersuchung einer Wechselbeziehung, in: Jahrbuch für Europäische Geschichte 12 (2011), S. 153-178.

17 Vgl. auch Bodo von Borries, Art. Geschichtsbewusstsein, in: Stefan Jordan (Hg.), Lexikon Geschichtswissenschaft. Hundert Grundbegriffe, Stuttgart 2002, S. 104-108, hier S. 105: »Freilich steckt der Begriff >Geschichtsbewusstsein` voller Tücken: Wenn man nur die ausdrücklich thematisierten und reflektierten Aspekte einbezieht, greift er zu kurz. Wenn man sich auf die kognitive Domäne beschränkt, bekommt man die zentralen Steuerungsmechanismen der Zuwendung zur und Abwendung von Geschichte nicht in den Griff. Der motivatio- 
rische Forschung kann es dennoch fassbar sein. Ein philosophischer Sammelband müsste zweifellos einen enger definierten Begriff von Geschichtsbewusstsein bevorzugen. Eine solche Definition würde aber die historische Untersuchung von Geschichtsbewusstsein vor dem 19. Jahrhundert verbieten und könnte auch danach nur Elitenphänomene in den Blick bekommen. Daher haben wir uns bewusst für die weitere Definition entschieden.

Im Mittelpunkt der Beiträge steht nicht die Interpretation der Existenz in der Fremde, sondern die Frage, wie sich die Begegnung mit Fremden auf die Verortung der Menschen in der Zeit auswirkte.

Für die europäische Frühe Neuzeit ist das bisher vor allem für das Vordringen der Osmanen nach Europa untersucht worden. So hat Thomas Kaufmann gezeigt, dass die Bedrohung Wiens durch die Türken im 16. Jahrhundert das apokalyptische Zeitbewusstsein der Europäer verstärkte ${ }^{18}$. Und Gerdien Jonker hat in einem »Islambilder« titulierten Heft der Zeitschrift für Geschichtswissenschaft anschaulich vor Augen geführt, wie die Türken Eingang in die frühen protestantischen Kalender gefunden haben. Diese Kalender enthielten für »jeden Tag durchs ganze jar eine namhaffte Geschichte oder Historien/aus heiliger schrifft oder sonsten/so sich voriger Zeit oder neulicher Zeit hin und wieder in der Welt zugetragen«. Die Gläubigen wurden jetzt also nicht mehr mit mittelalterlichen Heiligen, sondern mit Personen ihrer unmittelbaren Gegenwart bekannt gemacht. Dazu gehörten eben auch aggressive Türken und »Muselmanen«, die wie die anderen Protagonisten in den göttlichen Heilsplan eingeordnet wurden ${ }^{19}$.

Auch wenn die Türken für die frühneuzeitlichen Europäer sicherlich die Fremden par excellence gewesen sind, so waren sie selbstverständlich nicht die einzigen Fremden, denen Europäer vom 16. bis zum Ende des langen 19. Jahrhunderts begegnen konnten: Jüdische Wanderhändler, Glaubensflüchtlinge, fremde Soldaten und viele andere wären hier noch zu nennen. Außerdem reisten die Europäer - aus ganz unterschiedlichen Gründen - in zunehmendem Maße in fremde Länder und begegneten dort ihnen fremd erscheinenden Menschen und wurden von diesen ebenso als fremd wahrgenommen. Die folgenden Beiträge untersuchen, ob und auf welche Weise diese Begegnungen das Verständnis der Wandernden wie der Sesshaften von ihrem Verständnis der Geschichte und ihrer Verortung in der Geschichte veränderten. Der Sammelband definiert also in dieser historischen Perspektive

nale und triebdynamische Aspekt ist unverzichtbar, um an die Relevanzzumutungen und -ausblendungen heranzukommen, die für 〉historische Sinnbildung konstitutiv sind «.

18 Thomas KaUfmanN, »Türckenbüchlein«. Zur christlichen Wahrnehmung »türkischer Religion« in Spätmittelalter und Reformation, Göttingen 2008.

19 Gerdien Jonker, Kalender, Polemiken, Geschichtsbücher. Die Verankerung islamfeindlicher Bilder im Zeitalter der Reformation, in: Zeitschrift für Geschichtswissenschaft 58 (2010), S. 614-626, hier S. 616-618. 
wie die klassische Soziologie den Fremden als wandernden Fremden. Die Begegnung mit Fremden kam durch Migration, Reisen oder durch von politischen oder sozialen Erschütterungen ausgelöste Bewegungen zustande. Auch geht es in den Beiträgen um »den « Fremden, nicht um »das « Fremde. Ausschließlich die Begegnung zwischen verschiedenen Menschen wird in den Blick genommen. So kann die weite Forschung zur Alterität wieder auf ein - wenn auch zugegeben großes - Thema eingeschränkt werden, und es bleiben Vergleichspunkte zwischen den verschiedenen Beiträgen, die weitergehende Schlüsse ermöglichen.

Des Weiteren ist zu betonen, dass "Veränderung« nicht unbedingt einen völligen Wechsel des Geschichtsbewusstseins bedeuten muss - auch wenn die klassische Soziologie des Fremden dies vermutete. Vielmehr kann sich das Geschichtsbewusstsein auch in dem Sinne verändern, dass sich lang gehegte Auffassungen verfestigen. Einige Beiträge in diesem Band werden zeigen, dass Menschen durch die Begegnung mit Fremden eher noch stärker von der Richtigkeit ihres Geschichtsbewusstseins überzeugt waren als vorher.

Das Spektrum der behandelten Fallbeispiele wurde dabei geographisch wie zeitlich und von der Art der Begegnung (Kolonisierung, Mission, Militär, Wissenschaft) bewusst breit gewählt. Zum einen erlaubt die Forschungslage es zum gegenwärtigen Zeitpunkt noch nicht, sich hier auf einen engeren Bereich zu konzentrieren, da bis jetzt erst sehr wenige Studien zu dieser Frage vorliegen. Zum anderen aber und vor allem scheint es gerade aufgrund der Tatsache, dass es sich hier um ein sehr junges Forschungsfeld handelt, sinnvoll, möglichst unterschiedliche Beispiele zu versammeln, um so den Blick auf Bedingungen und Ausprägungen für ein sich im Gefolge der Begegnung mit Fremden veränderndes Geschichtsbewusstsein zu schärfen. Die Beiträge werden deshalb nach der Art der Fremdheitserfahrung (»Fremd im eigenen Land «, »Fremd im anderen Land « und »Rezeptionen von Erfahrungen mit Fremden «) und nicht nach chronologischen, geographischen oder thematischen Gesichtspunkten angeordnet. Für eine Synthese ist es momentan sicherlich noch zu früh. Der Schlusskommentar vermag aber Perspektiven der künftigen Forschung aufzuzeigen und wird hoffentlich weitere Arbeiten in diese Richtung anregen. 
I. Grundsatzreferate 



\author{
Rudolf Stichweh
}

\title{
Die Begegnung mit Fremden und die Selbstbeobachtung von Gesellschaften
}

\section{Gesellschaftliche Selbstbeobachtung}

Das System der Gesellschaft teilt mit allen anderen Sozialsystemen die Fähigkeit zur Selbstbeobachtung. Für die Bezeichnung dieses Sachverhalts existieren eine Reihe miteinander verwandter Begriffe: »Selbstbeobachtung «; »Selbstbeschreibung«, ein Begriff, der deutlicher eine systematisch organisierte und eventuell als Text verfasste Selbstbeobachtung vermuten lässt; »Reflexivität«, als ein Terminus, der die Rückbezüglichkeit von Akten der Selbstbeschreibung hervorhebt und zugleich sichtbar macht, dass sie mit alltäglichen operativen Vollzügen unaufhebbar verflochten sind; schließlich das »Geschichtsbewusstsein«, das einen Spezialfall von Selbstbeobachtung verkörpert, eine Beobachtung, die gegenwärtige operative Vollzüge auf einen Deutungsrahmen projiziert, der diesen Vollzügen eine historische Dimension hinzufügt, sie als Kontinuitäten oder auch als Bruch erscheinen lässt.

Für die Selbstbeobachtung von Gesellschaft ist die Frage, ob in diesen Selbstbeobachtungen das Wort »Gesellschaft« vorkommt oder die Einheit dieser Ebene der Systembildung unbezeichnet bleibt, von nachrangiger Bedeutung. Die Systembildungsebene Gesellschaft ist manchmal gar nicht in ihrer Eigenständigkeit bekannt; in anderen Fällen ist sie umstritten und kann sogar heftigen Widerspruch erregen. Bemerkenswert war, dass es vor einiger Zeit einer britischen Premierministerin (Margaret Thatcher) wichtig war, mit großer Entschiedenheit zu postulieren, »There is no society«, womit vermutlich gemeint war, dass die Verwendung des Gesellschaftsbegriffs Mitglieder der Gesellschaft von der Übernahme von Verantwortung entlastet und dass diese Begriffsverwendung deshalb unterbleiben sollte. Zwei Jahrzehnte später formuliert eine neue und erneut konservative britische Regierung eine durchaus verwandte politische Gestaltungsabsicht mit der programmatisch gemeinten Formel von der Big Society, wobei sie diese »große Gesellschaft« in einen Gegensatz zu einem Staat rückt, der als hypertroph erlebt wird. Diese neue Variante soll offensichtlich besagen, dass die Gesellschaft ein sich selbstorganisierender Zusammenhang von Handlungsbereitschaften ist und dass, weil dies so ist, der Gesellschaftsbegriff 
mit einer Positivwertung ausgestattet und der Staat zurückgedrängt werden sollte'.

Welches ist die Form, in der Selbstbeschreibungen der Gesellschaft vorkommen? Unabhängig von der Frage, wie diese Selbstbeschreibungen mitgeteilt werden, ob diese Mitteilung beispielsweise in der Form von Texten erfolgt, handelt es sich bei diesen Selbstbeschreibungen ausnahmslos um Kommunikationen; und für Kommunikationen lässt sich zugleich sagen, dass elementare kommunikative Akte prinzipiell als die Form des operativen Vollzugs von Gesellschaft fungieren. Daraus folgt, dass die Selbstreproduktion und die Selbstbeschreibung von Gesellschaft nicht leicht voneinander zu unterscheiden sind.

Man kann dies gut an den beiden wichtigsten Termini für Selbstbeschreibung demonstrieren: Semantik und Kultur. Semantik ist - so hat es Niklas Luhmann wiederholt formuliert - höherstufig generalisierter Sinn und tritt in dieser Form Mitgliedern von Gesellschaft als objektiver Sachverhalt gegenüber ${ }^{2}$. Fast dieselbe Definition wird auch für den Begriff der gesellschaftlichen Struktur vorgeschlagen. Strukturen bestehen aus Erwartungen, und diese Erwartungen wirken nur dann strukturbildend, wenn sie generalisierte Erwartungen sind, also eine Vielzahl von (sachlichen, sozialen, zeitlichen) Unterschieden übergreifen. So verstanden, unterscheiden sich Semantik und Struktur aber nicht signifikant, und damit wird die Vorstellung enttäuscht, dass Semantik eine Art zweite Wirklichkeit meint, die unabhängig von den Strukturen diese gleichsam in einer zweiten Sinnschicht kommentiert. Ähnliche Schwierigkeiten handelt man sich mit dem Begriff der Kultur ein, dem eine expansive Tendenz eigen ist, sodass er immer mehr Aspekte der gesellschaftlichen Strukturbildung in sich inkorporiert und damit erneut die erhoffte Leistung verloren geht, über eine Art Gegenbegriff zu objektivierten gesellschaftlichen Wirklichkeiten zu verfügen. Es gibt also keine Unterschiede oder allenfalls kleine Unterschiede, die dafür verantwortlich sind, dass man in diesen zweistelligen Unterscheidungen von der einen auf die andere Seite der Unterscheidung wechselt (also beispielsweise aus dem

1 Siehe die vermutlich erste Formulierung dieser These bei Wilhelm von Humboldt, Ideen zu einem Versuch, die Grenzen der Wirksamkeit des Staats zu bestimmen, Stuttgart 1982 [ND der Ausgabe 1792], der das Wort Gesellschaft aber noch nicht kennt. Für den Gesellschaftsbegriff als Vergleich interessant Nicolas BAUDEAU, Première introduction à la philosophie économique ou analyse des États policés, Paris 1771.

2 Niklas Luhmann, Gesellschaftliche Struktur und semantische Tradition, in: Ders. (Hg.), Gesellschaftsstruktur und Semantik. Studien zur Wissenssoziologie der modernen Gesellschaft, Bd. 1, Frankfurt a.M. 1980, S. 9-71; vgl. Rudolf Sтісншен, Semantik und Sozialstruktur. Zur Logik einer systemtheoretischen Unterscheidung, in: Dirk TÄNZLER/Hubert KNOBLAUCh /Hans-Georg Soeffner (Hg.), Neue Perspektiven der Wissenssoziologie, Konstanz 2006, S. $157-171$. 
Bereich der affirmierten und eventuell sanktionsbewehrten Normen in den Bereich einer kontingenzbewussten Deskription von Normen, die Veränderungen und Alternativen mit sichtbar macht).

Vergleichsweise einfach voneinander unterscheiden kann man aber Kultur und Semantik. Kultur ist oft implizit, ist dann auch für die, um deren Kultur es sich handelt, nicht leicht zu erschließen und wird erst von einem Fremdbeobachter im Vergleich zu anderen Kulturen in ihrer Eigenart entdeckt. Außerdem kann Kultur sogar latent sein, also über längere Zeiträume fortdauern, selbst wenn sie operativ nicht angesprochen oder reaktualisiert wird $^{3}$. Mit Semantik verhält es sich anders. Diese ist auf Explizitheit angewiesen und muss auf Nachfrage hin erläutert werden können. Und auch das Moment des Manifestseins, der Unübersehbarkeit der Handhabung einer je bestimmten Semantik zu einem gegebenen Zeitpunkt verbindet sich mit dem Begriff der Semantik deutlicher, als dies bei Kultur der Fall ist. Insofern liegt die Folgerung auf der Hand, dass der Begriff der Semantik sich besser als eine Deutung dessen eignet, was wir mit Selbstbeschreibung meinen.

Selbstbeschreibungen in diesem Sinn können sich auf mindestens vier verschiedene Weisen mit dem verknüpfen, was wir Strukturbildung in einem Sozialsystem nennen ${ }^{4}$ :

1. Selbstbeschreibungen sind in manchen Fällen antizipativ. Sie zeichnen dann zukünftige und beabsichtigte Strukturbildungen vor, die sich noch nicht ereignet haben. Selbstbeschreibungen dieses Typs kommen als programmatische Selbstbeschreibungen vor, die Bindungseffekte erzeugen wollen; sie können auch prognostisch sein und entwerfen in diesem Fall eine Zukunft, von der man glaubt, dass sie auch ohne signifikante eigene Handlungsbeteiligung eintreten wird. Oder sie sind schließlich utopisch, also mit einer Zukunft befasst, die sich vermutlich nie ereignen wird.

2. Ein zweiter Typus sind rekonstruktive Selbstbeschreibungen. Diese versuchen vorhandene soziale Strukturen und Prozesse adäquat zu erfassen und dadurch verständlich werden zu lassen. Zugleich haben solche rekonstruktiven Selbstbeschreibungen oft die Wirkung, dass sie etwas, das eine

3 Diese These war für Parsons' Theorie der Kultur zentral. Vgl. Peter J. Richerson/ Robert Boyd, Not by Genes Alone. How Culture Transformed Human Evolution, Chicago 2005, S. 32: »Cultural continuity is not maintained solely by its daily performance. Rather, it rests in longer-lived memory. If culture, not self-policing institutions, creates continuity, people of a culture might be compelled by circumstance to behave according to someone else's rules but still transmit some, much, or all of their culture to their children. If the force of circumstance disappears before the culture is readapted to the new environment, all or most of the old culture may still exist, and behavior may revert to the old ways if the compulsion is removed «.

4 Vgl. hierzu Rudolf Stichweh, Selbstbeschreibung der Weltgesellschaft, in: Jörg BaberowsKi/ Hartmut KAELble / Jürgen SchriewER (Hg.), Selbstbilder und Fremdbilder. Repräsentation sozialer Ordnungen im Wandel, Frankfurt a.M. 2008, S. 21-53, hier S. 46-51. 
festgeschriebene Wirklichkeit zu sein scheint, durch Beschreibung wieder in den Modus der Potenzialität versetzen, weil in der Beschreibung Alternativen sichtbar werden.

3. Selbstbeschreibungen können drittens einen normativen Schwerpunkt haben. Dann sind sie einerseits deskriptiv, erfassen Wirklichkeiten, die in einer Gegenwart vorhanden sind oder sein sollten; aber sie machen zugleich auch sichtbar, dass sie mit dieser deskriptiven Ausrichtung stabile normative Erwartungen verknüpfen, die an diesen Wirklichkeiten auch festhalten werden, wenn sich deren Fortdauer Widerstand entgegenstellen sollte.

4. Selbstbeschreibungen sind in einer vierten Variante konstitutiv oder operativ. In dieser Variante fällt der Vollzug der Selbstbeschreibung mit der Reproduktion des betreffenden Sozialsystems zusammen. Dieser vierte Typus ist derjenige Fall, mit dem sich am deutlichsten der Zweifel verknüpft, ob es möglich sein wird, Selbstbeschreibung und Strukturbildung verlässlich zu unterscheiden und das Verhältnis dieser beiden als eine Korrelation zu beschreiben. Dies ist auch die Variante, die am deutlichsten die Konsequenzen aus der kommunikationstheoretischen Wendung der Sozialwissenschaften sichtbar macht, weil Kommunikation als operative Basis der Gesellschaft auch das mediale Substrat von Semantik und Sozialstruktur ununterscheidbar werden lässt.

\section{Elementare Dimensionen der Beobachtung des Fremden}

In der Begegnung mit Fremdem vollzieht sich die Selbstbeobachtung von Gesellschaften in drei elementaren Hinsichten: Die erste dieser Hinsichten wird durch die Sozialdimension des Sinns repräsentiert. Die Begegnung mit Fremden zwingt Gesellschaften, zwischen Mitgliedern und Nichtmitgliedern zu unterscheiden, Bedingungen und Kriterien für Mitgliedschaft zu identifizieren und diese kommunikativ mitzuteilen. Damit konsolidiert sich eine Gesellschaft nach innen und erwirbt zugleich ein soziales Außen (die von Mitgliedschaft ausgeschlossenen Fremden), das die Eigenheit der Gesellschaft sichtbar macht ${ }^{5}$.

Fremdes ist zugleich immer sachlich Fremdes und in dieser Hinsicht werden nicht bestimmte Adressen von Mitgliedschaft ausgeschlossen, es geht vielmehr um die Identifikation kultureller Themen der Bestimmung von Sinn, im Verhältnis zu denen andere Sinnkomponenten als fremd, als unver-

5 Vgl. zu den folgenden Überlegungen Rudolf Sтісншен, Der Fremde. Studien zu Soziologie und Sozialgeschichte, Berlin 2010. 
ständlich und als rätselhaft erscheinen. In der soziokulturellen Evolution von Gesellschaften und der Hinsichten dessen, was für Gesellschaften fremd ist, überlagern, konkurrieren und ergänzen sich unablässig diese beiden Dimensionen von Fremdheit.

In einer dritten Hinsicht hat Fremdheit mit Distanz und Nähe zu tun, und der unterstellte Begriff der Distanz (und Nähe) schließt zeitliche und räumliche Distanzen ein. Etwas Fremdes ist immer etwas, was entfernt ist (zumindest seiner Herkunft nach), zugleich ist es zum gegenwärtigen Zeitpunkt, sonst wäre es nicht in seiner Fremdheit relevant, in angebbaren Hinsichten nahe: fremdartige Händler treffen ein; eine vergangene und eigentlich fremde Zeit wird als Vorbild vorgestellt ${ }^{6}$. Das verbindet sich mit und erzeugt Ambivalenz als eines der Grundmuster in der Einstellung zum Fremden?

\section{Fünf Strukturen der Beobachtung und der institutionellen Einbettung des Fremden}

Unter der Voraussetzung dieser drei Sinndimensionen lassen sich historisch fünf einander abwechselnde und aufeinander folgende Formen identifizieren, in denen Gesellschaften Erfahrungen mit Fremden und mit Fremdheit institutionell verarbeiten. Diese bilden historisch verschiedene und in langer historischer Sicht sogar radikal verschiedene Erfahrungsmodi und institutionelle Verarbeitungsmuster:

1. In frühen gesellschaftlichen Formationen - insbesondere in tribalen Gesellschaften - gibt es viele Beispiele, dass Gesellschaften nicht in der Lage oder nicht bereit sind, Fremde als Fremde zu erkennen. Dies hängt mit der Geschlossenheit des Weltbildes vieler Gesellschaften zusammen. Fremde werden dann als Ahnen, als Götter oder Geister »erkannt $\varkappa^{8}$. Als solche sind sie Teil der Gesellschaft und ihres Weltbildes. Narrative und Techniken der Behandlung stehen zur Verfügung; darin liegen eine Nichterkennbarkeit der Andersartigkeit des Anderen und auch ein Verkennen der Chancen und Gefahren, die sich mit dem Fremden verknüpfen. So

6 Novalis verbindet dieses Ineinander von Nähe und Ferne mit dem Begriff der Romantik (und der Poesie): „So wird alles in der Entfernung Poesie, [...] ferne Berge, ferne Menschen, ferne Begebenheiten usw. (alles wird romantisch, quod idem est) [...] Poesie der Nacht und Dämmerung«. (Novalis, Fragmente, in: Jakob MinOR [Hg.], Novalis Schriften, Bd. 2, Jena 1907, S. 109-315, hier S. 301f.). Eine ideale Versinnbildlichung dieses Ineins von Nähe und Ferne ist das offene Fenster in der Malerei der Romantik, vgl. den Ausstellungskatalog Sabine RewaLD, Rooms with a View. The Open Window in the $19^{\text {th }}$ Century, New Haven 2011.

7 Vgl. Stichweh, Der Fremde, Kapitel 9.

8 Siehe als ein interessantes Beispiel Bob Connolly/Robin Anderson, First Contact. New Guinea's Highlanders Encounter the Outside World, New York 1988. 
hatte die selbstverständliche Einordnung überraschend eintreffender spanischer Konquistadoren in das Weltbild der Gesellschaften, mit denen sie in Kontakt kamen, in einigen Fällen (Azteken) fatale Konsequenzen.

2. Eine zweite Variante unterscheidet sich genau dadurch, dass am Anfang einer Handlungssequenz das Erkennen des Fremden in seiner Beunruhigungsqualität steht. Der für Sozialsysteme fundamentale Sachverhalt der doppelten Kontingenz - der Unsicherheit der eigenen Handlungswahl, weil Unsicherheit über die Absichten und die Situationsdeutung des jeweiligen Gegenübers besteht -, tritt gegenüber dem völlig unbekannten Fremden in seiner elementarsten Form auf ${ }^{9}$. Daraus folgt die Dringlichkeit einer Strategie für den Umgang mit dem Fremden. Man kann den Fremden umstandslos töten ${ }^{10}$ oder in anderen drastischen Formen die Wegweisung des Fremden vollziehen. Auf der anderen Seite des Alternativenspektrums stehen Formen der Inklusion des Fremden, die aber gleichfalls seine Fremdheit in kürzester Zeit und rückstandslos zum Verschwinden bringen. Dazu gehört die Adoption in eine Verwandtschaftseinheit, die typischerweise mit Reinigungsriten verknüpft ist, die ihn aller beunruhigenden Qualitäten des Fremden entkleiden. In diesem zweiten Muster der Behandlung des Fremden wird die Fremdheit des Fremden zwar erkannt, aber sie wird nur kurze Zeit ausgehalten. Auch im Fall der Inklusion des Fremden bedeutet Inklusion hauptsächlich das Entfernen der fremden Momente.

3. Erst in den stratifizierten Systemen der alten Welt, die sich mit der Entstehung von Landwirtschaft vor acht- bis zehntausend Jahren herausbildeten, gewinnt ein neuartiges Strukturmuster die Oberhand. Entscheidend wird jetzt eine komplexere, vielfältigere Rollenmuster hervorbringende Sozialstruktur, die sich durchsetzt. In diesen vielfältigeren Rollenmustern wird das sichtbar, was der amerikanische Soziologe David Rinder »Statuslücken« genannt hat ${ }^{11}$. Damit sind Rollen und Status gemeint, die ein Sozialsystem mit »eigenem Personal« nicht gut besetzen kann. Die Tätigkeiten sind zu statusniedrig und zu beschämend in ihrer Ausführung; ihre Ausübung verlangt die Nichtbeachtung von normativen Prämissen, die in anderen Hinsichten für das Sozialsystem zentral sind (Zinsverbot etc.); man traut niemandem die Unparteilichkeit zu, die für bestimmte Ämter

9 Zu doppelter Kontingenz siehe Niklas Luhmann, Soziale Systeme. Grundriß einer allgemeinen Theorie, Frankfurt a.M. 1984.

10 Ein historisch interessantes Beispiel ist der sogenannte »Mudan Vorfall« an der Südküste Taiwans 1874: Angehörige eines Stammes von Aborigines töten 54 schiffbrüchige Seeleute aus Okinawa. Da die eigentlich zuständige chinesische Regierung beteuert, keinen Einfluss auf diese »Wilden« zu haben, war dies für Japan ein Auslöser und eine Rechtfertigung für den Versuch, die Kontrolle über Taiwan zu erlangen.

11 Irwin D. RindeR, Strangers in the Land. Social Relations in the Status Gap, in: Social Problems 6 (1958), S. 253-260. 
(Richter, hohe Berater) als erforderlich gedacht wird. In diesen und in verwandten Situationen entsteht ein Raum für die Besetzung dieser Positionen mit Fremden, für deren Tätigkeit es jetzt auch wichtig werden kann, dass ihre Fremdheit »konserviert» wird und sichtbar bleibt. Sie erfüllen eine wichtige Rolle; sie können dies nur als Fremde tun und die Wahrnehmbarkeit ihrer Fremdheit bleibt erhalten, und sei es, damit man, wenn irgendetwas schiefgeht, immer noch für Expulsion des Fremden optieren kann.

Der Zuordnung von Fremden zu Statuslücken entspricht eine Hierarchie von Situationen, in denen Fremde sich typischerweise befinden. Fremde sind in manchen Situationen »unterworfen«, wie beispielsweise jene Sklaven afrikanischer Herkunft, die der transatlantische Sklavenhandel in die Vereinigten Staaten (und in viele andere Länder) transportiert hatte. Fremde werden in anderen Fällen »geduldet«, wie dies für viele Situationen in der Geschichte des europäischen Judentums zutrifft. Und es kommt drittens vor, dass Fremde sogar privilegiert sind, dass man sie in das eigene Land zu holen versucht und für diesen Zweck mit Privilegien ausstattet (z.B. eine eigene Gerichtsbarkeit), die man der eigenen Bevölkerung nicht konzedieren würde. Im mittelalterlichen und frühneuzeitlichen Europa sind derartige Privilegierungen beispielsweise für fremde Studenten (und Lehrer) an Universitäten, die als Korporationen selbst einen vergleichbaren privilegierten Status aufweisen, häufig ${ }^{12}$. Populationen von Fremden können sich auch durch diese Status hindurch bewegen, auf- und absteigen. Dafür bietet die Geschichte des europäischen Judentums reiches Material.

Diese Charakterisierung von Fremden durch eine abgestufte Skala von Graden der Unterdrückung und Privilegierung wird in der Selbstbeschreibung von Gesellschaften vor allem durch zwei Gesichtspunkte ergänzt: Räumlich wird typischerweise zwischen »inneren« und »äußeren« Fremden unterschieden; zeitlich tritt der Unterschied zwischen den Fremden, die sich nur für kurze Zeit in einem Land aufhalten (und als »Gast« häufig privilegiert sind), und denjenigen, die eine dauerhafte Wohnberechtigung haben, also auch erwerbstätig sein müssen (»Gast« vs. »Gastarbeiter«; »xenos« vs. »metoikos«; »nokhri« vs. »ger«) in den Vordergrund ${ }^{13}$.

12 Die hier verwendete dreistellige Klassifikation von Status für Fremde liegt Gilissen zugrunde, einem umfangreichen vergleichenden Werk, das historische Rollen für Fremde in sehr verschiedenartigen Gesellschaften beschreibt. Vgl. John GiLissen, Le statut des étrangers, à la lumière de l'histoire comparative, in: L'Étranger. Recueils de la société Jean Bodin, Bd. 9 u. 10, Brüssel 1958, S. 5-57.

13 Vgl. zur jüdischen Tradition Alfred Bertholet, Die Stellung der Israeliten und der Juden zu den Fremden, Freiburg i.Br. 1896; zur griechischen Antike Philippe GAUTHIER, Symbola. Les étrangers et la justice dans les cités grecques, Nancy 1972. 
4. Die komplexe Statusvielfalt der stratifizierten Welt der Vormoderne wird im Nationalstaat des 19. bis 21. Jahrhunderts durch eine radikale Vereinfachung überformt. An die Stelle der Vielfalt der lokalen Bürgerrechte tritt das letztlich allein entscheidende Bürgerrecht des Nationalstaats. Und im Verhältnis zum Nationalstaat sind alle, die diesen Status des Citizen nicht aufweisen, Fremde. Der Autor dieser Zeilen hält sich, während er dies schreibt, mit einem Visum aus einer der vielen Kategorien, die der Diversität der Besucher Rechnung tragen (in diesem Fall J-Visum), in den Vereinigten Staaten auf. Was der Prozess der Beantragung dieses Visums aber vor allem gelehrt hat, ist, dass die Motivlage der amerikanischen Administration im Kern auf Kontrolle des einen Sachverhalts zielt: Es soll nicht zu einer Einwanderung kommen, über die nicht als Einwanderung ausdrücklich entschieden worden ist. Und dass man diesen Willen zu einer nicht ausdrücklich entschiedenen Einwanderung nicht heimlich hegt, muss an einer Stelle des Verfahrens vom Antragsteller extra »bewiesen« werden ${ }^{14}$. Dies illustriert gut, wie sehr eine binäre Situation (»Mitglied « oder »Nichtmitglied«) an die Stelle einer unübersichtlichen Vielfalt von Status getreten ist.

Zugleich unterminiert derselbe Nationalstaat seinen Willen zur Binarität aus innerem Zwang heraus auch wieder. Er greift als Steuerstaat beherzt zu, praktiziert als ein solcher den Willen zur Vollinklusion »Einheimischer« und »Fremder« - und muss im Gegenzug Inklusion in wohlfahrtsstaatliche Leistungen akzeptieren. Die Zahl der Steuerformulare, die einem nach wenigen Wochen vorliegen, wird nur durch die Zahl der Formulare für »Health Plans« übertroffen, in die man inkludiert werden könnte - und deren Studium lehrt in hoher Anschaulichkeit, warum die Verschuldung aller Akteure unabweisbar ist. Damit übernehmen die Funktionssysteme die Macht und zeichnen Inklusionsprofile, die die mit dem Nationalstaat entstandene Binarität gleich auch wieder unterminieren.

5. Parallel zur Genese und weltweiten Durchsetzung des Nationalstaats (die sich als weltweite Durchsetzung erst in der postkolonialen Konstellation seit 1960 vollzieht) entsteht eine Situation, die für das Profil der Moderne noch weit bestimmender wird: Die Herausbildung der Weltgesellschaft, für die der Nationalstaat nur eine der Strukturen ist, die die Innendifferenzierung dieses weltweiten Gesellschaftssystems charakterisiert. Weltgesellschaft ist die Welt der ausnahmslos globalen Funktionssysteme; globaler Netzwerke, die sich innerhalb von Funktionssystemen bilden, aber teilweise auch die sinnhaft bestimmten Grenzen von Funktionssystemen

14 Beim Besuch der amerikanischen Botschaft (Bern) sollen »beweiskräftige« Unterlagen für alle drei Familienmitglieder vorgelegt werden. 
überschreiten; formaler Organisationen mit weltweiter Expansion und Wirkungsfähigkeit; immer neuer Typen von Weltereignissen, die die Aufmerksamkeit weltweiter Öffentlichkeiten temporär binden.

In einem System der Weltgesellschaft, das u.a. die gerade genannten Eigentümlichkeiten aufweist, verändert sich die Form der Begegnung mit dem Fremden und der Beobachtung des Fremden radikal. Eine Erfahrungs- und Deutungsmöglichkeit besteht darin, die Fremdheit des Anderen gleichsam als ein Universal aufzufassen, also davon auszugehen, dass, jenseits des relativ kleinen Netzwerks von persönlich Bekannten, in der Regel diejenigen, auf die man in einem Funktionssystem, in einem Netzwerk, in einer Organisation oder bei einem Weltereignis trifft, Fremde sind. Globale Kommunikation (und das schließt lokale Kommunikation ein, weil diese die Selektionshorizonte globaler Kommunikation teilt) ist dann per se Kommunikation, die sich im Kontakt mit Fremden vollzieht ${ }^{15}$. Der in diesem Sinne universalisierte Fremde ist aber zugleich ein Fremder, dem die Beunruhigungsqualitäten des Fremden verlorengegangen sind. Er ist nicht mehr ein Fremder, mit dessen Wahrgenommenwerden zugleich ein Problemlösungs- und Bearbeitungsbedarf entsteht. Insofern ist sowohl die Aussage möglich, dass (beinahe) jeder Andere ein Fremder ist, wie alternativ die Aussage sinnvoll ist, dass in der pragmatisierten Welt der Funktionssysteme und der Organisationen niemand mehr ein Fremder ist. Die beiden Aussagen unterscheiden sich nicht mehr signifikant.

Eine soziohistorische Situation dieses Typs, in der die Universalisierung des Fremden und das Verschwinden des Fremden gewissermaßen konvergieren, kann man auch so auffassen, dass ein Freiraum entsteht, in dem die Individualisierung des Anderen als ein Grundsachverhalt unterstellt werden kann. Der Andere ist nur selten ein Freund, er ist noch viel seltener ein Feind und die ihm zugeschriebene Fremdheit verliert an deskriptiver Kraft. Also wird es sinnvoll, ihm Individualität zu unterstellen und es von seinen Engagements und von den eigenen Engagements abhängig zu machen, wie genau diese Individualität dargestellt und wie intensiv sie vom Beobachter exploriert werden soll.

15 Das ist für vielfältige Kommunikationssysteme registriert worden. Siehe nur für die Wirtschaft Paul Seabright, The Company of Strangers. A Natural History of Economic Life, Princeton 2004. 


\section{Entstehende funktionale Perspektiven und die Beobachtung des Fremden}

Die Auffassungsweisen und institutionellen Verarbeitungsformen, die im letzten Abschnitt diskutiert wurden, waren vom Gesichtspunkt der Gesellschaft als umfassendes Sozialsystem aus konzipiert. Sie stellten sich die Frage, wie ein Gesellschaftssystem die kompakte Figur des Fremden auffasst und institutionelle Lösungswege für den Umgang mit dem Fremden skizziert. Neben diesen gesamtgesellschaftlichen Perspektiven auf den Fremden existieren in dem Maße, in dem das Moment funktionaler Differenzierung historisch an Bedeutung gewinnt, zusätzlich spezifischere Beobachtungsweisen des Fremden, die sich die Kognitionen und Normen der Funktionssysteme zu eigen machen, um den Umgang mit dem Fremden zu strukturieren.

Eine erste funktionsspezifische Perspektive auf den Fremden wird in Gesichtspunkten des Rechts und rechtlich geschützter Erwartungen formuliert. Bereits in vielen Gesellschaften der Antike existiert ein Gastrecht als ein Set von Erwartungen, die ein Fremder unter bestimmten Bedingungen legitimerweise haben kann, dass er als ein Gast für eine begrenzte Zeit aufgenommen und in Leib und Eigentum nicht beeinträchtigt wird. Am Ende der Frühen Neuzeit fügen Rechtstheoretiker und Philosophen wie Carl Gottlieb Suarez und Immanuel Kant dem Gastrecht die Idee eines Besuchsrechts hinzu, das als ein Recht verstanden wird, das allen Bewohnern der Erde zusteht, mit Einwohnern anderer Länder einen »Verkehr« zu versuchen und zu diesem Zweck die jeweiligen Länder aufzusuchen ${ }^{16}$. Interessant ist an Konstruktionen dieses Typs, dass sie im Prinzip eine Rechtsgemeinschaft voraussetzen müssen, die die Grenzen der jeweiligen Gesellschaft und ihrer Mitglieder überschreitet, damit im Rahmen dieser Gemeinschaft und auf der Basis dieser übergreifenden Zugehörigkeit dem Fremden gewisse Rechte eingeräumt werden können. Es gibt also eine Art (unbeabsichtigten) Globalisierungseffekt dieser Konstruktionen.

Ähnliches tritt in Termini von »Politik« auf, sobald man die Bürger und Mitglieder eines politisch-gesellschaftlichen Systems als Citizen auffasst, denen Fremde gegenübertreten, die Citizen in einem anderen gesellschaftlich-politischen System sind. Erneut wird eine implizite politische Gemein-

16 Siehe Immanuel Kant, Zum ewigen Frieden. Ein philosophischer Entwurf [1795], in: Wilhelm Weischedel (Hg.), Werke in zehn Bänden, Bd. 9: Schriften zur Anthropologie, Geschichtsphilosophie, Politik und Pädagogik, Darmstadt 41975, S. 191-251, hier S. 213f. [4. ND der Ausg. Darmstadt 1964]; Carl Gottlieb SuArez, Vorträge über Recht und Staat, hg. v. Hermann CoNRAD/Gerd Kleinheyer, Köln u.a. 1960, S. 188. 
schaft sichtbar, der beide angehören und die jenen semantisch-politischen Raum konstituiert, in dem die Benennbarkeit dieser politischen Mitgliedschaft mit ungefähr demselben Terminus erst erzeugt wird.

Ein drittes Beispiel bietet die Religion, wenn sie beispielsweise diejenigen, die nicht Christen sind, mit Termini wie »Heide«, »Wilder«, »Barbar« belegt. Dies sind klare Innen/Außen-Unterscheidungen, die Gemeinsamkeiten zu verweigern versuchen. Sobald an die Stelle dieser Exklusionsbegrifflichkeiten aber die Bezeichnung einer anderen, alternativen religiösen Zugehörigkeit tritt (also etwa »Hindu «, »Muslim «) $)^{17}$, werden erneut auch Gemeinsamkeiten in einer Welt der Religionen sichtbar, in der die Grenzen der Religion nicht mehr mit den Grenzen jener lokalen und regionalen Verbünde zusammenfallen, die Fremde ausgrenzen.

Man könnte als ein viertes Beispiel die Besonderheiten menschlicher Verwandtschaftssysteme nennen. Diese ruhen bekanntlich darauf, dass man eine Partnerbindung/eine Ehe mit einer Fremden/einem Fremden eingeht und diese Fremde oder dieser Fremde auf der Basis der monogamen Stabilisierung dieser Partnerbindung in den Gruppenzusammenhang eintritt, dem sein/ihr Partner angehört und dass zusätzlich die Verbindungen zu der Herkunftsgruppe (im Unterschied zu allen anderen Primaten) nicht abreißen, sondern fortdauern. Diese Verwandtschaftsstruktur ist der Ursprung der Großgruppen und komplexen Ineinanderschachtelungsverhältnisse in menschlichen Sozialsystemen und fungiert als eine entscheidende Dynamik hinter dem Wachstum menschlicher Sozialsysteme, das auf Gesellschaften hinführt, für die es bei anderen Primaten keine Parallelen gibt ${ }^{18}$.

Die Liste der Beispiele lässt sich leicht verlängern. Sie alle weisen dieselbe Logik auf. Wenn man die Beobachtung des Fremden in den Sondersystematiken der Funktionssysteme vollzieht, kann sich die Globalisierungsdynamik geltend machen, die den Sonderperspektiven der Funktionssysteme als eine Möglichkeit inhärent ist. Unterscheidungen, die zunächst ausgrenzende

17 Derselbe Effekt tritt auf, wenn man eine Hierarchie akzeptiert, die den Begriff des Menschen auf einer höheren Ebene verortet, als dies für den Begriff des Christen gilt. So beispielsweise 1765 Thomas Abbt, der gegen die seit Thomasius vertraute evolutionäre Stufenfolge von »Bestien«, »Menschen« und »gottselige Christen« einwendet, dass der Begriff des Christen »eine eingeschränktere und engere Beziehung als der Name Mensch mit sich führet« (Vom Verdienste $1765 / 72$, zit. n. Hans Erich BöDEKER, Menschheit, Humanität, Humanismus, in: Otto Brunner/Werner Conze/Reinhart Koselleck [Hg.], Geschichtliche Grundbegriffe. Historisches Lexikon zur politisch-sozialen Sprache in Deutschland, Bd. 3, Stuttgart 1982, S. 10631128, hier S. 1087f.).

18 Siehe dazu Bernard Chapais, Primeval Kinship. How Pair-Bonding Gave Birth to Human Society, Cambridge, Mass. 2008; ders., The Deep Social Structure of Humankind, in: Science 331 (2011), S. 1276f.; R. Hill KIM u.a., Co-Residence Patterns in Hunter-Gatherer Societies Show Unique Human Social Structure, in: Science 331 (2011), S. 1286-1289. 
Unterscheidungen waren, können dann in langen Zeiträumen internalisiert werden und die Binnendynamiken eines Funktionssystems bestimmen, das nur noch variierende Inklusionsformen, aber keine Fremden mehr kennt.

\section{Weltgesellschaft ohne Fremde}

Die gesellschaftliche Situation der Gegenwart ist dadurch gekennzeichnet, dass das Attribut »Gesellschaft« nur noch einmal vergeben und verwendet werden kann. Gesellschaften gibt es im Unterschied zur bisherigen Geschichte menschlicher Sozialsysteme nicht mehr im Plural, sondern nur noch in der Form eines einzigen Systems der Weltgesellschaft, das die ungeheure Vielzahl und Vielfalt von fortexistierenden und sich neu bildenden Sozialsystemen ausnahmslos in sich inkorporiert. Im Blick auf Fremde ist die entscheidende Bedingung der Weltgesellschaft, dass dieses System alle Menschen als Inklusionsadressen in sich einschließt, auch wenn es sich in vielen einzelnen Fällen um prekäre Formen der Inklusion handeln wird. Aber dennoch gibt es niemanden, den man einen »Fremden der Weltgesellschaft« nennen könnte, so dass die Weltgesellschaft das erste Sozialsystem in der menschlichen Geschichte ist, das ohne ein soziales Außen auskommen muss. Alles Soziale, alle Kommunikation und alle Beschreibungen finden in der Weltgesellschaft statt; also muss dieses System seinen sozialen Zusammenhalt formulieren, ohne auf soziale Grenzziehungen setzen zu können. Die »Gemeinsamkeit des Schicksals« (Commonality of Fate) ist die wichtigste Formulierung des sozialen Zusammenhalts der Weltgesellschaft, dem das negative Moment der Stabilisierung durch Ausgrenzung von Fremden abhanden gekommen ist. Auf der Außenseite der Weltgesellschaft stehen nicht mehr soziale Andere, für die wir negative Stereotype erfinden könnten, sondern ökologische Bedingungen der Fortsetzbarkeit der menschlichen Lebensform, die wir vermutlich respektieren müssen, wenn uns an dieser Fortsetzung der Form des menschlichen Lebens liegt. Eine angemessene Selbstbeschreibung der Weltgesellschaft wird dann mindestens diesen zwei Bedingungen einer Sozialwelt ohne Fremde und ohne soziales Außen und der ökologischen Abhängigkeit der Fortdauer dieser Sozialwelt auf kognitiv überzeugende Weise Rechnung tragen müssen. 


\title{
Theo Sundermeier
}

\section{Die Begegnung mit dem Fremden}

\author{
Plädoyer für eine Hermeneutik des Vertrauens
}

1.

"Vertrauen« und »Fremde« sind Kernbegriffe des Themas. Was darunter zu verstehen ist, muss vorab geklärt werden. Zwei Begegnungen sollen das Problem erläutern.

Das kleine Mädchen eines Missionars, das in Westafrika aufgewachsen ist, sieht in Deutschland auf dem Bahnhof Afrikaner. »Papa«, ruft sie, »schau doch, da sind Menschen«!

Als ich in Thailand vor Jahren ein buddhistisches Kloster besuchte, traf ich dort einen jungen Deutschen, der sich dem Mönchsleben verschrieben hatte. In einem längeren Gespräch kam ich auch auf das Thema »Glauben« zu sprechen, wohl wissend, dass der Buddhismus sich nicht als Glaubensreligion, sondern als Erfahrungsreligion oder gar als Philosophie versteht. »Nein«, sagte er, »ein im Sinne des Christentums verstandener Glaube wird nicht gefordert. Den gibt es nicht. Aber Vertrauen muss man schon haben, Vertrauen darauf, dass der Buddha die Wahrheit erkannt hat. Vertrauen muss man haben, um sich darauf einlassen zu können, Vertrauen, dass man Erleuchtung erlangen wird «.

Wer ist ein Fremder? Und wie verhalten sich die Menschen ihm gegenüber? Jahrelange Erfahrungen in einer Kleingesellschaft haben mich gelehrt, dass es letztlich drei Kategorien von Fremden gibt. Da ist 1. der aus der Ferne kommende Fremde. Er wird als potenzieller Feind angesehen. Er lebt außerhalb des schutzgewährenden begrenzten Territoriums. Die Gesetze des Hauses und des Stammes gelten nicht. Er wird nicht notwendigerweise als Mensch angesehen. Sich selbst nennen die Stammesangehörigen »Menschen«, nicht jedoch notwendigerweise die jenseits der Grenze lebenden Fremden. Sie sind potenzielle Feinde, die man bei einer Fehde tötet oder zu Sklaven macht. Als Sklaven sind sie rechtlos und können bei einer Einheirat nur über Generationen hinweg in die Gemeinschaft integriert werden.

2. Auch die Händler sind Fremde. Sie wohnen z.B. bei den im heutigen Ghana beheimateten Ashanti in besonderen Stadtvierteln. Sie haben keine Rechte, außer dass sie handeln dürfen. Sie sind gleichsam tolerierte Gäste, jedoch ohne den Gaststatus. Sie dürfen nur innerhalb ihres Viertels wohnen 
und nur Nicht-Ashanti heiraten. Sie leben außerhalb ritueller Begehungen und unterliegen keinen religiösen Verpflichtungen. Sie unterstehen anderen Ahnen und Göttern. Handelsbündnisse auf Gegenseitigkeit können geschlossen werden, wie natürlich auch mit den potenziellen Feinden außerhalb aus Verteidigungszwecken Bündnisse geschlossen werden können.

Von diesen beiden Gruppen ist 3. der Fremde zu unterscheiden, der als Gast nur wenige Tage bleibt oder der sich hier ganz niederlassen will. Das Gastrecht gilt in verschiedener Weise überall in allen Kulturen. Dass er sich den Gesetzen und Gewohnheiten des Hauses und Landes einfügt, wird als Selbstverständlichkeit angenommen. Seinen ursprünglichen Status verliert er, wenn er für immer bleiben will. Die südafrikanischen Tswana sagen: »Der Elefant, der über den Fluss kommt, wird kleiner«.

Die ethnosoziologische Sicht des Fremden muss ergänzt werden durch die sozialpsychologische. Es geht nicht nur um die Frage wer ist fremd, sondern auch was ist fremd am Fremden. Was macht ihn fremd, abgesehen davon, dass er exterritorialer Herkunft ist.

Wir müssen zwei Ebenen unterscheiden. 1. Das Fremde, begriffen als Fremdartigkeit, ist auf der emotionalen Ebene angesiedelt und beschreibt die spontane, unreflektierte Reaktion auf die Begegnung mit Menschen, die nicht der eigenen Lebenswelt angehören. »Fremd« ist dabei durchaus ein relationaler Begriff. Der Andere ist mir fremd im Verhältnis zum mir Vertrauten. Für das Missionarskind waren Afrikaner vertraut, darum freute es sich »Menschen « zu sehen. Die Erscheinung, die Bewegung, das Auftreten, all das vermittelt Vertrautheit oder eben Fremdheit.

Das Auge ist das erste Wahrnehmungsorgan, das Ohr kommt sekundär hinzu. Es achtet auf die Differenz der Aussprache, auf die Tonmelodie, die Artikulierung. Ebenso wichtig wie das Auge ist der Geruchssinn. Der Grund ist entwicklungspsychologisch bedingt und hat symbolische Bedeutung. Der Geruchssinn ist ein $»$ Sinn der Nähe $\ll^{1}$. Er internalisiert das Fremde und legt fest, was vertraut, fremd oder als eklig-feindlich begriffen wird. Der Körpergeruch kennzeichnet den Menschen. Durch den Oralsinn wird er zum eigenen. Das ist der Grund, warum wir auf Gerüche so sensibel reagieren, selbst dann noch, wenn der Geruch vergangen ist, denn sie prägen sich ein, stiften Erinnerung und richten Grenzen auf oder bauen sie ab. »Ich kann den anderen nicht riechen«, diese Unmutsäußerung signalisiert höchste Fremdheit und richtet eine kaum zu überwindende Barriere auf.

Die durch Auge, Nase und Ohr empfundene Fremdartigkeit des Fremden darf nicht verwechselt werden mit dem Befremden, das durch Krankheit, Altersunterschied und ungewöhnliches Sozialverhalten hervorgerufen wird.

1 Hubert Tellenbach, Geschmack und Atmosphäre. Medien menschlichen Elementarkontakts, Salzburg 1968, S. 27. 
Hier ist das Fremdartige der Mantel, der sich um das immer noch Vertraute legt. Es genügt, den Kern des Vertrauten zu wissen oder auch nur zu vermuten, um diese Fremdheit abzubauen. Hier hat der Begriff des Fremden eine stark subjektiv besetzte ästhetische Komponente.

Die zweite Ebene des Fremdbegriffes berührt die fremde Ordnung. Sie ist der Grund dafür, warum Stammesgesellschaften und Religionen den Fremden aussondern und nur partiell bereit sind, ihn einzuordnen. Die fremde Ordnung zeigt an, dass das Phänomen der Fremdartigkeit mehr ist als eine individuell und subjektiv bestimmte Äußerlichkeit. Sie stellt eine grundlegende Differenz dar, die das ganze Lebensmuster ausmacht und die mit dem Vertrauten gar nicht oder nur begrenzt kompatibel ist. Das Lebensmuster, oder sagen wir die Kultur, meint das Gesamte der menschlichen Errungenschaften, die das Leben einer Gruppe bestimmen: die Sprache, die religiösen, gesellschaftlichen und politischen Gestaltungen, die ästhetische Emotionalität sowie das Verhältnis zur Welt und Umwelt.

Auch kulturelle Fremdheit wird relational erfasst, denn die Fremdheit wird immer an der eigenen Kultur, an der eigenen Umgebung gemessen und im Vergleich zu ihr begriffen. Die Unsicherheit in der Begegnung mit Fremden zu überwinden, dem dient das Gastrecht. Es gewährt für eine bestimmte Zeit Schutz und Sicherheit. Der Fremde und der Gast sind gleichsam für eine kurze Zeit exterritorial, leben jenseits der vorgegebenen sozialen und familiären Ordnung. Das gemeinsame Essen hat rituellen Charakter und spiegelt etwas von der Heiligkeit, die den fremden Gast umgibt. Der Gast ist heilig, das gilt für alle Kulturen. »Heiligkeit« aber birgt beides, Gefahr und Segen. Darum ist das Gastrecht mit Meidungen und Tabus umgeben, damit weder die eigene Ordnung noch die des Fremden tangiert wird. In vielen traditionalen Kulturen gibt es deswegen speziell ausgewählte Personen, die den fremden Gast in den Stamm oder das Dorf einführen, ihn begleiten, ihm helfen, keine Fehler zu machen, die aber auch aufpassen, ob der Gast sich nicht als heimlicher Feind entpuppt, der dem Ort Schaden zufügen will. Diese »Fremdenführer« sind Brückenbauer und übernehmen stellvertretend die Aufgabe, die letztlich jeder wahrnehmen sollte, aber dazu nicht imstande ist.

Für den Fremden aber gilt das folgende afrikanische Sprichwort als Grundregel seines Auftretens: Der Fremde hat große Augen, aber sieht nichts. Er hat große Ohren, aber er hört nichts.

Ehe wir uns weiter auf dem Weg des Fremdverstehens begeben, muss ein wichtiger Einwand bedacht werden. Ist es angemessen, mit diesem Rekurs auf die Verhaltensweisen traditionaler Kulturen die Probleme unserer Zeit 
anzugehen? Wir leben im Zeitalter der Globalisierung. Sind das nicht alles überholte Kategorien, in denen wir uns bewegen? Das Fernsehen hat in der Tat eine der entscheidendsten Veränderungen in den Gesellschaften gebracht wie in gleicher Weise der Internetzugang. Wenn z.B. Star TV, das in Hongkong seinen Sitz hat und zum Murdoch-Imperium gehört, seine Sendungen zeitverschoben von Korea in den Persischen Golf sendet und etwa 2 Milliarden Zuschauer auf vier Kanälen rund um die Uhr erreicht und Spielfilme mit Sylvester Stallone, Arnold Schwarzenegger, Sportsendungen vom American Football etc. sendet und Internationalität darin besteht, dass die Comics aus Japan und dessen Samurai-Soapsendungen mit Untertiteln in den verschiedensten Sprachen ausgestrahlt werden, leichte chinesische Musik und der ganze Ausstoß indischer rührseliger Filmproduktionen, dann werden kulturelle Unterschiede eingeebnet. Geschmäcker und Lebensstile werden vereinheitlicht und nivelliert. United Colours of Benetton reduziert die Farbenpalette der Kleidung, setzt Trends, die nachgemacht werden. Können sich dagegen die von Samuel Huntington $^{2}$ so vehement beschworenen Unterschiede der japanischen, hinduistischen und islamischen Welt noch halten? Andererseits bedeutet das Internet Zugang zum Wissen, bietet Informationsvorsprung, schließt Freiheitserfahrungen ein und internationalisiert Rechtsvorstellungen, wie man - wenn auch noch zögerlich - in verschiedenen islamisch geprägten Ländern sehen kann.

$\mathrm{Zu}$ Globalisierung gehört weiter der rasant wachsende Verelendungsprozess, die wachsenden Slums in den kaum noch zu regierenden Megastädten der Welt, die sprunghaft anwachsenden Flüchtlingsströme, die zunehmenden Umweltkatastrophen, die vor kulturellen Grenzen keinen Halt machen. Ist also eine tiefgreifende Nivellierung und Einebnung kultureller Lebensweisen unsere Zukunft, in der die verschiedenen ökonomischen Marktgesetze eine beherrschende Rolle spielen?

Gewiss, der Nationalstaat verliert seine Bedeutung angesichts der Internationalisierung und Ökonomisierung aller Bereiche. Tiefe kulturelle Abbrüche sind in Ost und West, Nord und Süd erkennbar. Ein kultureller Relativismus breitet sich aus und führt zu Identitätsverunsicherungen.

Die Gegenbewegung ist weltweit zu erkennen: Refundamentalisierung und ein Ethnoprotektionismus sind der Versuch, die ursprüngliche Souveränität und Identität wieder zu gewinnen und sich nicht wehrlos der Macht des Cyberspace zu überlassen. Partikularismus, Stärkung des Wir-Gefühls (und sei es durch Weltmeisterschaften in den verschiedenen Sportarten, die

2 Vgl. Samuel Huntington, Kampf der Kulturen. Die Neugestaltung der Weltpolitik im 21. Jahrhundert, München 1996. 
die Kohärenz nach innen festigen) sind Kennzeichen dieser Reaktion. Welche Bedeutung die Ethnizität selbst in unserer multikulturellen Gesellschaft bekommt, zeigt Ulrich Menzel am Beispiel Frankfurts auf:

Das Kürschner-Handwerk ist in den Händen von Griechen (aus Kastoria), die Änderungsschneider sind Türken, den Straßenverkauf von Zeitungen betreiben Pakistani, den Rosenverkauf in den Kneipen Inder, die illegalen Kolonnen auf den Großbaustellen werden von Polen rekrutiert, der Putzfrauenmarkt wird von Polinnen bedient, das Hütchenspiel von Kosovo-Albanern kontolliert, und die Kleindealer mit Drogen sind Ghanaer - nicht zu sprechen von den diversen Jugo- oder Chinesen-Gangs, die in der Schutzgelderpressung engagiert sind oder den wohlfeilen transkontinentalen personellen Nachschub für die China-Restaurants organisieren ${ }^{3}$.

Die Ethnisierung, so wird deutlich, restituiert oder setzt die Verhaltensweisen der primären Kleingesellschaften fort.

Das gilt in bemerkenswerter Weise auf religiösem Gebiet durch den Islam, der damit diesem Verhalten weltweite religiös-juristisch sanktionierte Geltung verschafft. Wo der Koran und seine Ansprache auf das Leben umfassende Gültigkeit besitzt, also in islamischen Staaten, da ist »Haus des Friedens«, Haus des Islam. Draußen aber ist »Haus des Krieges«. Da die ganze Welt dazu ausersehen ist, Haus des Friedens zu werden, ist es die Pflicht eines jeden Muslim, sich dafür zu engagieren (»djihad«).

Der Islam unterscheidet drei Gruppen von Menschen: die Muslime, die Angehörigen der Schriftreligionen und die Ungläubigen. Damit setzt sich das aus den Stammesreligionen bekannte Schema der Einteilung der Menschen im Islam weltweit fort. Innerhalb des Hauses des Islam sind alle Menschen gleich, allein der Unterschied der Geschlechter zählt sowie der der Frömmigkeit und guten Werke, die den einen höher gestellt sein lassen als den anderen. Außerhalb des Hauses des Islam leben die Ungläubigen, die beides sind, potenzielle Feinde und potenzielle Gläubige. Sie müssen mit dem Islam konfrontiert werden, damit sie die Möglichkeit der freien Bekehrung und Unterwerfung haben. Bekehren sie sich nicht, muss das Schwert sprechen. Anders verhält man sich gegenüber den Christen und Juden. Wenn sie sich nicht bekehren wollen, werden sie nicht gezwungen den Islam anzunehmen, sondern bekommen den Status der »dhimmi«, der sogenannten Schutzbefohlenen zugewiesen, was dem niederen Stand der Metöken in Griechenland, dem der Fremdlinge in Israel und dem der Händler in den Stammesgesellschaften entspricht. Sie haben Wohnrechte, dürfen den eigenen Kultus begrenzt beibehalten und müssen höhere Steuern zahlen.

3 Ulrich Menzel, Globalisierung versus Fragmentierung, Frankfurt a.M. 1998, S. 51. 
Es sollte nicht übersehen werden, dass diesen drei ethnosozialen Zuordnungen von Fremden und Einheimischen drei sozial-psychologische Begegnungsmodelle entsprechen, die auch für unser Verhalten gegenüber dem Fremden bestimmend sind. Selbst in bestimmten parteipolitischen Entscheidungen sind sie erkennbar.

Ich nenne das erste das »Alteritätsmodell«. Die Andersheit der Anderen wird hervorgehoben, zum Guten wie zum Schlechten. Die Anderen sind diejenigen, die von außen in das Land kommen. Abwehr ist dabei die erste und elementarste Reaktion. Die Andersheit wird als Bedrohung empfunden, denn das eigene Wertgefühl und der engere soziale Zusammenhang stehen in Gefahr. Je nach Kontext werden die Anderen dämonisiert, zu »Heiden« gemacht (Heide ist man nicht, das ist man nur aus der Sicht anderer), zu »Pollacken«, zu »Kümmeltürken« ${ }^{4}$. Die Metaphern, mit denen die Anderen bezeichnet werden, verdüstern sich, Monstermetaphern, rassistische Begriffe nehmen überhand ${ }^{5}$. Die Anderen sind das Beängstigende, weil sie und ihre Kultur unbekannt sind. Es kann kein Vertrauen aufkommen, Unordnung droht im Zusammenleben.

Zugleich wirkt die Distinktion nach innen stabilisierend und verfestigt den sozialen Zusammenhang gegenüber dem Anderen, Fremden. Grenzziehungen, auch kulturelle, haben immer die doppelte Wirkung, sie haben eine limitische Funktion nach außen und sollen einen konfliktfreien Raum nach innen schaffen.

Das »Komplementaritätsmodell« entspricht dem »Händlermodell«. Hier ist die Faszination treibendes Motiv für das Interesse am Fremden. Die andere Kultur und ihre Religion stellen das zur Verfügung, was der eigenen zu fehlen scheint. Man braucht die Ergänzung. Die Händler waren in allen Kulturen diejenigen, die den Austausch zwischen den Völkern bewerkstelligten. Ihre Präsenz soll bereichern, Defizite ausfüllen. Ein wechselseitiger Austausch findet jedoch nicht statt.

Die Präsenz fremder Religionen bei uns bestätigt diesen Eindruck. Der Buddhismus wirkt auf viele faszinierend, einige Elemente werden aufgegriffen und verinnerlicht. Der Buddhismus selbst aber verändert sich nicht. Im Dialog mit dem Islam zeigen christliche Dialogpartner eine weiche, offene Seite. Auf Seiten des Islam konnte ich das bisher nicht feststellen.

Das »Gleichheitsmodell«, das heute vor allem von den »Multi-Kulti«Befürwortern und Psychologen vertreten wird, weitet das Modell des Gastrechts universal aus und geht von dem Bewusstsein von der Gleichheit der

4 Vgl. Medienprojekt Tübinger Religionswissenschaft (Hg.), Der Islam in den Medien, Gütersloh 1994.

5 Vgl. dazu Jutta Bernard u.a., Auf der Suche nach einem neuen Feindbild. Eine vergleichende Metaphernanalyse zu Kommunismus und Islam, in: Ebd., S. 198-207. 
Menschen (in Ursprung und Wesen) und ihrer Zusammengehörigkeit aus. Die Bezeichnung »Menschen« (»Bantu«) erleichtert den Zusammenschluss mit anderen Stämmen, mit denen man durch eine gemeinsame Ursprungsmythe, durch Sprachverwandtschaft oder territorial verbunden ist oder ein Zusammenschluss durch Krieg und Naturkatastrophen notwendig wird. Wechselseitige rituelle Partizipation wird dann möglich. Die Händler brauchten allemal diese Gleichheitsgrundlage, denn Warenaustausch war nur möglich und Bündnisse konnten nur geschlossen werden, wenn sie im Namen eines Gottes stattfanden. Der Göttervergleich in der Antike hat hier seinen Ursprung, der in der hellenistischen Welt zu einer offenen Religionstoleranz führte, gepaart mit echtem philosophischen Interesse an den anderen Religionen, die allerdings ganz im Rahmen des eigenen Systems interpretiert wurden ${ }^{6}$.

Die Frage, ob diese Grundhaltung das Interesse an der anderen Kultur fördert und ein Verstehen ermöglicht oder notwendig macht, muss verneint werden. Die andere Kultur, ihre Religion eingeschlossen, wird am eigenen Maßstab gemessen. Sie wird nicht in ihrer Andersheit wahrgenommen. Auch wenn diesem Modell das eigene philosophische und religiös geprägte Kulturbewusstsein das Maß aller Dinge ist, besitzt es genügend Potenzial, zu echtem, vertrauensvollem Verstehen, wenn der entscheidende Fehler überwunden wird, die Distanz zum anderen zu verlieren.

Worum es geht, lässt sich mit einem Gedicht des hintergründigen Christian Morgenstern verdeutlich:

\section{Der Lattenzaun}

Es war einmal ein Lattenzaun, mit Zwischenraum hindurchzuschaun.

Ein Architekt, der dieses sah, stand eines Abends plötzlich daund nahm den Zwischenraum heraus und baute draus ein großes Haus.

Der Zaun indessen stand ganz dumm, mit Latten ohne was herum.

Ein Anblick gräßlich und gemein, drum zog ihn der Senat auch ein.

Der Architekt jedoch entfloh nach Afri- oder Ameriko.

6 Vgl. dazu Jan Assmann, Translating Gods. Religion as a Factor of Cultural (Un)translatability, in: Sanford Budick/Wolfgang Iser (Hg.), The Translatability of Cultures. Figurations of the Space Between, Stanford u.a. 1996, S. 25-36. 
Präziser kann es kaum gesagt werden: Nur wo der Abstand zwischen den Latten (sprich Kulturen, Religionen, Gesellschaften) bewahrt wird und kein Architekt (sprich ein Vertreter des New Age, einer pluralistischen Religionstheologie o.ä.) kommt, um daraus ein gemeinsames Haus zu bauen - es werden nur Luftschlösser daraus - nur wo zugleich die Zusammengehörigkeit, die Zuordnung der Latten (Kulturen, Religionen, politischen Systeme), wo also Differenz und Relationalität respektiert werden, ist die Voraussetzung zu vorurteilsfreier Begegnung gegeben, kann Vertrauen und Verstehen wachsen.

Es ist aufschlussreich, dass auch aus der Germanistik in der interkulturellen Interpretation ähnliche Handlungsmodelle entworfen werden. Sie sind durchaus übertragbar auf den eingespielten Umgang mit den Fremden in Gegenwart und Geschichte.

Jürgen Wertheimer nennt drei Modelle, wie mit dem Fremdphänomen umgegangen wird:

1. Das Schema der Mac-Donaldisierung, also jene Art des Zugriffs, die auf der Basis der Überbewertung der Fremdkultur reüssiert. Dabei handelt es sich um eine Art kolonialistischen Zugriffs, einer sich mittels der Transplantation absolut setzenden eigenen Kultur. Ein Übertragen europäisch-westlicher Verfahrensweise auf das Territorium fremder Gebiete [...].

2. Das zweite Modell wird mit der Chiffre Saint-Exupéry benannt. Es handelt sich um jene Vorgehensweise, die aus dem Kleinen Prinzen bekannt ist: Dort wird die fremde Kultur durch Bezähmung vertraut gemacht, verwandelt, nicht ohne zugleich Verantwortung für diese verwandelte Kultur zu übernehmen. In Bezug auf diese Verantwortung unterscheidet sich dieses zweite Modell grundsätzlich von dem zuerst genannten.

3. Das dritte der Modelle [...] sei mit dem Begriff der Verfremdung überschrieben. Diese Vorgehensweise beinhaltet ein ganzes Bündel von Verfahrenstechniken, die vom Verfremden der eigenen Wirklichkeit bis hin zum verfremdeten Blick auf die unbekannte Kultur reichen. Weit über Brechts didaktisches Modell hinausweisend, findet sich dieser Ansatz insbesondere im Kontext postmoderner und dekonstruktivistischer Methoden?

Das dritte Modell gehört fraglos in die Rubrik Literaturwissenschaft, hat aber doch auch Übereinstimmungen mit dem Komplementärmodell.

7 Jürgen Wertheimer, Literatur als Medium der Wahrnehmung und Verarbeitung von Fremdheit, in: Erfahrungen des Fremden. Vorträge im Sommersemester 1992, Heidelberg 1992, S. 81-96, hier S. 82. 
3.

Welche methodischen Konsequenzen ziehen wir aus diesen Überlegungen? Ist der Ruf nach einer Hermeneutik des Vertrauens methodisch zu leisten? Wenn Dietrich Ritschl selbst im Blick auf die interkonfessionelle Verständigung und das ökumenische Verstehen fragt, ob überhaupt »inmitten differierender semiotischer Systeme« eine »Hermeneutik des Vertrauens« möglich is ${ }^{8}$, wie viel mehr ist Skepsis im Blick auf interkulturelles Verstehen angesagt. Aus ethnologischer Sicht wird diese Skepsis verstärkt. Es ist, schreibt Klaus Müller,

zu bezweifeln, daß man eine fremde Kultur, in die man nicht hinein sozialisiert wurde, überhaupt jemals verstehen kann. Und die ethnomethologische `Normalität der interkulturellen Kommunikation scheint das wechselseitige Nicht-Verstehen zu sein?.

Ich meine nicht, dass zu solcher Skepsis Anlass besteht. Allerdings ist das von Gadamer anvisierte Ziel des Verstehens, die »Horizontverschmelzung«, nicht nur illusionär, sondern auch falsch. Horizontverschmelzung heißt Aufhebung der Differenz. Nur wenn zwei Subjekte miteinander verschmelzen, findet eine Horizontverschmelzung, wie der schöne suggestive Ausdruck sagt, statt. Darum aber darf es gerade nicht gehen. Die Würde der Differenz ist gerade Leitmotiv und Grundlage vertrauensvollen Verstehen ${ }^{10}$.

Aufgrund meines langjährigen Aufenthalts und Lebens in afrikanischen Kulturen, meine ich folgende "praktische Kunstlehre des Verstehens«, um einen Ausdruck Schleiermachers zu gebrauchen, entwerfen zu können. Praxis und Theorie gehen dabei Hand in Hand. Die angezeigten Schritte sind nicht nur einlinig zu verfolgen. Sie sind einerseits von oben nach unten zu befolgen, das Raster ist weiter von links nach rechts zu lesen, aber zugleich können die Schritte zirkulär verstanden werden, insofern das Verstehen ein Prozess ist, der in den sich wiederholenden Schritten neue Erkenntnisse vermittelt.

8 Dietrich Ritschl, Theorie und Konkretion in der Ökumenischen Theologie. Kann es eine Hermeneutik des Vertrauens inmitten differierender semiotischer Systeme geben?, Münster 2003, bes. Teil II.

9 Klaus MüLleR, Konstruktivistische Perspektiven kultureller Wirklichkeit, in: Alois WIERLACHER / Andrea Bogner (Hg.), Handbuch interkultureller Germanistik, Stuttgart 2003, S. 88-96, hier S. 95 f.

10 Vgl. Jonathan SACKs, The Dignity of Difference. How to Avoid the Clash of Civilizations, London u.a. 2002 (ND 2007). 
Schritte zum interkulturellen Verstehen ${ }^{11}$

\begin{tabular}{|c|c|c|c|}
\hline $\begin{array}{c}\text { Das fremde } \\
\text { Gegenüber }\end{array}$ & $\begin{array}{c}\text { Subjektive } \\
\text { Haltung }\end{array}$ & $\begin{array}{c}\text { Objektive } \\
\text { Erfassung }\end{array}$ & Handlungsebene \\
\hline Phänomenebene & Epoché & $\begin{array}{c}\text { Beschreibende } \\
\text { Analyse }\end{array}$ & $\begin{array}{c}\text { Wahrnehmung } \\
\text { in Distanz }\end{array}$ \\
\hline Zeichenebene & Sympathie & $\begin{array}{c}\text { Kontextua- } \\
\text { lisierung }\end{array}$ & $\begin{array}{c}\text { Teilnehmende } \\
\text { Beobachtung }\end{array}$ \\
\hline Symbolebene & Empathie & $\begin{array}{c}\text { Vergleichende } \\
\text { Interpretation }\end{array}$ & $\begin{array}{c}\text { (Teil-) } \\
\text { Identifikation }\end{array}$ \\
\hline Relevanzebene & Respekt & $\begin{array}{c}\text { Übersetzung / } \\
\text { Transfer zu uns hin }\end{array}$ & Konvivenz \\
\hline
\end{tabular}

Der erste Schritt, die erste Ebene ist die Grundlage aller weiteren. Alles Verstehen beginnt damit, dass ich die andere Kultur und ihre sie prägende Religion als eine andere, fremde Kultur wahrnehme und respektiere. Die psychologischen Versuche, die das Fremde (mit Freud) als das von mir Verdrängte oder als das zutiefst mir Eigene ansehen, haben hier keinen Platz, ebenso wenig wie die Tendenz, das Fremde mir anzugleichen, wie es Husserl in seiner Phänomenologie propagierte ${ }^{12}$. Die Religionsgeschichte hat der Phänomenologie Husserls (s. u.a. van der Leeuws große Religionsphänomenologie) viel zu verdanken. $\mathrm{Zu}$ Recht ist sie jedoch in ihrer Tendenz zu Ontologisierung in die Kritik geraten. Ich selbst versuche ihr mithilfe der Semiotik ein neues Gesicht zu geben. D.h. wir müssen lernen, dem Fremden so zu begegnen, wie wir uns einem fremden Bild nähern, sei es dem aus der eigenen oder einer fremden Kultur. Wir müssen lernen, die Phänomene selbst sprechen zu lassen. Das bedeutet, dass wir die Tugend der Epoché einüben müssen, nämlich sich in der ersten Begegnung allen Urteilens zu enthalten, so dass eine vorurteilsfreie Begegnung stattfindet. Das erfordert Distanz. Nur so kann das »Phänomen« des Fremden in seiner Andersartigkeit und Fremdheit zur Geltung kommen. Nur so ist eine sachliche Wahrnehmung möglich.

Doch die Wahrnehmung muss in einem 2. Schritt, auf der zweiten, der Symbolebene konkretisiert werden. Das kann letztlich nur durch eine teilnehmende Beobachtung geschehen, eine methodische Forderung, die heute in der ethnologischen Forschung selbstverständlich ist. Wer tiefer in eine andere Kultur und Religion eindringen will, muss an ihren religiösen sowie sozia-

11 Zum Folgenden vgl. Theo Sundermeier, Den Fremden verstehen. Eine praktische Hermeneutik, Göttingen 1996, S. 153-173.

12 Edmund Husserl, Cartesianische Meditationen und Pariser Vorträge, Den Haag 1950, S. 126f. 
len Ritualen und Selbstdarstellungen teilnehmen, denn Riten sind die Architektur einer Kultur. Ihre Zeichen müssen wahrgenommen und im jeweiligen Kontext wahrgenommen werden, wiederum so objektiv wie möglich, aber mit Sympathie, oder besser gesagt, mit vorlaufendem Vertrauen, das davon ausgeht, dass das, was man wahrnimmt, auch die Sache meint, um die es geht. Der Neuling in einer fremden Kultur muss lernen genau hinzuschauen und hinzuhören. Es mag in der fremden Kultur zum Umgang mit Fremden gehören, auf dessen Fragen eine ihm sympathische Antwort zu geben, oder eine, von der man annimmt, dass er sie versteht und annimmt. Was in Wirklichkeit gemeint ist, bleibt ungesagt. Darum muss man auf die Zeichen der sinnlichen Präsenz einer Kultur achten, auf die Gestik, Kleider, die Verhaltensregeln. Sie sind Grenzziehungen, »limitische Symbole« wie W.E. Mühlmann sie nennt. Sie signalisieren Abgrenzungen, Hierarchien und wollen als Identitätszeichen respektiert werden. Reines Fragen führt nicht zum Ziel. Schon Parzival wurde davor gewarnt, Fragen zu stellen. Bloße Instruktion ist wenig nütze, denn die kontextspezifische Deutungskompetenz gewinnt man nur dadurch, dass man sich auf die Situation einlässt. Wechselseitiges Vertrauen wird nur erworben, wenn eine Vorleistung von Vertrauen eingebracht wird.

Die Semiotik hilft uns auch den Unterschied zwischen Zeichen und Symbol zu erfassen. Zeichen sind Hinweise, Symbole aber verhüllen und erschließen Sinn. Hier ist ein Perspektivenwechsel nötig. Die andere Kultur will aus der Perspektive der betroffenen Menschen selbst wahrgenommen werden. Dazu bedarf es auf dieser Ebene, im dritten Schritt, einer gewissen Identifikation mit der anderen Kultur. Identifikation führt nicht zum Verlust der eigenen Identität, insofern ist immer nur eine Teilidentifikation möglich. Aus der Lektüre von Texten ist bekannt, wie solch eine Identifikation mit dem Helden eines Textes zum Verstehen hilfreich ist $\mathrm{t}^{13}$.

Da es jetzt um das Erfassen des Sinnganzen geht, sind dem Verstehen Grenzen gesetzt. Doch es besteht kein Grund zu früh zu resignieren. Die Perspektive und Interpretation der Mitglieder einer Kultur, das muss festgehalten werden, ist in der jetzt anstehenden Phase nicht das allein gültige Kriterium, ebenso wenig wie die Interpretation eines Kunstwerkes seitens des Künstlers alleinige Gültigkeit besitzt. Hier kann der Vergleich, auch mit Aspekten der eigenen Kultur helfen, die Mehrdimensionalität der Symbolik zu erschließen.

13 Eine kulturübergreifende und -vergleichende Identifikationstypologie fehlt bis heute. In der literarischen Hermeneutik wird gelegentlich von einer administrativen, einer sympathetischen, einer kathartischen und ironischen Identifikation gesprochen und im jeweiligen Kontext (Schule u.a.) unterschieden. Vgl. Edith Michel/Willy Michel, Kulturelle Reichweiten und Kategorientransfer, in: Wierlacher/Bogner, Handbuch, S. 8-88, bes. S. 83f. 
Am Beispiel des jungen deutschen Mönches in Thailand kann noch einmal deutlich werden, worum es geht. Er hat sich vollständig mit der anderen Religion in einer fremden Kultur identifiziert, wobei er in doppelter Weise vertraut, dass man ihn, den Fremden, nicht nur im Kloster rituell aufnimmt, sondern auch an den spezifischen Ritualen dieses Landes teilnehmen lässt, die die eigentliche Prägung thailändischer Klöster ausmachen, und dass er hier den letzten Sinn des Mönchslebens und Lebens finden wird.

Ich selbst habe bei meinen ethnologischen Forschungen erfahren, dass mein Gegenüber geradezu begierig war, mich in die Traditionen der Ethnie einzuführen, nachdem ein wechselseitiges Vertrauen gewachsen war. Nun wurde ich dazu auserwählt, die bis dahin nur oral und bruchstückhaft überlieferte Geschichte dieser Ethnie aufzuschreiben, weil man befürchtete, dass mit den noch lebenden Alten das kulturelle Gedächtnis aussterben und die religiösen und historischen Traditionen dem Vergessen anheimfallen würden ${ }^{14}$.

In der Begegnung mit der Symbolwelt einer anderen Kultur kann ein Vergleich mit den entsprechenden Symbolen der eigenen Kultur hilfreich sein (Empathie). Die Schwierigkeit interkulturellen Verstehens besteht hier darin, dass unmittelbare Wahrnehmung und Verstehen leicht auseinanderklaffen. Auch hier ist beides nötig, der Perspektivenwechsel, um das Fremde aus seinem Kontext heraus zu verstehen und eine gewisse Kenntnis der eigenen Kultur und Religion, so dass das oft zu hörende vorschnelle Urteil »das haben wir auch bei uns« außen vor bleibt, die Faszination des Exotismus nicht überhand nimmt und der Wert der eigenen Kultur nicht in Frage gestellt wird.

Am Beispiel des Schleiertragens sei das Problem der Mehrdimensionalität von Symbolen kurz beleuchtet. Bei uns gilt der Schleier als Symbol der Unterdrückung der Frau. In Frankreich galt das Tragen des Kopftuches seitens der Mädchen als ein Symbol, das die Trennung von Religion und Staat in Frage zu stellen schien. Im Iran trugen nach der Revolution selbst moderne Frauen plötzlich den Schador, auch solche, die sich weiterhin der Moderne verpflichtet fühlten. Was später fraglos auf Zwangsvorschriften des KhomeiniRegimes zurückzuführen war, war anfangs ein Zeichen der Solidarität mit der Revolution und eine Protesthandlung gegen den Westen und den amerikanisierten Lebensstil.

14 Vgl. dazu Theo Sundermeier, Die Mbanderu. Studien zu ihrer Geschichte und Kultur, St. Augustin 1977. Zur Situation, in der ich gleichsam zum »König David Report Schreiber« ernannt wurde, vgl. ders., Von der Schriftwerdung oraler Traditionen. Ein Fallbeispiel, in: Ulrich Dehn/Klaus Hock (Hg.), Jenseits der Festungsmauern. Verstehen und Begegnen, Erlangen 2003, S. 466-479. 
In den arabischen Ländern ist das Schleiertragen ein Zeichen sozialer Ordnung. Dem Mann gehört der Außenbereich, der Frau ein Teil des inneren Hauses. Hier hat sie das Sagen, draßßen ist der Mann die Schutzmauer für die Frau. Das bringt der Schleier zum Ausdruck.

In der Türkei hat sich in manchen ländlichen Gegenden eine nonverbale Kultur mit einer eigenen Zeichensprache entwickelt. Die Kopftücher werden mit verschiedenen Zeichen besetzt. Mit der Wahl ihres Kopftuches für das Treffen am Dorfbrunnen kann die Frau ohne Worte sagen, wie sich ihr Mann in der letzten Nacht ihr gegenüber verhalten hat, ob er zärtlich und liebevoll oder roh und grob war, ob sie glücklich oder unglücklich ist.

Wenn eine zum Islam konvertierte deutsche Frau bewusst das Kopftuch trägt, dann ist dies ein öffentliches Bekenntnis zum Islam und ein Zeichen der Solidarität mit den türkisch-islamischen Frauen, aber zugleich auch ein Protest gegen den Körper- und Sexualkult modernen westlichen Lebensstils. Dass darin zugleich eine Absage an das Emanzipationsstreben junger türkischer Frauen enthalten ist, wird von den Frauen vielfach nicht bedacht.

Wir sehen, das Kopftuch bzw. der Schleier hat religiöse, soziale, kulturelle und kommunikative Funktionen und ist in höchst unterschiedlicher Weise sinnstiftend. Dabei wird sich oftmals das, was die Trägerin zum Ausdruck bringen wird, fundamental unterscheiden von dem, was der Rezipient wahrnimmt. Interkulturelle Verständigung muss diese Differenz beachten.

Mit dem 4. Schritt kommt der hermeneutische Verstehensprozess zu seinem Ziel. Hermeneutik ist kein Glasperlenspiel, sondern hat eine eminente praktische Bedeutung für das Zusammenleben in der Nachbarschaft und der Gesellschaft. Das Ziel ist das gelingende Zusammenleben, in dem jeder er selbst sein darf, niemand vereinnahmt wird und dennoch ein gegenseitiges Vertrauen herrscht, so dass ein Austausch möglich wird, der die Würde des anderen respektiert und stärkt.

Den hier notwendigen Brückenschlag, diesen Auftrag des »Fremdenführers« kann nicht jeder durchführen. Doch es muss in Gemeinden, Parteien, Parlamenten und natürlich in den Kirchen Menschen geben, die diese Funktion wahrnehmen können. Brückenfunktion heißt, dass die Brücke nach beiden Seiten hin geschlagen wird: Der Respekt vor dem Fremden muss eingeübt werden, aber auch die Kunst des Übersetzens. Jede Übersetzung ist Veränderung. Damit sie nicht zur Verfremdung führt, bedarf es einer sensiblen Einübung in die Kunst der Hermeneutik. Die hier erforderliche ethische Grundhaltung kann man mit einem abgewandelten Grundprinzip der Ethik Albert Schweitzers »Ehrfurcht vor dem Menschen« nennen. Ehrfurcht vor dem Menschen schließt beides ein, Respekt und Anerkennung. Beides ist nicht dasselbe und sollte auch nicht verwechselt werden. Respekt ist eher subjektiv gefärbt und orientiert sich nicht am Besonderen, sondern am Alltäglichen. Respekt öffnet die Tür zum Erstaunen. Staunen ist nicht nur die 
Mutter der Philosophie, sondern auch der Mutterboden der Hermeneutik. Anerkennung setzt Auseinandersetzung, Hegel zufolge Kampf voraus, nämlich die Auseinandersetzung der sozial unterschiedlichen Klassen. Anerkennung zielt auf Gleichstellung der Menschen, meint die Einsetzung des anderen Menschen in die ihm zugehörige Würde ${ }^{15}$. Sie meint in unserem Zusammenhang Anerkennung der jeweiligen Ordnung, in der der Mensch sich zu Hause fühlt.

Das Ziel des Zusammenlebens habe ich mit dem Begriff »Konvivenz« umschrieben. Die Sache habe ich in Afrika gelernt, den Begriff und seine innere Struktur jedoch von der Befreiungstheologie Lateinamerikas. Der Begriff stammt aus der Nachbarschaftshilfe. Das ist an erster Stelle gemeint: Wir helfen einander, unspektakulär, wo Hilfe nötig und möglich ist. Aber wir lernen auch voneinander. Gerade weil der andere aus einer anders geprägten kulturellen Lebenswelt kommt, meint Konvivenz eine Lerngemeinschaft: Alltagswissen wird ebenso ausgetauscht wie religiöses Wissen. Die gegenseitige Einladung zum Fest aber überwindet Schranken. Das gemeinsame Fest ist der Protest gegen Resignation und der fruchtbare Boden dafür, dass das gegenseitige Vertrauen wächst.

Ich schließe mit einem kleinen Erfahrungsbericht. In ein Mehrfamilienhaus in Stuttgart zieht ein türkisches Ehepaar ein. Ein christlich geprägtes Ehepaar in diesem Haus beschließt, den neuen Mietern durch ein herzliches Willkommen das Einleben zu erleichtern. So kochen sie Kaffee und backen Kuchen, sodass das türkische Ehepaar, wenn es denn einzieht und sich den Mitbewohnern vorstellt, an den gedeckten Tisch eingeladen werden kann.

Das türkische Ehepaar überlegt sich: Wir wollen von Anfang an ein gutes Verhältnis zu den Mitbewohnern haben. Deshalb bereiten wir ein gutes türkisches Essen zu: Wenn nun die anderen Hausbewohner kommen und uns begrüßen, sollen sie gleich in die Wohnung und zum Essen eingeladen werden. Denn Essen stiftet am besten Gemeinschaft.

Doch beide Paare bleiben allein ihn ihrer Wohnung. Niemand kommt. Die Enttäuschung ist groß. »Es lohnt sich halt doch nicht, so gastfrei zu sein«, schließen beide enttäuscht.

Es waren die beiden Hausfrauen, die sich im Supermarkt trafen und sich austauschten. Sie merkten, dass sie beide Gefangene ihrer Kultur gewesen waren, denn im Schwäbischen stellt sich der neue Mieter den Mitbewohnern des Hauses vor, in der Türkei aber kommen diese und begrüßen - gleichsam zum »house warming« - die Neuen.

15 Vgl. Charles TAYLoR, Multikulturalismus und die Politik der Anerkennung, hg. u. komm. v. Amy Gutmann, Frankfurt a.M. 1993. 


\title{
Walter Jaeschke
}

\section{Vom ruhigen Ufer der Selbstsucht zur Selbsterkenntnis des Geistes}

\author{
Hegel über die konstitutive Funktion des Fremden \\ für die Entstehung von Geschichtsbewusstsein
}

\section{Einleitung}

(1) Die Begegnung des christlichen Abendlandes mit den Völkern und Kulturen jener Teile der Erde, die bis zum Beginn des Zeitalters der Entdeckungen entweder völlig oder doch nahezu unbekannt geblieben waren [...], machte nicht nur die zeitliche Begrenzung der Menschheitsgeschichte durch den Rahmen der biblizistischen Chronologie zum Problem, sondern stellte zugleich auch die räumliche Beschränkung des universalhistorischen Blickfeldes in Frage, wie sie bis dahin durch die antik-mittelalterliche Weltbildvorstellung vom orbis terrarum gegeben war. [...] erst nachdem die geschichtliche Erschließung Chinas und die der Neuen Welt zu einem gewissen, wenn auch nur vorläufigen Abschluss gekommen war, folgte der schon längst vollzogenen Erweiterung des Erdbildes auch eine neue Betrachtung der Menschheitsgeschichte unter dem Aspekt der räumlichen Universalität ihres globalen Zusammenhangs.

Es ist nicht die Stimme Hegels, die Sie soeben gehört haben, aber auch nicht etwa meine Stimme, sondern die Stimme des Verfassers einer Göttinger Dissertation aus dem Jahr 1955: von Adalbert Klempt ${ }^{1}$. Ich habe sie hier an den Anfang gestellt, weil ich keine Publikation kenne, die so umfassend und zugleich präzise auf unseren Thema Die Begegnung mit Fremden und das Geschichtsbewusstsein antwortet wie diese Dissertation. Leider ist ihre Rezeption durch das zur Zeit ihres Erscheinens dominierende theolo-

1 Adalbert KLempt, Die Säkularisierung der universalhistorischen Auffassung. Zum Wandel des Geschichtsdenkens im 16. und 17. Jahrhundert, Göttingen u.a. 1960, ${ }^{2} 2001$, S. 106. Dem zum Zeitpunkt des Erscheinens dominanten theologischen Interesse an der Verfügung über den Geschichtsbegriff ist offensichtlich auch der gänzlich unpassende Titel dieser Dissertation geschuldet: Sie beschreibt ja gerade nicht einen »Säkularisierungsprozess«, sondern vielmehr die Verdrängung und Ersetzung früherer theologischer Konzeptionen und die Herausbildung von etwas gänzlich Neuem, von einer zwar »säkularen«, aber keineswegs »säkularisierten« Konzeption. 
gische Interesse an der Okkupation des Geschichtsbegriffs verhindert worden - und ich wünsche ihr, dass ihrer Neuauflage vor wenigen Jahren ein besseres Schicksal beschieden sein möge.

Schon diesen wenigen Sätzen Klempts ist eine Einsicht von entscheidendem Gewicht zu entnehmen: »Geschichtsbewusstsein« ist nicht etwas dem Menschen »Natürliches« - nichts, was man so einfach »hat« und immer schon gehabt hat. Es ist ein kulturell erworbenes Bewusstsein, etwas, was unter bestimmten, zum Teil (aber eben nur zum Teil!) sogar zufälligen kulturellen Bedingungen entstehen kann, jedoch - soweit sich bisher erkennen lässt - trotz modischen Geredes von "post-histoire « vielleicht im Auf und Ab bewusstseinsgeschichtlicher Konjunkturen partiell zurücktreten, sich aber nicht wieder verlieren kann, wenn es erst einmal ausgebildet ist, da es die in langen Epochen gewachsenen Überzeugungen und Institutionen durchzieht, auf denen unser gesellschaftliches Leben beruht. Geschichtliches Denken kann sich jedoch von seinen Entstehungsbedingungen auch ablösen, das Denken einer Kultur insgesamt prägen und sogar auf andere Kulturen »abfärben" - auch Begriffe haben zuweilen einen »Migrationshintergrund«. Denn auch wenn andere Kulturen einen anderen Entwicklungsgang genommen haben, so ist in ihnen ja doch derselbe menschliche Geist wirksam: der Mensch als erkennender und handelnder. Sein bloßes Erkennen und Handeln ist zwar noch keine hinreichende Bedingung für Geschichtsbewusstsein sonst wäre das Geschichtsbewusstsein überall und zu allen Zeiten identisch. Im Erkennen und Handeln eines geistigen Wesens ist jedoch die Rezeptivität für den Geschichtsgedanken angelegt - auch wenn er gleichsam nicht ursprünglich erworben, sondern durch Rezeptionsprozesse vermittelt sein mag.

(2) Aber auch die bloße Begegnung mit dem Fremden führt noch nicht notwendig zur Ausbildung von Geschichtsbewusstsein - dann nämlich nicht, wenn der Fremde oder das Fremde als ein bloß Anderes oder Anderer erfahren wird. Das beste Beispiel hierfür bietet Herodot. Auch wenn er als der "Vater der Geschichtsschreibung" bezeichnet wird (und ich möchte da gar nicht widersprechen) und eine zutiefst beeindruckende wissenschaftliche Leistung erbracht hat: Seine Historien sind eben das, was das Wort damals bedeutet: Sie sind Beschreibungen, Berichte, auch abwägende, kritische Berichte, aber sie sind keineswegs ein Beleg für »Geschichtsbewusstsein« - oder schärfer gefasst: Sie sind ein Beleg für die Absenz von »Geschichtsbewusstsein«. Von »Geschichtsbewusstsein« in einem spezifischen und auch theoretisch prägnanten Sinne ist vielmehr erst dort zu sprechen, wo - im wörtlichen Sinne - »Bewusstsein von Geschichte« vorliegt, dort, wo Geschichte als eigentümlicher Gegenstand ins Bewusstsein tritt, als »objektive Geschichte«, wie Hegel formuliert, also als ein (freilich nur gedachter, also durch Erkenntnisleistungen konstituierter!) »objektiver Zusammen- 
hang«. Hierzu braucht »Geschichte« nicht etwa Gegenstand theoretischer Erkenntnis zu sein - aber sie muss ein eigentümlicher, von einzelnen Ereignissen oder Ereignisfolgen, die man erzählen kann, unterschiedener Gegenstand sein, der als solcher freilich nur eine gedachte Wirklichkeit hat - ob es sich nun um die »europäische Geschichte« oder um die »Geschichte der Stadt Mainz« handelt.

Diese Ausbildung von »Geschichte« zum Gegenstand eines Bewusstseins kann plausibler Weise so lange - und damit letztlich bis ans Ende des 18. Jahrhunderts - nicht erfolgen, als »Geschichte«, »historia«, primär den »Bericht«, die »Erzählung« meint. Sonst wäre »Geschichtsbewusstsein« ja ein »Bewusstsein von Erzählung«, und dies wäre nichts als eine unsinnige Verdoppelung. Die Herausbildung von »Geschichte« zu einem eigenständigen Gegenstand des Bewusstseins aber vollzieht sich in einem Jahrhunderte langen bewusstseinsgeschichtlichen Prozess, der sich in der Frühen Neuzeit andeutet (und dies ist das Thema der genannten Dissertation) und der eben erst Ende des 18. Jahrhunderts zu einem Ergebnis und gewissen Abschluss kommt: in der als »objektiven Zusammenhang« verstandenen Geschichte und im reflektierten Geschichtsbegriff insbesondere Hegels. Andere Geschichtsdenker dieser Epoche - insbesondere Johann Gottfried Herder - sollen hiermit keineswegs marginalisiert oder gar ignoriert werden, doch ist es - denke ich - nicht fraglich, dass sich die eindringliche Konzeptualisierung, die Klärung des Begriffsfeldes »Geschichte und Geschichtsbewusstsein«, und auch ihr Weiterwirken im 19. Jahrhundert und bis zur Gegenwart insbesondere Hegel verdankt. Es lässt sich nur schwer ermessen, in welchem Ausmaß unser Geschichtsdenken durch sein Denken geprägt ist - ich erinnere nur an seine Einführung des Begriffs der »Geschichtlichkeit«, den Denker des 20. Jahrhunderts sich dann auf ihre Fahnen geschrieben haben - unter sorgfältiger Verwischung der Spuren seiner Herkunft.

(3) Diese Behauptung der Schlüsselstellung des Hegelschen Geschichtsdenkens ist - bevor ich auf das eigentliche Thema zu sprechen komme zunächst mit einigen Worten zu erläutern - und vielleicht ja auch gegen eine Reihe von lang gehegten Überzeugungen $\mathrm{zu}$ profilieren. Ist es nicht vielmehr so, dass Hegels »spekulativer« Zugriff auf das Thema »Geschichte« längst als obsolet erkannt ist - letztlich schon durch das - wie man immer wieder hört: »empirische« Vorgehen Rankes, das die Geschichte nicht »spekulativ« überfliegt, sondern alles so beschreibt, wie es wirklich gewesen ist? Doch diese - vor allem bei denjenigen, die keinen der beiden gelesen haben, beliebte - Kontrastierung geht in doppelter Hinsicht am Problem vorbei. Denn zum einen gibt ja auch Hegel mit großem Nachdruck die Devise aus, man müsse bei Aussagen über Geschichte empirisch verfahren: »die Geschichte aber haben wir zu nehmen wie sie ist; wir haben his- 
torisch, empirisch zu verfahren $\aleph^{2}$. Und zum anderen ist Ranke dort, wo er nicht über Einzelnes, sondern allgemein über »Geschichte« spricht, ein von jeglicher Empirie weit entfernter Geschichtstheologe, der den Begriff des Fortschritts etwa schon deshalb ablehnt, weil dieser »eine Ungerechtigkeit der Gottheit« wäre, und auch sonst nicht wenig über die »unmittelbare Beziehung zur Gottheit« und das Walten der Vorsehung auszuführen weiß33. Ganz so rasch und säuberlich, wie es so oft unterstellt wird, lassen sich die Ansätze deshalb nicht unter epistemische oder gar moralische Bewertungen bringen.

(4) 》Geschichte « - auch dies sei hier noch vorweg betont - ist für Hegel auch keineswegs der sich immer schon, von Natur her, der theoretischen Erkenntnis darbietende Gegenstand. In seinen Vorlesungen über die Philosophie der Weltgeschichte unterscheidet er - um eine seiner Wendungen aus anderem Kontext zu adaptieren - gleichsam »drei Stellungen des Gedankens zur Geschichte«. Die erste, grundlegende Stellung ist nicht etwa, wie man heute auch ohne Textlektüre gemeinhin kolportiert, der siegesgewisse Optimismus hinsichtlich des unaufhaltsamen Fortschritts der Weltgeschichte im Gegenteil: Die Geschichte bietet uns das »Schauspiel der Leidenschaften « dar; sie zeigt uns »die Zertrümmerung der edelsten Gestaltungen von Völkern und Staaten«, das »furchtbarste Gemählde«, ja die »Schlachtbank«, »auf welcher das Glück der Völker, die Weisheit der Staaten und die Tugend der Individuen zum Opfer gebracht worden«. Um diesen Eindruck zu gewinnen, bedarf es keines eigentlichen Geschichtsbewusstseins, und vor allem: Er ist auch selber nicht mit Geschichtsbewusstsein zu verwechseln. Er erlaubt ebenfalls keine stabile Haltung; man kann nicht dauernd verweilen bei dieser Empfindung der »tiefsten rathslosesten Trauer«, die sich »trübselig« »in den leeren, unfruchtbaren Erhabenheiten« herumtreibt und gefällt. Die »Empörung des guten Geistes« in uns über das Geschehene und Geschehende fällt deshalb unvermeidlich in die »Langeweile« herab, so dass wir

aus der Langeweile, welche uns jene Reflexion der Trauer machen kann, zurück in unser Lebensgefühl, in die Gegenwart unserer Zwecke und Interessen, [...] auch in die Selbstsucht zurüktreten, welche am ruhigern Ufer steht, und von da aus sicher des fernen Anblicks der verworrenen Trümmermasse

2 Georg Wilhelm Friedrich Hegel, Philosophie der Weltgeschichte. Einleitung 1830/31, in: Hegel: Gesammelte Werke (=GW), Bd. 18, hg. v. Walter JAEschke, Hamburg 1995, S. 142.

3 Leopold von Ranke, Über die Epochen der neueren Geschichte. Vorträge dem Könige Maximilian II von Bayern gehalten. Gehalten 1854, Erstveröffentlichung 1888, ND Darmstadt 1973, S. 7, 11 u. 111. 
genießen ${ }^{4}$ - vornehmlich abends am Fernseher, mit einem Glas Bier in der Hand, um den Genuss abzurunden. Den Weg, der von diesem ruhigen Ufer der Selbstsucht wegführt, und zugleich die dritte Stellung des Gedankens zur Geschichte bildet für Hegel schließlich - und dies ist nicht überraschend die philosophische Erkenntnis sowohl des Prinzips als auch der »Mittel« der Weltgeschichte, vor allem aber das Wissen des Geistes um seine Geschichtlichkeit, also: seine durch die Erkenntnis der Geschichte vermittelte Selbsterkenntnis.

\section{Zur Entstehung des Geschichtsbewusstseins}

(1) Die beiden ersten »Stellungen zur Geschichte« erfordern kein spezifisches »Geschichtsbewusstsein«. Das »Glück der Völker und Individuen« ist immer schon und überall zertreten worden, und die darauf folgende Abstumpfung und Abwendung von diesem Anblick ist so alt wie er selbst. Doch wie kommt es (Ende des 18. Jahrhunderts) zu dieser dritten Stellung gegenüber der »Geschichte«: zur Erkenntnis der Geschichte und weiter zu der durch die Erkenntnis von Geschichte vermittelten Selbsterkenntnis? Zu dieser genealogischen Frage hat Hegel fast gar nicht Stellung genommen, und auch das Problem der Entstehung des neuzeitlichen Geschichtsbewusstseins und damit überhaupt erst des Geschichtsbewusstseins hat er nicht eigens thematisiert. Die von Klempt behandelte Epoche, die Frühe Neuzeit, hat er zwar in sozialgeschichtlicher Hinsicht angesprochen, jedoch nicht im Blick auf die Genese von Geschichtsdenken. Von den Autoren und Werken, auf die Klempt seine These über die Genese des neuzeitlichen Geschichtsbewusstseins stützt, dürften die wenigsten Hegel bekannt gewesen sein - und dies nicht etwa auf Grund der habituellen historischen Ignoranz des spekulativen Philosophen, sondern aus einem durchaus plausiblen und deshalb auch entschuldbaren Grund: Die übergroße Zahl von historischen Darstellungen, auf die Hegel sich in seinen Vorlesungen über Philosophie der Weltgeschichte, aber auch über Philosophie der Kunst und der Religion, ja sogar der Geschichte der Philosophie ohnehin stützt, hat ihm schlicht nicht erlaubt, in größerem Umfang noch weitere Berichte und Reflexionen heranzuziehen und die gelegentlich verlautende aufgespreizte Kritik, dass er diese oder jene Darstellung nicht herangezogen habe, empfinde ich angesichts der beispiellosen Weite und Intensität seiner Rezeption als beckmesserisch und unredlich. Doch trotz dieser Differenz in der Blickrichtung ist eine Analogie bemer-

4 Hegel, Philosophie, S. 157; vgl. Georg Wilhelm Friedrich Hegel, Vorlesungen über die Philosophie der Weltgeschichte. Kolleg 1830/31. Nachschrift Karl Hegel, S. 15f. 
kenswert: Klempts Beobachtungen über die Bedeutung des Fremden für die Entstehung des Geschichtsbewusstseins werden von Hegel - mit Blick auf andere Völker und Epochen - antizipiert und damit sinngemäß bestätigt.

Bevor ich auf diese Analogie eingehe, sehe ich mich zu einer letzten, auch nur kleinen Vorbemerkung genötigt: Es ist eine Folge des lediglich literarisch vermittelten Zugangs zum »Fremden « - durch Vermittlung von Reiseberichten, ob von italienischen Missionaren, von englischen Handlungsreisenden oder von französischen Offizieren -, dass ein heute vielfach erörterter, ja die Diskussion dominierender Aspekt für Hegel wie für seine Zeitgenossen insgesamt keine Bedeutung hat: das Problem des persönlichen Verstehens des Fremden. Seine Reisen ins benachbarte europäische Ausland (nach Frankreich und in die - damals - »Vereinigten Niederlande «) haben ihn nicht vor dieses Problem gestellt, ja vielleicht damals, vor der nationalistischen Zersplitterung Europas, sogar noch weniger als heute unter den Bedingungen der Europäischen Union. Und die Begegnung mit dem Fremden im Inland, etwa in Form des Verstehens von Bevölkerungsgruppen mit Migrationshintergrund, dürfte im Berlin der 1820er Jahre nicht sonderlich brisant gewesen sein. Hegels Blick richtet sich deshalb auf ihm lediglich literarisch vertraute historische Prozesse, und diese Prozesse betrachtet er in einer doppelten Perspektive.

(2) Die Begegnung mit Fremden oder auch mit dem Fremden, als Neutrum verstanden, kann ja auf (mindestens) zwei Ebenen betrachtet werden: auf der Ebene ihrer Bedeutung für das Bewusstsein derer, die im Verlauf der Geschichte diesem Fremden begegnet sind, und auf der Ebene ihrer Bedeutung für unser Selbstbewusstsein - sei es nun in der vermittelten Weise, dass wir diese Begegnung uns Fremder mit ihnen Fremden thematisieren, oder sei es, dass wir dem Fremden - wenn auch nur literarisch - unmittelbar begegnen. Die erste Ebene möchte ich hier, kurz, als »exoterische« Ebene ansprechen - in dem Sinne, dass ihre Abhandlung keine spezifischen Vorgaben der Philosophie Hegels enthält und erfordert, während die zweite, die esoterische, nur innerhalb des Rahmens seiner Philosophie zu beschreiten ist. Zunächst zur exoterischen; hier geht es mir um die kulturgestaltende Kraft des Fremden.

\section{Die kulturgestaltende Kraft des Fremden}

(1) Hegel begreift das Fremde als ein Incitament der kulturellen Entwicklung. Doch erkennt er diese kulturgestaltende Kraft des Fremden nicht etwa an den großen Kulturen des Fernen Ostens, die dem heutigen Betrachter vielleicht zunächst im Blick stehen, wenn man von seiner »Begegnung mit dem Fremden« spricht, zumal er ja in seinen späteren Vorlesungen so ausführlich über 
sie handelt - insbesondere über China und Indien. Dennoch spielt »Asien« auch für Hegel von Anfang an eine Rolle. Denn diejenige Begegnung mit dem Fremden, an der er seine Einsicht in ihre kulturgestaltende Kraft gewinnt, ist die Begegnung der griechischen Kultur mit der Kultur orientalischer Völker und Reiche. Hegel kontrastiert - wie dies auch bei anderen zeitgenössischen Autoren, etwa bei Herder, anzutreffen ist - die ungeheuren Landmassen Asiens mit der geographischen Zerklüftung Griechenlands, die dort weiten Ebenen, auf denen der Horizont immer derselbe bleibt, mit den kleinen Erhebungen und Tälern hier, die physische Macht der Berge und Flüsse Asiens, die den Menschen bindet, mit der Verteiltheit und Vielfältigkeit Griechenlands, die seine Bewohner frei lässt - und die Erwartung liegt nahe, dass sich diese Differenz in der Gestaltung des Bodens auf den Charakter derer auswirkt, die ihn bewohnen; hierfür bietet ja schon die Kontrastierung von Berg- und Küstenbewohnern hinreichend Anschauungsmaterial. Es ist aber nicht bloß um die geographischen Bedingungen zu tun: Der »substantielle[n] Gediegenheit« und »patriarchalische[n] Einheit« des Orients steht die »mannigfaltigste Vermischung« in Griechenland entgegen; die »natürliche Mannigfaltigkeit und das Prinzip der Fremdartigkeit« haben Bedeutung für die »Bildung der Völkerschaften«, und Hegel verallgemeinert und resümiert:

es ist sehr wichtig zu bemerken, daß gerade diese ursprüngliche Fremdartigkeit in den Elementen, die ein Volk constituirt haben, den Autochthonen entgegengesetzt, die Bedingung zur Lebendigkeit, zur Regsamkeit wird 5 .

Die »ursprüngliche Fremdartigkeit« also, nicht als ein schwächendes, störendes, die »Reinheit« kultureller Entwicklung (und im schlimmsten Falle die »Reinheit« des Blutes) verderbendes Element, sondern, ganz im Gegenteil, als »Bedingung zur Lebendigkeit« und zur »Regsamkeit«: Dies ist eine weitreichende Aussage, und man würde sie heute in aktuellen Kontexten gerne öfter hören. Die geographische wie auch die soziale Gleichförmigkeit tragen, wie Hegel sagt, keine »Aufregung in sich« »zum heraustreten aus der Beschränktheit « ${ }^{6}$. Diese Aussage lässt sich jedoch in einer schwächeren und einer stärkeren Richtung interpretieren: Die kulturgestaltende Kraft des Fremden könnte auf der Rezeption seines fortgeschrittenen Entwicklungsstandes beruhen, wie etwa später zur Zeit der Völkerwanderung ${ }^{7}$. Dies wäre nicht weiter bemerkenswert: Die höhere kulturelle Entwicklung eines unterworfenen Landes teilt sich dem Eroberer mit. Nach der stärkeren Lesart hin-

5 Nachschrift Karl Hegel, S. 226.

6 Ebd.

7 Ebd., S. 378: »Die Germanen haben den Trieb innrer Entwicklung durch eine fremde Kultur erhalten; ihre Bildung, Staatsbildung, Gesetze, Religion sind fremd«. 
gegen kommt dem Fremden diese Funktion bereits kraft seiner Fremdheit zu, kraft seiner Differenz, durch die es die Identität des Autochthonen aufbricht und in Bewegung versetzt. Allein schon das Moment des Negativen, könnte man in diesem Sinn sagen, ist die Bedingung der Entfaltung der gesellschaftlichen und kulturellen Dynamik. Und fraglos ist dies gemeint, wenn Hegel die Fremdartigkeit als die »Bedingung zur Lebendigkeit« auszeichnet.

(2) Aber auch das Denken, das sich unter dieser Bedingung entwickelt, ist nicht notwendig schon »geschichtliches Denken« oder gar »Geschichtsbewusstsein«. Dies spricht Hegel auch selber aus:

Die Anfänge zu einiger Bildung hängen von ${ }^{8}$ der Ankunft von Fremden in Griechenland ab; und die Griechen haben diese Anfänge des sittlichen Lebens mit dankbaren Andenken aufbewahrt in einem Bewusstseyn, das wir mythologisch nennen können?.

Die Frage aber, wie aus diesem mythologischen Bewusstsein Geschichtsbewusstsein wird, hat Hegel weder gestellt noch beantwortet - und ich denke, sie lässt sich auch gar nicht beantworten, ja nicht einmal prägnant formulieren, weil die Entstehung von Geschichtsbewusstsein ohnehin nicht als Transformation des mythologischen Bewusstseins, sondern nur als die Entstehung von etwas Neuem zu begreifen ist. Es reicht auch nicht aus, einfach auf Herodot zu deuten, um den Gegenbeweis zu führen - auch wenn seine Historien fraglos ganz von der »Begegnung mit Fremden « leben. Sie sind eher ein Zeichen dafür, dass die bloße »Begegnung mit Fremden« zwar in Historien, also in »Berichten« oder in »Forschungen« resultiert, aber nicht notwendig in der Ausbildung von »Geschichtsbewusstsein«. Hierzu scheinen mir zwei zusätzliche Bedingungen erforderlich, und zumindest diese eine: dass das Fremde in der Perspektive der Ungleichzeitigkeit begriffen wird - so, wie es in der Frühen Neuzeit, im Zeitalter der Entdeckungen, geschehen ist.

Einen Ansatz hierzu hat Hegel aber auch schon in der griechischen Welt diagnostiziert: »der griechische Geist« hat das Fremde ja nicht nur im mythologischen Bewusstsein aufbewahrt; vielmehr hat er »das Fremde zu dem Seinigen umgebildet; Spuren solcher fremden Anfänge kann man überall entdecken $\aleph^{10}$. Und dieses Fremde wird nicht nur als ein »abstrakt Fremdes «, bloß Anderes, wahrgenommen, sondern als Zeugnis einer untergeordneten, überwundenen Kulturstufe. Diese Umbildung und Aneignung des Fremden hat in Hegels Sicht das Gefühl der »Heimatlichkeit« entstehen lassen, das die griechische Welt durchwirkt und ihr ihren zeitlosen Reiz verleiht - aber diese $»$ Heimatlichkeit« ist eben keine »unmittelbare«, gleichsam immer schon vor- 
handene, differenzlose und deshalb regungslose, sondern eine durch die Aneignung und Anverwandlung des Fremden gewordene, geschichtlich vermittelte »Heimatlichkeit«, ähnlich derjenigen zu Beginn der Neuzeit, mit der Hegel die griechische »Heimatlichkeit« zu Beginn seiner philosophiegeschichtlichen Vorlesungen vergleicht ${ }^{11}$. Im Prozess dieser Umbildung und Aneignung des Fremden in der griechischen Welt sieht Hegel die geschichtliche Differenz wirksam und auch ins Bewusstsein gehoben:

in diesem Charakter der freien, schönen Geschichtlichkeit, daß, was sie sind, auch als Mnemosyne bei ihnen ist, liegt auch der Keim der denkenden Freiheit und so die Notwendigkeit, daß bei ihnen die Philosophie entstanden ist ${ }^{12}$.

So führt Hegel den Gedanken der Begegnung mit Fremden und mit dem Fremden als der »Bedingung zur Lebendigkeit» schließlich doch noch den einen Schritt über die Einsicht in die Kulturgestaltungskraft dieser Begegnung hinaus, bis zum Gedanken der »Geschichtlichkeit« - auch wenn er diese Geschichtlichkeit mit gutem Grund hier noch nicht bis zu derjenigen Einsicht entwickelt sieht, die das Geschichtsbewusstsein erst der - späteren - Neuzeit auszeichnet: zu dem Wissen, dass unser Sein mit dem vermeintlich Vergangenen unzertrennlich verknüpft ist, und dass, was wir sind, wir zugleich geschichtlich sind ${ }^{13}$.

\section{Die Bedeutung des Fremden für das Selbstbewusstsein}

(1) Doch selbst wenn man Hegels hier sehr weitausgreifenden und wohl auch vorgreifenden Ausführungen folgt: Das griechische Gefühl der »Heimatlichkeit« und auch das Walten der »Mnemosyne« sind noch kein »Geschichtsbewusstsein«, und von ihm aus verläuft auch keine - und schon gar keine ungebrochene - Tradition bis in die Frühe Neuzeit. Wie kommt es in dieser zu solchem Wissen des Geistes - es versteht sich: des menschlichen Geistes, auf den wir ja alle mehr oder weniger Anspruch erheben - von seiner Geschichtlichkeit, und wie kommt es zur Ausbildung des Hegelschen Geschichtsdenkens? Für die Frühzeit der Genese des geschichtlichen Denkens im Allgemeinen darf ich nochmals auf die Dissertation von Klempt verweisen - auch wenn sie dieses umfassende Thema fraglos nicht erschöpft und ja auch gar

11 Georg Wilhelm Friedrich Hegel, Vorlesungen über die Geschichte der Philosophie, hg. v. Walter JAEschKe, Teil 2: Griechische Philosophie, Hamburg 1989, S. 1f.

12 Georg Wilhelm Friedrich Hegel, Vorlesungen über die Geschichte der Philosophie. Freundesvereinsausgabe, Bd. 13, hg. v. Karl Ludwig Michelet, Berlin 1833, S. $173 \mathrm{f}$.

13 Georg Wilhelm Friedrich Hegel, Vorlesungen über die Geschichte der Philosophie, hg. v. Walter JAESchKe. Teil 1, Hamburg 1994, S. 6. 
nicht erschöpfen kann. Der entscheidende Umschlag im Denken des 18. Jahrhunderts - die Verlagerung vom Primat der »subjektiven« Bedeutung von »Geschichte« als »Bericht«, »Erzählung«, hin zum Primat der »objektiven Bedeutung « von »Geschichte« als quasi-objektiver Zusammenhang, der dann Gegenstand des Bewusstseins werden kann, Gegenstand von »Geschichtsbewusstsein «, ist meines Erachtens trotz der begriffsgeschichtlichen Arbeit der zweiten Hälfte des 20. Jahrhunderts auch nicht einmal ansatzweise geklärt. Gemessen daran sind wir über Hegels Geschichtsbegriff gut unterrichtet. Doch gerade deshalb muss ich etwa vorhandene Erwartungen lieber gleich enttäuschen: Am Beginn des Hegelschen Geschichtsdenkens steht nicht die Begegnung mit dem Orient und ebenso wenig die Begegnung mit der Weltgeschichte. Um eine Geschichtsdenken initiierende Funktion ausüben zu können, treten beide - und insbesondere der Orient - viel zu spät in Hegels Denken ein.

(2) Noch in seinem ersten Kolleg über Religionsphilosophie, im Sommer 1821, behandelt Hegel keine orientalischen Religionen; lediglich an einer einzigen Stelle bezieht er sich auf eine Rezension über ein Buch Alexander von Humboldts in einem im Vorjahr erschienenen Rezensionsorgan, in dem ein hinduistischer Brauch angesprochen wird. Ein gutes Jahr später hingegen, in seiner ersten Vorlesung über die Philosophie der Weltgeschichte, geht Hegel ausführlich auf »Die orientalische Welt« ein, auf China, Indien, Persien und Ägypten, und er nimmt sich hierfür so viel Zeit wie für die Abhandlung der griechischen, der römischen und der germanischen Welt zusammengerechnet $^{14}$. Insofern also ist Hegels Begegnung mit dem Orient zwar ein konstitutiver, ja ein dominierender Bestandteil seiner späteren Behandlung der Weltgeschichte, aber nicht eine sein Geschichtsdenken begründende Begegnung. Ich halte es sogar für wahrscheinlich, dass Hegel seine Vorlesungen über die Philosophie der Weltgeschichte erst deshalb so spät, als letzte seiner Vorlesungsdisziplinen, vorgetragen hat, weil er zuvor über den Orient recht wenig zu sagen gewusst hat. Noch im Kompendium zu seinen rechtsphilosophischen Vorlesungen, in den Grundlinien der Philosophie des Rechts, im Jahr 1820, hat Hegel zur Strukturierung des Abschnitts über die Weltgeschichte auf den antiken Weltreichgedanken (des Buches Daniel und der hinter ihm stehenden wie auch der weit späteren Historiographie) zurückgegriffen $^{15}$, der eigentlich schon seit der Geschichtsschreibung der Frühen Neuzeit als Gestaltungsprinzip ausgedient und abgedankt hat. Ich zweifle, dass

14 Georg Wilhelm Friedrich Hegel, Vorlesungen über die Philosophie der Weltgeschichte, Berlin $1822 / 23$. Nachschriften von Karl Gustav Julius von Griesheim, Heinrich Gustav Hотно und Friedrich Carl Hermann Victor von KeHLer, hg. v. Karl-Heinz Ilting / Karl Brehmer / Hoo Nam Seelmann, Hamburg 1996, S. 121-314 (Orient) gegenüber S. 314-521 (Okzident).

15 Georg Wilhelm Friedrich Hegel, Gesammelte Werke, Bd. 14,1: Grundlinien der Philosophie des Rechts, hg. v. Klaus Grotsch, Hamburg 2009, S. 278: §§ 352-354. 
Hegel nach seiner ersten Vorlesung über die Philosophie der Weltgeschichte mit ihrer ausführlichen Abhandlung des Orients die Weltgeschichte weiterhin so strukturiert hätte.

Diese späte Verknüpfung von »Orient« und »Philosophie der Weltgeschichte« schließt aus, dass die Begegnung mit dem Orient als Incitament für Hegels Geschichtsdenken gewirkt hat. Und noch mehr: Seinen spezifischen Geschichtsbegriff gewinnt Hegel überhaupt nicht im Kontext einer Philosophie der Weltgeschichte, sondern im Zuge seiner Einführung und Ausarbeitung des Geistbegriffs und seiner Vorlesungen über die Geschichte der Philosophie, im Jena der Jahre 1802 bis 1806, also rund zwei Jahrzehnte vor seiner ersten Vorlesung über die Philosophie der Weltgeschichte und somit auch über den Orient, im Berlin des Jahres 1822/23: Geschichte ist die eigentümliche Explikationsform des Geistes, und deshalb ist alles Geistige geschichtlich und alles Geschichtliche geistig.

(3) Doch auch wenn Hegel diese interne Verfassung des Geistes als tiefste Grundlage von geschichtlichem Denken und Geschichte vergleichsweise früh, im Kontext der Ausarbeitung seines Geistbegriffs, gewonnen hat: Die »Grundlage« ist - wie er in anderem Zusammenhang gern sagt - eben »nur die Grundlage«, nämlich die notwendige Bedingung für Geschichtsbewusstsein, aber keine hinreichende - sonst wäre »Geschichtsbewusstsein« ubiquitär, was es evidenter Maßen nicht ist (wenn man das Wort nicht in ganz verwaschenem Sinne verwendet - aber darüber wäre nicht zu reden oder gar nachzudenken). Deshalb widerspricht diese Feststellung nicht der Vermutung, die Begegnung - und auch die bloß literarische Begegnung! mit dem Fremden bilde ein wichtiges, ja unverzichtbares Moment für die wirkliche Herausbildung von Geschichtsbewusstsein auf der genannten Grundlage. So ist also näher nach den spezifischen Bedingungen für die Genese von Hegels Geschichtsdenken zu fragen. Wenn man unter den vielen Bereichen der Wirklichkeit, denen Hegels Interesse vom Beginn seiner systematisch-philosophischen Arbeit an gegolten hat und die für die Genese von Geschichtsdenken in Frage kommen, einen Bereich auszeichnen will, so ist dies unstrittig die Philosophiegeschichte. Sie ist ja der erste Bereich, den Hegel in seinen Vorlesungen geschichtlich ausführt; die Geschichte der Religion tritt erst später hinzu, zeitgleich mit der allgemeinen Bewusstseinsgeschichte der Phänomenologie des Geistes (1807), und die Geschichte der Kunst erst erheblich, mehr als ein Jahrzehnt, später - und als letztes folgt schließlich die Konzeption einer »Weltgeschichte«.

(4) Damit ist jedoch die Vermutung, die »Begegnung mit dem Fremden« könne eine auslösende Rolle auch für Hegels Geschichtsdenken gespielt haben, keineswegs dementiert - im Gegenteil: Hegels Konzeption der Philosophiegeschichte, in der sein Geschichtsdenken sich erstmals ausspricht, entspringt ja selber der Begegnung mit einem »fremden Denken«, mit dem Den- 
ken einer vielleicht lange vergangenen Epoche - jedoch zugleich mit einem »fremden Denken«, das zwar einer vergangenen Epoche angehört, selber aber keineswegs vergangen ist. Dieses »fremde Denken« ist jedoch - mit dem Kantischen Ausdruck, der bei ihm aber etwas anderes meint - keine »fremde Vernunft«. Oder um es wieder mit einer Formulierung Hegels zu sagen, auch wenn sie sprachlich etwas holprig ist: »wie in dem, was in [...] der Geschichte des Denkens, das Vergangene nur die Eine Seite ist, so ist in dem, was wir sind, das gemeinschaftliche Unvergängliche unzertrennt mit dem, dass wir geschichtlich sind, verknüpft«. Unser »Besitz an selbstbewußter Vernünftigkeit« ist die »Arbeit aller vorhergegangener Generationen des Menschengeschlechts«, und wir sind, durch die »heilige Kette« der Tradition, mit einer »Vorwelt« verbunden, die uns auf diese Weise fremd und vertraut zugleich ist ${ }^{16}$.

Insofern also bekräftige ich die Annahme, dass die »Begegnung mit dem Fremden« eine unverzichtbare Bedingung für die Entstehung von Geschichtsbewusstsein sei, weil erst sie einen Horizont aufspannt, der geschichtlich gedeutet werden kann - und somit ist sie noch keine hinreichende Bedingung. Deshalb möchte ich ihr zwei weitere, präzisierende Bedingungen hinzufügen - hier zunächst die erste, die ich vorhin bereits berührt habe: Für die Entstehung von Geschichtsbewusstsein ist es erforderlich, dass diese Begegnung in einem temporalen Deutungshorizont erfolgt - dass das Fremde zugleich als ein zeitlich Früheres zu deuten ist. Man muss nicht befürchten, dass das Argument durch diese weitere Bedingung zirkulär würde - dass es etwa die Form der Behauptung annehme, Geschichtsbewusstsein entstehe nur unter den Bedingungen einer geschichtlichen Deutung von Prozessen. Dies wäre in der Tat fatal. Aber es geht um etwas anderes: Die Ordnung alles Geschehens in räumlichen und zeitlichen Koordinaten ist ja in der Antike, in Griechenland wie auch im Vorderen Orient, allgemein bekannt und vorausgesetzt. Wenn man aber, wie der »Weltreisende« Herodot, von seinen Reisen vor allem Gegenwärtiges berichtet (auch wenn darin Berichte über Vergangenes eingewebt sind), so werden diese Historien, getreu der Bedeutung des Wortes, eben Berichte, Forschungen sein, aber sie werden weder den Gedanken der Geschichte noch auch Geschichtsbewusstsein initiieren. Sie werden die Andersartigkeit des Anderen artikulieren, aber nicht auf das eigene Gewordensein abheben.

(5) Meiner zweiten ergänzenden Bedingung möchte ich selber den Status zuweisen, dass sie eine für das Entstehen von Geschichtsbewusstsein fraglos förderliche, jedoch eine vielleicht nicht notwendige Bedingung nennt - und dies schiene mir einer weitergehenden Untersuchung wert, als ich sie hier leisten kann: Mir scheint, dass das begegnende Fremde nicht ein abstrakt

16 Hegel, Vorlesungen über die Geschichte der Philosophie, S. 6 f. 
Fremdes sein darf, sondern dass es zugleich durch eine Identität mit dem Betrachter verknüpft sein muss - oder nochmals mit dem bereits zitierten Wort Hegels: dass »das gemeinschaftliche Unvergängliche unzertrennt mit dem, dass wir geschichtlich sind, verknüpft« ist. Ich formuliere vorsichtig, dass ich den Eindruck habe, dass die Schlüsselsituation für die Genese von Geschichtsbewusstsein nicht so sehr die Begegnung mit einem bloß differenten Fremden ist, sondern die Begegnung mit demjenigen Fremden, mit dem ich zugleich durch eine Identität verknüpft bin: mit dem ich in einer objektiven Kontinuität stehe und dadurch genötigt bin, diese von einer zeitlichen Differenz geprägte Kontinuität zu konzeptualisieren - sie als Entwicklung zu verstehen. Hierauf deutet auch Hegels Rede von »Erbschaft« und »Arbeit« des Geistes. Diese Grundstruktur von Identität und Differenz weisen auch alle von der Lebensalter-Metaphorik oder vom Erziehungs- oder Bildungsgedanken inspirierten Formen des Geschichtsbewusstseins des späten 18. Jahrhunderts auf. Zur Genese von Geschichtsbewusstsein reicht die bloße Verschiedenheit des Fremden meines Erachtens nicht aus - zumindest scheint sie mir keine starke Bedingung zu sein. Unberührt von diesen Bedenken bleibt es natürlich richtig, dass auch die bloße, abstrakte Andersartigkeit des Fremden geeignet sein kann, einen festgefügten Rahmen - etwa den der biblischen Weltchronologie - zu durchbrechen und dadurch zu einer neuen Orientierung beizutragen.

(6) Wenn meine Bedenken gegen die Geschichtsbewusstsein initiierende Kraft des abstrakt Fremden und nicht zugleich Identischen zutreffen, dann ist anzunehmen, dass die bloße Begegnung mit dem Orient nicht allein im besonderen Falle Hegels, sondern generell keine privilegierte Situation für die Entstehung von Geschichtsbewusstsein bildet. Man kann sich dies auch am frühromantischen Rückgriff auf die »Schätze des Orients« veranschaulichen: Er erfolgt nicht im Kontext der Ausbildung von Geschichtsbewusstsein, sondern des Rufes nach einer »Neuen Mythologie $\ll^{17}$. Doch wenn dies so ist: Warum spielt der Orient dann erstmals für Hegel eine Rolle und sogleich eine so wichtige Rolle - und sogar für mehrere Disziplinen seiner Philosophie, nämlich für die Philosophie der Weltgeschichte, der Kunst, der Religion und schließlich sogar - wenn auch nicht in vergleichbarem Ausmaß - für die Geschichte der Philosophie? Hierauf möchte ich noch drei - miteinander zusammenhängende, jedoch etwas unterschiedlich akzentuierende - Antworten geben.

17 Siehe etwa Friedrich Schlegel, Gespräch über die Poesie. Rede über die Mythologie, in: Walter JAESChKE (Hg.), Früher Idealismus und Frühromantik. Der Streit um die Grundlagen der Ästhetik (1795-1805). Quellenband, Hamburg 1995, S. 119. 
Zunächst die allgemeine Antwort: Die Kulturen des Orients bilden einen für die Selbsterkenntnis des Geistes konstitutiven Bereich. Der Geist - und ich sage nochmals: der Geist des Menschen - ist für Hegel stets auf seine Selbsterkenntnis ausgerichtet, und so greift der Geist - nach dem Wegfall der Beschränkungen, die ihm die zuvor dominante religiöse Tradition auferlegt hat, aber auch im Zuge der in der Neuzeit möglichen realen Begegnungen - auf die früher weitgehend ignorierten, »fremden « Kulturen über. Die Erkenntnis dieser »fremden« Kulturen des Orients ist ein unverzichtbares Moment der Selbsterkenntnis des Geistes - glücklicherweise nicht nur des Dranges nach Herrschaft und Ausbeutung, sondern auch des Verlangens nach Erkenntnis und Selbsterkenntnis. In der Zeit nach Hegel gewinnt dieses Verlangen nach Selbsterkenntnis noch erheblich an Dynamik, auch wenn es sich dann nicht mehr im Sinne Hegels als ein solches Interesse des Geistes an seiner Selbsterkenntnis artikuliert, sondern sich als empirische Forschung unter den Bedingungen des Historismus und Positivismus versteht. Doch dies ändert ja nichts daran, dass das treibende Interesse an solcher Erkenntnis dennoch immer das Interesse des Geistes an seiner Selbsterkenntnis ist. Warum er dieses Interesse hat, kann man ihn nicht fragen - man kann es nur als ein Faktum konstatieren, und vielleicht ist es ja ebenfalls ein »Faktum der Vernunft $\ll$.

Sodann eine speziellere Antwort - verbunden mit einer Präzisierung der Frage: Was erkennt der menschliche Geist, wenn er sich in seiner Beziehung zum Fremden selbst erkennt? Es ist ja die menschliche Geistigkeit, die uns auch aus dem »Fremden« entgegentritt: aus seinen Sitten und aus seinem Selbstverständnis, das sich in seiner Kunst ausspricht. Er erkennt die Einheit des Geistes in der Mannigfaltigkeit seiner Entwicklung - eine Einheit, die auch das fremd Erscheinende übergreift -, und hierbei erkennt er auch, dass die naturbedingten Verschiedenheiten des Menschen wie Hautfarbe und Rassenzugehörigkeit diese Einheit des Geistes, die Identität der Vernunft und deshalb auch das daraus fließende Recht des Menschen als Menschen nicht beeinträchtigen:

Diese - sc. naturbedingten - Unterschiede betreffen [...] nicht die Vernünftigkeit selbst, sondern die Art und Weise der Objectivität derselben, und begründen nicht eine ursprüngliche Verschiedenheit in Ansehung der Freyheit und Berechtigung unter den sogenannten Racen ${ }^{18}$.

18 Georg Wilhelm Friedrich Hegel, Fragment zur Philosophie des subjektiven Geistes, in: Friedrich Hogemann / Christoph Jamme (Hg.), Hegel. Gesammelte Werke, Bd. 15: Schriften und Entwürfe I (1817-1825), Hamburg 1990, S. 225; vgl. jetzt auch die ausführliche Behandlung dieses Themas in Georg Wilhelm Friedrich Hegel, Vorlesungen über die Philosophie des subjektiven Geistes, in: Christoph J. BAUER (Hg.), Hegel. Gesammelte Werke, Bd. 25,1, Hamburg 2008. 
Die »Fremdheit« des Fremden, könnte man sagen, betrifft etwas letztlich bloß Äußerliches, und das Tragende in der Begegnung mit dem Fremden ist die Erkenntnis der geistigen Einheit mit ihm.

Und schließlich noch eine letzte, ein Spezifikum des neuen Geschichtsbewusstseins betreffende Antwort: Der sich selbst erkennende Geist erkennt auch, dass er eine sich geschichtlich entwickelnde Wirklichkeit ist, oder anders: dass die Geschichte eben die Entwicklungsform des Geistes ist. Diese Einsicht in die Entwicklung als die Wirklichkeitsform des Geistes widerlegt die einem mythischen Weltbild angehörenden Behauptungen, am Beginn der Zeiten habe ein Zustand der ursprünglichen Vollkommenheit gestanden - Behauptungen, wie sie zur Zeit Hegels selbst Schelling und Friedrich Schlegel noch wortreich und engagiert vertreten haben, und stets folgerichtig verknüpft mit der Behauptung, dass es gelte, diesen einmal Wirklichkeit gewesenen und schuldhaft zerstörten Zustand wieder zu erlangen. Die Einbeziehung des Orients in eine Darstellung der Weltgeschichte, das geschichtliche Verständnis auch seiner so unterschiedlichen kulturellen Entwicklungen, befreit nachhaltig von derartigen mythischen Zwangsvorstellungen, die eben kein Zeugnis von »Geschichtsbewusstsein« bilden, sondern vielmehr den mythisch-phantastischen Gegenpol zu ihm.

So mag es denn der Mühe lohnen, sich durch den »Anblick der verworrenen Trümmermasse« der Weltgeschichte nicht in »die Empfindung der tiefsten rathslosesten Trauer« zu versenken, sich aber auch nicht bloß an das »ruhigere Ufer der Selbstsucht« zu retten, sondern nach der Erkenntnis von »Geschichte « zu streben und durch die Begegnung mit dem Fremden - wenn auch primär mit einem Fremden, das ebenso sehr ein Nicht-Fremdes ist - ein Bewusstsein von der Geschichte als einer eigentümlichen Wirklichkeitsform und zugleich der spezifischen Wirklichkeitsform des menschlichen Geistes zu entwickeln. Denn »der Verlauf der Geschichte ist es, welcher uns « - und ich ergänze: auch in der Begegnung mit dem Fremden - »nicht das Werden fremder Dinge, sondern dies unser Werden [...] darstellt « ${ }^{19}$.

19 Hegel, Vorlesungen, S. 9. 

II. Der Fremde im eigenen Land 



\section{Geschichte und aktueller Status der indigenen Andenbevölkerung in den Chroniken Martín de Murúas (1616) und Felipe Guaman Poma de Ayalas (1615)}

Als im Andenraum des 16. Jahrhunderts die damals dort ansässige Bevölkerung und die erobernden Spanier aufeinander trafen, waren sie einander so fremd, dass nicht einmal ihre Begriffe des »Fremden « von dieser Begegnung unberührt bleiben konnten. Wie die präkolumbianischen Hochkulturen Mittelamerikas beriefen sich auch die Inka in der Folge vergeblich auf Alter und Dauer ihrer Zivilisation; ihre Lebenswelt wurde durch physische und ideelle Inbesitznahme zur Neuen Welt der Europäer.

Das von Antike und Christentum geprägte Weltbild der Spanier und die Kosmovision der Andenbevölkerung transformierten sich dabei in dem $\mathrm{Maße}$, wie versucht wurde, eine Vorstellung vom Wesen des Anderen zu formen und zu integrieren. Prozesse der Transkulturation - der Aushandlung, Anpassung, Abwehr, Adaption auf verschiedenen Ebenen dessen, was jeweils als kulturell eigen und »normal« beziehungsweise als »fremd « empfunden wird - fanden und finden zu allen Zeiten statt, selten jedoch so massiv und gewalttätig wie bei der Konfrontation von Amerikanern und Europäern im 16. Jahrhundert. Die beiden hier untersuchten kolonialzeitlichen Schriften bieten zwei durchaus exemplarische Reaktionen auf die Begegnung mit dem Fremden und mit seiner Sicht auf die Dinge. Die Werke sind zeitgleich, etwa achtzig Jahre nach Ankunft der Spanier in Peru, entstanden, stellen aber zwei höchst unterschiedliche Deutungen präinkaischer, inkaischer und kolonialzeitlicher Geschichte dar. Ihre Autoren kannten sich: Die Primer nueva corónica y buen gobierno [Erste neue Chronik und Gute Regierung $]^{1}$ wurde von Don Felipe Guaman Poma de Ayala, einem indigenen Provinzadeligen verfasst. Die Historia general del Perú, orígen y descen-

1 Felipe Guaman Poma de Ayala, Primer nueva corónica y buen gobierno [Ms. 1615], Königliche Bibliothek Kopenhagen, GKS $22324^{\circ}$, Permanent, in: URL: <http://www.kb.dk/ permalink/2006/poma/info/es/frontpage.htm> (11.02.2012). Im Folgenden abgekürzt »GP«, wobei im Falle fehlerhafter Paginierung des Ms. die tatsächliche Seitenzahl in eckigen Klammern vermerkt wird. Übersetzungen von der Verfasserin dieses Beitrages (»M.K.«) auf der Basis von Ursula Thiemer-Sachse (Hg.), Felipe Guamán Poma de Ayala. Die neue Chronik und gute Regierung, Berlin 2004. 
dencia de los Incas [Generalhistorie Perus, Ursprung und Abfolge der Inka] ${ }^{2}$ hingegen stammt von dem Mercedarier-Mönch und gebürtigen Spanier Martín de Murúa. Zu Murúas Schrift existiert eine Vorversion, die hier ebenfalls von Interesse sein wird ${ }^{3}$. Diese Werke werden seit ihrer Publikation im 20. Jahrhundert intensiv erforscht $t^{4}$. Bekannt sind sie heute vor allem wegen der außergewöhnlichen Anzahl darin enthaltener Zeichnungen, die an dieser Stelle allerdings nicht berücksichtigt werden können ${ }^{5}$.

Das Erkenntnisinteresse der vorliegenden Untersuchung liegt bei den scheinbar individuellen Sichtweisen der Autoren, wobei eine simple Opposition von Sieger und Besiegtem, Einheimischem und Fremden, hier zu kurz greifen würde. Wenngleich die Schriften keine Auftragsarbeiten waren, ist davon auszugehen, dass Auswahl und Bewertung des Beschriebenen von den Diskursen der frühkolonialen Gesellschaft geprägt waren. Das Bild der eigenen Geschichte und das darin implizite Geschichtsbewusstsein einer Gesellschaft sind nicht nur Symptom und Verkörperung ihres allgemeinen Weltverständnisses, sondern wirken sich wiederum aus auf die konkrete Entscheidung und Definition dessen, was das Eigene und was das Fremde ist. Die jeweils aktuellen Vorstellungen von sich selbst und den Anderen sind somit unweigerlich mit dem Verständnis der eigenen Geschichte verbunden ${ }^{6}$.

2 Martin de Murúa/Manuel Ballesteros-Gaibrois (Hg.), Historia general del Perú, orígen y descendencia de los Incas I, II, Madrid 1962, 1964 [Ms. 1616]. Im Folgenden werden die Bände »MM HG 1« bzw. »MM HG 2« abgekürzt. Übersetzungen M.K.

3 Martin de Murúa [Ms. 1590], Historia del origen y genealogia real de los reyes ingas del Piru ..., in: Juan M. Ossio (Hg.), Códice Murúa. Manuscrito Galvin, Madrid 2004, S. 75-252. Im Folgenden abgekürzt »MM Galvin«. Übersetzungen M.K.

4 Eine hervorragenden Überblick über den Stand der Forschung und umfassende Bibliographien bieten die Aufsätze auf obengenannter Webseite zu Guaman Poma von der Königlichen Bibliothek Kopenhagen sowie die Aufsätze in: Thomas B.F. Cummins/Barbara Anderson (Hg.), The Getty Murúa. Essays on the Making of Martín de Murúa’s »Historia General del Piru«, J. Paul Getty Museum Ms. Ludwig XIII 16, Los Angeles 2008. Zum Galvin-Manuskript Murúas bisher vor allem Juan M. Ossio, Introdución, in: Ders., Códice Murúa, S. 7-72.

5 Diese Bilder sind keinesfalls nur Illustrationen. Sie ermöglichen einen unmittelbaren Zugang auch ohne Beherrschung alphabetischer Schrift, beinhalten jedoch auch konventionelle Informationen. So stellt bei Guaman Poma die Platzierung des Dargestellten im Raum eine Bewertung dar, mithin eine in Europa so nicht bekannte Raumsymbolik. Vgl. hierzu Carlos González Vargas/Hugo Rosati Aguerre/Francisco Sánchez Cabello, Guaman Poma. Testigo del mundo andino, Santiago 2003 und zahlreiche Publikationen Rolena Adornos, z.B. Rolena Adorno, From Oral to Written Expression. Native Andean Chronicles of the Early Colonial Period, Syracuse 1982. Die Aussagen des visuellen Diskurses widersprechen dem des schriftlichen Textes in keinem Fall grundsätzlich. Der Zusammenhang dieser Diskursebenen kann in diesem Rahmen jedoch nicht diskutiert werden, zumal die Bilder des Galvin-Manuskripts Murúas der Autorin nicht alle bekannt sind.

6 Vgl. z.B. Jan Assmann, Das kulturelle Gedächtnis. Schrift, Erinnerung und politische Identität in frühen Hochkulturen, München ${ }^{2} 1997$; John URRY, Wie erinnern sich Gesellschaften ihrer Vergangenheit?, in: Rosemarie BeIER (Hg.), Geschichtskultur in der Zweiten Moderne, Frankfurt a.M. u.a. 2000 , S. $29-52$. 
Es sind zwei miteinander verbundene Bündel von Fragen, die hier geklärt werden sollen: Das erste betrifft das in den Werken Guaman Pomas und Martín de Murúas dokumentierte Geschichtsbewusstsein. Welche Unterschiede bestanden hier zwischen europäischen und andinen Vorstellungen von Zeit und Geschichte? Wie gingen die beiden Autoren mit dieser Andersartigkeit um, und welche durch den Kulturkontakt beförderten Veränderungen sind in ihren Werken dokumentiert? Hierzu soll zunächst die Lebensgeschichte der Autoren anhand der wenigen bekannten Daten sowie ihrer Selbstdarstellungen in den Werken rekonstruiert werden. Zusammen mit einer groben Skizze der Geschichtsvorstellungen im frühneuzeitlichen Europa und im Andenraum ist damit ein Hintergrund für die Analyse der beiden Chroniken bereitet. Anhand Guaman Pomas Aussagen über die Ersten Andenbewohner und Martín de Murúas Darstellung der Inka-Herrscher und Herrscherinnen lässt sich ihr jeweiliger Umgang mit der eigenen und fremden Geschichte demonstrieren. Die Frage nach ihren Motiven rückt dann ein zweites Bündel Fragen in den Blick, welches das Verhältnis von Geschichtserzählung und Gegenwart der Autoren betrifft: Welches Interesse bestand an der Geschichte des jeweils Anderen? Welche Konsequenzen ergeben sich aus den jeweiligen Erzählungen für den gesellschaftlichen Status verschiedener Gruppen der kolonialen Gesellschaft?

Vorab sind jedoch einige Bemerkungen zum hier untersuchten Veränderungsprozess von Weltbild und Kosmovision angebracht, da seine Erforschung durch eine seiner Konsequenzen erschwert wird, nämlich den damals erfolgten Medienbruch: Binnen der einhundert Jahre vor der Conquista hatten die Inka die im Andenraum ansässigen Ethnien - insgesamt bis zu vierzehn Millionen Menschen ${ }^{7}$ - erobert und dieses mehr als eine Million Quadratkilometer umfassende Großreich allein mithilfe von Knotenschüren, "Quipus«, verwaltet. Andines Wissen wurde von Experten mithilfe dieser Quipus, aber auch durch Keramiken und Webereien bewahrt und in mündlichem Vortrag, sowie mittels ritueller Tänze und Gesänge aktualisiert und weitergegeben ${ }^{8}$. Diese Medien waren die geeigneten Träger einer gelebten Erinnerung, die gleichzeitig anpassungsfähig und widerstandsfähig war. Mit der Ankunft der Spanier wurde die Alphabetschrift zum Kommunikationsmedium der Machthaber im Andenraum. Mündlicher Diskurs erhielt etwaige Autorität nur mehr unter Berufung auf die Schrift (etwa durch Bibel und

7 Die Schätzungen variieren hier stark, je Berechnungsmodell wird von 4 bis 14 Millionen Einwohnern ausgegangen. Vgl. dazu: Noble David Cook, Demographic Collapse. Indian Perú, 1520-1620, Cambridge u.a. 1981.

8 Für einige jüngere Beispiele vgl. z.B. Martin Lienhard, Das »geschichtliche« Denken in einigen Quechuagesängen und -erzählungen, in: Max Peter Baumann (Hg.), Kosmos der Anden. Weltbild und Symbolik indianischer Tradition in Südamerika, München 1994, S. 190-201. 
Gesetze) oder durch ihre Verschriftlichung, etwa als Zeugenaussage vor Gericht.

Die »hechos«, die von den Schreibern der Eroberer zu Beginn der Conquista Südamerikas als juristisch relevant dokumentiert wurden, waren somit Taten und Tatsachen zugleich. Die Spanier machten Geschichte und trugen dafür Sorge, dass diese auch geschrieben wurde.

Als sie mit einer systematischen Erforschung und Dokumentation der andinen Kultur(en) und ihrer Geschichte begannen, waren viele Träger andinen Expertenwissens bereits durch Kampfhandlungen, Epidemien und die Folgen erzwungener Arbeitsdienste ums Leben gekommen und andine Medien von wohlmeinenden christlichen Priestern zerstört worden. Die indigenen Informanten solcher Geschichtswerke galten letztlich als die Gegner des spanischen Unternehmens christlicher Zivilisierung und Mission. Martín de Murúa schreibt:

[...] und die normalen Indios profitieren weiterhin von der Religion, so dass die Erinnerung von den alten Riten verloren geht; und sie wäre schon völlig verschwunden, wenn man die indigenen alten Männer und Frauen herausgesucht hätte, in denen sie sich erhält ${ }^{9}$.

Hinzu kamen sprachliche wie konzeptuelle Verständigungsprobleme; ein unverstellter Blick auf die vorspanische Kultur des Andenraums ist im Medium der Schrift per Definition unmöglich. Die Transkulturationsprozesse finden darin jedoch ihren Ausdruck.

Beide Autoren stellten sich bereits durch die Wahl der Titel in die Tradition der in Europa gebräuchlichen Textgattung der Chronik oder Historie. Ein solcher Text sollte durch die chronologische Anordnung der erzählten Ereignisse Ursache und Wirkung über große zeitliche und räumliche Zusammenhänge explizieren. Seine soziale Funktion bestand gleichermaßen in einem Erinnern wie in der legitimierenden Erklärung und Bewertung der Gegenwart. Das Medium der Schrift und die Textgestalt der Chronik waren der europäischen Vorstellung von Geschichte angemessen. War die mittelalterliche Scholastik dabei vor allem um die Entwicklung ihrer Argumentation aus anerkannten schriftlichen Quellen bemüht gewesen, so machte nun die Expansion nach Amerika die Integration von Augenzeugenberichten notwendig. Dies führte zu freieren Formen sowie zu einer expliziten Diskussion der Wahrhaftigkeit dieser Quellen ${ }^{10}$.

9 MM HG 2, S. 183 (= fol.307r).

10 Vgl. dazu z.B. Kathleen Ross, Historians of the Conquest and Colonization of the New World. 1550-1620, in: Roberto GonzÁlez Echevarría/Enrique Pupo-Walker (Hg.), The Cambridge History of Latin American Literature. Discovery to Modernism, Cambridge 1996, S. 101-142. 


\section{Die Autoren}

Martín de Murúa wurde Mitte des 16. Jahrhunderts in Nordspanien ${ }^{11}$ geboren, seine Muttersprache war baskisch ${ }^{12}$. Nach Peru muss er einige Jahre vor 1590 gereist $\operatorname{sein}^{13}$, als sich das Vizekönigreich nach jahrzehntelangen Kämpfen und Aufständen unter der Regierung Vizekönig Toledos 1568-1581 zu konsolidieren begonnen hatte.

Angehörige des »Ordens unserer Lieben Frau der Barmherzigkeit zum Loskauf der Gefangenen «, kurz Mercedarier (von spanisch »Merced «=Barmherzigkeit), hatten bereits die Konquistadoren begleitet und gehörten zu den ersten Siedlern im Vizekönigreich Peru. Ihre ursprüngliche Berufung bestand im Sammeln von Spenden und dem Freikauf christlicher Sklaven im Mittelmeerraum. In Amerika übernahmen sie auch missionarische Aufgaben; doch sind von ihnen aus der frühen Kolonialzeit so gut wie keine theoretischen oder praktischen Schriften zur Mission oder zu den Kulturen der indigenen Bevölkerung bekannt. Martin de Murúas Werk bildet hier die große Ausnahme. Seine Historia General erhielt zwar die zur Drucklegung nötigen Lizenzen vom Orden und vom König in Spanien, wurde jedoch erst 1946 veröffentlicht.

In Peru arbeitete Martín de Murúa als Doctrinero, also als Priester in den Siedlungen, in denen die Indigenen zwangsweise zusammengefasst wurden und zum christlichen Glauben geführt werden sollten. Er scheint sich hauptsächlich in der Umgebung der ehemaligen Inka-Hauptstadt Cuzco aufgehalten zu haben ${ }^{14}$, wo er die zur Diözese Cuzco gehörigen Doctrinas in Pocohuanca, Pacsica und Pichigua sowie in Yanaca in der Provinz Aimaraes ${ }^{15}$

11 Vgl. Murúas Angaben in MM Galvin, S. 221f. (= fol. 126r).

12 Vgl. Annalyda Àvarez-Calderón, La crónica de Fray Martín de Murúa. Mentiras y legados de un mercedario vasco en los Andes, in: Revista Andina 45 (1997), S. 159-186, hier S. 179.

13 Vgl. Ossio, Introdución, S. 55-57. An anderer Stelle vermutet Ossio 1577 als Einreisedatum: Juan M. Ossio, Murúa’s Two Manuscripts. A Comparison, in: Cummins / Anderson, The Getty Murúa, S. 77-94, hier S. 93, Anm. 11, unter Bezug auf Manuel Victor BARriga, Los Mercedarios en el Peru en el siglo XVI. Documentos del Archivo de Indias de Sevilla 1518-1600, Bd. III, Arequipa 1942, S. 290 (sic! 293).

14 Für zwei 1585 und 1588 datierte Erwähnungen vgl. Eudoxio de Jesús PALAcio, Provinciales del Cuzco de la Orden mercedaria (1556-1944), Rom 1999, S. 223. Palacio zitiert aus Cuzco Archivo Notarial [= CAN], »Protocolo de Juan de Aquino«, fol. 658, respektive »Protocolo de Alonso Herrero«, fol. 151. 1595 arbeitete Murúa im Tal von Curaguasi, vgl. Archivo Mercedario de Cuzco [= AMC], Leg. Sin Encuadernar 01, fol. 0065r-v (Auszüge auch in: Palacio, Provinciales del Cuzco, S. 249f. Weitere Auszüge in Barriga, Los Mercedarios III, S. 352f.). Für einen weiteren Beleg für Murúas Anwesenheit in Cuzco 1608 vgl. AMC Leg. $17 \mathrm{~s} / \mathrm{f}$. (auch in Palacio, Provinciales del Cuzco, S. 280. Allerdings irrt Barriga, wenn er Murúa als Comendador des Hauses bezeichnet, vgl. BArriga, Los Mercedarios III, S. 352f.).

$15 \mathrm{Zu}$ Pocohuanca und Pacsica, vgl. MM Galvin, S. 226 (= fol. 128v). Zu Pacsica vgl. auch Servero Aparicio Quispe, La Orden de la Merced en el Peru 1, Cuzco 2001, S. 73. Zu Pichigua und Yanaca vgl. ebd., S. 71f. sowie GP, S. 906 [920] u. 648 [662]. 
betreute. Bei diesen Gelegenheiten stand Murúa in direktem Kontakt mit den indigenen Bewohnern dieser Gegend und hatte bei dem Versuch, ihre Weltanschauung und Gebräuche nach christlichem Vorbild umzuformen, reichlich Gelegenheit, ihre Kultur und Geschichtserzählungen kennenzulernen. 1590 beendete er eine erste bebilderte Reinschrift, die in der Folge zu einer Materialsammlung für die ausführlichere und neu strukturierte Historia General wurde. Nach jahrelanger Bearbeitung des Textes und dem Einholen von Empfehlungsschreiben, vor allem aus dem südlichen Teil des Vizekönigreiches, brachte Murúa sein Werk persönlich nach Madrid, wo er nach 1616 verstarb.

Guaman Poma de Ayala durchzog seine Corónica mit zahlreichen Selbstbeschreibungen, die oftmals durch Übertreibungen oder absichtlich missverständliche Beschreibungen seines gesellschaftlichen Status gekennzeichnet sind. Er nutzte die spanische Unkenntnis andiner Kategorien der Verwandtschaftsbeziehungen, um sich als legitimen Ansprechpartner für den primären Adressaten seiner Schrift, König Philipp III. von Spanien, zu präsentieren. So sei sein Vater engster Berater des Inka und Herrscher in seiner Provinz, seine Mutter eine Tochter des Inka gewesen ${ }^{16}$.

Im Andenraum lebten üblicherweise Teile der »Ayllu« genannten Familienverbände in weit entfernten Enklaven. Dies diente der bestmöglichen Nutzung natürlicher Ressourcen und beeinträchtigte weder die Identifikation der Teilgruppen mit dem jeweiligen Siedlungsgebiet noch mit dem Rest der geographisch entfernten Gruppe. Die inkaische Herrschaftspolitik schloss die Umsiedlung ganzer »Ayllus« oder von Teilen davon ein, so auch Guaman Pomas Vorfahren. Sie stammten aus Huánuco, wurden von den Inka erobert, mit Frauen aus dem weiteren Inkaadel verheiratet und nach Huamanga umgesiedelt. Solche als »Mitmac« bezeichneten Gruppen bewahrten in ihrem neuen Siedlungsgebiet ihre distinkte Identität und genossen bestimmte, von den Inka garantierte Privilegien. In der Kolonialgesellschaft wurde dieses System als temporärer Frondienst, »Mita«, ausgelegt und fortgeführt. »Mitimays« [oder »Mitmaqs«] wie die Familie Guaman Pomas galten den Spaniern als zugezogene Fremde, »forasteros«, denen beispielsweise Landrechte abgesprochen werden konnten ${ }^{17}$.

16 Vgl. GP, S. 15. Zur Familie vgl. auch GP, S. 5, 20, 340 [342]f., 818 [832] u. 948 [962].

17 Mumford zeigte, wie Polo de Ondegardo das prähispanische System zwar verstand und grundsätzlich befürwortete, jedoch ignorierte, wenn es sich zu seinen persönlichen Ungunsten auszuwirken drohte: Jeremy Ravi Mumford, Litigation as Ethnography in Sixteenth-Century Peru. Polo de Ondegardo and the Mitimaes, in: Hispanic American Historical Review 1 (2008), S. 5-40. 
Guaman Pomas Muttersprache war Quechua, er beherrschte jedoch auch Aymara und Spanisch ${ }^{18}$; er war überzeugter Christ. Er arbeitete als Schreiber und Übersetzer bei Gericht und für Kircheninspektoren wie Cristóbal de Albornoz in der Provinz Lucanas ${ }^{19}$. In den 1590er Jahren führte Guaman Poma einen Prozess um Landbesitz seiner Familie, in dem er unterlag ${ }^{20}$. Das von ihm bei seiner Arbeit für spanische Kirchen- und Verwaltungsbeamte beobachtete und das selbst vor Gericht erlittene Unrecht wie auch die Bekanntschaft mit Martín de Murúa werden in der Corónica nur am Rande thematisiert, waren jedoch wesentliche Motivationen für sein Werk. Mit seiner belehrenden und anklagenden Schrift wandte er sich in erster Linie an den König von Spanien, aber auch an die verschiedenen von ihm beschriebenen Bevölkerungsgruppen des Vizekönigreiches, und letztlich an »die ganze Welt und Christenheit; selbst die Ungläubigen ${ }^{21}$.

Wie dasjenige Murúas blieb auch das Werk Guaman Pomas zunächst unpubliziert. Seit ihrer ersten Veröffentlichung 1936 ist die Corónica zu einem viel zitierten Beleg vermeintlich authentisch indigener Kultur und Identität bzw. zu einem als erste amerikanische Literatur verstandenem Werk avanciert. Es ist deshalb bis heute ein in der Forschung umstrittenes Politikum, ab wann und in welchem Umfang Guaman Poma für Murúa arbeitete. In dessen Historia General werden weder Guaman Poma noch andere Mitarbeiter oder literarische Vorbilder namentlich erwähnt. Fraglich bleibt, ob Guaman Poma nur an der Illustration oder auch am Text der ersten Version von Murúas Geschichtswerk beteiligt war ${ }^{22}$. Die Zusammenarbeit der beiden selbstberufenen Historiographen endete jedenfalls mit einem Zerwürfnis. Guaman Pomas Corónica enthält an mehreren Stellen scharfe persönliche, aber auch fachliche Kritik an Murúa ${ }^{23}$. Gerade diese fachliche Kritik verspricht Hinweise auf die unterschiedlichen Vorstellungen der Autoren von Geschichte

18 Rosario Navarro Gala, Lengua y cultura en la »Nueua corónica y buen gobierno« aproximación al español de los indígenas en el Perú de los siglos XVI-XVII, Valencia 2003.

19 Vgl. GP, S. 283 [285] u. 675 [689].

20 Vgl. Rolena Adorno, The Genesis of Felipe Guaman Poma de Ayala's Nueva Corónica y buen Gobierno, in: Colonial Latin American Review 2 (1993), H. 1/2, S. 53-92; vgl. URL: <http://www.kb.dk/permalink/2006/poma/info/es/docs/adorno/1993/index.htm> (11.02.2012). Die Gerichtsakten sind einsehbar unter: URL: <http://www.kb.dk/permalink/2006/manus/21/ eng/> (28.02.2011).

21 GP, S. 1168 [1178].

22 Adorno und Boserup finden Argumente für eine Zusammenarbeit kurz vor 1600, bei der Guaman Poma nur zeichnete, vgl. Rolena Adorno/Ivan Boserup, The Making of Murúa's Historia General del Piru, in: Cummins / Anderson, The Getty Murúa, S. 7-75, hier S. 43. Ossio hingegen argumentiert für eine Zusammenarbeit auch an den Texten, die von vor 1590 bis zu einem Zeitpunkt zwischen 1604 und 1606 dauerte. Vgl. Ossio, En busca del orden perdido. La idea de la Historia en Felipe Guaman Poma de Ayala, Lima 2008, S. 52 u. 58.

23 Vgl. GP, S. 517 [521], 611 [625], 647 [661], 906 [920] u. 1080 [1090]. Vgl. auch die Besprechung weiterer Chronisten und ihrer Werke in GP, S. 1078 [1088]-1081 [1091]. 
und ihrer Interpretation. Am augenfälligsten sind jedoch zunächst die Ähnlichkeiten der Schriften. Beide sind reich bebildert, und es existieren deutlich Parallelen in Thematik und Makrostruktur ${ }^{24}$ : Murúas um 1590 abgeschlossene Vorversion Historia del origen y genealogia real de los reyes ingas del Piru [Geschichte des Ursprungs und der königlichen Genealogie der inkaischen Könige von Peru, Ms. 1590] beschrieb in vier Büchern, seine Historia General in drei Büchern und Guaman Pomas Nueva Corónica in wesentlich zwei Abschnitten die Herrscherinnen und Herrscher der Inka, ihre Regierung sowie die Regionen und Städte des Vizekönigreichs Peru. Deutliche Unterschiede zeigen sich freilich bei der Gewichtung dieser Themen. Der als Gute Regierung bezeichnete Teil der Corónica macht fast zwei Drittel dieser Schrift aus. In Stil und Intention an das Genre der Fürstenspiegel angelehnt, kritisierte Guaman Poma hier die Missstände der Kolonialgesellschaft und machte Vorschläge zu ihrer Verbesserung. Bei Murúa ist der entsprechende Abschnitt wesentlich kürzer und auch wesentlich unkritischer. Die fachliche Kritik Guaman Pomas betrifft weder linguistische ${ }^{25}$ Überlegungen noch Murúas von späteren Forschern nachgewiesene und z.T. verurteilte Praxis des »Plagiats $\aleph^{26}$. Sie nimmt auch kaum Bezug auf Murúas Bewertung der Kolonialgesellschaft - Guaman Poma kritisiert vor allem den rein historischen Teil von Murúas Werk:

Er schrieb über die Geschichte der Inka. Er begann zu schreiben und brachte es nicht zu Ende, besser gesagt, er hat es weder begonnen noch zu Ende gebracht, weil er nicht erklärt, wo der Inka herkam, und auch nicht, wie, auf welche Art und wodurch, und er erklärt ebenso wenig, ob es ihm von Rechts wegen zustand und wie sein ganzes Geschlecht zugrunde ging ${ }^{27}$.

\section{Geschichtsbewusstsein, -erzählung, -schreibung}

Der zentrale Vorwurf lautete also, Murúa habe die Geschichte »weder begonnen noch zu Ende gebracht«. Kann man aus dieser Kritik auf ein unterschiedliches Geschichtsverständnis der beiden Autoren schließen? Ist dasjenige

24 Diese ist in dieser Form allerdings auch bei anderen Autoren wie Bartolomé de Las Casas und Román y Zamora zu finden, vgl. Ossio, Murúa’s Two Manuscripts, S. 90f.

25 Regina Harrison, The Quechua Oral Tradition. From Waman Puma to Contemporary Ecuador, in: Review. Latin American Literature and Arts 28 (1981), S. 19-22, hier S. 20.

26 Vgl. z.B. John Howland Rowe, La mentira literaria en la obra de Martin de Murua, in: Estuardo NuñEz (Hg.), Libro de homenaje a Aurelio Miró Quesada Sosa, Lima 1987, S. 753-762. Vgl. auch Marti PÄrssinen, Tawantinsuyu. El Estado Inca y su organización política, Lima 2003, S. 54-56. Vgl. auch Àvarez-Calderón, La crónica de Fray Martín de Murúa, S. 159-186.

27 GP, S. 1080 [1090]. Hervorhebung M.K. 
Guaman Pomas ein spezifisch »indigenes« Geschichtsbewusstsein, unvereinbar mit dem des Fremden?

Die Angaben in den kolonialzeitlichen Schriften und auch die beobachtete Ritualpraxis sprechen für ein ahistorisches, zirkuläres Zeitverständnis der präkolonialen andinen Kulturen. Es war im Hoch- und Tiefland an verschiedenen Naturzyklen orientiert, wobei mythische Erzählungen zur Erklärung von Naturphänomenen, des eigenen Ursprungs und des gegenwärtig Gegebenen dienten. Geographie, Gesellschaft und Mythologie waren zu einer Kosmovision verbunden, in der alles seinen rechtmäßigen Ort besa $\beta^{28}$. In dieser Vorstellung beendeten als »Pachacutis«, Weltenwendungen, bezeichnete Naturkatastrophen den jeweiligen Zeitzyklus und reinitiierten ihn gleichzeitig unter umgekehrten Vorzeichen. Insofern existierten in der andinen Zeitvorstellung tatsächlich klar definierte Anfänge und Enden. Ein »Pachacuti« war jedoch nicht gleichzusetzen mit einem absoluten Ende von Zeit oder Menschheitsgeschichte; die beendete Zeit wurde nicht ausgelöscht, sondern akkumuliert, kulturelle Errungenschaften etwa blieben von Zyklus zu Zyklus erhalten ${ }^{29}$.

$\mathrm{Ab} 1438$ unserer Zeitrechnung begann unter Inka Cusi Yupanqui der rasante Aufstieg der Inka von einer kleinen Gruppe zu einem Imperium. Cusi Yupanqui nannte sich selbst »Pachacuti« [»Weltenwender«], und ließ eine Genealogie aufstellen, in der er selbst als neunter Inka-Herrscher erschien, wobei das erste Königspaar von der nun als oberste Gottheit verehrten Sonne geschaffen worden war. Die spanischen Chronisten berichteten später von Anwesenheit und Verehrung der Mumien verstorbener Inka-Herrscher zu verschiedenen Anlässen ${ }^{30}$ : Auch als Verstorbene galten die Inka als den von ihnen abstammenden Familienverbänden vorstehend. Die Inka präsentierten sich in ihren Zeremonien als Herrscher über Naturgewalten und den Rhythmus kalendarischer Zeit: Als Mumien herrschten sie noch über die menschliche Zeit hinaus ${ }^{31}$.

Man geht davon aus, dass dieser politisch motivierte lineare Geschichtsentwurf der Inka sich zum Zeitpunkt der Eroberung durch die Spanier nur in den städtischen Zentren gegen das ahistorische, zirkuläre Zeitverständ-

28 Vgl. z.B. Nathan Wachtel, The Vision of the Vanquished. The Spanish Conquest of Peru through Indian Eyes 1530-1570, Hassocks 1977, S. 82.

29 Vgl. z.B. Abdón Yaranga Valderrama, La concepción del tiempo y de la historia en la crónica de Waman Puma de Ayala y su supervivencia en la region andina, in: Hanns-Albert STEgER (Hg.), La concepcion de tiempo y espacio en el mundo andino, Frankfurt a.M. 1991, S. 69-93, hier S. 71.

30 Vgl. MM HG 2, S. 98-100 (= fol. 252r-v); vgl. MM Galvin, S. 83 (= fol. 15r); vgl. MacCormacks Analyse der verschiedenen Berichte und Chroniken: Sabine MacCormack, Religion in the Andes. Vision and Imagination in Early Colonial Peru, Princeton 1991.

31 Vgl. ebd., S. 131. 
nis durchgesetzt hatte ${ }^{32}$. Dies wäre also in Martín de Murúas Wirkungsstätte Cuzco der Fall gewesen, jedoch nicht unbedingt in den Provinzen, in denen Guaman Poma aufwuchs und arbeitete.

Die hier besprochenen Werke entstanden in einer Gesellschaft, in der die andinen Zeitvorstellungen durch christliche Konzepte ersetzt werden sollten. Auch die europäische Vorstellung beinhaltete Zyklen und Theorien von Zeitaltern $^{33}$ : Das einzelne Jahr wurde durch die kirchlichen Feste, die gesamte Geschichte durch die Einteilung in Weltzeitalter strukturiert, wobei es Verfechter einer Drei-, Vier-, Sechs- oder Siebenteilung gab ${ }^{34}$. Insgesamt war dieses Zeitverständnis jedoch linear und teleologisch. Dominant war die Vorstellung einer einzigen, zielgerichteten Geschichte, in der nichts typisch, sondern alles singulär ist. Die Menschen waren dabei die Akteure im sinnvollen, aber undurchschaubaren Heilsplan Gottes und konnten Erlösung, Gerechtigkeit und Frieden erst am Ende der Geschichte, jenseits der weltlichen Zeit erwarten ${ }^{35}$.

Sowohl Guaman Poma als auch Martín de Murúa mussten in ihren Schriften die Kultur des jeweils Anderen besonders berücksichtigen: Für Martin de Murúa waren Sujet und Informanten Fremde, für Guaman Poma dagegen vor allem sein Publikum, von dem er nur geringes Vorwissen, aber feste Anforderungen an Medium und Form einer historischen Erzählung erwarten konnte.

Die unterschiedlichen Vorstellungen der Anderen, vom Wesen der Geschichte und vom Lauf der Zeit werden in den Werken vor allem unter dem Aspekt der Glaubwürdigkeit thematisiert.

Weder Murúa noch Guaman Poma de Ayala hatten die Inkaherrschaft selbst erlebt. Beide Autoren behaupten, einen privilegierten Zugang zu Infor-

32 Vgl. Iris Gareis, Las religiones andinas en la documentación de la extirpación de las idolatrías, in: Manuel M. Marzal/Krzysztof A. Makowski (Hg.), Religiones Andinas, Madrid 2005, S. 115-141. Vgl. auch Lienhard, Das »geschichtliche« Denken, S. 192.

33 Vgl. Thomas Vogtherr, Zeitrechnung. V. Kirchengeschichtlich, in: TRE 36, Göttingen 2004, S. 606-615.

34 Dreiteilung z.B. nach Joachim von Fiore im 12. Jahrhundert analog zur Dreifaltigkeit: Von der Schöpfung bis zum Erscheinen des Messias Jesus Christus, das christliche Reich nach Christus, das Reich des Heiligen Geistes. Prominente Modelle einer Vierteilung sind die griechisch-hellenistische Theorie von goldenem, silbernen, erzenem und eisernem Zeitalter (z.B. Hesiod) und die Weltreichlehre, die sich auf die Traumdeutung in Daniel 2,4 bezieht (Babylonier, Meder/Perser, Alexander/Makedonen und Römisches Reich einschließlich Translatio imperii). Die Theorie der vier Weltreiche geriet im 16. und 17. Jahrhundert durch neue Kenntnisse über die Geschichte Asiens ins Wanken. Der Dispensationalismus kannte (mindestens) vier Äonen, die je mit der völligen Auflösung alter Ordnungen einhergingen: Eine ehemalige Welt, die jetzige Welt, die kommende Welt, Neuer Himmel und Erde-Abschluss. Auch eine Siebenteilung war (nach den Sendschreiben in Johannes 2,3) möglich.

35 Gustav Adolf BenRath, Geschichte/Geschichtsschreibung/Geschichtsphilosophie. VII. Reformations- und Neuzeit 1. 16.-18. Jahrhundert, in: TRE 12, Göttingen 1984, S. 630-643, bes. S. $630 \mathrm{f}$ 
mationen über die andine Geschichte zu haben. Sie berufen sich - durchaus dem neuen Geist ihrer Zeit entsprechend - auf Augenzeugenschaft, aber auch auf Knotenschüre, »Quipus«, und auf die Aussagen »alter und weiser« Männer ${ }^{36}$. Letzteren begegnet Murúa dabei skeptisch. Er versucht, wahre Geschichte, »verdadera historia«, von unsinniger Fabel, »fabula ridícula«, zu unterscheiden $^{37}$. Sein explizites Hadern mit der Glaubwürdigkeit der Information erweckt dabei den Anschein von Ehrlichkeit und diskreditiert die Informanten, ja den Zustand der indigenen Geschichtsüberlieferung überhaupt, was seine eigene Leistung nur noch mehr hervorhebt.

Guaman Poma ist dagegen bemüht, die spanischen Vorurteile gegenüber den nicht-christlichen Informanten und den Genres ihres Erzählens zu entkräften. Er betont den Nutzen von »Fabeln«, die auch »zum Dienst an Gott« taugen $^{38}$, und führt an, dass unter den von den Spaniern als Autoritäten akzeptierten Philosophen ebenfalls Heiden gewesen seien ${ }^{39}$. Vor allem aber spricht er den »alten und weisen« Informanten dieselbe Glaubwürdigkeit wie vereidigten Zeugen vor Gericht zu. Ihre Aussagen seien »rechtsgültig $\ll^{40}$.

\section{Guaman Pomas Geschichtsbild - Anfang, Ende und eine neue Zeit}

Wie entwirft nun Guaman Poma seine Geschichte? Wo liegt bei ihm der historische Anfang, den er in Murúas Werk vermisst? Murúas Umgang mit dem Problem des Anfangs ist pragmatisch. Da die Frage nach der Herkunft der ersten Indianer im Andenraum durch Augenzeugen nicht zu klären war, folgt er dem scholastischen Reflex der Erklärung des Neuen durch die Suche nach Hinweisen in den anerkannten Quellen. Murúa referiert die Theorie einer Abstammung von einem der zehn Stämme Israels und präsentiert sich - wenn auch ohne viel Ambition - mit Berufung auf eine Schrift von Aristoteles als Anhänger der These, die Bevölkerung Amerikas stamme von Siedlern aus Karthago $a^{41}$. Überhaupt wisse man wenig über die Zeit vor den Inka. Man habe sie unter Vizekönig Toledo erforschen wollen, »[...] und das sicherste, das man herausfand, war, dass es keine großen Herren gab, jede Gruppe wurde von ihrem jeweiligen Oberen regiert ${ }^{42}$. Murúa dokumentiert

36 MM HG 1, S. 19 (= fol. 1v); GP, S. 8.

37 Vgl. z.B. MM HG 1, S. 5 (= fol. 7v) u. 44 (= fol. 23).

38 GP, S. 912 [926].

39 Vgl. GP, S. 72.

40 GP, S. 8.

41 Vgl. MM HG 2, S. 144-147 (= fol. 284r-v).

42 Vgl. MM HG 1, S. 20 (= fol. 2r-v). Vgl. auch MM Galvin, S. 78 (= fol. 8v.). Murúa folgt darin im Wortlaut der Schrift Orés: Luis Jerónimo Oré, Symbolo Catholico Indiano, hg. v. Antonine Tibesa, Lima 1992 [Ms. 1598], S. 155 (= fol. 39). 
gleich mehrere Versionen des inkaischen Ursprungsmythos, die ihm sämtlich als interessante, aber unglaubwürdige Fabeln gelten ${ }^{43}$. Wie bei den meisten spanischen Chronisten galt auch das Interesse Murúas nicht der frühen Geschichte, sondern den »großen Herren«, den Inka als den ehemaligen Herrschern des besiegten Großreiches. Diese Fokussierung degradiert die frühe Geschichte zu einer bloßen »Vorgeschichte« und macht sie eher beiläufig zu einer des Verfalls: Seit ihrer Ankunft in Amerika hatten die Menschen Glauben und Kulturtechniken wie die Schrift verloren. Erst die Inka führten sie zu einer Blüte, die ohne den christlichen Glauben jedoch keinen Bestand haben konnte und durfte.

Guaman Poma widerspricht dieser Vorstellung und füllt die Lücken, die er bei Murúa und anderen Autoren bemängelt. Die von ihm konstruierte vorspanische andine Geschichte dient dann als Basis seiner weiteren Argumentation bezüglich der spanischen Hegemonie im Vizekönigreich. Der andine Autor verwahrt sich zunächst gegen eine etwaige Verwandtschaft der Andenbewohner mit den für die Spanier typischen, und typischerweise eher negativ besetzten, »Fremden « seiner Zeit: Die Andenbewohner könnten nicht von Juden, Türken oder Mauren oder gar von Tieren abstammen, da sie keine physiologische Ähnlichkeit und vor allem weder mosaische oder mohammedanische Gesetze noch wie die Tiere gar kein Gesetz gehabt hätten ${ }^{44}$. Ein andiner Schöpfungsmythos wird nicht präsentiert. Guaman Poma geht davon aus, dass die Indigenen von der biblischen Gestalt Noahs abstammen. Als "Söhne Noahs $«{ }^{45}$ hatten die ersten Andenbewohner demnach ein schattenhaftes Wissen von Gott, das »im Verlauf der Zeit« (und diese Zeit und ihren Verlauf gilt es im Folgenden näher zu betrachten) verloren ging ${ }^{46}$. Er bezeichnet sie sogar als »Barbaren«, wobei dieser Begriff sich nur auf ihr mangelndes Wissen von Gott bezieht, in dem sie im Übrigen den Spaniern zu Zeiten der Römer ähnlich seien ${ }^{47}$. Keinesfalls seien sie Sklaven von Natur aus. Ihre Unwissenheit sei ein durch den Mangel an Schrift begründetes Vergessen. Guaman Poma propagiert folgerichtig Bildung als Christenpflicht und als Voraussetzung für gute Herrschaft ${ }^{48}$. Letztere scheint jedoch auch ohne die Nutzung von Alphabetschrift möglich zu sein: Den ersten Andenbewohnern mangelte es ihm zufolge - im Gegensatz zu den Spaniern seiner Zeit - nicht

43 Vgl. MM Galvin, S. 79 (= fol. 9r); MM HG 1, S. 21f (= fol. 7r).

44 Vgl. GP, S. 60f.

45 Vgl. GP, S. 25, 49, 74 u. 367 [369].

46 Vgl. GP, S. 52, 56 u. 62.

47 Vgl. GP, S. 1080 [1090]. Zu Guaman Pomas Gebrauch europäischer Kategorien und Textsorten vgl. auch Maret Keller, Der Einsatz diskursiver Traditionen in der »Primer Nueva Corónica y Buen Gobierno« (1615), in: Anne EBert u.a. (Hg.), Differenz und Herrschaft in den Amerikas. Repräsentationen des Anderen in Geschichte und Gegenwart, Bielefeld 2009, S. 265-270.

48 Vgl. GP, S. 782 [796]. 
an guten Gesetzen und einer Lebensführung, die christlichen Ansprüchen genügen müssten ${ }^{49}$. Die religiöse und juristische Argumentation Guaman Pomas ist an die von Bartolomé de Las Casas angelehnt und widerlegt alle Argumente, die spanische Gelehrte wie Vitoria, Sepúlveda und Acosta als Rechtfertigung der Conquista ins Feld führten ${ }^{50}$.

Mit seiner Schilderung der vorinkaischen Zeiten liefert Guaman Poma dann einen mathematischen Beweis seiner Theorie. Er nutzt hierfür die in Europa weithin akzeptierte Vorstellung von Weltzeitaltern. Mithilfe leichter Abänderungen gelingt Guaman Poma die Korrelation vier andiner Menschengeschlechter ${ }^{51}$ und der Inka mit einer Einteilung, die derjenigen von Augustinus ähnelt ${ }^{52}$. Die andine Vorstellung von Zeitzyklen und »Pachacutis« erwähnt er nicht.

Unter etwas unbestimmter Berufung auf »Philosophen«, »Propheten« und »Kirchenväter« geht er von 2.000.612 Jahren »seit dem Beginn bis zum Ende « der Zeit aus ${ }^{53}$. In seinem Text verknüpft er dann die andine mit biblischer und profaner Geschichte Europas, wobei das europäische Modell das Gerüst bildet:

In dem Zeitalter, in dem dieser Inka Cinche Roca herrschte, da er achtzig Jahre alt war, wurde Jesus Christus in Bethlehem geboren. Der erste Kaiser von Rom war Julius Cäsar, Augustus Cäsar, Tiberius $[\ldots]^{54}$.

Diese Art der Darstellung suggeriert, dass die spanische Weltgeschichtsschreibung bis dato unvollständig gewesen und nun zu ergänzen sei. Die Andenbewohner und Europäer sind sich in dieser Vorstellung nur scheinbar fremd: Guaman Poma behauptet nicht nur eine biologische Verwandt-

49 Vgl. GP, S. 211 [213] u. 949 [963].

50 Vgl. Rolena Adorno, Felipe Guaman Poma de Ayala. An Andean View of the Peruvian Viceroyalty 1565-1615, in: JSAm 65 (1978), S. 121-143.

51 Das in der »Nueva Corónica« entworfene kosmologische Modell hat zuerst Ossio in seiner mittlerweile im Internet veröffentlichten Arbeit untersucht, vgl. Juan M. Ossio, The Idea of History in Felipe Guaman Poma de Ayala, Oxford 1970, jetzt auch in: URL: <http://www2.kb. $\mathrm{dk} / \mathrm{elib} / \mathrm{mss} /$ poma/docs/ossio/1970/index.htm> (11.02.2012). Vgl. dazu auch Ossio, En busca, bes. S. 267-272, wo Ossio eine strukturalistisch-synchrone Lesart anbietet, oder doch eine, die Raum und Zeit verbindet: Die vier Geschlechter seien mit den Einwohnern der vier sukzessive von den Inka eroberten Regionen ihres Reiches gleichzusetzen.

52 Augustinus ging von sechs Weltzeitaltern analog zu den sechs Schöpfungstagen aus. Guaman Poma erwähnt Augustinus nicht. Auch eine Übernahme der Einteilung von Jerónimo de Chaves in dessen Werk »Chronografía o Repertorio de los tiempos« (Sevilla 1548), wäre möglich. Vgl. die Zusammenfassung Adornos, in: URL: <http://www2.kb.dk/elib/mss/poma/presentation/ index-en.htm>, Abschnitt III, Absatz 7 (11.02.2012).

53 GP, S. 13.

54 GP, S. 31. 
schaft über die Nachkommen Noahs, sondern entwirft eine zwar räumlich getrennte, doch durch ihre Existenz in derselben gottgegebenen Zeit gemeinsame Vergangenheit.

Für den europäischen Leser ungewöhnlich bleibt die Art der Zeitangaben dieser Menschengeschlechter. Es ist keine Addition der Jahre seit der Schöpfung, sondern im Wesentlichen eine Subtraktion von der ermittelten Gesamtzeit von 2.000.612 Jahren $^{55}$ :

Von den besagten sechstausendsechshundertdreizehn Jahren entnimmt man seit dem Geschlecht Uari Uira Cocha Runa und diesem Uari Runa zweitausendeinhundertundfünfzig Jahre $[. . .]^{56}$.

Dies könnte schlicht der Tatsache geschuldet sein, dass Guaman Poma selber diese Einteilung zum ersten Mal vornahm und die Jahre unterbringen musste. Die Offenlegung der Rechenschritte wäre dann als ein Lapsus zu verstehen. Guaman Pomas sorgfältige Berechnungen erlauben jedoch eine noch gewagtere Interpretation. Wenn man sein »bis zum Ende« wörtlich nimmt, dann führt ihn seine Subtraktion bis zum Ende der Zeit, das in seiner Gegenwart oder in der nahen Zukunft erwartet wird. Ein Indiz für diese Auslegung findet sich in einer weniger prominenten Passage der Corónica: In einem als »Betrachtungen « betitelten Abschnitt fasst Guaman Poma seine Einteilung in Zeitalter noch einmal auf Quechua zusammen und erweitert sie, wie mir scheint, signifikant um die Zeitalter der »Veränderungen«,

55 Augustinus teilte die Zeitalter folgendermaßen ein: Adam bis Noah, Noah bis Abraham, Abraham bis Moses, Moses bis David, David bis Jesus und Jesus bis zur Gegenwart. Guaman Poma nimmt eine Schöpfung 2.000.612 Jahre (GP, S. 13) vor seiner Zeit an, und subtrahiert 2000-3000 Jahre (GP, S. 25) für die Zeit von Abraham bis Noah, in der die Andenregion noch unbesiedelt gewesen sein muss. Von Noah bis zu seiner Zeit seien es noch 6612/3 Jahre (GP, S. 25 / 49 u. 59). Das erste Zeitalter der Indios Uari Vira Cocha Runa entspricht dann Augustinus' Noah-bis-Abraham-Zeitalter und lässt 5813/5783 Jahre übrig (GP, S. 49); das zweite Indio-Geschlecht Uari Runa (GP, S. 54f.) existierte wie das dritte Indio-Geschlecht der Purun Runa (GP, S. 58f.) in der Zeit von Abraham bis David (GP, S. 27) was einer Zusammenziehung zweier augustinischer Zeitalter gleichkommt. Das vierte Indio-Geschlecht der Auca Pacha Runa lebte von den Zeiten Davids bis zu denen Jesus' (GP, S. 64f.), was nach Augustin das fünfte, nach Guaman Poma das vierte Zeitalter darstellt. Die Zeit nach Jesu Geburt gilt bei Augustin bereits als das sechste und letzte Zeitalter, bei Guaman Poma ist dies die Zeit der Inka. Da dies aber »erst« das fünfte Zeitalter der Bibel und auch der Andenbewohner ist, impliziert dies, so er sich tatsächlich an Augustin orientiert, das Ausstehen eines weiteren, des letzten Zeitalters (GP, S. 8). Zu den Zeitberechnungen Guaman Pomas vgl. auch die Untersuchungen von Ossio und Wachtel: Nathan Wachtel, Sociedad e ideología. Ensayos de historia y antropología andinas, Lima 1973, v.a. S. 202-208. Wachtel folgt hier den Überlegungen Ossios von 1970, die dieser später noch vertiefte: Ossıo, En busca. Eine »von Christi Geburt ausgehende Rückwärtszählung der davorliegenden Jahre« wurde erstmals von Beda Venerabilis unternommen und später in den Bettelorden stark rezipiert, vgl. VogTherR, Zeitrechnung, S. 606-615, hier S. 612.

56 GP, S. 55 u. $58 f$. 
»Kriege«, »Umwälzung«, »Conquista«, »Pizarros Aufstand« bis zum Zeitalter »der Könige Karl V., Philipp II. und Philipp III.«. Doch auch diese ihm gegenwärtige Zeit scheint ihr Ende in sich zu tragen, das allerdings wiederum nicht das absolute Ende aller Zeit zu sein scheint. Guaman Poma nennt an dieser Stelle ein zehntes Zeitalter, welches er als »cristiano cayninchic yallin« [»unser christliches Wesen trägt den Sieg davon«] bezeichnet und das somit als ein Ausblick in die Zukunft zu verstehen wäre ${ }^{57}$. Diese Interpretation fügt sich durchaus in eine Gesamtschau des Werkes: die Corónica ist beredtes Zeugnis für Guaman Pomas Hoffnung auf einen Wandel der Verhältnisse in der menschlichen Lebenswelt, auf eine Umkehrung der ihm gegenwärtigen verkehrten Welt durch Intervention des spanischen Königs, den er auch als Inka tituliert ${ }^{58}$.

Die Konzeption von Raum und Zeit in der Corónica ist nicht mehr »komplett indigen «, wie dies der Quechua-Spezialist Yaranga annimmt ${ }^{59}$, sondern in ihrer Verschmelzung mit christlichen (End-)Zeitvorstellungen bereits mestizisch, eine Melange, eine Momentaufnahme im fortdauernden Prozess der Transkulturation. Die Kombination der primär zyklischen andinen Vorstellung mit der primär teleologisch-linearen Vorstellung europäischer profaner und biblischer Geschichte führt hier zu einer neuen Form millenniaristischer Utopie ${ }^{60}$. Sie ermöglicht die Hoffnung auf eine »neue, bessere Zeit«,

57 GP, S. 911 [925], vgl. auch GP, S. 857 [871].

58 Vgl. GP, S. 904 [918].

59 Vgl. Yaranga Valderrama, La concepción del tiempo, S. 69.

60 Vgl. dazu Juan M. Ossio, El mesianismo andino, in: Marzal/Makowski, Religiones Andinas, S. 201-230. Ossio definiert wie folgt: »[...] der andine >Mesianismo< ist ein höchst religiöses Phänomen dessen grundlegendes Charakteristikum ein kollektives Gefühl des Unbehagens ist, welches mit einer kosmischen Unordnung begründet wird, die in einer radikalen Transformation der Gesellschaft durch die Vermittlung eines göttlichen oder metaphysischen Wesens überwunden werden kann«. Ebd., S. 201, Übersetzung M.K. Ein prominentes Beispiel einer solchen Utopie ist die Taqui-Onkoy-Bewegung, die zwischen 1564 und 1572 in der ländlichen Provinz Huamanga beobachtet wurde, etwa vom Kircheninspektor Albornoz. Diese Bewegung erhoffte eine Stärkung andiner Gottheiten, »Huacas«, durch rituellen Tanz, sodass diese den christlichen Gott besiegen und die Spanier vertreiben könnten. Zu Quellen und Stand der Forschung vgl. z.B. Thomas A. ABercrombie, La perpetuidad traducida. Del »debate« al Taki Onqoy y una rebelión comunera peruana, in: Jean-Jacques DeCoster (Hg.), Incas e indios cristianos. Elites indígenas e identidades cristianas en los Andes coloniales, Cusco 2002, S. 79-120, bes. S. 84-89. Guaman Poma erlangte als Begleiter des Kircheninspektors Albornoz Kenntnis von dieser Bewegung (vgl. GP, S. 283 [285] u. [690]), erwähnt sie in der »Corónica« jedoch nicht. Er erwähnt eine vom Tanz verursachte Krankheit »Taquí Oncoc« (GP, S. 253 [255]), deren Verursacher oder Erfinder die »Zauberer der Inka« seien (GP, S. 280 [282]). Die TaquiOnkoy-Bewegung als solche war allerdings ein kolonialzeitliches, anti-spanisches Phänomen. Guaman Poma, der in der gesamten »Corónica« das Christentum als einzig wahre Religion propagiert, plädiert hier für die Beibehaltung andiner Formen der Gottesverehrung. Die Praxis des Tanzens bewertet er positiv (z.B. GP, S. 67), solange sie nicht mit Alkoholgenuss einhergehe (vgl. GP. S. 782 [796], 863 [877] u. S. 971 [989]). Als Dienst an Gott schreibt Guaman 
schon vor dem christlichen Jüngsten Gericht. Auf diese Weise hätte Guaman Poma die Geschichte zu Ende gedacht und im Gegensatz zu Murúa tatsächlich schreibend »zu Ende gebracht $\ll$.

\section{Martin de Murúas Umgang mit andiner Geschichte - die Inka}

Während Guaman Poma sich um eine Integration des für die Europäer fremden Stoffes in das bekannte Schema der Weltchronik bemühte ${ }^{61}$, zog Martín de Murúa es vor, die Vergangenheit der Fremden separat, im Stil einer Königschronik zu beschreiben. Seine Beschreibung der Inka-Herrscherinnen und Herrscher soll hier als Beispiel seines Umgangs mit den Zeitvorstellungen von Andenbewohnern und Europäern betrachtet werden.

In der Forschung wurde diskutiert, inwieweit eine lineare Zeitvorstellung bereits Bestandteil andiner Kultur war. War das bei den Spaniern populäre Genre der Inka-Herrscherchronologie eine rein spanische Erfindung, eine Konstruktion in Analogie zu den Ahnentafeln europäischer Könighäuser ${ }^{62}$ ? Da die inkaischen Familienverbände in Cuzco sich von je einem bestimmten verstorbenen Inka abstammend und ihm unterstehend betrachteten, diente die Genealogie durchaus auch der Erklärung und Legitimierung der soziokulturellen Struktur Cuzcos. Sie war jedoch keine spanische Projektion, sondern ein typisches, mithilfe von »Quipus« tradiertes Genre der Inkakultur ${ }^{63}$.

Bei der Präsentation dieses inkaischen Stoffes gibt es in den zwei bekannten Versionen Murúas einen bedeutsamen formalen Unterschied: In seiner ersten Schrift beschrieb Murúa (wie auch Guaman Poma) Inka und Coyas separat. Für die Historia General zog er vor, die Herrscher paarweise zu präsentieren, was den europäischen Gewohnheiten entsprach ${ }^{64}$.

Auch an anderer Stelle kann man ein solches Bemühen Murúas um europäische Standards beobachten: In der Historia General verzichtet er auf die Präsentation von ethnographischen Informationen aus der ersten Version, die

Poma den Tanz sogar vor (GP, S. 703 [797] und verwahrt sich gegen ein Verbot seitens der Spanier (GP, S. 784 [798]). Die Rolle eines »metaphysischen Wesens«, das die Gesellschaft transformieren könnte, bekleidet in Guaman Pomas Text der König von Spanien.

61 Hier geht es eher um Gleichberechtigung denn um legitimierende Kontinuität. Vergleichbaren Impulsen mag die Interpretation der römischen als Teil der spanischen Geschichte durch kastilische Historiographen geschuldet sein, vgl. Odilio EnGELs, Geschichte/Geschichtsschreibung/Geschichtsphilosophie. VI. Von Augustin bis zum Humanismus, in: TRE 12, Göttingen 1984, S. 608-630, hier S. 624.

62 Reiner Tom Zuidema, El sistema de ceques del Cuzco. La organización social de la capital de los incas, Lima 1995, bes. S. $155 f$.

63 Catherine Julien, Reading Inca History, Iowa 2000. Vgl. auch MM Galvin, S. 230 (= fol. 131r).

64 Murúa äußert sich hierzu explizit, vgl. MM HG 1, S. 28 (= fol. 7v). Vgl. dazu auch Ossio, Murúa's Two manuscripts, S. 87. 
vielleicht nur ihm bekannt waren ${ }^{65}$. Stattdessen strebt er den Konsens mit den anderen westlichen Geschichtsschreibern seiner Zeit an, indem er ganze Textpassagen dieser Autoren in sein Werk integriert. Weder Guaman Poma noch die Verfasser der guten Referenzen, die der Historia General vorangestellt sind, bemängeln dieses Vorgehen ${ }^{66}$.

Martín de Murúas Werk ist voll der Bewunderung für die Großartigkeit der Inka, von Anekdotischem und Exotischem. Er schreibt ihnen eine suchende Ahnung des christlichen Gottes $\mathrm{zu}^{67}$. Kritik an den Inka übt er selten, und wo er es tut, scheint sie eher eine Konzession an die politische Ideologie der Spanier zu sein: Die christlichen Gesetze seien besser als die der Inka, die zu "grausamen und unbarmherzigen Strafen« führten ${ }^{68}$. Diese Kritik relativiert Murúa dann allerdings auf Kosten der Indigenen, wenn er schreibt:

Man kann den Inka nicht absprechen, dass sie in der politischen Führung dieses immensen Reiches sehr bedachtsam und besonnen waren, indem sie diese Indios so regierten, wie es deren Natur und Konstitution erforderte $[\ldots]^{69}$.

Guaman Pomas Beurteilung der Inka fällt in vielerlei Hinsicht gegenteilig aus: Er macht die Inka für die Korrumpierung des von ihm behaupteten Wissens von Gott der früheren Menschengeschlechter und die Einführung von Götzenanbetung verantwortlich ${ }^{70}$. Ihre politische Herrschaft sei jedoch rechtmäßig, ihre Gesetze gut gewesen ${ }^{71}$. Die politische Kategorie »Tyrann « wird in der Corónica allein zur Verurteilung aufständischer Spanier genutzt ${ }^{72}$. Die Geschichte der Inka endet bei Guaman Poma mit einer friedlichen Machtübergabe an den König von Spanien ${ }^{73}$, so dass auch »Widerstand gegen die Spanier« als Legitimationsgrund der Conquista entfällt.

65 Dies waren vor allem Information über die Gruppen der Colla, Uro und Puquina, vgl. z.B. MM Galvin, S. 187 (= fol. 104r), Vgl. dazu auch Àvarez-CALderón, La crónica de Fray Martín de Murúa, S. 161, und Ossio, Introdución, S. 31, 33 u. 37.

66 So schreibt etwa Don Luis de Quiñones Osorio, Bürgermeister der Stadt Quintanilla und Gouverneur und Generalkapitän der Provinz Tucumán: »[Hiermit] bestätige ich den Lesern des vorliegenden Schreibens, dass es sich um wahre Geschichte handelt und dass in ihr nichts hinzuzufügen oder fortzunehmen ist - dadurch dass ich in verschiedenen Teilen dieses Reiches unter vielen hier Einheimischen gewesen bin und dieselbe Kunde kenne [...], die ich aus Neugier mir zu Wissen gemacht habe und mit eigenen Augen sah«, MM HG 1, S. 5.

67 Vgl. MM HG 1, S. $37 f$ (= fol. 15r); MM Galvin, S. 81 (= fol. 14r).

68 MM HG 2, S. 185 (= fol. 308v).

69 MM HG 2, S. 36 (= fol. 207r).

$70 \mathrm{Ihm}$ zufolge gab es ein erstes Inkageschlecht, das von den »ersten Menschen« abstammte, und ein zweites, dass durch Coya Mama Uaco und mithilfe des Teufels an die Macht kam, vgl. GP, S. 81.

71 Vgl. GP, S. 70.

72 Ebd., S. 413 [415], 422 [424] u. 1108 [1118].

73 Ebd., S. 375 [377]f. Selbst beim Zusammentreffen von Konquistadoren und Inka Atahualpa in Cajamarca kamen nach Guaman Poma Spanier nur versehentlich, und durch die eigenen 


\section{Der Status der indigenen Andenbevölkerung}

Jede Geschichte ist in einer und für eine Gegenwart gemacht. Bei den bisher vorgenommenen Betrachtungen der unterschiedlichen Geschichtskonzeptionen und ihrer Veränderungen wurde bereits deutlich, dass diese von bestimmten Zwecken nicht zu trennen sind. Beide hier untersuchten Geschichtswerke sollen nicht zuletzt den Ruhm der Autoren befördern das Publikum unterhalten (vor allem bei Murúa), die Leserschaft unterrichten und bekehren (vor allem bei Guaman Poma). Sie erklären jedoch immer auch die Gegenwart und ermöglichen ihre Bewertung vor dem Hintergrund der dargestellten Vergangenheit. Welcher Status ergibt sich also aus den Erzählungen Murúas und Guaman Pomas für die indigenen Bewohner des Vizekönigreichs Peru, welcher für die Spanier?

Die Natur der Indigenen beschreibt Murúa biologisierend als von der der Spanier verschieden im Sinne der Säftelehre: Die Indigenen seien im Gegensatz zu den cholerischen Spaniern »phlegmatisch $\aleph^{74}$. Auch seien sie

zum größten Teil faul [...], traurig, melancholisch, feige, schlapp, lau, niederträchtig, zum Schlechten neigend, lügnerisch, undankbar gegenüber denen, die ihnen Gutes wollen, ohne Bestimmtheit in angefangenen Unternehmungen, und einige sind Diebe $[\ldots .$.$] und generell alle zu Aberglauben und Zauberei neigend [. . .]^{75}$.

Murúa kritisierte allerdings auch die Spanier, welche in ihrer Praxis von Religion und Justiz kein gutes Vorbild abgäben ${ }^{76}$.

Der Aspekt des Heils ist in der Geschichtsschreibung Murúas nicht besonders präsent. Das Seelenheil der Indigenen dient jedoch als Rechtfertigung der spanischen Eroberung und Kolonialisierung Perus. Die Spanier brachten den katholischen Glauben und retteten die Seelen der Indigenen vor protestantischer Häresie ${ }^{77}$. Diese Sichtweise erlaubt ihm an geeigneter Stelle ein positives Resümee und einen optimistischen Ausblick:

Und so kommt es, dass der Zustand der Indios von Peru glücklicher und förderlicher ist als der damalige, indem nun die Rettung ihrer Seelen auf den Weg gebracht ist,

Landsleute ums Leben, vgl. ebd., S. 386 [388].

74 MM Galvin, S. 224 (= fol. 127v).

75 MM HG 2, S. 36 (= fol. 207).

76 MM HG 2, S. 91 (= fol. 247).

77 MM Galvin, S. 224 (= fol. 127v); MM HG 2, S. 169 (= fol. 229). Die theologischen Implikationen sind noch kaum untersucht, vgl. dazu Gumersindo Placer López (O. de M), Fray Martín de Murúa, apostol del Perú, in: Estudios 169 (1990), S. 49-62. 
und sie unter heiligen und gerechten Gesetzen leben, und regiert werden von liebenden Vätern, denn so kann man die Könige und Kirchenleute nennen, die sie haben ${ }^{78}$.

Die Frage nach der Legitimität der Inka ist für Martín de Murúa nur noch von theoretischem Interesse. Die spanische Herrschaft war bereits »hecho«, eine vollendete Tatsache. Das Schreiben über die Inka diente einer Rekonstruktion und Archivierung des vergangenen Fremden. Primäres Ziel Murúas war die Gefälligkeit seines Werkes, weshalb er den inkaischen Stoff europäischen Mustern anpasste, Informationen nicht-inkaischer Informanten verwarf und stattdessen zunehmend Passagen anderer Geschichtsschreiber in seinen Text integrierte. Diese Annäherung des Fremden an »das Eigene« betraf allerdings nur die formale Ebene der Textgestaltung und die Beurteilung der Quellen und des Berichteten nach Kriterien der Wahrhaftigkeit und Gottgefälligkeit. Inhaltlich war Murúa gerade nicht an einer Annäherung, sondern an der Betonung und Darstellung der Fremdartigkeit, an Kuriosem und Exotischem interessiert.

Was Guaman Poma anbelangt, so ist in seiner Beschreibung das Hauptcharakteristikum der Indigenen eine grundsätzliche Vollkommenheit nach den Maßstäben der Spanier. Er bezeichnet sie als »fiel«, was sowohl »treu« (hier im Sinne von »königstreu«) als auch »gläubig« bedeutet ${ }^{79}$. Die Spanier werden als Überbringer der christlichen Doktrin geschätzt, ihre weitere Anwesenheit ist für ihn allerdings weder notwendig noch legitim.

Der Autor der Corónica versuchte nicht, divergierende andine Vorstellungen von Raum, Zeit und Sozialstruktur zu explizieren, sondern eher diese zu nivellieren. Er bewertet die dauerhafte Anwesenheit der Spanier in Peru als unrechtmäßig, entscheidet sich jedoch dafür, dieses Unrecht mit den »Waffen« der neuen Herrscher anzuklagen, zu beweisen und somit zu bekämpfen - mit der Schrift, mit der spanischen Sprache und spanischen Kategorien.

Eine dieser Kategorien ist die des »Fremden«. Nach Guaman Poma waren die Indigenen als Söhne Noahs in gewisser Weise christlich, und die Korrumpierung ihres Glaubens war vor allem den von ihm als fremde Macht konzipierten Inka zur Last zu legen. Auch die Spanier sind für ihn Fremde, deren Gesetz nur für sie selbst gelten soll ${ }^{80}:$ »Und die Indios sind gebürtige/ natürliche Eigentümer dieses Reiches, und die Spanier [sind] gebürtig aus Spanien. Hier in diesem Reich sind sie Fremde, Mitimays $«{ }^{81}$.

Guaman Poma konstruiert und konstatiert eine Alterität der im Vizekönigreich Peru ansässigen Gruppen, auch wenn er zu diesem Zweck das Kon-

78 MM HG 2, S. 185 (= fol. 308v).

79 GP, S. 447 [449].

80 »Das Gesetz Kastiliens ist nämlich nicht das eines anderen Geschlechts [...], sondern das der Mitmac, Castillamanta Samoc [Umsiedler, der aus Kastilien gekommen ist]《. GP, S. 915 [929].

81 Ebd. 
zept des Fremden negativer besetzen muss, als es in der andinen Kultur der Fall war. Der ehemalige Mitmaq übernimmt die negative Konnotierung des spanischen Konzeptes des »Fremden«, um seine Argumentation zu stützen.

»Hier in diesem Reich sind sie Fremde« - mit diesem Verdikt würde Guaman Poma seine Geschichte gerne beenden. Doch die Spanier benahmen und fühlten sich im Vizekönigreich Peru nicht wie Fremde. Aus der Sicht gebürtiger Spanier - wie der des Mercedariers Martín de Murúa - war die indigene Bevölkerung das fremdeste Element in ihrer neu eroberten Welt. Gegenseitige Annäherung fand jedoch nicht nur auf diskursiver Ebene wie in den untersuchten Texten statt. Im Vizekönigreich lebten außer gebürtigen Andenbewohnern, Spaniern und aus Afrika Verschleppten und Versklavten schon bald auch ihre Nachkommen. Mit Begriffen wie »Mestizen« und »Kreolen « wurde eine Kategorisierung dieser neuen Generationen unternommen. Auch um ihren Status wurde gestritten. Die gebürtigen Spanier unterstellten den Kreolen üblicherweise eine Neigung zu Aufständen und klimabedingter Degeneration. Murúa hingegen schrieb: »[...] die kreolischen und in diesem Reich Geborenen sind zum größten Teil von klarem Geist und scharfem Verstand und den Wissenschaften zugetan $\ll^{82}$. Sein positives Urteil überrascht, zumal zu dieser Zeit auch in den religiösen Orden Spanier mit den SpanischPeruanern um Ämter und Vorherrschaft rangen.

Guaman Poma thematisiert die Kreolen, die sich als »naturales «, als gebürtig-natürliche Herren in diesem Land fühlten, auffallend wenig. Sie werden in der Corónica meist in syntaktisch fester Verbindung mit den Mestizen genannt ${ }^{83}$, deren Existenz Guaman Poma als Verletzung der kosmischen Ordnung anzusehen scheint. Er empfiehlt Reformen,

[...] damit Mestizen, Cholos, Mulatten, Sanbahigos sich nicht länger vermehren, [die] ohne Nutzen für die königliche Krone [sind]; [...] schlechte Menschen, zum großen Schaden der königlichen Krone und der armen Indios dieses Königreichs ${ }^{84}$.

Die vergangene Zeit wird in Erzählung und Erinnerung zu einer Interpretation, sie lässt sich jedoch nicht zurückgewinnen. Die Sprache - eigentlich Sinnbild und Mittel der Kommunikation, der Annäherung und des Austausches von Ideen - diente in den Werken Martín de Murúas und Guaman Pomas aus unterschiedlichen Motiven heraus der Konstruktion und Festschreibung von Fremdheit. Die Autoren hatten somit Anteil an der stetigen Aushandlung und Zuschreibung dieser Kategorie, die als Denkfigur mit realen Konsequenzen bis in die heutige Zeit so wirksam wie umstritten bleibt.

82 MM HG 2, S. 202 (= fol. 327v).

83 Vgl. GP, S. 733 [747], 735 [749], 855 [869] u. 1123 [1133].

84 GP, S. 213 [215]. 


\title{
Anja Bröchler
}

\section{Bilder/Schreiben/Geschichte: Tlatelolcos zukünftige Vergangenheit}

\author{
Indigene Geschichtsschreibung über die \\ Eroberung Mexikos im 16. Jahrhundert
}

Die Sonne ist fast untergegangen, doch noch ist es hell. Die Leichen der toten Krieger werden geborgen und identifiziert. Von den Vätern und Müttern erhebt sich ein Wehklagen, sie weinen und schluchzen. Vor den hohen und mächtigen Mauern des großen Palastes hat sich eine aufgebrachte und zornige Menge versammelt. Dort haben sich die spanischen Konquistadoren verbarrikadiert. Bei ihnen ist Moteucçoma, der Herrscher der aufgebrachten Menge, der Herrscher der Mexica. Die Spanier haben ihn in Ketten gelegt. Moteucçomas Staat und seine Stadt Tenochtitlan sind auf dem Höhepunkt ihres Einflusses und ihrer territorialen Ausdehnung. Aber jetzt ist er ein Gefangener der Fremden, die über das Meer gekommen sind. »Ca amo titenamicvan - wir sind ihnen nicht gewachsen«, warnt er sein Volk ${ }^{1}$.

Die Begegnung mit den Fremden im Zuge der europäischen Expansion des 16. Jahrhunderts steht im europäischen Geschichtsbewusstsein für eine Zäsur. 1492, das Jahr, in dem der Genuese Columbus für die spanische Monarchie eine aus europäischer Sicht »neue« Welt entdeckte, markiert das Ende der autochthonen Entwicklung der indigenen Kulturen Amerikas. Für sie, so das europäische Narrativ, beginnt eine neue Zeit. Im bis heute gebräuchlichen, wenn auch inzwischen kritisch hinterfragten Begriff »präkolumbisch « kommt das zum Ausdruck. Die Einteilung in die Zeit vor und nach Columbus konstruiert indigene Geschichte als eine Diskontinuität, als eine Geschichte, die durch die Conquistas zerteilt, ja zerschnitten wird².

1 James Lockhart, We People Here. Nahuatl Accounts of the Conquest of Mexico, Berkeley 1993, S. 138.

2 Zur Problematik von Zeitzäsuren für die außereuropäische Geschichte siehe Monica JunEJA, Pre-colonial oder early modern. Das Problem der Zeitzäsuren in der indischen Geschichte, in: Helmut Neunaus (Hg.), Die Frühe Neuzeit als Epoche, München 2009, S. 449-467. 
Insbesondere Arbeiten der Postcolonial Studies tradieren dieses Narrativ einer Zäsur unter den Vorzeichen von Zerstörung, Trauma und Verlust ${ }^{3}$. Wahre indigene Identität und Kultur, die noch nicht durch westlichen Einfluss kontaminiert ist, wird dabei oft nur als vorkolonial wahrgenommen und anerkannt. Sobald kein Affix »prä« vorangestellt ist, wird ein Wandel indigener Kultur als hybrid, »mestizo« oder »nepantla« gekennzeichnet, alles Begriffe, die auf eine Mischung und auf ein Dazwischen verweisen ${ }^{4}$. Diese Traumatisierung indigener Kultur diagnostiziert eine Reihe von Autoren insbesondere auch für den Bereich indigener Erinnerung und Geschichte. In seiner einflussreichen Arbeit The Darker Side of Renaissance argumentiert Walter Mignolo, dass die europäische Schriftlichkeit die indigene autochthone Erinnerung überschreibt. So wie ihr Land werden auch das Gedächtnis und die Geschichte der indigenen Völker erobert ${ }^{5}$.

Dem Narrativ einer Zäsur stehen jedoch Forschungsergebnisse entgegen, die mit indigen-sprachlichen Quellen arbeiten. Die Arbeiten von James Lockhart, Stephanie Wood, Robert Haskett, Laurie Diel und Camilla Townsend zeigen, dass indigene Kulturen und ihre Art und Weise Geschichte zu schreiben, sehr wohl in der Lage waren, mit den Fremden in ihrer Mitte umzugehen ${ }^{6}$. Dabei geht es nicht darum, die Brutalität der Eroberungskriege, die katastrophalen Folgen der Seuchen und die asymmetrische Konstruktion von Herrschaft im kolonialen Lateinamerika auszublenden oder zu ver-

3 Mabel Moraña/Enrique D. Dussel/Carlos A. Jáuregui, Colonialism and its Replicants, in: Dies. (Hg.), Coloniality at large. Latin America and the postcolonial debate, Durham 2008, S. 1-20.

4 Einen wichtigen Beitrag zur Debatte über »Hybridität« leistet der Aufsatz von Carolyn Dean/Dana Leibsohn, Hybridity and Its Discontents. Considering Visual Culture in Colonial Spanish America, in: Colonial Latin American Review 12 (2003), S. 5-35.

5 Walter Mignolo, The Darker Side of the Renaissance. Literacy, Territoriality, and Colonization, Ann Arbor 1995; Enrique Florescano, Memory, Myth, and Time in Mexico. From the Aztecs to Independence, Austin 1994; ders., National Narratives in Mexico. A History, Norman 2006; Serge Gruzinski, The Mestizo Mind. The Intellectual Dynamics of Colonization and Globalization, London u.a. 2002. Zu einer Kritik an den Positionen von Gruzinski und Florescano siehe Amos Megged, Social Memory in Ancient and Colonial Mesoamerica, New York 2010. Eine Kritik seitens der »Postcolonial Studies« an Mignolo findet sich in José RABASA, Thinking Europe in Indian Categories, or, »Tell me the Story How I Conquered You«, in: Moraña, Coloniality at large, S. 43-77.

6 James Lockhart, Nahuas and Spaniards. Postconquest Central Mexican History and Philology, Stanford, CA 1991; ders., The Nahuas. After the Conquest. A Social and Cultural History of the Indians of Central Mexico. Sixteenth to Eighteenth Centuries, Stanford, CA 1992; ders., We People Here; Stephanie Wood, Transcending Conquest. Nahua Views of Spanish Colonial Mexico, Norman 2003; Robert Stephen Haskett, Visions of Paradise. Primordial Titles and Mesoamerican History in Cuernavaca, Norman 2005; Lori Boornazian Diel, The Tíra de Tepechpan. Negotiating Place under Aztec and Spanish Rule, Austin 2008; Camilla TownsEnd, Here in this Year. Seventeenth Century Nahuatl Annals of the Tlaxcala-Puebla Valley, Stanford, CA 2009; dies., Glimpsing Native American Historiography. The Cellular Principle in Sixteenth-Century Nahuatl Annals, in: Ethnohistory 56 (2009), S. 625-650. 
harmlosen. Jedoch stellen die Forschungen die Dichotomie Sieger-Besiegte in Frage, die für lange Zeit - und teilweise immer noch - unsere Vorstellung von der Eroberung Mexikos bestimmt hat ${ }^{7}$.

Die Begrifflichkeit von einer »Sichtweise der Besiegten« geht zurück auf eine Textsammlung des mexikanischen Historikers Miguel León-Portilla aus dem Jahr 1959. La Visión de los Vencidos versammelte Auszüge aus Quellen zur Eroberung, die aus dem Nahuatl ins Spanische übersetzt worden waren. Einer der wichtigsten Textausschnitte aus dieser Sammlung stammt aus dem Buch XII des Florentiner Codex, ein auf Nahuatl verfasster Bericht über die Eroberung Mexikos. Wenn die Berichte der spanischen Eroberer Hernando Cortés und Bernal Díaz del Castillo die Sichtweise der heroischen Siegergeschichtsschreibung dokumentieren, gilt zumeist das Buch XII als die Gegenerzählung, die Sichtweise der besiegten Mexica, die dramatische Geschichte der Zerstörung einer Kultur ${ }^{8}$.

Aber das Buch XII des Florentiner Codex, so möchte ich im Folgenden argumentieren, lässt sich als ein Gegennarrativ auf eine andere Art und Weise lesen. Michel de Certeau weist in seiner Studie über das Schreiben der Geschichte auf die Ambivalenz historischer Produktion hin, denn »der Ort, den sie der Vergangenheit entwirft, ist ebenso eine Weise einer Zukunft Platz zu machen « ${ }^{9}$. Es wird gezeigt, dass im Buch XII des Florentiner Codex die Konfrontation mit den Fremden auch dazu genutzt wird, die eigene Geschichte zu re-konstruieren, d.h. ganz in der Art und Weise traditioneller indigener Geschichtsdarstellung die Vergangenheit mit der Gegenwart und der Zukunft zu verknüpfen. Der Artikel argumentiert, dass die Migrationsund Gründungsmythen sowie die piktographisch-orale Geschichtsrepräsentation in vorkolonialer Zeit einen flexiblen Umgang mit der Vergangenheit ermöglichten, der notwendig war, um offen zu sein für die Erfordernisse wechselnder politischer Allianzen im Herrschaftsraum Mesoamerikas. Die spanische Invasion als eine gewaltsame Begegnung mit den neu angekommenen Fremden nimmt keine singuläre Stellung im Geschichtsbewusstsein der Nahuas ein. Der Krieg mit den Fremden kostete die indigenen Kleinstaaten immerhin die politische Souveränität, bedeutete aber weder das Ende

7 Insbesondere Arbeiten der »new conquest history« beurteilen die Rolle der indigenen Völker differenzierter. Matthew Restall, Seven Myths of the Spanish Conquest, Oxford 2003; Lisa Sousa/Kevin Terraciano, The »Original Conquest « of Oaxaca. Nahua and Mixtec Accounts of the Spanish Conquest, in: Ethnohistory 50 (2003), S. 349-400; Laura E. Matthew/Michel R. Oudisk, Indian Conquistadors. Indigenous Allies in the Conquest of Mesoamerica, Norman 2007; Susan Schroeder, The Conquest All Over Again. Nahuas and Zapotecs Thinking, Writing, and Painting Spanish Colonialism, Sussex 2010.

8 Hernán Cortés, Cartas de relación. Edición de Mario Hernández, Madrid 1985; Bernal Díaz Del Castillo, Historia de la conquista de la Nueva España (manuscrito Guatemala), hg. v. José Antonio Barbón Rodríguez, México 2005.

9 Michel de Certeau, Das Schreiben der Geschichte, Frankfurt a.M. 1991, S. 111. 
der indigenen Geschichte noch ihrer Geschichtsdarstellung. Mit der Aneignung der lateinischen Schriftlichkeit nach der Conquista wandelte sich zwar der Aufzeichnungsmodus. Doch bewahren sich die indigenen historischen Repräsentationsformen ihre Mehrdeutigkeit und Vielschichtigkeit - selbst dann, wenn sie wie der Florentiner Codex geschrieben und illustriert wurden, um den König von Spanien zu beeindrucken.

Analysiert wird im Folgenden die Bedeutung der Illustrationen im Florentiner Codex. Insbesondere die visuelle Repräsentation der Ereignisse der Conquista in Buch XII zeigt, dass der Krieg mit den Fremden im Geschichtsbewusstsein der Nahuas weniger als ein Bruch mit der eigenen Geschichte konstruiert wird, sondern mit der eigenen Geschichte verflochten und in eine Kontinuität eingebettet wird.

\section{Texte und Illustrationen des Florentiner Codex}

Das Buch XII des Florentiner Codex ist die umfangreichste indigen-sprachliche Darstellung über die Eroberung Mexiko-Tenochtitlans (1519-1521). Der Bericht entstammt einem bis heute faszinierenden historisch-kulturellen Projekt, das maßgeblich mit dem Franziskanerpater fray Bernardino de Sahagún verbunden ist. Sahagún kommt nur kurze Zeit nach der Eroberung im Jahr 1529 nach Mexiko. Für die Franziskaner ist es das goldene Zeitalter ${ }^{10}$. In Spanien regiert Karl I. (= Kaiser Karl V.). Die religiösen Orden genießen die Unterstützung der ersten beiden neuen Vizekönige don Antonio de Mendoza (1534-1550) und don Luis de Velasco (1550-1564). Die alten Tempel werden zerstört und darüber neue Kirchen gebaut, die alten indigenen Schriften verbrannt und neue Schulen gegründet, in denen die Kinder der indigenen Eliten eine christliche und humanistische Bildung erhalten. 1536 wird das »Colegio Imperial de Santa Cruz de Tlatelolco« eingeweiht, das für Sahagún und den Florentiner Codex eine so entscheidende Rolle spielen wird. Gelehrt werden am Colegio die Fächer des Trivium und Quadrivium, entscheidender aber ist, dass sich am Colegio eine intellektuelle indigene Elite herausbildet, die in der spanischen Sprache in Wort und Schrift unterrichtet wird und die Kenntnis ihrer Muttersprache Nahuatl einbringt. Die Mehrsprachigkeit und Kompetenz der Studenten ist ein entscheidender Faktor für die Durchführung des Projekts. Denn Sahagún erhält den Auftrag, eine Geschichte der Kultur der

10 John Leddy Phelan, The Millennial Kingdom of the Franciscans in the New World, Berkeley ${ }^{2}$ 1970. Eine jüngere Studie zur franziskanischen Evangelisierung ist Viviana DíAz BALsERA, The Pyramid Under the Cross. Franciscan Discourses of Evangelization and the Nahua Christian Subject in Sixteenth-Century Mexico, Tucson 2005. 
indigenen Bevölkerung zu schreiben. Es werden zwölf Bände, die unser Wissen über die Welt der Nahuas entscheidend bereichern.

Sahagúns innovativer Ansatz wird in der Literatur vielfach hervorgehoben. »Pionero de la antropología« - als einen Ethnologen avant la lettre sieht ihn der Doyen der mexikanischen Sahagúnforschung Miguel León-Portilla in seiner einschlägigen Biographie ${ }^{11}$. Sahagún selbst schreibt darüber, wie er seine Aufgabe anging:

Alles, was wir diskutierten, gaben sie mir mithilfe von Bildern, da dies ihre alte Art und Weise des Schreibens war und die Grammatiker erklärten es in ihrer Sprache, indem sie die Erklärung am Seitenende aufschrieben ${ }^{12}$.

Denn Sahagún befragt an verschiedenen Orten die »tlatinime«, die Interpreten der Schriften, die ihm die Bildschriften zeigen und erläutern ${ }^{13}$. Vor der Ankunft der Spanier verwendeten die Nahuas ein semasiographisches Notationssystem, eine Bildschrift mit Piktogrammen, Ideogrammen und phonetischen Elementen. Wenn Sahagún sagt, dass ihm die Bilder erklärt wurden, bezieht er sich auf den im Gedächtnis eingeprägten mündlichen Text, der vorgetragen wurde. Im mesoamerikanischen Kontext wurden Bücher nicht still gelesen, sondern im öffentlichen Raum inszeniert und vorgetragen. Die Schriften waren deswegen Teil einer umfassenderen Kommunikation, die durch einen mündlichen Vortrag begleitet wurde ${ }^{14}$. Insbesondere die mündliche Präsentation trug die Inhalte und die Erzählung, und sie wurde von Sahagúns Mitarbeitern, vor allem ehemalige Studenten aus dem Kolleg von Tlatelolco, auf Nahuatl in lateinischen Buchstaben aufgeschrieben.

Im Codex stehen der Nahuatltext und eine spanische Übertragung in parallelen Spalten nebeneinander. Die spanische Kolumne, die sich links auf der Seite angeordnet findet, ist kürzer als der Nahuatltext in der rechten Spalte. Denn Sahagúns spanischer Text leistet keine wortgetreue Übersetzung, sondern gibt den Inhalt mit Blick auf eine spanische Leserschaft sinngemäß wieder, erläutert an manchen Stellen und verkürzt an anderen ${ }^{15}$. Alle zwölf Bücher sind illustriert.

11 Miguel León-Portilla, Bernardino de Sahagún. Pionero de la antropología, México, D.F. 1999.

12 Bernardino de Sahagún, Florentine Codex. General History of the Things of New Spain, übers. v. Arthur J.O. Anderson/Charles E. Dibble, 13 Bd., Salt Lake City 1950-1982, hier Bd. 1, S. 53.

13 Alfredo López Austin, The Research Method of Fray Bernardino de Sahagún. The Questionaires, in: Munro S. Edmonson (Hg.), Sixteenth Century Mexico. The Work of Sahagún, Albuquerque 1974, S. 111-149.

14 Lockhart, The Nahuas. After the Conquest, insb. Kapitel 8: Ways of writing, S. 326-374.

$15 \mathrm{Zu}$ den Unterschieden zwischen dem spanischen und dem Nahuatlext im Buch XII siehe Kevin Terraciano, Three Texts in One. Book XII of the Florentine Codex, in: Ethnohistory 57 (2010), S. 51-72, hier S. 58-61 und Anja BRÖCHLER, Sprechende Bilder - bildhafte Texte. Das Verhält- 
Der Entstehungsprozess des Florentiner Codex ist komplex und durchläuft verschiedene Phasen, bis er zwischen 1578 und 1580 fertiggestellt wird $^{16}$. Der Prozess der Niederschrift des Nahuatltextes beginnt um 1547 und ist vor 1569 weitgehend abgeschlossen ${ }^{17}$. In dieser Zeitspanne ändern sich die politischen Vorzeichen. Unter Philipp II. folgt für die Franziskaner nach dem »goldenen« unter Karl I. nun das nur »silberne« Zeitalter. Statt der Orden wird der weltliche Klerus gestärkt. Nach dem Tod von Bartolomé de las Casas 1566, der Bewegung der Gegenreformation und der Gründung eines Inquisitionsgerichts in Mexiko im Jahr 1571 war die Erforschung der Sitten und Gebräuche der indigenen Bevölkerung nicht mehr gewollt. Der franziskanische Provinzial fray Alonso de Escalona beschlagnahmte sogar Sahagúns Schriften, da befürchtet wurde, dass sie Kenntnisse über Idolatrie bewahren würden, die besser dem Vergessen anheimfallen sollten. Sahagún bekam die Manuskripte zwar zurück, weil er auf eine königliche Anordnung von 1575 hin eine spanische Übersetzung seiner Schriften anfertigen und nach Spanien schicken sollte. Zu dieser Zeit forderte der Vorsitzende des Indienrates, Juan de Ovando, alle kolonialen Behörden auf, die Chroniken und Manuskripte über die Conquista und die neuen Gebiete nach Madrid zu schicken, da der neu ernannte königliche Hofchronist Juan López de Velasco eine autorisierte offizielle Geschichte Amerikas verfassen sollte ${ }^{18}$. Nach Ovandos Tod reguliert Philipp II. die Wissensproduktion aus und über Amerika noch stärker. 1577 verbietet er mit einer königlichen Order alle weiteren Studien über die indigene Kultur und Religion. Alles Material soll konfisziert und nach Madrid gesandt werden. Zwar sind königliche Befehle und koloniale Umsetzung nicht immer deckungsgleich, aber der Vizekönig Mar-

nis von Bild und Text im Buch XII des »Florentiner Codex« (1578-80) des Fray Bernardino de Sahagún, in: Zeitenblicke 7 (01.10.2008), H. 2, URL: <http://www.zeitenblicke.de/2008/2/ broechler/index html> (01.12.2010).

16 Zur Entstehungsgeschichte des »Florentiner Codex« siehe Luis Nicolau D'Olwer/Howard F. Cline, Sahagún and His Works, in: Robert Wauchope (Hg.), Handbook of Middle American Indianas, Bd. 13: Guide to Ethnohistorical Sources, Pt. 2, Austin 1973, S. 186-206; Charles E. Dibble, Sahagún's Historia, in: de Sahagún, Florentine Codex, Bd. 1, S. 9-23; José Luis Martínez, El códice florentino y la Historia general de Sahagún, México 1982; Miguel LeónPortilla, Bernardino de Sahagún. First Anthropologist, Norman 2002; John Frederick SchwaLLER, Tracking the Sahagún Legacy. Manuscripts and Their Travels, in: Ders. (Hg.), Sahagún at 500. Essays on the Quincentenary of the Birth of Fr. Bernardino de Sahagún, Berkeley 2003, S. $265-274$.

17 Lockhart, We People Here, S. 27.

18 Arndt Brendecke, Imperium und Empirie. Funktionen des Wissens in der spanischen Kolonialherrschaft, Köln 2009, zu Juan de Ovando siehe S. 217-260. Brendecke schreibt aus Sicht des spanischen Hofes und der Vizekönige Neuspaniens und Perus. Wünschenswert wäre eine Ergänzung durch eine transkulturelle Perspektive, die berücksichtigt, wie seitens der Regierten das Informationsbedürfnis der Krone und ihrer Vertreter genutzt wurde, Interessen zu dokumentieren. Siehe die Studie von Barbara Mundy, The Mapping of New Spain. Indigenous Cartography and the Maps of the Relaciones Geográficas, Chicago 2000. 
tín Enríquez (1568-1580) will alle Manuskripte Sahagúns beschlagnahmen lassen. Für Sahagún droht die Zerstörung seines Lebenswerks. Erschwerend kommt hinzu, dass 1576 eine verheerende Seuche in ganz Neu-Spanien ausbricht, die unzählige Todesopfer fordert, darunter vermutlich auch Mitarbeiter des Codex.

Mit Unterstützung von Seiten des franziskanischen Ordensprovinzials fray Rodrigo de Sequera gelingt es Sahagún trotz aller Schwierigkeiten, den Codex fertigzustellen. Im Buch XII, dem letzten Band, zeugen die Leerstellen in der spanischen Spalte von der Hast, mit der gegen Ende gearbeitet werden musste. Denn weil dieser Text kürzer war, hatte der Schreiber Platz für die Illustrationen gelassen, die nachträglich eingefügt wurden. Publiziert wurde das Manuskript erst 1829, und zwar nur der spanische Text ohne Illustrationen unter dem Titel Historia general de las cosas de Nueva España ${ }^{19}$. Eduard Seler veröffentlichte 1927 erste Auszüge einer deutschen Übersetzung aus dem Nahuat ${ }^{20}$. Der gesamte Nahuatltext aller zwölf Bücher ist von Arthur Anderson und Charles Dibble ins Englische übersetzt worden ${ }^{21}$. Nur von Buch XII gibt es eine kritische Edition von James Lockhart ${ }^{22}$. Es ist die einzige Publikation, in der sowohl der spanische Text als auch der Nahuatltext in parallelen Spalten nebeneinander stehen und übersetzt sind. Zusätzlich sind Schwarz-Weiß-Abbildungen der Illustrationen abgedruckt. Nur die Faksimile-Ausgabe von 1978 gibt die Illustrationen in Farbe und an ihrem angestammten Ort innerhalb des Textes wieder ${ }^{23}$.

Weder der Nahuatltext noch die Bilder geben ein zeitnahes Zeugnis von der Conquista. Der Nahuatltext von Buch XII liegt um 1555 vor. Die Illustrationen entstehen erst Ende der siebziger Jahre des 16. Jahrhunderts. Wie der Nahuatltext stammen auch die Illustrationen von den Nahua Tlacuiloque ${ }^{24}$. Sahagún übersetzte oder überarbeitete die Übersetzung der Mitarbeiter aus dem Nahuatl ins Spanische. Insbesondere für die Illustrationen zur Conquista ist die Zeitdifferenz zwischen Ereignis, textlicher und bildlicher Dar-

19 Bernardino de Sahagún, Historia general de las cosas de Nueva España, que en doce libros y dos volumenes escribío. Dala á luz con notas y suplementos Carlos María Bustamente, 3 Bd., México, D.F. 1829/30.

20 Eduard Seler, Einige Kapitel aus dem Geschichtswerk des Fray Bernardino de Sahagun, Stuttgart 1927.

21 Sahagún, Florentine Codex.

22 Lockhart, We People Here.

23 Fray Bernardino de Sahagún, Códice florentino. Historia general de las cosas de la Nueva España. Manuscrito 218-220 de la Colección Palatina de la Biblioteca Medicea-Laurenziana. Edición facsimilar, 3 Bd., Florenz 1979.

24 »Tlacuilo« (Plural »Tlacuiloque« - Schreiber/Maler) kommt von »icuiloa« - schreiben/malen. Anders als im europäischen Denken, in dem Schreiben und Malen zwei getrennte Tätigkeiten sind, unterscheiden die Nahuas nicht zwischen den beiden Aktivitäten. Die Nahuas bezeichneten Ausmalungen der Tempel, piktographisches Schreiben und postkoloniales alphabetisches Schreiben unterschiedslos als »icuiloa«. 
stellung relevant. Denn die indigenen Zeichner illustrieren einen Text, der fast zwanzig Jahre zuvor entstanden ist und der selbst über Ereignisse berichtet, die mehr als dreißig Jahre zurückliegen. Während für den Nahuatltext noch Zeitzeugen Auskunft geben konnten, was dem Text teilweise anzumerken ist, sind die Illustratoren keine Augenzeugen mehr. Sie bilden etwas ab, das sie selbst weder erlebt noch gesehen haben.

Darüber hinaus entsprechen die Illustrationen kaum noch der traditionellen indigenen piktographischen Repräsentation. Für Kunsthistoriker und Mesoamerikanisten wie Ellen Baird, Amos Megged und Elizabeth Boone, die mit altmexikanischen Codices arbeiten, zeigen die Illustrationen des Florentiner Codex, dass sie stark von europäischen Bildkonventionen beeinflusst sind ${ }^{25}$. Der mexikanische Historiker Enrique Florescano bezeichnet sie als von den europäischen ikonographischen Traditionen kontaminiert ${ }^{26}$. Weil die Tlacuiloque eine europäische Ikonographie verwenden, wird in ihnen auch eine europäisierte Perspektive der Eroberung gesehen. Für den französischen Historiker Serge Gruzinski vermitteln die Bilder eine spanische Sichtweise der Conquista ${ }^{27}$. Den Krieg der Bilder hätten die Mexica damit ebenfalls verloren ${ }^{28}$.

Im Folgenden wird gezeigt, dass die Einbeziehung europäischer Bildkonventionen keineswegs eine europäisierte Sichtweise determiniert. Es wird argumentiert, dass die Tlacuiloque sich eng am Nahuatltext orientieren. Gleichzeitig aber nutzen sie die Mehrdeutigkeit der Bilder, um eine zusätzliche Dimension der Interpretation ihrer Geschichte zu vermitteln, die sich aus dem Text so nicht erschließt. Diese Polyvalenz und ihre politische Relevanz zeigt der Aufsatz an den Illustrationen zum Tod und Begräbnis von Moteucçoma und Itzquauhtzin.

\section{2. »Ca amo titenamicvan - wir sind ihnen nicht gewachsen«}

Der Tod eines Herrschers stellt in allen Gesellschaften ein bedeutendes Ereignis dar. Das gilt besonders für vormoderne Staaten mit ihrer Verschränkung von religiöser und politisch-dynastischer Herrschaft, deren Souverän die politische Ordnung verkörperte ${ }^{29}$. Moteucçoma, der neunte »huey tlatoani«

25 Ellen T. Baird, Sahagún and the Representation of History, in: Schwaller, Sahagún at 500, S. 117-136; Elizabeth Hill Boone, The Multilingual, Bi-visual World of Sahagún's Mexico, in: Ebd., S. 137-167; Megged, Social Memory, S. 37.

26 Florescano, National Narratives in Mexico, S. 160.

27 Serge GruZINSKI, Painting the Conquest. The Mexican Indians and the European Renaissance, Paris 1992, S. 49.

28 Ders., La guerre des images de Christophe Colomb à »Blade Runner« (1492-2019), Paris 1990.

29 Zur Bedeutung des Todes eines Herrschers in der europäischen Geschichte der Frühen Neuzeit siehe die Beiträge der von Christoph Kampmann geleiteten Sektion »Der Tod des Herrschers 
(wörtlich: großer Sprecher) der Mexica, dessen Einflussgebiet sich vom Golf von Mexiko bis zum Pazifik erstreckte, wurde als göttlicher Herrscher und als die menschliche Inkarnation des Gottes Huitzilopochtli gesehen. Der Tlatoani personifizierte nicht allein die weltliche staatliche Herrschaft, sondern repräsentierte darüber hinaus die Aufrechterhaltung der kosmischen Ordnung selbst ${ }^{30}$.

Am 8. November 1519 trifft Moteucçoma zum ersten Mal von Angesicht zu Angesicht auf den spanischen Konquistador Hernando Cortés, eine Begegnung, die oft als ein Moment von welthistorischer Bedeutung stilisiert wurde. Darüber, was Moteucçoma zu Cortés gesprochen haben soll - Cortés interpretiert es als eine »translatio imperii« - gehen die Interpretationen bis heute auseinander ${ }^{31}$. Aber was für die Begegnung mit den Fremden, so wie sie im Florentiner Codex berichtet wird, vielleicht symbolträchtiger ist, drückt sich in den Gesten und weniger in Worten aus. Moteucçoma bereitet den Fremden einen spektakulären Empfang, es ist ein Meisterstück politischer Inszenierung von Reichtum und Ritual. Schier endlose Reihen des Mexica Adels verneigen sich vor den Ankömmlingen und küssen den mit vielfarbigen Blumen gesäumten Boden. Moteucçoma beschenkt Cortés mit Blumengirlanden und heißt ihn mit einer Halskette aus Gold willkommen. Es ist ein langes Zeremoniell, wie Cortés seinem König berichtet ${ }^{32}$. Den Höhepunkt bildet Moteucçomas berühmte Rede, die von Marina, Cortés’ Dolmetscherin, übersetzt wird ${ }^{33}$. Der Florentiner Codex stilisiert die prachtvolle Inszenierung

als Grenze und Übergang«, in: Christine Roll u.a. (Hg.), Grenzen und Grenzüberschreitungen. Bilanz und Perspektiven der Frühneuzeitforschung, Köln u.a. 2010, S. 261-332.

30 Susan D. Gillespie, Blaming Moteuczoma. Anthropomorphizing the Aztec Conquest, in: Rebecca P. BRIENEN/Margaret JACKSON (Hg.), Invasion and Transformation. Interdisciplinary Perspectives on the Conquest of Mexico, Boulder 2007, S. 25-56.

31 Für eine kritische Lesart der Geschichtsschreibung über die Conquista und die Rede, siehe Restall, Seven Myths. Im »Florentiner Codex« wird es so dargestellt, dass Moteucçoma geglaubt habe, dass Hernando Cortés die Inkarnation des Gottes Quetzalcoatl sei. Die Ethnologin Susan D. Gillespie zeigt auf, dass es sich dabei um eine koloniale Konstruktion handelt. Susan D. Gillespie, The Aztec Kings. The Construction of Rulership in Mexica History, Tucson 1989; dies., Blaming Moteuczoma, S. 25-56. Ein guter Überblick über die CortésQuetzalcoatl-Story findet sich in Camilla Townsend, Burying the White Gods. New Perspectives on the Conquest of Mexico, in: AHR 108 (2003), S. 659-687, URL: <http://www. historycooperative.org/journals/ahr/108.3/townsend.html> (01.12.2010). Zur Frage der Spanier als Götter in den Annalen von Tlatelolco siehe auch Anja Utgenannt, Gods, Christians and Enemies. Representations of the Spanish Conquerors in an Indigenous Account. Vortrag im Juni 2002 auf der Konferenz Cambio cultural en el México del siglo XVI, Göttweig/Wien 2002. Spezifisch zur Frage der Repräsentation der Spanier im »Florentiner Codex« siehe LockHART, We People Here, S. 19-21.

32 CoRTÉs, Cartas de relación.

33 Marina oder Malintzin gilt als eine der zentralen, faszinierenden und umstrittenen Personen der Eroberung Mexikos, aber die Quellenlage über sie ist spärlich. Als eine Nahua Frau an der Seite von Hernando Cortés war sie als seine »lengua«, seine Dolmetscherin, von entscheidender Bedeutung für die Kommunikation zwischen den Spaniern und den Nahuas. Von den 
der Mexica, den spanischen Konquistadoren hingegen bringt der Nahuatltext weit weniger Ehrfurcht entgegen. Über Cortés' Antwort heißt es wenig respektvoll:

Und als der Marqués [Cortés] gehört hatte, was Moteucçoma gesagt hatte, vermittelte er seine Antwort über Marina, er brabbelte, er antwortete in seiner stammelnden Sprache $^{34}$.

Die spanische Übertragung des Nahuatltextes lässt diesen Teil aus, der den strahlenden Glanz der ersten Begegnung unterläuft und die Konquistadoren eher wie stammelnde Barbaren und weniger wie Göttergestalten aussehen lässt. Gleichzeitig aber kündigt der Text bereits hier das Ende von Moteucçomas Herrschaft an. Denn dem »huey tlatoani« gebührte großer Respekt, niemand durfte ihm in die Augen sehen und niemand ihn berühren. Aber die Spanier verhalten sich entsprechend respektlos ${ }^{35}$. Sie nehmen ihn an der Hand, sie streichen ihm über das Haar, und jeder der Spanier geht zu ihm hin, um ihn direkt anzusehen. Aus der Perspektive des Florentiner Codex blieb die Entweihung Moteucçomas politisch nicht folgenlos. Ein Teil des Adels trägt seine Politik gegenüber den Spaniern nicht mehr mit: »sie wendeten sich im Zorn von ihm ab $\ll^{36}$.

Von diesem politischen Dissens ist es nicht mehr weit bis zu der Szene, die zum Tod des Herrschers führt. Als Gefangener der Spanier verliert Moteucçoma zunehmend an Einfluss. Die angespannte Situation eskaliert, als Cortés Tenochtitlan verlässt. Sein Statthalter Pedro de Alvarado erlaubt den Mexica, die alljährliche Toxcatl-Zeremonie zu Ehren von Huitzilopochtli abzuhalten. In der Version des Florentiner Codex nutzen die Spanier die zeremonielle Feier zu einem Überraschungsangriff auf die ahnungslosen Mexica. Während der Adel, die Priester und die Bevölkerung im Innenhof vor dem großen Tempel versammelt sind und die rituellen Tänze beginnen, kommen die Spanier gerüstet und bewaffnet hinzu, schließen die Tore, damit niemand entkommen kann und metzeln die unbewaffneten und überraschten Mexica

Spaniern wurde sie auf den Namen Marina getauft, der Name Malintzin, mit dem sie auch in den Quellen bezeichnet wird, ist eine davon abgeleitete Nahuatlversion. Während Cortés ihre Bedeutung in seinen Berichten sehr herunterspielt, wird sie in alphabetischen wie piktographischen Nahuatl-Quellen in ihrer einflussreichen Funktion wahrgenommen und dargestellt. Zu Malintzin in ihrem historischen Kontext siehe die einschlägige Biographie von Camilla TownSEND, Malintzin's Choices. An Indian Women in the Conquest of Mexico, Albuquerque 2006.

34 Lockhart, We People Here, S. 118.

35 Der Nahuatltext verwendet durchgehend die Bezeichnung »españoles« für die Konquistadoren oder spricht im Krieg von »toiaovan« - »unseren Feinden«. Lockhart führt die einheitliche Verwendung von »españoles« auf Sahagún zurück. Ebd., S. 19-21.

36 Ebd., S. 118. 
nieder ${ }^{37}$. Im Anschluss an das Massaker verbarrikadieren sich die Spanier mit Moteucçoma sowie weiteren Mitgliedern der königlichen Familie und des Adels als Geiseln in seinem Palast. Es kommt zum Aufstand. Moteucçoma soll die dramatische Situation für die Spanier retten. Der Florentiner Codex vermittelt seine bewegende Rede. Im Florentiner Codex hält sie nicht Moteucçoma selbst. Diese Aufgabe übernimmt Itzquauhtzin, der Herrscher von Tlatelolco:

Oh Mexica, oh Menschen von Tenochtitlan und Tlatelolco, Euer Herrscher der Tlacateuctli Moteucçoma sagt: lasst es die Mexica hören, wir sind ihnen nicht gewachsen, mögen sie davon abgehalten werden weiter zu kämpfen. Mögen die Pfeile und die Schilde des Krieges abgelegt werden. Die armen alten Männer und Frauen, die einfachen Leute, die Kinder, die gerade laufen lernen und krabbeln, die in der Wiege oder auf ihrem Wiegenbrett ${ }^{38}$ liegen und noch nichts wissen, sie alle leiden. Deswegen sagt euer Herrscher, wir sind ihnen nicht gewachsen, jeder soll davon abgehalten werden. Sie haben ihn in Eisen gelegt. Sie haben Eisen um seine Füße gelegt ${ }^{39}$.

Trotz ihrer Eindringlichkeit sind es nicht die richtigen Worte. Der Zorn der Menge steigert sich, erst werden Moteucçoma und der Redner Itzquauhtzin beschimpft, dann fliegen die Pfeile. Darüber, ob der Herrscher der Mexica durch die Pfeile und damit von der Hand der Mexica starb oder ob er von den Spaniern ermordet wurde, wie andere Quellen nahelegen, lässt uns der Florentiner Codex jedoch im Unklaren. Aber aus der Logik der Erzählung im Florentiner Codex spielt das nur eine unwesentliche Rolle. Seit seiner Begegnung mit Cortés hat Moteucçoma als der gefangene Souverän und als Marionette der Spanier seine Macht und seinen Einfluss immer mehr verloren. $\mathrm{Ob}$ ihm nicht bereits vor seinem Tod sein Bruder Cuitlahuac als »huey tlatoani« nachfolgte, ist eine offene Frage ${ }^{40}$. Die Bilder vom Tod Moteucçomas legen eine solche Lesart zumindest nahe.

37 Zur Darstellung des Toxcatl-Massakers im »Florentiner Codex« siehe BRÖCHLER, Sprechende Bilder - bildhafte Texte.

38 Ein Wiegenbrett war eine bei der indigenen Bevölkerung Nord- und Südamerikas gebräuchliche Tragevorrichtung für Säuglinge und Kleinkinder. Ein Brett wurde mit Stoff und Riemen so geschnürt, dass das Kind darin sicher transportiert werden konnte. URL: $<$ http://chnm.gmu. edu/cyh/primary-sources/432> (01.12.2010).

39 Lockhart, We People Here, S. 138.

40 Gillespie, Blaming Moteuczoma, S. 25-56, hier S. 50. 


\section{Polyvalenz und Politik}

Im Florentiner Codex erzählt eine Bildfolge von fünf Bildern vom Tod und Begräbnis Moteucçomas (Abb. 1-3). Auf den ersten Blick bestätigen die Illustrationen die Kritik vom Einfluss europäischer Bildkonventionen. So sind die beiden spanischen Figuren in der oberen Bildhälfte der ersten Abbildung (Abb. 1) eher naturalistisch gezeichnet. Auch entspricht die Kleidung des Spaniers in der oberen rechten Bildhälfte nicht der Mode zur Zeit der Conquista, sondern ist zeitgenössisch zur Entstehungszeit der Bilder. Genauso zeugen die folgenden Illustrationen von europäischen Darstellungsweisen (Abb. 2 und 3). Figuren und Gebäude sind eher naturalistisch als konventionell abgebildet, Schattierungen verleihen den Bildern Tiefe. Einmal sehen Gebäude und angedeutete Landschaft sogar so aus, als seien sie unmittelbar einem europäischen Druck entnommen (Abb. 3 oben). Die ikonographische Mehrsprachigkeit der indigenen Zeichner zeigt sich besonders deutlich bei den weinenden Mexica (Abb. 3 unten). Tränen als Ausdruck der Trauer werden auch in der altmexikanischen Bildsymbolik eingesetzt und funktionieren daher in beiden Bildwelten ${ }^{41}$. Gleichzeitig aber integrieren die Zeichner auch allein indigene piktographische Elemente, wie das Symbol für Wasser (Abb. 1) oder die stilisierte Zunge als Zeichen für Rede.

Der Bildinhalt folgt der Perspektive des Nahuatltexts. Nachdem Moteucçoma und Itzquauhtzin von den Mexica beschimpft und mit Pfeilen beschossen wurden, bringen die Spanier ihre Leichen aus dem Palast zu einem Platz nahe am Wasser. Die Illustration (Abb. 1) zeigt in der oberen Bildhälfte einen steifen und flach ausgestreckten Körper, der von zwei Spaniern getragen wird. Der Spanier links trägt eine Ritterrüstung mit heruntergelassenem Visier, die rechte Figur ist in der Art eines eleganten Edelmannes gekleidet. Der Leichnam trägt indigene Kleidung, den um die Hüften geschlungenen Lendenschurz sowie den »tilmatli«, den über der Schulter geknoteten weiten Umhang. In der unteren Bildhälfte schwebt ein ganz ähnlich aussehender Körper über einer Fläche von kleinen Strudeln. Sie symbolisieren das Wasser, an dem laut Text die Leichen aufgefunden wurden. Beide Tote tragen das »xiuhhuitzolli«, das mit Türkisen besetzte Stirnband. Es weist sie als Herrscher aus ${ }^{42}$.

41 Daniel Graña-Behrens, Wenn Azteken und andere Völker weinen. Emotionen und kulturelle Praktiken in den autochthonen Bilderhandschriften und alphabetschriftlichen Dokumenten Zentralmexikos, in: August Nitschke/Justin Stagl/Dieter R. Bauer (Hg.), Überraschendes Lachen und gefordertes Weinen. Gefühle und Prozesse, Kulturen und Epochen im Vergleich, Wien u.a. 2009, S. 237-264.

42 Justyna Olko, Turquoise Diadems and Staffs of Office. Elite Costume and Insignia of Power in Aztec and Early Colonial Mexico, Warschau 2005; dies., Convenciones y estrategias en la iconografía del rango de la nobleza indígena del centro de México en el siglo XVI, in: Revista Española de Antropología Americana 38 (2008), H. 2, S. 207-240. 


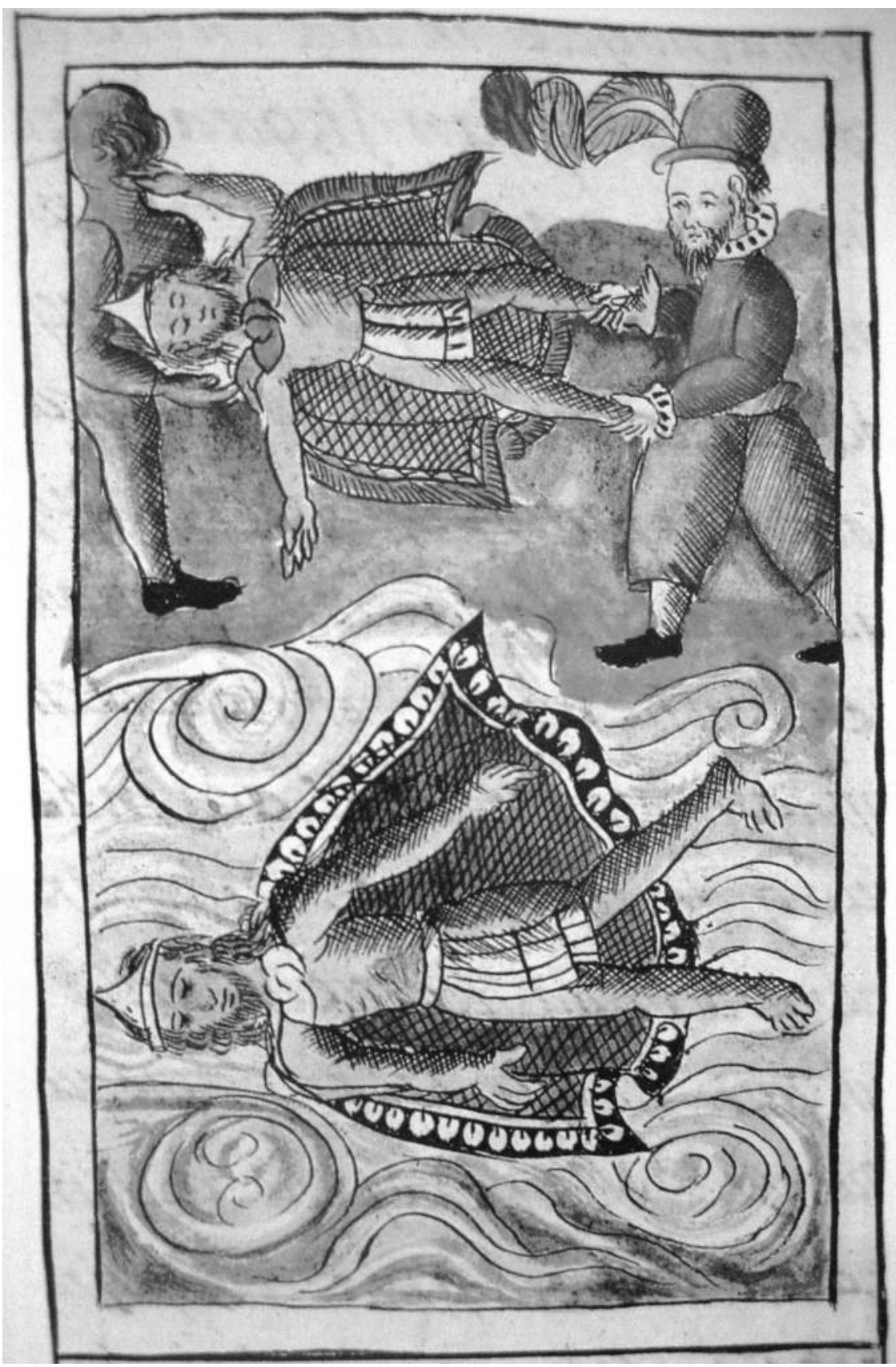

Abbildung 1: Die Spanier entledigen sich der toten Herrscher Moteucçoma und Itzquauhtzin. Florentiner Codex, Buch XII, f.40v. 


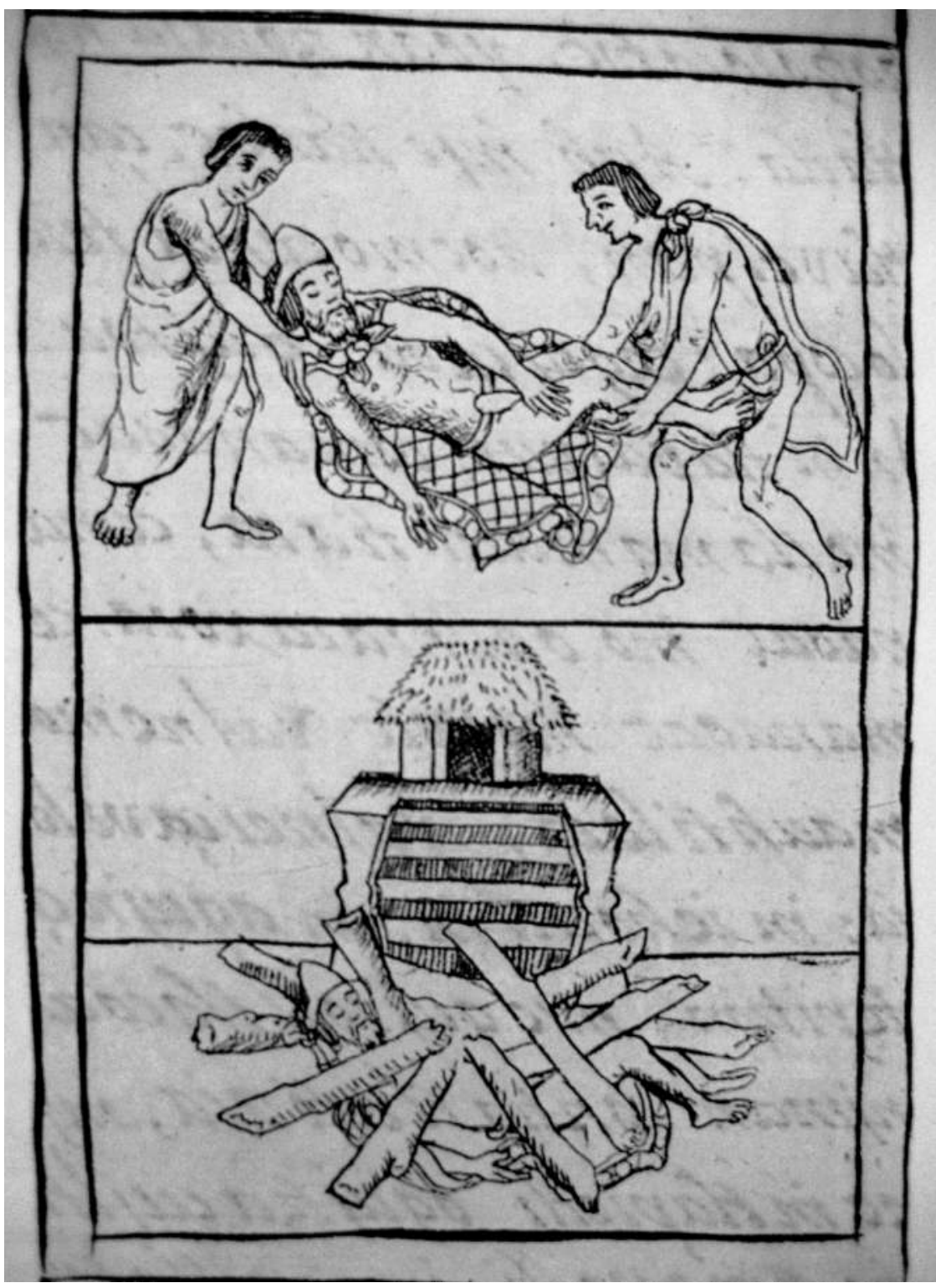

Abbildung 2 oben und unten: Die rituelle Bestattung von Moteucçoma.

Florentiner Codex, Buch XII, f. 40v. 


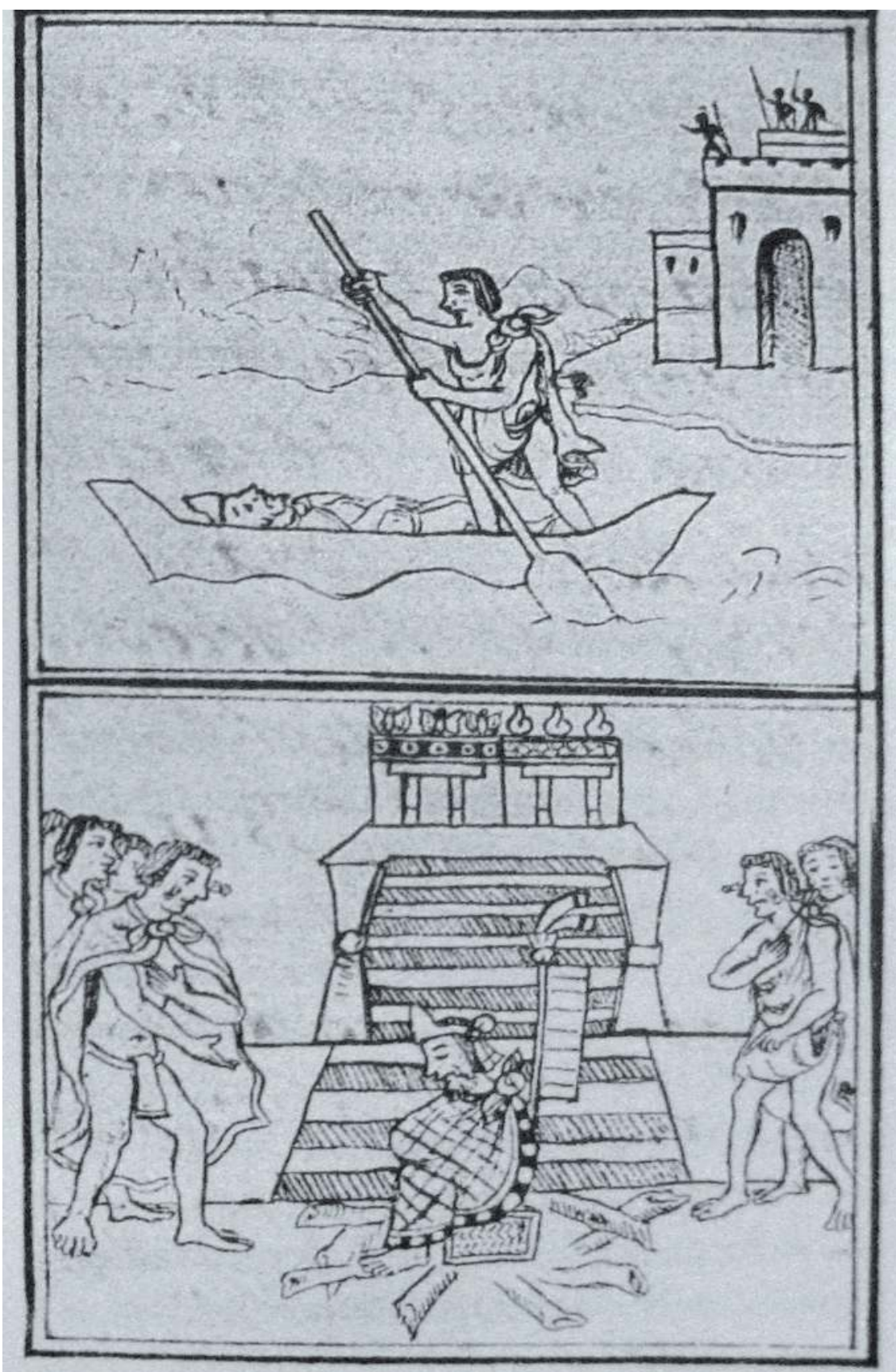

Abbildung 3 oben und unten: Die rituelle Bestattung von Itzquauhtzin. Florentiner Codex, Buch XII, f.41. 
Beide sind mit Bart dargestellt, ein visueller Hinweis auf ihren hohen sozialen Status ${ }^{43}$. Die Bedeutung des Bildes wird dadurch herausgehoben, dass es als eines der wenigen Illustrationen im Buch XII farbig ist. Aus der bildlichen Darstellung geht nicht hervor, welche Leiche die jeweilige Person darstellt. Im Tod wird zwischen Moteucçoma und Itzquauhtzin nicht unterschieden. Das ändert sich mit der Darstellung ihres Begräbnisses.

Betrachtet man die beiden Bilder von Moteucçomas Begräbnis parallel zu den beiden Bildern vom Begräbnis von Itzquauhtzin, so zeigt sich ein deutlicher Unterschied. Moteucçoma erhält im Vergleich zu Itzquauhtzin kein würdevolles Begräbnis. In den Bildern wird Moteucçoma von zwei Mexica, so wie er aufgefunden wurde, vor die Stufen eines mit Stroh bedeckten Gebäudes gelegt und mit Holzscheiten bedeckt (Abb. 2). Itzquauhtzin hingegen wird von einem Mexica in einem Boot transportiert (Abb. 3 oben). Das nächste Bild (Abb. 3 unten) zeigt ihn nun anders ausgestattet. Itzquauhtzin sitzt in traditioneller Herrschaftspose und versehen mit dem königlichen Banner auf einer Schilfmatte, Symbol für den Herrschersitz, vor großen Stufen, die zu einer Plattform mit zwei Gebäuden führen. Banner und Schilfmatte weisen ihn als Herrscher aus. Das Gebäude mit den Stufen ist ein zeremonielles Zentrum, der »huey teocalli« mit zwei Schreinen für die Götter Huitzilopochtli und Tlaloc. Um den toten Herrscher herum stehen weinende Mexica. Die Aussage ist deutlich: Im Gegensatz zu Itzquauhtzin trauert niemand um Moteucçoma und anders als Itzquauhtzin wird er auch nicht ehrenvoll bestattet ${ }^{44}$.

In der Kontrastierung von Moteucçoma und Itzquauhtzin und der Herabwürdigung von Moteucçoma durch das Begräbnis und die Mexica folgen die Illustrationen dem Nahuatltext. Sahagúns spanischer Text hingegen weicht erkennbar davon ab. Bei Sahagún werden die beiden toten Körper der Herrscher zum gleichen Ort namens Copolco geleitet:

43 Der Bart als Ausweis eines hohen sozialen Status funktionierte in beiden Welten. Für die europäische Konvention siehe Horst Pietschmann, »Kulturtransfer« im kolonialen Mexiko. Das Beispiel der Malerei und Bildlichkeit im Dienst indigener Konstruktionen neuer Identitäten, in: Michael North (Hg.), Kultureller Austausch. Bilanz und Perspektiven der Frühneuzeitforschung, Köln u.a. 2009, S. 369-390. Für die Nahua-Konvention siehe TERraciano, Three texts, S. $51-72$.

44 Eine kontroverse Interpretation der Bilder entwickelt Diana Magaloni-Kerpel. Sie sieht Moteucçoma als bewusste Christusanalogie dargestellt. Diane MAGALONI-KERPEL, Visualizing the Nahua/Christian Dialogue. Images of the Conquest in Sahagún's »Florentine Codex« and their Sources, in: Schwaller, Sahagún at 500, S. 193-222; Diane Magaloni-Kerpel, Painting a New Era. Conquest, Prophecy, and the World to Come, in: Brienen/JACKson, Invasion and Transformation, S. 125-149. Kritisch dazu Anja BRöchlER, Re-visioning the Conquest of Mexico. Image and Text in the Florentine Codex (1578-80), in: Medieval History Journal 12 (2009), S. 47-76. 
Dort vollzogen sie die rituellen Handlungen, die sie traditionellerweise für Tote mit großem Ruhm durchführen. Danach äscherten sie die Körper ein, wie sie es traditionellerweise mit allen Herrschern machen und sie vollzogen alle Zeremonien, die sie üblicherweise durchführen ${ }^{45}$.

Im Nahuatltext wird über Moteucçomas Begräbnis hingegen berichtet, dass sie ihn auf einen Holzstoß legten und verbrannten. Dabei habe der Körper einen üblen Geruch verbreitet. Die Bevölkerung beschimpft den aufgebahrten Moteucçoma. Ganz anders verfährt der Nahuatltext mit Itzquauhtzin. Die Anwesenden trauern, er wird speziell eingekleidet und mit großem Prunk eingeäschert.

An Sahagúns abweichender spanischer Version zeigt sich deutlich, dass das Begräbnis des Herrschers als ein politischer Akt inszeniert wird und dass durch die Art und Weise, wie später darüber berichtet wird, politische Interessen und Absichten vermittelt werden sollen. Sahagún geht dabei nicht so weit, die Differenz, die der Nahuatltext zwischen Moteucçoma und Itzquauhtzin legt, gänzlich einzuebnen. Er fügt durchaus hinzu, dass einige über Moteucçoma schlecht sprachen, weil er grausam gewesen sei, während Itzquauhtzin betrauert wurde, weil er beliebt gewesen sei. Aber seine Version unterschlägt die bedeutsamen politischen Implikationen der Beerdigung. In Cortés' Interpretation der Rede, die Moteucçoma bei ihrer Begegnung gehalten hat, konstruiert er einen freiwilligen Herrschaftstransfer, indem Moteucçoma sich zum Vasallen Karls I. erklärt habe. Wie es Nahuatltext und die Bilder nahelegen, ist Moteucçoma zum Zeitpunkt seines Todes nicht mehr der anerkannte legitime Herrscher. Die Legitimationskette einer Übertragung von Moteucçomas Herrschaft an die spanische Krone ist gerissen. Sahagúns spanische Darstellung lässt diesen Aspekt erst gar nicht aufkommen.

\section{Die Bedeutung des »huey teocalli«}

Die Illustrationen setzen den Nahuatltext kongenial um, aber sie sind nicht allein eine visuelle Interpretation der Textvorlage. Interessant ist in der bildlichen Umsetzung der Begräbnissequenz eine signifikante Differenz zum Text. Über Itzquauhtzin heißt es im Text, dass sie seine Leiche zum Tempelinnenhof brachten, zu einem Ort, den sie Quauhxicalco nennen ${ }^{46}$. Aber in der bildlichen Darstellung ist die Leiche stattdessen vor den Stufen des »huey teocalli«, dem großen Tempel, sitzend aufgebahrt. 
Für Nahua Herrscher und insbesondere für die Mexica Tlatoque ist der pyramidenförmige Tempel das Zentrum ihrer politischen und religiösen Macht. Nach ihrem Tod und ihrer Einäscherung wurde zumindest ein Teil ihrer Asche dort aufbewahrt und wurde so Bestandteil des »huey teocalli« als Zeichen für die enge Verbindung von Herrscher und Tempel. Als »axis mundi« stand der Tempel am Kreuzungspunkt der Nord-Süd- und der OstWest-Achsen, die Tenochtitlan in vier Stadtteile und vier Herrschaftsgebiete (tlaxilacalli) mit jeweils eigenen Tlatoque aufteilte ${ }^{47}$. In der Einteilung überlagern sich politische Strukturen und kosmologische Programme.

Dass die Zeichner des Florentiner Codex Itzquauhtzin vor dem »huey teocalli« abbilden, besitzt einen hohen Symbolwert, der eng mit den Gründungsmythen der Mexica zusammenhängt. Der »huey teocalli« war ein Zwillingstempel: Zwei mächtige parallele Aufgänge führten zu zwei Schreinen. Der südliche Schrein diente Huitzilopochtli, dem Kriegs- und Sonnengott. Der Schrein wird häufig mit Schmetterlingen abgebildet, die sein Dach verzieren. Sie symbolisieren die gefallenen Krieger. Im nördlichen Schrein wurde Tlaloc verehrt, der Regen- und Fruchtbarkeitsgott. Die Hälfte der Pyramide, die Huitzilopochtli geweiht war, symbolisiert den Hügel von Coatepetl (wörtlich: Schlangenberg) und erinnert an die Geburt des Gottes. Durch einen Federball, der vom Himmel fiel, wurde Huitzilopochtlis Mutter Coatlicue mit ihm schwanger. Aufgehetzt von seiner älteren Schwester Coyolxauhqui wollen seine Brüder, die Centzonhuitznahua, seine Mutter töten. Vom Mythos existieren unterschiedliche Versionen. In einer wird Huitzilopochtli bereits ausgewachsen und voller Kriegsrüstung geboren. Er tötet seine Schwester und zerschmettert ihren Körper, der den Hügel hinabstürzt und dessen Glieder zerstreut werden. Allegorisch vermittelt der Mythos den Aufgang der Sonne (Huitzilopochtli). Die Sonne vertreibt den Mond (Coyolxauhqui) und Sterne (Centzonhuitznahua) in die Unterwelt im Westen. Die Nahuas nutzten diese kosmischen Metaphern auch, um politischen und sozialen Erfolg und Misserfolg zu symbolisieren ${ }^{48}$. Jeder gewonnene Krieg der Mexica feierte Huitzilopochtlis Sieg über seine Schwester. Dabei wird Krieg als eine schöpferische Kraft verstanden, um die alternierenden Zyklen von Schöpfung und Zerstörung fortzuschreiben ${ }^{49}$. Der Tempel diente zugleich als Chronik der Herrscher, ihrer Kriege und Siege, so wie die Herrscher selbst Huitzilopochtli verkörperten und durch ihr Leben, ihre Taten und die zeremoniellen Handlungen die Geschichte des Gottes zelebrierten. Der »huey teocalli« symbolisierte für den Herrscher dynastische und politische Legitimität. Diese sich

47 Lockhart, The Nahuas. After the Conquest, Kap. 2: Altepetl, S. 14-59.

48 Emily Umberger, The Metaphorical Underpinnings of Aztec History, in: Ancient Mesoamerica 18 (2007), S. 11-29, hier S. 14.

49 Eduardo de J. Douglas, In the Palace of Nezahualcoyotl. Painting Manuscripts, Writing the pre-Hispanic Past in Early Colonial Period Texcoco, Mexico, Austin 2010, S. 100. 
überlagernden mythologischen, historischen und politischen Schichten sind zentral für ein Verständnis der Mexica Geschichtsschreibung und für die Interpretation der Illustrationen im Florentiner Codex.

Indem die Illustrationen - anders als der Text - den »huey teocalli«, das Sinnbild religiöser und politischer Macht in ihre Perspektive aufnehmen, werden über den Text hinausgehende Deutungsräume eröffnet. Denn im Bild des »huey teocalli« überlagern sich die Bedeutungsebenen und sie verknüpfen die Conquista mit der Geschichte Tenochtitlans vor der spanischen Invasion.

\section{Migration und Eroberungen: Tenochtitlans Aufstieg zur Macht}

Tenochtitlans Geschichte beginnt mit einem Gründungsmythos, der die enge Verbindung der Mexica mit Huitzilopochtli begründet. Wiederum finden sich variierende Versionen. Zumeist beginnt die Geschichte mit dem Aufbruch von Aztlan, einem Ort, der in einem See gelegen ist. Auf Geheiß von Huitzilopochtli trennt sich die Ethnie der Mexica von den anderen, es folgen Jahrhunderte der Wanderung über verschiedene Stationen bis hin zum Ort der Prophezeiung: Spiegelbildlich zum Ursprungsort Aztlan zu Beginn der Migration schließt die Wanderung mit der Gründung des neuen Gemeinwesens, das wiederum in einem See liegt. Entsprechend der Weissagung sollten die Mexica ihren Bestimmungsort dort finden, wo ein Kaktus auf einem Stein wächst, auf dem sich ein Adler niedergelassen hat, der eine Schlange frisst. Aus den Silben ergibt sich der Name: aus »tetl« - Stein, »nochtli« - Kaktus und dem Ortssuffix »tlan« für »in der Nähe« wird Tenochtitlan. Kurz nach der Gründung kommt es zu einer weiteren Abspaltung. Auf dem begrenzten Raum der Inseln im Texcoco-See wird wenig später im Norden Tlatelolco gegründet.

Das Entscheidende an diesem Gründungsmythos sind zwei Elemente, die für die Geschichtsdarstellung wichtig sind: erstens die Migration als der Bezug auf eine ethnische Identität, die sich von anderen abgrenzt und zwar sowohl von Ethnien gemeinsamen Ursprungs als auch von Gruppen, mit denen sie während ihrer Wanderung in Kontakt treten. Diese Dynamik der ethnischen Identität und der Abgrenzung ist ein wichtiges Element der Staatsbildung wie der Geschichtsschreibung. Der Gründungsmythos verweist zweitens auf die Überwindung der Migration und die Bedeutung des Ortes, der Gründung des Gemeinwesens, in Nahuatl das »Altepetk . Das »Altepetk ist die zentrale politische und sozio-kulturelle Organisation der Nahuas vor und auch noch lange Zeit nach der Conquista ${ }^{50}$. 
In der Zeit vor und um die Gründung Tenochtitlans und Tlatelolcos entwickeln sich in Zentralmexiko eine ganze Anzahl ähnlich strukturierter Stadtstaaten. Diese Staaten interagieren intensiv untereinander, sowohl in friedlicher als auch in antagonistischer Weise. Allianzen und Heiraten zwischen den Dynastien wechselten sich mit Angriffen und Kriegen ab. In der Regel schlossen sich zwei oder mehrere Staaten zusammen, um einen anderen Staat gemeinsam zu erobern und zu unterwerfen. Zumeist wird ein neuer Regent eingesetzt, der von den neuen Machthabern abhängig ist. Der Verlierer muss Tribute zahlen, anteilig an die an der Eroberung beteiligten Sieger. Zudem muss der unterlegene Staat sich an künftigen Kriegen beteiligen. Die Allianzen bilden aber keine starre politische Struktur, sondern sie werden immer wieder durch Kriege, Heiraten und diplomatische Verhandlungen rekonfiguriert $^{51}$. Aus diesem Prozess bildet sich seit dem Sieg im Jahr 1428 über die Regionalmacht Azcapotzalco Tenochtitlan in der Allianz mit zwei weiteren Staaten, Texcoco und Tlacopan, als durchsetzungsfähigster Staat heraus. Diese Dreierallianz wird als aztekischer Dreibund oder auch als Reich der Azteken bezeichnet ${ }^{52}$. Mit der Formation der Allianz nehmen die Spannungen zwischen den beiden Schwesterstaaten Tenochtitlan und Tlatelolco zu und es kommt im Jahr $1473 \mathrm{zu}$ einem Krieg, in dem Tlatelolco unterliegt.

In diesem Krieg spielen die beiden großen Tempel von Tenochtitlan und Tlatelolco eine zentrale Rolle. So soll die Auseinandersetzung damit begonnen haben, dass der Herrscher von Tlatelolco, Moquihuix, seinen »huey teocalli« ausbaute und damit seinen Machtanspruch gegenüber Tenochtitlan demonstrierte. In den verschiedenen Erzählungen mischen sich die mythischen und historischen Elemente ${ }^{53}$. In der Schlacht gelang es den Kriegern der Tenochca, die Tlatelolca bis zu ihrem Tempel zurückzudrängen. Der Herrscher der Tenochca, Axayacatl, erklimmt die Stufen des Tempels, die zum Schrein von Huitzilopochtli führen. Auf der Plattform kommt es zum Zweikampf der beiden Herrscher, den Moquihuix verliert. Moquihuix stürzt sich die steilen Stufen des Tempels hinunter in den Tod. Die Erzählungen des Krieges zwischen den beiden Altepetl wiederholen so die mythische Geschichte vom Kampf Huitzilopochtlis gegen seine Schwester Coyolxauhquix. Den Herrscher der Tlatelolca, Moquihuix, ereilt dasselbe Schicksal wie die Göttin. Nach dem Sieg Tenochtitlans wurde der Tempel Tlatelolcos geschändet. Die siegreichen

organized outside their own settlements in the sixteenth century - the encomienda, the rural parishes, Indian municipalities, the initial administrative jurisdictions - was built solidly upon individual, already existing altepetl«. Lockhart, The Nahuas. After the Conquest, S. 14.

51 Michael Ernest Smith, The Aztecs, Oxford ${ }^{2} 2003$, bes. Kap.: The Rise of Aztec Civilization, S. $28-56$.

52 Ebd., S. 156-172; Susan D. Gillespie, The Aztec Triple Alliance. A Postconquest Tradition, in: Elizabeth Hill Boone, Native Traditions in the Postconquest World, Dumbarton Oaks 1998, S. 233-265.

53 Umberger, The Metaphorical Underpinnings, S. 11-29. 
Tenochca entfernten die Statue Huitzilopochtlis aus dem Schrein und brachten sie vermutlich nach Tenochtitlan ${ }^{54}$. Mit dem Tod Moquihuix' endete das Herrscherhaus der Tlatelolca. Regiert wurde Tlatelolco fortan von einem von den Tenochca eingesetzten und abhängigen Herrscher und musste Tribut zahlen. Mit dem Sieg Tenochtitlans symbolisierte nun allein der »huey teocalli« der Tenochca den heiligen Berg der Schlangen, Coatepetl, den Geburtsort von Huitzilopochtli und die axis mundi des Universums.

Indem die Illustrationen Itzquauhtzin mit dem »huey teocalli« darstellen, machen sie eine politische Aussage. Sie nutzen die Geschichte der spanischen Invasion, um sich die Souveränität Tlatelolcos zurückzuerobern.

\section{Déjà-Vu}

Wie in einer Endlosschleife der Geschichte spielt der »huey teocalli« von Tenochtitlan eine entscheidende Rolle bei den Ereignissen, die zum Tod von Moteucçoma und Itzquauhtzin führen. Nach dem Massaker an den Mexica während der Toxcatl-Feier hatten sich die Spanier mit ihren Gefangenen im Palast von Moteucçoma verbarrikadiert. Die Mexica versuchen die Blockade zu brechen und rufen ihre besten und tapfersten Krieger zusammen. Sie sollen die Pyramide erklimmen, um den königlichen Palast von oben unter Beschuss zu nehmen und in ihn einzudringen. Als jedoch die Spanier die Taktik erkennen, schicken sie selbst ihre Männer bewaffnet mit Büchsen, Armbrüsten und Schwertern zum Tempel. Nacheinander erklimmen die Spanier Stufe für Stufe, und die Mexica haben ihrem Aufstieg wenig entgegenzusetzen. Die schweren Holzklötze, die sie als Wurfgeschosse vorbereitet haben, können die Spanier mit ihren Schilden abwehren. Als sie oben angekommen sind, stechen und hauen sie auf die Mexica ein, die sich die Stufen des Tempels hinunterwerfen; »wie schwarze Ameisen stürzten sie sich hinunter«, heißt es im Text ${ }^{55}$.

Der Florentiner Codex gibt immer wieder Hinweise darauf, dass Moteucçomas Autorität infolge seiner Gefangennahme durch die Spanier zunehmend erodierte. Noch bevor er physisch stirbt, ist er mit den Ereignissen des Toxcatl-Massakers und der Niederlage am großen Tempel bereits politisch tot. Vier Tage nach der Niederlage werden die Leichen von Moteucçoma und Itzquauhtzin vor den Mauern des Palastes aufgefunden.

Angesichts der sich überlagernden Bedeutungen, die dem »huey teocalli« in der politischen und religiösen Konstruktion der Mexica und in ihrer Geschichte und ihren Geschichtsnarrativen zukommt, klingt die Episode

54 Ebd.

55 Lockhart, We People Here, S. 148. 
nach einer nachträglichen Geschichtsrekonstruktion. Aber auch Cortés berichtet darüber, triumphierend, weil es ihm gelungen war, die gefährliche Bedrohung abzuwenden. Zu diesem Zeitpunkt ist der »huey teocalli« für die Mexica auch noch nicht endgültig verloren. Im Gegenteil, in den darauffolgenden Tagen bereiten sie den Spaniern eine verheerende Niederlage, die aus spanischer Perspektive als »noche triste«, als traurige Nacht, in die europäische Geschichte eingegangen ist. Nur unter großen Verlusten gelingt es den Invasoren und ihren Verbündeten, aus Tenochtitlan zu entkommen: »Und als die Spanier gegangen waren, dachten alle, dass sie für immer gegangen waren, dass sie nie zurückkehren würden, niemals umkehren würden ${ }^{56}$.

In die dramatische Geschichte vom Krieg um Tenochtitlan und den politischen Verwerfungen innerhalb der Mexica gelingt es den Zeichnern des Florentiner Codex, ihre Antwort auf Tlatelolcos zurückliegende Niederlage einzufügen. Denn Itzquauhtzin, der so prominent an die Seite des huey tlatoani Moteucçomas gestellt und im Vergleich so viel vorteilhafter dargestellt wurde, ist der Herrscher von Tlatelolco. Er ist der von den Tenochca eingesetzte Herrscher, der Quauhtlatoani, ein Interimsherrscher, der zwar dem Adel, aber nicht der direkten königlichen Linie entstammt ${ }^{57}$. Seine Position als ein von den Tenochca eingesetzter Herrscher ist ambivalent und trotz der Tlatelolca Voreingenommenheit des Florentiner Codex ist seine Rolle zwiespältig $^{58}$. Im Nahuatltext wird er als loyal gegenüber Moteucçoma porträtiert und als er für ihn die Rede vom Dach des Palastes hält, dass die Mexica den Spaniern nicht gewachsen seien, da wird er beschimpft mit den Worten: »Was sagt Moteuç̧oma, Du Schurke? Bist Du nicht einer seiner Männer « ${ }^{59}$. Aber bei den Beerdigungen ist es Moteucçoma, dem allein die Schuld zugewiesen wird.

In den Illustrationen wird die Leiche Moteuç̧omas vor einem Tempel mit einem mit Stroh gedeckten Dach abgelegt. Dass er nicht vor dem »huey teocalli« eingeäschert werden konnte, war vielleicht auch der Kriegssituation geschuldet. Aber genau das war sein Problem und seine Schuld, und das ist auch die Botschaft der Bilder. Moteucçoma verkörpert nicht mehr Huitzilopochtli. Wie Moquihuix im Krieg zwischen den Tenochca und den Tlateloca stürzen sich die Krieger der Mexica die Stufen des Tempels hinunter. Im Leben wie im Tod hat er den »huey teocalli« verloren, das Symbol seiner Vergöttlichung und der Legitimation seiner Herrschaft.

56 Ebd., S. 176.

57 »And after the altepetl of Tlatelolco had been destroyed, it began that Itzquauhtzin tlacochcalcatl was installed and acted as quauhtlatoani there. He no longer became tlatoani, and they no longer gave him a copilli, but he counted as if he were a king and governed all the Tlatelolca«. Susan Schroeder, Chimalpahin and the kingdoms of Chalco, Tucson 1991, S. 192.

$58 \mathrm{Zu}$ Itzquauhtzin siehe BRöCHLER, Re-visioning the Conquest of Mexico.

59 Lockhart, We People Here, S. 138. 
Im traditionellen piktographischen Aufzeichnungssystem sind die Bilder polyvalent. Sie können mehr als nur eine Bedeutung haben oder diese nahelegen $^{60}$. Piktographisch geschriebene Geschichten waren absichtlich mehrdeutig, um politische Intentionen je nach Zuhörerschaft und strategischen Zielen anpassen zu können. Die Polyvalenz der Bedeutungen und ihrer Möglichkeiten bildlicher Repräsentation nutzen auch die Zeichner des Florentiner Codex. Sie illustrieren den Text, also die Ereignisse der spanischen Invasion. Gleichzeitig entwickeln sie auch ein politisches Argument, indem sie die Vergangenheit rekonfigurieren.

Itzquauhtzin, der Herrscher von Tlatelolco, erhält im Bild symbolträchtig den »huey teocalli« zurück, den Moquihuix im Kampf gegen die Tenochca verloren hatte. Im Boot bringen sie ihn nach Tlatelolco und bestatten ihn so, wie es einem Herrscher gebührt. Die Darstellung zeigt Itzquauhtzin zudem mit den königlichen Insignien. Die Schilfstrohmatte symbolisiert den Sitz der Schlangen, der demjenigen zusteht, der über Coatepec, den Hügel der Schlangen, herrscht. Er trägt das Xiuhuitzolli, das türkisfarbige Stirnband des Tlatoani und das königliche Banner. Die spanische Invasion dient den Zeichnern des Florentiner Codex dazu, die Position Tlatelolcos gegenüber Tenochtitlan neu zu definieren und die Eroberung Tlatelolcos rückgängig zu machen. Als Herrscher verkörpert Itzquauhtzin das Altepetl von Tlatelolco, das mit der Niederlage der Tenochca gegen die Spanier seine Souveränität wiederhergestellt sieht.

\section{Tlatelolcos Vergangenheit in der kolonialen Gegenwart}

Die neuen Machtverhältnisse werden dazu genutzt, eine alte Rechnung zu begleichen. Der Geschichtsrevisionismus dient aber nicht allein der ReGlorifizierung der Vergangenheit, sondern soll Tlatelolcos Position in der kolonialen Gegenwart sichern. Tlatelolco sah sich als eigenständiger Staat und nicht Tenochtitlan untergeordnet. In der kolonialen Nachkriegsordnung hatte Tlatelolco erfolgreich durchgesetzt, als eine Munizipalität (»Cabecera«) anerkannt zu werden. Die Position als souveränes Altepetl vor der Conquista galt dabei als ein entscheidendes Kriterium, den wichtigen Status einer »Cabecera« mit einem eigenen indigenen »Cabildo« (Stadtrat) zu bekommen. Denn wie in vorkolonialer Zeit waren damit Prestige, Tribute und Land außerhalb der eigentlichen Stadt verbunden. Sowohl Tlatelolco wie Tenoch-

$60 \gg$ The difficulty with reading the Mexican manuscripts has always been, first, in understanding the pictorial abstractions and conventions and then, second, on knowing on what level to interpret them. It is a multivalent writing system and can mean (and suggest) several things at one time«. Elizabeth Hill Boone, Stories in Red and Black. Pictorial Histories of the Aztecs and Mixtecs, Austin 2000, S. 38. 
titlan erhielten diesen Status, und die Rivalitäten zwischen den beiden Stadtstaaten setzten sich fort. So kommt es im 16. und 17. Jahrhundert immer wieder zu gewaltsamen Auseinandersetzungen zwischen der Bevölkerung von Santiago Tlatelolco und San Juan Tenochtitlan ${ }^{61}$.

In der Entstehungszeit der Illustrationen zwischen 1570 und 1580 gibt es verschiedene Entwicklungen, die für die jeweiligen Städte problematisch sind. Für das Colegio von Tlatelolco sind die euphorischen und vielversprechenden Anfangszeiten der vierziger und fünfziger Jahre vorbei. 1555 wird beschlossen, keine indigenen Priester zu ordinieren und sie auch nicht als Laienbrüder in den Orden zuzulassen. Die spanischen Autoritäten unterstützen die Einrichtung nicht mehr, und zusätzliches Missmanagement führt zur zunehmenden Bedeutungslosigkeit der Institution.

Vielleicht hatte das Colegio aber auch aus indigener Perspektive seinen Zweck erfüllt. Die Kollegiaten übernehmen wichtige Funktionen in den indigenen kolonialen Administrationen und als Notare ${ }^{62}$. Einer der herausragenden Kollegiaten ist Antonio Valeriano, einer der indigenen Co-Autoren des Florentiner Codex ${ }^{63}$. Sahagún nennt ihn seinen besten und klügsten Mitarbeiter ${ }^{64}$. Valeriano macht eine bemerkenswerte politische Karriere. Er wird zunächst »juez gobernador « in seiner Heimatstadt Azcapotzalco und übernimmt dann 1573 das Amt eines indigenen Gouverneurs in Tenochtitlan. Chimalpahin, der Nahua Historiker des 17. Jahrhunderts, betont Valerianos einfache Herkunft, fügt aber anerkennend hinzu, dass er ein sehr gelehrter Mann gewesen sei, der fließend Latein gesprochen und geschrieben habe. Der Hinweis auf »amo pilli«, kein Adliger zu sein, fällt nicht grundlos. Denn wie in anderen Altepetl auch befindet sich das Amt des Tlatoani im Umbruch. Nach dem Tod von don Luis de Santa Maria Cipactzin im Jahr 1565 endet für Tenochtitlan die Periode, in der zumeist die Nachkommen Moteucçomas die Position des Tlatoani und Gouverneurs innehatten ${ }^{65}$. Tenochtitlan

61 Charles Gibson, The Aztecs Under Spanish Rule. A History of the Indians of the Valley of Mexico, 1519-1810, Stanford 1964, S. 207.

62 Frances Karttunen, From Court Yard to the Seat of Government. The Career of Antonio Valeriano, Nahua Colleague of Bernardino de Sahagún, in: Amerindia 19/20: La »decouverte« des langues et des écritures d'Amérique, S. 113-120, URL: <http://celia.cnrs.fr/FichExt/ Am/A_19-20_08.htm> (01.12.2010). Von der ausgehenden zweiten Hälfte des 16. Jahrhunderts bis zum Ende des 17. Jahrhunderts lässt sich vom goldenen Zeitalter der Nahuatlliteratur sprechen. Die indigenen Eliten waren auf vermittelnde Institutionen wie das Colegio von Tlatelolco nicht mehr unbedingt angewiesen. Zur Entwicklung der indigenen Schriftlichkeit siehe Matthew Restall, Heirs to the Hieroglyphs. Indigenous Writing in Colonial Mesoamerica, in: Americas 54 (1997), S. 239-267.

63 Manchmal, aber nicht oft, findet sich auch der Titel »don« vor seinem Namen als don Antonio Valeriano. Lockhart, The Nahuas. After the Conquest, S. 34.

64 SAhagún, Florentine Codex 1, S. 55.

65 Siehe dazu Lockhart, The Nahuas. After the Conquest, S. 30-35. 
hatte damit keinen Tlatoani, keinen dynastischen Herrscher, mehr ${ }^{66}$. Stattdessen herrschte ein »homo novus« und das erfolgreich; zumindest regierte Valeriano bis 1599 sechsundzwanzig Jahre, und auch sein Sohn wurde Gouverneur von Tenochtitlan.

Für Tlatelolco hingegen stand die Eigenständigkeit auf dem Spiel. Neben dem Niedergang des Kollegs machte der Stadt verstärkt der Bevölkerungsrückgang aufgrund von Seuchen und Wassermangel zu schaffen. Hinzu kamen in den siebziger Jahren politische Überlegungen, Tlatelolco und Tenochtitlan administrativ zusammenzulegen. Von spanischer Seite wurde argumentiert, dass Tenochtitlan und Tlatelolco in vorkolonialer Zeit eine Stadt (»una ciudad «) gewesen $\operatorname{seien}^{67}$.

Die Bilder der beiden Herrscherbegräbnisse lassen sich als ein politisches Argument auch in diesem zeitgenössischen Entstehungskontext verstehen. Die Darstellung des Begräbniszeremoniells von Moteucçoma, das eines »huey tlatoani« nicht würdig war, interpretiert die Vergangenheit wie die Gegenwart. Die Art und Weise, wie Moteucçoma ohne die Symbole seiner Herrschaft dargestellt wird, verweist auch auf die koloniale Gegenwart, in der es keinen Tlatoani, keinen dynastischen Herrscher von Tenochtitlan, mehr gibt.

Mit der Darstellung Itzquauhtzins hingegen dokumentieren die Illustrationen den Anspruch Tlatelolcos, als souveränes Altepetl zu gelten. Itzquauhtzin verkörpert das Altepetl und anders als Moteucçoma wird er mit allen Insignien eines Tlatoani und dem »huey teocalli« als Symbol seiner Herrschaft gezeichnet. Die Bilder machen eine klare politische Aussage. In der kolonialen Gegenwart, in welcher der Status Tlatelolcos angezweifelt wurde, bekräftigen die Illustrationen Tlatelolcos Anspruch in der Vergangenheit und damit die Position in der kolonialen Gegenwart und suchen die Zukunft des Gemeinwesens zu sichern. Wer wäre für eine solche Dokumentation politischer Interessen ein besserer Adressat als der König von Spanien, der den Florentiner Codex angefordert hatte?

66 Das lag nicht daran, dass es keine potenziellen Nachfolger aus der königlichen Linie mehr gegeben hätte. Don Hernando de Alvarado Tezozomoc, der Verfasser der »Crónica Mexica« (Spanisch) und der »Chroníca mexicayotl« (Nahuatl), war ein Enkel Moteucçomas. Sein Bruder don Cristóbal de Guzmán Cecetzin war »tlatoani« von Tenochtitlan in den Jahren 15571562. Antonio Valeriano allerdings stand durch Heirat in Verbindung mit der königlichen Linie. Er hatte eine Tochter von don Diego Alvarado de Huanitzin geheiratet und war damit der Schwager von Tezozomoc. Zur Bedeutung von Tezozomoc als Historiker siehe LockHART, The Nahuas. After the Conquest, S. 389-391.

67 Gibson, The Aztecs, S. 37. 


\section{Die Mehrdeutigkeit der Geschichte}

Im Geschichtsbewusstsein der Tlatelolca nach der spanischen Invasion lassen sich die neu angekommenen Fremden in vertrauten Kategorien denken. Nahua Geschichtsschreibung in vorkolonialer Zeit musste flexibel sein. Krieg war endemisch in Mesoamerika, und das sogenannte $»$ Reich der Azteken « wurde geprägt durch wechselnde Allianzen und Heiratspolitiken zwischen den Staaten. Trotz der vielfältigen Verflechtungen grenzten sich die Staaten stark voneinander ab, und jedes Altepetl definierte sich über seine Migrationsgeschichte und seinen Gründungsmythos, über Ethnie und Herrscherhaus als ein grundlegend eigenständiges und verschiedenartiges Gemeinwesen. In einer Welt wechselnder Allianzen blieb immer das Altepetl die Konstante, der Bezugspunkt, um den sich alles drehte. Die Kategorie des Fremden traf deshalb auf alle außerhalb des eigenen Gemeinwesens zu. Deswegen wurden die spanischen Konquistadoren als neu hinzugekommene Fremde, als ein weiterer Akteur in der mesoamerikanischen Politik, der politischen Umwelt des Altepetl hinzugefüg ${ }^{68}$. Ein Akteur, der mit dem Krieg gegen die dominierenden Mexica seine militärische Stärke demonstrierte: »Ca amo titenamicvan - wir sind ihnen nicht gewachsen«, so hatte Moteuç̧oma die Spanier eingeschätzt. Dementsprechend richteten sich die Interessenpolitiken der jeweiligen Altepetl neu aus.

Traditionelle piktographische Geschichtsschreibung wurde von gelehrten Priestern und Adligen verfasst, die oft eng mit dem Herrscherhaus verwandt waren und die durch ihre Schriften und Reden die Perspektiven und Interessen des Altepetls und seiner Eliten repräsentierten. Der dafür notwendigen Flexibilität der Geschichtsdarstellung kommt die traditionelle piktographisch/orale Repräsentationsform sehr entgegen. Es werden nur wenige Ereignisse fixiert, so der Tod des Herrschers und seine Eroberungen, und der narrative mündliche Teil kann entsprechend gewichten und variieren. Auch der bildliche Teil konnte durch subtile Veränderungen umgeschrieben, neu kontextualisiert und anders gedeutet werden ${ }^{69}$.

In den Illustrationen der beiden Herrscherbegräbnisse in Buch XII des Florentiner Codex verbindet sich die Flexibilität und Polyvalenz des bildlichen historischen Narrativs mit der Interessenpolitik von Tlatelolco. Zwar haben die Kritiker der Bilder insofern Recht, dass die Illustrationen sehr europäisiert wirken. Sie sind für einen europäischen Adressatenkreis entstanden. Der Codex sollte an den spanischen Hof Philipps II. geschickt wer-

68 In Buch XII fallen sowohl die Spanier als auch ihre indigenen Verbündeten wie die Tlaxcalteca und Xochimilca unter den Begriff »toiaoavan« - »unsere Feinde«. Innerhalb der indigenen Feinde wird manchmal zusätzlich differenziert und sie werden spezifisch nach ihrer Ethnizität identifiziert. Terraciano, Three Texts, S. 51-72, hier S. 61.

69 Diel, The Tíra de Tepechpan, S. 4-6. 
den. Aber genau deswegen vermitteln die Illustrationen ihre eigene und keine spanische Sichtweise. Sie konstruieren ein Kontinuum der Geschichte des Altepetls, die eine Unterscheidung zwischen indigener Vergangenheit und kolonialer Gegenwart einebnet. Mit Blick auf die aktuellen politischen Herrschaftsverhältnisse wird die eigene Geschichte entsprechend rekonfiguriert. Die Geschichte Tlatelolcos wurde weder infolge der Eroberung durch Tenochtitlan noch durch die spanische Invasion beendet. Das historische Narrativ aus der Perspektive des Altepetl erweist sich - wie das Altepetl selbst als in bemerkenswerter Weise flexibel, um mit den neuen Fremden der spanischen Invasion umzugehen. Im Geschichtsbewusstsein bleibt das Altepetl vor und nach der Conquista die Konstante. Die Illustrationen in Buch XII des Florentiner Codex zeigen die Kreativität, Persistenz und Zukunftsorientierung indigener Erinnerung und Geschichtsschreibung und nicht ihre Traumatisierung. 



\title{
Perry Johansson
}

\section{Recovering History in China}

\author{
War, Sinology, Sources ${ }^{1}$
}

\section{Introduction}

Harboring a history profession over many centuries, a modern scientific historiography appears first in China from the late 1920s. The typical understanding of this is that Western-educated historians responded to the need for a new historiography to support the construction of a modern Chinese nation. However, the exposure of the logic behind Orientalism and postcolonial critique of Eurocentrism in the humanities have left a question mark on such modernization narratives. This article further challenges the validity of modernization narrative by unpacking the geopolitics of knowledge as it played out between Western sinologists and Chinese Historians during the decades leading up to World War II.

War is fought about land, wealth, and legitimacy. At the core of legitimating conquest stands culture and memory. Historical remains and symbols of the nation, archives and libraries, art objects and »truth « all become victims of war. China in the 1920s and 1930s witnessed sinologists, orientalists, and Western scientists roam the land for source material and new discoveries. In China the modern understanding of history, this article claims, is born out of the resistance to this foreign scholarship and takes shape against the practice of Western archaeology, looting, and smuggling. A concern of this article is therefore what historians call »sources«: manuscripts, art objects, and the interior of tombs; and practices like archeology, collecting, plundering, and legislation which are used for obtaining and controlling these sources. The importance of sources for modern historians is often understood in heuristic terms only, with »Quellenkritik» as the cornerstone of a "wissenschaftliche«, objectivist approach to the writing of history. But, since positivist thinking in European humanities appeared simultaneously with imperialism,

1 I want to thank »The Royal Swedish Academy of Letters History and Antiquities« for a contact scholarship supporting a two week long visit at SOAS London and Stiftelsen Längmanska kulturfonden for a grant that provided me with the means to put together the conference paper on which this article is based. 
it is hard not to search for a connection. How did the racial history of imperialism shape the humanities in China?

This article is an attempt to rethink the relation between Nation and History in China. Although inspired by these titles it does not attempt to »rescue history from the nation«, neither does it believe that »China was invented through history «². The nation, the people, or the »race«, was rather always the reason for historical thinking. Being first at the service of the new European nations, history was always about a people, a race or a »class « claiming its rights against other people, races, or social classes ${ }^{3}$. In Modern historiography all this was effectively masked over in a critique of Hegel and by making the only purpose of historiography seem to be objectivity and critique of the sources. So what did it mean to appropriate such a tradition in China? This article tries to put some facts about the unfolding of a modern historical practice - I dare not call it »historical consciousness « - among a small number of influential Chinese historians. They are influential not just because of their historical research, or for building up scholarly institutions, but also, and maybe foremost, for their role as historians in a broader nationalist project of their time.

The 1920s and 1930s was a time of imperial expansion in China, and the Chinese historians understood well the important connection between history and the nation for resisting effectively this foreign threat. They perceived well the value Western and Japanese put into researching the history and origins of China, and their greed for Chinese antiques and historical relics. As part of European expansionist ambition, the hunt for historical sources, from archaeology and other forms of collection, joined geographical discoveries towards the building up of imperial archives such as the British Museum ${ }^{4}$. Looting, as well as the taking of trophies has always been part of war, but in spite of their professional pretenses, some of these activities were taken over by scholars. In China, after the fall of the empire and during the three decades of civil and anti-imperialist wars, Western archeology and collecting reached new heights. Sweden, probably because it did not fight in the Grand War, and not being guilty of any imperialist grabbing of Chinese land had a special position that enabled it to emerge as a leading European nation in

2 I am referring here of course to Prasenjit Duara's and Edward Wang's fine studies on history and the Chinese nation. Prasenjit DuARA, Rescuing History from the Nation. Questioning Narratives of Modern China, Chicago 1995; Edward WANG, Inventing China Trough History. The May Fourth approach to Historiography, New York 2001.

3 See Michel Foucault, Il faut défendre la société, Paris 1997, lesson five, for a discussion on the genealogy of modern historiography.

4 See Thomas Richards, The Imperial Archive. Knowledge and the Fantasy of Empire, London 1993, for an imaginative account of the role of institutions like the British Museum for representing the empire trough knowledge and information. 
sinology, and as an international clearing house for newly attained antiques from China ${ }^{5}$. A Swedish archeologist uncovered the first known Stone Age relic in China and with possession of such unique sources searched for its western origin. All this was problematic for the Chinese intellectuals who were looking for ways to reinvent their scholarly tradition as well as to save the nation in a time of Western imperial onslaught. As shown in this article, scholars like Fu Sinian and Li Ji, after being educated in the West had on the top of their research agenda the objective to gain control of the sources from which to write a new Chinese history. Furthermore, they wanted to catch up with orientalist scholarship on China. From this perspective the cause for modern Chinese historiography was not so much the impact of historical Wissenschaftichkeit as it was the challenge from Western sinology to define what China was, and should become.

\section{Chinese history up for grabs}

The fall, early in the $20^{\text {th }}$ century of a two thousand year old imperial system also implied the collapse of a similarly ancient regime of knowledge which was tied close to the state and its legitimacy. That collapse also witnessed the end of an ancient Chinese tradition of historiography, of a metaphysical cyclical view of history - tied to the will of Heaven and the rights of man -, the belief in history as a mirror: something to guide future action, and of a golden age to emulate. Instead new ideas, new thinking, new literature, new technology, fashion, food, architecture intruded from the west. Paradoxically, this thirst for the new exploded in the aftermath of the Great War. Having helped the allied with over hundred thousand men China expected to get back its German colonies but instead these were handed over to Japan. From this betrayal erupted the May Fourth movement, which was simultaneously cultural and political, and which, as the grand narrative of modern China goes, produced the communist New China (»Xinhua«).

Developments during the inter-war years (1920s and 1930s) had significant impacts on scholarly production in China. The collapse of the empire and of the Republic following it reduced China to a nation cut up among many warlords. On the other hand, Western and Chinese imperialism and penetrations further created a confusing situation for China's scholarly community. In the first instance, the crises shattered the symbolic universe which scholars had inhabited. They now doubted everything they had known for

5 Perry Johansson, Rescuing History from the Nation. The untold origins of the Stockholm Museum of Far Eastern Antiquities, in: Journal of the History of Collections (2008), pp. 1-13. 
sure. As the critical scholarship of Gu Jiegang's in Gushi bian [= Debates on Ancient History $]^{6}$ shows, the first thousand plus years of Chinese history began to appear as mythology.

With Chinese scholars at a loss about their history, their symbolical universe and the future of the nation, Western scholars were quick to fill the gap, arriving en masse, just like they had at other scenes of imperial destruction: ready to send another great culture to the imperial archive in London, Paris, Berlin, or Washington. Western scientists and scholars invaded China not only for scientific explorations but also to collect source material to bring home for further research. The collection of »raw materials « »for further research « is a well-known strategy of cultural imperialism. For instance, during the second Opium War the summer palace was plundered and when the Eight Nation Alliance army occupied Beijing they not only crushed the Boxer uprising but they also looted the imperial palace. These two incidents produced a European trade in Chinese antiques. Then in the early years of the $20^{\text {th }}$ century, Europeans like Aurel Stein, Albert von Le Coq and Albert Gruenwedel plundering the Silk Road on its treasures, including a thousand year old library. And it would happen later as the Japanese occupation under the codename Golden Lily let military and Triads plunder China systematically, including countless of libraries 8 .

In between these extremes of plunder and war we have a period when a considerable measure of materials disappeared on the market. As the Chinese were afraid of the future, they sold off their treasures; even ancient artifacts kept in the Forbidden Palace disappeared. The dethroned emperor, worried about those wanting to get rid of him, had with the help of a scheming English tutor become infatuated with Europe and wanted to move there for a new life, and possibly a come back to power'. Together with his brother he disposed of the most valuable paintings, calligraphies, and other antiques from the imperial treasures in order to finance their escape for Europe ${ }^{10}$.

The Swedes were unusually active around this time, both in the production of new knowledge about China's history and in the collection of Chinese cultural artifacts - source material - for Stockholm. Some well-known collectors include Osvald Siren who met the emperor around this time photographing the imperial inner quarters, Sven Hedin and the linguist Bernhard

6 Seven volumes of articles ed. by Gu Jiegang, published between 1926 and 1941.

7 John Tosh, The Pursuit of History. Aims, methods and new directions in the study of modern history, Harlow 2010.

8 See Jianmin Zhaо, The Looting of Books in Nanjing, in: Peter Li (ed.), The Search for Justice. Japanese War Crimes, New Brunswick 2003; Sterling Seagrave/Peggy Seagrave, Gold Warriors. America's Secret Recovery of Yamashita's Gold, London 2003.

$9 \mathrm{Pu}$ Yi Aisin-Giono, From Emperor to Citizen. The Autobiography of Aisin-Gioro Pu Yi, Peking 1979, p. 128.

10 Ebd., p. 129. 
Karlgren. But it was another Swede, the geologist Johan Gunnar Andersson who stumbled onto the first ever proof of a Chinese Stone Age. After Gu Jiegang's critical readings of the Chinese classics had concluded that China's early history, including the first dynasties was simply legends, Andersson's discovery became the new building block from which to reconstruct the origin of the Chinese civilisation. For new Chinese scholars it then became extremely worrying when Andersson came up with a hypothesis that connected the Yangshao culture he had discovered with finds in Eastern Europe and western Russia to argue a Western origin of China. Andersson's idea got many followers and encouraged further searches and excavations for establishing a link between East and West ${ }^{11}$.

\section{European Sinology, National Studies}

At the same period that the Swedes and other Westerners were active in scholarly pursuits, young Chinese scholars were going the other way. In this period many thousands travelled to the West to study. They did not always know what subjects to pursue, but were mainly motivated to understand the reasons behind Western superiority which they assumed may be found in "science«. Some came to study history in Germany just like the Americans some decades earlier, taking in the German tradition of historiography, positivism, and other dreams of a scientific historical Wissenschaft ${ }^{12}$.

Fu Sinian, who would become China's most important historian, was one of the Chinese educated in Berlin in the 1920s. Although not enlisted in history he was influenced by Rankean Quellenkritik as well as positivist ideas as he spent most of his time in Berlin to study the writings of Ernst Mach ${ }^{13}$. In the distraught times Chinese scholarship found itself in, combining these two ideas of positivism and Quellenkritik turned into an obsessive occupation with the sources themselves. Fu Sinian became known by the idea: »No sources no history $\ll^{14}$. He tied the faith of the Chinese nation to how well Chinese historians could win back the momentum by controlling the sources. If the Chinese scholars did not control the sources - which for Fu and most positivist Western historians at the time was history - then the West with its

11 For more on this see Johansson, Rescuing History, or Chen XingCAN/Magnus FiskesJö, China before China. Johan Gunnar Andersson, Ding Wenjiang, and the Discovery of China's Prehistory, Stockholm 2004.

12 Berlin had a thousand Chinese students in 1924 encouraged by the better lifestyles that their Chinese currency scholarships offered against German inflation.

13 Fan-shen Wang, Fu Ssu-nien. A Life in Chinese History and Politics, Cambridge 2000.

14 However, his slogan has been mistranslated. »Wu shiliao ji wu shixue« should rather be »no historical sources, no writing of history«. 
modern scientific methods and the sources, would reinterpret China's history in its liking ${ }^{15}$. He expressed this fear in the program declaration of the Institute for History and Philology which he was running for Academia Sinica:

China is rich in sources on history and philology but the way Europeans strive to have them they might soon be difficult to access for us. Despite this we have just been sitting with arms crossed watching them getting ruined and disappear in front of our eyes. We are certainly not happy with this situation. We are certainly not appreciating how, not just material sources, but scholarly source material is being brought out, sometimes even stolen by the Europeans. We decided to engage some fresh approaches to deal with this problem, and to secure the source material. We have for that function set up this Research Institute for History and Philology ${ }^{16}$.

The need for taking better control of China's historical sources was indeed great. Not only were ancient tombs being plundered and destroyed for science and valuable antiques moved to Western museums and universities, but also Chinese archives and libraries were threatened. In the early years of the $20^{\text {th }}$ century, during the plundering of the Silk Road, Pelliot and Stein had smuggled out parts of the invaluable Dunhuang library. The Japanese would, from the 1930s when attacking and trying to occupy China not only pillage its gold and art treasures but also removed whole libraries ${ }^{17}$. The Nanjing government managed to safeguard from the Japanese much of the treasures, libraries, and archives relating to the Qing dynasty and the Forbidden Palace, but even these were in the 1920s under serious threat. We have already dealt with how the last emperor smuggled precious imperial objects out of the palace. As students, it was easiest for the emperor and his brothers to bring precious books out from the palace collections. Even the Inner Chancery archives from the Ming and Qing dynasties were threatened, much because rulers in these chaotic times of division could not see the value of documents that were pertaining to the history of imperial Chinese rule. It was also because ancient China was seen by the Chinese modernizers as the abject Other. These priceless documents were stolen, sold, even used as scrap paper until Fu Sinian convinced Academia Sinica of their importance ${ }^{18}$.

15 See Edward Wang or Wang Fan-shen for a lengthier discussion on Fu Sinian and his ideas on sources and Western scholarship on China.

16 Sinian Fu, Lishi yuyan yanjiusuo gongzuo zhi zhiqu [Aspirations and objectives for the work of the Institute of History and Philology], in: Lishi yuyan yanjiusuo jikan. Bulletin of the Institute of History and Philology 1 (1928), pp. 3-10.

17 Tosh, The Pursuit of History.

18 WANG, Inventing China, p. 125. 
As Chiang Kai-shek and the Guomindang army advanced further and established a government in Nanjing 1928, the Central Commission for the Preservation of Antiquities was set up. It proved quite efficient in dealing with some of the well known Western plunderers like Sir Aurel Stein ${ }^{19}$, but problem with Chinese tomb raiders and Western collectors still remained. As the nationalist government further consolidated itself following the Northern expedition of Chiang Kaishek, laws and research institutions were set up. With a unified country and greater national consciousness, Westerners looking for art or archaeology were viewed with much more suspicion. The Swedish collector Orvar Karlbeck writes about this new situation in letters to Osvald Sirén and the China collecting Karlbeck Syndicate in Stockholm. The first Chinese archaeologist Li Ji - member of Academia Sinica's Institute for History and Philology and who will excavate the Anyang royal city - Karlbeck claims, wants to monopolize all archaeology in China, and »will most likely petition the government to issue an order prohibiting westerners from writing on things Chinese $\ll^{20}$. This must be something his friend Carl Whiting Bishop, who had employed and educated Li Ji in archaeology only to see him leave for Academia Sinica, had told Karlbeck. At the time Karlbeck was out scouting for things he could buy or plunder secretly for Johan Gunnar Andersson's Museum of Far Eastern Antiquities in Stockholm. That Li Ji wanted to prohibit Westerners from researching China was of course an exaggeration from exactly these people from the West who now felt shut out from the China field. Certainly, along with the historian Fu Sinian, Li Ji did criticize the activities of Western sinologists in China, and he was central to the construction of laws prohibiting foreign archaeologists and export of antiques from China.

Li Ji had himself experienced competition from provincial and private excavators, as well as Western collectors when excavating the Shang capital at Anyang. Sharing Fu Sinian's views on how Europeans were putting their hands on precious Chinese source material Li Ji, in his Chinese research memories from 1967, comments on the foreign research organisations that arrived in Beijing during the fragile rule of the Beiyang Army:

Forceful as they were, these organisations become increasingly unrestrained. With the sole exception of the Geological Survey these enterprises were all run by foreign research organisations. These foreigners were all richly supported financially and materially, having new and skilful methods at their means. Not only did they go after

19 For a fuller account of how Aurel Stein's last attempts for plunder along the Silk Route was thwarted by the Chinese read Shareen Blair-Brysac/Karl E. Meyer, Tournament of Shadows. The Great Game and the Race for Empire in Asia, London 2001.

20 Letter dated Dec $19^{\text {th }}, 1930$ at The Karlbeck Archive, Museum of Far Eastern Antiquities in Stockholm. 
and remove, bit by bit, specimen for the natural sciences but also historical, archaeological and other human sciences related source material fell prey to their eager attention. Determinedly they came running to China, to investigate our language, measuring our bodies, excavating our yet unearthed antiques, and research our traditional customs. These »scholarly sources « are day for day »brought out, sometimes even stolen by the Europeans $\ll^{21}$ !

Li Ji also complained about the complicity of his compatriots. They did not, he writes, recognise the value of the things the foreigners are bringing out under the guise of science. It was not until the 1920s that a sense of national ownership started to take shape round the cultural heritage of China. The modern nation was still so new. Only ten years earlier had the empire been toppled and the old order replaced by a republic. It would have to wait until 1924 before even the most important treasure, that of the former imperial family began to be taken care of properly by the state ${ }^{22}$. But that did not solve all other problems. Li Ji grumbles in an article in Dongfang Zazhi still in 1934 about the displaced Chinese love of antiquity. Although, he writes, the Chinese have a long tradition of loving the old (»hao gu«) they do not, like the Europeans and the Americans, or »even the Japanese «, know to preserve their antiques ${ }^{23}$. The trend of the last few years, he complains,

has shown the Chinese destroying antique sites in a scale far surpassing that in any other nation. The lucrative market in antiques lures every person to become a customer, surprisingly even including scholars and those who advocate superiority ${ }^{24}$.

He adds that people would be surprised if they knew about some of the cases he himself was familiar with. His admonition to get to grips with this is to declare that everything found in the earth belongs to the nation, and that no individual can claim ownership to these things. Such rules were already at place. In the late 1920s Li Ji himself had worked hard to bring about regulations to this meaning, and in 1930 the Legislative Yuan had passed such a $l a w^{25}$.

So far, we have come a long way from modernisation narratives for explaining the rise of modern Chinese historiography. It is starting more to resemble a war; for sources, for identity, and between races. History here is not an

21 Li Ji, Gan jiu lu [recorded impressions from the past], Taipei 1967, p. 74.

22 Jeannette Shambaugh Elliotr/David L. Shambaugh, The Odyssey of China's Imperial Art Treasure, Seattle 2005.

23 Li Ji, Zhongguo kaoguxue zhi guoqu yu weilai [the past and future of Chinese archaeology], Dongfang 1934, pp. 46-52.

24 Ibid., p. 51.

25 Li Ji, Anyang, Seattle 1977. 
abstract science but the materiality needed in order to create a new subject, to forge this new powerful agent, the nation whose first objective it was to save itself from extinction. This modern, historically determined subject rested on two pillars that came along with the nationalist government who had help set up Academia Sinica and created the new laws and agencies for preserving national heritage. First a new genealogy of genetics is created together with the notion of a racialized Han people being the »real« Chinese ${ }^{26}$. A troublesome notion since it disturbed the multiethnic grid of the Manchu Qing Empire. After tracing the blood of the nation back to one Yellow Emperor the other task of the new nation therefore became to take control of the »land «. This was achieved by Chiang Kai-shek's Northern Expedition and the striking down on the »non Chinese« people like the Uyghur, Tibetan and Mongolian when they tried to make the same, modern, equation between an ethnicity and ownership of the land; between a people, its history and its territory.

We should therefore accept the paradox as purely logical, that the modern humanities in China are not formed by the integration of a scientific Western learning in the form of disciplines like history and philosophy. It was in the meeting of foreigners trying to write the history of China that a modern Chinese historiography arose. In reality the modern humanities in China, came in the form of »Guoxue«, or »National Studies«. It was because research and education institutes in National Studies had been set up in China that $\mathrm{Fu}$ Sinian decided to come back home. These institutes were manned by people like him, returning from Europe and the US with great expectations on the new nationalist movement of their home country. The famous May Fourth figure and modernizer Hu Shi became the director of the most important of these, the Qinghua College Institute of National Learning (»guoxue «) in Beijing. Avant-garde institutions like this were staffed by the small number of foreign educated elite intellectuals to create the scholars of tomorrow. These scholars perceived of their discipline, not as the supposedly universalistic disciplines of Europe, but as one connected with what was really Western Chinese Studies. There was a sense among Chinese scholars educated in the West that Western sinology with its modern methods, the money supported from universities and museums, and the access to Chinese source materials was becoming superior to the Chinese scholars in fields such as linguistics, philology, history, archaeology. Chinese scholars even got together and protested this. They were not just against the fact that Westerner conducted research in China or bringing out historical and other artefacts for research. The main reason behind setting up the National Scientific Union in 1927, for example, was the dire situation of the Chinese researchers.

26 For an excellent account of this see Frank Dikötter, The Discourse of Race in Modern China, Stanford 1992. 
Not only did no one support them but they were even hindered from doing research. At the same time, foreigners came, and with their invincible amount of resources took what they wanted of our research material! Forcefully they took out from our country limitless amounts of rare materials. If this was not stopped then the future of our national studies (»guoxue«) skills would suffer unimaginable damage ${ }^{27}$.

Fu Sinian also argues that the Westerners and Japan excelled in orientalist studies, but that the Chinese could catch up, if only they could control and monopolise the sources. They could also reach up to the foreigners' level of scholarship by controlling research in history, philology, linguistics and other disciplines crucial for any modern nation building ${ }^{28}$.

Interestingly many of the Chinese historians while studying in Europe had often moved towards Oriental Studies. The historian Yao Congwu became a fan of Ranke while he despised Hegel, and argued that historians worked with "well grounded records, remainders of the past and antique substances $\ll^{29}$. Yao Congwu had studied with the sinologists Otto Franke and Eric Haenisch and also worked at the Oriental Institute in Bonn ${ }^{30}$. Another historian Chen Yinke had started as a philologist, and worked with the Orientalist, Friedrich W.K. Müller. In China he associated with the French sinologist Paul Pelliot while also learning more Sanskrit from Baron Stael Holstein ${ }^{31}$. The first courses Chen Yinke taught at the Qinghua College Institute of National Learning were Buddhist Sanskrit texts and a bibliographical course on Western Sinology. Fu Sinian and others were likewise assisting Western sinologists and taking a course in oriental languages while in Europe. From all this we can draw the conclusion that it was probably as much from Western sinologists as from historians the Chinese new historians learned their trade ${ }^{32}$. The courses that the Chinese historians studied extended well beyond the core history subjects. Fu, for example, studied psychology in London, and then Tibetan in Berlin. Importantly, the places they chose for studying were also the leading cities for orientalism and sinology, namely Paris, London, and Berlin.

$27 \mathrm{Xu}$ Xusheng, Xu Xusheng xiyou riji [A diary of Xu Xushengs travels to the West], Ningxia 2000, p. 2.

28 Fu, Lishi.

29 WANG, Inventing China, p. 96. For the American misrepresentation of Ranke's ideas see that chapter in Peter Novick, That Noble Dream. The »Objectivity Question« and the American Historical Profession, Cambridge 1988.

30 WANG, Inventing China, pp. 93-94.

31 Ibid., p. 192.

32 He Bingsong translated American textbooks on historiography (the positivist misinterpretation of Ranke). 
When China was again united, the nationalist government set up a central research institute named the Academia Sinica. For the first director of this important organization was chosen the former President of the Beijing University Cai Yuanpei ${ }^{33}$. At the same time it was the staff of the Qinghua College Institute, for National Learning that transferred to the Institute of History and Philology (IHP) section of Academia Sinica. So not only was the research areas that Fu Sinian picked for his IHP section of the Academia Sinica the same as those in »Guoxue « it was actually made up of people from such backgrounds as well. Thus Chen Yinke who headed the History section and Zhao Yuanren of the Philology section were both from the Qinghua "Guoxue « institute. Li Ji who had worked with Carl Whiting Bishop headed the Archaeology section. The first real project of the IHP was the Anyang excavations, targeted at proving the existence of the Xia dynasty and laying to rest $\mathrm{Gu}$ Jiegang doubts on the existence of early Chinese history. Besides leading this excavation, Li Ji also successfully debunked Andersson's ideas on a Western origin by linking the Stone Age finds with the early dynasties in a linear temporal order. It is clear therefore that this was not the modern historiography in the European sense. The Chinese made little effort to mask their agenda behind objectivity and Quellenkritik, but instead used the new methods and means at their disposal to recreate a national narrative. In the 1930s this would be taken a step further when some of these new historians partook directly in cultural politics of the Nationalist Party in power and when the otherwise rigourous Fu Sinian started writing history that clearly strayed from objectivity and Quellenkritik in order to fit the political agenda of nationalism ${ }^{34}$. Historiography in the Peoples Republic would move yet another giant step in this direction and, despite its Marxist rhetoric, turn into full blown nationalist propaganda.

\section{Conclusion}

The Chinese managed to shut out the Westerners from collecting and excavating sources for China's history and also to rewrite China's history to their own liking. By rediscovering the discarded ancient dynasties and connecting them with Stone Age and Peking man, they now had an even older Chinese history in the modern sense of the term. These triumphs in a couple of years before the Japanese invasion had the Chinese proudly inviting foreign scholars they had formerly competed with. The picture of Paul Pelliot visiting

33 This important individual was also Minister of Education in the Nationalist Party government and later became a hero in the historical narrative of China's Communist Party.

34 WANG, Inventing China, ch. 5. 
the excavation is always displayed in texts about the Anyang explorations. Pelliot lauded the excavations as the greatest discovery in Asian studies, and as Edward Wang writes it certainly must have felt good when the Swedish sinologist Bernhard Karlgren praised the achievement of the linguistic section of the IHP ${ }^{35}$. Now the Chinese were in control of their sources. History had become a modern scientific discipline, but not before the new Chinese historians had made it theirs, taking its back from the sinologists of the West and made its interpretive framework sinocentric again. The amassing of historical sources to, by foreigners through archaeology, collecting, plunder and war, was not an objective and strictly scientific order of knowledge. The Chinese scholars saw this clearly, understanding the importance of interpretation, of knowing, and of history to legitimate the state. To rescue the sources to Chinese history was a fight for national survival; to loose these signifiers of legitimate power and origin would risk the disintegration of the nation. The methodology of modern historiography thus reads like a means only for the Chinese. In a sense they were not mainly interested in the discipline of history, they were interested in incorporating the methods, and the perspectives that made modern humanities come off as objective; that is, not ruled by any particular interests. But while studying in the West they turned as much to Sinology as history.

What threatened them in Sinology was its scholarly success. That is why the first new research institutions in the humanities focused on National Studies, a discipline whose name they took directly from that of Sinology, or Chinese studies. Michel Foucault's reading of politics as a continuation in other means of war, and historiography as politics, tallies well with the Chinese situation of the early century just described. In that sense the important question to ask may not be how a modern Chinese historiography arose, but rather, what was modern historiography, and how did it relate to the era of imperialism with which it cohabited, but whose themes it rarely touched upon?

35 Ibid., p. 126. 


\title{
Eno Blankson Ikpe
}

\section{Those Obnoxious Cultures}

\author{
European Encounters with Ibibio People of \\ Eastern Nigeria 1850-1960
}

\section{Introduction}

The arrival of Europeans heralded a new era in the history of the peoples of eastern Nigeria. Ibibio encounter with European missionaries impacted on the lives of the people in profound ways and has remained in the historical consciousness of the people. It thus provides a landmark for narratives about change. Ibibio encounters with European missionaries and colonial agents led to the abolition of the so-called obnoxious cultures including human sacrifice, divination, the killing of twins and ostracizing of their mothers, slavery and slave trade. The translation of the Bible by Christian missionaries led to the reduction of Efik and Ibibio languages to writing and promoted literacy and western education in the area.

This article examines the perceptions of European presence in the historical consciousness of the Ibibio people and their imagery of the European. It discusses European perception of the cultures and the processes of their elimination. It examines the lasting legacies of encounters of the Europeans with Ibibio people on the historical consciousness of the people.

\section{Ibibio People}

The Ibibio people are located in the south eastern corner of Nigeria. They are found mostly in the present in Akwa Ibom State. They speak a language also known as Ibibio and number about three million. Other related groups are the Efik of the Cross River State, Annang and Oron in Akwa Ibom State. Though culturally and linguistically related with mutually intelligible languages, they often claim individual identities ${ }^{1}$. In pre-colonial times, the Ibibio developed clear cultural forms which guided their lives and contributed to the development of ordered and harmonious society; nevertheless some of

1 Edet Akpan Udo, Who are the Ibibios?, Onitsha 2003. 
the cultures were sometimes oppressive especially to ordinary citizens who were victims of such cultures.

\section{Encounters with the Europeans}

By virtue of their location on the coast, the Ibibio experienced an early contact with Europeans. This is usually dated as early as the fifteenth century. With popular trading ports such as Calabar, Bonny, Opobo, Itu and Ikpa around them, the Ibibio participated actively in all the stages of the Atlantic trade $^{2}$. These encounters shaped Ibibio's perception of the Europeans.

The first stage of these encounters was the trading stage which spanned from the fifteenth century to the nineteenth century. The next stage was the missionary stage and the later the colonization stage. The colonisation stage also saw the intensification of missionary activities and the movement of European trading firms from the coast where they had been restricted for centuries, into the interior of Nigeria including Ibibioland. At this stage, European traders were more interested in buying agricultural and forest produce and selling different European manufactures than their forerunners who were involved in the slave trade. Some of the prominent trading companies that operated among the Ibibio included George Watts, McEaohen, Miller Brothers, Johnstone, Cooper and Company, G.B. Olivant, Messrs Charlie de Cardi (French) and United Africa Company.

The majority of the Ibibio did not encounter the Europeans directly until European missionaries started work in Ibibioland although they felt the impact of their activities. One of the earliest missionaries in Ibibioland was Samuel Alexander Bill, an Irish independent missionary from Belfast who arrived Ibibioland in 1887 and started his missionary work at Ibuno on the Qua Iboe River. Hence the Church he established in Nigeria is known as the Qua Iboe Church. Other missionaries of the Scottish Missionary Society (SMS) led by Hope Masterton Waddell had established a station in Calabar in 1846 and worked from there into Ibibioland, Mary Mitchel Slessor, a SMS missionary from Aberdeen, Scotland, who succeeded in carving out her name in the historical memory of the Ibibio was one of such missionaries. Ibibio encounters with these early missionaries impacted on their histories and led to the abolition of what the Europeans regarded as obnoxious cultures. Mary Slessor is remembered for her readiness to confront practitioners of obnoxious cultures. Ibibio encounters with these few Europeans mostly of Scottish and Irish extraction profoundly changed Ibibio history

2 Kenneth Onwuka Dike, Trade and Politics in the Niger Delta 1830-1885. An Introduction to the Economic and Political History of Nigeria, London 1956. 
especially many of their cultures which Europeans - missionaries and later colonial agents - saw as obnoxious. European missionaries therefore occupy a central position in historical consciousness and the narratives of historical change in Ibibioland ${ }^{3}$.

\section{Ibibio perceptions of the Europeans}

European encounters with the Ibibio of eastern Nigeria engendered different kinds of reactions including: awe, fear, respect, admiration, suspicion and hatred. Apart from calling them »afia owo« (singl.) and »mfia owo« (plural) - which referred to the colour of their skin, the Ibibio refer to white people with the name "mbakara (those who rule over anything, others or area they happen to see or come in contact with). This name was initially derogatory but later gained new flattering meanings. It has not been possible to locate when the name was first used to describe white people. Oral evidence points to the coming of the Portuguese which the Ibibio refer to as the »potoki«. However, it would seem that the Ibibio for a long time did not know the difference between the various Europeans until about the eighteenth century when they started coming in contact with Europeans of English extraction whom they referred to as »mminicosi« - derived from »how many « and »much does it cost? « However, from the early days of encounters, a certain behavioural pattern of all the early Europeans was recognisable. They were all eager to take part in trade, especially trade in people. They sometimes went on land in a surprise attack to gather slaves. Their practice of going for slave raid to catch people led to the name "mbakara - a name which has stuck till date but has acquired new meanings through the ages. This word is made up of two words »aba« and »akara«. »Aba« in this context is a verb used when someone finds a valuable thing (e.g. money) unexpectedly and takes possession even though it does not belong to him. »Akara《 is also a verb which means to overwhelm, to overcome, to beat and rule over. In the imperative form these words become »ba! kara! «. In the now form this becomes »mbakara « which is a plural form. This is a common method of forming plural in Ibibio language. For instance »obong" (king, leader) in singular form becomes »mbong" (kings, leaders, rulers). »Mbakara« though a plural form is also used as singular as the word does not exist in singular. »Mbakara" was initially derived from the method of slave raiding which had element of surprise, beating and overwhelming. So the Ibibio regarded the white people as opportunists who would overwhelm the people and take their most valuable

3 Udo, Who are the Ibibios?, pp. 312f. 
possession - sons, daughters, wives, brothers and relations. Partly for this reason and for the fact that they had more sophisticated weapons than the Ibibio possessed, the white people were feared and despised.

»Mbakara" as the name for Europeans became entrenched especially with the Ibibio encounters with European missionaries from the late nineteenth century. Because of their skin colour, their abilities to tread in areas the Ibibio believed were governed by evil spirits such as the evil forest, without dying - as Ibibio belief thought they should -, it was generally held that »the white men are spirits « - »mbakara edo ekpo«. Since they were thought to be spirits, it was assumed that they could communicate with spirits and could control them. This was held to account for their survival after committing offences against the Ibibio ancestors, breaking taboos and cutting down some evil groves and forests. Also missionary display of novel scientific knowledge, which they displayed in carpentry, house construction, lighting and curing of the sick confirmed to the Ibibio that certainly »mbakara edo ekpo«. In Ibibio belief system, »ekpo" (spirits or ghosts) have the knowledge and power to do anything. It was also generally believed that the white people possessed a powerful $» j u j u$ « which made them able to withstand the wrath of the ancestors and deities and solve all the problems they faced. With this, the Ibibio accidentally acknowledged white superiority over them. Indeed some early male converts to Christianity gave the reason for their conversion as the desire to »learn the source of white man's power and acquire it«. The Ibibio generally believed that malevolent people use powers of witchcraft, and other such supernatural powers to harm people, cause sickness and death. Such people were greatly feared. Hence, Ibibio constantly sought powerful antidotes to protect themselves and their families. This is why the white men's power to which one would be initiated after conversion and seemingly free of charge was seen by many as protection from malevolent powers.

Following the establishment of colonial rule in Ibibioland, Europeans lived up to their name »mbakara« as colonial soldiers were used to conquer the area with brute force in the process known as pacification ${ }^{4}$. Hence the name »mbakara « became more associated with conquest, beating the people, overpowering and ruling over the people. As colonial rule progressed, and colonial officers and missionaries settled down to government and humanitarian work, the name »mbakara « became associated with power, modernity, progress, expertise, goodness, desired way of life and beauty. Recently in a valedictory service for the outgoing Vice Chancellor of the University of Uyo, Professor Akaneren Essien, the Deputy Vice Chancellor acknowledged his expertise in university administration by saying: »Akanaren Essien, you

4 Toyin Falola a.o., History of Nigeria 3. Nigeria in the Twentieth Century, Lagos 2003, pp. $2-4$. 
are indeed mbakara! - afo ado mbakara«; even though the man in question is very black. ${ }^{5}$ This goes to show one of the associations Ibibio people now attach to the name »mbakara

\section{The obnoxious cultures}

Europeans saw many of the Ibibio cultures as obnoxious and tried to abolish them. The obnoxious cultures were those cultures which were different from European cultures and Christian traditions, especially those concerning the destruction of human life. These included: human sacrifice to deities, burying human beings alive especially at the burial of important chiefs; killing of twins and ostracizing of twin mothers who gave birth to twins, divination, human leopard or »ekpo« society, trial by ordeal, slave trade and slavery among others ${ }^{6}$.

One of those obnoxious cultures for which the Efik/Ibibio area was notorious was the killing of twins. In the Ibibio world view, human beings should have children but one at a time. According to the Ibibio, multiple births were bad omens to the society and were abhorred. It was believed that one of the babies was indeed the personification of an evil spirit which has come into the world to cause one form of havoc or the other. Since it could not be established which one of the babies was a spirit and which one was human, the two babies suffered the same fate. Multiple births, it was also believed was natural to animals and not to human beings and women who gave birth to twins were seen as lower than human beings since through giving birth to twins they had displayed their animalistic nature. Mothers of twins were also seen as cursed people who must have secretly committed some heinous crime such as incest and were now punished for it. It was also believed that if humans indulge in multiple births, it would lead to a sudden increase in population which might strengthen the families of the owners of twins to the detriment of the families without; and strain the resources of the whole community ${ }^{7}$. Above all, it was thought that it would be impossible for a mother to suckle two or more babies successfully especially at a time when there was no other source of milk for babies. Women lived constantly in fear of having multiple babies

5 I was present at the Valedictory service for the outgoing Vice Chancellor of the University of Uyo Professor Akanaren Essien November 28, 2010 where this statement was made. There is no written evidence for it.

6 Cyril A. Umanah, The History of Offot Ukwa and the Influence of Colonialism, Uyo 2010, pp. 78-82.

7 D. Amaury Talbot, Women's Mysteries of a Primitive People. The Ibibio of Southern Nigeria, URL: <http://www.sacred-texts.com/afr/wmp/index.htm> (July 06, 2010). 
as this would automatically mean ostracism from the society 8 . Mothers of twins were feared because it was thought that they could transfer the powers to have twins to other women and so were ostracised. Fathers of twins were however not exposed to any form of societal punishment; hence the consequence of bearing twin children was born only by women.

Twin babies were disposed of by putting them out in the forest where they died through the elements or were devoured by wild beasts especially the leopard which were many in the area in those days. Their mothers were killed or banished to the evil forest where they spent the rest of their lives. Some were sold into slavery. Interaction with them by the general public was discouraged and minimized. Sexual interaction attracted the death penalty or selling into slavery. On the fear of twins in Ibibio land Talbot commented as follows:

Wretched indeed, in the old days, was the lot of any unfortunate mother of twin, since, though most men now deny this, averring that twin babes were only hated and feared as something monstrous and unnatural, a considerable number of women confessed that they, like those of many neighbouring tribes, believed that one of the pair at least was no merely mortal offspring but that of some wandering demon. Till a comparatively short time ago such a birth was followed by the death of both mother and babes, except where the fear of the white man is too strong, twins are not allowed to live even now ${ }^{9}$.

European missionaries and colonial agents saw the killing of twins as very obnoxious. Since this happened very often, they fought against it thereby bringing succour to the women concerned.

\section{Attempts to abolish obnoxious cultures}

The arrival of missionaries in Ibibioland marked the beginning of far reaching cultural change. Calabar, a town, partly inhabited by an Ibibio sub-group the Efik had been a major slave trading port for centuries ${ }^{10}$. In the nineteenth century, it became a major port for the palm oil trade which the Ibibio produced. Being opened to interactions with the Europeans for centuries, Calabar was the first town to attract missionaries. The Scottish Missionary Society led by Hope Masterton Waddell in 1846 established a station in Calabar. This was followed by the establishment of Hope Waddell Institute - a school

8 Umanah, The History of Offot Ukwa, pp. 38-39.

9 TALвот, Woman's Mysteries of a Primitive People, ch. 2, pp. 23-24.

10 Efiong Ukpong Aye, Old Calabar through the Centuries, Calabar 1967. 
which taught students how to read and write English and trained them in some modern vocations. Missionary activities soon had positive impact in Calabar, gave the town a new look, mitigated some obnoxious cultures and gave the people new professions.

Generally, the Ibibio were cut off from direct trade in Calabar. They only participated in the trade through Calabar middlemen. So Ibibio encounters with the Europeans were not as intensive as those of the people in Calabar. Ibibio hinterland was generally therefore backward in terms of » modern development $\ll$. Hence the Efik of Calabar regarded the Ibibio as backward and "primitive $\ll$. By the late nineteenth century, some Ibibio were trading in palm oil directly in Calabar. They came to appreciate the developments taking place in Calabar. Ibibio traders who frequented Calabar appreciated the work of the missionaries and sought for such activities and development in Ibibioland. This led to their famous letter to the Presbyterian Church in Calabar an outpost of the Scottish Missionary Society. Mr Foster, one of the SMS missionaries at Calabar directed the letter to Harley Missionary College in London where he had received his training. The request by some Ibibio chiefs for a teacher was read by Dr. Grattan Guiness, the principal of Harley College to his students. Samuel Alexander Bill from Belfast answered the call and took up the challenge. Samuel Alexander Bill arrived in Ibibioland via Calabar in 1887 and started his missionary work at Ibuno ${ }^{11}$. Strengthened by the arrival of other missionaries, he spread his mission work to cover the whole of Ibibioland and environs. He was the first missionary in Ibibioland.

Apart from the Scottish missionaries, there were also Presbyterian Missionaries in Calabar. From there they worked their way into Ibibioland. One of the most renowned of SMS missionaries to carve her name in the historical memories of the Ibibio was Mary Mitchel Slessor from Aberdeen, Scotland who arrived in Calabar in 1876. In 1888 she left Calabar into the interior and worked in Efik, Ibibio and Igbo hinterland especially in Okoyong, Itu, Ibiono and Arochukwu. Mary Slessor is remembered for her readiness to confront practitioners of obnoxious cultures. Whenever she was told of one of these obnoxious cultures about to be executed she is known to have always said: »I must go« to stop it ${ }^{12}$.

By 1910, missionaries of diverse extractions, Catholics, Methodists, Lutherans, African Church and diverse breakaways were working in Ibibioland. They were at the forefront of the abolition of obnoxious cultures. They did this through the propagation of the Christian faith by curing the sick, buil-

11 URL: <http://www.quaiboechurch.org/history.html> (December 03, 2010).

12 Jeanette Hardage, Slessor, Mary 1848 to 1915. Presbyterian Nigeria, in: Dictionary of African Christian Biography (URL: <http:/www.dacb.org/stories/nigeria/slessor_mary.html> [December 05, 2010]). 
ding modern houses, possessing effective tools for all situations and by defying traditional laws and taboos without expected repercussions. The efficacy of Western medicine was quickly appreciated by the Ibibio and even the diviners - »mbong idiong " who were generally antagonistic to the missionaries sought their medicines. Indeed Ekechi in his examination of missionary activities in Igboland attributed the successes of the Catholic missionaries to their investment in medical services which according to him »helped tremendously in the consolidation of Catholic influence before $1900 \ll^{13}$. This display of European »power« fascinated the Ibibio greatly. For instance, the saw-mill established by the Qua Iboe missionaries attracted spectators who were fascinated by the work of the mill and technology became a tool of propagation. In her discussion of the early days of the Qua Iboe Mission, Elaine Doyle observes that »missionaries eagerly used science to astonish, to cajole and above all, to impress themselves on the local population $\aleph^{14}$. This $»$ power $"$ was thought to be entrenched in Christianity and could be acquired through conversion. This appealed especially to ordinary people who lacked »power« in the traditional sense of it, and who hoped to acquire some sort of "power" that could help them overcome their adversaries. Discussing the quest for power in Ibibioland Westgarth a Qua Iboe missionary commented as follows:

To get power one over the other becomes almost a cult. It cuts in two directions, i.e., one, to prevent the others from getting power over them as well as striving to get it over others. This unseen struggle is very real. Rising and falling fortunes are attributed not so much to ability or fortuitous circumstances, as to some secret opponent working their »magic« in the dark ${ }^{15}$.

This quest to acquire power to enhance one's own power and protect self and family from the powers of wicked people was central in the conversions to Christianity.

The war against obnoxious cultures was strengthened with the establishment of schools, through which new ideas were propagated. Almost all the Christian missions in Ibibioland established schools. The Ibibio were quick to realise the value of school for the acquisition of the white man's knowledge and power. By 1960 many villages desired to own schools so they usu-

13 Felix K. Eкеснi, The Holy Ghost Fathers in Eastern Nigeria, 1885-1920. Observations on Missionary Strategy, in: African Studies Review 15 (1972), No. 2, pp. 217-239, here p. 224 (URL: <http://www.jstor.org/stable/523920>).

14 Elaine Doyle, Gender, Science and Empire. The Qua Iboe Mission, 1887-1900, in: URL: $<$ http://www.qub.ac.uk/sites/QUEST/FileStore/Issue3GRFSpecial/Filetoupload,55493, en. pdf $>$ (December 05, 2010).

15 J.W. Westgarth, The Holy Spirit and the Primitive Mind, in: M.B. Abasiattai/G.I Jones/J.W. Westgarth (ed.), The African Pentecost in Qua Iboe Church of Nigeria 1927 and After. The Outpouring of the Holy Ghost among the Ibibio of Nigeria, Uyo 2008, pp. 22-92. 
ally teamed up with the missionaries to build schools. One of the earliest schools in Ibibioland was Etinan Institute built by the Qua Iboe Mission. Other Christian Missions soon established primary and secondary schools. The most prominent early mission schools were the Methodist Boys High School, Oron, Holy Family College, Abak (Catholic) and Lutheran High School, Obot Idim. Although, early in the colonial period, a few government elementary schools were established, government soon lost interest in running schools and abdicated responsibilities to missionaries so that the few government schools became mission administered but government assisted ${ }^{16}$. This means that education was in the hands of the missionaries although the colonial government laid down the rules and regulations to be followed. Schools belonged to the various Christian missions who competed with one another in the establishment of schools and standards. Products of the mission schools who were converts joined in the propagation of the Christian doctrines and European culture and the fight against obnoxious cultures. Some products of the mission schools became teachers and they intensified the drive for the abolition of obnoxious cultures. Obnoxious cultures were seen as backward, non-progressive, associated with the elders and static traditions while Christian teachings were associated with the youths, modernity, dynamism, government and progress.

In his discussion of missionary activities in Ibibioland, Udo Udoma notes their destructive and disruptive activities to the culture of the people. However he acknowledges the importance of their contribution to the educational development of Ibibioland. According to him:

The redeeming feature in all this was the introduction of formal education as an adjunct to the development and growth of the Christian church. The introduction of schools alongside the church acted as magnet and attracted many young people, even non-believers of the Christian faith to the church. To the Ibibio people the school in mission premises was the real carrot offered them by the missionaries. Education, that is to say, acquisition of the right type of knowledge and moulding of character, became the passport to all sorts of white collar jobs - clerks, teachers, shop assistants, beach master, catechists, nurses and interpreters in the various courts of the land. It then dawned on the Ibibio people that there could be no progress in the Western World's sense without education. There developed an extraordinary longing for book learning and the ability to learn, speak, read and write English ${ }^{17}$.

16 Udo Udoma, The Story of the Ibibio Union. Its background, emergence, aims, objectives and achievements. A successful experiment at re-integration of a people, Ibadan 1987, pp. 17-20.

17 Ibid., p. 17. 
The abolition of obnoxious cultures was quickened by Ibibio Christian converts mainly of the Qua Iboe Church, who experienced the Pentecostal revival which engulfed the Ibibio area 1927/28. People wondered but no one could explain the phenomenon that what was regarded as the Holy Ghost gripped not just the Christians but also some unconverted people. At different locations people claimed to have been seized by the spirit and they spoke in tongues. Writing about this event one of the Christian missionaries of the time, J.W. Westgarth noted that $\gg$ it was never possible to discover exactly where or how it began«. However, Westgarth saw the work of the Holy Spirit as important in the spread of Christianity and the personal conviction of those who experienced it. He observed that for one of his evangelists:

This marked a new state in the development of his Christian life, and impressed him with the reality and nearness of the Spirit of God. He must have looked upon this visitation as a sign of God's special interest in him. This alone was a great inspiration and an incentive to preach the Gospel with greater earnestness, and with the consciousness that he was preaching what he himself had actually experienced ${ }^{18}$.

Led by the spirit, these people lost the fear of traditional rulers, taboos, rituals, traditional religion and cultural symbols. Even people who had not yet converted to Christianity were seized by the spirit. Most times, they ran to the church, confessed their sins, gave up their traditional religious and cultic symbols and relics and converted to Christianity. Some of them known as »spirit men« went into the nooks and crannies of Ibibio land destroying shrines, symbols of traditional religion, belief and power and challenged people who held unto those beliefs and practices associated with obnoxious cultures $^{19}$. This movement frightened many people to give up their traditional religion and convert to one form of Christianity or the other. This movement though destructive of traditional cultures, beliefs and artefacts, actually contributed to the spread of Christianity and the abolition of obnoxious in Ibibioland. Nevertheless, the »spirit men« caused so much commotion and pandemonium in the land as some people refused to give up their traditional religions and practices and fought back. Especially the fervent witch-hunting which followed this movement attracted the attention of the colonial government to stop the activities of the "spirit men« by arresting and imprisoning the leaders, and running the movement to go underground.

One Ibibio teacher and preacher who experienced the spirit commented on the effect of the Holy Ghost experience on his personal life as follows:

18 Talbot, Woman's Mystries of a Primitive People, ch. 2.

19 Udoma, The Story, p. 16. 
From that moment I was a different man. Praying, scripture reading and preaching were a pleasure to me. Now what was the result of this event in my life? Rich spiritual blessings and temporal too. Jesus became a living person in my life. His presence abode with me in trials and in joys. Fear of evil power ceased. I felt that there was a greater power around me - I was snatched from the clutches of superstition. I lived in him and in him I still live till today [my emphasis $]^{20}$.

It is important to note the loss of the fear of evil power and the feeling that »there was a greater power around me« in this description. This loss of fear of evil power was seen to be a blessing by those who experienced the Holy Ghost, and a higher step to the acquisition of the white man's power. It made the people bolder in the attack of traditional religion with their obnoxious practices. Freedom from fear, from superstition and the feeling that one was surrounded by a "greater power" and so could not be hurt by the activities of the malevolent people, spirits and powers was a major consequence of the spirit experience.

A major factor in the abolition of obnoxious cultures and spread of Christianity was the establishment of colonial rule. Colonial rule was established in Nigeria at different stages, beginning with the appointment of John Beecroft as the British Consul to the Bight of Benin in 1847 which was closely followed by the bombardment of Lagos in 1851 and the establishment of the Lagos Colony in $1861^{21}$. The Ibibio began to feel the power of British imperial and later colonial government with the appointment of John Beecroft as Consul in 1847 whose activities from Fernando Po adjacent to Ibiboland affected the people. Consular administration led to the deposition of rulers and bombardment of towns which were not in agreement with the imperial designs of Britain as preached by John Beecroft. The Ibibio town of Itu on the Cross River was bombarded because their rulers were accused of blocking trade on the river by collecting tolls. By 1856, a Court of Equity was established in Calabar in order to regulate trade relations between indigenous and European traders and by 1872 the Consul was empowered to oversee the activities of the court of equity. The consuls were empowered to execute and enforce fines, imprisonment or banishment and the observance of the stipulations of any treaty, convention or agreement made or to be made between Great Britain and the local chiefs in these areas, and to keep peace, order and good government of her Majesty's subjects within the said territories. With this, Beecroft and later other consuls began to interfere in the politics of the

20 Westgarth, The Holy Spirit and the Primitive Mind, p. 89.

21 Tekena Nitonye Tamuno, British Colonial Administration in Nigeria, in: Obaro Ikime, Groundwork of Nigerian History, Ibadan 1999, pp. 393-409; Tekena Nitonye TAmuno, The Evolution of the Nigerian State. The Southern Phase, 1896-1914, London 1972. 
area deposing kings and bombarding towns. With the Berlin Conference of 1884/ 85 the area now known as Nigeria was partitioned for the British and the Oil Rivers Protectorate over South Eastern Nigeria and Niger Delta with its headquarters at Calabar. Effective government did not begin until 1891 with the appointment of Sir Claude Macdonald as the Consul General to the Oil Rivers Protectorate. In 1893, the name of the protectorate was changed to the Niger Coast Protectorate and in 1900, the Niger Coast Protectorate became the Protectorate of Southern Nigeria still with headquarters in Calabar $^{22}$. It was from this time that the Ibibio began to feel the real impact of colonial take over. Agents of colonial government were sent into the interior of Ibibioland for reconnaissance purposes and to pacify the Ibibio between 1901 and $1905^{23}$. The establishment of colonial rule hastened the abolition of obnoxious cultures because at defeat and conquest the abolition of obnoxious cultures was part of the agreement between the conquered and the conqueror. Indeed with the establishment of colonial rule, missionaries sometimes became agents of colonial rule. Mary Slessor of the SMS became so successful in her crusade for the abolition of obnoxious cultures especially the killing of twins because she was appointed the first president of Okoyong Native Court established by British colonial government in 1888 therefore acquiring political backing. She was so valuable to the colonial agents that she was invited to accompany the British expeditionary force sent to destroy the Long Juju of Arochukwu in 1901/02, an expedition which partly conquered some areas of Ibibioland such as Itu. Missionary activities were greatly enhanced because of the colonial presence and the threat of the use of force by the colonial government ${ }^{24}$.

Colonial government introduced the indirect rule system in which the people of Nigeria were ruled through their traditional rulers, subject to the approval of the colonial officials. Through the instruments of Native Courts, Court Messengers and Colonial Police Force, colonial policies were impressed upon the people. Obnoxious cultures were abolished and the abolition enforced by the colonial agents. So it could be said that British colonial rulers with their laws, courts and soldiers put the death nail on obnoxious cultures.

Since the missionaries lived among the people and carried out practical work towards the abolition of obnoxious cultures, the Ibibio credit them with the abolition of obnoxious cultures more than the colonial government. Mary Slessor is known to have established a centre in Okoyong for the twin mothers. She rescued them from the evil forests and took care of them. In that centre, twin mothers could learn new skills such as sewing, baking, progres-

22 Udo, Who are the Ibibios?, pp. 299-309.

23 Ibid.

24 Ibid. 
sive farming which became useful in colonial Ibibioland. With time, Slessor's station became a shelter not just for twin women but for other women who had cause to run away from home. Other missionaries such as the Catholics and the Qua Iboe missionaries were also known for rescuing twins and their mothers ${ }^{25}$. One of the colonial officers, M.W.D. Jeffreys, became notorious for tracking down practitioners of obnoxious cultures and punishing them thereby acquiring the Ibibio name »ntokon « - pepper $^{26}$ !

\section{Legacies of Encounters}

In his Missionary Impact in Modern Nigeria ${ }^{27}$ A.E. Ayandele examines the consequences of the work of Christian missionaries on Nigerian societies. He credits the missionaries for the abolition of cultures which were regarded by them as obnoxious. In Ibibioland by 1960 most of the so-called obnoxious cultures were no longer practiced. Twin killings and the ostracizing of their mothers, human sacrifice and man-leopard society were abolished. Man-leopard society whose killings were very rampant during the colonial era, was hunted down by the colonial government. Cultures such as »idiong « divination were outlawed though still practiced underground ${ }^{28}$. Nowadays, »idiong « is practiced in some so-called Christian churches which claim to see vision and practice prophesy using the same methods as the »idiong" society but camouflaging in the name of Jesus. »Ekpo« society with its obnoxious practices has turned into a purely cultural society whose masquerades dance for entertainment purposes also for the uninitiated. Witchcraft is still practiced by some but detested by the majority. However, witch hunting was outlawed, although people have now and then engaged in it against the law and with consequences. Slave trade and slavery was abolished in 1901 although it took a longer period to stamp it out entirely. Nevertheless, this was replaced with voluntary and sometimes forceful trafficking in human beings for domestic servitude, prostitution, and sex and plantation slavery for which the Ibibio area has been notorious since the colonial period. Trial by ordeal and the burying of people along with a dead chief are things of the past whose abolitions are ascribed to the missionaries and their work. Although

25 Talвот, Woman's Mystries of a Primitive People, chap. III.

26 G.I. Jones, Recollections of the Spirit Movement in the Ibibio Area of Calabar Province, in: Abasiattai/Jones/Westgarth, The African Pentecost, p. 95.

27 Emmanuel Ayankanmi Ayandele, The Missionary Impact on Modern Nigeria 1842-1914. A political and social analyses, London 1966.

28 In the colonial period it went underground but today it is practiced but no longer commonly practiced. 
Edet Akpan Udo is very critical of missionary activities in Ibibioland seeing them as the destroyers of Ibibio civilisation, he concludes his criticism however as follows:

Though some aspects of imperialism in Ibibioland seemed destructive, it is the writer's conviction, however that the constructive effects of European imperialism in Ibibioland far outweigh the initial losses, and that appreciation of its permanent legacy will grow in future 29 .

By 1960, majority of the Ibibio claimed to be Christians and this has affected the culture tremendously. Though many of their cultures have been maintained, and there are still beliefs which Christians think are not in consonant with Christianity, nevertheless, those beliefs and cultures regarded as obnoxious have been done away with to a great extent. Christianity is seen as a source of power to guard against evil of all kinds especially those practiced by the perpetrators of obnoxious cultures. In recent years, the rise and growth of Pentecostalism with its fanatical prayers and claims of miracle healing and protection against evil has drawn almost all Ibibio people to Christianity.

Missionaries introduced western medicine to Ibibioland by establishing dispensaries and hospitals. Some of the earliest mission hospitals in the area included: Qua Iboe Mission hospital, Etinan; St. Lukes Hospital, Anua-Uyo; Prebyterian Hospital, Ituk Mbang; Mary Slessor Hospital, Itu and Methodist Hospital Iquita-Oron. Till the end of colonial rule in 1960 Ibibioland was served by these mission hospitals. Both the Qua Iboe mission and Presbyterian mission also established and ran Leper Colonies at Ekpene-Obom and Itu respectively. These hospitals greatly improved the health of Ibibio people endearing them to the missionaries and impacting on the Ibibio historical memories.

One of the greatest consequences of missionary education was that educated Ibibio soon found that their segmentary political system did not allow for unity of purpose which was necessary for the Ibibio in a multi-ethnic Nigeria. This led to the formation of Ibibio State Union in 1928, the first such union in Nigeria ${ }^{30}$. According to Udo Udoma, the emergence of the Ibibio State Union was due to complex reasons:

It might be identified as a mixture of the activities of the various missionary bodies in the country interacting with the social structure and development of various Ibibio communities which successfully aroused the consciousness of the people to the fact of

29 Udo, Who are the Ibibios?, p. 313.

30 Udoma, The Story, pp. 12f. 
their segmentation. This consciousness resulted in a genuine desire for unification as a source of strength ${ }^{31}$.

This union was able to rally Ibibio people and integrate them for collective activities for the improvement of the Ibibio people, and position them to take part in the politics of the Nigerian nation. It built and ran a government approved secondary school to give many Ibibio children a chance to acquire education at an affordable rate. In the 1930s it sponsored many Ibibio young men and women to acquire university education abroad. These were the first group of Ibibio people to acquire such degrees. In post independent Nigeria, these became the people who represented Ibibio in national and regional government. Hence, the Ibibio State Union became the platform for the development of Ibibio land and its human resources. The contributions of missionaries in the creation of a new group of elites which became important in colonial and post colonial Nigeria was discussed by Ade-Ajayi ${ }^{32}$ and Ibibio elites were created in that process. This Union was very important to the development of Ibibio land until it was proscribed by the government of Eastern Nigeria in $1966^{33}$.

\section{Conclusion}

In the narratives of European imperialism in Africa, it is common to see missionaries as tools of imperialism and colonization. European enterprise in Africa has been seen especially by African scholars as root of underdevelopment. It is true that the Ibibio were robbed of some of their cultures; the Christian Missionaries and converts destroyed cultural artefacts of the Ibibio. Indeed, the Ibibio were made to bow to an outside mightier power through colonization thereby robbing them of their culture, traditional knowledge and self esteem. However we may want to assess the impact of European enterprise in Africa and in Ibibioland in particular, the majority of Ibibio people cherish the memory of their encounters with European missionaries who stayed in their midst and impacted on their historical memories through the eradication of the feared obnoxious cultures. Without the missionaries and their schools, the Ibibio would not have been prepared to participate in the new economy and politics established by forces of colonialism which they could not control. Being minority people, this would have led to the total

31 Ibid.

32 Jacob F. Ade-Ajayi, Christian Missions in Nigeria, 1841-1891. The Making of a New Élite, London 1965.

33 Udoma, The Story, pp. 32-52. 
marginalisation of the people in the scheme of things in the multi-ethnic Nigerian nation into which they were co-opted. Encounters with the Europeans, especially the missionaries led to the eradication of obnoxious cultures which impacted greatly on Ibibio historical consciousness and their narrative of change. 
III. FREMD IM ANDEREN LAND 



\title{
Viviane Rosen-Prest
}

\section{Willkommene Fremde?}

\author{
Zwei Jahrhunderte Geschichtsschreibung über Hugenotten \\ im deutschen Refuge (17.-19. Jahrhundert)
}

In den Jahren 2005/06 veranstaltete das Deutsche Historische Museum in Berlin eine Doppelausstellung unter dem Motto: »Zuwanderungsland Deutschland «. Der eine Teil dieser Ausstellung hieß: »Migrationen 1500$2005 \ll$, der andere Teil schlicht »Die Hugenotten «'. Schon diese Themenwahl weist auf die besondere Rolle hin, welche der Geschichte der Hugenotten in Deutschland beigemessen wird. Unter den nach Deutschland zugewanderten Fremden genießen die Hugenotten sicherlich den besten Ruf. Dahinter stecken zwar Tatsachen, aber auch viele in der mehr oder weniger legendären Geschichtsschreibung verwurzelte Repräsentationen. Die Hugenottengeschichtsschreibung in Deutschland ist nämlich ganz besonders ideologisch beladen und wurde oft - und in jeder Epoche anders - zu demonstrativen Zwecken instrumentalisiert. Zweck dieses Beitrags ist, die Wandlungen dieser Instrumentalisierung hugenottischer Geschichte im Laufe dreier Jahrhunderte zu zeigen. Dabei wird der Schwerpunkt der Darstellung auf Brandenburg-Preußen liegen, ganz einfach, weil die überwiegende Mehrzahl der Geschichtswerke über die Hugenotten im 17. und 18. Jahrhundert dort entstanden ist.

Am 18. Oktober 1685 widerrief der französische Sonnenkönig Ludwig XIV. nach langjährigen Verfolgungen der französischen Reformierten das Edikt von Nantes ${ }^{2}$. Tausende von Flüchtlingen verließen heimlich Frankreich und suchten in ganz Europa und bis nach Amerika und Südafrika Zufluchtsorte. Bekannt ist, dass Kurfürst Friedrich Wilhelm von Brandenburg wenige Tage nach der Revokation (29. Oktober 1685, julianische Zeitrechnung) das Edikt von Potsdam erließ, in dem er »unsere[n] der Evangelisch-Reformierten Religion zugethane[n] Glaubens-Genossen« freie

1 Sabine Beneke/Hans Ottomeyer (Hg.), Zuwanderungsland Deutschland. Die Hugenotten. Ausstellungskatalog, Wolfratshausen 2005.

2 Von zahlreichen Publikationen dazu hier nur zwei: Élisabeth Labrousse, La Révocation de l'Edit de Nantes. Une foi, une loi, un roi?, Paris 1985; Janine Garrisson, L'Édit de Nantes et sa Révocation. Histoire d'une intolérance, Paris 1985. 
Ausübung ihrer Religion sowie mannigfache Privilegien versprach ${ }^{3}$. Er war weder der Einzige, noch der Erste. Andere Fürsten, zum Beispiel in Hessen-Kassel ${ }^{4}$ oder in Brandenburg-Bayreuth, versuchten ebenfalls, die Flüchtlinge durch Privilegien anzuziehen ${ }^{5}$. Aber in keinem anderen Zufluchtsland entstand eine so große und dauerhafte Kolonie wie in Brandenburg-Preußen. Hatte die erste Generation der Emigranten noch gehofft, der Druck der protestantischen Mächte würde einen Wandel der Politik des Sonnenkönigs bewirken und ihr die Rückkehr nach Frankreich ermöglichen, so schwand diese Hoffnung nach den Verträgen von Rijswijk (1697) und Utrecht (1713). Allein in Berlin lebten ungefähr 5.000 französische Flüchtlinge, die am Ende des 17. Jahrhunderts bis zu einem Fünftel der Stadtbevölkerung ausmachten ${ }^{6}$. Nach Friedrich Wilhelms Tod 1688 folgte auf ihn sein Sohn Friedrich III., ab 1701 Friedrich I. König in Preußen, der ihr größter Wohltäter und Gönner wurde. Trotz mancher Schwierigkeiten während der Regierungszeit seines Nachfolgers, des Soldatenkönigs Friedrich Wilhelm I., blieben die Privilegien der Hugenottenkolonie in Brandenburg-Preußen bis 1809 grundsätzlich unangetastet: Über das weite und zerstreute Gebiet waren 47 Kolonien verteilt, von Kleve bis nach Königsberg, die nicht nur über ihre eigenen Gerichte und Kirchen verfügten, in denen bisweilen bis ins 19. Jahrhundert hinein französisch gepredigt wurde, sondern auch über ein ausgebautes Schulsystem mit dem hochangesehenen, heute noch bestehenden Berliner Collège français (heute: Französisches Gymnasium) und selbstverwaltete milde Stiftungen wie die Maison française de Charité, das Hôtel de Refuge oder das Hôpital français ${ }^{7}$. In keinem anderen Zufluchtsort, ob in England, den Niederlanden oder in anderen deutschen Territorialstaaten, existierten Hugenottenkolonien so dauerhaft wie in Brandenburg-Preußen. Kein Wunder, dass gerade dort eine reiche Historiographie entstand.

Aus der Vogelperspektive kann die Hugenottengeschichte folgendermaßen beschrieben werden: Wie aus einer großen Anzahl von armen, entwurzelten Migranten, die mehrheitlich aus Provinzstädtchen oder vom Land

3 Der zweisprachige Text des Edikts ist zu lesen im Standardwerk von Eduard Muret, Geschichte der Französischen Kolonie in Brandenburg-Preußen unter besonderer Berücksichtigung der Berliner Gemeinde. Aus Veranlassung der Zweihundertjährigen Jubelfeier am 29. Oktober 1885. Im Auftrage des Konsistoriums der Französischen Kirche zu Berlin, Berlin 1885, S. 301306, von dem unten die Rede sein wird.

4 Schon am 18.04.1685 hatte Landgraf Karl von Hessen-Kassel eine »Freyheits-Concession« erlassen. Eckart Birnstiel/Andreas Reinke, Hugenotten in Berlin, in: Stefi JerschWenzel/Barbara John (Hg.), Von Zuwanderern zu Einheimischen. Hugenotten, Juden, Böhmen, Polen in Berlin, Berlin 1990, S. 13-152, hier S. 30.

5 Ebd., S. 30f.

6 Ebd., S. 92.

7 Ursula Fuhrich-Grubert, Die Französische Kirche zu Berlin. Ihre Einrichtungen 1672-1945, Bad Karlshafen 1992. 
kamen und denen nichts anderes gemeinsam war als der feste Wille, nicht auf ihren reformierten Glauben zu verzichten, und welche - das gilt für alle Migrantengruppen - an andere Nahrung und anderes Klima gewöhnt waren, wie aus diesen Menschen eine wohl integrierte Bevölkerungsgruppe entstand, die durch ihre vielfältigen beruflichen Kapazitäten signifikant zu der wirtschaftlichen Entwicklung des Gastlandes beitrug, eine Vielzahl allgemein bewunderter Einrichtungen, Schulen und Wohlfahrtsanstalten besaß und deren französischen Gottesdiensten Hof und Adel beiwohnten. Es ist also die Geschichte einer »success story«, die in Deutschland noch heute im kollektiven Geschichtsbewusstsein weiterlebt und zum Bilderbogen eines »guten Preußen« gehört. Es ist hier nicht der Ort zu überprüfen, ob diese grobe Schilderung der Hugenottengeschichte in Deutschland der Wirklichkeit entspricht ${ }^{8}$. Hier sollen ausschließlich die Wandlungen der Geschichtsschreibung über die Réfugiés untersucht werden.

\section{Charles Ancillon}

Im Jahre 1690 erschien in Berlin in französischer Sprache ein kleines Werk von Charles Ancillon: Histoire de l'Etablissement des François Refugiez dans les Etats de Son Altesse Electorale de Brandebourg. Ancillon war der Sohn eines bekannten, aus Metz in Lothringen nach Brandenburg geflüchteten, hochangesehenen alten Predigers und selber Jurist und Richter am französischen Obergericht. Damals kamen noch täglich Flüchtlinge nach Berlin, und die gewaltigen, mit der Ansiedlung so vieler Emigranten verbundenen Probleme waren keineswegs gelöst. Zweck des kleinen, nur vierhundert kleinformatige Seiten umfassenden Werks war es, dem Kurfürsten Friedrich III. die Dankbarkeit der Réfugiés zu bezeugen, ihn zu ermutigen, seinen Schutz aufrechtzuerhalten und außerdem den Verleumdern zu widersprechen, welche behaupteten, die Réfugiés würden ein elendes, umherirrendes Leben führen ${ }^{9}$. Ancillon ging so weit, dass er den Wohltäter der Refugiés mit Gott verglich, der sie aus dem Nichts gezogen und ihnen sozusagen ein zweites Leben gewährt hatte:

8 Vgl. dazu Gerd Heinrich, Religionstoleranz in Brandenburg-Preußen. Idee und Wirklichkeit, in: Manfred Schlenke (Hg.), Preußen. Versuch einer Bilanz, Bd. 2, Reinbek b. Hamburg 1981, S. $61-88$.

9 Zur Wirklichkeit dieser Umherirrungen: Michelle Magdelaine, Reisen und Irrfahrten. Das Exil der Hugenotten, in: Beneke/ Ottomeyer, Zuwanderungsland, S. 45-53; Michelle MagdeLAINE, Francfort-sur-le-Main et les réfugiés huguenots, in: Guido Braun/Susanne LACHENICHT (Hg.), Hugenotten und deutsche Territorialstaaten. Immigrationspolitik und Integrationsprozesse, München 2007, S. 35-49 (mit deutscher Zusammenfassung). 
IHRE KURFÜRSTLICHE DURCHLAUCHT hat das Los dieser Unglücklichen überwunden, Sie hat ihnen ein neues Schicksal verliehen, Sie hat sie gleichsam wieder geschaffen, indem Sie sie aus dem Nichts zog, wohin sie sonst unvermeidlich zurückgefallen wären; und man kann sagen, dass Sie dadurch Gott nachgefolgt ist ${ }^{10}$.

Im für die Barockzeit typischen Stil gebraucht Ancillon viele Vergleiche mit der Antike sowie biblische Anspielungen. Das Edikt von Potsdam sei ein »neues Evangelium « und Brandenburg das »Tal des Segens $«{ }^{11}$. Dem Theseus gleich, der mithilfe von Dädalus den Weg aus dem Labyrinth fand, habe der Kurfürst Auswege aus den tausend Problemen gefunden, die mit der Etablierung der zuströmenden, größtenteils mittellosen Flüchtlinge verbunden gewesen seien. Dabei vergisst der Autor auch nicht zu erwähnen, dass die Aufnahme dieser vielversprechenden Neuankömmlinge vorteilhaft für das Land sein könne, auch wenn sie noch des mächtigen Schutzes des allmächtigen Herrschers bedürften. Nur er könne die armen, vom Sturm erschütterten Verfolgten in den Stand setzen, schöne Blüten und Früchte zu tragen ${ }^{12}$. In diesem frühen Werk erscheint der Barockfürst übergroß gegenüber den Réfugiés.

Sachlicher klingt die Ausdrucksweise des irischen Philosophen John Toland (1670-1722). In seinem kleinen Werk über Preußen und Hannover, dessen französische Übersetzung 1706 erschien ${ }^{13}$, sucht er nach den Gründen für den florierenden Zustand der Stadt Berlin.

Der erste ist eine große Anzahl französischer Flüchtlinge und anderer verfolgter Protestanten, die dort einen ganz sicheren Schutz und sicheres Asyl gefunden haben. Sie genießen außerordentliche Privilegien und Freiheiten, die ihnen großzügig vom Herrscher gewährt wurden; was nicht verfehlen kann, ihm die Himmelsgunst zuzuziehen \& zugleich auch die zeitlichen Vorteile zu bringen, welche zwangsläufig von einem

10 »VOTRE ALTESSE ELECTORALE a surmonté la fortune de ces malheureux, Elle leur a donné de nouvelles destinées, elle les a, pour ainsi dire, créez de nouveau, en les tirant du néant, où ils allaient infailliblement retomber; \& l'on peut dire, qu'en cela, Elle a imité Dieu«. Charles Ancillon, Histoire de l'Etablissement des François Refugiez dans les Etats de Son Altesse Electorale de Brandebourg, Berlin 1690, Widmung, S. III.

11 Ebd., S. 23.

12 »Comme c'est Vous, MONSEIGNEUR, qui avez établi solidement ces pauvres Persècutez qui étoient ébranlez par la tempête; qui les avez transplantez lors même qu'ils étoient renversez, \& qu'ils n'étoient plus que des troncs abattus, \& qui les avez mis en état de produire de belles fleurs \& de bons fruits, c'est VOTRE ALTESSE ELECTORALE qui les doit protéger. Continuez donc, MONSEIGNEUR, à les couvrir de vôtre Protection toute puissante, sans laquelle il leur est impossible de subsister [...]«. Ebd., Widmung, S. X. u. XI. Übersetzungen der Verfasserin (im Folgenden »R.P.«) dieses Beitrags.

13 John Toland, Relation des cours de Prusse et de Hanovre, avec les caractères des principales personnes qui les composent, envoïe à une personne de considération en Hollande, traduite de l'anglois de J.T., La Haye 1706. 
so weisen und so menschlichen Betragen herrühren. [...] Es mag wohl sein, dass man vorerst diese zeitlichen Vorteile nicht beabsichtigte und dass die Religion allein der Grund für die großzügige Güte des Herrschers diesen armen Verfolgten gegenüber war; aber sobald man die sich daraus ergebenden Folgen wahrgenommen hatte, wurde nichts vernachlässigt von dem, was den vom Staat daraus gezogenen Vorteil vermehren kann. Mehrere Fürsten Deutschlands fangen an, diesem Beispiel zu folgen [... $]^{14}$.

Hier erscheinen zwei langlebige, im Gedankengut der Aufklärung wurzelnde Themen der Hugenottenhistoriographie: 1.) Tolerant zu sein bringt materielle Vorteile mit sich, christliche Barmherzigkeit trifft sich mit Staatsinteresse, und 2.) der brandenburgisch-preußische Kurfürst oder König gilt durch sein aufgeklärtes Verhalten als Vorbild für die anderen deutschen Fürsten, sodass das Werk die Rolle eines Fürstenspiegels erhält.

\section{Die Mémoires des Réfugiés von Erman und Reclam}

Fast achtzig Jahre später feierte die französische Kolonie Brandenburg-Preußens im Jahre 1785 das Jubiläum des Edikts von Potsdam. Obwohl zu diesem Zeitpunkt die Réfugiés-Abkömmlinge der dritten und vierten Generation meist assimiliert waren und bis auf den Gottesdienst kein Französisch mehr sprachen, bestanden die Kolonie-Privilegien noch wie am ersten Tag. Die Angehörigen der Kolonie-Oligarchie sprachen noch im Privaten französisch, wie übrigens viele Deutsche der gleichen Gesellschaftsschicht, wobei für die Réfugiés-Abkömmlinge der französische Sprachgebrauch einen hohen Identitätswert besaß. Denn den Gottesdiensten in den französisch-reformierten Kirchen wohnten oft Adlige, wenn nicht sogar Mitglieder des Herrscherhauses, bei. Zum Jubiläum wurden Medaillen geprägt, den Armen Festessen gespendet, Festpredigten gehalten und zum Besten der Armen gedruckt. In diesem Zusammenhang erschien in französischer Sprache ein berühmt gewordenes Werk, die Mémoires pour servir à l'histoire des réfugiés françois dans les Etats du Roi von Jean Pierre Erman (1735-1814) und Pierre

14 »La premiére est un grand nombre de François Refugiez, \& autres Protestans persecutez, qui y ont trouvé une protection \& un Asile très assuré. Ils y jouissent de priviléges \& franchises extraordinaires qui leur ont été généreusement accordez par le Souverain; ce qui ne peut manquer d'attirer sur lui la faveur du Ciel, \& lui procurer en même tems les avantages temporels qui resultent nécessairement d'une conduite si sage \& si humaine. [...] Il se peut bien faire qu'on n'avoit pas eu d'abord en vûë ces avantages temporels, \& que la Religion seule avoit été le motif de la généreuse bonté du souverain envers ces pauvres persecutez; mais aussi-tôt qu'on se fut aperçeu des suites qui en provenoient, on n'a rien négligé de ce qui peut contribuer à augmenter l'avantage que l'Etat en retire. Plusieurs autres Princes d'Allemagne commencent à suivre cet exemple [...]«. Ebd., S. 36f. Übersetzung R.P. 
Chrétien Frédéric Reclam (1741-1789) ${ }^{15}$. Der erste Band kam 1782 heraus, der neunte und letzte Band wurde von Erman allein 1799 veröffentlicht Reclam war im Januar 1789 gestorben. Beide Autoren waren Prediger der französischen Kirche in Berlin, Erman war außerdem Principal am Collège français, später auch Konsistorialrat, und er war der angesehenste Prediger der französischen Kolonie.

Das erste von den Autoren angegebene Ziel ihres Vorhabens war, eine Art »Archiv des Refuge« zu konstruieren. In den achtziger Jahren des 18. Jahrhunderts war die zweite Réfugiés-Generation am Verschwinden, und es war deshalb dringend nötig, ihre Erinnerungen zu sammeln, bevor der Tod sie zum Schweigen brachte. Eine umfangreiche, zum Teil noch im Archiv des Französischen Doms in Berlin liegende Korrespondenz Ermans gibt über diese breite Spurensuche Auskunft, welche sich übrigens bei weitem nicht mit Zeugnissen Überlebender oder Familienerinnerungen begnügte: Erman durfte nämlich nicht nur in Archivalien der französischen Kirche, sondern auch in staatliche Archive Einsicht nehmen - eine für damalige Verhältnisse außerordentliche Vertrauensbezeugung. Zweitens sollte der jungen Generation, der Leichtsinn und religiöse Gleichgültigkeit vorgehalten wurden, der Geist der ersten Réfugiés nahegelegt werden, deren fromme, tugendhafte und arbeitsame Lebensführung sie zum Wohlstand geführt habe. Den Autoren ging es nämlich nicht darum, eine Geschichte des Refuge zu schreiben, sondern eine Geschichte der Wohltaten, die dank der Unterstützung der Hohenzollern und dem Fleiß und Können der zugewanderten Franzosen dem Land erwiesen wurden. Im ganzen Werk gehen das Lob der schützenden Hohenzollern und das Lob der Réfugiés Hand in Hand. Konsequent folgen für alle Gesellschaftsschichten und Tätigkeitsbereiche drei Bilder aufeinander: Wie war es in den Ländern des Großen Kurfürsten vor 1685 bestellt? Wie war zu dieser Zeit die Lage in Frankreich? Was brachten die Réfugiés ihrem Adoptivland an positiven Entwicklungen? Wie zu erwarten war, fällt mit wenigen Ausnahmen die Schilderung zum Vorteil der Réfugiés aus, wobei immer wieder wiederholt wird, dass nur die kluge und beständige Unterstützungspolitik durch den Großen Kurfürsten und seine Nachfolger zum Erfolg führte. Bei dieser demonstrativen Verfahrensweise war es natürlich ein Leichtes, die Schwierigkeiten, die gescheiterten Versuche, das Elend vieler Réfugiés, die Feindseligkeit der Einheimischen zu verschweigen.

Nacheinander werden alle Kategorien von Réfugiés, von den Adligen bis zu den Bauern über die Manufakturisten und Handwerker jeder Art, behandelt. In vielen Aspekten werden sie als richtige »Lehrer der Nation« hingestellt. Bahnbrechend ist dabei der behandelte Gegenstand: Es geht nicht vor-

15 Jean Pierre Erman/Pierre Chrétien Frédéric Reclam, Mémoires pour servir à l'histoire des réfugiés françois dans les Etats du Roi, 9 Bd., Berlin 1782-1799. 
nehmlich um berühmte Heeresführer oder Adlige, sondern um alle sozialen Schichten einer menschlichen Gruppe, deren einzige Gemeinsamkeit darin besteht, der Verfolgung in Frankreich aus religiöser Überzeugung entkommen zu sein. Alle besitzen dieselbe Würde, weil sie einerseits alle »Glaubensflüchtlinge« sind, andererseits das Know-how aus dem damals fortschrittlichen Land Frankreich mit sich tragen. Sehr oft wird zur Kennzeichnung der Personen ein sogenanntes »epitheton ornans" gebraucht - »honorable, respectable, distingué« (vornehm, achtbar, ehrwürdig) - und zwar für Angehörige aller Gesellschaftsschichten. So bewegt sich das Werk dauernd an der Grenze zwischen ernsthafter Sammlung von Informationen und Legendenbildung, wohlgemerkt zu einer Zeit, als noch keine systematische Quellenkritik betrieben wurde, die das von ihnen angestrebte Archiv des Refuge hätte bereichern können. Jedem Band wird ein Kupferstich von Daniel Chodowiecki, dem berühmten Kupferstecher und aktiven Mitglied der Berliner französischen Kirche, vorangestellt. Anekdoten werden gesammelt, ein Schatz der oft mündlich übermittelten Erinnerungen, von denen hier als Beispiele die zwei berühmtesten kurz erzählt werden sollen:

In der ersten wird dem Großen Kurfürsten von seinem Minister Grumbkow vorgehalten, es sei ganz unmöglich, die nötigen Geldsummen zur Etablierung neu angekommener Réfugiés freizugeben, weil der Staatsschatz erschöpft sei.

»Nun«, antwortete der große Mann, »man verkaufe mein Geschirr, ehe man es an Hilfe für sie mangeln ließe!« Erhabener Ausdruck der Weisheit und Güte! Welcher Réfugiés-Abkömmling würde nicht darin den ehrwürdigsten Grund sehen, ein Vaterland zu lieben, dessen Herrscher für sie immer weiter das gleiche Herz hatten wie ihr erster Wohltäter ${ }^{16}$ ?

In der zweiten Anekdote ertappt der Große Kurfürst seine Frau dabei, einem Juwelier aus der Französischen Kolonie, Pierre Fromery, ohne Weiteres alle Juwelen der Krone zu einer Reparatur anzuvertrauen. Der etwas verdutzte Kurfürst gibt seiner Überraschung über ein solches Vertrauen Ausdruck.

16 »Quelques Réfugiés nouvellement arrivés, avoient présenté à l'Electeur des placets pour demander les secours nécessaires à leur établissement, ce Prince voulut que l'on assignât aussitôt les sommes qu'il falloit, Mr. de Grumbkow, qui avec Mr. de Gaultier, Ministre de la Cour, étoit chargé de présenter les Réfugiés \& leurs demandes à ce Prince, lui représenta l'épuisement total du trésor \& l'impossibilité de faire face à des dépenses si considérables. Eh bien! dit le grand homme, il faudra vendre ma vaisselle plutôt que de les laisser manquer de secours. Expression sublime de la sagesse \& de la bonté! Quel est le descendant des Réfugiés qui n’y voie le motif le plus respectable d'aimer une patrie, dont les Souverains ont toujours eu pour eux ce même cœur qu'avoit leur premier Bienfaiteur?«. Erman/Reclam, Mémoires, Bd. 5, S. 336. Übersetzung R.P. Vgl. Frontispiz Chodowieckis am Anfang des Bandes. 
»Mais c'est un Réfugié!« antwortet seine Frau ${ }^{17}$. Gegenseitiges Vertrauen und Großzügigkeit sind also die Grundsteine der Beziehung zwischen den Réfugiés und den Hohenzollern. Solche von Erman und Reclam überlieferten Anekdoten bereicherten dauerhaft die hugenottische Legendenbildung in Deutschland; sie haben auch bei ernsthaften Historikern des 20. Jahrhunderts Spuren hinterlassen ${ }^{18}$.

Von vornherein wurde aber auch Wert darauf gelegt, dass die Geschichte der Réfugiés einen wichtigen Bestandteil der Geschichte Brandenburg-PreuBens darstellte. Der Graf von Mirabeau hatte bei seinem Aufenthalt in Berlin die Mémoires erworben und daraufhin behauptet, man hätte die Geschichte der französischen Glaubensflüchtlinge »in 30 Seiten« schreiben können. Pikiert glaubte Erman, sich an verschiedenen Stellen für die Länge des Werkes rechtfertigen zu müssen. Er schreibt, die »Details« des Refuge seien

interessant für jeden, der es gerne mag, die Gründe für das Glück der Nationen zu erforschen, interessant vor allem für den Patrioten, der bei der zufriedenen Betrachtung von Preußens Größe gefällig seine Blicke auf alles, was deren Keim ausmachte, schweifen läßt. Wahrlich hat das Refuge in der Geschichte Brandenburgs Epoche gemacht. Als Historiker der Réfugiés würden wir meinen, das zu versäumen, was wir dem Land schuldig sind, das uns ein neues Vaterland wurde, wenn wir irgendetwas von dem, was zur Klärung und Ergänzung seiner Geschichte dienen kann, verschweigen sollten ${ }^{19}$.

Dass die Geschichte für Erman und Reclam »Magistra vitae« ist, unterliegt keinem Zweifel. Die Geschichte der Aufnahme der Réfugiés durch aufgeklärte Fürsten besitzt einen allgemeingültigen Charakter. Es liegt auf der Hand, dass diese Geschichtsauffassung nur vor dem kulturellen Hintergrund der deutsch-protestantischen Aufklärung zu verstehen ist, zu der diese frankophonen Prediger völlig gehören. In ihrem Weltbild sind evangelische Religion und Toleranz untrennbar verbunden, die Lehre Calvins mit ihren

17 »Mr. Pierre Fromery de Sedan [...] étoit souvent appellé chez l'Electrice qui l'honoroit de ses commissions \& de sa confiance; un jour qu'elle le chargeoit de lui remonter ses pierreries l'Electeur, malade de la goutte, entra sur sa chaise roulante dans l'appartement de l'Electrice au moment où elle lui remettoit tous les joyaux de la Couronne, qui déjà alors étoient d'un prix très considérable, l'Electeur, qui apparemment ne connoissoit pas Mr. Fromery, témoigna quelque surprise à son Epouse sur sa grande confiance - Mais c'est un Réfugié, répondit-elle. Ce mot dit plus en faveur des Réfugiés que le plus long panégyrique«. Ebd., Bd. 3, S. 182-185. Vgl. Frontispiz Chodowieckis am Anfang des Bandes.

18 So erwähnt Erich HaAse, Einführung in die Literatur des Refuge, Berlin 1959, S. 100, ohne Quellenangabe die Anekdote von Pierre Fromery: »Ihre Ehrlichkeit und Treue wurden sprichwörtlich. Die Kurfürstin glaubte, dem aus Sedan geflüchteten Pierre Fromery ohne weiteres ihren wertvollsten Schmuck zu einer Reparatur anvertrauen zu können, da er doch ein Réfugié war«.

19 Erman/Reclam, Mémoires, Bd. 4, S. $308 f$. 
Appellen an die Vernunft in Religionssachen bedeutet für sie den Anfang der »Lumières«. Diese Erfolgsgeschichte der klugen Aufnahme der Réfugiés wird aber nicht einfach an sich dargestellt, sondern steht paradigmatisch für die Wohltaten dessen, was eine Toleranzpolitik zu bewirken vermag und für die damit verbundenen Fortschritte der Menschheit überhaupt. So erstreckt sich die Schilderung der Aufnahme der Flüchtlinge in Brandenburg-Preußen vom kleinsten Detail bis in die Universalgeschichte. Mit gutem Recht wurde Erman - auf sein Ersuchen - im Jahre 1792 zum Historiographen Brandenburgs ernannt.

Hinsichtlich der übrigen Historiographie dieser Zeit in Deutschland sollen nur zwei Punkte hervorgehoben werden. Außerhalb Preußens gab es zum Jubiläum von 1785 zwar Festpredigten, aber kaum Geschichtswerke, mit einer einzigen Ausnahme: In Hessen-Kassel schrieb der Hofhistoriograph und Professor schwedischer Abstammung Wilhelm Johann Casparson (1729-1802) eine Geschichte sämmtlicher Hessen-Casselischen französischen Colonien ${ }^{20}$. Sie ist im Ton sachlicher und auch weniger anspruchsvoll als die Mémoires von Erman und Reclam, welche in der von Brandenburg handelnden Beilage Q ausführlich zitiert werden. Das führt zur zweiten Feststellung, dass nämlich im ausgehenden 18. Jahrhundert, d.h. am Ende der Aufklärung, ein breiter Konsens über den positiven Einfluss der Réfugiés auf den Fortschritt der deutschen Gastländer herrschte. Schon 1735 schrieb der Kammerherr von Pöllnitz in seinen Memoiren: »Wir haben ihnen unsere Manufakturen zu danken, und sie gaben uns die erste Idee vom Handel, den wir vorher nicht kannten « ${ }^{21}[$ !]. Ähnliche Äußerungen finden sich sowohl bei dem Minister Christian Wilhelm von Dohm (1751-1820)22 als auch bei Friedrich dem Großen ${ }^{23}$.

\section{Philipp Jakob Wenz}

Danach kam es in Deutschland zu großen Umwälzungen. Infolge der napoleonischen Kriege, der preußischen Niederlage bei Jena und Auerstedt sowie der französischen Besatzung war es kein Leichtes, sich als »Franzosen« zu

20 Wilhelm Johann Christian Gustav CAsparson, Kurze Geschichte sämmtlicher Hessen-Casselischen französischen Colonien vom Jahre 1685 bis auf die diesjährige Jubelfeyer der Colonie in der Haupt- und Residenzstadt Cassel den $28^{\text {sten }}$ October, Kassel 1785.

21 Zitiert nach Ruth Glatzer (Hg.), Berliner Leben 1648-1806. Erinnerungen und Berichte, Berlin (Ost) 1956, S. 52.

22 Christian Wilhelm von Doнm, Denkwürdigkeiten meiner Zeit oder Beiträge zur Geschichte vom letzten Viertel des achtzehnten und vom Anfang des neunzehnten Jahrhunderts, Bd. 5, Lemgo 1819, Beilage 9.

23 CEuvres de Frédéric LE GRAND, Bd. 1: Des mœurs, des coutumes, de l'industrie, des progrès de l'esprit humain dans les arts et dans les sciences, Berlin 1846, S. 102. 
erkennen zu geben ${ }^{24}$. Im Jahre 1819 gab der Prediger der französisch-reformierten Kirche in Emden, Philipp Jakob Wenz, zusammen mit einer Jubelpredigt eine Geschichte seiner Kirche heraus, in der es heißt:

Ob nun gleich jede französisch-ref. Gemeinde im Auslande ein rührendes Denkmal der Gastfreundschaft eines[theils], und der ihrer Ueberzeugung alles aufopfernden beharrlichen Frömmigkeit ihrer Stifter anderntheils ist und folglich keineswegs ihres Ursprungs sich zu schämen brauchet: so hat man doch in neuern Zeiten, durch unchristlichen Nationalhaß verleitet, das Andenken an die Stifter desselben verkannt, die französischen Gemeinden manchmal verschrieen, wiewohl sie mit den jetzigen Franzosen durchaus nichts gemein haben, als die Sprache, darum aber eben so wenig Franzosen sind, als die Schweizer, Brabanter oder Amerikaner, welche Französisch sprechen. Um daher manchem lieblosen Urtheile zu begegnen, glaube ich es an seiner Stelle, hier noch einige Gründe für die fortdauernde Erhaltung der französischen Kirchen im Auslande, sodann ihren wohltätigen und merkwürdigen Einfluß auf die Länder und Städte zu bemerken, die sie gastfreundlich aufnahmen ${ }^{25}$.

Hier finden sich einige der Standardausdrücke wieder, denen wir schon begegnet sind: Gastfreundschaft des Aufnahmelandes, beharrliche Frömmigkeit der Réfugiés, wohltätiger und bemerkenswerter Einfluss der Einwanderer auf die Fortschritte des Gastlandes. Neu ist die Notwendigkeit, sich gegen den französischen Feind abzugrenzen, mit dem man außer der Sprache nichts gemeinsam haben will, sowie der Versuch, diejenigen zu widerlegen,

welche aus Germanomanie gegen alles eingenommen sind, was nur französisch ist und das Gute nicht vom Bösen zu trennen wissen, welche sich berechtigt glauben, ein ganzes Volk zu beurtheilen, um Einzzelner [sic] willen, die alles hassen was aus Frankreich kommt, nur nicht die fr. Weine und andere Produkte, die mit einem Worte die fr. Sprache mit den Franzosen verwechseln ${ }^{26}$.

Dabei seien die Abkömmlinge der Flüchtlinge genauso gute Deutsche wie andere:

Auch in unsern Tagen hat sich keine fr. Gemeinde, weder in Holland noch in Deutschland, von der allgemeinen Sache getrennt. Wenigstens haben von meiner Gemeinde

24 Das Wort »Hugenotte« wurde vor dem Ende des 19. Jahrhunderts kaum gebraucht, da es als abschätzig empfunden wurde.

25 Prediger Philipp Jakob Wenz, Die Kirchenverbesserung des 16. Jahrhunderts ein Werk des Herrn, dargestellt in der am 31. October 1817 gehaltenen Jubel-Predigt. Nebst Geschichte der französich-reformirten Kirche in Emden von Philipp Jacob Wenz, Prediger derselben, Emden 1819. [Die Predigt und das Gebet umfassen 42 Seiten, der geschichtliche Teil 211 Seiten].

26 Ebd., S. 158f. 
alle jungen Leute in dem letzten Befreiungskriege größtentheils freiwillig die Waffen ergriffen, zwei kränkliche ausgenommen. Die jungen Herren de Pottere verließen sogleich die Akademie und dienten als freiwillige Jäger $[. . .]^{27}$.

Wenz bekennt sich also zu seinem Hugenottentum, muss sich aber dafür rechtfertigen, weshalb er sich von den zeitgenössischen Franzosen genau abgrenzt.

Nach jener defensiven Phase kamen Jahrzehnte, die zur hugenottischen Geschichtsschreibung nichts Neues beitrugen, da die wenigen Werke nur aus den Mémoires von Erman und Reclam schöpften ${ }^{28}$. Im letzten Viertel des 19. Jahrhunderts änderte sich der Standpunkt wieder deutlich. 1871 wurde das Deutsche Reich in Versailles verkündet und damit die Einheit Deutschlands um Preußen verwirklicht. Eine deutsch-nationale Ideologie zog ihre verhängnisvollen Fäden. Die hugenottische Geschichtsschreibung blieb davon nicht unberührt. 1874 erschien das Werk von Max Beheim-Schwarzbach: Hohenzollernsche Colonisationen. Ein Beitrag zu der Geschichte des preußischen Staates und der Colonisation des östlichen Deutschlands ${ }^{29}$. Im Vorwort erläutert der Autor seine Zielsetzung. Ihm geht es nicht um Religion oder Moral, sondern um die deutsche Nation; es gilt nämlich, die polnischen Gebiete in Ostpreußen dem Staat einzuverleiben. Die Grundfrage stellt er folgendermaßen:

Wie ein neuerworbenes, mit fremden Elementen durchsetztes Land dem siegreichen Stamme dauernd erhalten werden kann, um sich am leichtesten und passendsten dem größeren Staatskörper gutwillig einzufügen, ist von jeher ein schwieriges Problem gewesen. [Das gelinge am besten durch] Vermischung der Alteingesessenen mit einer Fülle vorgeschobener germanischer oder doch im Dienste der Germanisierung wirkender Elemente ${ }^{30}$.

Für ihn unterliegt es keinem Zweifel, dass zu diesen »im Dienste der Germanisierung wirkenden Elemente[n]« die Hugenotten gehörten, wie von folgendem Zitat bestätigt wird:

27 Ebd., S. 165.

28 Erinnerungshalber seien folgende Werke erwähnt: Paul Henry, Das Edict von Postdam vom 29. October 1685 und Mehreres auf die Geschichte der Refugiés Bezügliche, Berlin 1832; C. Reyer, Geschichte der französischen Kolonie in Preußen, Berlin 1852; W.F. Paul (Hg.), Les Réfugiés français dans les Etats prussiens (d'après Erman et Reclam). Zunächst zum Schulgebrauch, Berlin 1866; Karl Friedrich KöHLER, Die Réfugiés und ihre Kolonien in Preußen und Kurhessen, Gotha 1867.

29 Max Beheim-Schwarzbach, Hohenzollernsche Colonisationen. Ein Beitrag zu der Geschichte des preußischen Staates und der Colonisation des östlichen Deutschlands, Leipzig 1874.

30 Ebd., S. V. 
Großartig war die Einwanderung der verfolgten Glaubensbedrängten in den NordOsten, dessen Herrscher, aus Gründen der Toleranz sowohl wie innerer Politik, ihnen gern ein Asyl in ihren Staaten anboten; die Reformation wurde hier fast das Kriterium der Nationalität, des Deutschtums, eine Besiegelung und Bestätigung der früheren Cultur- und Colonisationsbestrebungen. Die Staaten des Ostens, die diese Aufgabe verkannten, [...] sind auch nicht bloß in der Germanisierung ihrer slawischen Länder, sondern überhaupt in der Entwickelung der Cultur oder politischen Machtstellung stehen geblieben, oder gar zurück geschritten ${ }^{31}$ !

Mit anderen Worten: Dadurch, dass die hugenottischen Flüchtlinge protestantischer Konfession waren, wurden sie gleich zu echten Deutschen und konnten als solche der Germanisierung slawischer »Stämme« im Osten dienen. Dabei wird die Feindseligkeit der Lutheraner gegenüber den Reformierten ganz verschwiegen. Beheim-Schwarzbach polemisiert auch gegen diejenigen, die über den schlechten Einfluss der Franzosen auf die Deutschen schreiben und unterscheidet dabei deutlich zwischen Hugenotten und Emigrés der Französischen Revolution:

Die oft gehörten Vorwürfe, dass der Einfluss unseres westlichen Nachbarstaates auf unsere guten deutschen Sitten und Zustände ein nur schädlicher sei, kann ebenfalls die nüchternen, orthodoxen, sittenreinen Familien nicht treffen, die aus tief moralischen Gründen den Stab nach der deutschen Erde kehrten. [...] Die Réfugiés waren aus dem edelsten Kern des Volkes, fleißige, tüchtige Arbeiter, die Emigranten durchschnittlich Leute, die wenig gelernt hatten ${ }^{32}$.

Die Formulierung »Familien, die [...] den Stab nach der deutschen Erde kehrten« setzt eine Art Wahlverwandtschaft zwischen den Hugenotten und Deutschland voraus. Ähnliche Ausdrücke tauchen schon bei Erman und Reclam und allgemein bei vielen deutschen Geschichtsschreibern auf. Hier ist allerdings Vorsicht geboten. Die Hugenotten haben sich nämlich über eine große Anzahl von europäischen und nicht-europäischen Ländern zerstreut, unter denen die Niederlande oder England ihnen viel naheliegendere Ziele waren als das ferne, unbekannte und arme Land Brandenburg-Preußen. Durch einen Taschenspielertrick schafft es Beheim-Schwarzbach auch, die Überlegenheit Deutschlands mit dem positiven Einfluss der französischen Reformierten auf das Land zu vereinigen: 
Wir sehen, durch das Leben und Treiben der Réfugiés ist ein mächtiger industrieller Aufschwung in Brandenburg-Preußen angebahnt worden. Fast in jedem Fache, und sei es scheinbar noch so unbedeutend, wurden Verbesserungen, Verfeinerungen durch die Franzosen eingeführt oder vorbereitet, sie wurden bald gültige Muster für die Einheimischen, [bis dahin könnte der Satz von Erman und Reclam stammen] und da sie sich selbst im Wesen, Charakter und Anschaunngen entschieden zu Deutschen ummodelten, behielten auch diese durch sie verbesserten Industrien lediglich einen deutschen Typus, oder nahmen denselben wenigstens mit der Zeit wieder $a n^{33}$.

Der Ausdruck »da sie sich [...] entschieden zu Deutschen ummodelten« suggeriert, die Hugenotten seien willens gewesen, sich ein »deutsches Wesen« anzueignen, wovon höchstens bei der vierten Generation, wenn überhaupt, die Rede sein kann. So überwog in den Gründerjahren ganz deutlich die deutschnationale Sicht der Hugenotten als der »besten Deutschen«, um mit Bismarck zu sprechen. Noch 1890 hieß es in einem Aufruf für einen deutschen Hugenottenbund, der zur Gründung des Deutschen Hugenottenvereins führen sollte:

In der gesamten Geschichte des Protestantismus klingt kein Name so rein, so voll, so edel als der der »Hugenotten«. Die Hugenotten sind ein Segen gewesen für die Welt. [...] Die deutschen Réfugiés haben sich des Hugenottennamens allezeit würdig erwiesen. Deutsch durch und durch, königstreu aus innerster Seele, leben sie heute durch Deutschland zerstreut [...]. Da gilt es sammeln. Das will der Hugenottenbund.

Diese »deutschnationale Linie« kann man bis ins 20. Jahrhundert und in den Hitlerfaschismus $^{34}$ verfolgen.

\section{Eduard Muret}

Aber am Ende des 19. Jahrhunderts entsteht auch eine andere Geschichtsschreibung, deren zwei Hauptvertreter Eduard Muret und Henri Tollin heißen. Zur zweihundertjährigen Jubelfeier des Edikts von Potsdam veröffentlichte Dr. Muret, Oberlehrer in Berlin und Autor eines berühmten deutsch-englischen Wörterbuchs, eine stattliche Geschichte der französischen Kolonien in Preußen ${ }^{35}$. Das 360 Seiten in Folio umfassende Werk schildert nicht nur die Geschichte der Berliner Kolonie, sondern auch alle ihre Institutionen - mit

33 Ebd., S. 67. Hervorhebung R.P.

34 Helmut Erbe, Die Hugenotten in Deutschland, Essen 1937; Ursula Fuhrich-Grubert, Hugenotten unterm Hakenkreuz. Studien zur Geschichte der Französischen Kirche zu Berlin, 19331945, Berlin 1994.

35 Muret, Geschichte der Französischen Kolonie. 
zahlreichen Illustrationen - und gibt eine Beschreibung der 47 preußischen Hugenottenkolonien von Kleve bis Königsberg. Der Autor gibt an, das Werk sei »im Auftrage des Konsistoriums der Französischen Kirche zu Berlin und auf Grund amtlicher Quellen bearbeitet« worden ${ }^{36}$. Im Nachwort äußert er den bescheidenen Wunsch, es möge »für die Glieder genannter Gemeinden ein Familienbuch [...] werden « ${ }^{37}$. Es soll also ein von einem Hugenotten für Hugenotten geschriebenes Werk sein.

Dabei beruht es auf einer "unter Mitwirkung des hierzu berufenen Komitees« gründlichen, peinlich genauen Archivarbeit. Die zahlreichen Namen werden zum Schluss in einem umfangreichen Sach- und Personenverzeichnis erfasst. Das Buch enthält Porträts von vielen bekannten Hugenotten sowie die Porträts aller preußischen Herrscher vom Großen Kurfürsten bis zu Kaiser Wilhelm I. Trotz seines durchweg nüchternen Stils verfehlt der Autor nicht, den Hohenzollern und den ehrwürdigen Vorfahren zu huldigen. Zum Schluss erklärt er, er übergebe sein Werk »den Mitgliedern der Kolonie, den Gönnern und Freunden derselben und allen denen, welche sich für diesen hervorragenden Abschnitt aus der Geschichte der Hohenzollerschen Kolonisationen interessieren $\ll^{38}$. Damit - aber nur in diesem Schlusssatz - wird es einem weiteren Rahmen, demjenigen preußischer Kolonisationen und preuBischer Geschichte einverleibt. Immerhin ist das Buch bis heute ein Standardwerk der Forschung über Hugenotten in Brandenburg-Preußen geblieben.

\section{Henri Tollin}

Der in Berlin geborene Prediger Henri Tollin (1833-1902) war 1890 Hauptbegründer des Deutschen Hugenottenvereins, von dem er »der geistige Vater, die Seele und die Triebfeder « war ${ }^{39}$, sowie von dessen Geschichtsblättern ${ }^{40}$. Neben seinen amtlichen Pflichten schrieb er zahlreiche historische Studien über die brandenburgisch-preußischen Hugenottenkolonien. Sein Hauptwerk ist die fünfbändige, etwa 4.000 Seiten umfassende Geschichte der französischen Kolonie von Magdeburg ${ }^{41}$. Es bildet das Ergebnis einer gründlichen Archivarbeit, die heute umso kostbarer ist, als das Archiv der Magdeburger Französischen Kirche im Zweiten Weltkrieg zerstört wurde. »Alle

\footnotetext{
36 Ebd., Titelblatt.

37 Ebd., S. 360.

38 Ebd.

39 Aus dem Nachruf auf Tollin, in: Die Französische Colonie 6 (1902), S. 54f.

40 Geschichtsblätter des Deutschen Hugenottenvereins (GDHV), 1890-heute.

41 Henri Tollin, Geschichte der Französischen Colonie von Magdeburg, 3 Tle. in 5 Bd., Halle a.d. Saale 1886-1894.
} 
Geschichtsforschung beruht auf Urkunden«, verkündet er in einer Vorrede ${ }^{42}$. Deshalb erblickte er eine seiner wichtigsten Pflichten darin, schwer zugängliche Urkunden zur Hugenottengeschichte herauszugeben.

Tollin ist Irrtümern und Legendenbildungen gnadenlos auf der Spur. Er polemisiert zuweilen gegen Erman und Reclam, denen er vorwirft, »alles rosig « zu färben ${ }^{43}$. Er zeigt die tausend Schwierigkeiten, die es bei der Ansiedlung der Flüchtlinge zu überwinden galt. Bei ihm gibt es keine vorgegebene Wahlverwandtschaft zwischen Hugenotten und Preußen, keine direkt von Frankreich nach Berlin oder Magdeburg führende Linie. So schreibt er etwa: »Es war von wenig Belang, wie das Land hiess [sic], in welches man hinüber geflogen war. War es doch nicht Frankreich. Und fern von Frankreich zu leben, das empfand jedweder Hugenotte als Elend und Verbannung « ${ }^{44}$. Zwar wurde den französischen Flüchtlingen vom Großen Kurfürsten erlaubt, ihren Ansiedlungsort selber zu wählen, aber »recht viele kehrten dem Lande selbst den Rücken, nachdem sie es ganz durchwandert hatten«. Die sehr verbreitete Armut gerade in Magdeburg zwang viele dazu, ihr Glück anderswo zu suchen, so dass »[t]rotz aller Schwierigkeiten, welche die Obrigkeit in fast allen Landen dem Wiederfortziehen der Hugenotten entgegensetzte, [...] in den ersten drei Jahrzehnten das Refuge einem Taubenschlage [glich] «, ein sonst allgemein verschwiegener Tatbestand, der von der heutigen Forschung immer mehr bestätigt wird ${ }^{45}$.

Wie schwierig in der ersten Zeit die Beziehungen der oft aus Südfrankreich stammenden Flüchtlinge, der »schwarzen Kerls« und »dunklen Mamsells« zu den lutherischen Einheimischen waren, beschreibt er sehr anschaulich:

Mit ihren schwarzen umherlodernden Augen schienen ja die unheimlichen Fremden alles in Brand setzen zu wollen. Ihre schmerzgefurchten Züge versprachen keine heitere Gesellschaft. [...] Überdies sprachen die Flüchtlinge eine fremde näselnde Sprache, mit der Geschwindigkeit des Sturmwinds und unter der heftigsten, fast leidenschaftlichen Gestikulation ${ }^{46}$.

Die weitverbreitete Feindlichkeit der deutschen Bevölkerung den Neuankömmlingen gegenüber betraf sogar die Geistlichen. Folgendes Zitat ist ein überzeugendes Beispiel für den Abbau einer historischen Legende:

42 Henri Tollin, Urkunden zur Geschichte hugenottischer Gemeinden in Deutschland, in: GDHV II (1893), H. 10, Vorrede S. I.

43 Tollin, Geschichte von Magdeburg, III, 1, S. 354.

44 Ebd., I, S. 297.

45 Ebd., I, S. 494. Vgl. dazu Magdelaine, Reisen und Irrfahrten; dies., Francfort-sur-le-Main et les réfugiés huguenots.

46 Ebd., II, S. $263 f$. 
Die kirchlichen Behörden aller deutschen Länder gerade wie die deutschen Unterthanen überhaupt, haben allüberall die Fremdlinge, mochten es Wallonen, Waldenser oder Franzosen sein, beargwöhnt, verleumdet, ausgehungert, verdrängt oder der Hölle als Ketzer übergeben. Nur die Fürsten haben sie in ihr Land gerufen, in die Pfalz, Hessen, Brandenburg, Hannover, Braunschweig, Mecklenburg, Württemberg, Baiern, Lippe u.s.w. $[\ldots]^{47}$.

Mit größter Genauigkeit beweist Tollin aus den Akten, dass die Manufakturbesitzer in Magdeburg keinen Erfolg hatten und recht arm blieben. In seiner etwas schwülstigen Ausdrucksweise behauptet er, dass die Hugenotten sich im Dienst anderer dauernd aufopferten und sagen konnten: »Morituri te salutamus $\ll^{48}$.

Tollin erzählt also gar keine Erfolgsgeschichte. Er schreibt das erste modern-wissenschaftliche Werk über die Hugenotten in Deutschland. Jedoch kann auch er nicht umhin, den Hohenzollern mit seinem ganzen Wesen zu huldigen. So schreibt er:

Wer die hugenottische Colonisation in Deutschland aus den Quellen studirt, der findet ein und dieselbe wirksam bittende, heilsam ordnende, schützend sammelnde Hand in ganz Deutschland; der hört schlagen ein und dasselbe grosse deutsche Herz, an das die Bedrängten und Verjagten appelliren [...]: das ist die Hand und Herz des grossen Kurfürsten Friedrich Wilhelm von Brandenburg. [...] Des grossen Kurfürsten feinhörige, bibelgläubige Toleranz und energisch umfassende Barmherzigkeit war wie eine prophetische Vorwegnahme der Einigung Deutschlands unter dem evangelischen Scepter der Hohenzollern ${ }^{49}$.

Fortwährend bemüht er sich, die rühmlichen Vorfahren zu typisieren, aus ihnen übergroße »Riesen des Glaubens«, »Geladene Gottes« zu machen, die er, der engagierte Pfarrer, seinen Zeitgenossen als Mustergestalten hinstellen will. Noch heute, meint er, seien die französischen Protestanten

ernst, gründlich, arbeitsam, ehrlich und fromm, sie bilden, nach unserer unerschütterlichen Ueberzeugung, den sittlichsten, begabtesten und darum lebenskräftigsten Bruchteil der französischen Nation, augenscheinlich berufen, den Nationalcharakter unserer Nachbarn zu regenerieren[! $]^{50}$.

47 Rede des Lic. Dr. Tollin, Vorsitzender des Vereins auf der vierten General-Versammlung des Deutschen Hugenotten-Vereins, in: Die Französische Colonie 12 (1898), H. 1, S. 9f.

48 Ebd.; Tollin, Geschichte von Magdeburg, III, 1B, S. 354.

49 Henri Tollin, Die Hugenotten in Magdeburg, in: GDHV 1 (1890), H. 1, S. 9.

50 Henri Tollin, Ein Ahnherr der Hohenzollern. Charakterbild gezeichnet von Henri Tollin. Zum Besten der verwundeten Soldaten, Frankfurt a.d. Oder 1866. Dieses Werk über den protestan- 
Man sieht, trotz allem Ernst bei der Urkundensuche und -behandlung entrichtet Tollin einen Tribut einerseits der hugenottischen Tradition, andererseits der Ideologie seiner Zeit. Das bedeutet aber keine Minderung seiner ungeheuren Quellenforschung und -bearbeitung.

Im Hinblick auf den Buchtitel seien hier zusammenfassend die Hauptmerkmale der deutschen Hugenottengeschichtsschreibung hervorgehoben. Versucht man, sie in die von Rudolf Stichweh vorgeschlagenen Muster des Umgangs mit Fremden einzuordnen, kommt meines Erachtens ganz eindeutig Modell 3 in Frage: »Gesellschaften, die Fremde nutzen, um für die in ihnen vorhandenen Statuslücken und unbesetzten Rollen Besetzungsmöglichkeiten zu finden $\aleph^{51}$ : Dank ihrer Privilegien waren sie die besten Stützen der Herrschenden bei deren Entwicklungspolitik. Das erklärt einerseits die oft feindliche Gesinnung breiter Bevölkerungsschichten ihnen gegenüber, andererseits das Zustandekommen einer reichhaltigen Legendenbildung, deren Hauptmerkmale die Typisierung der frommen und arbeitsamen Réfugiés einerseits und die starke Bindung zu den schützenden Fürsten und ganz besonders zu den Hohenzollern andererseits sind.

Das hohe Ansehen der Hugenotten in Deutschland hatte einen verhängnisvollen Nebeneffekt: Die Geschichtsschreibung über das Refuge in Deutschland ist oft gefühlsbeladen und ideologisch stark belastet gewesen, auch wenn sie von Nicht-Hugenotten herrührte. Es ist die Kehrseite der fast durchweg positiven Einstellung der deutschen Historiographie zu den Hugenotten, dass sie öfter zu Zwecken missbraucht wurde, die wenig mit einer Geschichtsforschung »sine ira et studio« zu tun hatten, sodass manche Werke fast mehr über den eigenen Standort als über die - bei Weitem nicht so problemlos verlaufene - Integrationsgeschichte der Réfugiés Aufschluss geben. Vielleicht war das der Preis, der dafür zu bezahlen war, dass die Hugenottengeschichte ein so völlig integrierter Bestandteil der deutschen Geschichte ist, der bis heute zu einer breiten, sachlicher und nüchterner gewordenen Forschung Anlass gibt.

tischen Feldherrn Gaspard de Châtillon, comte de Coligny, wird »Dem Sieger von Sadowa allerunterthänigst gewidmet vom Verfasser«.

51 Siehe Beitrag Rudolf Stichweн, Die Begegnung mit Fremden und die Selbstbeobachtung von Gesellschaften, S. 15-26, in diesem Band. 



\section{Carsten Schliwski}

\section{Joseph ha-Kohen (1496-1577) als Historiograph im Exil}

\section{Zur Ausgangslage: Galut}

Seit der Zerstörung des Zweiten Tempels im Jahre 70 ist die Situation der »galut«, also des Exils, diejenige, die das Judentum besonders prägt ${ }^{1}$. Exil bedeutet mehrerlei: Zum einen ist man aus seinem Heimatland, dem Lande Israel, vertrieben und hat keine Möglichkeit, dorthin zurückzukehren, wie es von Judah Halevi (gest. 1141) in den Zionsliedern beklagt wurde ${ }^{2}$. Zum anderen bedeutet Exil aber auch, dass die Juden als Minderheit einer christlichen oder islamischen Mehrheit ausgeliefert sind: Diese Mehrheit bestimmt durch ihre Dekrete die Lebenssituation der Juden, erweist sich mal als tolerant, mal als intolerant, und hat außerdem die Macht, die Juden aus ihrem Gebiet zu vertreiben ${ }^{3}$.

Damit einher geht eine gewisse Entfremdung, die immer das Verhältnis zwischen Juden und Christen bzw. Muslimen bestimmt. Juden können sich durchaus in einem bestimmten Gebiet heimisch fühlen, wie es zum Beispiel bei den spanischen Juden vor 1492 der Fall war, aber sie werden nie als gleichberechtigte Einwohner des Landes betrachtet. Gerade für die spanischen Juden bedeutet die Vertreibung von der Iberischen Halbinsel im Jahre 1492 eine weitere Exilserfahrung, sie befinden sich sozusagen in einer zweifachen $»$ galut $\iota^{4}$.

\section{Stellenwert der Geschichtsschreibung im Judentum}

Wenn man nach der klassischen jüdischen Ansicht geht, die beispielsweise von Moses ben Maimon (1138-1204) ausgedrückt wird, hat Geschichtsschreibung nichts in der jüdischen intellektuellen Welt verloren. Hintergrund

1 Zum Exilsbegriff im Judentum Haim Hillel Ben-Sasson, Galut (Golah), in: EJ, Bd. 7, Detroit ${ }^{2} 2007$, S. 352-363.

2 Zu Judah Halevi als Poet vgl. Angel Sáenz-Badillos, Judah Halevi, in: EJ, Bd. 11, Detroit ${ }^{2} 2007$, S. 492-497.

3 Eine gute Einführung zu dem Thema bietet: Mark R. CoHEN, Unter Kreuz und Halbmond. Die Juden im Mittelalter, München 2005. Weiterhin wichtig ist: Bernd Martin/Ernst Schulin (Hg.), Die Juden als Minderheit in der Geschichte, München ${ }^{4} 1989$.

4 Zur Situation der Sepharden vgl. Jane S. Gerber, The Jews of Spain. A History of the Sephardic Experience, New York u.a. 1994, S. 145-211. 
dieser Vorstellung ist das jüdische Konzept von Heilsgeschichte, das davon ausgeht, dass sich jüdische Geschichte und Geschichte allgemein nur in der Präsenz Gottes auf Erden, also mit der Existenz des Tempels von Jerusalem, vollziehen $\mathrm{kann}^{5}$. Die Zeit zwischen der Zerstörung des Zweiten Tempels und dem Aufbau eines neuen Tempels durch den Messias ist damit heilsgeschichtlich irrelevant, es vollzieht sich in ihr keine Geschichte.

Trotzdem kennt auch das rabbinische und mittelalterliche Judentum Formen von Geschichtsschreibung, die sich in drei Kategorien unterteilen:

1. Rewritten Bible: Da die Ereignisse bis zur Zerstörung des Zweiten Tempels überlieferungswürdig sind, wurden sie auch gerne in neuer Form präsentiert. Das wichtigste Beispiel dieser Kategorie ist der in Italien entstandene Sefer Josippon aus dem neunten Jahrhundert ${ }^{6}$.

2. Torah-Überlieferung: Es gehört zu den Grundbedürfnissen des rabbinischen Judentums, zur Untermauerung des eigenen Anspruchs als jüdische Autoritäten, z.B. gegen die Karäer, die unverfälschte Überlieferung der Torah seit der Sinaioffenbarung zu dokumentieren. Die erste kurze Darstellung dieser Art findet sich zu Beginn des Mischnah-Traktates Avot, weitere wichtige Beispiele sind der Seder Olam Rabbah (Große Weltchronik), der vermutlich nach 200 redigiert wurde und im Jahre 1513 in Ferrara zum ersten Mal als Druck erschien, und der Seder Olam Zuța (Kleine Weltchronik), der nach 700 zusammengestellt wurde ${ }^{7}$. Auch Abraham Ibn Dauds Sefer ha-Qabbalah (Buch der Tradition) aus dem zwölften Jahrhundert gehört überwiegend in diese Gattung.

3. Martyrologien: Die Darstellung jüdischer Märtyrer hielt nicht nur in der synagogalen Poesie Einzug, wo sie zu bestimmten Trauertagen für den gottesdienstlichen Vortrag bestimmt war. Auch in der Prosa wurden entsprechende Verfolgungen und Zwangsbelehrungen thematisiert, so zum Beispiel in den Berichten über Verfolgungen zur Zeit der Kreuzzüge9.

5 Vgl. dazu den weiterhin maßgeblichen Aufsatz von Salo W. BAron, The Historical Outlook of Maimonides, in: PAAJR 6 (1935/36), S. 5-113.

6 Kritische Edition: David Flusser (Hg.), Sefer Yosippon, 2 Bd., Jerusalem 1978-1980. Vgl. auch ders., Jossipon, in: EJ, Bd. 11, Detroit ${ }^{2} 2007$, S. 461f.

7 Editionen der beiden Texte: Baer Ratner (Hg.), Seder Olam Rabbah. Die große Weltchronik, Wilna 1897 und Moshe Y. Weinstock (Hg.), Seder Olam Rabbah ha-šalem, Seder Olam Zuṭa ha-šalem, 2 Bd., Bnei-Brak 1990. Vgl. auch Günter Stemberger, Einleitung in Talmud und Midrasch, München ${ }^{8} 1992$, S. 319f.

8 Edition: Gerson D. Cohen (Hg.), Sefer ha-Qabbalah. The Book of Tradition, Philadelphia 1967. Vgl. auch Resianne Fontaine, Ibn Daud, Abraham Ben David Halevi, in: EJ, Bd. 9, Detroit ${ }^{2} 2007$, S. 662-665.

9 Einführung und Edition: Eva Haverkamp (Hg.), Hebräische Berichte über die Judenverfolgungen während des Ersten Kreuzzugs, Hannover 2005. 
Nach der Vertreibung der Juden aus Spanien 1492 und aus Portugal 1496/97 setzt eine neue Blüte der jüdischen Historiographie ein ${ }^{10}$, die von den einen als ein neues Phänomen betrachtet wird, während sie die anderen als den letzten Ausläufer der mittelalterlichen Geschichtsschreibung bezeichnen ${ }^{11}$. Die Wahrheit liegt wohl irgendwo in der Mitte: Zwar weist diese Geschichtsschreibung noch deutliche Bezüge zu ihren mittelalterlichen Vorläufern auf, doch finden sich auch neue Elemente wie ein gesteigertes Interesse an der Geschichte der nichtjüdischen Welt, die jetzt nicht nur im Zusammenhang mit antijüdischen Maßnahmen dargestellt wird, und die Verwendung nichtjüdischer Quellen in einer neuen Intensität. Wie die Erfahrung eines Lebens in der Fremde sich auf die jüdische Geschichte nach 1492/96 auswirken konnte, soll im Folgenden exemplarisch am Euvre Joseph ha-Kohens gezeigt werden

\section{Joseph ha-Kohen: Leben und Werk}

Die Familie ${ }^{12}$ des Joseph ben Josua ha-Kohen (1496 - nach 1577) stammte ursprünglich aus dem kastilischen Huete und musste noch vor Josephs Geburt während der Vertreibungen von 1492 das Land verlassen. Joseph ha-Kohen kam in Avignon zur Welt, wo sich die Familie zwischenzeitlich niedergelassen hatte. Allerdings bot auch die Provence nur kurze Zeit Zuflucht, sodass sich die Familie im Jahre 1501 nach Genua begab und sich dort endgültig niederließ. Joseph ha-Kohen verbrachte sein Leben zunächst in Genua und, als das nicht mehr möglich war, im nahegelegenen Novi. Im Jahre 1550 siedelte er sich in Voltaggio an, im Jahre 1567 wich er ins Herzogtum Montferrato aus. Da er als Arzt tätig war, fiel es ihm leichter als anderen Juden, ein Niederlassungsrecht zu erhalten. Trotzdem war auch er von antijüdischen Restriktionen, die immer wieder einmal in Norditalien verhängt wurden, betroffen. Über Joseph ha-Kohens Ausbildung zum Arzt ist nichts bekannt. Da er keinen Doktortitel führte, wie ihn zum Beispiel die Universität von Padua ermöglichte, ist auch nicht sicher, an welchem Ort er seine Studien betrieb.

10 Für dieses Thema im Allgemeinen ist immer noch bedeutsam: Salo W. BAron, A Social and Religious History of the Jews, Bd. 13: Inquisition, Renaissance, and Reformation, New York ${ }^{2} 1969$, S. 100-143.

11 Vgl. dazu die unterschiedlichen Standpunkte von Robert BonfIL, Jewish Attitudes towards History and Historical Writing in Pre-Modern Times, in: Jewish History 11 (1997), H. 1, S. 7-40 und Josef Hayim Yerushalmi, Zachor: Erinnere Dich! Jüdische Geschichte und jüdisches Gedächtnis, Berlin 1988, S. 65-84.

12 Eine kurze Biographie bieten: Ephraim KuPFER, Joseph ha-Kohen, in: EJ, Bd. 11, Detroit ${ }^{2} 2007$, S. 429; Karin Almbladh (Hg.), Joseph ha-Kohen: Sefer 'Emeq ha-Bakha. (The Vale of Tears) with the Chronicle of the Anonymous Corrector, Uppsala 1981, S. 11-15 und Martin JACOBS, Islamische Geschichte in jüdischen Chroniken. Hebräische Historiographie des 16. und 17. Jahrhunderts, Tübingen 2004, S. 82-86. 
Joseph ha-Kohens literarisches Schaffen umfasst folgende historiographische und geographische Werke:

\section{Divrei ha-yamim le-malkhe Șarefat u-malkhei bet Oțoman ha-Togar (Chro-} nik der Könige Frankreichs und der Osmanen), eine in zwei Teile gegliederte Chronik der christlichen und islamischen Mittelmeerwelt. Das mit Ereignissen aus dem Jahre 1553 endende Werk wurde 1554 in Sabbioneta zum ersten Mal gedruckt, allerdings erfolgten in der Zeit danach zwei Überarbeitungen durch den Autor: In der ersten Revision hat er neben inhaltlichen und stilistischen Korrekturen das Ende des zweiten Teils neu geschrieben und bis 1556 fortgeführt. Zusätzlich hat er einen dritten Teil angefügt, der im Jahre 1574 endet. Die dritte Fassung aus dem Jahre 1575 stellt eine Neubearbeitung des gesamten Werkes dar ${ }^{13}$.

2. Sefer cEmeq ha-Bakhah (Jammertal) $)^{14}$, eine Zusammenstellung von Judenverfolgungen von der Antike bis in die Zeit des Verfassers. Das Werk wurde $1557 / 58$ beendet, jedoch bis 1575 von Joseph ha-Kohen mehrfach überarbeitet. Eine letzte anonyme Revision stammt aus der Zeit um 1600.

3. Mașsiv gevulot cammim (Der die Grenzen der Völker setzt) ${ }^{15}$, eine paraphrasierende hebräische Übersetzung der Weltbeschreibung des Humanisten Johannes Böhm (ca. 1485 - ca. 1533/35), die Joseph ha-Kohen im Jahre 1555 anfertigte.

4. Sefer ha-Indiah ha-ḩadašah (Neuindien-Buch) ${ }^{16}$, eine hebräische Übersetzung des Werkes La istoria de las Indias y conquista de Mexico von Francisco López de Gómara. Joseph ha-Kohen übersetzte dieses zweiteilige Werk im Jahre 1557, wobei er es an Mașșiv gevulot cammim anschließen ließ.

13 Es existiert keine kritische Edition dieses Werkes, nur eine unvollständige Edition des dritten Teils durch: David Abraham Gross (Hg.), Sefer Divrei ha-yamim le-malkhei Șarefat u-malkhei beit Oṭoman ha-Togar. Heleq šeliši, Jerusalem 1955. Zum Werk vgl. JACOBS, Geschichte, S. 86-104.

14 Editionen des hebräischen Textes: Meir LetTeris (Hg.), Emek habaca. Historia persecutionum judeorum comprehendens periodum ab anno p. Ch. n. LXX usque MDLXXV a Josepho Hacohen (nat. 1496), Wien 1852; die Textedition stammte ursprünglich von Samuel David Luzzatto, Letteris revidierte sie und versah sie mit Anmerkungen. Eine alle verfügbaren Manuskripte berücksichtigende Edition ist die von Almbladh, Sefer 'Emeq ha-Bakha. Vgl. auch JACOBS, Geschichte, S. 104-106.

15 Vgl. JACOBS, Geschichte, S. 106f. Ein Druck oder eine kritische Edition liegen nicht vor. Auszüge wurden ediert von Raphael Sh. Weinberg (Hg.), Yehoshu'a ha-Kohen we-sifro Mașsiviv gevulot 'ammim, in: Sinai 37 (1983), S. 333-364.

16 Vgl. die Edition von Moshe LazAr (Hg.), Sefer ha-Indiah ha-ḥadašah ve-sifro Fernando Qorțes, Lancaster 2002. Vgl. JACOBS, Geschichte, S. 107f. 


\section{Joseph ha-Kohen als Historiker im Exil}

Joseph ha-Kohen war sich immer seiner spanischen Herkunft bewusst, sodass die Vertreibung von der Iberischen Halbinsel eine große Rolle als Motivation für sein historiographisches Werk spielte. In seinem Hauptwerk, den Divrei ha-yamim stellt Joseph ha-Kohen seine Herkunft dar, als er von seiner Geburt berichtet:

In jenen Tagen, im Jahre 5257, das ist 1496, am 20. Dezember, das ist der Monat Tevet, wurde ich, Joseph Ben Josua aus der Familie der Priester, die aus Spanien vertrieben wurden, im Lande Provence, in Avignon am Fluss Rhone geboren. Und mein Vater führte mich von dort weg, als ich fünf Jahre alt war, und wir ließen uns im Gebiet der Stadt Genua bis heute nieder ${ }^{17}$.

Damit wird deutlich, dass sich Joseph ha-Kohen weiterhin als Emigrant betrachtete, heutzutage würde man ihn vielleicht als »Vertreibungsopfer der zweiten Generation« bezeichnen, wobei ihn die erzwungene Migration seiner Eltern erst dazu gebracht hat, sich als Historiograph zu beschäftigen:

Joseph ha-Kohen spricht: Die Vertreibungen aus Frankreich und diese bittere und schreckliche Vertreibung haben mich aufgerüttelt, dieses Buch zu verfassen, auf dass die Nachkommen Israels wissen, was sie uns in ihren Ländern, ihren Höfen und ihren Palästen angetan haben ${ }^{18}$.

Dieser Passus findet sich nicht nur in den Divrei ha-yamim, sondern auch in der Vertreibungschronik 'Emeq ha-Bakha' ${ }^{19}$. Er ist also programmatisch für das historiographische Werk Joseph ha-Kohens. Ohne die Vertreibungen, von denen seine Familie direkt betroffen war, wäre Joseph ha-Kohen nicht zum Historiker geworden. Dabei ist es interessant zu sehen, dass dieser Passus in beiden Schriften nicht in der Einleitung auftaucht, sondern in den Abschnitten, in denen Joseph ha-Kohen sich mit der Vertreibung aus Spanien beschäftigt, wobei man allerdings sehen muss, dass diese Vertreibungen in beiden Werken keine zentrale Rolle spielen, sondern nur zwei Episoden in der langen Geschichte von Verfolgungen und Vertreibungen darstellen. Insofern stellt sich die Frage, ob die beiden Vertreibungen wirklich das entscheidende Motiv für das Geschichtswerk bilden. Martin Jacobs bezweifelt

17 Joseph HA-Kohen, Divrei ha-yamim le-malkhei Șarefat u-malkhei beit Oṭoman ha-Togar, Sabbioneta 1554, fol. 118b. Wenn nicht anders gekennzeichnet, stammen die Übersetzungen der Zitate vom Verfasser (im Folgenden »C.S.«) dieses Beitrags.

18 Ebd., fol. 113a.

19 Almbladh, Sefer 'Emeq ha-Bakha. Hebräischer Teil, S. 62. 
dies $^{20}$, allerdings könnte man einwenden, dass die Fülle des Materials, das Joseph ha-Kohen zusammengestellt hat, den eigentlichen Anstoß in den Hintergrund gerückt hat. Dazu noch ein zweiter Gedanke: Ein »Anstoß« muss nicht identisch mit dem »Hauptinteresse« sein. Es wäre also möglich, als »Anstoß« für Joseph ha-Kohens historiographisches Werk die Vertreibungen aus Frankreich und Spanien anzunehmen, schließlich war er durch seine Eltern betroffen, während das »Hauptinteresse« auf der Behandlung der Juden durch christliche und muslimische Mehrheitsgesellschaften liegt, um somit die Vertreibungen in einen weiteren Kontext zu stellen.

\section{Warum schreibt Joseph ha-Kohen Geschichte?}

Wie wir gesehen haben, beruht Joseph ha-Kohens Impetus, Geschichte aufzuschreiben, auf seiner Exilsituation. Doch welchen Zweck beabsichtigt er mit seinem Geschichtswerk? Darüber gibt das Vorwort zum Divrei hayamim Auskunft:

So spricht Joseph, Sohn des Josua, Sohn des Meir, Sohn des Juda, Sohn des Josua, Sohn des Juda, Sohn des David, Sohn des Mose aus der Familie der Priester, die aus Huete im Lande Spanien weggingen: Jeder aus meinem Volk weiß, dass in Israel kein Schriftsteller mehr auftrat wie Josippon der Priester, der den Krieg des Landes von Juda und von Jerusalem beschrieb. Es existierten keine Erinnerungsschreiber mehr in Israel, sie existierten nicht mehr, bis ich auftrat, ich Joseph, der ich als Erinnerungsschreiber in Israel auftrat und es mir vornahm, in einem Buche die Erinnerungen der meisten Drangsale zu schreiben, die uns in den Ländern der Nichtjuden seit dem Tage der Vertreibung Judas aus seinem Land bis heute getroffen haben, sowie die Kriege der Könige der Nichtjuden, die sie im Lande von Juda und Jerusalem führten, und die Vertreibung aus Frankreich und Spanien, auf dass sie den Israeliten bekannt seien. Und ich will auf dem Feldsaum hinter den Schnittern auflesen, was meine Hand findet, hier ein wenig, dort ein wenig, Daher schüttete ich meinen Rockschoß aus, um eine Chronik der Könige von Frankreich und der Könige der Dynastie von Osman zu schreiben und ihre Chronologie in einem Buch niederzulegen, was die Ägypter uns und unseren Vätern Übles taten, damit es unter den Juden nicht verloren gehe und die Erinnerung daran bei ihren Nachkommen nicht aufhöre, bis der Lahme wie ein Hirsch springen und die Zunge des Stummen jubeln wird: Singt dem Herrn, denn Herrliches hat er kund getan. Kundgetan sei dies im ganzen Lande ${ }^{21}$.

20 Vgl. JACOBS, Geschichte, S. 94.

21 Ha-Kohen, Divrei ha-yamim, fol. $1 \mathrm{~b}$. 
An diesem Vorwort sind einige Dinge auffällig: So definiert sich Joseph haKohen als spanischer Jude, sein italienischer Aufenthaltsort ist ihm keine Erwähnung wert. Angeblich ist es die Absicht dieses Werkes, eine Schilderung der Verfolgungen vorzunehmen, die die Juden getroffen haben. Tatsächlich bildet die Darstellung der Verfolgungen nur einen ganz geringen Teil des Werkes, im Mittelpunkt steht vielmehr die Geschichte der christlichen und islamischen Reiche ${ }^{22}$. Zugleich stellt Joseph ha-Kohen einen Gegensatz her: Die Juden stehen auf der einen Seite, die Nichtjuden auf der anderen Seite - für eine gemeinsame Geschichte ist kein Raum, nur für die Schilderung der Unterdrückungsmaßnahmen. Dabei ist es interessant, dass innerhalb der Darstellung der Geschichte des christlichen Raumes die Ereignisse, die in Italien stattfinden, einen besonders breiten Raum einnehmen ${ }^{23}$.

Joseph ha-Kohen möchte also jüdische Geschichte schreiben, tatsächlich schreibt er jedoch nichtjüdische Geschichte. Eine Geschichte der Verfolgungen verfasst er erst kurze Zeit später, allerdings in einem anderen Rahmen, nämlich als bloße Aneinanderreihung dieser Ereignisse, ohne eine genauere Schilderung der Zusammenhänge. In dem Vorwort dieses Werks heißt es:

Es spricht Joseph, Sohn des Josua, Sohn des Meir, Sohn des Juda, Sohn des Josua, Sohn des Juda, Sohn des David, Sohn des Mose aus der Familie der Priester, die aus Huete im Lande Spanien weggingen: Da die Leiden, welche, seitdem Juda aus seinem Lande vertrieben wurde, bis auf den heutigen Tag über uns gekommen sind, hier und dort vereinzelt geschildert werden, habe ich mir vorgenommen, sie in einer kleinen Schrift zusammenzustellen, die alles enthalten soll, was ich in Schriften der Autoren, die Hebräisch geschrieben haben, und in ihren Büchern gefunden habe. Ihren Titel nenne ich Jammertal, denn sie ist wie ihr Name, da jeder, der darin liest, staunen und aufschnauben wird und ihm Tränen aus den Augen fließen werden und er seine Hände an die Hüften legen wird und er sagen wird: Wie lange noch, Herr? Ich flehe zu meinem Gott, dass die Tage unserer Trauer aufhören und er unseren gerechten Messias sende, damit er uns schnell in unseren Tagen erlöst gemäß seinem Erbarmen und seiner Gnade. Amen und amen ${ }^{24}$.

Zunächst einmal nennt Joseph ha-Kohen wieder seine Herkunft, er bezeichnet sich als Abkömmling spanischer Juden und nicht als Angehöriger italienischer jüdischer Gemeinden. Zugleich betont er die besondere Situation der Juden nach der Vertreibung aus dem Heiligen Land, die sie zu Exilanten gemacht hatte. Was die Christen betrifft, so erwähnt er sie nicht namentlich,

22 Vgl. JACOBS, Geschichte, S. 94.

23 Zum Inhalt des Werkes vgl. ebd., S. 88-91.

24 Almbladh, Sefer 'Emeq ha-Bakha. Hebräischer Teil, S. 2. 
sondern spricht lediglich von »ihren Büchern«. Durch diese Nichterwähnung wird die Kluft zwischen Juden und Christen deutlich, letztere finden nur als Verfolger Berücksichtigung.

Aber warum hat Joseph ha-Kohen überhaupt diese Verfolgungschronik verfasst? Während man als Motiv für sein Werk Divrei ha-yamim das allgemeine Bedürfnis annehmen kann, die Juden auch über außerjüdische Geschichte zu informieren, damit sie aktuelle Ereignisse, von denen sie ja auch betroffen sind, besser einordnen können, verhält es sich bei der Verfolgungschronik ein wenig anders: Bei ihr handelt es sich um die letzte von drei Chroniken dieser Art, die innerhalb kurzer Zeit erschienen sind, nämlich außer ha-Kohens Werk der Consolaçam ás tribulaçõens de Israel von Samuel Usque aus dem Jahre 1553 in portugiesischer Sprache ${ }^{25}$ und dem hebräischen Werk Ševet Yehuda von Salomon Ibn Verga, das 1554 erstmals in Adrianopel gedruckt wurde ${ }^{26}$.

Alle drei Werke behandeln dasselbe Thema, nämlich die Verfolgung der Juden im Laufe der Zeit, gehen dabei jedoch unterschiedlich vor: Usques Schrift stellt eine Klage und Trostschrift für die Vertriebenen und Zwangskonvertierten dar ${ }^{27}$. Ibn Vergas Werk ist weniger eine Chronik der Vertreibungen, sondern versucht vielmehr, Vertreibungen in einen bestimmten Zusammenhang zu stellen, um geschichtsphilosophische Themen zu illustrieren und ist nicht an einer chronologischen Reihenfolge der Ereignisse interessiert ${ }^{28}$. Dagegen schildert Joseph ha-Kohen die Ereignisse in ihrer historischen Reihenfolge, bemüht sich also, eine Chronik der Verfolgungen zu erstellen ${ }^{29}$.

25 Ausgaben des portugiesischen Textes: Joaquim Mendes dos RemÉdios (Hg.), Consolaçam ás tribulaçõens de Israel, 3 Bd., Coimbra 1906-08; Samuel Usque, Consolação às tribulaçõens de Israel. Edição de Ferrara 1553. Com estudos introdutórios por Josef Hayim Yerushalmi e José de Pina Martins, Bd. 2, Lissabon 1989.

26 Editionen des hebräischen Textes: Meir Wiener (Hg.), Liber Schevet Jehuda auctore R. Salomone Aben Verga, Hannover 1855 (ND 1924); Azriel Sноснат (Hg.), Sefer Ševet Yehudah le-Rabbi Šelomoh b. Verga, Jerusalem 1947.

27 Vgl. Josef H. Yerushalmi, A Jewish Classic in the Portuguese Language, in: Samuel Usque (Hg.), Consolação às tribulaçõens de Israel. Edição de Ferrara 1553. Com estudos introdutórios por Josef Hayim Yerushalmi e José de Pina Martins, Bd. 1, Lissabon 1989, S. 15-112 und JACOBS, Geschichte, S. 48f. Wichtig sind auch: Abraham A. Neuman, Samuel Usque. Marrano Historian of the Sixteenth Century, in: Ders. u.a. (Hg.), Landmarks and Goals. Historical Studies and Addresses, Philadelphia 1953, S. 105-132; Maria Teresa Guerrini, New Documents on Samuel Usque, the Author of the Consolaçam as tribulaçoens des Israel, in: Sefarad 61 (2001), S. 83-89.

28 Vgl. JACOBS, Geschichte, S. 45-48. Eine gute Einordnung des Werkes bieten: Abraham A. Neuman, The Shebet Yehudah and Sixteenth Century Historiography, in: Louis Ginzberg, Jubilee Volume. English Section, New York 1945, S. 253-273, und Margarethe SCHLÜTER, Zuchtrute und Königszepter. Zur Frage der Komposition des »Shevet Yehuda«, in: Ulf HaxeN u.a. (Hg.), Jewish Studies in a New Europe. Proceedings of the Fifth Congress of Jewish Studies in Copenhagen 1994, Kopenhagen 1998, S. 712-731.

29 Vgl. Jacobs, Geschichte, S. 104-106. Wichtig ist auch: Josef H. Yerushalmi, Messianic 
Es handelt sich bei diesen Werken also weniger um historiographische Schriften im eigentlichen Sinn, sondern vielmehr um Martyrologien. Damit gehören diese Berichte einer Literaturgattung an, die bereits im Mittelalter existierte, wenngleich es einen wichtigen Unterschied gibt: Die mittelalterlichen Martyrologien waren vor allem auf ein Ereignis oder eine bestimmte Gegend beschränkt, beispielsweise die Verfolgungen während des Ersten Kreuzzuges im Rheinland, während in den hier angesprochenen drei Werken eine Gesamtschau verschiedener Verfolgungsereignisse im Laufe der Zeit geliefert wird. Es geht nicht mehr nur darum, ein konkretes Ereignis zu beklagen, sondern darum, die jüdische Geschichte als eine Geschichte von Verfolgungen zu behandeln.

Warum hat also Joseph ha-Kohen eine dritte Verfolgungschronik verfasst? In seinem Vorwort äußert er sich nicht dazu, sondern verweist lediglich darauf, dass er seine Schilderungen diversen anderen Büchern entnimmt. Dabei bildet Usques Werk seine Hauptquelle. Vielleicht geht Joseph ha-Kohen von der Annahme aus, dass ein Werk in portugiesischer Sprache auf weniger Resonanz beim jüdischen Leser stoßen wird als ein entsprechendes in hebräischer Sprache. Er geht also zunächst von Lesern aus, die sich vor allem mit hebräischer Literatur beschäftigen und nicht mit den Schriften in der Umgebungssprache.

Dazu kommt noch ein liturgischer Grund: Joseph ha-Kohen intendiert wohl, dass sein Werk als Grundlage für die gottesdienstliche und private Lektüre am »Tischa' be-Av« dient, an dem der Zerstörung der beiden Tempel und der Verfolgungen von Juden gedacht wird ${ }^{30}$. In einem solchen Rahmen hätte natürlich nur eine hebräische Schrift Berücksichtigung finden können.

Auch die anderen Werke, die Joseph ha-Kohen verfasst hat, dienen dem Zweck, jüdische Leser in hebräischer Sprache über Ereignisse in der Umgebung zu informieren, indem er von Christen verfasste geographische und historiographische Werke übersetzt. Dabei geht er davon aus, dass ein solches Anliegen passender auf Hebräisch verfolgt wird. So heißt es im Vorwort zu Mașsiv gevulot 'ammim:

Ich möchte mich seiner Übersetzung in unsere heilige Sprache widmen, um die Angehörigen unseres Volkes Dinge wissen zu lassen, die ihr Ohr bis heute nicht gehört hat, auf dass sie etwas von allen Taten Gottes wissen, die er tat, als sie unter den Völkern waren $^{31}$.

Impulses in Joseph ha-Kohen, in: Bernard D. Cooperman (Hg.), Jewish Thought in the Sixteenth Century, Cambridge, Mass. 1983, S. 460-487.

30 Vgl. JACOBS, Geschichte, S. 105.

31 Weinberg, Mașșiv gevulot ‘ammim, S. 339. 
Damit wird deutlich, dass Joseph ha-Kohen zumindest eine informative Teilhabe der Juden an den Entdeckungen und Ereignissen der Welt anstrebt, die eine Beteiligung ohne Aufgabe der eigenen Identität ermöglicht.

\section{Zusammenfassung}

Joseph ha-Kohen ist als sephardischer Jude in Italien zweifach in der Fremde: zum einen als Abkömmling der Juden, die aus Spanien vertrieben wurden, zum anderen durch die Tatsache, dass er als Jude generell nach der Zerstörung des Tempels außerhalb des Heiligen Landes, also im Exil, lebt. Im Rahmen dieses zweifachen Exils bemüht er sich darum, die jüdische Leserschaft über nichtjüdische Geschichte zu informieren, um ihnen ein Zusammenleben mit der Umgebung zu erleichtern, sie aber auch gleichzeitig durch die Verwendung der hebräischen Sprache und der Schilderung antijüdischer Verfolgungen in ihrer jüdischen Identität zu stärken. Seine Heimat Spanien ist dabei weniger das tatsächlich existierende geographische und politische Gebilde auf der Iberischen Halbinsel, als vielmehr die sephardische Kultur, aus der er seine Identität schöpft. 


\section{Westjüdische Wahrnehmungen jüdischer Lebenswelten im Osten}

»Brothers and Strangers « - dieses Begriffspaar aus dem Titel der Studie von Steven E. Aschheim ${ }^{1}$ charakterisiert sehr treffend die Ambivalenz, die das Verhältnis der deutschen Juden zu den Juden und ihren Lebenswelten in den östlichen Regionen Europas spätestens seit dem 19. Jahrhundert bestimmte. Mit der Akkulturation der deutschen Juden an ihre nichtjüdische Umgebung und den Bemühungen um eine Neudefinition jüdischer Existenz auf rein konfessioneller Grundlage ging eine Distanzierung von den Juden im Osten einher, welche weitgehend isoliert am Rande der Mehrheitsgesellschaften lebten und ihre kollektiven Strukturen über den religiösen Bereich hinaus beibehalten hatten. Weit verbreitet war eine Auffassung, die das Judentum im Osten als eine rückständige Gemeinschaft sah, die fernab von Modernisierung und Fortschritt in mittelalterlichen Traditionen verhaftet geblieben war und unter den Bedingungen von Ghettoisierung, Überbevölkerung und Armut ein unkultiviertes und unzivilisiertes Leben fristete. Mit der Ausprägung der Unterscheidung zwischen »Ost-« und »Westjuden« verfestigte sich eine typologisierende Betrachtungsweise, die nicht zwischen den unterschiedlichen jüdischen Gemeinschaften im Osten Europas differenzierte, sondern sie in ihrer Gesamtheit als Gegensatz zu den modernen, emanzipierten westeuropäischen Juden auffasste, ganz gleich, ob diese zu den orthodoxen, den liberalen, den zionistisch gesinnten oder aber zu den vollständig assimilierten Juden zählten.

In der Wahrnehmung vieler deutscher Juden standen die Ostjuden insgesamt auf einer Entwicklungsstufe, die es zu überwinden galt und die sie selbst meinten, lange hinter sich gelassen zu haben. Doch es existierten, insbesondere seit der Wende zum 20. Jahrhundert, auch andere Einstellungen, die das Judentum im östlichen Europa als das verlorene Judentum betrachteten, das es für die westeuropäischen Juden wiederzugewinnen galt: Während Vertreter der Orthodoxie die Juden im Osten als die Bewahrer des religiösen Erbes schätzten und hofften, mit ihrer Unterstützung das jüdische

1 Steven E. Aschнеim, Brothers and Strangers. The East European Jew in German and German Jewish Consciousness, 1800-1932, Madison u.a. 1982. 
religiöse Leben in Deutschland neu beleben zu können, betrachteten viele Zionisten die osteuropäischen Juden als die Hüter des jüdischen Volkstums und der jüdischen kulturellen Traditionen und unterstützten ihre Forderung nach verfassungsmäßiger Anerkennung als eigene Nationalität mit autonomen Rechtsbefugnissen ${ }^{2}$. Vor dem Hintergrund des wachsenden Antisemitismus und der Neoromantik des Fin-de-siècle entwickelte sich ein sogenannter Ostjudenkult, der jedoch bis zum Ersten Weltkrieg kaum mehr als eine Stimmung war, die sich zu einem wesentlichen Teil auf literarische Darstellungen der Welt der osteuropäischen Juden gründete ${ }^{3}$.

Gemeinsam war den meisten deutschen Juden, dass sie kaum Kenntnisse über die Lebenswelten der Juden in den östlichen Regionen Europas besaßen. Aus eigener Anschauung kannten viele die osteuropäischen Juden nur »in der Rolle des lästigen, unzivilisierten und mittellosen Einwanderers, der die Juden in Deutschland kollektiv zu diskreditieren drohte $\iota^{4}$. Erst im Zuge des Ersten Weltkriegs kamen zahlreiche deutsch-jüdische Soldaten in Kontakt mit den bis dahin fremden jüdischen Lebenswelten in den westlichen Gebieten des Zarenreichs und hatten Gelegenheit, ihr Vorkriegsbild von den Ostjuden auf den Prüfstein zu stellen. Viele fühlten sich in ihren bisherigen Vorurteilen gegenüber den Juden im Osten bestätigt. Sie versuchten sich abzugrenzen und Verbindungen zwischen deutschen und osteuropäischen Juden zu leugnen. Andere sahen sich angesichts der Kriegserlebnisse gezwungen, sich zwischen den beiden Polen Deutschtum und Judentum neu zu positionieren - für sie spielten die Kontakte zu den osteuropäischen Juden häufig eine besondere Rolle .

Innerhalb einer kleinen, aber sehr bedeutsamen Gruppe führte die Begegnung mit den Juden im Osten zu einer Bekräftigung und Ausweitung des Ostjudenkults der Vorkriegszeit, was sich insbesondere in einer weitgehenden Glorifizierung des sehr stark religiös geprägten Lebens ausdrückte. Solche positiven Wahrnehmungen der osteuropäisch-jüdischen Lebenswelten äußerten sich zwar in unterschiedlichen Ausprägungen, dennoch lassen sich oft ähnliche Schwerpunktsetzungen feststellen. Meist gingen Wertschätzung und Bewunderung der Lebensweise der Juden im Osten für die betroffenen deutschen Juden einher mit einer Neuverortung, die sich häufig in einer veränderten Einstellung zum Judentum zeigte.

Aus dieser Beobachtung ergibt sich die Frage, wie sich die Begegnung mit den osteuropäisch-jüdischen Lebenswelten auf die Geschichtssicht jener deutsch-jüdischen Soldaten auswirkte, die sich für das Ostjudentum begeis-

2 Vgl. Egmont Zechlin, Die deutsche Politik und die Juden im Ersten Weltkrieg, Göttingen 1969, S. 133.

3 Vgl. Aschнеiм, Brothers and Strangers, S. 187.

4 Zechlin, Die deutsche Politik, S. 133.

5 Vgl. Asсннеim, Brothers and Strangers, S. 153. 
terten. Aussichtsreich erscheint vor allem die Untersuchung, ob und inwieweit grundlegende Veränderungen des Geschichtsverständnisses bzw. Neuinterpretationen bestimmter Aspekte der jüdischen Geschichte festzustellen sind. Im Folgenden soll diese Frage insbesondere anhand der Schilderungen des Schriftstellers, Journalisten und Rechtsanwalts Sammy Gronemann untersucht werden, der mit seinem 1924 publizierten literarischen Bericht Hawdoloh und Zapfenstreich. Erinnerungen an die ostjüdische Etappe 1916-18 die Vorurteile gegen die ostjüdische Welt aufzubrechen und dem Leser eine neue Perspektive auf das Judentum im Osten zu eröffnen versuchte. Dieses Buch wird - wie auch das 1919 erschienene Werk Das ostjüdische Antlitz von Arnold Zweig und Hermann Struck - zu den für den Ostjudenkult während der Weimarer Republik äußerst bedeutsamen Publikationen gezählt ${ }^{6}$. Bevor hier jedoch die Person Gronemanns und seine Schilderungen der osteuropäisch-jüdischen Lebenswelten in den Fokus der Betrachtungen rücken, sollen zunächst die Stimmungen skizziert werden, die zu Beginn und während des Ersten Weltkrieges unter den deutschen Juden herrschten.

\section{Der Erste Weltkrieg - Stimmungen im deutschen Judentum}

In seinem Leitartikel zur ersten Ausgabe der Zeitschrift Der Jude schrieb Martin Buber 1916:

Der Krieg hat die Lage des Judentums inmitten der Völker in ihrer tragischen Problematik gesteigert und furchtbar verdeutlicht. [...] [Es] darf daran geglaubt werden, daß diese Zeit der schwersten Prüfung für das Judentum eine tiefe Selbstbesinnung und damit den Beginn einer wahrhaften Sammlung und Einigung bedeutet. [...] Um nur von denen zu sprechen, die den Krieg unmittelbar erfahren haben: aus allen Briefen vom Felde, aus allen Gesprächen mit Heimgekehrten empfing ich den gleichen Eindruck - den einer Stärkung des Verhältnisses zum Judentum durch Klärung des Blicks und Festigung des Willens. [...] In den durch das jüdische Erlebnis dieses Krieges erschütterten Juden, die sich für das Schicksal ihrer Gemeinschaft verantwortlich fühlen, stellt sich die neue Einheit des Judentums dar. [...] Der erste Ausdruck dieser neuen Einheit ist die gewandelte Selbsterkenntnis?

6 Beide Werke werden oft in einer Reihe mit Alfred Döblins »Reise in Polen« (1925) und Joseph Roths Buch »Juden auf Wanderschaft« (1927) genannt. Vgl. etwa Michael Brenner, Jüdische Kultur in der Weimarer Republik, München 2000, S. 160. Alle vier Publikationen glorifizieren die ostjüdische Spiritualität und vermitteln die Botschaft, »jüdische Juden« seien nur im Osten zu finden; vgl. ebd., S. 160-163.

7 Martin Buber, Die Losung, in: Der Jude 1 (1916), S. 1-3, hier S. $1 f$. 
Dass die von Buber hier angesprochene »tiefe Selbstbesinnung« und »gewandelte Selbsterkenntnis« nicht nur auf die Begegnung mit den osteuropäischen Juden zurückzuführen war, sondern die Kriegserlebnisse im Allgemeinen und die Entwicklung des Verhältnisses zwischen nichtjüdischen und jüdischen Deutschen während des Krieges ebenfalls bedeutsame Faktoren darstellten, ist bereits verschiedentlich dargelegt worden ${ }^{8}$. Mit Ausbruch des Krieges hatten viele deutsche Juden eine Chance zur Demonstration ihrer Loyalität zu Deutschland gesehen. Sie waren mit der Erwartung in den Krieg gezogen, das gemeinsame Fronterlebnis werde nichtjüdische und jüdische Soldaten einander näherbringen und letztlich zu einer vollständigen Integration der Juden in Deutschland führen. Diese Hoffnungen wurden im Laufe des Krieges bitter enttäuscht. Insbesondere die »Judenzählung« von 1916, eine statistische Erhebung des Einsatzes der Juden an der Front, die durch den antisemitischen Vorwurf, die Juden seien »Drückeberger«, veranlasst worden war, führte zu einer großen Ernüchterung unter denjenigen deutsch-jüdischen Soldaten, die auf die endgültige und vollständige Gleichberechtigung der Juden in Deutschland gehofft hatten. Diese Enttäuschung stärkte häufig das Gefühl der Solidarität gegenüber den Juden im Osten.

Angesichts des Krieges wurde die Beschäftigung mit dem Judentum in Osteuropa auch für jene jüdischen Gruppierungen zum Thema, die bis dahin für die Glaubensbrüder im Osten wenig Interesse aufgebracht hatten. Nun schien die Chance gekommen zu sein, das Judentum im Zarenreich zu befreien und die Lage der Ostjuden grundsätzlich zu verändern. Bald nach Kriegsbeginn waren von deutschen Juden Organisationen ins Leben gerufen worden, die die Interessen der Ostjuden vertraten und versuchten, diese mit der deutschen Politik zu verbinden. Hauptziel der Organisationen war die Verbesserung der rechtlichen Situation der jüdischen Minderheit im Osten; sie setzten sich aber ebenso für die Schaffung von Bildungsmöglichkeiten und für eine soziale Umschichtung ein?. Vor allem deutsche Zionisten, aber auch andere Kreise betrachteten das Ostjudentum als »Reservoir jüdischer Kraft«, das zwar in seiner Eigenart erhalten werden müsse, aber

8 Vgl. dazu etwa Eva G. Reichmann, Der Bewusstseinswandel der deutschen Juden, in: Werner E. Mosse (Hg.), Deutsches Judentum in Krieg und Revolution 1916-1923, Tübingen 1971, S. 511-612.

9 Während das »Komitee für den Osten« dafür eintrat, dass die Ostjuden innerhalb eines zu schaffenden Nationalitätenstaates als autonome Nationalität anerkannt werden sollten, verlangte die »Vereinigung für die Interessen der osteuropäischen Juden« für sie lediglich die bürgerliche Gleichberechtigung. Diese Forderung vertrat auch die $»$ Freie Vereinigung für die Interessen des orthodoxen Judentums«, die darüber hinaus vor allem für Juden im Osten die Anerkennung als Religionsgemeinschaft sicherstellen wollte. Vgl. dazu Trude MAURER, Ostjuden in Deutschland 1918-1933, Hamburg 1986, S. 33. Vgl. dazu auch Aschнeim, Brothers and Strangers, S. 157-163 und ausführlich Zechuın, Die deutsche Politik, S. 117-120, 126-138, 144-147, 167-172 u. 189-191. 
doch »zur Höhe der westlichen Kultur emporzuheben« sei ${ }^{10}$. Verbreitet war die Sicht, die Juden im Osten seien angesichts der Herausforderungen der Gegenwart hilflos und bedürften einer Führung von außen ${ }^{11}$. Jedoch gab es auch bereits vor dem Krieg insbesondere unter jungen Zionisten Anhänger der osteuropäisch-jüdischen Kultur und Lebensweise, die gleichzeitig grundlegende Kritik am deutschen Judentum übten. $\mathrm{Zu}$ diesem Personenkreis ist Sammy Gronemann zu zählen, dessen »Ostjudenerlebnis« im Folgenden näher betrachtet werden soll.

\section{Sammy Gronemanns Sicht auf West- und Ostjudentum}

Sammy Gronemann, 1875 in Westpreußen als Sohn eines Rabbiners geboren, wuchs in Danzig und Hannover auf. Nach einem einjährigen Talmudstudium in Halberstadt absolvierte er sein Jurastudium in Berlin, wo er später auch eine Anwaltskanzlei führte ${ }^{12}$. Angesichts der immer wieder erlebten antisemitischen Anfeindungen hatte Gronemann schon recht früh erkannt, dass zwischen dem Ideal und der Wirklichkeit jüdischer Emanzipation und Integration in die deutsche Gesellschaft eine große Diskrepanz bestand ${ }^{13}$. Um die Jahrhundertwende schloss er sich der zionistischen Bewegung an. Obwohl er neben der religiösen auch eine säkular-nationale Dimension jüdischer Identität anerkannte, war er dennoch überzeugt, dass Nation und Religion als die zentralen Elemente der jüdischen Existenz eine grundlegende Einheit darstellten $^{14}$. 1902 schrieb er in einem Beitrag in der Israelitischen Rundschau:

Ich möchte behaupten, daß die jüdische Religion nur eine christliche Einrichtung ist, - soll sagen, daß ohne das Vorbild der Kirche wir nicht zu einer Abstrahierung der Religion gekommen wären. [...] Das Judentum ist eine Einheit. Das Einheitsprinzip ist das Wesen unserer Gemeinschaft und unserer Kultur. Wer vom religiösen Judentum abgeht, wird bald auch den nationalen Halt verlieren und umgekehrt ${ }^{15}$.

Obwohl Gronemanns Mutter sowie seine Frau aus dem Russländischen Reich stammten und er auch in seinem Bekannten- und Freundeskreis viele Kontakte zu ostjüdischen Einwanderern pflegte, hatte er - seinen eigenen Darle-

10 Adolf Friedemann, Wir und die Ostjuden, in: Neue jüdische Monatshefte 1 (1916/17), S. 58-66, hier S. 60.

11 Vgl. ebd., S. 61f.

12 Vgl. dazu die ausführlichen Schilderungen seiner Jugend- und Studienzeit in Sammy GroneMANN, Erinnerungen. Aus dem Nachlaß, hg. v. Joachim SchlÖr, Berlin u.a. 2002.

13 Vgl. Hanni Mittelmann, Sammy Gronemann (1875-1952). Zionist, Schriftsteller und Satiriker in Deutschland und Palästina, Frankfurt a.M. 2004, S. 29.

14 Vgl. ebd., S. 37.

15 Sammy Gronemann, Israelit, Orthodoxie und Zionismus. Schluß, in: IsrRd 7 (1902), H. 28, S. 4. 
gungen zufolge - doch nur geringe Kenntnisse über das traditionsgebundene Leben der Juden in Osteuropa. Bei einer Reise nach Wolhynien 1905 erhielt Gronemann zum ersten Mal direkten Einblick in die Lebenswelt der Ostjuden. Er zeigte sich tief beeindruckt von der Feststimmung, die während der Pessach-Tage in Šitomir herrschte, obwohl sich bereits Pogrome ankündig$\operatorname{ten}^{16}$. Ein derart selbstbewusstes Judentum war ihm aus Deutschland unbekannt. Intensiver lernte er das jüdische Leben im Osten aber erst kennen, als er sich 1916 auf Anraten des Malers Hermann Struck zum Dienst in der Zensurabteilung Ober-Ost meldete. Wie Gronemann in seinen Erinnerungen schreibt, spielte die Möglichkeit zur Begegnung mit den Ostjuden eine wichtige Rolle für seine Entscheidung, an die Ostfront zu gehen:

Kaum je im Leben würde sich mir eine Gelegenheit wie diese bieten, jüdisches Volksleben und jüdisches Milieu so in der Nähe kennenzulernen. Hatte ich doch bis dahin immer nur kurz und von der Peripherie aus in diese mich so interessierende Welt hineinblicken können, und diese wenigen Möglichkeiten hatten mein Interesse nun gewaltig gesteigert ${ }^{17}$.

Wie er die jüdische Welt im Osten erlebte, schildert Gronemann in seinen 1924 erschienenen Aufzeichnungen Hawdoloh und Zapfenstreich. Erinnerungen an die ostjüdische Etappe 1916-18, die in einem humorvollen Stil mit vielen Anekdoten über seine Kriegstätigkeit als Jiddisch-Dolmetscher für die deutsche Armee in Kowno und Białystok berichten. Nach Hanni Mittelmann stellt Hawdoloh und Zapfenstreich einen der Meilensteine der Neuorientierung jener deutschen Juden dar, die aufgrund persönlicher Erfahrungen mit dem ostjüdischen Leben während des Krieges ihre Einstellung zum Ostjudentum änderten und infolgedessen oft auch eine veränderte Selbstwahrnehmung zeigten ${ }^{18}$.

Während viele Berichte deutscher Juden von der Ostfront noch während des Krieges in Zeitschriften publiziert wurden, lagen zwischen Gronemanns Kriegserlebnissen und der Publikation seines Berichts 1924 mehrere Jahre. In diese Zeit fallen die Diskussionen um die Grenzsperre gegen die ostjüdische Einwanderung und die verschiedenen »Ostjuden-Erlasse« der preuBischen Regierung, die vielfach Abschiebungen, Internierungen und Ausweisungen ostjüdischer Arbeiter zur Folge hatten ${ }^{19}$. Der Antisemitismus hatte sich in diesen Jahren stark ausgebreitet und die deutschen Juden sahen

16 Vgl. dazu Gronemann, Erinnerungen, S. 283-285.

17 Sammy Gronemann, Erinnerungen an meine Jahre in Berlin. Aus dem Nachlaß hg. v. Joachim SchlÖR, Berlin u.a. 2004, S. 239.

18 Vgl. Mittelmann, Sammy Gronemann, S. 66f.

19 Vgl. Ludger HeID, Maloche - nicht Mildtätigkeit. Ostjüdische Arbeiter in Deutschland 1914-1923, Hildesheim u.a. 1995, S. 146-155; Maurer, Ostjuden in Deutschland, S. 192-435. 
sich immer wieder herausgefordert, zur Frage der ostjüdischen Einwanderung Position zu beziehen. Insbesondere unter jenen um die Anerkennung ihres Deutschtums besorgten Juden »intensivierte der anwachsende Antisemitismus die Tendenz [...], sich von den Ostjuden zu distanzieren $\aleph^{20}$. Während andere Bücher, die wie etwa Joseph Roths Juden auf Wanderschaft oder Alfred Döblins Reise in Polen ebenfalls Vorurteile gegen die ostjüdischen Lebenswelten abbauen wollten, von »emanzipatorischen Menschheitsvisionen« geprägt sind, stellt Sammy Gronemann - wie auch Arnold Zweig in seinem Buch Das ostjüdische Antlitz - das Judentum im Osten nicht als reformbedürftig, sondern als »Vorbild für das sich selbst entfremdete Westjudentum « dar ${ }^{21}$. Hieraus ergibt sich die Frage, ob seine Darstellung, einem idealisierten Bild folgend, lediglich bestehende Auffassungen hinsichtlich der jüdischen Geschichte, Gegenwart und Zukunft bestätigte oder ob seine Darlegungen erkennen lassen, dass ihn die Erfahrungen im Osten zum Überdenken seines Geschichtsverständnisses und in diesem Kontext zu einer intensiven Auseinandersetzung mit der historischen Entwicklung der ostjüdischen Lebenswirklichkeit geführt haben.

\section{Die ostjüdischen Lebenswelten in Hawdoloh und Zapfenstreich}

Mit den Begriffen »Hawdoloh« und »Zapfenstreich« stellt Gronemann zwei unterschiedliche Zeremonien nebeneinander: Die »Hawdala« oder jiddisch »Hawdole« - übersetzt etwa: Unterscheidung, Trennung - ist eine Zeremonie, die am Ausgang des Sabbats oder eines Festtags vollzogen wird. Dabei wird an den heiligen Charakter des gerade zu Ende gehenden Sabbats oder Festtags und an den profanen des beginnenden Werktags gedacht. Während die Hawdala einen Moment der Rückverwandlung bezeichnet, der auf die jüdische Kultur des Geistes und des Herzens verweist, markiert die nichtjüdische, militärische Zeremonie des Zapfenstreichs dagegen das Ende der Ausgehzeit der Soldaten, also einen Moment der Rückverwandlung vom Zivilisten zum Soldaten. Im Kontext des von Gronemann gewählten Titels lässt sich der Zapfenstreich als Symbol für die auf das Irdische bezogene technische Zivilisation interpretieren ${ }^{22}$.

Insgesamt geht es Gronemann in Hawdoloh und Zapfenstreich darum, die Kultur des Ostjudentums mit der Zivilisation des Westens zu kontrastieren und dabei das traditionsgebundene Leben der Juden im Osten dem zerfallen-

20 Avraham Barkai, Jüdisches Leben in seiner Umwelt, in: Ders. / Paul Mendes-Flohr / Steven M. Lowenstein, Deutsch-jüdische Geschichte in der Neuzeit, Bd. 4: 1918-1945, München 1997, S. 50-73, hier S. 68.

21 Mittelmann, Sammy Gronemann, S. 67f.

22 Vgl. ebd., S. 68. 
den traditionellen jüdischen Leben im Westen gegenüberzustellen. Von der weitgehend oberflächlichen Begeisterung für das Ostjudentum zu Beginn des Krieges setzt er sich deutlich ab; die Vereinnahmung der Juden in den östlichen Regionen Europas für die deutsche Kultur beschreibt er mit ironischer Distanz:

In den ersten Kriegsjahren aber herrschte eitel Jubel und Begeisterung ob der Entdeckung der Ostjuden als der Wahrer deutscher Art und Sprache. Es entstanden begeisterte Lobgesänge auf ihre Treue, und eine Reihe deutscher Literaten, beileibe nicht nur Juden, bewiesen in tiefgründigen Abhandlungen, daß die Ostjuden eigentlich echte und rechte Deutsche seien, Träger deutscher Kultur, die in unerhörter Zähigkeit und Anhänglichkeit ihr germanisches Volkstum durch die Jahrhunderte slawischer Unterdrückung gewahrt hätten ${ }^{23}$.

Gronemann geht es dagegen vielmehr um das Kennenlernen des - wie er es nennt - »eigenen Volkslebens« der Juden im Osten, das ihm bis dahin fremd gewesen war:

[...] ich lernte kennen, was Juden sind, wie unbefangen und nicht nach Fremdem schielend sie ihr eigenes Volksleben führten, und begann damals erst recht so vieles von jüdischen Dingen zu verstehen, die ich zwar schon gelernt hatte, deren Wesen mir aber doch vielfach dunkel geblieben war. [...] Ich sah dort zum ersten Mal die Juden wirklich ihr eigenes Leben führen, so natürlich, wie es ein Deutscher oder Franzose lebt ${ }^{24}$.

Hatten die verbreiteten Vorurteile gegen die Ostjuden stets ihre »Kulturlosigkeit« hervorgehoben und dabei das deutsche bzw. westeuropäische Kulturund Bildungsverständnis zugrunde gelegt, so verwendet Gronemann nach der Begegnung mit dem Ostjudentum einen anderen Kulturbegriff: In Hawdoloh und Zapfenstreich berichtet er über einen »jungen, protestantischen Gelehrten «, dem er in Kowno begegnet war und der angesichts seiner Erfahrungen mit den Juden im Osten angekündigt habe, nach dem Krieg nach

23 Sammy Gronemann, Hawdoloh und Zapfenstreich. Erinnerungen an die ostjüdische Etappe 1916-1918, Königstein i.T. 1984, S. 31. In seinen Erinnerungen führt Gronemann dazu das Beispiel des Zionisten Heinrich Loewe an: »Heinrich Loewe verfaßte eine Broschüre, in der er nachwies, daß die jiddische Sprache eigentlich nichts anderes sei als ein weiterentwickeltes Mittelhochdeutsch. Da lag dann die Folgerung nahe, daß in Wirklichkeit die Juden Rußlands, seinerzeit aus Deutschland ausgewandert, und von Kasimir dem Großen aufgenommen, eigentlich nichts anderes wären als Pioniere deutscher Kultur, und man verstieg sich wirklich zu solchen weitgehenden Schlüssen. Es herrschte kurze Zeit geradezu ein Taumel sentimentaler Bewunderung für jene bis dahin so verpönten Ostjuden, die jetzt plötzlich als Märtyrer des Deutschtums die deutsche Flagge hochgehalten hatten«. Gronemann, Erinnerungen an meine Jahre in Berlin, S. 173.

24 Gronemann, Erinnerungen an meine Jahre in Berlin, S. 265f. 
Litauen ziehen zu wollen, da er endlich unter »Kulturmenschen« leben wolle. Gronemann kommentiert dies folgendermaßen: »Kulturmenschen in Massen, das war für uns eine unerwartete und überwältigende Entdeckung. Freilich mußte man sich über den Begriff Kultur klar werden [...] und er fügt erläuternd hinzu, »daß Kultur letzten Endes unabhängig von dem ist, was der einzelne erlernt hat $\ll^{25}$.

Aufschlussreich ist seine Schilderung einer Begegnung mit einem Lehrer in Białystok, der zahlreiche Nebenbeschäftigungen hatte, seine meiste Zeit aber »recht brotlosen Künsten«, d.h. der Dichtung, dem Übersetzen westeuropäischer Dramen und Romane sowie der Komposition, widmete. Gronemanns Beschreibung stellt ihn als typischen Repräsentanten des Ostjudentums dar:

In seiner ganzen Art, seiner Kultursehnsucht, seinem rastlosen Mühen, die naturgemäß breiten Lücken seiner Bildung aufzufüllen, lag etwas zugleich Rührendes und Erhabenes. Der kleine, unansehnliche Mann, dem die Sorgen des Alltags [...] so ganz und gar nebensächlich erschienen, dem nur geistige Dinge von Bedeutung waren, war ein echter und rechter Vertreter ostjüdischen Wesens überhaupt ${ }^{26}$.

Gronemanns Verständnis von Kultur, wie er sie bei den litauischen und polnischen Juden vorzufinden meinte, schließt das Utilitaristische des verbreiteten Kultur- und Bildungsbegriffs aus und steht im Gegensatz zu den materiellen Bereichen von Wirtschaft und Technik ${ }^{27}$. Welche Elemente diese von Gronemann bewunderte Kultur ausmachen, wird vor allem aus seinen Schilderungen des religiösen Lebens und der Spiritualität der Juden im Osten deutlich.

Zu Beginn des Kapitels Die Synagoge des Ostens stellt Gronemann fest:

Seit ich die Synagoge des Ostens kennen gelernt habe, ist mir der Tempel des Westens mit seinem Gottesdienst einigermaßen verleidet. [...] Ich fühle mich unbehaglich in der geordneten, geruhigen, ich möchte sagen, »militärisch geregelten « Art des gottesdienstlichen Betriebes, wie er sich hier abwickelt ${ }^{28}$.

Dieser »deutschen Ordnung ${ }^{29}$ setzt Gronemann seine Beschreibung des Gemeindelebens in den Synagogen im Osten entgegen, die im eigentlichen Sinne des Wortes als »Versammlungshaus« dienten. Im Gegensatz zu Feier-

25 Gronemann, Hawdoloh und Zapfenstreich, S. 53.

26 Ebd., S. 127.

27 Vgl. Mittelmann, Sammy Gronemann, S. 69.

28 Gronemann, Hawdoloh und Zapfenstreich, S. 60.

29 Ebd., S. 62. 
lichkeit und Andacht der westlichen Gottesdienste, die er als »unerträglich" empfinde $^{30}$, gehe es in den Synagogen der Ostjuden scheinbar chaotisch $\mathrm{zu}:$

Die einen sitzen und brüten über ihren Büchern, andere debattieren laut und ungeniert über irgendwelche Fragen der Lehre, andere wieder unterhalten sich, auch ebenso laut, über durchaus profane Dinge, einer wandert, den Mantel lang hinter sich herschleppen lassend, hin und her, scheinbar im Selbstgespräch, Kinder balgen sich oder spielen um die Bimah herum Verstecken, ein alter Jude fährt dazwischen und teilt rechts und links Ohrfeigen aus, von der Frauengalerie [...] ertönt eine kreischende Weiberstimme, die gegen die Mißhandlung ihres Jungen protestiert - kurz, es bietet sich etwas ganz anderes dar, als sich der auf Feierlichkeit gestimmte Besucher erwarten lie $\beta^{31}$.

Die gemeinsamen Gebete hingegen beschreibt Gronemann als Momente »höchster Ekstase«, die selbst denjenigen mitreißen würden, der kein Wort der Gebettexte verstehe ${ }^{32}$. Statt pathetischer Predigten in einer volksfernen »Kanzelsprache« wie im Westen gebe es Lehrvorträge, die den Zuhörern lebensnah Stellen aus dem Talmud und ethische Grundsätze erläutern würden $^{33}$. Im Ostjudentum meint Gronemann die »richtige Freude an der Lehre, am Gesetz $\ll^{34}$ gefunden zu haben, die seiner Ansicht nach den westlichen Juden abhanden gekommen sei. Sehr anschaulich schildert er das unmittelbare und unbefangene Verhältnis der Ostjuden zu Gott sowie die Einheit von Volksleben und Religion, die er im Ostjudentum zu erkennen glaubt. Diese Erkenntnis führt Gronemann zu einer neuen Sicht auf das religiöse Leben der Juden im Westen:

Man hat versucht, den lieben Gott und das Judentum in die Synagoge zu sperren, und wacht sorglich darüber, daß beide die Schwelle nicht nach außen hin überschreiten. Mir ist das unerträglich, seit ich im Osten etwas anderes gesehen - etwas ganz und gar anderes ${ }^{35}$.

Die Synagoge des Ostens erfährt Gronemann als »das Zentrum jüdischen Willens und jüdischer Kraft ${ }^{36}$, im Beth ha-Midrasch, dem der Synagoge angegliederten Lehrhaus, meint er die Juden »wie sie [eigentlich] sind « zu sehen: »Hier im Lehrhaus kommt das Ewigkeitsgefühl, das Gefühl absolu-

\footnotetext{
30 Ebd., S. 61.

31 Ebd., S. 62-64.

32 Ebd., S. 62.

33 Ebd., S. $68 f$.

34 Ebd., S. 64.

35 Ebd., S. 61.

36 Ebd., S. 71.
} 
ter Freiheit und Unabhängigkeit von äußeren Umständen zum monumentalen Ausdruck! $\ll{ }^{37}$. Im Lehrhaus, in dem die alte Tradition der Vermittlung der jüdischen Lehre aufrechterhalten wurde, lernt Gronemann das Ostjudentum als in der Spiritualität, in der Sehnsucht nach geistigen Dingen verankert kennen. Damit erscheinen ihm die Juden im Osten als vorbildhaft und den assimilierten Westjuden mit ihrer - seiner Auffassung nach - materialistischen Geisteshaltung weit überlegen ${ }^{38}$.

Insbesondere die Art und Weise, wie die Ostjuden den Sabbat begehen, empfindet Gronemann als den Inbegriff jüdischer Spiritualität. Obwohl »von Jugend auf an strenge Sabbathaltung gewohnt $\ll^{39}$, habe er erst im Osten erfahren, was der Sabbat eigentlich sei:

Aus dem Sabbat, aus dem Lehrhaus [...] hat der Jude die Kraft gezogen, um sich durch alle die Jahrhunderte des Schreckens zu halten. Die Welt da draußen mit all ihren Sorgen und Kümmernissen, ihrer Hetze ist für ihn nebensächlich. Er hat seine Zuflucht im Sabbat und im Lehrhaus - er lebt in einem unentrinnbaren und unabwendlichen Rhythmus - mag passieren, was da will, nach sechs Tagen kommt der Sabbat und dann sitzt er in einer sicheren Stellung mit unübersteigbaren Mauern. Diese Mauern sind wirklich unübersteigbar und es gibt keine Macht, die sie mit Erfolg brechen kann $^{40}$.

Neben der Religiosität und Spiritualität zeigt sich Gronemann besonders von dem jüdischen Gemeinschaftsgefühl beeindruckt, das er unter den Juden im Osten erlebte. Angesichts seiner Erfahrungen mit der Lebensweise der Ostjuden erscheint es Gronemann mehr und mehr unangebracht, als »Retter der Ostjuden« aufzutreten, wie es viele deutsche Juden taten. Von Tag zu Tag, so berichtet er, habe er mehr eingesehen, dass er sehr wenig geben und sehr viel empfangen könne ${ }^{41}$. Aufgrund ihrer alle Aspekte des Lebens durchdringenden Religiosität erscheinen ihm die Ostjuden nicht als Gläubige, sondern als »Wissende«:

Aber es ist ein Wissen, das nicht durch das Hamstern von Kenntnissen erlangt werden kann. [...] Sie wissen vielleicht nicht, welchen Weg sie gehen und zu welchem Ziele aber sie wissen, daß sie auf dem Wege sind und in sicherer Führung wandern ${ }^{42}$.

37 Ebd., S. $102 \mathrm{f}$.

38 Vgl. Mittelmann, Sammy Gronemann, S. 72.

39 Gronemann, Hawdoloh und Zapfenstreich, S. 84.

40 Ebd., S. 86.

41 Ebd., S. 128.

42 Ebd., S. 225f. 
Sie lebten in dem glücklichen Bewusstsein, »[u]nabhängig [zu] sein von den Geschehnissen des Tages, zu wissen, es kann mir nichts geschehen! « ${ }^{43}$. Dagegen sieht er die Juden im Westen als »Kulturmenschen nur auf Widerruf und auf Zeit « ${ }^{44}$, deren Moral, Religion und Sittenkodex nur unter gewissen Bedingungen Geltung behalte. Während es in ihnen und für sie »nichts Bleibendes, nichts Unabänderliches « gebe, wüssten die Juden im Osten »das Ewige vom Vergänglichen, das Wesentliche vom Unwesentlichen zu scheiden« $«{ }^{45}$.

\section{Ostjudenbegeisterung und Geschichtsverständnis}

Die folgenden abschließenden Überlegungen wollen die anfangs gestellte Frage wieder aufgreifen, welchen Einfluss die Begegnung mit den ostjüdischen Lebenswelten auf die Geschichtssicht der vom Ostjudentum begeisterten deutsch-jüdischen Soldaten hatte. Sammy Gronemanns Aufzeichnungen Hawdoloh und Zapfenstreich vermitteln Geschichtsauffassungen, die so oder ähnlich im Kontext des Ostjudenkults des Ersten Weltkriegs und der Nachkriegszeit durchaus häufiger zu finden waren. Viele deutsche Juden, die während des Krieges erstmals dem Ostjudentum begegneten und sich für dessen Leben begeisterten, empfanden diese Begegnung als ein Kennenlernen der eigenen Wurzeln. Sie meinten im ostjüdischen Gottesdienst die »Jahrtausende alte Vergangenheit des jüdischen Volkes « zu erleben ${ }^{46}$, sie empfanden die Reise nach Osteuropa als Zeitreise in die eigene Vergangenheit ${ }^{47}$. Insbesondere für viele jüngere, zionistisch gesinnte Soldaten wie Sammy Gronemann bedeutete die Begegnung mit dem Ostjudentum eine Bestätigung ihrer bereits vor dem Krieg ausgeprägten Ablehnung des als bourgeois, oberflächlich und erstarrt empfundenen deutsch-jüdischen Lebens: »Eastern Jews were seen as a genuine national proletariat, authentic embodiments of a proud tradition, foil to everything that these young Jews disliked in their own homes $\ll^{48}$.

Der Ostjudenkult der Kriegs- und Nachkriegsjahre lässt sich auch als Ausdruck eines Generationenkonflikts verstehen: War in der Vätergeneration die Scham für die Ostjuden eine Grundkomponente gewesen, die das Streben nach Integration in und Akkulturation an die deutsche Umwelt begleitete, so diente den Söhnen der Enthusiasmus für die Ostjuden nun als Mittel einer radikalen Kritik am Leben der deutschen Juden. Verstärkt wurde die

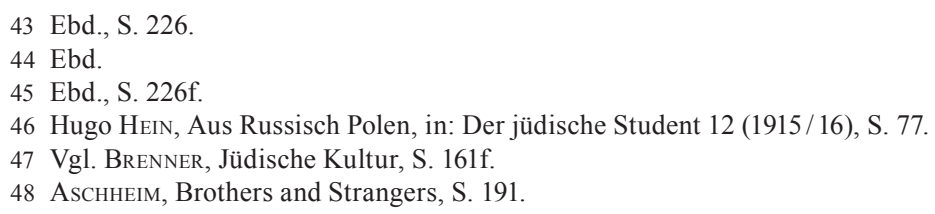


Anziehungskraft des ostjüdischen Lebens durch die Konfrontation mit dem Kriegsgeschehen, denn angesichts der erlebten Brutalität schien die vielfach verkündete Überlegenheit des »zivilisierten Europas«, des »fortschrittlichen Westens« gegenüber dem »östlichen Primitivismus« nicht länger glaubwürdig ${ }^{49}$.

Wie Gronemann empfanden viele westliche Beobachter die Religiosität der Ostjuden als Ausdruck einer tiefen Spiritualität. Mit Bewunderung wurde festgestellt, dass die Religion das gesamte Leben der Ostjuden prägte und diese sich ihres jüdischen Eigenlebens nicht schämten, wie es viele deutsche Juden taten. Vielmehr schienen die Juden im Osten genau das zu verkörpern, was der Zionismus für das gesamte Judentum anstrebte: sie traten nicht als »Staatsbürger jüdischen Glaubens« auf, sondern als - so Gronemann "sich ihres Volkstums bewusste und ihre nationale Eigenart frei betätigende Menschen, - eine Nation, die ihr Recht auf Leben wie jede andere betätigt $\aleph^{50}$. Der Bewunderung für die Lebenswelten der Juden im Osten lag somit insbesondere auch eine starke politische Motivation zugrunde ${ }^{51}$.

Die Begegnung mit einem im Wesentlichen religiös bestimmten, als nationalbewusst empfundenen Leben der Juden im Osten, die vor dem Hintergrund der Kriegswirklichkeit und dem schwierigen Verhältnis zwischen nichtjüdischen und jüdischen Deutschen umso beeindruckender war, führte bei Gronemann und anderen zu einem erneuten Nachdenken über die Situation der deutschen Juden und prägte die eigene Positionierung zwischen den Polen Assimilation und jüdisch-nationalbewusstem Leben. Obwohl bei vielen zionistisch gesinnten deutsch-jüdischen Soldaten bereits vor der Begegnung mit den Ostjuden eine ablehnende Einstellung zum Assimilationsprozess im deutschen Judentum dominierend gewesen war und oft schon eine Grundsympathie für das national bestimmte Leben der Ostjuden existiert hatte, erhielten sie erst jetzt wirklich Einblick in unterschiedliche Bereiche der ostjüdischen Lebenswirklichkeit. So konnten sie ihre bisherigen Vorstellungen überprüfen bzw. sich erstmals ein eigenes Bild von den jüdischen Lebenswelten im Osten machen, aus dem häufig zusätzliche Begründungen ihrer bisherigen Ansichten hervorgingen.

Zwischen der Reflexion über die eigene Verortung, der Wahrnehmung des Lebens der osteuropäischen Juden und dem jeweiligen Verständnis und der Bewertung der geschichtlichen Entwicklung bestand ein enger Zusammenhang. Mit der Ablehnung der Assimilation ursächlich verbunden war eine kritische Sicht auf den gesamten Emanzipations- und Verbürgerlichungspro-

49 Vgl. ebd., S. $191 f$.

50 Gronemann, Hawdoloh und Zapfenstreich, S. 168.

51 Vgl. dazu auch Sander Gilman, Die Wiederentdeckung der Ostjuden. Deutsche Juden im Osten, 1890-1918, in: Michael Brocke (Hg.), Beter und Rebellen. Aus 1000 Jahren Judentum in Polen, Frankfurt a.M. 1983, S. 11-32, hier S. 24. 
zess der deutschen Juden seit dem 19. Jahrhundert. Insbesondere die Konfessionalisierung wurde von Gronemann und anderen als eine Fehlentwicklung interpretiert, die zu einer Erstarrung des lebendigen Judentums und zu einer Verzerrung jüdischer Traditionen geführt habe ${ }^{52}$. Die Forderung nach einer Neubewertung der Assimilation und des Konfessionalisierungsprozesses war bereits in der Vorkriegszeit in manchen zionistischen Kreisen verbreitet gewesen. Allerdings erfuhr diese kritische Sicht auf die deutsch-jüdische Geschichte durch die Begegnung mit osteuropäischen Juden und ihren Lebenswelten im Kontext der Kriegserfahrungen eine deutliche Bekräftigung. Nun konnten die kritisierten Entwicklungen im deutschen Judentum mit konkreten Gegenbildern konfrontiert werden und die bislang häufig recht theoretischen Alternativentwürfe ließen sich durch selbst erfahrene, lebensnahe Beispiele veranschaulichen und stützen oder gegebenenfalls auch korrigieren.

Besonderen Einfluss hatte die Begegnung mit den osteuropäisch-jüdischen Lebenswelten auf die Auseinandersetzung mit den verbreiteten Sichtweisen von »Modernisierung« und »Rückständigkeit« im Judentum. Wie am Beispiel Gronemanns gezeigt, konnte die positive Wahrnehmung des traditionsgebundenen ostjüdischen Lebens eine Forderung nach Rückbesinnung auf die nun als »ursprünglich « verstandenen Lebensweisen implizieren. Dem Stereotyp vom unzivilisierten, kulturell rückständigen Ostjudentum setzt Gronemann einen anderen Kulturbegriff entgegen, demzufolge die besondere »Geistigkeit« der religiösen Ostjuden dem »Materialismus des Westens«, der nach seiner Auffassung das Leben der deutschen Juden prägt, weit überlegen zu sein scheint. Damit knüpft er an die bereits in der Vorkriegszeit entstandene kritische Sichtweise jener Modernisierungsprozesse an, die sich im deutschen Judentum im 19. Jahrhundert vollzogen hatten und die von vielen deutschen Juden als vorbildhaft für die Juden in Osteuropa betrachtet wurden. Diese Kritik verknüpft er nun mit einem Kulturbegriff, zu dessen Begründung er seine Erfahrungen mit dem religiös bestimmten, spirituellen jüdischen Leben im Osten heranzieht. Auf diese Weise erhalten die Neubewertung der bisher verbreitet positiv konnotierten »Überwindung der Traditionen « im deutschen Judentum und die damit verbundene Forderung nach »Rückbesinnung auf die Traditionen« zusätzliches Gewicht.

Die Schilderungen Sammy Gronemanns, aber auch Berichte anderer deutsch-jüdischer Soldaten über ihre Erfahrungen mit dem Judentum im Osten lassen erkennen, wie stark ihre Autoren doch in der deutschen Kultur verwurzelt waren, von der sie sich weder lösen konnten noch wirklich 
lösen wollten ${ }^{53}$. Trotz ihrer Begeisterung für die traditionelle Lebensweise der osteuropäischen Juden und trotz ihrer oft grundlegenden Kritik am deutschen Judentum blieb eine deutliche Distanz zu den jüdischen Lebenswelten im Osten bestehen. Zwar hatte sich vielfach der Bezug zum Judentum, das heißt vor allem zum religiös bestimmten jüdischen Leben, verstärkt und die bis dahin weitgehend fremden Traditionen wurden nun als die eigenen historischen Wurzeln erkannt. Ob mit einer derart veränderten Wahrnehmungsweise aber auch ein neues Verständnis der Lebenswelten der osteuropäischen Juden und der geschichtlichen Entwicklung dieser Judenheiten einherging oder ob die positiven Berichte über das Leben der Juden im Osten nicht vielmehr von einem - politisch motivierten - idealisierten, undifferenzierten Bild vom Ostjudentum geprägt waren, dem eine grundlegende Offenheit gegenüber dem Anderen und seiner Lebensweise fehlte, bleibt im Einzelnen zu prüfen.

Für Sammy Gronemann und seine hier untersuchten Schilderungen lässt sich feststellen, dass seine vor dem Ersten Weltkrieg im Kontext seiner zionistischen Überzeugungen ausgebildete kritische Sicht auf die Geschichte der deutschen Juden seine Wahrnehmung der jüdischen Lebenswelten im Osten deutlich beeinflusst und geleitet hat. Obwohl Gronemann während seiner Stationierung im Osten jüdische Gemeinden an verschiedenen Orten kennenlernte und Unterschiede in deren Lebensweise auch durchaus wahrnahm, führten diese Erfahrungen insgesamt aber kaum zu einer differenzierteren Sicht auf die Lebenswelten und die Geschichte der verschiedenen Judenheiten in Osteuropa. Vielmehr behielt das verallgemeinernde Gegensatzpaar von »Ost-« und »Westjude« auch nach dem Ersten Weltkrieg weitgehend seine Gültigkeit. Das Buch Hawdoloh und Zapfenstreich zeigt jene »Spaltung der Identität« in zwei polare Gegensätze, die Sander Gilman als Folge der sich seit der Jahrhundertwende vollziehenden tiefgreifenden Wandlung des Ostjudenbildes bei vielen deutschen Juden feststellt ${ }^{54}$. Gronemanns Wahrnehmung der ostjüdischen Lebenswelten, wie sie aus seinen Schilderungen deutlich wird, ist geprägt von den Stereotypen des »guten« Ostjuden und des »schlechten«, assimilierten und akkulturierten Westjuden. Somit lässt seine Darstellung des von der Religiosität durchdrungenen Lebens der

53 Aschheim bezeichnete diese Verwurzelung in der deutschen Kultur als das zentrale Problem des Ostjudenkults: »The Paradox of the German Zionist revolt against German culture was that the revolt itself was couched deeply in German terms. In many ways the cult reflected this. The difficulties of establishing an East-West-Jewish community along new Jewish cultural lines remained unresolved. The glorification of Eastern Jews was simultaneously a challenge to and a demonstration of the tenacity of German cultural assumptions among even the most radically committed German Jews«. Aschнeim, Brothers and Strangers, S. 190.

54 Vgl. Sander Gilman, Jewish Self-Hatred. Anti-Semitism and the Hidden Language of the Jews, Baltimore 1986, S. $270 \mathrm{f}$. 
Ostjuden eine offene Beschäftigung und kritische Auseinandersetzung mit den ostjüdischen Lebenswirklichkeiten und ihren historischen Entwicklungen weitgehend vermissen.

Dass die Begegnung mit den ostjüdischen Lebenswelten auch unter zionistisch gesinnten deutschen Juden zu anderen Betrachtungsweisen führen konnte, die deutliche Kritik an der Glorifizierung der Juden im Osten und an der in diesem Zusammenhang vielfach geforderten »rückwärtsgewandten Assimilation « deutscher Juden übten ${ }^{55}$, zeigt beispielsweise ein Kommentar, mit dem sich Gustav Witkowsky in der zionistischen Zeitschrift Der jüdische Student in die Diskussion um die Frage der jüdischen Identität einmischte:

Es ist mir natürlich bekannt, daß es im Osten ein jüdisches Gemeinschaftsleben gibt, das uns verschlossen ist. Ich habe während der Brussilow-Offensive Monate lang in Galizien geweilt [...]. Tief haben sich in mein Bewußtsein die Tage eingeprägt, die ich in Pohheice, einem chassidischen Städtchen, verleben durfte. Erschüttert stand ich vor einem Stück jüdischer Geschichte, noch lebend und doch mit allen Merkmalen des Niedergangs behaftet. [...] Ich bin mir [...] bewußt, daß einmal diese Art von natürlicher Jüdischkeit gebunden ist an eine wirtschaftliche und politische Rückständigkeit, die zu erhalten weder in der Richtung unserer Wünsche noch in unsern Kräften liegt, daß andrerseits der Wunsch des Westjuden, jenem gleich zu werden, romantischen Gepräges ist ${ }^{56}$.

Auch Gronemann wusste um die sozialpolitischen Ursachen der Armut sowie um die historisch bedingte Rückständigkeit in den jüdischen Siedlungsgebieten im Osten, insbesondere, da er viele Kontakte zu aus Osteuropa emigrierten Juden pflegte. Dennoch verzichtet er in seinen Schilderungen in Hawdoloh und Zapfenstreich weitgehend darauf, die geschichtliche Entwicklung der ostjüdischen Lebenswelten einzubeziehen und den historischen Zusammenhang zwischen Armut und Rückständigkeit einerseits und der Bewahrung der jüdischen Traditionen andererseits herauszustellen. Vielmehr vermittelt er ein weitgehend idealisiertes Bild vom Ostjudentum, das als Vorbild dem westeuropäischen Judentum gegenübergegengestellt wird und damit seine bereits vor dem Ersten Weltkrieg entwickelten Beurteilungen der historischen Entwicklung der deutschen Juden bestätigt und bekräftigt. Die Einschätzung, Hawdoloh und Zapfenstreich stelle hinsichtlich des Ostjudenbildes und der veränderten Selbstwahrnehmung einen der Meilensteine der Neuorientierung unter deutschen Juden dar ${ }^{57}$, lässt sich somit

$55 \mathrm{Zu}$ der Diskussion um die »rückwärtsgewandte Assimilation« vgl. auch Аsсннеiм, Brothers and Strangers, S. 207.

56 Gustav Witkowsky, Hie Zwirn!, in: Der Jüdische Student 15 (1917), S. 429-440, hier S. 438f.

57 Vgl. Mittelmann, Sammy Gronemann, S. 66f. 
nicht auf den Aspekt des in den Aufzeichnungen vermittelten Geschichtsverständnisses ausweiten. Diesbezüglich muss vielmehr von einem Beharren auf jener Geschichtssicht gesprochen werden, die Gronemann vor der Begegnung mit den jüdischen Lebenswelten im Osten ausprägte, die insbesondere auch im Kontext seiner zionistischen Arbeit zu sehen ist, die aber trotz ihrer fundamentalen Kritik am deutschen Judentum doch stark in der deutschen Kultur verwurzelt war. 



\section{Die Christianisierung fremder Völker - ein Zeichen für die nahende Endzeit?}

In der Literatur zu der erweckungsgeprägten Missionsbewegung des frühen 19. Jahrhunderts wird die Überzeugung, in der Nähe der Endzeit zu leben, als eines der wichtigsten Motive für die Mission genannt ${ }^{1}$. Dabei gilt als erste Frage häufig nicht die in der Überschrift gestellte, ob die Christianisierung der Völker das Näherkommen der Endzeit beweise, sondern es wird vielmehr umgekehrt argumentiert: Die Gewissheit, dass das Weltende näher rückte, motivierte die Menschen zum Engagement in der und für die Mission. Somit könnte auch formuliert werden: »Die nahende Endzeit - eine Motivation für die Christianisierung der Völker? «²

Folgende Fragen ergeben sich damit für diesen Beitrag: In welcher Beziehung standen die Zukunftserwartung der Missionsbewegung und die Christianisierung fremder Völker? Und welche Bedeutung hatte die tatsächliche Begegnung mit den fremden Menschen für das Geschichtsbewusstsein der Missionare? Wenig überraschend schließen die titelgebende und die entgegengesetzte Blickrichtung einander nicht aus, sondern bedingten sich vielmehr gegenseitig: Die Endzeiterwartungen der Missionare waren Motivation für die großangelegten Missionsanstrengungen, und gleichzeitig galten

1 Vgl. z.B. Ulrich GÄBLER, Erweckung im europäischen und amerikanischen Protestantismus, in: PuN 15 (1989), S. 24-39; Stephan Holthaus, Prämillenniarismus in Deutschland. Historische Anmerkungen zur Eschatologie der Erweckten im 19. und 20. Jahrhundert, in: PuN 20 (1994), S. 191-211. Die führenden Mitglieder der Erweckungsbewegung hatten zumeist auch in der Missionsbewegung tragende Rollen inne. Zum Geschichtsbewusstsein der Erweckungsbewegung dieser Epoche vgl. Jan Carsten SchnurR, Geschichtsdeutung im Zeichen des Reiches Gottes. Historiographie- und begriffsgeschichtliche Anmerkungen zur Geschichtsliteratur der protestantischen Erweckungsbewegung im Vormärz, in: HZ 291 (2010), S. 353-383 sowie seine Dissertation: Ders., Weltreiche und Wahrheitszeugen. Geschichtsbilder der protestantischen Erweckungsbewegung in Deutschland 1815-1848, Göttingen 2011.

2 Vgl. Gerhard SAuter, Eschatologie. Dogmengeschichtlich, in: RGG 4, Bd. 2, Tübingen 1999, Sp. 1561-1567: »Zu den wirkungsreichsten Seitenbewegungen der Eschatologie im 19. und beginnenden 20. Jh. gehört der Aufbruch zur Mission zugunsten weltweiter Ausbreitung des Christentums als Zeichen der Endzeit [...] (Sp. 1565). Sauter analysiert unter systematischtheologischem Blickpunkt Endzeitvorstellungen und Geschichtsverständnis: Gerhard SAUTER, Endzeit- und Endvorstellungen und geschichtliches Denken, in: Manfred JAKUBOwSKI-TiesseN / Hartmut Lehmann/Johannes Schilling/Reinhart StaAts (Hg.), Jahrhundertwenden. Endzeitund Zukunftsvorstellungen vom 15. bis zum 20. Jahrhundert, Göttingen 1999, S. 377-402. 
Missionserfolge als Beweise für die nahende Endzeit. Wie andere Erfahrungen in das Geschichtsbewusstsein der Mission integriert wurden, wird die Analyse zeigen. Dabei deutet sich schon an: Das Geschichtsbild der konservativen Missionare war recht geschlossen. Daher ist ein vollständiger Wandel des Geschichtsbewusstseins weniger zu erwarten als vielmehr tatsächlich die Einbettung der in der konkreten Begegnung mit Fremden gemachten Erfahrungen in das Geschichtsbewusstsein. Inwieweit auch eine solche Integration einen Wandel darstellen kann, soll am Schluss dieses Beitrags erörtert werden.

Die Beziehung von Geschichtsbewusstsein und Begegnung mit Fremden wird exemplarisch anhand der Basler Mission untersucht werden, einer der größten und einflussreichsten Missionsgesellschaften innerhalb der deutschsprachigen von der Erweckung geprägten Missionsbewegung. Die Basler Mission war in der Schweiz angesiedelt, aber mehr als die Hälfte ihrer Mitglieder stammte aus Württemberg, hinzu kamen Missionare aus anderen deutschen Ländern. Auch die meisten Missionsinspektoren, die als Direktoren das Missionsseminar wie die Gesellschaft - gemeinsam mit der [sic] sogenannten Komitee - im 19. Jahrhundert leiteten, waren in Württemberg aufgewachsen. Das Einzugsgebiet der Basler Mission erstreckte sich über alle süddeutschen Länder und angrenzenden Gebiete (neben Württemberg vor allem Baden und das Elsass) sowie die Schweiz. Auch aus Norddeutschland kamen einige Missionskandidaten ${ }^{3}$. Die Basler Mission hatte mithin innerhalb Deutschlands eine große Ausstrahlung. Durch ihre intensive Zusammenarbeit mit anderen europäischen Missionsgesellschaften, insbesondere der englischen Church Missionary Society (CMS), prägte sie auch das europäische Missionsverständnis ${ }^{4}$. Der Austausch zwischen Deutschland, der Schweiz und England bezüglich des Geschichtsbewusstseins ist noch nicht untersucht. Mit Sicherheit kann bisher nur davon ausgegangen werden, dass sich die Akzentsetzungen zwischen den Ländern unterschieden ${ }^{5}$.

3 Vgl. z.B. Ferdinand Kittel (1832-1903) aus Ostfriesland, der einige Jahrzehnte für die Basler Mission in Indien arbeitete und später für seine sprachwissenschaftlichen Arbeiten ausgezeichnet wurde. Archiv, mission 21 / Basler Mission, Basel, BV 377 [Personalakte].

4 Zur Kooperation vgl. die Darstellung bei Wilhelm Schlatter, Die Heimatgeschichte der Basler Mission, Basel 1916. Wesentlich weniger ausführlich geht der Historiograph der CMS auf die gemeinsame Geschichte ein: Eugene Sтоск, The History of the Church Missionary Society. Its Environment, its Men and its Work, London 1899, 3 Bd., Supplementary Volume IV, London 1916. Die Arbeit der Basler Mission in den Missionsgebieten stellt Schlatter in zwei eigenständigen Bänden dar: Wilhelm Schlatter, Die Geschichte der Basler Mission in Indien und China, Basel 1916; ders., Die Geschichte der Basler Mission in Afrika, Basel 1916.

5 Deutlich wird dies auch bei einem Vergleich der Bewerbungsunterlagen und Veröffentlichungen der beiden Missionsgesellschaften, vgl. z.B. die Personalakten der Basler Mission mit denen der anderen großen englischen Missionsgesellschaft, der London Missionary Society (Answers to printed questions 1835-1885, Home. Candidates' Papers, London, SOAS CWM/LMS, 1796-1899) oder die großen Zeitschriften (Magazin für die neueste Geschichte 
Zunächst soll im Folgenden das Geschichtsverständnis der Missionsbewegung kurz dargestellt werden. Ein besonderer Akzent liegt dabei, der Geschichtsdeutung der Missionsbewegung entsprechend, auf ihren Zukunftsvorstellungen. In einem zweiten, größeren Kapitel wird dann die Beziehung zwischen dem Geschichtsbewusstsein der Missionare der Basler Mission und ihrer Begegnung mit Fremden sowie den Christianisierungserfolgen oder -misserfolgen an Fremden anhand der Berichte im Basler Evangelischen Heidenboten zwischen dessen erstem Erscheinen im Jahr 1828 und 1840 analysiert ${ }^{6}$. Abschließend folgen einige Thesen zur Beziehung von Endzeithoffnung und Missionserfolgen.

Als »Missionserfolg« wird hier im Sinne der Missionsgesellschaften die Christianisierung oder zumindest Öffnung der nicht-christlichen, oder genauer nicht-evangelischen, Völker für die Lehre der Missionsgesellschaften bezeichnet. »Misserfolg« bedeutet, dass die Missionare mit ihrer Botschaft keinen Anklang fanden. Das Ziel der Mission war die Bekehrung der Menschen zu einem wahren, innerlichen Christentum, wie sie selbst es lebten bzw. zu leben wünschten. Je nach Missionsgebiet und -kontext ließen jedoch solche Bekehrungen lange auf sich warten oder traten nur sehr vereinzelt auf. In solchen Fällen konnte die Missionsgesellschaft auch schon bei der Bereitschaft der Menschen, den Missionaren überhaupt zuzuhören, von Erfolg sprechen. Die folgenden Ausführungen bedienen sich dieser Terminologie der Missionsgemeinschaften, um das Welt- und Geschichtsverständnis der Missionare zu verstehen. Die Missionare selbst klassifizierten ihre Arbeit immer wieder nach »Erfolgen« und »Misserfolgen« bzw. »Erfolglosigkeit «?

Hauptquelle des Evangelischen Heidenboten waren die Berichte der Missionare von den Stationen bzw. von ihren Reisen. Daneben wurden Auszüge aus den Jahresberichten der Basler Mission abgedruckt und kleinere Texte aus anderen Quellen. Der Heidenbote gibt also Auskunft über die Ansichten der Missionare wie der Missionsgesellschaft. Inwieweit die Redaktion in die Edition der Briefe, Berichte und Tagebücher der Missionare eingriff, sie gegebenenfalls sogar zensierte, ist noch nicht umfassend untersucht ${ }^{8}$. Die Veröffentlichungen können bei aller gebotenen Vorsicht auch zur Analyse der Ansichten der Missionare genutzt werden.

der evangelischen Missions- und Bibelgesellschaften«, Basel 1816ff. und Church Missionary Record, London 1830ff.). - Die Personalakten der CMS aus den ersten Jahrzehnten des 19. Jahrhunderts sind zerstört.

6 Der evangelische Heidenbote. Monatsblatt der Evangelischen Missionsgesellschaft in Basel, Basel 1828ff.

7 Um der besseren Lesbarkeit willen wird von nun an auf die Anführungszeichen verzichtet.

8 Willy RüEgG, Die Chinesische Revolution in der Berichterstattung der Basler Mission, Zürich 1988, S. 174-241 analysiert die Berichterstattung zu China Anfang des 20. Jahrhunderts. Hier werden auch Unterschiede zwischen den Veröffentlichungen und den Originalbriefen angedeutet. Zur Organisationsstruktur, die wiederum Auswirkungen auf die Veröffentlichungspra- 


\section{Die Endzeiterwartung der Missionsbewegung}

In einem war sich die gesamte durch Pietismus und Erweckung geprägte Missionsbewegung einig: Die Endzeit schien nahe herbei gekommen'. Diese Überzeugung war im 17. Jahrhundert entstanden und hielt sich mit leichten Modifikationen bis in das 20. Jahrhundert hinein ${ }^{10}$. So bereitete sich die englische Church Missionary Society noch auf ihr hundertjähriges Jubiläum 1899 mit einem Three-Years-Enterprise vor, in dem auf das Kommen Gottes ebenso wie auf die weitere Ausbreitung des Christentums hingearbeitet werden sollte. In den vorbereitenden Verlautbarungen von 1898 hieß es:

xis hat, vgl. Jon Miller, Missionary zeal and institutional control. Organizational contradictions in the Basel Mission on the Gold Coast, 1828-1917, Grand Rapids/Cambridge 2003. Ein Wortvergleich ausgewählter Briefe aus dem 19. und 20. Jahrhundert zeigt, dass die Briefe vor der Veröffentlichung durchaus überarbeitet wurde. Zwar wurde bei den untersuchten Quellen nichts gedruckt, das die Missionare nicht auch so gesagt haben könnten bzw. an anderer Stelle so sagten, aus den veröffentlichten Briefen kann jedoch nicht zwingend geschlossen werden, dass sie es auch tatsächlich an dieser Stelle so geschrieben hatten. Die Veröffentlichungen sind also eine gute Quelle für die grundsätzlichen Ansichten der Missionare, nicht aber unbedingt wörtlich zu nehmen.

9 Vgl. Anm. 1. Mitarbeiter und Unterstützer der Missionen waren eben jene Erweckten, und aus der Personalunion folgt selbstverständlich die Geschichtsbewusstseins-Union. Eine detaillierte Untersuchung zum Geschichtsverständnis der Missionsbewegung gibt es noch nicht. Einen Vergleich religiöser und politischer Endzeitüberzeugungen und der daraus folgenden Handlungen unternimmt Lucian HöLscher, Weltgericht oder Revolution. Protestantische und sozialistische Zukunftsvorstellungen im deutschen Kaiserreich, Stuttgart 1989.

10 Selbstverständlich gab es auch vor dem 17. Jahrhundert apokalyptische Überzeugungen. Gut untersucht sind sie z.B. für das Luthertum der Reformationszeit. Vgl. z.B. Volker Leppin, Antichrist und Jüngster Tag. Das Profil apokalyptischer Flugschriftenpublizistik im deutschen Luthertum 1548-1618, Gütersloh 1999. Während jedoch von den Ansichten des 17. Jahrhunderts bis in die Gegenwart hinein in dieser Beziehung eine direkte Genealogie aufgestellt werden kann, ist die Beziehung zu den Auffassungen der Reformationszeit indirekter. Dies stärkt Hartmut Lehmanns These der Einheit des Pietismus seit seinen Anfängen. Vgl. dazu Hartmut Lehmann, Pietismus und weltliche Ordnung in Württemberg vom 17. bis. 20. Jahrhundert, Stuttgart u.a. 1969. Auf die gesamte Diskussion um das Verhältnis von Pietismus und Erweckungsbewegung kann hier nicht eingegangen werden, vgl. aber: Martin BRECHT, Pietismus und Erweckungsbewegung, in: PuN 30 (2004), S. 30-47. Die Endzeiterwartungen bezogen sich bis in die 1820er Jahre hinein zu einem großen Teil auf Albrecht Bengels Berechnungen. Danach wurde die genaue Berechnung des Weltendes in diesen Kreisen zumeist aufgegeben, vgl. Martin H. Jung, 1836 - Wiederkunft Christi oder Beginn des Millenniums? Zur Eschatologie Johann Albrecht Bengels und seiner Schüler, in: ders. (Hg.), Nachfolger Visionärinnen Kirchenkritiker. Theologie- und frömmigkeitsgeschichtliche Studien zum Pietismus, Leipzig 2003, S. 93-116; Martin BRECht, Chiliasmus in Württemberg im 17. Jahrhundert, in: PuN 14 (1988), S. 25-49 (dort wird für Christoph Besold die Bedeutung der Judenbekehrung herausgearbeitet); Friedhelm Grотн, Chiliasmus und Apokatastasishoffnung in der Reich-Gottes-Verkündigung der beiden Blumhardts, in: PuN 9 (1983), S. 56-116. Die Endzeitvorstellungen der württembergischen Erweckungsbewegung anhand von Liedern und Dichtungen Johann Michael Hahns stellt dar: Hartmut LehmanN, Endzeiterwartung und Erlösungshoffnung im württembergischen Pietismus, in: Haus der Geschichte Baden-Württemberg in Verb. mit der Landeshauptstadt Stuttgart (Hg.), Fortschrittsglaube und Zukunftspessimismus, Tübingen 2000, S. 25-45. 
[...] the watchful servants of God read in the signs of the times, not only the brighter hope of the coming Kingdom, but also a clearer call to make ready the way of the King, by preaching His Gospel to the uttermost parts of the earth. With this end in view, nothing can alter the duty of Christian men. [...] their chief business is to witness, to work, and to wait for Him and His return.

Unless that Advent intervene, the Society before its next anniversary will have completed the first hundred years of its existence ${ }^{11}$.

Die Naherwartung war so groß, dass man die Wiederkunft Christi jederzeit für möglich und wahrscheinlich hielt. Dass seit mehr als hundert Jahren, wenngleich in unterschiedlicher Intensität, mit dem unmittelbaren Weltende bzw. dem Beginn der Heilszeit gerechnet wurde und dies noch immer nicht eingetreten war, änderte nichts an den konkreten Zukunftserwartungen. Gott konnte jederzeit eingreifen und der Welt in ihrer jetzigen Form ein Ende bereiten.

Mit der plötzlichen Wiederkunft Christi rechneten Teile der Missionsbewegung erwiesenermaßen. Sie konnten sich dabei auf bestimmte Bibeltexte wie auf das Gleichnis von den zehn Jungfrauen beziehen, das mit der oft zitierten Aufforderung endet »Darum wachet! Denn ihr wisst weder Tag noch Stunde $«^{12}$. Parallel dazu war die durch eine spezifische Bibelexegese erhärtete Überzeugung weit verbreitet, dass vor dem Beginn der endgültigen Heilszeit noch alle Welt christianisiert oder zumindest mit dem Christentum in Berührung gebracht werden musste ${ }^{13}$. Die unmittelbare Naherwartung wurde durch die Erwartung der Wiederkunft Christi nach der Erfüllung des Missionsauftrags durch die Menschen ergänzt. Eigentlich sollten diese beiden Ansätze einander ausschließen, doch in der Missionsbewegung verstärkten sie sich eher. Die Auffassung, dass die Gläubigen durch die Mission das Kommen der Endzeit beschleunigen konnten, trug wesentlich zum energischen Ausbau des Missionswesens am Anfang des 19. Jahrhunderts bei. Dazu war es zunächst einmal unerheblich, ob man die Wiederkunft Christi vor oder nach dem Tausendjährigen Reich erwartete (Prä- bzw. Postmillenniarismus), ob es, wie bei Johann Albrecht Bengel, gar zwei Tausendjährige Reiche geben sollte ${ }^{14}$, oder ob - in der Missionsbewegung eine eher seltene

11 CMS Archives, Birmingham, G/A. AJ 4. Anniversary meetings, 1898.

12 Mt. 25,13.

13 Ein Bibelkommentar, der in den Gesprächen mit den Studenten am Missionsseminar der Rheinischen Missionsgesellschaft entstanden ist, wurde von den Brüdern Richter veröffentlicht: Heinrich RichteR, Richter's Bibelwerk. Erklärte Haus-Bibel oder Auslegung der ganzen heiligen Schrift alten und neuen Testaments, unter Mitarb. v. Wilhelm Richter, 6 Bd., Barmen/Schwelm 1834-1840.

14 Vgl. Jung, 1836 - Wiederkunft Christi oder Beginn des Millenniums? 
Auffassung - Weltende und jüngstes Gericht einträfen, ohne dass vorher tausend Jahre lang Christus als Friedensherrscher oder der Teufel als Schreckensherrscher regiert hätten.

In jedem Fall schienen alle Zeichen der Zeit auf eine nahe Veränderung der Welt hinzuweisen. Kriege und Revolutionen wurden in Anlehnung an die Offenbarung Johannis als Zeichen der nahen Endzeit gedeutet. In dem letzten Buch der Bibel fand sich auch eine der wichtigsten - und wenigen - biblischen Belegstellen für das Tausendjährige Reich ${ }^{15}$. Vom Apostel Paulus lernte die Missionsbewegung, dass die Heiden missioniert werden müssten, damit auch Israel Christus als Messias anerkennen könne ${ }^{16}$, aus den Evangelien zog sie die Überzeugung, dass die Zeit reif sei. Sie stützte sich nicht nur auf die Endzeitreden Jesu, sondern auch auf die Gleichnisse vom Ackerbau und Weizen und insbesondere auf Joh. 4: „Siehe, ich sage euch: Hebt eure Augen auf und seht auf die Felder, denn sie sind reif zur Ernte $\ll{ }^{17}$. Dem entnahmen die Missionare die Beauftragung und Ermutigung, die Welt zu missionieren. Als Ziel schwebte vielen die Vorstellung von der Völkerwallfahrt zum Zion vor, der endgültigen Huldigung Gottes durch alle Menschen ${ }^{18}$.

Die Württemberger Pietisten, die die Basler Mission dominierten, vertraten fast ausschließlich millenniaristische Auffassungen ${ }^{19}$. In der Nachfolge Bengels wurde der Beginn des Millenniums für das Jahr 1836 erwartet, und auch nachdem dieses ereignislos verstrichen war, hielt man an der unmittel-

15 Vgl. Offb. 20,1-6.

16 Vgl. Röm. 11,25-27. Zur Judenmission gab es, vor allem vor 1836, auch andere Auffassungen. Dort ging man davon aus, dass nach erfolgreicher Bekehrung der Juden sofort das Reich Gottes anbrechen werde. In manchen Kreisen wurde eine Herrschaft der Juden erwartet; aus einigen Landesteilen gab es Auswanderungsbewegungen nach Israel zum Berg Zion, bzw. - weil das näher und leichter zu erreichen war - nach Russland. Vgl. Michael KanNEnBerg, Verschleierte Uhrtafeln. Endzeiterwartungen im württembergischen Pietismus zwischen 1818 und 1848, Göttingen 2007, S. 25-32, 81-83, 200 u. 326; Hartmut Lehmann, Pietistic Millenarianism in Late Eighteenth-Century Germany, in: ders., Religion und Religiosität in der Neuzeit. Historische Beiträge, hg. v. Manfred JAKUBOwSKi-TiesSEN/Otto UlBRIcht, Göttingen 1996, S. 158166; Andreas Gestrich, »Am letzten Tag schon fertig sein«. Die Endzeiterwartungen der schwäbischen Pietisten, in: Ulrich Herrmann/Karin Priem (Hg.), Konfession als Lebenskonflikt. Studien zum württembergischen Pietismus im 19. Jahrhundert und die Familientragödie des Johannes Benedikt Stanger, Weinheim/München 2001, S. 93-126. In der Richter-Bibel lässt sich die verbreitete Ansicht finden, die Juden würden die letzten Heiden, insbesondere Muslime, bekehren, z.B. bei der Auslegung zu Ps. 102 (Bd. III, S. 469) oder zu Jes. (Bd. IV, S. 286), aber auch an vielen anderen Stellen. Vgl. aber auch ebd., Bd. IV, S. 133: »Je eifriger wir sorgen, daß die Fülle der Heiden eingeht, desto mehr zugleich auch dafür, daß dabei ganz Israel selig werde« (RichteR, Haus-Bibel).

17 Joh. 4,35.

18 Vgl. Mi. 4,1-5; Jes. 2,2-4; Jes. 60. 66,20 u.a.

19 Vgl. dazu und zum Folgenden: KannenBerg, Uhrtafeln. 
baren Naherwartung fest ${ }^{20}$. Die ganze Weltgeschichte schien darauf hinzudeuten, mit ihren Kriegen und Revolutionen, ihrer Umkehrung und Infragestellung der Ordnung ${ }^{21}$. Die Welt schien außer Rand und Band geraten. Gleichzeitig traten auch in der Kirche zunehmend Trennungen auf. Nicht nur das Papsttum, das schon traditionell als Antichrist gedeutet wurde, galt den Erweckten als Widerpart des Christentums. Auch Aufklärung und Rationalismus wurden als Zeichen für das Einbrechen des Antichrists in die Kirche verstanden. Die Reaktion der Pietisten war nicht nur eine bewusste Abwendung von der Welt wie von der offiziellen Kirche ${ }^{22}$ - sofern in ihren Gemeinden keine erweckten Pfarrer wirkten -, sondern auch der Aufruf zur persönlichen Entscheidung.

Entschieden für Christus und damit auf dem Weg zum Heil und zur endgültigen Rettung konnten nur diejenigen sein, die in pietistischer Frömmigkeit lebten ${ }^{23}$. Dies galt einerseits in Bezug auf die Innerlichkeit, die ständige Auseinandersetzung mit dem eigenen, inneren Erleben, den Anforderungen Gottes und den Hilfen, die er dem Menschen zum Bestehen von Herausforderungen gab, bzw. der Vergebung, die er trotz aller Sünden gewährte. Andererseits sahen sich die Gläubigen auch zur äußerlichen Aktivität aufgefordert, zur Gewinnung neuer Seelen für Christus, im eigenen Land, aber auch weltweit. Die Mission aller Menschen war Anforderung an jeden Bekehrten, ob er nun selbst zum Missionar wurde oder nur für die Mission spendete und betete. Missionsstunden und -feste dienten gleichzeitig als Rekrutierungsort neuer Missionare und der Festigung der eigenen pietistischen Identität.

In Besuchen, Korrespondenzen und sogenannten »Stunden«, wöchentlichen Zusammenkünften, bestätigten die Erweckten einander gegenseitig ${ }^{24}$. Ihre persönliche Frömmigkeit wurde dabei ebenso thematisiert wie theologische Gegenstände und eben auch ihre Zukunftserwartungen. Philipp Matthäus Hahn, der Erfinder der Weltuhren, die nicht nur die gegenwärtige Zeit, sondern auch den Gang der Weltgeschichte - teils mit zwei Millennien

20 In der Regel wurden die genauen Berechnungen aufgegeben. Auffällig ist, dass in der ab 1834 herausgegebenen »Richter-Bibel« Bengels Berechnung noch aufgenommen ist und diese auch in den nach 1836 erschienenen Bänden nicht korrigiert wird.

21 Dies wurde auch in der Missionspublizistik immer wieder hervorgehoben, vgl. z.B. Evangelischer Heidenbote 1831, S. 3; 1832, S. 3; 1833, S. 3 u. 6. Vgl. auch Hölscher, Weltgericht, S. 46.

$22 \mathrm{Zu}$ den Auseinandersetzungen um den Verbleib der Württemberger Erweckten in der Landeskirche vgl. im Blick auf deren politische Bedeutung Lenmann, Weltliche Ordnung, S. 135-187; Sowie KANNENBERG, Uhrtafeln.

23 Dies wird in der Missionspublizistik immer wieder betont. Vgl. zur pietistischen Frömmigkeit in Württemberg Andreas Gestrich, Pietismus und ländliche Frömmigkeit in Württemberg im 18. und frühen 19. Jahrhundert, in: Norbert HAAG/Sabine HoltZ/Wolfgang ZIMmERMANN/Dieter R. BAuER (Hg.), Ländliche Frömmigkeit. Konfessionskulturen und Lebenswelten 1500-1850, Stuttgart 2002, S. 343-357.

24 Vgl. Ulrike Gleixner, Pietismus und Bürgertum. Eine historische Anthropologie der Frömmigkeit. Württemberg 17.-19. Jahrhundert, Göttingen 2005, bes. S. 63-118. 
- anzeigten, war besonders erfolgreich in der Gründung solcher »Stunden $\ll^{25}$. Für diese Menschen war klar: Die Christianisierung der Völker ist angesichts der nahenden Endzeit gefordert, und die erfolgreiche Mission ist ein Zeichen für die Nähe des Weltendes.

\section{Christianisierung und Endzeiterwartung im Evangelischen Heidenboten}

Im Folgenden soll untersucht werden, wie Missionierung und Christianisierung im Basler Evangelischen Heidenboten dargestellt wurden. Die Berichte aus der Mission mussten sich mit einem für das Welt- und Geschichtsverständnis der Missionare fundamentalen Problem auseinandersetzen: Die fremden Völker ließen sich nicht ganz so leicht und willig bekehren, wie die Missionare sich das erhofft hatten. Nun gründete die Hoffnung der Missionare auf die biblischen Verheißungen und nicht auf weltliche Gegebenheiten, und da man an den »Zeichen der Zeit« die Nähe der Endzeit zu erkennen meinte, glaubte man auch auf Gottes Hilfe bei der Bekehrung der Völker rechnen zu können. Eine erste Frage lautet also: In welcher Weise wurde die Gegenwart als nahe der Endzeit dargestellt? In einem zweiten Schritt wird der Umgang mit Misserfolgen in der Missionierung fremder Völker untersucht. Zuletzt werden die für die Missionare erfreulichsten Berichte von erfolgreicher Missionierung, von echter Christianisierung fremder Völker analysiert, und es wird gezeigt, wie diese zur Untermauerung der These von der nahen Endzeit genutzt wurden.

\subsection{Die Gegenwart als nahe der Endzeit}

Dass die Ereignisse in Europa, aber auch in anderen Teilen der Welt, der Missionsbewegung als Zeichen für die nahende Endzeit galten, ist schon gesagt worden. Es soll hier nicht weiter ausgeführt werden, da die Interpretation der europäischen Entwicklung nicht in unmittelbarem Zusammenhang mit den Berichten von fremden Völkern steht. Auch Parallelen in der Geschichte und Beweise aus der Geschichte, etwa der Missionsgeschichte Europas, können hier lediglich am Rande erwähnt werden. Worauf es in unserem Zusammenhang ankommt, sind die Beweise aus den Missionsgebieten und die Schlüsse, die die Missionare aus ihrer Arbeit zogen. Woran konnte man auch in der Mission erkennen, dass die Endzeit nahe herangekommen war? 
Besonders überzeugend wirkten Berichte der Missionare über das Geschichtsbewusstsein fremder Völker, das mit ihrer eigenen Geschichtsauffassung übereinstimmte. Wiederholt berichteten Missionare, dass auch fremde Völker, selbst »Heiden«, das baldige Ende der Welt erwarteten. Der Glaube, dass die Welt in ihrer gegenwärtigen Form in Kürze nicht mehr bestehen werde, wurde also nicht nur von wenigen europäischen Pietisten vertreten, einer frommen Minderheit, sondern von Völkern auf der ganzen Welt. Man musste nicht Christ sein, nicht einmal von Gott gehört haben, um zu sehen, dass die Welt, wie man sie kannte, bald nicht mehr sein würde. Daraus erfuhren die Überzeugungen der Missionare eine mächtige Bestätigung.

1828 berichteten Missionare vom Kaspischen Meer, dass Juden, Russen (also orthodoxe Christen) und Muslime gleichermaßen die baldige Wiederkunft Christi erwarteten ${ }^{26}$. Die Muslime begründeten dies nach Auskunft der Missionare damit, dass laut ihrer Geschichtsauffassung am Ende der Zeiten viele Muslime wieder vom Glauben abfallen würden. Die Christianisierung der Muslime galt damit auch diesen als Zeichen für die nahende Endzeit. Für die Missionare bewies also die Christianisierung der Muslime die Nähe der Endzeit, weil damit die Zahl der Christen auf der Welt immer größer würde; für die Muslime wiederum bewies derselbe Vorgang die Nähe der Endzeit, weil damit die Zahl der Muslime kleiner würde und die echten Gläubigen von den unechten geschieden würden. Interessanterweise wird hier eine Geschichtsauffassung referiert, die jener der Missionare völlig entspricht: Am Ende der Zeit wird sich eine Scheidung zwischen wahren Gläubigen und Ungläubigen vollziehen, und dazu gehören auch die nicht richtig Gläubigen, die sich bisher innerhalb der eigenen Religion gehalten haben ${ }^{27}$. Sechs Jahre später bestätigte Missionar Felician Zaremba ${ }^{28}$ in einem Vortrag beim Missionsfest in Basel diese Beobachtung: Die Muslime am Mittelmeer, Persischen Golf und Kaspischen Meer erwarteten den Anbruch der Endzeit aufgrund der Bekehrungen ihrer Anhänger zum Christentum ${ }^{29}$.

Diese unmittelbare Parallelität der Geschichtsauffassungen, die Endzeitgewissheit der Anhänger unterschiedlicher Religionen, wird freilich insgesamt eher selten referiert. Häufiger sind Berichte von Endzeithoffnungen, die aus einigen Missionsgebieten nach Basel gesandt wurden. Die Endzeithoffnung beinhaltete die Hoffnung besserer Zeiten und enthielt mithin Anklänge an pietistische Ursprungstexte ${ }^{30}$.

26 Vgl. Heidenbote 1828, S. 104.

27 Diese Auffassung speiste sich aus der Schilderung des Gerichts in Mt. 25.

28 Der russische Graf Felician Zaremba (geb. 15.03.1794) wurde von 1818 bis 1821 im Missionshaus in Basel ausgebildet, vgl. Schlatter, Heimatgeschichte, S. $96 \mathrm{f}$.

29 Vgl. Heidenbote 1834, S. 73.

30 Vgl. Philipp Jacob Spener, Pia Desideria, hg. v. Kurt Aland, Berlin 1964, S. 9f. u. 86; vgl. auch Dietrich Blaufuss, Zu Ph.J. Speners Chiliasmus und seinen Kritikern, in: PuN 14 (1988), 
Die Afrikaner in Sierra Leone und Liberia »seufze[n] ihrer Erlösung entgegen $\aleph^{31}$, hieß es um das Jahr 1830 immer wieder, und damit war nicht nur die Befreiung von den Folgen der Sklaverei gemeint, sondern im Sinne der Missionare immer auch die Erlösung von den Sünden - selbst wenn die Betroffenen selbst das anders gesehen haben mögen. Sehnsuchtsvoll warteten die Liberianer, so der Heidenbote, auf den »Tag des Heils«. Aber nicht nur die jahrelang versklavten Schwarzen, sondern auch die unter muslimischer Herrschaft stehenden Perser und die Türken selbst harrten nach Auskunft der Missionare sehnsüchtig auf das Ende der »muhamedanischen Finsterni $\ll^{32}$. Die Sehnsucht der Völker nach Befreiung, von den Missionaren als Sehnsucht nach Christianisierung interpretiert, galt diesen als Beweis, dass sich Missionserfolge bald einstellen würden. Die Missionare konnten dies als Bestätigung ihres Geschichtsverständnisses interpretieren: Wenn erst einmal alle Völker christlich wären, dann hätten sich die Verheißungen von der Völkerwallfahrt erfüllt und das Weltende wäre gekommen, das Friedensreich Christi angebrochen ${ }^{33}$. Schon das Sehnen nach Befreiung wies damit auf den Beginn der Endzeit hin.

Dieser Gedanke steht auch hinter der häufigen Verwendung der TagNacht-Metapher durch die Missionare. Sie waren der Überzeugung, dass ihre Gegenwart die »Gnadenzeit« der Mission sei, dass ihnen in ihrer Gegenwart - jetzt - das heilige Werk der Mission anvertraut $\mathrm{se}^{34}$, und dass sie arbeiten müssten, »solange es Tag « ist ${ }^{35}$. Die Metapher von Tag und Nacht ist eine der meistbenutzten im Evangelischen Heidenboten. Mit ihr führten die Missionare bildhaft vor Augen, dass nun die Zeit zur Mission angebrochen sei, dass Tageslicht scheine, dass aber auch bald wieder die Nacht kommen könne und im natürlichen Ablauf der Zeiten auch kommen werde. Dadurch wurde der Aufruf zur Mission nur umso dringlicher.

Dieses direkt auf die Missionierung fremder Völker bezogene Geschichtsverständnis stand zudem in engem Zusammenhang mit den grundlegenden Werthaltungen der Missionare. Weil das Ende der Welt nahe war, mussten die Gläubigen missionieren, andere von der Bedeutung Gottes überzeugen, und

S. 85-108, sowie Johannes Wallmann, Pietismus und Chiliasmus. Zur Kontroverse um Philipp Jakob Speners »Hoffnung besserer Zeiten«, in: ZThK 78 (1981), S. 235-266. Vgl. auch Martin BRecht, Philipp Jakob Spener, sein Programm und dessen Auswirkungen, in: Ders. (Hg.), Der Pietismus vom siebzehnten bis zum frühen achtzehnten Jahrhundert, Göttingen 1993, S. $278-389$.

31 Heidenbote 1829, S. 50; 1831, S. 54.

32 Heidenbote 1830, S. 37; 1840, S. 37.

33 Vgl. Jes. 2,1-5; Mi. 4,1-5; Jer. 3,17f.

34 Vgl. Heidenbote 1830, S. 4.

35 Heidenbote 1828, S. 16 u. passim. Vgl. zur Tag-Nacht-Metapher auch Ulrich GäBleR, »Hoffen auf bessere Zeiten«. Daseinsangst und Zukunftssehnen der Pietisten, in: Johannes FISCHER/Ulrich GäBLER (Hg.), Angst und Hoffnung. Grunderfahrungen des Menschen im Horizont von Religion und Theologie, Stuttgart/Berlin/Köln 1997, S. 105-121. 
gleichzeitig mussten sie - teils durch die Missionsbemühung - ihrer eigenen Heiligung »nachjagen $\aleph^{36}$ - schon die Formulierung verdeutlicht die Dringlichkeit dieser Aufgabe. In Europa wie in den Missionsgebieten war Eile geboten. Jakob Friedrich Sessing ${ }^{37}$ blickte bei seiner ersten Reise nach Westafrika vom Schiff aus aufs Land, feierte Gottesdienst, und schrieb darüber:

Wenn ich über das Schiff weg nach den ungeheuren Ufern und Ländern blickte, wo so viele Tausende und Millionen im Schatten des Todes, ohne das Licht des Evangeliums, sizen [!], so ergriff mich der Gedanke: Wir alle können und dürfen nicht ruhen; wir alle müssen wirken, dieweil es Tag ist. Diese armen Schwarzen sind unsere Brüder, und wir sollen dereinst mit ihnen vor einem Herrn erscheinen ${ }^{38}$.

Auch andere Berichte verknüpften den Impetus zur Missionierung mit der Überzeugung, nun in der rechten Zeit dazu zu leben. Kaum ein Motiv wurde von den Missionaren häufiger genannt, kaum ein Bild häufiger verwandt als die Tag-Nacht-Metapher.

Zugleich sprach Sessing in seinem Bericht einen weiteren Bezugspunkt der Basler Missionare an, der ihr Geschichtsverständnis mit den Missionsbemühungen verband: Die Überzeugung von der Einheit der Welt und der Brüderlichkeit aller Menschen. Die Brüderlichkeit war zwar durch das Menschsein schon gegeben, sie enthielt aber zugleich eine noch nicht vollständig eingelöste biblische Verheißung: Die völlige Einheit aller Menschen wäre erst verwirklicht, wenn auch alle Christen geworden wären. Erst dann wären alle Menschen - in Gott - wirklich gleich. Auch hier findet sich also die Zukunftshoffnung als Motiv. Nikolaus von Brunn ${ }^{39}$, Präsident der Komitee der Basler Mission, gab bei der Aussendung 1828 seiner Freude Ausdruck, »daß die Zeit so sichtbarlich heranbreche, wo unter einem Hirten nur eine Heerde seyn wird « ${ }^{40}$. Die Überzeugung von der Einheit aller Menschen gipfelte in der Hoffnung auf die Völkerwallfahrt zum Zion. Sie gründete in der Überzeugung der Brüderlichkeit aller Menschen durch die Bruderschaft Christi, die in der Nächstenliebe - diese wiederum gelebt als Mission - ihren Ausdruck fand. Diese Überzeugung von der Einheit und das Wirken auf die auch sichtbare Einheit aller Menschen hin bildeten einen Grundpfeiler der

36 Heidenbote 1840, S. 35.

37 Jakob Friedrich Sessing (1802-1856), ausgesandt 1828 durch die CMS nach Sierra Leone bzw. Liberia, vgl. Karl Friedrich LedDerhose, Art. Sessing, Jakob Friedrich, in: ADB 34 (1892), S. 42-44 [Onlinefassung]; URL: <http://www.deutsche-biographie.de/pnd138425566.html> (15.02.2011).

38 Heidenbote 1828, S. 16: »Wie können wir aber an dieses Erscheinen denken, ohne hienieden alles mögliche zu thun, um ihnen diesen Heiland bekannt zu machen, der uns und sie mit seinem theuren Blute erkauft hat!

39 Geb. 1766, vgl. Schlatter, Heimatgeschichte, S. 15.

40 Heidenbote 1828, S. 98. 
Ideale der Basler Mission. Sie wurde im Heidenboten mit dem Geschichtsverständnis in Beziehung gebracht und motivierte so zur weiteren Missionierung. Wenn der für die Missionierung zur Verfügung stehende Tag bald zur Neige gehen konnte, so galt es, mit Eifer in höchster Eile möglichst vielen Menschen die Bekehrung nahezubringen.

\subsection{Misserfolge als Beweise für die nahende Endzeit}

Dass auch Misserfolge der Motivierung zur Mission und dem Nachweis des Nahens der Endzeit dienen konnten, mag zunächst erstaunen. Sie fügten sich jedoch in das von Dichotomie geprägte Weltbild der Missionare ein. Der Widerstand gegen die Mission durch bestimmte Völker wurde mit der Resistenz mancher Menschen in Europa gegenüber dem wahren Glauben - die Missionare sprachen hier von »Namenchristen« - parallelisiert. Gleichzeitig hoffte man weiter auf die endgültige Bekehrung der Völker. Man erklärte sich die Weigerung, die Botschaft der Missionare anzunehmen, mit einer (möglicherweise gottgewirkten) Verstockung. Dazu konnten die Missionare auf genügend Beispiele aus der Bibel zurückgreifen, so auf die Verstockung des Pharao, der das Volk Israel nicht aus Ägypten ziehen lassen wollte, wie auf die Verstockung des Gottesvolkes selbst ${ }^{41}$. Während Nichtisraeliten häufig durch Gottes Einwirken und zum Wohl des Volkes Israel verhärtet wurden, so klagt Gott in der Bibel die Israeliten der selbstgewirkten Verstockung an. Der Ausgang beider ist derselbe: Die Bibel berichtet davon, wie Gott am Ende die Verstockung bestimmter Personen oder des ganzen Volkes Israel aufhebt und ihnen die Augen für seine Wahrheit öffnet. Auf ein solches Eingreifen Gottes, die Aufhebung der Missionsresistenz, die Aufweichung der verhärteten Herzen ihrer Hörer, hofften auch die Missionare.

So schrieb schon Theodor Müller im Jahr 1828 aus Kairo, die Muslime seien durch Gott verstockt, bis der ihre Herzen öffne ${ }^{42}$. Zunächst aber müssten die Christen im Orient umkehren und sich zum wahren Glauben bekehren. Das koptische Christentum wurde als nahezu heidnisch wahrgenommen. Rituale, Frömmigkeit und religiöse Überzeugungen der Kopten passten nicht ins Welt- und Glaubensverständnis der Missionare. Die gemeinsamen Wurzeln wurden zwar anerkannt, aber die Geschichte der Konfessionen war schon so lange auseinandergegangen, dass die koptischen Christen als Fremde wahrgenommen wurden.

41 Vgl. z.B. Ex. 7-14.

42 Vgl. Heidenbote 1828, S. 91. Müller stammte aus Württemberg, vgl. Schlatter, Heimatgeschichte, S. 75 . 
Ein Jahr später stand nicht mehr die Verstockung der ägyptischen Christen im Mittelpunkt der Aufmerksamkeit der Missionare, die »Zeichen der Zeit« schienen nicht mehr auf eine zu erhoffende Öffnung ihrer Herzen für das nach Ansicht der Missionare wahre Christentum zu deuten, sondern die Zeit der Mission war infrage gestellt. 1829 hatte der Heidenbote zu berichten, dass Müller sich aus seinem Missionsgebiet hatte zurückziehen müssen und nun im Libanon arbeitete. Der Ratschluss Gottes »in unsern verhängnisvollen Tagen « war Inspektor Blumhardt ${ }^{43}$, der dies den Lesern mitteilte, unbegreiflich; er tröstete sich damit, dass die Basler Missionare im Orient bereitstünden, um bei jeder Veränderung zum Besseren, »beim sichtbaren Anbruch einer neuen Zeit« sofort wieder mit der Missionierung und Christianisierung zu beginnen ${ }^{44}$. Die Hoffnung auf die endgültige Missionierung, hier wieder mit einem Anklang an die Tag-Nacht-Metapher ausgedrückt, überwog alle Misserfolge.

Erst in der zweiten Hälfte der 1830er Jahre sah sich die Missionsgesellschaft gezwungen, Misserfolge ausführlich zu thematisieren und zu erklären. In der ersten Nummer des Heidenboten von 1836 bewies Blumhardt aus der Missionsgeschichte, dass Gott die Mission zu allen Zeiten unter scheinbaren Niederlagen zum Ziel geführt habe. Den Missionaren bleibe einzig, auf Gott zu vertrauen. Auf diese Weise wolle Gott sie lehren, nicht sich selbst zu rühmen, sondern, wie Paulus schreibt, Gott ${ }^{45}$. Er allein habe die Missionsgeschichte wie die Geschichte der ganzen Welt in der Hand. Seine Regierung sei für Menschen nicht immer zu verstehen. Deshalb bleibe den Frommen nichts anderes übrig, als ganz auf Gott zu vertrauen und trotz Rückschlägen weiterzuarbeiten. Ohne Vertrauen auf Gott sei die Missionsgeschichte der Gegenwart nicht zu verstehen ${ }^{46}$.

Neben der Bemühung um die Einheit aller Menschen wird hier ein für die Basler Mission zweiter grundlegender Wert angeführt und mit dem Geschichtsbewusstsein verknüpft: das Vertrauen auf Gott. Das Vertrauen, das auf Gottes Verheißungen gründet, die die Missionsarbeit fundierten, half den Missionaren, auch Rückschläge zu verkraften und Misserfolge im Licht Gottes als Stufen auf dem Weg zur endgültigen Christianisierung der ganzen Welt zu sehen. Die Basis des Vertrauens war die biblische Vergangenheit, seine Blickrichtung die Zukunft. Die Wirkung war auf die Gegenwart gerichtet: Das Vertrauen befähigte die Missionare, alle Rückschläge in ihr Geschichtsverständnis zu integrieren.

43 Christian Gottlieb Blumhardt, 1779-1838, vgl. für eine Kurzbiographie Friedrich Wilhelm BAutz, Art. Blumhardt, Christian Gottlieb, in: BBKL 1, Nordhausen 1990, Sp. 630-631, bzw. URL: <http://www.bbkl.de/b/blumhardt_c_g.shtml> (15.02.2011).

44 Heidenbote 1829, S. 50.

45 Vgl. Heidenbote 1836, S. 3 (1 Kor. 1,26-29).

46 Vgl. Heidenbote 1837, S. 57. 
1838, im zwanzigsten Jahr des Bestehens der Basler Mission, betonte der Heidenbote abermals, dass Menschen nicht beurteilen könnten, wie das Reich Gottes voranschreite, dass Missionserfolge nicht nach menschlichen Maßstäben beurteilt werden dürften und dass die »Christenliebe « nicht um sichtbarer Früchte willen, sondern aus der Liebe Christi arbeite ${ }^{47}$. Hier wird ein dritter grundlegender Wert genannt: die Nächstenliebe, die in der Liebe Christi zu den Menschen und der Liebe der Gläubigen zu Christus gründet.

1840 stärkte sich die Missionsgemeinde durch den Rückblick auf ihre Missionsgeschichte, nicht so sehr in Bezug auf ihre Erfolge, sondern vielmehr in der Erwartung noch bevorstehender Kämpfe. Nicht das Erreichte stand im Mittelpunkt, sondern das Schwere, das noch auf die Missionare zukommen könnte. Trotzdem machte gerade dies ihnen Mut, auch im Blick auf die Geschichte Gottes mit Israel. Gott hatte bis hierher geholfen, er würde auch weiterhin helfen. Am Ende würden dann die Missionare unter den von Gott Geretteten, unter den Seligen sein, denn sie waren seine Zeugen ${ }^{48}$. Im Blick auf die Endzeit konnten sie alles ertragen, im Gehorsam gegen Gottes Gebot und in der Liebe zu Christus und den Menschen arbeiteten sie trotz aller möglicher Rückschläge, trotz jahrelanger Erfolglosigkeit weiter. Dabei wird hier deutlich, dass ihr Motiv nicht nur in der Rettung heidnischer Seelen lag, sondern auch in der Rettung der eigenen Seele. Die Mitarbeit in der Mission garantierte den Platz im Himmelreich.

Ein sprechendes Beispiel für die Beharrlichkeit und die Treue der Missionare zu ihrem Auftrag trotz Rückschlägen und im Angesicht des kommenden Reichs Gottes bot der Missionar Johann Jakob Bär ${ }^{49}$, der seit 1822 in Makassar auf den Molukken arbeitete, als einziger Weißer und bis 1834 völlig erfolglos. Ab $1831 \mathrm{kam}$ in den Berichten über seine Arbeit die Referenz auf »liebliche Spuren der beginnenden Morgenröthe« auf $\mathrm{f}^{50}$, auch wenn die Missionsgesellschaft weiterhin zugeben musste, dass Bärs Bemühungen keinen Erfolg hatten. 1832 fand die Basler Mission eine »erste Morgendämmerung « auf den Molukken ${ }^{51}$, und 1834 jubelte sie: »ein neuer Tag des Heils [ist] angebrochen ${ }^{52}$. Genauer beschreibt der Bericht die Veränderung nicht, es bleibt also im Dunkeln, in welcher Weise sich der Anbruch des Tages, der Erfolg der Mission äußerte, ob in ersten Bekehrungen oder nur in einer Offenheit gegenüber der christlichen Botschaft. In unserem Zusammenhang ist wichtiger, wie mit den jahrelangen Misserfolgen Bärs umgegangen wurde:

47 Heidenbote 1838, S. 3, vgl. auch S. 1f., 61 u. 67.

48 Vgl. Heidenbote 1840, S. 1-6.

49 Bär trat 1816 ins Missionshaus ein und wurde durch die Niederländische Missionsgesellschaft ausgesandt, vgl. Schlatter, Heimatgeschichte, S. 58 u. 60.

50 Heidenbote 1831, S. 50.

51 Heidenbote 1832, S. 52.

52 Heidenbote 1834, S. 60. 
Seine Treue zu seinem Auftrag und zugleich die Hoffnung auf die Zukunft standen im Vordergrund der Berichterstattung. Während die Missionsgesellschaft jahrelang Misserfolge eingestehen musste, die sie mit der Zukunftshoffnung erklärte, strich sie gleichzeitig erste kleine Veränderungen hervor und bezeichnete sie als beginnende Morgenröte und Morgendämmerung. Der Misserfolg ließ also kleinste Öffnungen gegenüber dem Evangelium schon als große Schritte erscheinen ${ }^{53}$. So wurden die Misserfolge umgedeutet und in die Zeitmetaphorik der Missionare aufgenommen.

Die Verbindung dieser Interpretation der kleinen Erfolge vor dem Hintergrund der langen Misserfolge mit dem Bild von Tag und Nacht machte die Beziehung zur Endzeit deutlich. In Bezug auf die Missionsgebiete galt nicht die europäische Zeitrechnung, dass jetzt Tag sei und man arbeiten solle, bevor die Nacht hereinbreche, sondern hier sah man die nichtmissionierten Völker als in der Nacht lebend. Erst die Mission brachte das Tageslicht, das Evangelium, welches das Licht verbreitete. Der Tag wurde mit dem »Tag des Heils« gleichgesetzt, und dieser »Tag des Heils« war die erwartete Endzeit ${ }^{54}$. Auf diese Weise ließen jahrelange Misserfolge der Missionsbemühungen wie bei Bär das Näherkommen des Reichs Gottes umso deutlicher in Erscheinung treten. Sie dienten als dunkle Folie, die den Beginn der Zukunft umso heller strahlen ließ.

\subsection{Missionserfolge als Beweise für die nahende Endzeit}

Als wirksamste Beweise für die nahende Endzeit dienten aber selbstverständlich die Erfolge in der Mission. Diese wurden in aller Ausführlichkeit dargestellt und immer wieder hervorgehoben. Allerdings konnte die Basler Mission in den ersten Jahren des Heidenboten nur von seltenen und kleinen Erfolgen berichten. Im Jahr 1828 war der einzige Anhaltspunkt für die »Dämmerung eines kommenden Tages«, dass die Plantagenbesitzer in Südamerika zu der Überzeugung kamen, dass christlicher Unterricht den Sklaven (d.h. den Sklavenhaltern) nicht schade ${ }^{55}$. Von einem echten Missionserfolg, der Bekehrung eines Volkes oder auch nur einzelner, konnte die Missionsgesellschaft aus ihrer eigenen Arbeit in diesem Jahr noch nicht berichten. Umso wichtiger war ein Bericht über die Erfolge der London Missionary Society

53 Vgl. auch die Argumentation Heidenbote 1828, S. 3 im Anschluss an Mk. 9: Je mehr Arbeit nötig sei, desto tröstlicher würden gute Nachrichten, desto größer werde auch die Hoffnung auf die endgültige Christianisierung.

54 Vgl. Jes. 49,8. In 2 Kor. 6,2 wird die Jesaja-Rede aufgenommen, nun aber als Aufforderung zum Handeln in der Gegenwart gedeutet. In dieser Deutung nahm auch die Missionsbewegung sie auf; 2 Kor. 6,2 gehört zu einer der sehr häufig zitierten Bibelstellen.

55 Heidenbote 1828, S. 93. 
auf den Gesellschaftsinseln. Der Heidenbote gab ein Gespräch der dortigen Häuptlinge wieder, in dem sie ihren Zustand vor der Missionierung mit dem gegenwärtigen, zivilisierten verglichen. Interessant ist, auch in Bezug auf das Geschichtsverständnis, die Schlussfolgerung der Häuptlinge: »Wenn Gott wollte unsere Lehrer von uns nehmen, wir wären bald wieder Wilde $\aleph^{56}$. Der historische Vergleich und auch dieses Fazit können, aber müssen nicht unbedingt den Häuptlingen in den Mund gelegt sein, sie spiegeln jedenfalls genau die Geschichtsauffassung der Missionsgesellschaften wider: Vor ihnen herrschten Wildheit, Rohheit, Nacht, durch sie sind Zivilisation und Tag zu den Völkern gekommen. Diese galt es zu bewahren.

Die Zivilisierung wurde in der ersten Hälfte des 19. Jahrhunderts jedoch nur sehr selten auf das Geschichtsverständnis bezogen. 1829 fanden die Missionare Saltet ${ }^{57}$ und Wöhr an der Kura am Kaspischen Meer, dass mit der kirchlichen Ordnung, also der von ihnen vertretenen Ordnung, auch das Zutrauen und der Segen Gottes nach Georgien zurückkehrten ${ }^{58} .1837$ deutete der Heidenbote die zivilisatorischen Erfolge der Mission in Persien als »Vorboten einer neuen und bessern Zeit « ${ }^{59}$. Sesshaftigkeit, Schulunterricht, häuslicher Friede und Friede unter benachbarten Stämmen und Völkern wurden als Teil der »Wiedergeburtsgeschichte der Welt« gesehen. Der zentrale Teil der erweckten Bekehrung, die Wiedergeburt, wurde hier auf die ganze Welt bezogen und geschichtlich gedeutet. An der Welt als Ganzes sollte sich vollziehen, was jeder einzelne wahre Christ in seinem eigenen Leben erfahren sollte. Dies konnte in der Welt nur als geschichtlicher Prozess vonstattengehen. Dass dieser Prozess im Gange war, bewiesen den Missionaren die Reaktionen der fremden Völker auf ihre Missionsbemühungen, und in seltenen Fällen war auch die Zivilisierung in den Ablauf einbezogen.

In dem Bericht über Persien sah der Heidenbote aufgrund der dortigen Erfahrungen jubelnd dem Reich Gottes und der endgültigen Wiedergeburt der ganzen evangelischen Kirche entgegen. Hier wurde also aus der Zivilisierung der Perser auf die Erneuerung der evangelischen Kirche auch in Deutschland und der Schweiz geschlossen. Dieser Rückschluss war möglich, weil für die Missionare die ganze Welt eine Einheit bildete, weil alle Menschen zusammengehörten und am Ende allen Gottes Herrschaft bevorstand.

56 Heidenbote 1828, S. 71.

57 Saltet (1792-1830) kam aus dem Rheinland, vgl. Schlatter, Heimatgeschichte. Beim Geburtsort scheint Schlatter unsicher, vgl. S. 66: Köln, S. 87: Wesel. Saltet war 1820 zunächst von einer schottischen Gesellschaft zur Judenmission nach Odessa gesandt worden, vgl. ebd., S. 96. Vgl. auch Karl Friedrich LedDERHose, Art. Saltet, Johann Bernhard, in: ADB 30 (1890), S. 283-285 [Onlinefassung]; URL: <http://www.deutsche-biographie.de/pnd138097666.html> (15.02.2011).

58 Vgl. Heidenbote 1829, S. 51.

59 Heidenbote 1837, S. 67. 
Das von den Missionaren vertretene Geschichtsverständnis blieb nicht auf Europäer begrenzt, sondern wurde von manchen Missionierten übernommen $^{60}$, so z.B. von den oben erwähnten Häuptlingen der Gesellschaftsinseln. Ein Birmane berichtete ausführlich in einem Brief über seine Bekehrung und verglich wie die Häuptlinge der Gesellschaftsinseln seine frühere Situation mit der gegenwärtigen. In diesen Bericht eingebunden war die Aussage: »viele werden noch kommen, um ihren Durst zu stillen, und sich zu reinigen. Dann wird Alles neugeschaffen und umgestaltet werden«. Der Brief endete mit dem Satz: »Wie lieblich wird es seyn, wenn der gute Hirte einmal seine Schaafe aus allen Ländern und Völkern gesammelt haben wird ${ }^{61}$. Der christianisierte Fremde formulierte hier die Endzeithoffnung der Missionsbewegung ebenso wie ihre Hoffnung auf die Einheit der Menschen. Dass die ehemals Fremden mit der Missionierung auch das Geschichtsverständnis der erweckten europäischen Christen übernahmen, konnte als weitere Bestätigung ihrer Geschichtsinterpretation verstanden werden. Die Fremden wurden in das Eigene integriert.

Die Geschichtsinterpretation konnte durch Berichte von den eigenen Missionserfolgen verstärkt werden. Die erste Erwähnung eines solchen fand sich im Heidenboten 1830 und wurde sofort mit der Zukunftshoffnung, ja eigentlich der Zukunftsüberzeugung, verbunden: Isaak Schaffter ${ }^{62}$ schloss seinen Bericht von einer Inderin, deren Sohn sich in seiner Missionsschule bekehrt hatte und die ihm nun ihren zweiten Sohn brachte, mit dem Gedanken: »Viele dieser wahrheitssuchenden Gemüther werden einst kommen von Morgen und von Abend, und mit Abraham, Isaak und Jakob im Himmelreich zu Tisch sitzen ${ }^{63}$. Schaffter bezog sich hier auf Lk. 13, die Vorstellung von der letztlichen Einheit aller Menschen im Reich Gottes, einem anderen Bild für denselben Gedanken wie die Völkerwallfahrt zum Zion. Die einzelne Bekehrung wurde sofort als auf alle kommenden Bekehrungen und das nahende endgültige Heil für die ganze Welt weisend gedeutet.

Auch wenn der Heidenbote weiterhin nicht von massenhaften Bekehrungen berichten konnte, so befand er doch in diesem dritten Jahr seines Bestehens, dass die Sehnsucht nach dem Wort Gottes bei den fremden Völkern zunehme ${ }^{64}$. Schon kleine Missionserfolge galten dem Heidenboten als

60 Gegenbeispiele wurden selbstverständlich nicht erwähnt. Für ihre Anführung gab es keine Gründe, wollte man die Leser doch von der Korrektheit der eigenen Ansichten überzeugen, nicht neutral die anderer referieren.

61 Heidenbote 1830, S. 44.

62 Isaak Theoph. Schaffter aus Münster im Kanton Bern trat 1819 ins Missionshaus ein, vgl. SCHLATTER, Heimatgeschichte, S. 65.

63 Vgl. Heidenbote 1830, S. 6f., Zitat S. 7.

64 Vgl. Heidenbote 1830, S. 16. 
Vorausblick auf die endgültige Christianisierung aller Menschen und die einbrechende Endzeit.

Im Jahr 1830 jährte sich die Gründung der Basler Mission zum 15. Mal. Damit kam die Missionsgesellschaft auch zum ersten Mal in echte Erklärungsnöte, warum nicht schon größere Missionserfolge sichtbar waren. Die Betonung der gegenwärtigen Zeit als rechter Zeit zur Mission und die Herausstellung der kleinen ersten Erfolge als Beweise für die künftigen groBen Christianisierungswellen nahmen in diesem Jahr einen besonders prominenten Raum ein und wurden beständig wiederholt ${ }^{65}$. Jeder kleine Erfolg bezeugte den kommenden großen Erfolg und bestätigte die Missionsgemeinde in ihrer Überzeugung, jetzt in der rechten - und vorerst einzigen - Zeit zur Mission zu leben und verstärkte somit ihre Anstrengungen, das ersehnte und erwartete Ergebnis herbeizubringen.

Ab 1831 kam im Rückblick auf das Revolutionsjahr 1830 und die folgenden Unruhen ein neues Motiv hinzu: Die Missionserfolge in den fernen Ländern wurden dem Abfall vom Christentum, den man in Europa beobachtete - und ein Revolutionär konnte nie ein wahrer Christ sein, lehnte er sich doch gegen die Obrigkeit auf ${ }^{66}$ - entgegengesetzt. 1834 wurde der Zustand wieder mit dem Tag-Nacht-Bild beschrieben:

Dieses Licht geht im fernen Morgenlande mit jedem Jahre schöner und herrlicher auf, und fesselt den Hoffnungsblick des Gläubigen, der mit tiefem Kummer unter so manchem Volke der abendländischen Christenheit eine grauenvolle Nacht hereinbrechen sieht, da Niemand wirken kann ${ }^{67}$.

Abschließend soll an einem Beispiel die in den Berichten zum Ausdruck gebrachte Verbindung zwischen Missionserfolgen, theologischen Überzeugungen, Werthaltung der Missionare und ihrem Geschichtsverständnis deutlich gemacht werden: an der Mission in Afrika, genauer in Westafrika. 1830 berichtete Karl Ferdinand Salbach ${ }^{68}$ von der Goldküste, dass die Afrikaner jeden Tag das Wort Gottes hören wollten. Er konnte also einen echten Missionserfolg verzeichnen. Salbach meinte, die Afrikaner hätten durchaus das Recht zu fragen, warum nicht schon früher Missionare zu ihnen gekommen seien. Es sei das Mindeste, nun »durch verdoppelten Eifer das Versäumte«

65 Vgl. z.B. Heidenbote 1830, S. 3, 16f., 40, 43, 47f., 53, 71, 74, 78 u. 99.

66 Vgl. Hölscher, Weltgericht, S. 79; für eine Analyse der Beziehung zwischen Erweckungsbewegung und Obrigkeit vgl. Lehmann, Weltliche Ordnung, S. 188-226, zur Mission und Obrigkeit Hermann Wellenreuther, Mission, Obrigkeit und Netzwerke. Staatliches Interesse und Missionarisches Wollen vom 15. bis ins 19. Jahrhundert, in: PuN 33 (2007), S. 193-213.

67 Heidenbote 1834, S. 4; vgl. auch ebd., S. 67f.

68 Karl Ferd. Salbach, geb. 1799 in Köpenick, vgl. Schlatter, Afrika, S. 22. 
nachzuholen ${ }^{69}$. Hier wies der Missionserfolg weniger in die Zukunft, vielmehr trieb er im Blick auf die Vergangenheit zum Engagement in der Gegenwart an. Ob nun die Missionserfolge in Hinsicht auf die Vergangenheit oder auf die Zukunft gedeutet wurden: Immer ging es darum, in der Gegenwart tätig zu werden.

1831 hieß es in einem Bericht über Sierra Leone:

O daß die heiß ersehnte Stunde bald erscheinen möge, in welcher die klirrenden Sklavenketten Afrikas für immer zerbrochen, und dem mißhandelten Negervolke die Wege Zions allenthalben aufgeschlossen seyn werden ${ }^{70}$.

Hier ist zum einen auf der politisch-sozialen Ebene vom Ende jeglichen Sklavenhandels die Rede. Zum anderen wird in der theologischen Rede der Missionare »Sklaverei« auch als Ausdruck für die Herrschaft der Sünde verwendet, das Zerbrechen der Sklavenketten als Metapher für die Annahme und Durchsetzung der Rechtfertigung des Menschen durch Christus. Afrika sollte nach Überzeugung der Missionare christlich und dadurch frei werden. Der Wert der Freiheit war einerseits auf die innerliche Freiheit von der Sünde bezogen, andererseits auf die äußerliche Freiheit von Sklaverei, Krankheit und frühzeitigem Tod - ein stetes Thema für die Mission in diesem gesundheitsgefährdenden Gebiet. So wurden politische und soziale Gegebenheiten, individuelles Leben und theologische Überzeugungen durch die religiösen Hoffnungen und Zukunftserwartungen in eins gesetzt.

Gleichzeitig wurde die Befreiung Afrikas mit der Endzeit, der Zionszeit, in Verbindung gebracht. Sie galt als Vorschein wie Ausdruck der Durchsetzung des Reiches Gottes auf Erden. Auch hierin lag ein Grund dafür, dass die Missionsbewegung an Afrika besonderes Interesse hatte und die Christianisierung Afrikas in dieser Weise ideologisch auflud. Die Situation in Afrika wurde als so schlecht wahrgenommen, dass hier Missionserfolge nach menschlichem Ermessen besonders unwahrscheinlich schienen. Die Missionare jedoch verließen sich auf die Verheißungen Gottes auch für Afrika $^{71}$. Fünf Jahre später erklärte der Heidenbote die geringen Missionserfolge an der afrikanischen Westküste mit der tausendjährigen Finsternis, in der Afrika gelebt habe. Es gebe jedoch Beweise für eine Besserung: Dass ein Missionar lehren dürfe, obwohl in seiner Umgebung Menschenopfer dargebracht würden, dass er freundlich begrüßt werde und die Einheimischen ihn in die umliegenden Dörfer trügen, wurde als Beleg für die langsame Öff-

69 Heidenbote 1830 , S. 36.

70 Heidenbote 1831, S. 50.

71 Vgl. Heidenbote 1832, S. 64. Vermutlich bezog man sich hier wiederum auf die Völkerwallfahrt. 
nung Afrikas für das Evangelium genannt. In derselben Aufzählung wurde auch berichtet, dass die Afrikaner den Missionar aufforderten, »recht viele Gehülfen seines Sinnes « nach Afrika einzuladen ${ }^{72}$. Der Ruf nach Missionaren durch Afrikaner konnte wiederum als Erfolg und gleichzeitig als Aufforderung zu noch stärkerem Engagement in der Gegenwart - welches dann die Zukunft schneller näher brächte - verstanden werden.

1840 konnte der Heidenbote dann von großen Erfolgen berichten: Hunderte Einheimische ließen sich bekehren, wenn auch nicht unbedingt von der Basler Mission, so doch von mit ihnen im Glauben verbundenen englischen und amerikanischen Missionaren - der Heidenbote bezog sich hier auf eine Rede des bekannten und in diesen Kreisen berühmten Afrika-Missionars der London Missionary Society, Robert Moffat. Er endete mit der Hoffnung:

Wenn Gott fortfährt mit Seinem Segen die Arbeiten der Missionarien zu begleiten, so wird bald Afrika wieder werden, was es in den Tagen der Vorzeit war, da es die Kirche Europa's mit Lehrern und Bischöfen versah, und Tausende seiner Märtyrer in den Flammen starben, um mit ihrem Tode den Namen Jesu zu preisen ${ }^{73}$.

Nicht eine Rückkehr zu alten Verhältnissen wurde hier erhofft, sondern eine Rückkehr zu den Ursprüngen der Kirche, zur wahren, reinen Kirche, und damit eine Annäherung an die Zeit Jesu. Auch dies konnte als Hoffnung auf dem Weg zur Endzeit verstanden werden. Die Missionare hofften, dass die Kirche wieder so werde wie zur Zeit Jesu, zu ihren Ursprüngen zurückkehrte und dadurch wieder »rein« werde, nachdem sie im Laufe ihrer Geschichte so oft von Gottes Geboten abgefallen war und sich von dem, wie sie eigentlich sein und was sie eigentlich tun sollte, abgewandt hatte. So wäre die Rückkehr zu den »Tagen der Vorzeit« eine Möglichkeit, sich Gott zu nähern und damit auch die Näherung Gottes, das Herankommen der Endzeit herbeizuführen. Die Bekehrung Afrikas war für die Missionare ein wichtiger Meilenstein auf dem Weg zur Endzeit und damit grundlegend für ihre Zukunftshoffnungen.

\section{Schluss}

Die Analyse des Evangelischen Heidenboten hat gezeigt, dass das Welt- und Geschichtsbild der Missionare recht geschlossen war. Sie waren überzeugt, in unmittelbarer Nähe der Endzeit zu leben, und erwarteten für die nahe Zukunft das Reich Gottes auf Erden. Alle Erlebnisse in und mit fremden Kulturen wurden in dieses Weltbild integriert.

72 Heidenbote 1837, S. 65.

73 Heidenbote 1840, S. 55. 
Dadurch war es innerhalb dieses Systems relativ unerheblich, ob die Missionsgesellschaft von Erfolgen berichten konnte oder ob die Missionsbemühungen wenig erfolgreich waren: Erfolge wie Misserfolge konnten als Beweise für das Handeln Gottes und die Nähe der Endzeit dienen. Sie wurden jeweils innerhalb des Geschichtsverständnisses der Basler Mission gedeutet und auf die nahende Endzeit bezogen.

Nur bei langanhaltender Erfolglosigkeit bekam das Geschichtsbild kleinste Risse. Die Gesellschaft und ihre Missionare mussten Erklärungen finden, warum sie so lange ohne sichtbare Erfolge arbeiteten. Sie verwiesen dazu auf das verborgene Handeln Gottes in der Geschichte: Kein Mensch kann ergründen, was Gott sich denkt und welchen Plan er genau verfolgt, sicher ist aber, dass Gott in der Geschichte handelt und dass man zumindest im Rückblick sein Handeln und den Fortgang seines Reiches und seiner Herrschaft erkennen kann. Ebenso sicher stehen seine Verheißungen für die Zukunft.

Das unmittelbare Ausbleiben der Parusie wurde nicht thematisiert, sondern die Naherwartung immer festgehalten und durch Beispiele aus der Missionsgeschichte, Erfolge wie Misserfolge, belegt. Die Überzeugung von der Nähe der Endzeit gab der Missionsbewegung Anlass zu ihrem Engagement und spendete Trost bei Erfolglosigkeit und Hoffnung für die Zukunft. Dies galt für die gesamte Missionsbewegung und die Missionsgesellschaft in Basel, in besonderer Weise jedoch galt es für die einzelnen Missionare, die teilweise, wie Johann Jakob Bär auf den Molukken, jahrzehntelang in Abgeschiedenheit und Einsamkeit unter fremden Menschen arbeiteten, ohne Erfolge ihrer Bemühungen zu sehen. Die Hoffnung auf die Treue Gottes zu seinen Verheißungen und die Gewissheit der Richtigkeit des eigenen Handelns, weil man selbst sich treu an Gottes Gebote hielt, gab ihnen Trost und Stärkung.

Diese Hoffnung auf die Treue Gottes zu seinen Verheißungen richtete sich nicht unbedingt auf die allernächste Zukunft; die meisten Missionare haben die Parusie nach 1836 wohl nicht zu ihren eigenen Lebzeiten erwartet; aber sie blieb als Endzeitvision weiterhin lebendig und für die Mission motivierend.

Die Begegnung mit den Fremden wurde in das eigene Geschichtsverständnis integriert. Das Geschichtsverständnis der erweckten Europäer bekam eine weltweite Ausdehnung, wenn die neu missionierten Christen diese Geschichtskonzeption übernahmen. Es erfuhr also, wenn auch keine grundlegende Veränderung, so doch eine - es im Grundsatz bestätigende Ausweitung. Die Missionserfolge und insbesondere die Misserfolge mussten ebenfalls in die Geschichtsauffassung eingearbeitet werden. Letztere waren in diesem Maße nicht erwartet worden. Ihre Integration erfolgte zum einen durch die Umdeutung der Misserfolge im Hinblick auf die erwartete Zukunft, zum anderen wandelte sich durch sie das Geschichtsbewusstsein der Missio- 
nare. Wenn auch die Geschichtskonzeption im Grunde dieselbe blieb, so veränderte sich doch das Geschichtsbewusstsein: Die eigene Gegenwart wurde zu einer Zeit, in der der Mission zwar viele Wege geöffnet waren, aber nicht alle Herzen. Bis zum Eintreffen der erwarteten Zukunft musste nicht nur durch die Gläubigen missioniert, sondern auch durch Gott die »Verstockung " der Fremden aufgehoben werden. Gegenwartsverständnis und Zukunftsperspektive $^{74}$ der Missionare veränderten sich durch die Begegnung mit den konkreten Fremden in der Mission. So wurde nicht ihr Geschichtsverständnis, aber ihr Geschichtsbewusstsein durch diese Erfahrungen modifiziert.

74 Geschichtsbewusstsein wird in der Regel als das Zusammenspiel von Vergangenheitsdeutung, Gegenwartsverständnis und Zukunftsperspektive definiert, vgl. z.B. Karl-Ernst JeismanN, Geschichtsbewußtsein - Theorie, in: Klaus Bergmann, u.a. (Hg.), Handbuch der Geschichtsdidaktik, Seelze-Velber ${ }^{5} 1997$, S. 42-44, hier S. 42. 
IV. Rezeptionen von Erfahrungen mit Fremden 



\title{
Felix Wiedemann
}

\section{Zwischen Völkerflut und Heroismus ${ }^{1}$}

\author{
Zur Repräsentation der Beduinen in kulturhistorischen \\ Deutungen des Vorderen Orients um 1900
}

Dass Beduinen in der Geschichte und Kultur des Vorderen Orients eine zentrale Rolle spielen, scheint zu den Allgemeinplätzen zu gehören. In diesem Sinne wird dem Leser im Jordanien-Band (2010), einer auf das bildungsbürgerliche Publikum zugeschnittenen deutschen Reiseführer-Reihe, folgendes universalhistorisches Panorama geboten:

Seit der Zeit der altorientalischen Großreiche diente das Ostjordanland als Pufferzone gegen Wüstenarabien. Im Verbund der römischen Provincia Arabia wurde es fest an den mediterranen Raum angeschlossen. [...] Dennoch besaß das Wort Arabien für die mittelmeerische wie für die persische Kulturwelt einen unheilvollen Klang. Beduinen [...] übten mit ihren Wanderzügen Druck auf die zivilisatorischen Grenzräume aus ${ }^{2}$.

Anschließend springt der »kulturhistorische Überblick« ein paar hundert Jahre vor und erklärt auch den »Araber-Sturm « - gemeint ist die Ausbreitung des Islams - als Teil der ausgemachten Auseinandersetzung zwischen Wüste und Zivilisation: »Der seit Alexander expansive Westen gerät in eine kritische Defensive, die Wüste erobert das Mittelmeer « ${ }^{3}$. Abgesehen von der anachronistischen Vereinnahmung Alexanders des Großen für »den Westen « und der anklingenden Charakterisierung des Islams als »Wüstenreligion « - eine ebenso gängige wie bedenkliche Floskel populärer Religionskritik $^{4}$ - wird die Geschichte des zu bereisenden Raums der letzten drei- bis

1 Für wertvolle Hinweise und eine kritische Durchsicht des Textes danke ich Gisela Eberhardt. Der Beitrag beruht auf Forschungen während eines Fellowships der CSG-V (»Space and Collective Identities «) des Berliner Exzellenzclusters »Topoi - The Formation and Transformation of Space and Knowledge in Ancient Civilizations« 2010.

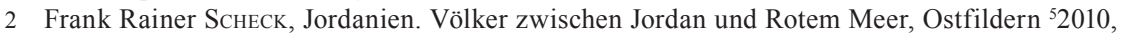
S. 69.

3 Ebd.

4 Dahinter steht die religionshistorisch unhaltbare Behauptung einer genuinen Verbindung von Wüste und Monotheismus. Vgl. Herbert DonNER, Die religiöse Wüstenromantik. Über eine fehlgeleitete Metapher, in: Volker Drehsen u.a. (Hg.), Der »ganze Mensch«. Perspektiven lebensgeschichtlicher Individualität, Berlin u.a. 1997, S. 1-12. 
viertausend Jahre auf die simple Funktion der »Pufferzone gegen die unberechenbaren beduinischen Kräfte $\ll^{5}$ reduziert.

Größere Buchhandlungen werden in der Reiseabteilung allerdings noch ein weiteres Buch im Angebot führen, das mit einer anderen Perspektive auf die »beduinischen Kräfte« aufwartet und das negative Urteil des Reiseführers scheinbar korrigiert: Die Brunnen der Wüste (1959), den immer wieder aufgelegten Bericht Sir Wilfred Thesigers über seine abenteuerliche Durchquerung des sogenannten Leeren Viertels im südlichen Arabien ${ }^{6}$. Dieser Klassiker der Wüstenliteratur richtet sich natürlich weniger an Bildungsbürger als an die Outdoor- und Aussteiger-Fraktion. Auch hier findet der Leser Reflexionen über die Bedeutung der Beduinen in der arabischen Kultur und den daraus resultierenden »Einfluss Arabiens auf die Weltgeschichte«:

Seine besten Tugenden verdankt der Araber der Wüste: die tiefe Religiosität, die ihren Ausdruck im Islam gefunden hat, das Zusammengehörigkeitsgefühl, das ihn mit seinem Glaubensbruder verbindet, den Rassestolz, die Großzügigkeit und Gastlichkeit. [...] Es schien mir bedeutsam, dass es die Wüstenaraber waren, die dem arabischen Menschen seine charakteristischen Merkmale verliehen hatten. [...] Es waren die Sitten und Maßstäbe der Wüste, die die Städter und Dörfler übernommen hatten und die von den arabischen Eroberern in Nordafrika und im Mittleren Osten verbreitet und vom Islam in einen großen Teil der Welt getragen worden waren?

Wie im Kultur-Reiseführer wird hier folglich die determinierende Kraft der Wüstennomaden betont - allerdings unter umgekehrten Vorzeichen: Werden die Beduinen dem Bildungsbürger als negativer Faktor in der Geschichte der Zivilisation präsentiert, kann sich der Aussteiger über deren scheinbar noch authentisches, tugendreiches Leben informieren. Das eine Mal also erscheinen die Wüstennomaden als Verhängnis, das andere Mal als Segen. Mit diesen Aussagen und Bewertungen stehen beide Texte keineswegs isoliert da, gehört die ambivalente Repräsentation der Beduinen doch bis heute zu den zentralen Elementen kulturhistorischer und journalistischer Darstellungen der Geschichte und Kultur des Vorderen Orients. Dabei ist diese Ambivalenz Teil eines umfassenderen Deutungsmusters, das die Geschichte dieses Raumes auf den vermeintlich naturräumlich bedingten Gegensatz zwischen Nomaden und Städtern, den Kräften der »Wüste« und des »fruchtbaren Halbmondes $~^{8}$ reduziert und als »geohistorisches Narrativ« bezeichnet werden kann. Darunter soll hier ganz allgemein ein als plausibel erachtetes Dar-

5 Scheck, Jordanien, S. 45.

6 Wilfred Thesiger, Die Brunnen der Wüste. Mit den Beduinen durchs unbekannte Arabien, München 2002.

7 Ebd., S. 108f.

8 Vgl. Thomas Scheffler, »Fertile Crescent«, »Orient«, »Middle East«. The Changing Mental 
stellungsmuster verstanden werden, das Raum und Zeit einer bestimmten Region so eng miteinander in Beziehung setzt, dass auf diese Weise scheinbar disparate »Fakten« in einer Kausalkette verbunden und »Ereignisse« aus weit auseinanderliegenden Epochen analog erzählt und scheinbar erklärt werden können. Dies führt schließlich zur fortwährenden Reproduktion ähnlicher Erzählungen mit ähnlichen Plots und Rollenmustern.

Woher aber bezieht das Narrativ vom ewigen Ringen zwischen Beduinen und Städtern, Wüste und Kulturraum seine Überzeugungskraft? Wann und in welchen Kontexten hat es sich als Erzähl- und Erklärungsmuster für die Geschichte und Kultur des arabischen Raums etabliert und welche Rolle spielten dabei tatsächliche oder vermittelte Begegnungen mit Beduinen? Um diese Fragen soll es im Folgenden gehen - d.h. es soll die Genese und Funktion dieses geohistorischen Narratives in kulturhistorischen Modellen zur Geschichte des Vorderen Orients aus dem 19. und frühen 20. Jahrhundert aufgezeigt werden. Als Quellen dienen dabei einerseits historiographische Abhandlungen, vor allem aus der entstehenden Altorientalistik bzw. Assyriologie $^{9}$. Die Orientwissenschaftler des 19. Jahrhunderts verfügten aber in der Regel über keine eigene Ortserfahrung und waren in vielen Fragen auf empirische, geographische und ethnographische Informationen von Anderen angewiesen. Dies gilt insbesondere für die hier relevanten Reflexionen über die Beduinen und deren vermeintliche Rolle in der Geschichte des arabischen Raums. Aus diesem Grund werden andererseits ausgewählte Berichte europäischer Arabienreisender herangezogen, die einen nicht zu unterschätzenden Einfluss auf die historischen Abhandlungen hatten ${ }^{10}$. Dabei liegt der Schwerpunkt auf dem deutschen Kontext. Abgesehen von pragmatischen Gründen

Maps of Southwest Asia, in: European Review of History - Revue européenne d'Histoire 10 (2003), H. 2, S. 253-272.

9 Aufgrund der Herkunft der Altorientalistik aus der Keilschriftforschung firmierte das Fach zunächst als »Assyriologie«. Vgl. Johannes RENGER, Die Geschichte der Altorientalistik und der vorderasiatischen Archäologie in Berlin von 1875 bis 1945, in: Willmuth Arenhövel/Christa SchneIder (Hg.), Berlin und die Antike. Architektur, Kunstgewerbe, Malerei, Skulptur, Theater und Wissenschaft vom 16. Jahrhundert bis heute, Berlin 1979, S. 151-192; Stefan R. HAUSER, Not out of Babylon? The Development of Ancient Near Eastern Studies in Germany and its Current Significance, in: Tzvi Abush u.a. (Hg.), Historiography in the Cuneiform World. Papers read at the $45^{\text {th }}$ Rencontre Assyriologique Internationale, Bethesda 2001, S. 211-237; Ludmila Hanisch, Die Nachfolger der Exegeten. Deutschsprachige Erforschung des Vorderen Orients in der ersten Hälfte des 20. Jahrhunderts, Wiesbaden 2003; Ursula WoKOECK, German Orientalism. The Study of the Middle East and Islam from 1800 to 1945, London 2009, bes. S. 146-163; Suzanne L. Marchand, German Orientalism in the Age of Empire. Religion, Race, and Scholarship, New York 2009, bes. S. 196-202.

10 Die Berichte europäischer Orient- und Arabienreisender des 19. Jahrhunderts sind in den letzten Jahren vielfach Gegenstand historischer und literaturwissenschaftlicher Untersuchungen gewesen. Vgl. die Diskussion der neueren Forschungsansätze bei Hilal AL-HAJRI, British Travel-Writing on Oman. Orientalism Reappraised, Bern 2006, S. 27-71; Radhouan BEN Amara, The Desert in Travel Writing, Cagliari 2006, S. 85-88. 
rechtfertigt sich dies zum einen durch die international führende Rolle der deutschen Orientalistik - wie insbesondere der Assyriologie - zu dieser Zeit und zum anderen durch die spezifische Bedeutung, die den Wüstennomaden in der Debatte um die Herkunft der Juden und den aufkommenden Antisemitismus am Ende des 19. Jahrhunderts in Deutschland zukam. Dabei wird sich zeigen, dass die ambivalente Repräsentation der Beduinen als Ausdruck einer generellen Ambivalenz des Nomadischen angesehen werden kann und weniger aus einem konkreten Wissen über - oder einer konkreten Erfahrung mit - Beduinen in der arabischen Kultur resultierte als vielmehr aus dem Behagen oder Unbehagen der jeweiligen Autoren in der eigenen Kultur.

\section{Nomadismus und Orientalismus}

So gilt es zunächst, sich den fundamental ambivalenten Charakter zu vergegenwärtigen, den »das Nomadische« in diversen Kulturtheorien bis heute einnimmt. Voraussetzung dieser symbolischen Bedeutung scheint dabei gerade der von Jürgen Osterhammel als »Triumph des Sesshaften $\aleph^{11}$ bezeichnete Prozess einer weitgehenden Zurückdrängung tatsächlich nomadisch lebender Gesellschaften in der Moderne gewesen zu sein. Vor diesem Hintergrund mutet es paradox an, dass das Nomadische seit Beginn des 20. Jahrhunderts zu einem zentralen Symbol der Moderne selbst avanciert ist: In seiner Ambivalenz vermag das Nomadische demnach einerseits Wurzellosigkeit und Entfremdung sowie die Gefahren eines entgrenzten Kapitalismus zu verkörpern; und weil es seit Ende des 19. Jahrhunderts zu den Zentralmetaphern des Migrationsdiskurses gehört, ist es zudem immer wieder zur Inszenierung von Bedrohungsängsten vor Zuwanderern herangezogen worden. Auf der anderen Seite fungiert das Nomadische bis in postmoderne Kulturtheorien hinein ${ }^{12}$ als Ausdruck fundamentaler Freiheit und steht für die Subversion hegemonialer politisch-ökonomischer Identitäten und Machtverhältnisse ${ }^{13}$.

Diese Ambivalenz lässt sich bereits in Darstellungen des 19. und frühen 20. Jahrhunderts aufzeigen. Während der Nomadenbezug der jüngeren Kulturtheorie jedoch vornehmlich symbolischer Natur ist, sich also

11 Jürgen Osterhammel, Die Entzauberung Asiens. Europa und die asiatischen Reiche im 18. Jahrhundert, München 1998, S. 267-270.

12 Vgl. exemplarisch Gilles Deleuze/Félix Guattari, Tausend Plateaus. Kapitalismus und Schizophrenie, Berlin 1997; Uwe Lindemann, Das Ende der jüngeren Steinzeit. Zum nomadischen Raum-, Macht und Wissensbegriff in der neueren und Kultur- und Medientheorie, in: Rudolf Maresch/Niels Weber (Hg.), Raum - Wissen - Macht, Frankfurt a.M. 2002, S. 214-234.

13 Vgl. allgemein Isabel Toral-Niehoff, Der Nomade, in: Eva Horn/Stefan Kaufmann/Ulich BRÖCKLING (Hg.), Grenzverletzer. Von Schmugglern, Spionen und anderen subversiven Gestalten, Berlin 2002, S. 80-97. 
nicht auf tatsächliche Nomaden bezieht, korrespondierte die Prominenz des Nomadischen um 1900 durchaus mit einem kulturhistorischen und ethnologischen Interesse am Leben nichtsesshafter Gesellschaften. In der zeitgenössischen ethnologisch-anthropologischen Literatur erschien der »Nomadismus« dabei in der Regel als ein »Jenseits der Kultur« und wurde in den von »Naturvölkern « bewohnten »geschichtslosen Räumen« verortet $^{14}$. Insbesondere Andrea Polaschegg hat jedoch auf den prinzipiellen Unterschied in der Repräsentation dieser »geschichtslosen Räume« auf der einen und »des Orients « auf der anderen Seite hingewiesen ${ }^{15}$ - ein Unterschied, der in der Regel nur unzureichend reflektiert wird. Mit Edward Saids OrientalismusThese etwa, wonach »der Orient« in europäischen Darstellungen des 19. und 20. Jahrhunderts vornehmlich als das unterlegene »Andere« präsent gewesen $\operatorname{sei}^{16}$, lässt sich das komplexe Netz an Identifikationen und Gegenidentifikationen in den Rekursen auf die unterschiedlichen Epochen, Räume und Akteure der orientalischen Geschichte und deren Funktion als Projektionsfläche zur Inszenierung »historisch-kultureller Stellvertreterkriege $\ll{ }^{17}$ kaum adäquat erfassen. »Der Orient« erschien in der historiographischen Repräsentation mithin weder als ein homogener noch als ein geschichts- und kulturloser Raum. Vielmehr ließe sich eher das Gegenteil behaupten: Die durch die Entzifferung der Keilschrift und die archäologischen Funde am Ende des 19. Jahrhunderts erschlossene Kulturwelt des Alten Orients hatte geradezu eine geohistorische Überdeterminierung dieses Raums zur Folge. Die daraus resultierende Vorstellung vom Orient als dem Ursprungsraum aller Kultur überhaupt hat sich schließlich in der Figur des »ex oriente lux« - ebenfalls ein nachhaltiges geohistorisches Narrativ ${ }^{18}$ - verdichtet und in Strömungen wie

14 Vgl. zu dieser Differenzierung in der anthropologisch-ethnologischen Literatur allgemein Andrew Zimmermann, Anthropology and Antihumanism in Imperial Germany, Chicago u.a 2001.

15 Andrea Polaschegg, Der andere Orientalismus. Regeln deutsch-morgenländischer Imagination im 19. Jahrhundert, Berlin u.a 2005, S. 135-142.

16 Vgl. Edward W. SAID, Orientalism, London 2003. Vgl. auch die Zusammenfassung der Kritik an der Orientalismus-These von Daniel Martin VARISCO, Reading Orientalism. Said and the Unsaid, Seattle u.a 2007.

17 Polaschegg, Orientalismus, S. 203f. Vgl. zum Panorama historischer Orientrekurse in Deutschland um 1900 Marchand, German Orientalism; ferner die Problemskizze bei Stefan R. HAUSER, Greek in subject and style, but a little distortet. Zum Verhältnis von Orient und Okzident in der Altertumswissenschaft, in: Stefan Altekamp/Matthias René Hofter/Michael Krumme (Hg.), Posthumanistische klassische Archäologie. Historizität und Wissenschaftlichkeit von Interessen und Methoden. Kolloquium Berlin 1999, München 2001, S. 83-104; eher im Sinne Saids argumentiert hingegen Eckhard MeYER-Zwieffelhoffer, Orientalismus? Die Rolle des Alten Orients in der deutschen Altertumswissenschaft und Altertumsgeschichte des 19. Jahrhunderts (ca. 1785-1910), in: Robert Rollinger u.a. (Hg.), Getrennte Wege. Kommunikation, Raum und Wahrnehmung in der alten Welt, Frankfurt a.M. 2007, S. 501-594.

18 Vgl. Ingo Wiwjorra, »Ex oriente lux« - »Es septentrione lux«. Über den Streit zweier Identitätsmythen, in: Achim Leube (Hg.), Prähistorie und Nationalsozialismus. Die mittel- und ost- 
dem sogenannten Panbabylonismus ${ }^{19}$ niedergeschlagen. Auch wenn dieses Geschichtsbild implizierte, dass die »Fackel der Kultur« im Grunde längst an den Okzident übergeben worden sei, somit in der Regel auf eine kulturelle Unterlegenheit des gegenwärtigen Orients abstellte und die entstehenden kolonialen Machtverhältnisse legitimierte, blieb eine prinzipielle Differenz zur symbolischen Repräsentation der »geschichtslosen Räume« doch zweifellos bestehen ${ }^{20}$.

Die Wüstennomaden hingegen scheinen dieser Differenzierung zunächst $\mathrm{zu}$ widersprechen, stellten sie in ihrer ambivalenten Wildheit doch eher so etwas wie ein »primitives «, außerhistorisches Element innerhalb des eminent geschichtlichen Raums "Alter Orient» dar. Dass aber Beduinen in der Geschichte Vorderasiens eine wichtige Rolle gespielt hatten, konnten Kulturhistoriker des 19. Jahrhunderts etwa dem in Europa breit rezipierten arabischen Historiker Ibn Chaldun (1332-1406) entnehmen ${ }^{21}$. An dessen Reflexionen anknüpfend kam der Frage nach der historischen Rolle des Nomadischen schließlich eine zentrale Bedeutung zu.

\section{2. »Nomadische Völkerfluten«}

Bis in das frühe 19. Jahrhundert hinein erschienen Nomaden im europäischen Geschichtsbild vorwiegend als destruktives Element ${ }^{22}$. In der späteren ethnologisch-anthropologischen Literatur ging es hingegen nicht mehr nur darum, die vermeintliche Kulturfeindlichkeit nomadischer Völker bloß zu konstatieren, sondern diese auch zu erklären. Das in diesem Zusammenhang wohl einflussreichste Modell formulierte der berühmte Leipziger Völkerkundler und Geograph Friedrich Ratzel (1844-1904). Ratzel ging von einer ursprünglichen Mobilität und Fluidität aller Völker - eine Art nomadischer Naturzustand - aus und glaubte, diese Bewegungen folgten physikalischen Gesetzen: »Wo freier Raum ist, da ergießen sich die Völker wie eine Flüssigkeit über breite Flächen und fließen soweit, bis ein Hindernis entgegentritt « ${ }^{23}$. Mit der Zeit aber, so Ratzel, hätten sich einige Völker verfestigt und in bestimmten privilegierten Räumen als Ackerbauern niedergelas-

europäische Ur- und Frühgeschichtsschreibung in den Jahren 1933-1945, Heidelberg 2002, S. 73-106.

19 Vgl. Marchand, German Orientalism, S. 236-244.

20 Vgl. Polaschegg, Orientalismus, S. 135-142.

21 Vgl. Ibn Khaldun, The Muqaddimah. An Introduction to History, 3 Bd., London 1958; zur Rezeption vgl. Aziz Al-Azmen, Ibn-Khaldun in Modern Scholarship. A study in Orientalism, London 1981.

22 Vgl. Osterhammel, Entzauberung Asiens, S. 235-270.

23 Friedrich Ratzel, Der Ursprung und das Wandern der Völker geographisch betrachtet, Teil 1, in: BVSGW.PH 50 (1898), S. 1-75, hier S. 14. 
sen. Dabei erklärte er Sesshaftigkeit zur fundamentalen Voraussetzung von Kultur überhaupt: »Was festhält, ist kulturfördernd. Das ist das allgemeine Gesetz « ${ }^{24}$. Die umgebenen Wüsten und Steppen jedoch seien weiterhin von Völkern im flüssigen - nomadischen - Aggregatszustand bevölkert, deren »beständige[s] Ebben und Fluten $\aleph^{25}$ eine anhaltende Bedrohung der »Kulturgebiete« bedeute:

Wenn solche Völker einen Anstoß empfangen, der sie über die Grenzen ihres alten Wanderungsgebietes hinaus treibt, treffen sie mit einem zertrümmernden Gewicht auf ihre Nachbarn. [...] Für einen solchen Zug ist das Bild eines glühenden Lavastroms, der alles versengt, wohin er sich bewegt, nicht zu gewagt ${ }^{26}$.

Die Attraktivität Ratzels’ dichotomer kulturhistorischer Gegenüberstellung von Nomaden und Ackerbauern basierte dabei nicht zuletzt auf einer eingängigen Metaphorik. So griff er nachhaltig auf das seinerzeit modische geologische und thermodynamische Vokabular zurück und bezeichnete die Herkunftsgebiete der Nomaden als »Völkerkessel«, »in den von allen Seiten die Massen zusammenfließen und sich brodelnd mischen ${ }^{27}{ }^{27}$ Tatsächliche oder vermeintliche - historische wie aktuelle - Wanderungsbewegungen erschienen somit nicht als soziale Prozesse, sondern wurden als eruptive Erschütterungen oder Ausbrüche $»$ nomadische[r] Völkerfluten $«{ }^{28}$ imaginiert und naturalisiert.

Analoge Figuren haben schließlich nicht nur Eingang in den politischen Migrationsdiskurs zu Beginn des 20. Jahrhunderts gefunden ${ }^{29}$, sondern sind auch umgehend zur Interpretation historischer Wanderungsbewegungen herangezogen worden. Für die Kulturgeschichtsschreibung des Vorderen Orients sollte sich vor allem die Adaption dieses Modells durch den Berliner Assyriologen und Archäologen Hugo Winckler (1863-1913) als wichtig erweisen. Wincklers Texte kreisten um periodische $»$ Völkerwellen«, die die Geschichte des Orients bestimmten ${ }^{30}$. Von welcher Richtung her die »Überschwemmung der Kulturländer Vorderasiens« dabei immer am akutesten gedroht habe, machte er dabei unmissverständlich klar - es waren »die hungernden und beutegierigen Scharen Arabiens« - also die Beduinen:

24 Ders., Völkerkunde, Bd. 3: Die Kulturvölker der Alten und Neuen Welt, Leipzig 1890, S. 8.

25 Ebd., S. 35.

26 RATZEL, Ursprung und Wandern I, S. 36.

27 Ebd., S. 69.

28 Ders., Politische Geographie, München u.a ${ }^{3} 1923$, S. 74.

29 Vgl. Ute Gerhard, Nomadische Bewegungen und die Symbolik der Krise. Flucht und Wanderung in der Weimarer Republik, Opladen 1998.

30 Hugo Winckler, Auszug aus der vorderasiatischen Geschichte, Leipzig 1905, S. 3. 
Je länger seine [des Beduinen, F.W.] Angriffe vom Kulturlande aus durch eine starke Staatsgewalt zurückgewiesen werden, um so größer wird die Volksmenge, welche die Heimat Arabien in ihren weiten Steppen und Wüsten birgt, und umso wuchtiger schließlich der Anprall, der sich über das Kulturland ergießt, bis ihm die Umstände hier einen Abfluss eröffnen ${ }^{31}$.

Aus der Perspektive des Assyriologen aber stellten die Beduinen nur eine historische Völkergruppe der arabischen Wüste dar, betrachtete er die Araber doch lediglich als den jüngsten Zweig einer größeren Völkerfamilie der »Semiten«. Diese aber spielten im zeitgenössischen historisch-philologischen Diskurs generell eine zentrale Rolle ${ }^{32}$. Besonders kontrovers wurde dabei die seinerzeit als essentiell angesehene Frage nach der »Urheimat" dieser Völkerfamilie diskutiert ${ }^{33}$. Indem Winckler »Innerarabien« als zentrale »semitische Völkerkammer ${ }^{34}$ deklarierte, positionierte er sich in dieser Debatte, veränderte aber zugleich auch den geohistorischen Status dieses vermuteten Herkunftsraums: Während etwa Eberhard Schrader, der erste deutsche Lehrstuhlinhaber für Assyriologie, in einem klassischen Aufsatz über die Die Abstammung der Chaldäer und die Ursitze der Semiten (1873) Arabien als »Ausgangspunkt« konkreter historischer Wanderungen einzelner semitischer Völker zu bestimmen suchte ${ }^{35}$, fungierte die arabische Wüste bei Winckler als eine permanente »Völkerwellen« produzierende »Völkerkammer« und somit als ein eigenständiger historischer Faktor:

Die Geschichte des Altertums bis auf den Beginn des sogenannten Mittelalters zeigt ein unaufhörliches Auftauchen nomadischer, unzivilisierter Stämme, welche in die Kulturländer eindringen $[. . .]^{36}$.

Winckler glaubte sogar, ein Muster erkannt zu haben, wonach der Vordere Orient alle tausend Jahre von semitisch-nomadischen »Völkerwellen« aus der arabischen Wüste »überschwemmt« würde, die sich dann in den »Kul-

31 Ders., Die Völker Vorderasiens, Leipzig 1899, S. 10.

32 Im Gegensatz zur Genese der Kategorie des Semitischen an der Wende zum 19. Jahrhundert ist der Diskurs über die semitischen Völker um 1900 bisher nur unzureichend untersucht worden. Vgl. aber die Hinweise bei Marchand, German Orientalism, S. 321-323.

33 Grob lassen sich in dieser Debatte drei Lokalisierungen der semitischen »Urheimat« unterscheiden: Zentralasien (vgl. Fritz Hommel, Die semitischen Völker und Sprachen. Als erster Versuch einer Enzyclopädie der semitischen Sprach- und Alterthums-Wissenschaft, Bd. 1, Leipzig 1883), Nordafrika (vgl. Theodor NöLdEKE, Die semitischen Sprachen. Eine Skizze, Leipzig 1887) und eben Innerarabien (vgl. WiNCKLER, Völker Vorderasiens).

34 Ebd., S. 15.

35 Eberhard Schrader, Die Abstammung der Chaldäer und die Ursitze der Semiten, in: ZDMG 27 (1873), S. 397-424, hier S. 403.

36 Hugo Winckler, Die politische Entwicklung Babyloniens und Assyriens, Leipzig 21903, S. 3. 
turgebieten« in distinktiven »Schichten« quasi sedimentierten und akkulturierten $^{37}$. Auf diese Weise verdichtete sich die Geschichte dieses Raums zu einem ständigen Zyklus von Aufbau und Zerstörung, wobei der destruktive Part den semitischen Nomaden zugewiesen wurde.

Eine universitäre Karriere blieb Winckler allerdings zeitlebens verwehrt; vielmehr gehörte er zu der von Suzanne Marchand als »furiose Orientalisten« charakterisierten Strömung akademischer Außenseiter, die auf eine Popularisierung ihrer in der Regel weitreichenden Thesen in Form ")gemeinverständlicher« Schriften setzten ${ }^{38}$. Nicht zuletzt deshalb ist sein Modell semitisch-nomadischer Wanderungswellen auch außerhalb der Fachdisziplin - und über den deutschen Sprachraum hinaus - recht schnell rezipiert worden und hat die kulturhistorische Darstellung des Vorderen Orients zu Beginn des 20. Jahrhunderts nachhaltig geprägt ${ }^{39}$.

So präsentierte auch der berühmte Universalhistoriker Eduard Meyer (1855-1930) im Orientband seiner Geschichte des Altertums (1884) »die Wüstenstämme« vornehmlich »als Ursache plötzlicher und gewaltiger Katastrophen im Leben der Culturvölker ${ }^{40}{ }^{40}$ und bezog sich in diesem Zusammenhang in späteren Auflagen nachhaltig auf Wincklers Modell ${ }^{41}$. Für Meyer und andere Altorientalisten spielte der Topos des semitischen Kulturnomaden vor allem in der Debatte um die »sumerische Frage« eine zentrale Rolle ${ }^{42}$. Dabei ging es um die Sprecher jener offenkundig nicht-semitischen Sprache im frühen Südmesopotamien, die man nach Entzifferung der Keilschrift auf babylonischen und assyrischen Tontafeln ausgemacht und, einer zeitgenössischen philologischen Klassifizierung folgend, als »turanisch $\aleph^{43}$ identifiziert hatte. Für die vermeintlich aus Zentralasien eingewanderten babylonischen Turanier etablierte sich schließlich die Bezeichnung »Sumerer«, in Abgren-

37 Ders., Auszug, S. 3f.

38 Vgl. Marchand, German Orientalism, S. 212-251. Seine akademische Karriere litt darunter, dass er die zentrale Figur des umstrittenen Panbabylonismus war. Vgl. Renger, Altorientalistik, S. 164f.

39 Vgl. exemplarisch Bruno Meissner, Babylonien und Assyrien. Erster Band, Heidelberg 1920, S. 16f.; Carl Bezold, Ninive und Babylon, Bielefeld u.a. ${ }^{2} 1903$, S. 23f.; Alfred Cord Haddon, The Wanderings of Peoples, Cambridge 1911, S. 19f.; Egon Friedell, Kulturgeschichte Ägyptens und des alten Orients, München 1998 [1936], bes. S. 344-351.

40 Eduard Meyer, Geschichte des Altertums., Bd. 1: Geschichte des Orients bis zur Begründung des Perserreichs, Stuttgart 1884, S. 207.

41 Ders., Geschichte des Altertums, Bd. 1.2: Die Ältesten Geschichtlichen Völker und Kulturen, Stuttgart u.a. ${ }^{3} 1913$, S. 388.

42 Vgl. die zeitgenössische Darstellung der Debatte von Franz H. Weissbach, Die sumerische Frage, Leipzig 1898.

43 Unter der Kategorie des Turanischen versuchte man, verschiedene europäische und zentralasiatische Sprachen (Finnisch, Ungarisch, Mongolisch, die Turksprachen etc.) zu einer Familie zusammenzufassen. Vgl. exemplarisch Friedrich Max MülLER, Letter to Chevalier Bunsen on The Classification of the Turanian languages, London 1854. 
zung zu den semitischen »Akkadern $\aleph^{44}$. Im Zentrum dieser Debatte stand die Frage nach dem jeweiligen Anteil dieser, so Meyer, »scharf voneinander geschiedene[n] Volksstämme« an der »Erschaffung« der frühen Hochkultur $^{45}$. Die These der nomadisch-semitischen Völkerwellen aber schloss die Akkader von der Rolle als Kulturbegründer von vornherein aus. Diese Rolle wurde nahezu einhellig an die Sumerer vergeben. Exemplarisch sei hier auf den Heidelberger Assyriologen Carl Bezold verwiesen, der die Sumerer als »uraltes Kulturvolk«, die Semiten (Akkader) hingegen lediglich als eindringende nomadische »Völkermasse« präsentierte - »jenem ersten Volke an Kultur kaum ebenbürtig « ${ }^{46}$.

Zunehmend wurde in diesem Zusammenhang auch auf anthropologische und rassentheoretische Denkfiguren zurückgegriffen. Seine Brisanz bezog das Thema dabei nachgerade aus der zeitgleichen Debatte um die »Judenfrage«, und nicht zu Unrecht ist die Kontrastierung von Sumerern und Semiten denn auch als »eine historisch-archäologische Variante des Antisemitismus $\ll ~^{47}$ bezeichnet worden. Dezidierte Parallelen zur Gegenwart und damit der Schritt in den offenen Antisemitismus sind in der assyriologischen Literatur allerdings eher selten gemacht worden. Als Vorreiter tat sich in dieser Hinsicht aber ausgerechnet der bekannteste deutsche Assyriologe, Friedrich Delitzsch (1850-1922), hervor. Delitzsch erinnerte in seiner Spätschrift Die große Täuschung (1920) an das »hochbegabte, an Sinnesart dem deutschen Volk vergleichbare sumerische Volk«, dessen Kultur von einwandernden Semiten aus der Wüste "gründlich aus- und aufgesogen« worden sei - um anschließend die Bedrohung durch die aktuellen semitischen Nomaden heraufzubeschwören: »Die mindestens gleiche Gefahr stellt das jüdische Volk dar, seitdem es freiwillig vaterlandslos geworden $\aleph^{48}$.

An dieser Stelle kann die komplexe Beziehung des orientwissenschaftlichen Semiten- und Nomadendiskurses zum aufkommenden politischen Antisemitismus am Ende des 19. Jahrhunderts lediglich angedeutet werden. Keineswegs jedenfalls wurden die Semiten hier ausschließlich als unterlegenes Anderes repräsentiert; und neben der Anordnung als asymmetrische

44 Vgl. zur Forschungsgeschichte Svend Aage Palbis, The Antiquity of Iraq. A Handbook of Assyriology, Copenhagen 1956, S. 175-185 sowie BEzold, Ninive und Babylon.

45 Eduard Meyer, Sumerier und Semiten in Babylonien, Berlin 1906, S. 107.

46 Bezold, Ninive und Babylon, S. 22.

47 Andrea BECKER, Neusumerische Renaissance? Wissenschaftsgeschichtliche Untersuchungen zur Philologie und Archäologie, in: BaghM 16 (1985), S. 229-316, hier S. 237. Vgl. auch Jerrold S. Cooper, Sumerian and Aryan. Racial Theory, Academic Politics and Parisian Assyriology, in: Revue d'Histoire des Religions 210 (1993), S. 169-205; Arkadiusz SoltySIAK, Physical Anthropology and the »Sumerian Problem«, in: Studies in Historical Anthropology 4 (2004), S. 145-158.

48 Friedrich Delitzsch, Die große Täuschung. Kritische Betrachtungen zu den alttestamentlichen Berichten über Israels Eindringen in Kanaan, die Gottesoffenbarung am Sinai und die Wirksamkeit der Propheten, Stuttgart u.a. 1920, S. 103. 
Gegenbegriffe ${ }^{49}$ konnte das Verhältnis von »Ariern« und »Semiten« durchaus auch komplementär gedacht werden ${ }^{50}$. Von einem engen Bezug zwischen orientwissenschaftlicher und politischer Diskussion zeugt indes bereits der krause Begriff »Antisemitismus« selbst: Vermutlich zunächst in der kritischen Auseinandersetzung mit den Thesen des französischen Orientalisten Ernest Renan (1823-1892) über die vermeintliche Unterlegenheit der semitischen Völker geprägt, ist der Begriff später von Protagonisten der antisemitischen Bewegung als Selbstbezeichnung adaptiert worden ${ }^{51}$. Dass in diesem Kontext die Nomadismus-Theorien schon früh eine Rolle spielten, zeigt etwa das Machwerk des Wiener Orientalisten Adolf Wahrmund (1827-1913) Das Gesetz des Nomadentums und die heutige Judenherrschaft (1887), ein Schlüsseltext antisemitischer Ideologiebildung am Ende des 19. Jahrhunderts. Darin interpretierte Wahrmund die vermeintlichen Machenschaften der Juden vor dem Hintergrund ihres »nomadisch-semitischen« Charakters und beschwor entsprechend die Bedrohung durch diese »nomadisierenden Abschäumer und Abfeimer der ansässigen Völker« herauf ${ }^{52}$. In der Folge avancierte der ausgemachte ewige Gegensatz zwischen schaffenden Bauern- und schmarotzenden Nomadenvölkern in der judenfeindlichen Literatur zur Standardfigur, die vor allem die vermeintliche Verantwortung der Juden für die Folgen des modernen Kapitalismus belegen sollte ${ }^{53}$. In diesem Sinne glaubte noch der Soziologe Werner Sombart (1863-1941) in seiner Abhandlung über Die Juden und das Wirtschaftsleben (1911) die angebliche Prädestination dieses »Wüsten- und Wandervolkes« für den Handel aus einem nomadischen Erbe heraus erklären zu können, da sich der »Nomadismus in fast allen Punkten als der Vater des Kapitalismus« erwiesen habe ${ }^{54}$.

49 Vgl. Reinhart KoselLeck, Zur historisch-politischen Semantik asymmetrischer Gegenbegriffe, in: Ders., Vergangene Zukunft. Zur Semantik geschichtlicher Zeiten, Frankfurt a.M. 1979, S. 251-259.

50 Vgl. exemplarisch Hommel, Semitische Völker und Sprachen.

51 Vgl. Ernest Renan, Histoire générale et système comparé des langues sémitiques, Paris 1855. Renan fungiert in der postkolonialen Literatur als Inbegriff des »orientalistischen« Wissenschaftlers (vgl. SAID, Orientalism, S. 130-148). Indes scheint seine Repräsentativität durchaus zweifelhaft; so stand gerade die deutsche Orientalistik seinen Thesen skeptisch gegenüber (vgl. Hanisch, Exegeten, S. 23f.; Wоковск, German Orientalism, S. 8f.). Als mutmaßlich erster Beleg des Begriffs »Antisemitismus« im Kontext dieser Debatte gilt Moritz STeinschneIder, Hebräische Bibliographie, in: Blätter für neuere und ältere Literatur des Judentums 2 (1860), S. 16. Vgl. allg. Moshe Zimmermann, Aufkommen und Diskreditierung des Begriffs Antisemitismus, in: Ders., Deutsch-jüdische Vergangenheit. Der Judenhass als Herausforderung, Paderborn 2005, S. 25-40.

52 Vgl. Adolf Wahrmund, Das Gesetz des Nomadentums und die heutige Judenherrschaft, Leipzig 1887, S. 147.

53 Vgl. zur Figur des Nomadischen in der judenfeindlichen Literatur die Hinweise bei Uffa Jensen, Gebildete Doppelgänger. Bürgerliche Juden und Protestanten im 19. Jahrhundert, Göttingen 2005, bes. S. 180-183; Gerhard, Nomadische Bewegungen, S. 153-188.

54 Werner Sombart, Die Juden und das Wirtschaftsleben, Leipzig 1911, S. VII u. 425f. 


\section{3. »Der edle Beduine«}

Keineswegs jedoch verkörperten die Beduinen in europäischen Modellen zur Geschichte des Vorderen Orients ausschließlich ein destruktives Element - charakteristisch an der Figur des Nomadischen scheint ja vielmehr ihre Ambivalenz. Bereits in der antiken Literatur, etwa in Herodots Darstellung der Skythen, lässt sich denn auch ein dem negativen Nomadenbild entgegenlaufender Strang aufzeigen, der auf Romantisierung und Idealisierung abzielt und das Nomadische als Gegenbild eines dekadenten sesshaften Lebens präsentiert ${ }^{55}$. In der arabischen Tradition manifestierte sich das romantische Deutungsmuster schließlich in der Stilisierung der Beduinen zum Inbegriff authentischer arabischer Kultur und Lebensweise - ein Mythos, der bis heute Bestandteil arabisch-muslimischer Identitätsmodelle ist. Zweifellos haben diese Vorstellungen auch nachhaltig auf jene europäischen Arabien-Reisenden abgefärbt, durch deren Berichte sich die Figur des »edlen Beduinen« im Europa des 19. Jahrhunderts verbreiten sollte. Vor dem Hintergrund der europäischen Zivilisationskritik entwickelte sich daraus eine spezifische Variante der Beduinenromantik, die sich durchaus von der arabischen Tradition unterschied, keineswegs aber als rein europäische (»orientalistische«) Erfindung gelten $\mathrm{kann}^{56}$.

Unter den Reiseberichten des späten 18. und frühen 19. Jahrhunderts sind in diesem Zusammenhang vor allem zwei Darstellungen zu nennen, die lange Zeit als geradezu kanonisch galten: Die Beschreibung von Arabien (1772) Carsten Niebuhrs und die Bemerkungen über die Beduinen und Wahabi (1835) Johann Ludwig Burckhardts. Die 1760 gestartete dänische - aber von dem Göttinger Orientalisten Johann David Michaelis konzipierte - ArabienExpedition, der Carsten Niebuhr (1733-1815) angehörte und die er als einziger überlebte, gilt als das erste europäische Projekt zur empirischen Erforschung des arabischen Raums überhaupt ${ }^{57}$. In seinem berühmten Reisebericht zeigte sich Niebuhr bemüht, das die ältere Literatur durchziehende Vorurteil, die Araber seien grundsätzlich »ungesittet, habgierig und räuberisch $\aleph^{58}$, zu ent-

55 Vgl. Herodot, Historien 4, § 1-142.

56 Vgl. hierzu grundlegend Isabel Toral-Niehoff, Der edle Beduine, in: Monika Fludernik u.a. (Hg.), Der Alteritätsdiskurs des Edlen Wilden. Exotismus, Anthropologie und Zivilisationskritik am Beispiel eines europäischen Topos, Würzburg 2002, S. 281-296. Die Autorin zeigt, dass die europäische Beduinenromantik wiederum auf die arabische zurückwirkte, so dass der Topos des edlen Beduinen letztlich als Hybridbildung angesehen werden kann.

57 Vgl. Josef Wiesehöfer/Stephan Conermann (Hg.), Carsten Niebuhr (1733-1815) und seine Zeit. Beiträge eines interdisziplinären Symposiums vom 7.-10. Oktober 1999 in Eutin, Stuttgart 2002.

58 Carsten Niebuhr, Beschreibung von Arabien. Aus eigenen Beobachtungen und im Lande selbst gesammelten Nachrichten, Kopenhagen 1772, S. X. Vgl. zum tradierten Topos des arabischen Räubers Annette KATZER, Araber in deutschen Augen. Das Araberbild der Deutschen vom 16. bis zum 19. Jahrhundert, Paderborn u.a. 2008, S. 220-244. 
kräften. Von einer detaillierten ethnographischen Beschreibung der Beduinen kann hingegen erst ein halbes Jahrhundert später bei dem Schweizer Wüstenreisenden Johann Ludwig Burckhardt (1784-1817) die Rede sein, der allerdings weniger Glück hatte als Niebuhr und seinen Orientaufenthalt nicht überlebte ${ }^{59}$. In seinem posthum erschienenen Bericht rühmte er die Beduinen als »wildeste Söhne der Freiheit« und rechnete sie zu den »edelsten Nationen« überhaupt ${ }^{60}$. Wie Niebuhr wollte Burckhardt dem Stereotyp des barbarischen Nomaden entgegenwirken und betonte den hohen $»$ moralischen Charakter der Beduinen«, wie er sich in Tugenden wie Großmut, Geselligkeit und Mitleid manifestiere ${ }^{61}$.

Die Darstellungen Niebuhrs und Burckhardts trugen erheblich dazu bei, dass sich der »stolze« und »freie« Beduine in der Literatur bis hin zu Karl May als feste Größe etablierte. Vor allem aber dürften sie so manche Nachfolger angeregt haben, sich auf das Abenteuer einer Reise in die arabische Wüste einzulassen. Derartige Reisen waren während des 19. Jahrhunderts aus Gründen der kolonialen Machtverteilung zunächst ein vornehmlich britisches Metier. Angefangen von der legendären Lady Hester Stanhope hat die britische Tradition über den berühmten Thomas Edward Lawrence (»of Arabia «) bis zum eingangs zitierten Wilfred Thesiger eine Reihe schillernder Figuren hervorgebracht, deren Berichte im deutschen Sprachraum erstaunlich schnell rezipiert - oft auch übersetzt - worden sind und mithin das deutsche Beduinenbild nachhaltig mitgeprägt haben. Bei den britischen Wüstenreisenden stand die Faszination des Nomadischen zweifellos immer im Zentrum, so dass in diesem Zusammenhang sogar von einer »English obsession ${ }^{62}$ gesprochen worden ist. Dreh- und Angelpunkt war dabei der Topos vermeintlich fundamentaler Freiheit und Ungebundenheit des nomadischen Lebens, wobei sich »Freiheit» nicht nur auf den scheinbar unbegrenzten Raum, sondern vor allem auf die angebliche persönliche Freiheit von gesellschaftlichen Restriktionen bezog. Mehr und mehr avancierte die Wüste in dieser Literatur zum subjektiven Erfahrungsraum des Reisenden, und die persönliche Begegnung mit dem Nomadischen galt dabei als unverzichtbarer Bestandteil eines anvisierten Prozesses der Grenzerfahrung und Selbstfindung ${ }^{63}$.

59 Vgl. zur Biographie Katharine Sim, Desert Traveller. The Life of Jean Louis Burckhardt, London 1969.

60 Johann Ludwig Burckhardt, Bemerkungen über die Beduinen und Wahaby. Gesammelt während seiner Reisen im Morgenlande, hg. v.d. Gesellschaft zur Beförderung der Entdeckung des Innern Afrika, Weimar 1831 [engl. 1830], S. 130 u. 288.

61 Ebd., S. 148.

62 John Ure, In Search of Nomads. An English Obsession from Hester Stanhope to Bruce Chatwin, London 2004.

63 Vgl. allg. Sari J. NAsir, The Arabs and the English, London 1979; Kathryn Tidrick, Heart- 
Der Typus des zivilisationsmüden Aussteigers und Abenteurers taucht unter den deutschsprachigen Wüstenabenteurern erst mit einiger Verspätung auf ${ }^{64}$. Um 1900 scheint das Feld eher von Privatgelehrten dominiert, bei deren Entscheidung, durch die arabische Wüste zu reisen, von vornherein archäologische und kulturhistorische Fragen eine wichtige Rolle spielten. In diesem Rahmen sei exemplarisch auf den Kölner Bankierssohn Max Freiherr von Oppenheim (1860-1946) und den österreichischen Theologen und Orientalisten Alois Musil (1868-1944) eingegangen, die um die Jahrhundertwende in der Region unterwegs waren und wegen ihres diplomatischgeheimdienstlichen Engagements während des Ersten Weltkriegs oft sowohl miteinander als auch mit Lawrence verglichen worden sind ${ }^{65}$. Beide zeigten sich nach ihrer Begegnung mit den Beduinen äußerst beeindruckt vom nomadischen Leben. Im Hintergrund stand dabei weniger eine schlechthinnige Begeisterung für das scheinbar Primitive als vielmehr die Faszination des Authentisch-Ursprünglichen. In diesem Sinne fungierten die Beduinen für Oppenheim als Inbegriff eines dem Strom der Zeit enthobenen Daseins: »Wie die Wüstensteppe seit Jahrtausenden dieselbe geblieben ist, so auch der Beduine: ein Herrenvolk, urwüchsig, primitiv, wild und kriegerisch, von Europas Kultur noch unbefleckt $\aleph^{66}$. Während zudem der negative Nomadendiskurs auf die nomadische Masse abhob, war das romantische Beduinenbild von vornherein eher individualistisch, vor allem aber dezidiert aristokratisch konnotiert, was Musil entsprechend auf die Formel von den Beduinen als dem $»$ Adel der Wüste $«{ }^{67}$ brachte. Im Fokus der Betrachtung stand hier stets der mit den Attributen des Heroischen versehene beduinische Mann: In den Augen von Wüstenreisenden wie Oppenheim verkörperte dieser ein Dasein, welches vor dem Hintergrund einer scheinbar unbarmherzigen - maskulinierten ${ }^{68}$ - Natur einer täglichen Bewährungsprobe glich:

Beguiling Araby. English Romance with Arabia, London 1989; Ben Amara, Desert in TravelWriting; URE, Nomads.

64 Vgl. allg. zu deutschen Arabien-Reisenden im 19. Jahrhundert Dagmar Heinze, Fremdwahrnehmung und Selbstentwurf. Die kulturelle und geschlechtliche Konstruktion des Orients in deutschsprachigen Reiseberichten des 19. Jahrhunderts, in: Karl HöLz u.a. (Hg.), Beschreiben und Erfinden. Figuren des Fremden vom 18. bis zum 20. Jahrhundert, Frankfurt a.M. 2000, S. 45-92; KATZER, Araber in deutschen Augen, S. 376-432.

65 Vgl. zu Oppenheim Gabriele Teichmann/Gisela Völger (Hg.), Faszination Orient. Max von Oppenheim. Forscher, Diplomat, Sammler, Köln 2001; zu Musil Johannes Bauer, Alois Musil. Wahrheitssucher in der Wüste, Wien u.a. 1989.

66 Max Freiherr von Oppenheim, Die Beduinen, unter Mitarbeit v. Erich BräUnLICH/Werner CAskel, Bd. 1: Die Beduinenstämme in Mesopotamien und Syrien, Leipzig 1939, S. 3f. Vgl. zu Oppenheims Beduinenbild Annegret NipPA, Tugendreiche Männer. Beduinenforschung, in: Teichmann/VöLger (Hg.), Faszination Orient, S. 140-175.

67 Alois Musil, Arabia Petraea, Bd. 3: Ethnologischer Reisebericht, Wien 1908, S. 23.

68 Vgl. Birgit Haennel, Die Erschütterung des abendländischen Subjekts. Das existentielle Landschaftsbild der Wüste als authentischer Ort von Männlichkeit im 19. Jahrhundert, in: Viktoria 
»Hart ist sein Leben, ein dauernder Kampf um das Dasein gegen Natur und Mensch $«{ }^{69}$. Der vermeintlich aristokratisch-heroische Charakter der Beduinen schlug sich zudem in markanten Beschreibungen des äußeren Erscheinungsbildes nieder. Entsprechend ließ man die ausgemachte habituelle »Haltung« und »Vornehmheit ${ }^{70}$ der Beduinen mit körperlichen Merkmalen wie »scharf ausgeprägten Gesichtszügen, schöner Nase, spitzem Kinn und muskulösen Gliedern ${ }^{71}{ }^{71}$ korrespondieren.

So handelte es sich bei der Figur des »edlen Beduinen« um eine durch zeitgenössische Männerphantasien angereicherte spezifische Variante des immer schon zur europäischen Zivilisationskritik gehörenden »edlen Wilden « ${ }^{72}$. Der edle Beduine zeichnete sich allerdings nicht durch ein befreites und naturverbundenes Leben in einem schlaraffenlandartigen Südseeparadies aus, sondern vermochte durch die Kargheit und Härte seiner Existenz zu überzeugen. In seiner vermeintlichen Authentizität und Ursprünglichkeit schien er historischem Wandel entzogen und fungierte somit als Brücke in ein heroisches Archaikum.

Es war vor allem die Überzeugung, die Beduinen verkörperten sowohl von ihrer körperlichen Erscheinung als auch von ihrer Sprache und Kultur her ein vermeintlich ursprüngliches und authentisches Arabertum, die die ethnographischen Berichte über die Beduinen für die Historiographie und Orientalistik interessant werden ließ, glaubte man doch daraus auf eine unmittelbare Nähe zu jenen »Ursemiten« schließen zu können, die man als bestimmenden Faktor in der Geschichte des Vorderen Orients ausgemacht hatte. Am Anfang stand dabei die Identifizierung der Beduinen mit den »Hebräern« des Alten Testaments. Diese Vorstellung war bereits ein Leitmotiv der von Michaelis initiierten Arabien-Expedition Niebuhrs gewesen, durchzog dann im 19. Jahrhundert die bibelwissenschaftliche ${ }^{73}$ und kulturgeographische ${ }^{74}$ Literatur und inspirierte auch noch Wüstenreisende wie Musil ${ }^{75}$. Nicht zuletzt stellte

Schmidt-Linsenhoff u.a. (Hg.), Weiße Blicke. Geschlechtermythen des Kolonialismus, Marburg 2004, S. 54-74.

69 Oppenheim, Beduinen 1, S. 3f. Vgl. hierzu allg. Felix Wiedemann, Heroen der Wüste. Männlichkeitskult und romantischer Antikolonialismus im europäischen Beduinenbild des 19. und frühen 20. Jahrhunderts, in: Ariadne. Forum für Frauen- und Geschlechtergeschichte 56 (2009), S. $62-67$.

70 Max Freiherr von Oppenheim, Vom Mittelmeer zum Persischen Golf. Durch den Hauran, die syrische Wüste und Mesopotamien, Bd. 2, Berlin 1900, S. 119f.

71 Musil, Arabia Petraea 3, S. 25.

72 Vgl. u.a. Karl-Heinz KoHL, Entzauberter Blick. Das Bild vom Guten Wilden und die Erfahrung der Zivilisation, Berlin 1981 sowie die Beiträge in FLUDERNIK, Alteritätsdiskurs des Edlen Wilden.

73 Vgl. exemplarisch Julius Wellhausen, Prolegomena zur Geschichte Israels, Berlin 2001 [1878].

74 Vgl. Carl Ritter, Die Erdkunde von Asien, 8 Bd., Bd. 1, 1. Abtheilung: Die Halbinsel Arabien, Berlin ${ }^{2} 1846$.

75 Vgl. Musil, Arabia Petraea 3, S. V. 
die romantische Assoziation von Beduinen und Hebräern auch in der jüdischen Orientromantik um 1900 bis in den Zionismus hinein eine zentrale Figur dar, über die eine positive Identifikation mit dem Orient - vorgestellt als »Rückkehr« zu den Wurzeln - erreicht werden sollte ${ }^{76}$.

Die Orientwissenschaftler des 19. Jahrhunderts interessierten sich in diesem Zusammenhang schließlich zunehmend auch für Körperbau und Habitus der Beduinen. Unter Rückgriff auf Methoden der zeitgenössischen physischen Anthropologie versuchte man entsprechend, anhand der Beschreibungen der Wüstenreisenden einen spezifisch »semitischen Typus« zu konstruieren, dessen Spuren es nun galt, im historisch-archäologischen Material zu identifizieren. Als zentrale Objekte dienten dabei die Repräsentationen verschiedener historischer Akteure (»Völker«) auf antiken Monumenten, die nun einer anthropologisch-typologischen Deutung unterzogen wurden. Anregungen in dieser Richtung finden sich bereits bei den Pionieren der physischen Anthropologie $\mathrm{e}^{77}$. In der Historiographie des Alten Orients ist die anthropologische Untersuchung vor allem ägyptischer und assyrischer Monumente jedoch erst gegen Ende des 19. Jahrhunderts nachhaltig adaptiert worden ${ }^{78}$. Eine wichtige Rolle spielten derartige Spekulationen insbesondere bei der Unterscheidung zwischen »semitischen« Akkadern und »turanischen« Sumerern. Hier war die Referenz auf archäologische Funde bald so selbstverständlich, dass dem erwähnten Assyriologen Bezold 1910 bereits ein »flüchtiger Blick« auf die Monumente genügte, »um die beiderseitigen Menschenrassen als grundverschieden anzuerkennen $\ll^{79}$.

Während Bezold allerdings zu den Anhängern von Wincklers Theorie der »semitischen Völkerfluten« zählte, von einem romantischen Nomadenbild bei ihm also mitnichten die Rede sein kann, betonten andere Autoren gerade das »edle« und »heroische« Erscheinungsbild der »Ursemiten« und ließen

76 Vgl. Ivan Davidson Kalmar/Derek J. Penslar (Hg.), Orientalism and the Jews, Hanover u.a. 2005 sowie den Literaturbericht von Markus KIRCHноғF, Erweiterter Orientalismus. Zu eurochristlichen Identifikationen und jüdischer Gegengeschichte im 19. Jahrhundert, in: Raphael Gross/Yfaat WeIss (Hg.), Jüdische Geschichte als Allgemeine Geschichte, Göttingen 2006, S. $99-119$.

77 Vgl. Bruce G. TRIgGer, A History of Archaeological Thought, Cambridge 22006, S. 167-171.

78 Vorreiter waren hier britische Archäologen. Vgl. u.a. George Rawlinson, The Five Monarchies of the Eastern World. Or the History, Geography, and Antiquities of Chaldaea, Assyria, Babylon, Media and Persia, Vol. I, London 1862, bes. S. 53-76 u. 295-309; W.M. Flinders Petri, The Earliest Racial Portraits, in: Nature. A weekly ilustrated Journal of science 39 (1888), H. 997, S. 128-130; Archibald Henry SAYCE, The Races of the Old Testament, Oxford ${ }^{2} 1893$ für den deutschen Kontext W. Max MülLER, Asien und Europa nach altägyptischen Denkmälern, Leipzig 1893.

79 Carl Bezold, Die Kulturwelt des alten Orients, in: Julius von Pflugk-Hartung (Hg.), Weltgeschichte. Die Entwicklung der Menschheit in Staat und Gesellschaft, in Kultur und Geistesleben, Bd. 3: Geschichte des Orients, Berlin 1910, S. 3-129, hier S. 3. Als weitere Beispiele seien genannt: Fritz Hommel, Geschichte Babyloniens und Assyriens, Berlin 1885, S. 261f.; Meyer, Geschichte des Altertums 1.2, S. $436 f$. 
sich dabei eindeutig von den Schilderungen der Wüstenreisenden inspirieren. In diesem Sinne wird das Auftauchen der ersten semitischen Einwanderer (Akkader) im südlichen Mesopotamien und deren Begegnung mit der sumerischen Hochkultur durch den Breslauer Assyriologen Bruno Meissner (1868-1947) folgendermaßen beschrieben:

Mit ihren hohen schlanken Körpern, ihren schmalen Gesichtern, auf denen die etwas gekrümmte Nase kühn hervorragte, den langen wehenden Bärten boten sie ein ganz anderes, stattlicheres Bild als die behäbigen Sumerer. Aber der höheren Kultur beugten sich jene doch willig ${ }^{80}$.

An der Vorstellung einer fundamentalen kulturellen Differenz und Unterlegenheit der Semiten gegenüber den Sumerern änderte sich dadurch freilich nichts - lediglich die Vorzeichen wurden umgedreht: Anstatt als bloße Zerstörer erscheinen die Semiten hier als unverbrauchte Kraft, die auf eine im Niedergang befindliche sumerische Kultur trifft. Der bei Meissner nur angedeutete Gedanke, die Semiten hätten die sumerische Kultur dadurch entscheidend verjüngt und somit vor dem Untergang bewahrt, ist schließlich von anderen Autoren weiter ausgeführt worden. So pries der Berliner Arabist Otto Weber (1877-1928) nicht nur das »naturfrische, urwüchsige Element« der »kühnen Söhne der Steppe«, die belebend auf die »absterbenden Völker « ${ }^{81}$ der Kulturzentren eingewirkt hätten, sondern griff in diesem Zusammenhang sogar explizit auf Wincklers Modell der periodischen semitischen »Völkerwellen« zurück. Dieses münzte er nun allerdings zugunsten der Semiten um:

In Arabien ist die Wiege aller semitischen Völker gestanden, von dort aus haben die ersten Semiten sich die Kulturwelt erobert, von dort aus sind Jahrtausende hindurch immer wieder frische Elemente nachgerückt und haben den semitischen Stamm der an ihrer Kultur degenerierten Vorläufer ergänzt; noch heute ist Arabien das Land, das semitische Eigenart am reinsten erhalten hat ${ }^{82}$.

Nur unschwer lässt sich hinter diesen Ausführungen das kulturpessimistische Gedankengut des fin de siècle ausmachen: Zum einen der Gedanke, Kulturen verfügten über einen bestimmten Lebenszyklus und bedürften, um nicht »abzusterben«, regelmäßiger vitaler Impulse, und zum anderen das damit einhergehende Theorem der Dekadenz - d.h. die Angst vor einer »zersetzenden Wirkung« durch die zunehmenden Bequemlichkeiten der mate-

80 Meissner, Babylonien und Assyrien, S. 16.

81 Otto Weber, Arabien vor dem Islam, Leipzig 1902, S. 3-5.

82 Ebd., S. $6 f$. 
riellen Kultur ${ }^{83}$. Hier aufscheinende Charakterisierungen der arabischen Nomaden als »Eroberer-« und »Herrenvolk« waren in der allgemeinen zeitgenössischen Wahrnehmung zudem keineswegs negativ besetzt, verwiesen sie doch auf Jugendlichkeit, Willenskraft und die Fundamente des nationalen Machtstaates. In diesem Sinne erweist sich die Figur des Kriegerischen in der zeitgenössischen kulturhistorischen Reflexion denn auch als ebenso ambivalent wie die des Nomadischen. So erkannte selbst Ratzel »in dem kriegerischen Charakter der Nomaden« nicht nur Barbarei und Zerstörung, sondern zugleich »eine große staatenschaffende Macht $\aleph^{84}$. Vor diesem Hintergrund müssen auch die seit Beginn des 19. Jahrhunderts verschiedentlich hergestellten Parallelen zwischen historischen Arabern und Germanen gesehen werden: Demnach verkörperten beide die schöpferische Kraft »junger Völker«, die aus von der Natur benachteiligten Regionen vorgestoßen seien und die dekadenten Zivilisationen der Antike überrannten ${ }^{85}$.

\section{Ausblick auf den anderen Orient: Fellachen und Juden}

Keinesfalls jedoch sollte die Romantisierung der Wüstennomaden mit einer Romantisierung »des Orients« im Allgemeinen verwechselt werden, wurde der edle Beduine doch stets von einem »innerorientalischen Anderen« begleitet.

Dies zeigen die scharfen Differenzierungen, die die Reiseschriftsteller zwischen den Beduinen als den »echten Vertreter[n] des Arabertums « ${ }^{86}$ und der übrigen Bevölkerung des arabisch-islamischen Raums vornahmen. Im 18. und frühen 19. Jahrhundert wurde die negative Rolle dabei in erster Linie den als apathisch, hinterhältig und despotisch dargestellten Türken zugewiesen. So hatte Niebuhr das von Stolz geprägte Verhalten der Beduinen gegen das »hochmütige Betragen der Türken $\ll{ }^{87}$ scharf abgegrenzt. Die antitürkische Stoßrichtung durchzieht dann insbesondere die britische Orientliteratur und hatte ihren Hintergrund zweifellos in den politischen Konstellationen und kolonialen Interessen der europäischen Herkunftsländer ${ }^{88}$.

83 Vgl. hierzu allg. grundlegend Fritz StERn, Kulturpessimismus als politische Gefahr. Eine Analyse nationaler Ideologie in Deutschland, Stuttgart 2005.

84 Ratzel, Völkerkunde 3, S. 6.

85 Vgl. hierzu Georg Stauth, Islam und westlicher Rationalismus. Der Beitrag des Orientalismus zur Entstehung der Soziologie, Frankfurt a.M. u.a. 1993, S. 101-121; Richard HeigL, Wüstensöhne und Despoten. Das Bild des Vorderen Orients in deutschsprachigen Weltgeschichten des 19. Jahrhunderts, Regensburg 2000, bes. S. 78-95.

86 Musil, Arabia Petraea 3, S. 23.

87 Niebuhr, Beschreibung von Arabien, S. 43.

88 Vgl. zur Ausspielung von Türken und Arabern Klaus KreIser, »Haben die Türken Verstand?« Zur europäischen Orient-Debatte im napoleonischen Zeitalter, in: Hans Stein (Hg.), Ulrich 
Je mehr sich jedoch die machtpolitische Schwäche des Osmanischen Reiches offenbarte und umso weniger die Türken als reale Bedrohung wahrgenommen wurden, desto mehr rückte eine innerarabische Differenzierung ins Zentrum: Die Ausspielung der als Ursprung und Kraftquell reinen Arabertums präsentierten Beduinen gegen die vermeintlich degenerierte, lediglich arabisch sprechende Bevölkerung der levantinischen und mesopotamischen Städte. Im Vergleich zur frühneuzeitlichen Reiseliteratur hatte sich hier ein bemerkenswerter Wandel vollzogen: Während vormals die Städter und Bauern gegenüber den als wild und räuberisch dargestellten Nomaden eindeutig den positiveren Rang bekleideten, drehte sich das Verhältnis nun geradezu ins Gegenteil ${ }^{89}$. Auf diesem Gebiet hatte sich insbesondere Burckhardt als Vorreiter hervorgetan und eine regelrechte Dekadenztheorie entwickelt, wonach »der Character der Beduinen deutlich an Energie« einbüße, sobald diese in nähere »Verbindung mit Städten und cultivierten Districten « träten ${ }^{90}$. Am Ende des 19. Jahrhunderts wurde dieser ausgemachte Gegensatz zunehmend in rassentheoretischen Kategorien gedeutet: Demnach verkörperten nur die Beduinen wahre »Vollblutaraber«, während die »Stadtaraber« als rassisch gemischt präsentiert wurden ${ }^{91}$. Diese Figur avancierte zu einer Art Leitmotiv der gesamten romantischen Wüstenliteratur bis hin zu Winfred Thesiger, der noch in den 1950er Jahren die »Mischlinge in den Städten« des arabischen Raums als »schmutzige[n] Schaum am Rand des Sandmeeres « ${ }^{92}$ bezeichnete. Auch die klassische Gegenüberstellung von Nomaden- und Bauerntum erfuhr in diesem Kontext eine Änderung der Vorzeichen. So präsentierte Musil »den Fellachen«, also den arabischen Bauern, als Inbegriff des Negativen:

Eigennützig im höchsten Grade, fabelt er dem Fremden alles Mögliche vor [...]. Er ist ein geborener Intrigant, der, wenn er etwas für sich zu gewinnen glaubt, die ganze Welt aufhetzt und entzweit. Seine Verschmitztheit spiegelt sich auch in seinen Gesichtszügen, die runder und voller sind als beim Araber [gemeint ist hier nur der Beduine, F.W.]. Auch heuchelt er gern religiöse Überzeugung, hat jedoch gewöhnlich nie so tiefen religiösen Sinn wie der Araber ${ }^{93}$.

Jasper Seetzen (1767-1811), Leben und Werk. Die arabischen Länder und die Nahostforschung im napoleonischen Zeitalter. Vorträge des Kolloquiums vom 23. und 24. September 1994 in der Landesbibliothek Gotha Schloß Friedenstein, Gotha 1995, S. 155-173; zum Wandel des Türkei-Bildes um 1800 PolaschegG, Orientalismus, S. 126-133; Osterhammel, Entzauberung Asiens, S. 304-308.

89 Vgl. zu diesem Wandel Katzer, Araber in deutschen Augen, bes. S. 156-163 u. 396-399.

90 BurcKhardt, Beduinen, S. 289f.

91 Oppenheim, Vom Mittelmeer zum Persischen Golf 2, S. 117.

92 Thesiger, Brunnen der Wüste, S. 103.

93 Musil, Arabia Petraea 3, S. 25. 
Durch solche Beschreibungen hat das negative Bild des »Levantiners« und »Fellachen« auch Eingang in allgemeine, nicht auf die Geschichte des Orients fokussierte kulturhistorische Modelle gefunden und verdichtete sich zu einer universalhistorischen Negativfigur. Exemplarisch sei in diesem Zusammenhang auf Oswald Spenglers Der Untergang des Abendlandes (1918/1922) verwiesen, fungierte der »Typus des Fellachen« hier doch als Paradebeispiel einer ihres »kulturfähigen Menschentums« verlustig gegangenen Bevölkerung und sollte mithin auf einen post-kulturellen Zustand des Abgestorbenund Erloschenseins verweisen: »Was einer Kultur folgt, nenne ich Fellachenvölker $[. ..] \ll^{94}$.

Nicht zuletzt aber hatte die Ausspielung von edlen Beduinen und degenerierten Städtern Auswirkungen auf den judenfeindlichen Diskurs. Schien das negative Bild des Nomadentums als einem »Jenseits der Kultur« und das daraus abgeleitete Modell einer rein negativen Rolle der Semiten in der Geschichte des Vorderen Orients geeignet, die vermeintlich nomadische Abkunft der Juden und deren Verwandtschaft mit den Beduinen zu unterstreichen, so musste die Beduinenromantik dieser Assoziation entgegenlaufen. Entsprechend etablierte sich denn auch neben der von Wahrmund bis Sombart favorisierten Verbindung von Juden- und Nomadentum in der antisemitischen Literatur ein scheinbar gegenläufiger Strang, der auf die vermeintliche Herkunft der Juden aus den levantinischen Städten und eine fundamentale Differenz zu den »reinen Semiten«, d.h. den Arabern, abstellte - eine Unterscheidung, die sich spätestens in den 1930er Jahren auch aus politischen Gründen als nützlich erweisen sollte ${ }^{95}$.

\section{Abschied vom geohistorischen Narrativ}

Das Bild der arabischen Beduinen in kulturhistorischen Deutungen des Vorderen Orients aus dem 19. und frühen 20. Jahrhundert oszillierte mithin ständig zwischen gegensätzlichen Polen und erweist sich somit als fundamental ambivalent: Mal erschienen die Wüstenaraber als bedrohliche Masse, mal als edles Herren- und Eroberervolk. Welche Perspektive dabei jeweils eingenommen wurde, hing weniger von der - direkten oder durch die Berichte anderer vermittelten - Begegnung mit "wirklichen« Beduinen ab, sondern korrespondierte vielmehr mit bestimmten zeitgenössischen kulturellen und politischen Strömungen (Fortschrittsglaube, Kulturpessimismus, Antise-

94 Oswald Spengler, Der Untergang des Abendlandes. Umrisse einer Morphologie der Weltgeschichte, München ${ }^{15} 2000$, S. 681 u. 760.

95 Vgl. exemplarisch Ludwig Ferdinand Clauss, Semiten der Wüste unter sich. Miterlebnisse eines Rassenforschers, Berlin 1937. Vgl. hierzu Felix Wiedemann, Der doppelte Orient. Zur völkischen Orientromantik des Ludwig Ferdinand Clauß, in: ZRGG 61 (2009), S. 1-24. 
mitismus etc.) in der eigenen (europäischen, deutschen) Gesellschaft. Von einem durch Kulturkontakt bewirkten Wandel des Geschichtsbewusstseins kann hier also kaum die Rede sein.

In ihrer Ambivalenz waren die Repräsentationen der Beduinen dabei zudem in ein komplexes Netz von Projektionen und Identifikationen sowie kontrastiven Konstruktionen verschiedener »orientalischer Völker« eingebunden, das sich keineswegs auf die binäre Figur eines simplen »Othering « reduzieren lässt. Dass »der Orient« mitnichten als homogener Raum vorgestellt wurde, zeigen insbesondere die Figuren des »innerorientalischen Anderen «. Diese spielten schließlich insbesondere für den aufkommenden Antisemitismus eine wichtige Rolle. So bot der Nomadendiskurs sowohl Platz für die Negativfigur des heimatlosen und kulturfeindlichen Schmarotzers als auch für die dem edlen Beduinen entgegengesetzte Figur des degenerierten städtischen Krämers - beide Imaginationen aber waren im antisemitischen Diskurs von konstitutiver Bedeutung.

Nicht nur vor diesem Hintergrund freilich sollte vor simplifizierenden Narrativen, die uns die Geschichte distinktiver Räume aus vermeintlichen geohistorischen Konstanten à la »Kultur versus Wüste« zu erklären vorgaukeln, Abstand genommen werden. Dies darf man auch von Journalisten und den Verfassern kulturbeflissener Reiseführer erwarten. 



\title{
Jeffrey Jaynes
}

\section{African Christians - Christians Visiting Africa}

\author{
The Early Modern Narrative Cosmographies from Breydenbach \\ to al-hassan Ibn Muhammad al-Wazzan (Leo Africanus)
}

For most Europeans in the early modern era, Africa remained a mystery; a wonderland that often captured the imagination of the masses, but confused the learned. Even with the recovery of ancient learning that distinguished much of the $15^{\text {th }}$ and $16^{\text {th }}$ centuries, Africa, its peoples and places remained unknown. Part of the confusion emerged from Africans themselves, like Claudius Ptolemy, the ancient cosmographer and geographer from Alexandria. When his world-changing geography was first translated into Latin during the early fifteenth century, then widely disseminated through print beginning in 1475, much of Africa and its experience remained misunderstood ${ }^{1}$. The northern coast of Africa appeared in the new atlases of Ptolemy's work with greater detail, but much of the continent remained »terra incognita « as noted on the familiar 1482 Ulm edition of Ptolemy's work (Figure 1).

What was generally true for the understanding of Africa was especially true for comprehending the religious character of the continent, primarily Muslim but with a residual Christian presence. This essay will explore the descriptions of African Christianity available in the large travel accounts and cosmographies that began to appear at about the same time as Ptolemy's geography: in the late $15^{\text {th }}$ century. Although European Christians tended to view any African religious expression as culturally »other « in order to support ambitious programs of conversion and conquest, the new information available in these massive collections eventually yielded a more nuanced understanding of the African Christian experience. Particular attention will be directed to four important travel narratives: 1.) Bernhard von Breydenbach's Peregrinatio in Terram Sanctam, a pilgrimage account first published in $1486^{2}$; 2.) the Cosmographia of Sebastian Münster, with particular attention

1 See Patrick Gautier Dalché, The Reception of Ptolemy's Geography, in: David Woodward (ed.), The History of Cartography, Vol. 3: Cartography in the European Renaissance, Chicago 2007, pp. 285-358; and Evelyn Edson, The World Map 1300-1492. The Persistence of Tradition and Transformation, Baltimore 2007, pp. 114-140.

2 Bernhard von Breydenbach, Sanctaru[m] peregrinationu[m] in montem Syon ad venerandu[m] 


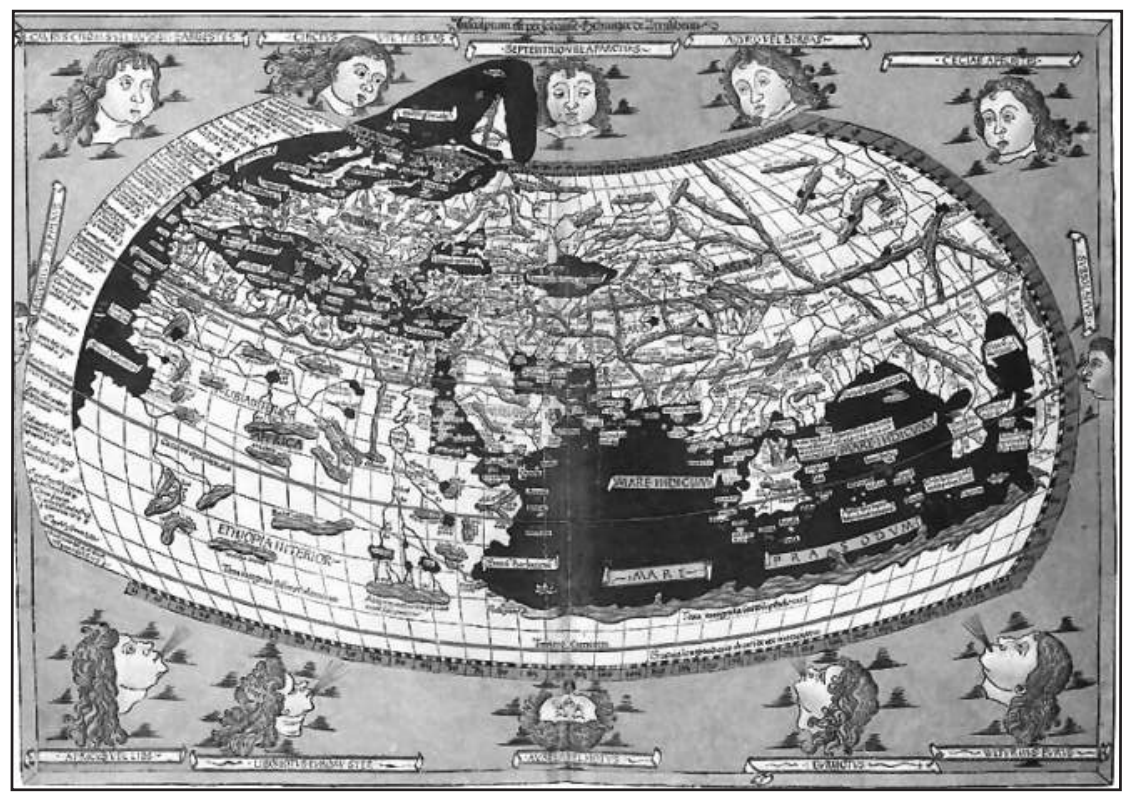

Figure 1: Claudius Ptolemy, Cosmographia, Ulm: Leinhart Holle, 1482, Newberry Library, Ayer *6 P9 1482.

to the much larger 1550 edition that was completed just before his death ${ }^{3}$; 3.) the accounts associated with Aloysius Cadamosto, made available in the travel collection of Fracanzano da Montalboddo, Paesi Novamenti Retrovati (1508) ${ }^{4}$; and 4.) the Descrittione dell' Africa written by al-Hasan ibn Muhammed al-Wazzan, later known as Leo Africanus and first published as part of Giovanni Ramusio's travel collection in $1550^{5}$.

Looking at African Christianity provides an important window into the larger theme of the encounter with the stranger. On the one hand these Africans were Christians, and therefore familiar to the religious understanding of their European observers. Yet, the construction of their exotic locale and

$\mathrm{x}[\mathrm{pis}] \mathrm{ti}$ sepulchru[m] in Jerüsalem at[que] in monte[m] Synai ad diua[m] virgine[m] et martire[m] Katherina[m] opusculum, Mainz 1486.

3 Sebastian MüNSTER, Cosmographia oder beschreibung aller lender, herschafften, fürnemsten stetten, geschichte[n], ... durch Sebastianum von Munsterum, Basel 1550.

4 Aloysius Cadamosto, in: Fracazano Da Montalboddo, Paesi novamente retrovati et novo mondo da Alberico Vesputio florentino intitulato, Vincenza 1507; as German translation: Jobst RUCHAMER (translator), Newe unbekanthe landte und ein newe weldt in kurtz verganger zeythe erfunden, Nürnberg 1508.

5 See Leo Africanus, Descrittione dell'Africa, in: Giovanni Battista Ramusio, Navigationi et Viaggi, Vol. 1, Venice 1550; also the French translation, Jean Temporal (transl.), Historiale Description de l'Afrique, tierce partie du monde, Lyon 1556. 


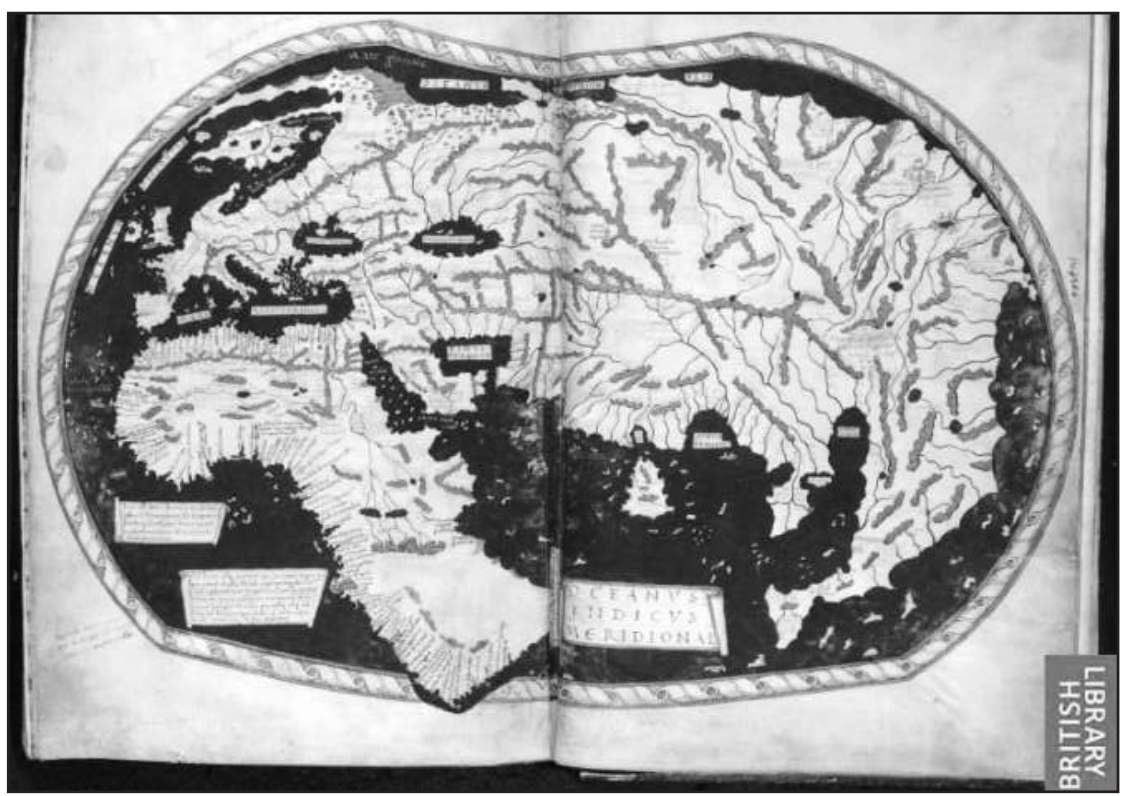

Figure 2: Heinrich Martellus Germanus, Insularium Illustratum, British Library Add. MS 15760, f. 68v-69.

their unfamiliar practice of a common faith tradition identified them as strangers. Myth and legend characterized most of these descriptions, as was often most evident in the fables associated with Prester John. Nevertheless, in some fashion, these accounts were attempts to grapple with something real: forms of Christian faith and experience that survived without the support or blessing of either Rome or Constantinople.

A glimpse of religious stereotypes, and in particular the understanding of African Christians, may be found on two important maps that accompanied this transitional era. The map associated with Heinrich Martellus Germanus (1489) was the first to depict the voyages of Bartholomew Dias around the South African cape in 1488, thus finally shattering the Ptolemaic image of Africa and the East $^{6}$ (Figure 2). Religious information is generally lean on this map, in contrast to earlier medieval »mappaemundi« or even the more recent Fra Mauro map of $1459^{7}$. Nevertheless, Martellus includes two impor-

6 The Martellus map appears in some printed versions of Cristoforo BuONDELMONTI, Insularium Illustratum (c. 1490); see British Library, Add MS 15760, fol. 68v-69.

7 For the dense religious iconography of the Fra Mauro map, see Piero FAlchettA, Fra Mauro's World Map with a Commentary and Translations of the Inscriptions, Turnhout 2006; and the earlier study of Fra Mauro illustrated, Placido ZurLA, Il mappamondo di Fra Mauro Camaldolese descritto e illustrato, Venice 1806. 


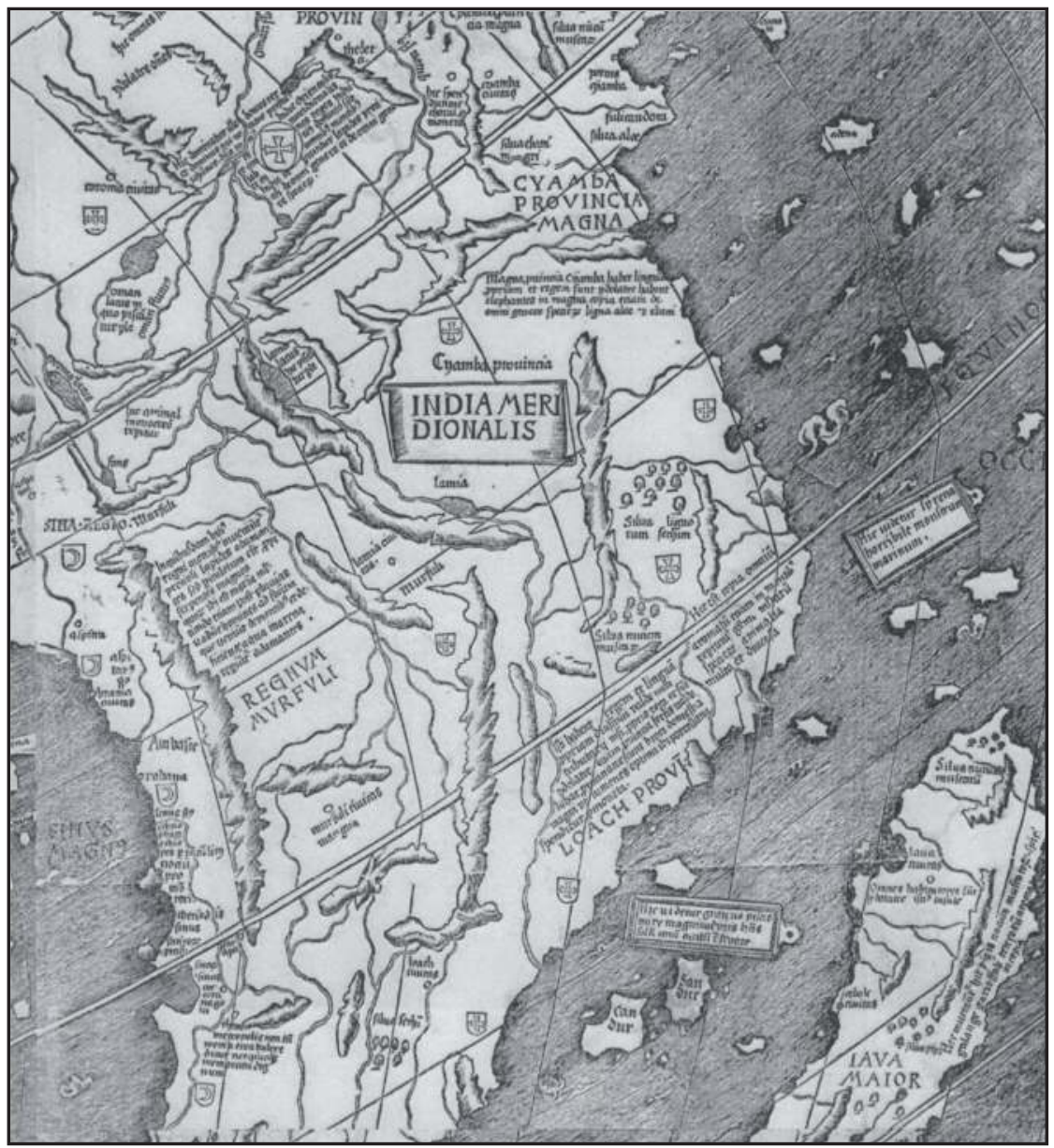

Figure 3: Detail of India from Martin WaldseemuelLer, Universalis Cosmographia Secundum Ptholomaei traditionem et Americi Vespucii aliorumque lustrationes, in: Joseph Fischer/Franz RitTER VON WiesER, Die aelteste Karte mit dem Namen Amerika aus dem Jahre 1507 und die Carta Marina aus dem Jahre 1516 des M. Waldseemueller (Ilacomilus), Innsbruck 1903, p. 14.

tant references to a Christian presence beyond the more carefully confined Western Christian empire. Following the lead of many, Martellus locates the legendary kingdom of the Christian prince, Prester John, in greater India, just above the dragon tail fragment later associated with Malaysia ${ }^{8}$. Martellus

8 The Martellus map inscription reads, »hic dominatus presbitur Johannes imperator totius Indie«, see Buondelmont, Insularium, British Library, Add MS 15760, fol. 69. 
also identifies a Christian kingdom in Western Africa, associated with another ruler labeled as Don Giovanni. This African Christian realm, however, was not ancient, but reflected more recent Portuguese mission efforts in the rim of Western Africa, notably in either Senegal or the Congo 9 . The information on the Martellus map is admittedly sketchy, but typical of the depictions available on maps or detailed in travel accounts, mired in myth and mildly confused with recent reports of conquests and conversion.

Just over a decade later, Martin Waldseemüller used the outline of the Martellus map to construct the first - and rather familiar - printed map that included the recently documented Western Hemisphere. Waldseemüller rehearsed the description of the Martellus map, locating the kingdom of Prester John in Asia ${ }^{10}$. He even constructed a rather elaborate schematic, employing crosses as boundary markers for the realm of the legendary ruler in India (Figure 3). Africa, on the other hand, he left mostly blank - at least regarding any religious claims - recognized most often for the elephant in Southern Africa.

Waldseemüller's second and lesser known large printed chart, the Carta Marina Navigatoria of 1516, essentially reversed the religious descriptions of the earlier map. The Carta Marina had much to say about the Christian presence in Africa. Waldseemüller's Carta Marina basically catalogued the various alienated Christian communities that existed outside of the sphere of the Western Latin Church. This residual and for Waldseemüller »heretical« Christian presence in Africa centered in the kingdoms of Nubia and Abyssinia (Ethiopia). By the early sixteenth century, the ancient Nubian kingdom and its Christian allegiance had severely eroded; nevertheless, Waldseemüller recalled the earlier presence of Christianity, associated in particular with the Coptic traditions of Egypt ${ }^{11}$. On the map, the legend states that the Nubians are schismatic Jacobite Christians, who practice a form of circumcision that is similar to that of the »Saracens«. In addition, he mentions their questionable understanding of original sin and even comments on their noteworthy monophysite Christology $\mathrm{y}^{12}$.

9 See Adrian Hastings, The Church in Africa 1450-1950, Oxford 1994, pp. 73-77; also Edson, World Map, pp. 215-219.

10 See the map reproduction and descriptions in Joseph FISCHER/Franz Ritter vON WIESER, Die älteste Karte mit dem Namen Amerika aus dem Jahre 1507 und die Carta Marina aus dem Jahre 1516 des M. Waldseemüller (Ilacomilus), Innsbruck 1903. The one known surviving copy of both maps is now on permanent display in the Jefferson Building, Library of Congress, Washington DC.

11 Hastings, The Church in Africa, pp. 67-70.

$12 » H i c$ omnes sunt Christiani iacobiti scismatici, circumcisione obseruant more saracenorum cremantus ferro in facien quo originali peccato nundari credunt nec mutuo conficetor peccata sed deo. Perfitentor quoque uniam naturam in Christo«, WaldSEEmüLler, Carta Marina 1516, in: Fischer/WIESER, Die älteste Weltkarte, p. 35. 


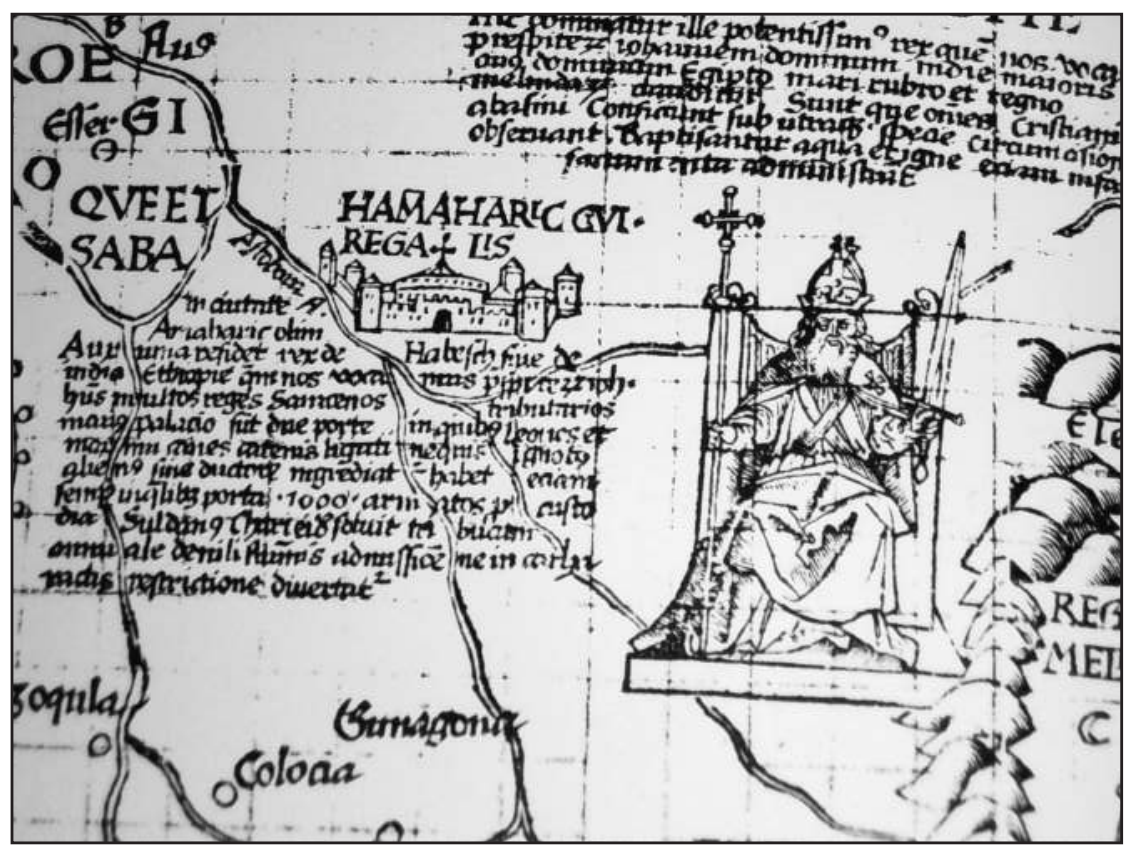

Figure 4: Detail of Prester John and his realm from Martin WaldSEemueller, Carta Marina Navigatoria, in: Joseph Fischer/Franz RitTer von Wieser, Die aelteste Karte mit dem Namen Amerika aus dem Jahre 1507 und die Carta Marina aus dem Jahre 1516 des M. Waldseemueller (Ilacomilus), Innsbruck 1903, p. 35.

Similar statements surround the figure of the legendary Prester John, the largest figure in Africa, identified as the $»$ Ruler of Habesch, of Greater India and Ethiopia " (Figure 4). Once again, the distinctive and troubling practices of these »Abyssinian Christians « are detailed ${ }^{13}$. The map notes how these Christians practiced a form of water baptism and also a rite of circumcision (again with fire), in a fashion somewhat similar to their Nubian neighbors. Both of these rituals were administered to infants. Overall, this very detailed religious information does not appear on any other printed map of the early $16^{\text {th }}$ century. In providing this primer on comparative Christianity, with an interest in clearly identifying religious outsiders, it appears that Waldseemüller has drawn rather extensively on the first printed travel literature of the early modern era.

$13 »$ Regnum Habesch et Habrici Prespiteri Iohannes Sive India Major Ethiopie ... hic dominatur ille potentissimus rex quem nos vocamus presbiterorum Iohannem, dominum indie maioris aug [atque] dominum Egipto mari rubro et regno melindarorum. Sunt que omnes Cristiani abasini. Confi[s]ciunt sub utraque specie, circumcisionem quoque obseruant, baptisantur aqua et igne etiam infanti faciam ante administrant «, WAldSEemüLler, Carta Marina. 
One very evident source for Waldseemüller's religious description of Africa was Bernard von Breydenbach's Peregrinatio in Terram Sanctam. As he described Jerusalem, Breydenbach gave special attention to the various religious parties represented in the Holy City: Muslims, Jews, and the broad spectrum of Christian communities which represented various parts of the world $^{14}$. His harsh polemic against what he regarded as infidel Muslims and stiff-necked, usurious Jews carried over into his unflattering descriptions of the Christian populations in the Holy City. These various Christian groups ranged from ancient Greeks and Syrians, to more geographically distant Nestorians, Armenians, and Abyssinians ${ }^{15}$. Breydenbach employed a similar formula in presenting each of these groups. First, he provided a general statement about the presence of the group in Jerusalem coupled with their land of origin. Next, he described particular religious customs or beliefs that deviated from the accepted understanding of the Roman church. Breydenbach then concluded each segment with some reference to the language of the group, often followed by an alphabetic table. In most editions of the Peregrinatio, the illustrator, Erhard Reuwich, included a rather stereotypical woodcut representation of the group and, in some instances, an alphabet.

Breydenbach was especially interested in African Christians: both Coptic Monophysites and adherents of the Abyssinian traditions. Breydenbach's discussion of the Nubian Coptic Christians provided the outline subsequently published on Waldseemüller's Carta Marina: first, a reference to the practice of circumcision, in the fashion of the Muslims; next a brief statement on their preference for making confession to God alone; and finally, an affirmation of their Monophysite identity, professing »the one nature of Christ ${ }^{16}$. Not surprisingly, Breydenbach commented fairly extensively on these traditions. In discussing circumcision, he explains that the Nubian Jacobites have misappropriated the Gospel reference to Jesus being baptized with »fire and water«, and erroneously applied this misunderstanding as they cauterized their children $^{17}$. Moreover, he notes that displaying a cross, branded on one's arm or

14 See Frederike Tiмm, Der Palästina-Pilgerbericht des Bernhard von Breidenbach und die Holzschnitte Erhard Reuwichs. Die Peregrinatio in terram sanctam (1486) als Propagandainstrument im Mantel der gelehrten Pilgerschrift, Stuttgart 2006, pp. 194-227.

15 See Vrej Nersessian, Bernard von Breydenbach's Peregrinatio in Terram Sanctam and Its Significance for Armenian Printing, Beirut 1992; also Tıмm, Palästina-Pilgerbericht, pp. 207-227.

16 See the German translation of Breydenbach's »Peregrinatio«: »Diese jacobini wan sÿ sich mit den creutz segnenen prauchen sÿ nitt mer dann eÿn finger/und das darumb als die kriechischen und Suriani von in sagen wann sÿ nit mer dann ein natur verjehen in Cristo«, Bernhard VON BREYDENBACH, Die fart oder reysz über mere zu dem heylige[n] grab vnsers herren Jhesu cristi gen Jherusalem Auch zu der heyligen iunckfrawen sant Katherinen grab auf dem berg Synai/Peregrinatio in terram sanctam, Augsburg 1488, p. [qv $\left.{ }^{\mathrm{v}}\right]$.

17 »Auch vil under inen zaichenen ire kinder wie die beschneidung an iren stirnen oder an baiden backen ... ursach genummen solichs zethus auß den wort sant Johannes baptista von cristo sprach Mathei am iiii Er wirt auch tauffen in den heiligen geist und feur/weliches wort vor ab 
back, was not a legitimate application of Jesus encouragement to »bear the cross $\aleph^{18}$. In discussing the Monophysite »heresy « of the Nubians, he even traces some early church history recalling how the teachings of Eutyches of Constantinople were condemned at the Council of Chalcedon. For later map readers, Waldseemüller simply condensed this material from Breydenbach.

Like Waldseemüller's map, the Peregrinatio also offered an evaluation of the Ethiopian Christians. In general, the tone evident in this text is slightly less derogatory, perhaps more tolerant of a Christian community, long isolated and understandably misinformed from Breydenbach's perspective. Both text and the later map note that the Ethiopians wrongly practiced the proper forms of Eucharistic observances, an error Breydenbach attributed directly to the Greeks ${ }^{19}$. Again, the practice of circumcision is noted, and Breydenbach criticizes the idea that somehow, John's reference to Jesus' baptism in fire and water provided the precedent for a form of circumcision that included cauterization with red-hot iron. Breydenbach even mentions a brief encounter he had with one of the Ethiopian Copts, and indicates how he tried to correct his erroneous literalism ${ }^{20}$.

Overall, Breydenbach provided important and distinctive glimpses into the African Christian presence. Undoubtedly, his characterization of African Christianity is predictably derogatory, and profoundly shaped by his own religious understanding. Nevertheless, Breydenbach's recognition of distinctive elements of Coptic and Abyssinian Christianities demonstrated some heightened awareness of these important ancient traditions.

Subsequently, Sebastian Münster's grand Cosmographia, also juxtaposed a militant vision of European Christianity with a subtle grasp of the ancient religious experiences of Africans ${ }^{21}$. Before looking at Münster's statements about Africa and the Christian experience there, it is important to highlight the tone of his writing. In his dedication to King Gustavus of Sweden, Mün-

das letzt seÿ allein nach den buchstaben halten und verstan/das doch in warheit ein gar andere mainung hat nach außlegung der heiligen lere das ich ÿetz fürgange«, vON BREYDENBACH, Peregrinatio, p. [qv].

$18 \leadsto$ Dye Iacobini tragen gemainklich creütz an iren armen mit eÿsen angetrucket umb reuerentz willen als sÿ sagen des heÿligen creutz Christi/das sÿ in großen eren halten«, ibid.

19 »Aber in warheit irren sÿ nitt allein in disem sunder auch in vil andern stucken/wan sÿ auch geheffelt brot prauchen als die kriechischen zu den sacrament des altars/und raichen das selb sacrament den iungen und alten under baider gestalt«, ibid., p. [qviii].

$20 » I c h$ het nit ein klein mitleiden mit inen/wann sÿ sunst güt lewt scheinen sind/darumb ließ ich sÿ fragen warumb sÿ solichs taten das wider die romisch kirch wäre/der sÿ sich neulich heten underworffen ...«, ibid.

21 For background on Münster and this grand project see, Matthew McLEan, The Cosmographia of Sebastian Münster. Describing the World in the Reformation, Aldershot 2007, pp. 5-44; Peter Meuer, Cartography in the German Lands 1450-1650, in: Woodward, The History of Cartography, pp. 1209-1213; and Karl Heinz Burmeister, Sebastian Münster. Versuch eines biographischen Gesamtbildes, Basel 1963. 
ster laments that Palestine and its holy shrines have become a wasteland: »Das heylig Landt hat vorzeiten geflossen mit Milch und Honig/aber jetzt ist es ein rauch/bitter/ungeschlacht Erdtrich $\aleph^{22}$. In the forward to the Cosmographia, he wrote even more pointedly about the tragic losses of large parts of the Christian world to Islam, notably in Africa:

und seinen anschlag dohin bracht/das die Volcker in dem kleinen Asia/und in Armenia / Arabia/Persia/Syria / Assyria/Media/Egypten/Numidia/Libya/Mauritania/ Thracia/Griechenlandt/sampt andere mehr lander/Christum den waren heyland der welt haben übergeben/und Mahumeto/dem falschen Propheten seine verfuhrische Lehr angenomen ${ }^{23}$.

The larger Christian world was under siege, notably by the Turks, driven from the land, and even where Christians were able to survive, they often compromised the truth, quoting Psalm 106, »Sie seind vermischet under die Volcker/ und haben ihre werck gelernet $\aleph^{24}$. Münster's opening sounds like what the American Puritan historian, Perry Miller, once described as a »Jeremiad«, a lamentation and longing for the glory and grandeur of days gone by ${ }^{25}$.

Münster's treatment of Africa is clearly shaped by these sentiments. Before commenting further, it is worth noting that the African section of the Cosmographia, or Book VI, is roughly 40 duo pages, less than half of the 100 pages given to Asia in Book V or the nearly 700 pages in Book III on the German Reich $^{26}$. For Münster, the exodus or extermination of Christianity in Africa left him with little more to say on the subject. In a few instances he noted historical matters. For example, in discussing northeastern Africa, notably the area around Cyrene, Münster observed that its ancient church, along with those of Libya and Eygpt were under the oversight of the Greek-speaking patriarchate at Alexandria, while the more western churches of Numidia and Mauritania were under the Latin church at Carthage ${ }^{27}$. In discussing Egypt, Münster also wrote specifically on the tragic episode at Damiata, when

22 I will be quoting the more extensive 1550 edition of the »Cosmographia«, translated into German. For citation see MüNSTER, Cosmographia, p. aii.

23 Ibid., p. aiiii.

24 Ibid., p. aiiii.

25 See Perry Miller, The New England Mind. From Colony to Province, Cambridge 1953, pp. 27-39; and Sacvan Bercovitch, The American Jeremiad, Madison 1978.

26 For the scope of the 1550 »Cosmographia« see McLean, Cosmographia, pp. 174-181.

27 Regarding Cyrene and other parts of Africa Münster writes, »Darumb auch die ersten Christen haben underwürffig gemacht der Alexandriner kirchen Egypten lannd/Libyam und Cyrenaicam. Aber Numidiam/Africam und Mauritaniam/haben sie geordnet in die Carthaginenser Kirch. Das Alexandrinisch bisthumm hat sich gebraucht der Griechischen Sprache/unnd das Carthagener der Lateinischen«, Münster, Cosmographia, p. 1202. 
Christians and crusaders fleeing the Holy Land were eventually crushed by the forces of the Mamluke Sultan ${ }^{28}$.

Not surprisingly, the gist of Münster's analysis of African Christianity comes in the familiar recounting of the realm of Prester John. Again here, it is noteworthy that the very last thing addressed in this huge narrative - and just before Münster's very brief conclusion - is this legendary Christian empire, located in Africa. Here and earlier in the section on Africa Münster noted the confusion about Prester John, who was not really a priest or an elder, but a king, with a legend that had him linked to both India and Ethiopia. Continuing, Münster discussed the Christian character of the region which sustained the gospel, but its teaching was flawed from his point of view. According to Münster, »sie vermischen es/ja verdunckeln es mitt dem alten gesatz/und stecken in vile und großen irthumben/wie du horen wirst $^{29}$. Their Patriarch, he wrote, is known as the Abuna, but a leader without the funds or authority associated with a bishop because this power belongs to the king. These Ethiopian Christians followed Levitical codes regarding their diet, yet honored Sunday as their Sabbath. They have adopted early Christian forms of confession and penance, but unlike Catholics, their priests can marry. They practice circumcision, but unlike the Jews, administered circumcision to both men and women ${ }^{30}$. Clearly, Münster's assessment of these alien African Christians in many ways paralleled the earlier hostile descriptions of writers like Breydenbach. However, Münster was relying on newer information to interpret the common faith of Christians living in a very different part of the world. For him, someone like Prester John was more than a simple myth conjured up in a false quest for Christian allies. The Ethiopian monarch and his realm represented earlier forms of Christian practice still misunderstood by European observers like Münster.

Münster, of course, never travelled to Africa but relied on the reports of others as he shaped his cosmography. In the section on Prester John, he mentioned specifically the writings of Father Juan Damiano, but certainly he drew on others, likely Francesco Alvarez, whose 1526 travels to Abyssinia were widely known, or most certainly the early account of the Venetian Alvise Ca Da Mosto [Cadamosto] ${ }^{31}$. Cadamosto's travel account was among the very first to detail Portuguese explorations of the Western Rim of Africa during the $15^{\text {th }}$ century. Eventually, the account of his African travels was

28 For the battles of Christians and Muslims at Damiata, see MünSTER, Cosmograhia, pp. $1211 \mathrm{f}$.

29 Ibid., p. 1231.

30 Overall, Münster's discussion of the Prester John's kingdom is rather brief, MüNSTER, Cosmographia, pp. 1231-1233; see too McLeAn, Cosmographia, p. 304.

31 See the reference to Damiano in MünSTER, Cosmographia, p. 1232. For additional accounts of early travelers to Ethiopia see Osbert Guy Stanhope CRAWFORD (ed.), Ethiopian Itineraries circa 1400-1524, Cambridge 1958; and, Hastings, Church in Africa, p. 46. 
widely circulated in Fracanzano da Montalboddo's Paesi novamente ritrovati and would have been very familiar to Münster ${ }^{32}$. Cadamosto did not have much to say about Christians in Africa, but his perceptions were shaped by the Christian heritage that accompanied him. Generally, Cadamosto visited African regions where Christian faith had never secured a foothold. Like other merchant travelers, he may have been too willing to highlight Christian communities encountered in the West African island regions as his companions travelled beyond the Canaries to the Cape Verde Islands, exploring the Gambia River and perhaps reaching as far as Cabo Rosso. Cadamosto observed scattered and isolated Christian populations, but in the ports of Senegal and Gambia, he met sub-Saharan Muslims. At Cabo Bianco and in coastal Senegal, near what would be Dakar, Cadamosto simply states: »they follow the faith of Mohammed $\aleph^{33}$. His description of Islam in Gambia, a region connected to the more prominent interior kingdom of Melli/Mali, offered great detail. »Their mosques«, wrote Cadamosto, »are their churches, and they gather there for prayers, led by a priest, prostrating themselves and kissing the ground « ${ }^{34}$. Though often referring to »heathens «, Cadamosto's account as a Christian traveler completely lacked the triumphalist rhetoric of either Breydenbach or Münster. In fact, Cadamosto even noted how volatile false perceptions could work in two directions. As he traveled up the Gambia, he recorded an encountered with a slave trader fearful of Christians cannibals, »das wir Cristen frassen menschen fleysch/und das wir nit kauffen moren dann allein das wir sie fressen $\aleph^{35}$.

Cadamosto's travels also appeared in one of the most ambitious travel narratives of the mid-sixteenth century, Giovanni Ramusio's Delle navigazione e viaggi. Volume One of Ramusio's collection concentrated on Africa and included chroniclers like Cadamosto, but the crown jewel of this volume was the description of Africa, or Descrittione dell' Africa, assembled by al-hassan Ibn Muhammad al-Wazzan or Leo Africanus ${ }^{36}$. Reared in the North African Maghreb, primarily in Morocco and Grenada, Africanus was captured by Spanish corsairs and eventually presented to Pope Leo X as a gift. Africanus converted to Catholicism, although many, and most recently Natalie Davis, have noted the religious ambivalence that was characteristic of alWazzan $^{37}$. Before proceeding with my analysis, I want to acknowledge the

32 See Fracanzano da Montalboddo, Paesi novamente retrovati; and the German translation, Newe unbekanthe landte und ein newe weldt in Kurtz verganger zeythe erfunden (1508).

33 »Sie sin des Machomets geloven«, Montalboddo, Unbekanthe landte, p. av

$34 »$ Von der mosthea/das ist ire kirchen/darinne sie anbetten/mit iren gewonheyten ... offt neygten sie sich gegen erdtricht und kusten es«; ibid., p. biii ${ }^{v}$.

35 Ibid., p. xxxviii.

36 See Ramusio, Delle navigatione et viaggi.

37 See Natalie Zemon DAvis, Trickster Travels. A Sixteenth-Century Muslim Between Worlds, New York 2006; and Pekka Masonen, The Ambivalence of al-Hasan or Leo Africanus, in: 
textual difficulties one encounters in this description of Africa. The available manuscripts, basically two, do not always match the Italian, Latin, French, or English translations. These divergences have been detailed in Dietrich Rauchenberger's study of Africanus ${ }^{38}$. This essay will draw principally from two important translations: Jean Temporal's Historiale Description, and John Pory's Geographical Description ${ }^{39}$.

It is my contention that al-Wazzan's description of his homeland is unique in the dual religious sensitivity that he brought to his writing. On the one hand, like Cadamosto, he viewed Africa as essentially part of the Dar-alIslam. He is keen to observe and often to praise the diversity of Muslim schools of thought and practice in cities like Fez and Cairo. In Book One, the first of nine books, he even claims that Islam had basically eliminated Christianity from Africa ${ }^{40}$. However, the larger narrative reveals a subtle yet significant Christian presence observed in various parts of the continent. Across the Maghreb, Africanus identifies both renegade Christian communities and remnant Jewish merchant colonies. In the highlands of Morocco, for instance, he writes of a Christian mercenary enclave, armed with cross-bows ${ }^{41}$. In Fez, Africanus describes how the sultan of the city had stolen candles from the Christians. He also notes how in the local population, »certain relics of festival days instituted of old by the Christians have remained; whereupon they use certain ceremonies which they themselves do not understand $\aleph^{42}$.

Further to the east, in Egypt and more to the interior, Africanus has even more to say about these fledging Christian communities. In the Egyptian upper Nile, he tells how a monastery, which he identifies with Saint George, was decimated by the plague then converted to a hostel by a local Muslim prince. The Coptic patriarch, however, appealed to the Sultan and a new monastery was built for a much smaller religious community ${ }^{43}$. Further up the Nile at Chian was another Coptic monastery, in the vicinity of a town, that according to al-Wassan, had been established by the Muslims, then overrun

Tabish Khair/Martin Leer/Hannah Ziadeh (ed.), Other Routes. 1500 Years of African and Asian Travel Writing, Bloomington 2005, pp. 131-145.

38 See Dietrich Rauchenberger, Johannes Leo der Afrikaner. Seine Beschreibung des Raumes zwischen Nil und Niger nach dem Urtext, Wiesbaden 1999.

39 See Temporal, Historiale Description, and John Pory (ed.), The History and Description of Africa and of the Notable Things Therein Contained, written by al-Hassan ibn Mohammed alWezaz al-Fasi, a Moor, baptized as Giovanni Leone, but better known as Leo Africanus. Done into English in the year 1600 by John PoRY, Three Volumes, London 1896. For the first German translation, see Georg W. LoRsBACH (ed.), Johann Leo's des Africaners Beschreibung von Afrika, Herborn 1805.

$40 »$ Neither is there any region in all the Negros land, which hath in it at this day any Christians at all«, PORY, Description of Africa I, p. 163.

41 PoRY, Description of Africa II, p. 268.

42 See Pory, Description of Africa III, p. 452; and Temporal, Historiale Description, p. 157.

43 See Pory, Description of Africa VIII, p. 901; and Temporal, Historiale Description, p. 366. 
by local Jacobite Christians ${ }^{44}$. Just to the west and north of Chian, now in a region Africanus labels as the land of the Negros, he locates a small principality named Gaoga. Here, according to Africanus, the inhabitants practice the Christian faith in a manner somewhat like the Egyptians. Finally, it is worth noting that Africanus basically ignores, or dismisses, the many legends associated with Prester John. His only passing reference may be found in Book One when he describes how certain religious friars, their faces branded with a hot iron, have come from Ethiopia, dispatched to various European courts and to Rome, as ambassadors of the ruler known as Prester John ${ }^{45}$. These are but a few examples of how al-Wazzan detailed this lingering Christian presence in Africa. Overall, his account lacks both the embellishment and the invective characteristic of earlier writers as they sought to comprehend the complexities of the African Christian experience. Africanus does not appear to find kindred spirits in Africa: he is himself no longer comfortably Muslim, yet fails to note a Christian community he can clearly recognize.

Overall, the blending of polemic, myth, and observation contained in these narratives point to important aspects of understanding the African Christian »stranger « of the sixteenth century. The descriptions contained in these detailed writings lead to several important conclusions. First, certain myths and stereotypes about African Christianity did not disappear, despite new information and increased contact with these communities. In some instances the legends, like that of Prester John, simply expanded to include new information. These myths proved both enduring and rather elastic. In addition, although coached in harsh polemic, travel accounts like Breydenbach's Peregrinatio or even Waldseemüller's Carta Marina, began to unveil a deeper appreciation for the distinctive elements in African Christian communities. Finally, despite assertions, from writers like Münster or Africanus, that earlier Christianity had disappeared from Africa or been exterminated, these accounts offer small glimpses of an alternative Christian experience that continued into these early years of the sixteenth century.

44 »This little city of Chian was built in times past neere unto Nilus by the Mahumetans, which notwithstanding is not now inhabited by them, but by the Christians called Jacobites«, PorY, Description of Africa VIII, p. 902; see also LorsBach, Africaners Beschreibung, p. 550.

$45 »$ From thence come certain religious Friars branded on the face with a hot iron [...] these people have an Emperour which they call Prete Gianni, the greater part of that land being inhabited with Christians «, Pory, Description of Africa I, p. 125; see also LoRsBACH, Africaners Beschreibung, p. 4. 



\title{
Simon Mills
}

\section{The Chaplains to the English Levant Company}

\author{
Exploration and Biblical Scholarship in Seventeenth- \\ and Eighteenth-Century England
}

In 1767 the German engineer and mathematician Carsten Niebuhr arrived in Denmark at the end of a six-year expedition. Niebuhr's travels had taken him to Greece and Turkey, through Egypt, to the Yemen, back across the Arabian peninsula, east to Mesopotamia, and even as far as Bombay. Stepping back onto European shores, Niebuhr must have felt himself lucky to be alive. He was the only survivor of a six-strong group of Danes, Germans, and Swedes which had set out on a journey of exploration, funded by the Danish crown, to chart the languages, geography, flora, fauna, and customs of the Near and Middle East. The Niebuhr expedition is often cited as the first state-sponsored scientific voyage to the region; scientific, in the sense that the ill-fated explorers followed a systematic plan of research which had been drawn up by Europe's leading authorities on philology, biblical and oriental studies, and natural history, and had prioritised the collection of empirical facts over the subjective experience of travel. It was this combination of an expedition organised according to purely scholarly principles which for the scheme's architect - the German scholar Johann David Michaelis - made it unique in the history of travel. As the American historian Jonathan Sheehan has recently put it, the enterprise became »a model of how exploration could be corralled and utilized by philological and historical researchers « ${ }^{1}$.

The scale and the attempted academic rigour of the Niebuhr expedition were, perhaps, unique. However, accounts of observations of the Near and Middle East were nothing new to the late eighteenth century. By the mid $1500 \mathrm{~s}$, fabulous descriptions of the region typical of the middle ages - such as the dean of Mainz, Bernhard von Breydenbach's depiction of unicorns and hominoid baboons which he claimed to have observed during his travels in the Holy Land in 1483 - were being replaced by more naturalistic accounts ${ }^{2}$.

1 Jonathan Sheehan, The Enlightenment Bible. Translation, Scholarship, Culture, Princeton 2005, p. 188.

2 Bernhard von Breydenbach, Peregrinatio in Terram Sanctam, Mainz 1486; Jan M.I. Klaver, Scientific Expeditions to the Arab World 1761-1881, London 2009, p. 11. 
The French naturalist, Pierre Belon du Mans's 1553 relation of his travels through Greece, Asia, Judea, Egypt, and Arabia, for example, has recently been cited by the literary scholar and historian Ivo Klaver as a work of »genuine scientific value« which was »based on direct observation« - despite Belon's rather dubious claims to have seen a phoenix and a flying serpent ${ }^{3}$. Botanists such as Leonard Rauwolf had set out to document the flora of the Levant many years before Forsskål and the Niebuhr expedition ${ }^{4}$. The Christian pilgrimage, which had been $»$ the dominant medieval framework for long distance, non-utilitarian travel $\aleph^{5}$, was, as Joan Pau Rubiés has argued, gradually transformed into a new kind of cosmography in the early modern period reflecting »a deep trend towards empirical curiosity within European travel writing $\ll^{6}$. Works such as George Sandys's A Relation of a Journey begun An. Dom. 1610 (1615) combined detailed descriptions of the holy sites at Jerusalem with astute observations on the geography, society, and commerce of the Levant?

Moreover, the link between travel and scholarship singled out by Michaelis as the defining feature of the Niebuhr expedition was by no means new. In the late sixteenth century a sub-genre of instructions for travellers emerged, aimed at encouraging intelligent adventurers to $»$ systematically seek, process, and assess the information they collected $\aleph^{8}$. As intellectual interest in the religions and antiquities of the Levant and the wider Orient increased during the early modern period a number of travellers set out for the East with instructions drawn up by scholars and princes 9 . From the sixteenth century, the expansion of European trade with the Ottoman Empire, and the attendant consular and diplomatic structures which this trade gave rise to, led a growing number of merchants, diplomats, and scholars to travel to the Near and Middle East ${ }^{10}$. One of the most significant forces behind this new

3 KLAVER, Scientific Expeditions, p. 13.

4 Karl H. Dannenfeldt, Leonhard Rauwolf. Sixteenth-Century Physician, Botanist and Traveler, Cambridge, Mass. 1968.

5 William H. Sherman, Stirrings and Searchings (1500-1720), in: Peter Hulme/Tim Youngs (ed.), The Cambridge Companion to Travel Writing, Cambridge 2002, pp. 17-36, here p. 24.

6 Joan Pau Rubiés, Travel writing and ethnography, in: Hulme/Youngs, Cambridge Companion, pp. 242-269, here p. 248.

7 George Sandys, A Relation of a Journey begun An. Dom. 1610, London 1615.

8 Anthony Grafton, What was History? The Art of History in Early Modern Europe, Cambridge 2007, p. 119. See also Joan Pau Rubiés, Instructions for Travellers. Teaching the Eye to See, in: History and Anthropology 9 (1996), pp. 139-190.

9 A good example is the career of Johann Michael Wansleben (1635-1679). On Wansleben's travels under the direction of the Saxon scholar Hiob Ludolf and the duke of Saxe-Gotha and, afterwards, Louis XIV's minister Jean-Baptise Colbert and Pierre Carcavy see Alastair HAміLтon, The Copts and the West 1439-1822. The European Discovery of the Egyptian Church, Oxford 2006, pp. 142-151. Also Dominik Collet, Die Welt in der Stube. Begegnungen mit Außereuropa in Kunstkammern der Frühen Neuzeit, Göttingen 2007, pp. 132-145.

10 Daniel Goffman, Britons in the Ottoman Empire 1642-1660, Seattle 1998. 
enterprise was the English Levant Company, which was chartered in 1581 under Queen Elizabeth $\mathrm{I}^{11}$. The communities of English merchants who subsequently arrived in the Levant soon set up trading centres, or »factories«, the most important being at Aleppo in Syria, and at Istanbul and Izmir (usually referred to by its Greek name Smyrna) in Turkey. By 1583 a vice-consul, William Barrett, was settled in Aleppo, and by 1586 the city was designated as the consul's chief residence for Syria ${ }^{12}$. A factory was established in Izmir in the $1610 \mathrm{~s}^{13}$. Some time around the end of the sixteenth century the company agreed to provide funds for a chaplain, which offered the opportunity for a Church of England clergyman, elected by the general court of the company in London, to travel to the Levant to minister to the expatriate communities of merchants ${ }^{14}$.

The figures elected to the chaplaincy were in many ways peripheral to the workings of the company itself. Their reasons for travelling to the East more often than not appear to have had less to do with preserving the spiritual health of their mercantile countrymen, and more concerned the opportunities for discovery which a sojourn in the Levant would present. Many of the chaplains were able scholars who had been trained in the classical languages, Hebrew, and theology at the English universities. In many cases, they were thoroughly engaged with the intellectual controversies of their age, whether concerning variant readings in the extant manuscripts of biblical texts or the theological doctrines of the eastern Christian churches. Many of them used the opportunity of their stay in the East to learn oriental languages, to travel, to collect manuscripts, and to record as much information as possible relating to the culture, religions, antiquities, geography, flora, and fauna of the Near East. This spirit of discovery is well captured in a letter by John Covel (16381722), chaplain to the embassy at Istanbul for four years in the early 1670s. Writing home from Pera in Istanbul in 1674, Covel noted that »Meer curiosity of learning some things whereof I thought we had but a slight account at

11 On the Levant Company see Alfred Cecil Wood, A History of the Levant Company, Oxford 1935; for the London-Aleppo trade in the eighteenth century see Ralph DAviEs, Aleppo and Devonshire Square. English Traders in the Levant in the Eighteenth Century, London 1967.

12 Bruce Masters, Aleppo. The Ottoman Empire's Caravan City, in: Edhen Eldem/Daniel Goffman / Bruce Masters, The Ottoman City between East and West. Aleppo, Izmir, and Istanbul, Cambridge 1999, pp. 17-78, here p. 27.

13 Daniel Goffman, Izmir. From Village to Colonial Port City, in: Eldem/Goffman/Masters, The Ottoman City, pp. 79-134, here p. 94.

14 An incomplete account of the chaplains is provided in John B. PEArson, A Biographical Sketch of the Chaplains to the Levant Company, maintained at Constantinople, Aleppo and Smyrna 1611-1706, Cambridge 1883. For a more recent account of the Aleppo chaplaincy see Alastair Hamilton, The English Interest in the Arabic Speaking Christians, in: Gül A. Russell, The »Arabick« Interest of the Natural Philosophers in Seventeenth-Century England, Leiden 1994, pp. 35-53, esp. pp. 41-48. 
home, was one of those motives which brought me hither « ${ }^{15}$. Although none of the chaplains made it as far as Niebuhr and his unfortunate associates, some of them did travel to places then largely unknown in the West; their intellectual curiosity led them to a number of »encounters with strangers«.

Moreover, many of the chaplains were well connected with some of the major intellectual figures of their age, corresponding with luminaries such as John Locke, Isaac Newton, and Robert Boyle. What makes them particularly interesting as travellers is the links they maintained with these networks of scholars; in fact, some of the chaplains were given specific instructions on how to make the best use of their time whilst in the Levant. One such case was Robert Huntington (1637-1701) who served as chaplain to the merchants at Aleppo between 1671 and 1681. In a letter written from Aleppo to John Locke, Huntington referred to the »Commands « and »Instructions « he had hoped for from Boyle, one of the founders of the Royal Society, and to »Requests « for information made by Locke himself ${ }^{16}$. A closer look at the ways in which the chaplains' accounts were fed back to scholars in England may provide a way into explaining how travel to the Levant and encounters with the strangers who inhabited it contributed to a shift in the historical consciousness of English Protestants.

In the remainder of this paper, I shall focus primarily on two accounts written by chaplains who visited the Levant at the end of the seventeenth century. The first of these, John Luke (1633/34-1702), was elected chaplain to the Levant Company at Izmir in 1664 and served for two periods between 1664 and 1669 and 1674 and 1683. During this time he travelled widely on a number of expeditions through Asia Minor and Syria. At Easter of 1668 he made a pilgrimage to Jerusalem via Cyprus, returning across the Lebanese mountains and the Mediterranean littoral ${ }^{17}$. Although Luke published very little, extensive notes of his travels and a diary from part of his time in Izmir survive in manuscript at the British Library in London (BL MS Harley 7021). These include a detailed account of his itinerary, with the local names of the many towns and villages he passed through written out in Arabic script ${ }^{18}$. The second, Henry Maundrell (1665-1701), travelled to Aleppo in 1696, where he served as chaplain to the Levant Company factory for five

15 British Library, Add. MS 22910: Original papers and correspondence of John Covel, D.D., Chaplain to the British Embassy at Constantinople, and Master of Christ's College, Cambridge, fol. $151 / 2$.

16 John Locke, The Correspondence of John Locke, ed. E.S. de Beer, 8 vols., Oxford 1976-1989, here vol. i, pp. 352-354.

17 On Luke see Alan Cadwallader, The Reverend Dr. John Luke and the Churches of Chonai, in: GRBS 48 (2008), pp. 319-338; Sonia P. Anderson, An English Consul in Turkey. Paul Rycaut at Smyrna 1667-1678, Oxford 1989, pp. 104-105.

18 As Cadwallader and Anderson have pointed out, Luke's journal has been »mined« for information, and parts of it are extant in a copy of the original, possibly in the hand of Jerome Salter, 
years until his death in 1701. He undertook a pilgrimage to Jerusalem at Easter of 1697, returning to Aleppo by way of Damascus and Tripoli. In 1699 he made another voyage to north-eastern Syria and across the Euphrates to Mesopotamia, visiting the sites of Menbij (Bambych) and Cyrrhus (Corus) on his return to Aleppo ${ }^{19}$. An account of both journeys was published at Oxford shortly after his death.

\section{Encounters with strangers}

When Luke and Maundrell arrived at Izmir and Aleppo respectively they would have found themselves at the heart of commercial entrepôts in which the lure of international trade had attracted resident communities of an extremely broad religious and ethnic diversity. In Aleppo, the English factors came into contact not just with Syrians and Turkish officials, but with Persian Armenians who were largely responsible for conveying the Iranian silk which was the company's chief import ${ }^{20}$. The city was, of course, predominantly Sunni Muslim, yet it had a large Christian population - Maronites, Jacobites, Nestorians, Greek Orthodox, Melkites, Armenians, as well as the European communities - which numbered more than 5,000 in $1695^{21}$. In the same year, there were more than 850 Jewish residents in the city, in part due to an influx of Sephardic Jews from Italy, which had begun in the sixteenth century ${ }^{22}$. After 1675 the European merchant houses employed local Christians as translators ${ }^{23}$, and many contracts were struck between British shippers and Syrian Christian merchants ${ }^{24}$. There is also evidence of locals attending the religious services of the merchant communities ${ }^{25}$. Moreover, Bruce Masters has shown using the Ottoman court records that there were resident merchant communities from as far afield as North Africa, India, and Bukhara, and that traders from Egypt, the Yemen, Damascus, Ankara, Mosul, and Salonika were active in the commerce of the city ${ }^{26}$. Maundrell

one of Luke's travelling companions. See Cadwallader, John Luke, pp. 329-330; Anderson, An English Consul, p. 218.

19 Where there is a significant difference between them, I have given the commonly-used modern names of the sites Maundrell and Luke visited followed by the spellings used by them in parenthesis.

20 Masters, Aleppo, p. 33.

21 Ibid., p. 37.

22 Ibid., pp. 39, 60.

23 Ibid., pp. 57-58.

24 Bruce Masters, The Origins of Western Economic Dominance in the Middle East. Mercantilism and the Islamic Economy in Aleppo 1600-1750, New York 1988, p. 103.

25 Masters cites an official decree forbidding local Christians from attending Latin mass offered for the French merchants, Masters, Aleppo, p. 54.

26 Ibid., pp. 34, 35. 
would have been at the very centre of Aleppo's commercial life: the English resided in the Khan al-Jumruk, built in 1574 by Mehmed Paşa, in the central »suq" area just south of the Great Mosque ${ }^{27}$.

A similar situation prevailed in Izmir. In the early seventeenth century Dutch, English, French, and Venetian merchants had joined Armenian, Greek, Jewish, and Muslim Ottoman traders and local officials ${ }^{28}$. Daniel Goffman has put the city's population in the 1650s and 1660s at 60-70,000 inhabitants $^{29}$. Although, as in Aleppo, this was comprised of a Sunni Muslim majority, the commercial centre of the town was dominated by foreign Christians, Armenians, Greeks, and Jews, the last of which group numbered 2,000 in $1660^{30}$. The Europeans clustered mostly around one street which lay behind the wharf. Here the consuls and traders employed »every Ottoman ethno-religious group « to supply their needs for »servants, brokers, moneychangers, middlemen, and translators $\aleph^{31}$. Goffman has evoked the international and ecumenical atmosphere of the so-called »Street of the Franks«:

Englishmen, Frenchmen, Venetians, and Ottomans freely conversed, and Anglicans, Calvinists, Catholics, Sephardic Jews, Muslim Turks, Orthodox Greeks, and Armenians worshiped almost shoulder to shoulder, and even socialised together ${ }^{32}$.

Despite these opportunities for foreign encounters, most accounts of the English traders to date have depicted them as living an isolated existence. Ralph Davies, for example, wrote of the eighteenth-century merchants in Aleppo that »Few Englishmen had any but business contacts outside the European community « and that »many, perhaps most, did not even learn the language of the country «33. Bruce Masters wrote that the Europeans in the Ottoman lands were »less than welcome guests in a strange land where immense barriers of language and culture [...] separated them from the people among whom they dwelt« and that »[w]ith very few exceptions, they were content to let those barriers remain $\aleph^{34}$. This picture is at least partly derived from the account of Alexander Russell (1715-68), physician to the Levant Company, who in occasional passages painted a bleak picture of relations between the

27 On the building, which is still in use for commercial purposes, see Ross Burns, The Monuments of Syria. A Guide, London 1992, p. 43.

28 Goffman, Izmir, p. 89.

29 Ibid., p. 95.

30 Ibid., pp. 95, 98.

31 Ibid., p. 99. On the early history of the Street of the Franks see Daniel Goffman, Izmir and the Levantine World 1550-1650, Seattle 1990, pp. 135-137.

32 Ibid., p. 95.

33 Davies, Aleppo and Devonshire Square, p. 80.

34 Masters, Origins of Western Economic Dominance, p. 78. 
English merchants and the local population in the $1740 \mathrm{~s}$ and $1750 \mathrm{~s}^{35}$. It is also derived from eighteenth-century merchants' letters and thus undoubtedly reflects a reality among those who had gone out to the Levant solely for the benefits of the trade - which, of course, was the majority.

Among the chaplains, at least those of the seventeenth century, the case appears to have been rather different. Of the chaplains that served at Aleppo, Edward Pococke (1604-1691), Robert Frampton (1622-1708), Robert Huntington, and Samuel Lisle (1683-1749) learned Arabic and probably Turkish ${ }^{36}$. Henry Denton (1640-1681) is said to have learned Arabic and some Turkish at Istanbul ${ }^{37}$. John Luke studied some Turkish under a certain »Shaml'y«, an Arabic-speaking Christian whom he met whilst awaiting a passage to Jerusalem at Antalya (Sattalia) ${ }^{38}$; he evidently learnt enough to contribute a poem in Ottoman Turkish to an honorific volume for the Duke of Cornwall printed at Cambridge in $1688^{39}$. By the time of his return to England, Luke had acquired sufficient Arabic to be appointed as the fourth Thomas Adams Professor of Arabic at the University of Cambridge. Although he appears to have contributed nothing to the field of oriental studies, there is some evidence that he taught the language ${ }^{40}$. There are various accounts of the atmosphere of the

35 Alexander Russell, The Natural History of Aleppo, 2 vols., vol. I, London ${ }^{2} 1794$, p. 216. On the Russell brothers see Maurits van DEN BoogerT, Aleppo Observed. Ottoman Syria Through the Eyes of Two Scottish Doctors Alexander and Patrick Russell, Oxford 2010.

36 Pococke became one of the leading Arabists of the seventeenth century, for an account of his achievement see Gerald J. Toomer, Eastern Wisedome and Learning. The Study of Arabic in Seventeenth-Century England, Oxford 1996, esp. pp. 116-126, 131-136, 155-167, 212-226 and Peter M. Holt, An Oxford Arabist: Edward Pococke, in: Peter M. Holt, Studies in the History of the Near East, London 1973, pp. 1-26. Frampton compiled a collection of Arabic proverbs "with an account of their original and present use and application«: Robert FrAMPTON, The Life of Robert Frampton, ed. by Thomas S. Evans, London 1876, p. 9. Huntington, according to his biographer Thomas Smith, was »accomplished in Arabic«, Robert Huntington, Epistolae, ed. by Thomas Sмiтh, London 1704, p. v. Lisle, according to his biographer, »mastered a number of oriental languages«, William GiBson, Lisle, Samuel (1683-1749), in: Oxford Dictionary of National Biography (hereafter ODNB), Oxford 2004, online edn. (URL: <http://www.oxford dnb.com> [February 08, 2011]).

37 Alastair Hamilton, Denton, Henry (c. 1640-1681), in: ODNB, online edn. Hamilton points to the Turkish-Latin grammar (Bodl. Oxf., Hyde MS 43) which Denton brought back to Oxford as evidence that he was »well advanced in the study of Turkish«.

38 British Library, MS Harley 7021: Historical papers and travels, fol. 372v.

39 Illustrissimi principis ducis Cornubiae et comitis Palatini, \&c, genethliacon, Cambridge 1688, unpaginated. Luke's contribution is headed »Hendecasyllabi Turcici«. Geoffrey Roper has described it as »a poem in rather strange Ottoman Turkish«, Geoffrey RoPER, Arabic Printing and Publishing in England before 1820, in: BBSMES 12 (1985), no. 1, pp. 12-32.

40 Martin Eagle referred to Luke in a letter to John Covel as »mu'allim [teacher] in litteratura Arabica«, British Library, Add MS 22911: Original papers and correspondence of John Covel, D.D. Chaplain to the British Embassy at Constantinople, and Master of Christ's College, fol. $81 / 163$. 
factories in the seventeenth century ${ }^{41}$. The chaplains, at least to some extent, recreated a collegiate environment: the factory at Aleppo had a library of 228 volumes in 1688, and at Izmir there were 111 volumes in the library in $1702^{42}$. Some of the chaplains themselves projected this image. Maundrell, for example, wrote that Our way of Life resembles, in some measure, the Academical. We live in separate Squares, shut up every night after the manner of Colleges « ${ }^{43}$. However, the evidence appears to suggest that they were anything but confined to their quarters. Many of the chaplains, like Luke and Maundrell, made the pilgrimage to Jerusalem. Moreover, they appear to have encouraged the Englishmen residing at the factory to make the journey as well: Frampton wrote to Heneage Finch (1627/28-1689), ambassador at Istanbul, in February 1667/68 that »For our factory the greatest part have been at Jerusalem already « ${ }^{44}$, and Thomas Smith noted that amongst the factors resident during Huntington's years as chaplain »the custom of visiting Jerusalem was so much in vogue, that it grew almost into a religious duty « ${ }^{45}$. When Maundrell made his own pilgrimage in 1697 he was accompanied by fourteen Englishmen - a large part of his congregation ${ }^{46}$. Many of the chaplains travelled much further afield: to Egypt and eastern Syria, and similarly they took factors along with them. When Huntington set out across the Syrian desert to find the ruins of Palmyra in the summer of 1678 he was one of a party of sixteen Englishmen ${ }^{47}$. When William Halifax (1655-1721 / 22), chaplain at Aleppo between 1688 and 1695, made the same journey thirteen years later he was part of a group of about thirty Europeans and servants ${ }^{48}$.

Nor were the chaplains slow to actively seek out encounters with strangers. In his quest for oriental manuscripts Huntington initiated correspondences with the Maronite patriarch of Antioch Estefan al-Duwayhi, the Greek Orthodox primate of Cyprus Hilarion Cigala, and the Greek Orthodox pat-

41 See, for example, Henry Teonge, The Diary of Henry Teonge. Chaplain on board his Majesty's Ships Assistance, Bristol, and Royal Oak Anno 1675 to 1679, London 1825, pp. 157-179. Teonge was a naval chaplain who visited the factory at Aleppo in May 1676. He described a jovial atmosphere and noted the »stately roome, which is their chappell«.

42 Wood, A History of the Levant Company, pp. 242-243.

43 Henry Maundrell, A Journey from Aleppo to Jerusalem at Easter, A.D. 1697, Oxford ${ }^{6} 1740$, p. 148.

44 British Library, Add. MS 32094: State papers, historical documents, and official and private letters, vol. iv, July 1660-1676, fol. 210v.

45 Huntington, Epistolae, pp. xi-xii; Thomas Smith, The Life and Travels of the Right Rev. and Learned Dr Robert Huntington, in: Gentleman's Magazine 95 (1825), No. 1, p. 14.

46 Maundrell, A Journey, p. 1.

47 An Extract of the Journals of Two Several Voyages of the English Merchants of the Factory of Aleppo, to Tadmor, Anciently Call'd Palmyra, in: Philosophical Transactions of the Royal Society 19 (1695-97), pp. 129-160, here p. 130.

48 William Halifax, Relation of a Voyage to Tadmor in 1691, in: PEFQSt. 22.4 (1890), pp. $273-$ 303, here p. 274. 
riarch of Mt Sinai Johannes Lascaris ${ }^{49}$. Pococke employed a learned Muslim to instruct him in classical Arabic and a Jew to improve his Hebrew, and corresponded with Arabic speakers in Aleppo after his return to Oxford ${ }^{50}$. The journal kept by Luke at Izmir records separate conversations with an imam, »a certain Jew«, and »A certain Arabian of Marocco«, the last of whom narrated a fabulous story concerning "a place about 12 daies journey from ffez and one from Marocco where remain to be seen men and beasts petrified a great number $\aleph^{51}$. Maundrell was clearly fascinated by the religious communities whom he encountered in the semi-autonomous regions of western Syria and the Lebanon. In a reference to the Nusayria, a sect found in the mountains of western Syria (whom Maundrell referred to as »Neceres $«$ ), for example, he wrote of a people who »adhere to no certain Religion; but Camelion-like, they put on the Colour of Religion, whatever it be, which is reflected upon them from the Persons with whom they happen to converse $\iota^{52}$. At Beirut Maundrell recounted the old (and wholly erroneous) story that the Druzes were descended from the European crusaders ${ }^{53}$. A sixth edition of his A Journey reproduced an engraving of the Druze emir Fakr al-Din, whose palace at Beirut Maundrell visited on his way to Jerusalem ${ }^{54}$.

One of the most interesting of these encounters detailed in Maundrell's narrative is his meeting with the Samaritans, the ancient Jewish sect who had long fascinated European scholars ${ }^{55}$. Maundrell was not the first English chaplain to make contact with the Samaritans: Huntington had visited them in the 1670 s on his way to Jerusalem, and had initiated a correspondence, which was continued by Thomas Marshall from Oxford until his death in $1685^{56}$. At Nablus - the ancient biblical town of Sechem - Maundrell took

49 Alastair Hamilton, Huntington, Robert (bap. 1637, d. 1701), in: ODNB, online edn. Huntington's letters are printed in Huntington, Epistolae, pp. 1-22.

50 See Toomer, Eastern Wisedome, p. 121 on the identity of Pococke's Arabic tutor. For Pococke's Arabic correspondence see ibid., p. 122-123.

51 British Library, MS Harley 7021, fol. 398v.

52 Maundrell, A Journey, pp. 12-13.

53 Ibid., p. 39.

54 Ibid. On the source of the engraving of Fakr al-Din see Hafez CHEHAB, Reconstructing the Medici Portrait of Fakhr al-Din al-Ma'ani, in: Maqarnas. An Annual on Islamic Art and Literature XI (1994), pp. 117-124.

55 On the background to European Protestants' interest in the Samaritans see David S. Katz, Isaac Vossius and the English Biblical Critics, in: Richard Popkin/ Arjo Vanderjagt (ed.), Scepticism and Irreligion in the Seventeenth and Eighteenth Centuries, Leiden 1993, pp. 142-184, esp. pp. 171-175. Also Peter N. Miller, A Philologist, a Traveller and an Antiquary Rediscover the Samaritans in Seventeenth-Century Paris, Rome and Aix. Jean Morin, Pietro della Valle and N.-C. Fabri de Peiresc, in: Helmut Zedelmaier/Martin Mulsow (eds.), Gelehrsamkeit als Praxis. Arbeitsweisen, Funktionen, Grenzbereiche, Tübingen 2001, pp. 123-146.

56 Huntington, Epistolae, pp. xii-xv; Sмith, Life of Huntington, pp. 14-15. The correspondence was reproduced in Silvestre DE SACY, Correspondance des Samaritains de Naplouse pendant les années 1808 et suiv., in: NEMBN 12 (1831), no. xvii-xxiii, pp. 162-225. 
the opportunity to call on the chief priest of the sect at Mount Gerizim. What is perhaps most interesting about Maundrell's subsequent account is that he was acting according to directions he had received from the Ethiopic scholar Hiob Ludolf, whom Maundrell had visited at Frankfurt before travelling to Aleppo. Ludolf himself had been in contact with the Samaritans since the 1680s, and corresponded with Huntington about their writings and religion in the subsequent decade ${ }^{57}$.

Since the first Samaritan Pentateuch had been brought back to Europe in 1616 by the Italian traveller Pietro della Valle, European scholars had been aware of the many differences between the Samaritan and the Hebrew versions of the Pentateuch. The conversation related by Maundrell between himself and the Samaritan priest concerned the conundrum that whereas the Hebrew version, and (following this) the King James Bible, has it that Mount Ebal (to the north of Nablus) was the site where God commanded the Israelites to build their temple (Deuteronomy 27.4), the Samaritan version holds that it was Mount Gerizim (to the south of Nablus). According to Maundrell's account, the priest explained this difference by maintaining that

the Jews had maliciously alter'd their Text out of odium to the Samaritans [...] upon no other account but only because the Samaritans Worshipped in the former Mountain, which they would have, for that reason, not to be the true place appointed by God for his Worship and Sacrifice ${ }^{58}$.

$\gg$ To confirm this«, continued Maundrell, the priest - quoting Deuteronomy $11.29-$

pleaded that Ebal was the Mountain of Cursing [...], and in its own nature an unpleasant place: but on the contrary Gerizim was the Mountain of Blessing by God's own appointment, and also in its self fertile and delightful ${ }^{59}$.

From this, continued Maundrell, »he inferr'd a probability that this latter must have been the true Mountain appointed for those religious festivals $\ll^{60}$. On this point, Maundrell was convinced by the priest's reasoning, observing that "tho' neither of the Mountains has much to boast of as to their pleasantness; yet as one passes between them, Gerizim seems to discover a somewhat more verdant fruitful aspect than Ebal $\aleph^{61}$. The subsequent conversation, which covered the nature of the »Selavæ« which fed the children of Israel in

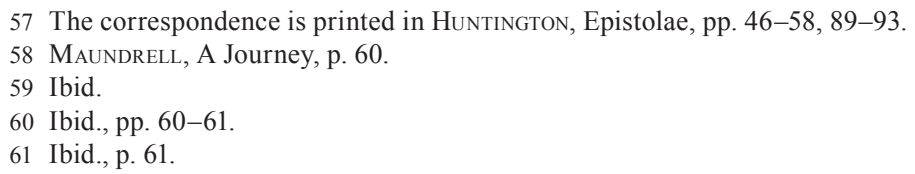


the wilderness at Numbers 11.9, the locusts mentioned at Exodus 10, and the »Dudaim« - or »Mandrakes" - referred to in the story of Jacob, Leah, and Rachel at Genesis 14-22, reflected the concerns of leading biblical scholars in Europe.

However, the groups that perhaps most interested the English chaplains were the Christian communities of the Levant. In the late sixteenth and early seventeenth centuries, Anglicans such as George Cranmer, Edwin and George Sandys, and Edward Brerewood had optimistically hoped to form a union between the Anglican Church and the eastern churches independent of Rome $^{62}$. In the seventeenth century, controversies between the confessional blocks in Europe concerning the theological doctrine of transubstantiation had led to the Greek Orthodox Church in particular becoming the subject of serious study on the part of European scholars. A number of chaplains and consuls associated with the Levant Company contributed to this debate ${ }^{63}$, and it is possible that descriptions taken by Luke of the rites of ordination and holy communion in the Greek and Armenian churches of Izmir supplied material for the work of the consul in the town Paul Rycaut ${ }^{64}$. The belief among Protestants of the theological similarities between the two traditions was heightened with the rise of Cyril Lucaris, who wrote sympathetic letters to the Dutch Arminians and corresponded with George Abbot, archbishop of Canterbury. Lucaris became something of a myth among Protestants, especially after his execution at the instigation of the sultan in 1638. In 1677 a Greek church was founded in London, and friendships such as that between Denton, chaplain at Istanbul, and Joseph Georgirenes, archbishop of Samos, reinforced the general feeling of a spiritual connection between the Greek Church and the Anglican ${ }^{65}$.

Yet the accounts recorded by Luke and Maundrell of the Christian communities outside the urban centres of Izmir and Aleppo conveyed a much less optimistic picture. And this was true, in particular, of the Greeks. Luke, for example, frustrated by the erroneous traditions he encountered regarding

62 See, for example, Edward Brerewood, Enquiries touching the Diversity of Languages, and Religions, through the Chiefe Parts of the World, London 1622; Hamilton, The English Interest, p. 34.

63 For example, Thomas Smith, An Account of the Greek Church as to its Doctrine and Rites of Worship, London 1680; John Covel, Some Account of the Present Greek Church, Cambridge 1722, and Paul Rycaut, Present State of the Greek and Armenian Churches Anno Christi 1678, London 1769. Smith was chaplain to the embassy in Istanbul and Rycaut was a consul at Izmir.

64 See British Library, MS Harley 7021, fol. 355v where Luke describes a Greek Orthodox ordination and the rite of holy communion in St George's Church in Izmir on 5 April 1670, and 405r-V where he describes watching holy communion in an Armenian Church in Izmir on 6 January 1676/77.

65 Hamilton, The Copts and the West, p. 180; Hamilton, Denton, Henry; Steven Runciman, The Great Church in Captivity. A Study of the Patriarchate of Constantinople from the Eve of the Turkish Conquest to the Greek War of Independence, Cambridge 1968, pp. 238-319. 
the sites of the early Christian churches around Koşadası, complained of »the present lamentable decay of literature among the Greeks $\ll^{66}$. When Maundrell met the Greek patriarch at Damascus he commented only that »The place of his residence is mean, and his Person and Converse promis'd not anything extraordinary $\ll^{67}$. At Baalbek, the ancient city of Heliopolis in the Bekka Valley in the Lebanon, Maundrell found the Greek population using the ruins of the ancient Temple of Venus as their church. »This part of it that remains «, he observed, »is at present in a very tottering condition«; the precarious state of the building led him to comment that

'twere well if the danger of its falling, which perpetually threatens, would excite those People to use a little more fervour in their Prayers, than they generally do; the Greeks being seemingly the most undevout and negligent at their Divine Service, of any sort of people in the Christian World ${ }^{68}$.

The primary cause for this dismissive attitude is the superstition and irrationality which Luke and Maundrell thought that the Greeks embodied. When Maundrell visited the Greek Orthodox Bell Mount Convent, south of Tripoli, for example, he observed their service, noting afterwards that:

The monks [were] very good natur'd and industrious, but certainly a very ignorant People. For I found upon enquiry, they could not give any manner of Rationale of their Divine Service ${ }^{69}$.

Maundrell's account of the Greek Orthodox and Armenian ceremony of the miracle of the Holy Fire, enacted on Easter eve in the Church of the Holy Sepulchre, is the climax of this satirical portrait of irrationality. Entering the church, Maundrell encountered what he described as »a numerous and distracted mob, making a hideous clamour very unfit for that sacred place $\ll^{70}$. The subsequent riotous scene during which the worshippers - in Maundrell's words - »act[ed] the most antick tricks and postures, in a thousand shapes of distraction « is described by Maundrell at some length. The climax of the miracle - at which the holy fire is thought to spontaneously descend on candles carried by the Greek patriarch and the Armenian archbishop into the sepulchre of Christ - is related by Maundrell in highly unflattering terms:

66 British Library, MS Harley 7021, fol. 357v.

67 Maundrell, A Journey, p. 129.

68 Ibid., p. 137.

69 Ibid., p. 28.

70 Ibid., p. 4. 
The two Miracle-Mongers had not been above a minute in the holy Sepulchre, when the glimmering of the holy Fire was seen, or imagin'd to appear, thro' some several chinks of the door; and certainly Bedlam it self never saw such an unruly transport, as was produced in the Mob at this sight ${ }^{71}$.

Not only the irrationality, but also the poverty of the Christians struck Luke and Maundrell. Goffman has described the decline of the rural population in south-eastern Anatolia and northern and central Syria in the seventeenth century, which was particularly prominent in the Arabic-speaking Greek Orthodox villages in the Tripoli and Hama regions of Syria ${ }^{72}$. Visiting Ephesus (modern Ayasoluğ), once home to a Christian population which was the recipient of an epistle from St Paul, Luke recorded that there was »Scarce a Christian now left in $\mathrm{y}^{\mathrm{e}}$ Town. but from neighbouring places they visit some times $\mathrm{y}^{\mathrm{e}}$ severall Churches and preserve $\mathrm{y}^{\mathrm{e}}$ memory of them $\aleph^{73}$. Maundrell was dismayed by the fact that the monks at the Bell Mount Convent were obliged to spend their time »not in Study, but in managing their Flocks, cultivating their Land, and other labours of Husbandry, which they accomplish with their own hands«, in part to pay the taxes (»jizya«) they were subject to as non-Muslims in the Ottoman domains ${ }^{74}$. At Jeble Maundrell found the Greek church to be »nothing but a small Grotto in a Rock, by the Sea shore, open at all sides towards the Sea; and having a rude pile of Stones erected in it for an Altar $\aleph^{75}$. At the village of Bahluliah (Bellulca) ${ }^{76}$ east of Lattakia in north-western Syria Maudell went to visit the local Christian inhabitants. He found their church, however, "so poor and pitiful a Structure, that here Christianity seem'd to be brought to its humblest State, and Christ to be laid again in a Manger « ${ }^{77}$. It was not until he reached Jerusalem that Maundrell had a positive word to say about the situation of the eastern Christians. Here he found the altars in the Armenian Church of St James »set out with extraordinary splendour« and the tortoise shell and mother of pearl decorating the pulpit »so exquisitely mingled and inlaid in each other, that the work far exceeds the materials $\iota^{78}$.

When it came to the Turks, Maundrell was clearly fascinated by the rituals of high society. Like Covel at the embassy in Istanbul, Maundrell seems to have rather enjoyed the novelties of coffee-drinking and beard-perfuming;

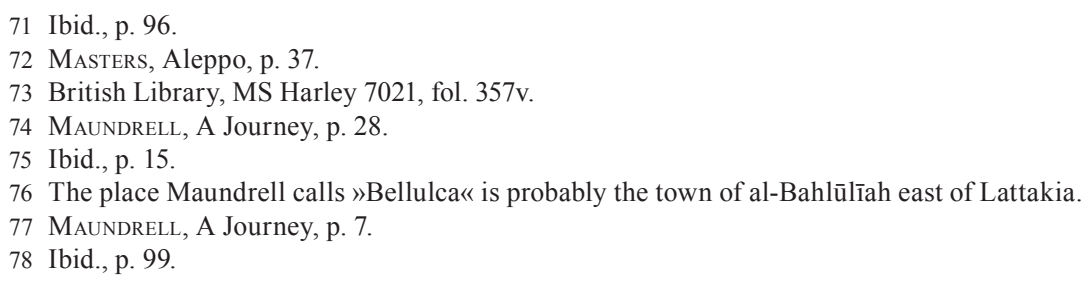


his description of the annual pilgrimage caravan setting out from Damascus to Mecca betrays his evident curiosity ${ }^{79}$. He appears though to have taken little interest in Islam: although his account is free of the long list of the impostures of the Prophet Muhammad which was a staple of early modern travellers' accounts, his comments on the »Pharisaical superciliousness « of the Muslims are fairly standard ${ }^{80}$. One exception is Maundrell's account of his visit to the mosque of the sultan Ibrahim bin Adham at Jeble. Here, he was shown the tomb held by Muslims to be the resting place of the renowned saint who, in Islamic tradition, renounced his throne to live the life of an ascetic. Whereas Maundrell refused to judge concerning the veracity of the tradition on the grounds that he could not validate it from any independent account, his observations on the saint's grotto are particularly interesting. Maundrell was fascinated by the hollow niches which he encountered in mosques, noting that they were »always form'd exactly resembling those usually made for Statues, both in their size, fabrick, and every circumstance«. In an interesting aside, Maundrell speculates on the reason for this:

if I may be allowed to conjecture, I believe they did it at first in testimony of their Iconoclastick principle; and to express to them both the reality of the Divine presence there, and at the same time also its Invisibility ${ }^{81}$.

This seems worth noting because it embodies a certain kind of rationality conspicuously missing from the irreverent chattering in the Bell Mount Convent and the miracle-mongering in the Church of the Holy Sepulchre.

Furthermore, both men appear to have been genuinely interested in Islamic eschatological traditions. In Jerusalem Maundrell noted the existence of a pillar in the wall of the Old City, »Upon which «, he says, »the Turks have a tradition that Mahomet shall sit in Judgment, at the last day; and that all the World shall be gathered together in the Valley below, to receive their doom from his Mouth $\ll^{82}$. Similarly, both men recorded the tradition that the Golden Gate in front of the Dome of the Rock on the Temple Mount had been walled up because, in Luke's words, »the Turks [...] have a tradition $\mathrm{y}^{\mathrm{t}}$ the xtians shall enter it [the city] and take possessio[n] of it at that gate $\ll^{83}$. »[T]he completion of which prediction «, noted Maundrell, »they endeavour by this means to

79 Ibid., pp. 29-31, 127-128. Covel's journals have been published in part in J. Theodore BENT (ed.), Early Voyages and Travels in the Levant, London 1893, pp. 99-287. The originals are British Library, MS Add 22912-14: Autograph journals of John Covel.

80 Maundrell, A Journey, p. 10, 146-149.

81 Ibid., pp. 14-15.

82 Ibid., p. 103.

83 British Library, MS Harley 7021, fol. 384r. 
prevent $\aleph^{84}$. In Damascus, Maundrell walked around the walls of the Umayyad Mosque, one of the most spectacular monuments of the Islamic world, built between 708 and 715 on the site of a Christian basilica dedicated to St John the Baptist. Here he was »told by a Turk of good fashion, that Christ was to descend into this Mosque at the day of Judgment, as Mahomet was to do into that of Jerusalem $\ll^{85}$. Interestingly, Maundrell tended to reserve passing any definitive judgment on these kinds of popularly held beliefs: he concluded only that $»$ the ground and reason of this tradition I could not learn $\aleph^{86}$. Luke appears to have taken a more serious interest in Islamic texts and traditions. His journal contains a number of folio pages including notes on »theire devotions \& $y^{\mathrm{e}}$ parations there unto « and on »the Turks opinion of our Lord and Saviour Jesus Christ $\ll^{87}$. Under the latter heading are fairly detailed notes on the role of Christ in Islamic eschatological tradition: he recorded the Muslim belief that Christ will reign for forty years in Damascus and destroy the anti-Christ as a prelude to the last judgment ${ }^{88}$. His notebook also includes passages from the Qur'an, copied out in the original Arabic with adjoining Latin translations ${ }^{89}$.

\section{Implications for historical consciousness}

What, if anything, might these encounters tell us about the wider historical consciousness of seventeenth-century English Protestants such as Luke and Maundrell? One possible way of answering this question is to look to a providential understanding of world history. How could a divinely ordained providence have allowed the degradation of the eastern Christians witnessed by Luke and Maundrell and the ascendancy of an Islamic civilization? Of course, Christians had wrestled with this question since the beginnings of the Islamic conquests of the Christian Byzantine Empire in the seventh century. Protestants since Luther had developed complex scriptural interpretations to explain why God would have allowed an anti-Christian force such as the Ottoman Empire such spectacular military successes. Interestingly, one such reading was set out by one of the first chaplains to the merchants

84 Maundrell, A Journey, p. 103.

85 Ibid., p. 126.

86 Ibid.

87 British Library, MS Harley 7021, fol. 231r-v.

88 Ibid., fol. $432 \mathrm{v}$. Some of these notes appear to be in a different hand, suggesting, perhaps, that they were replaced after being put to use elsewhere, see note 18. On the tradition see Emeri van Donzel/Bernard Lewis/Charles Pellat (ed.), The Encyclopaedia of Islam. New Edition, 12 vols., here vol. iv, Leiden 1990, p. 84.

89 See British Library, MS Harley 702, fol. 415. 
at Aleppo, William Biddulph ${ }^{90}$. Biddulph was in Aleppo in the first decade of the seventeenth century. He made a pilgrimage to Jerusalem, his account of which, along with a number of other journeys undertaken by his brother Peter, was printed at London in 1609. In a section on the religion of the Turks, Biddulph set out a theological interpretation of the Islamic conquests. His account drew on a reading of the book of Daniel, associating the horns of the beast described in the Prophet Daniel's dream (Daniel 7.8; 7.20) with the Turkish conquests of Egypt, Syria, and Africa ${ }^{91}$. The rudiments of this analysis can be traced back at least as far as the ninth-century Spanish author Paul Alvares ${ }^{92}$. The point of this kind of scriptural interpretation is to reassure Christians that the expansion of the Ottoman Empire is all part of a providential scheme, one which will culminate in the everlasting dominion brought about by the second coming of Christ. Whereas Alvares in 850 A.D. had predicted only another 16 years of Muslim rule, Biddulph was less specific about the precise timescale of Daniel's prophecy. He reassured his Christian readers, however, that

God would haue this prophecie to be extant for a strengthening of the godly against the crueltie of Turks, that when they should see the euent to asweare to the prophecie, they might not be offended at the stumbling blocke of so great persecution, and of such reuolting from the true Church.

$»[T]$ herefore«, he continues,

being thus forewarned by the Prophet, let us take heart to ourselues against this Turkish tyranny and wickednesse, especiallie seeing how the euent hath answered the prophecie ${ }^{93}$.

Luke and Maundrell, however, at the end of the seventeenth century, were, on the whole, more cautious about this kind of essentially mediaeval exegesis. Visiting Tyre on the Mediterranean coast Maundrell did allow himself to speculate that the city's present inhabitants, »a few poor wretches, harbouring themselves in the Vaults, and subsisting chiefly upon fishing «, had been »preserved in this place by Divine Providence« as a living illustration

90 Biddulph is described as »Preacher to the Company of English Merchants resident in `Aleppo « in the preface to William Biddulph, The Travels of Certaine Englishmen into Africa, Asia, Troy, Bythinia, Thracia, London 1609, unpaginated. On Biddulph see Gerald MacLean, The Rise of Oriental Travel. English Visitors to the Ottoman Empire 1580-1720, Basingstoke 2004, pp. 49-114.

91 Biddulph, Travels, pp. 6-49.

92 John V. Tolan, Saracens. Islam in the Medieval European Imagination, New York 2002, pp. 90-91.

93 Biddulph, Travels, p. 49. 
of the prophecy concerning the town set out in the book of the Prophet Ezekiel (Ezekiel 26.14). His only speculation concerning a providential interpretation of the Islamic conquests is much more tentative. Viewing the remains of the twelfth-century crusader cathedral in Tyre, Maundrell was led to the following reflection:

I cannot, in this place, omit an observation made by all our Company in this journey, viz. That in all the ruins of the Churches which we saw, tho' their other parts were totally demolish'd, yet the East end we always found standing, and tolerably entire ${ }^{94}$.

The subsequent passage is interesting for the way in which it offers three entirely naturalistic explanations for this preservation, before tentatively hazarding a providential interpretation:

Whether the Christians when over-run by Infidels, redeemed their Altars from ruin with Money; or whether, even the Barbarians, when they demolish'd the other parts of the Churches, might voluntarily spare these out of an Awe and Veneration; or whether they have stood this long by virtue of some peculiar firmness in their Fabrick; or whether some occult Providence has preserv'd them, as so many standing Monuments of Christianity in these unbelieving Regions, and presages of its Future Restauration, I will not determine ${ }^{95}$.

The question, then, of the extent to which the Islamic conquests are part of an explicable divine plan is left unanswered.

In fact, Maundrell's strategy for dealing with the evident decline of Christianity which he encountered in Syria and Palestine was rather different. It was not only the living Christian communities which Maundrell and Luke found in so lowly a condition, but the whole Christian heritage of the Levant. Both accounts are littered with descriptions of ruined monasteries, and of churches »usurp'd «, »perverted «, »subjugated «, and »abused « by the Turks ${ }^{96}$. On reaching the Holy Land, Maundrell appears to have been somewhat disappointed even with the very landscape. Riding between Kane Leban - the site thought to be associated with the $»$ Lebonah« mentioned in the book of Judges (Jud. 11.19) - and Beer - thought to be the place mentioned at Judges 9.21 -, for example, Maundrell observed the following:

\footnotetext{
94 Maundrell, A Journey, p. 49.

95 Ibid.

96 Ibid., pp. 41, 38; British Library, MS Harley 7021, fol. 369r, 394r.
} 
All along this day's travel from Kane Leban to Beer, and also as far as we could see round, the Country discover'd a different face from what it had before; presenting nothing to the view in most places, but naked rocks, mountains and precipices ${ }^{97}$.

By way of caution to future pilgrims, Maundrell continues thus:

At sight of which Pilgrims are apt to be much astonished and baulked in their expectations; finding that Country in such an inhospitable condition; concerning whose pleasantness and plenty they had before form'd in their Minds such high Ideas from the description given of it, in the word of God ${ }^{98}$.

Not only this, but, says Maundrell, »it almost startles their faith « when they reflect how it could have been possible for a land such as this to supply food for $1,800,000$ men, as reported in the second Book of Samuel (2 Samuel $24.9)^{99}$.

Here it is worth noting that Maundrell's account was written in part for future pilgrims; in fact a manuscript of the work was taken along by Aleppo factors who made the journey to Jerusalem some time between 1697 and 1703 when the book was first printed ${ }^{100}$. The solution to the obvious discrepancy between the reality of the Holy Land and the world depicted in the scriptures was the historical imagination required of the traveller. With an almost archaeological eye, Maundrell directed his readers to the "evident footsteps" of an ancient form of agriculture - the terraces which supported the vines and olive trees described in the Bible. Likewise, when charting the site supposed to be the place mentioned in the Book of Acts where St Philip baptised the Ethiopian eunuch (Acts 8.38). Maundrell advises future pilgrims, likely to be sceptical on account of the difficulty of conceiving how a chariot mentioned in the biblical story - could have passed along such a narrow and rocky path, to think historically: »It must not be judged «, he cautions his readers, "what the road was in ancient times, by what the negligence of the Turks has now reduced it to «. He continues:

for I observ'd not far from the Fountain, a place where the Rock had been cut away in old time, in order to lay open a good Road; by which it may be suppos'd that the same care was used all along this Passage, tho' now time and negligence have obliterated both the fruit and almost the signs of such labour ${ }^{101}$.

\footnotetext{
97 Maundrell, A Journey, pp. 64-65.

98 Ibid., p. 65.

99 Ibid., p. 65.

100 Ibid., unpaginated.

101 Ibid., p. 92.
} 
Similarly, the Arab farmers whom Maundrell observed become signs of a part historical, part imagined biblical landscape. The extraordinarily large goads which he witnessed in the fields around Kane Leban he conjectured to be the same as the one used by Shamgar, who, according to the Book of Judges (Judges 3.31), killed six hundred Philistines with an ox goad ${ }^{102}$. In this passage Maundrell anticipates the work of the nineteenth-century traveller and biblical scholar Edward Robinson in whose writings, as Billie Melman has pointed out, »contemporary Arab agricultural methods are but an illustration to a supposedly biblical one $\ll^{103}$.

But is there anything more profound going on? Is there any sense in which, rather than re-imagining the peoples and the landscape to fit the image of the Bible, travellers such as Maundrell and Luke might begin to re-interpret the Bible in light of their experiences of the peoples and the land? One passage in Maundrell's work stands out in this respect. In the countryside between Tripoli and Aleppo Maundrell observed the country people plucking corn from the root, something he had witnessed throughout Syria, and for which he deduced an entirely rational explanation ${ }^{104}$. This, he noted, $\gg$ seems to give light to that expression of the Psalmist, Ps. 129. 6. which withereth before it be plucked up, where there seems to be a manifest allusion to this custom ${ }^{105}$. The King James version of the Bible, as Maundrell subsequently pointed out, had translated this line: »let them be as grass upon the housetops, which witherth afore it groweth up«. In this, Maundrell continued, it differs »from most, or all other Copies « and in so doing is clearly erroneous ${ }^{106}$. The reference to a »mower« in the subsequent verse (Psalm 129.7) clearly proves the alternative translation the better. This may seem a very minor point, but it is significant in so far as it is part of a general methodology in Maundrell's account concerned with correcting error through the use of what he refers to at one point as »experimental observation ${ }^{107}$. Furthermore, Maundrell was not the first English chaplain to use his observations of the Levant for the improvement of the biblical text. Edward Pococke had concluded that the terms »tannim« (Psalm 44.19; Micah 1.8) and »shualim« (Psalm 63.10) were neither »dragons« nor »foxes« (as given in the King James version), but »jackals«. Although, as Sheehan has pointed out, Pococke defended these readings by recourse to the extant Syriac translations, he was led to

102 Ibid., pp. 110-111.

103 Billie Melman, The Middle East/Arabia. The cradle of Islam, in: Hulme/Youngs, Cambridge Companion, pp. 105-121, here p. 110. Melman is referring to Robinson's Biblical Researches in Palestine, 1838.

104 Maundrell, A Journey, p. 144.

105 Ibid.

106 Ibid.

107 Ibid., p. 36. 
them, according to his biographer, by his own »Observations [...] of those Animals $\ll^{108}$; his commentary on the Book of Micah noted that »none that have travelled in the night in those parts of Syria « could have failed to have heard the »lamentable howling noise « referred to at Micah 1.7 ${ }^{109}$. Pococke made similar observations concerning Levantine farming practices and »reached a number of currently accepted conclusions about the meaning and translation of certain words and passages « in the books of Joel, Micah, and Hosea $^{110}$.

However, to deduce any broader implications from these kinds of learned observations requires us to look beyond the chaplains' accounts themselves to the ways in which these accounts were drawn on by a scholarly community. Pococke (with the possible exception of Huntington) was perhaps the one example of a chaplain who made a major contribution to biblical and oriental studies. The rest, to varying degrees, were learned observers whose importance to the development of scholarship lies in part in their own accounts, in part in the manuscripts and other items which they collected, and in part in the links they maintained with scholars at home. We have seen a number of examples of this already and many more could be cited: John Covel sent Henry Moore information on the Jewish Karaites ${ }^{111}$; Huntington maintained correspondences with Narcissus Marsh, John Fell, Pococke, Thomas Marshall, Edward Barnard, and Thomas Hyde, and sent back, not just manuscripts, but Egyptian antiquities, coins, seeds, dried plants, fauna, and insects - in short anything »which might be of use to either polite learning or natural history « - for the library, museum, and physic garden at Oxford ${ }^{112}$. When Halifax made transcriptions of the Greek and Palmyrene-Aramaic inscriptions at Palmyra he communicated them Edward Bernard and Thomas Smith who published them in learned journals, where they could be, and were, discussed by a wider scholarly community ${ }^{113}$. In this way, the chaplains were essen-

108 Sheehan, Enlightenment Bible, pp. 203-204; Edward Pococke, The Theological Works of the Learned Dr Pococke, ed. Leonard Twells, 2 vols., vol. i, Oxford 1740, p. 5.

109 Edward Pococke, A Commentary on the Prophecy of Micah, Oxford 1677, p. 5.

110 Hamilton, The English Interest, p. 43-44; Pococke, Theological Works, vol. i, pp. 5-6.

111 Johannes van den Berg, Proto-Protestants? The Image of the Karaites as a Mirror of the Catholic-Protestant Controversy in the Seventeenth Century, in: Jan de Bruisn/Pieter Holtrop/ Ernestine van der Wall, Religious Currents and Cross-Currents. Essays on Early Modern Protestantism and the Protestant Enlightenment, Leiden 1994, pp. 43-64, esp. pp. 57-64, which reproduces Covel's letter to Henry Moore written in 1677.

112 Huntington, Epistolae, pp. vi, xxii-xxiii; Sмith, Life of Huntington, pp. 13, 118.

113 Halifax's transcriptions were published in Philosophical Transactions of the Royal Society 19 (1698), no. 217, pp. 83-110 and Inscriptiones Graecae Palmyrenorumque cum Scholiis \& Annotationibus, Utrecht 1698. See Peter T. Daniels, Shewing of Hard Sentences and Dissolving of Doubts. The First Decipherment, in: Journal of the American Oriental Society 108 (1998), pp. 419-436. 
tial contributors to late seventeenth-century scholarly discourses. They were among those who supplied the empirical data upon which advances in biblical and oriental studies and the natural sciences were grounded.

To conclude, a number of illustrations from the field of biblical studies, all of which illustrate the resolution of textual problems by »experimental observation«, will serve to illustrate the point. William Biddulph was no great scholar, but his account of the Holy Land was drawn on by someone with a more tenable claim to such a title. John Lightfoot (1602-1675) was a Hebraist who served on the Westminster assembly of divines between 1643 and 1649 and whose biblical exegesis influenced the views of the Presbyterian faction. He was appointed master of St Catherine's College, Cambridge and graduated DD in 1651. In the 1650s Lightfoot assisted Brian Walton with the London Polyglot Bible, commenting on the Samaritan Pentateuch and contributing a map of Judea and notes for the Jerusalem Talmud. His Chronological Observations prefaced the Bible. He was highly regarded by Walton and Edmund Castel, and he corresponded with a learned circle of biblical and oriental scholars in England and on the Continent ${ }^{14}$. Lightfoot's Horae Hebraicae et Talmudicae (1658-78) was an encyclopaedic commentary on the scriptures. In his notes on John's Gospel Lightfoot twice drew on Biddulph's account. To illustrate the text at John 4.4 - »And he must needs go through Samaria" - Lightfoot used Biddulph's relation of his own journey between Galilee and Jerusalem in 1601 to illustrate the point that the route taken by Christ was done so entirely out of necessity, in order to avoid a long detour through the country beyond the Jordan ${ }^{115}$. In his commentary on John 18.18 - »and it was cold « (describing Peter and the officers and servants outside the palace of the high priest Caiaphas) - he cited Biddulph's personal experience of the changeability of the Jerusalem weather to explain the seeming improbability of its being cold at the time of the Jewish Passover ${ }^{116}$. Lightfoot also drew on Biddulph's account to improve his map of the sea of Galilee and surrounding settlements ${ }^{117}$.

However, it was Maundrell's work which was most frequently drawn on by biblical scholars. Maundrell's book was read widely and was cited literally hundreds of times in works of scriptural interpretation and translation throughout the eighteenth century. Two examples of this from two of the

114 Newton E. Key, Lightfoot, John (1602-1675), in: ODNB, online edn.

$115 » I$ psa necessitas invenit viam à `Judea in Galilaeam‘, \& vice versa, per Samariam, nam non erat qua aliter iretur, nisi per Trans-Jordaninam longissima deviatione«; John Lightfoot, Horae hebraicae et talmudicae impensae in evangelium S. Johannis, London 1671, p. 83.

116 Ibid., pp. 212-213.

117 See John Lightғoот, The Works of the Reverend and Learned John Lightfoot D.D., London 1684, pp. 308-309. 
pre-eminent Hebrew scholars of the mid eighteenth century are particularly worth noting. For the first of these, it is necessary to return to the Samaritans and to the old problem of whether Mount Ebal or Mount Gerizim was the place where God commanded the Israelites to build their temple. By the mid eighteenth century much more was known about the Samaritans than had been when Huntington visited them in the 1670s. Seven copies of the Samaritan Pentateuch - including one in Arabic which had been acquired at Damascus in 1663 - had been deposited in the libraries at Oxford, Cambridge, and the British Museum ${ }^{118}$.

Thus, when the brilliant young Hebraist Benjamin Kennicott set out to argue, against the consensus of learned scholars across Europe, for the superior authority of the Samaritan Pentateuch in relation to Deuteronomy 27.4 (the Gerizim-Ebal problem) he had some substantial materials to work with. Kennicott's engagement with the Samaritan Pentateuch was part of his larger, ambitious project to piece together a definitive original text of the Old Testament by collating all the Hebrew manuscripts available to him at that time. In his The State of the Printed Hebrew Text of the Old Testament considered of 1753 he defined the $»$ rational and safe Method of proceeding in a Case of this important Nature« as being fourfold:

to compare Scripture with itself - to explain a difficult Phrase or Passage by a clear one, that bears some Relation to it - to consider the natural Force of the Original Words, the Tendency of the Context, and the Design of the Writer - to compare the most ancient Editions of the Original with one another, and with the best Copies of the most celebrated Versions ${ }^{119}$.

It is the third of these methods which is most of interest here. In presenting his case for the authority of the reading in the Samaritan Pentateuch, Kennicott advances a number of arguments which are contextual, rather than dependent on other passages in the scriptures or based on readings in other authoritative manuscripts. Firstly, he states - in an argument which will by now be familiar - that

The different nature of these mountains furnishes another strong argument for the preference in favour of Gerizim. For this mountain standing on the south, with its surface declining towards the north, is shelter'd from the heat of the sun by its own shade;

118 Katz, Isaac Vossius, p. 175.

119 Benjamin Kennicott, The State of the Printed Hebrew Text of the Old Testament considered, 2 vols., vol. i, Oxford 1753-1759, pp. 12-13. 
whereas Ebal, looking southward, is more open to the sun falling directly upon it. 'Tis no wonder therefore, that the former should be cloath'd with a beautiful verdure, while the surface of the latter is more scord'd up and unfruitful ${ }^{120}$.

Kennicott's authorities here are Pietro della Valle, the mediaeval Jewish traveller Benjamin of Tudela, the Samaritans themselves (who had written to Ludolf presenting the same argument), and Maundrell. Secondly, Kennicott advances another contextual argument, namely that being as the Samaritans had such a great veneration for the law of Moses, it is less likely that they would have wilfully corrupted it. Here one of his authorities is Huntington, who in a letter to Ludolf cited by Kennicott, had described how »one of the Samaritans had a MS copy of the Law hung round his neck, affectionately carrying it in his bosom $\ll^{121}$. In both of these examples the »experimental observations « of the traveller are drawn on to resolve a textual problem.

The final example comes from the work of Robert Lowth, one of Kennicott's mentors and, like Kennicott, one of the most important Hebraists of the eighteenth century ${ }^{122}$. In 1778 Lowth produced an influential translation of the Book of Isaiah. In a gloss on Isaiah 49.16 - which Lowth translates »Behold, on the palms of my hand I have delineated thee « - we find the following note:

This is certainly an allusion to some practice, common among the Jews at that time, of making marks on their hands or arms by punctures on the skin, with some sort of sign or representation of the City or Temple to show their affection and zeal for it ${ }^{123}$.

To further illustrate the observation, he continues:

It is well known, that the pilgrims at the Holy Sepulchre get themselves marked in this manner with what are called the Ensigns of Jerusalem. Maundrell [...] tells us how it is performed: and this art is practised by travelling Jews all over the world at this day ${ }^{124}$.

Here, again, the first-hand observations of the traveller are used to construct a contextual interpretation of the biblical passage.

120 Ibid., vol. ii, p. 36-38.

121 Ibid., vol. ii, p. 42.

122 On Lowth see John JARICK (ed.), Sacred Conjectures. The Context and Legacy of Robert Lowth and Jean Astruc, London 2007.

123 Robert Lowth, Isaiah. A New Translation. With a Preliminary Dissertation, and Notes, Critical, Philological, and Explanatory, Perth ${ }^{3} 1795$, p. 227.

124 Ibid., p. 227. 
These examples are arguably part of the same urge underpinning the Niebuhr/Michaelis expedition which I began this paper by discussing. The urge, that is, to piece together a context for understanding the Bible by rediscovering the people, the culture, the geography, and the natural history of the biblical lands. They are part of a broader transition within biblical exegesis often understood as the shift from the lower criticism of texts to the higher criticism of things. Whereas it would risk being anachronistic to suggest that the chaplains themselves were part of this process, their learned observations and those of travellers like them arguably made an important contribution to it. The connection between critical history and learned travel has long been recognised ${ }^{125}$. However, the use of the empirical data gleaned by travellers within the more exclusively textual domain of biblical studies is sometimes presented as a rare thing before the mid eighteenth century ${ }^{126}$. Hopefully Biddulph's musings on the volatility of the Jerusalem climate, Pococke's observations on howling jackals in the Syrian night, and Maundrell's speculations on Arab agricultural practices, and - specifically - the ways in which these nuggets of information were picked up and used by biblical scholars from Lightfoot to Kennicott, will demonstrate that there were attempts at a contextual understanding of the scriptures before the advent of »historicist « biblical scholarship. And here, perhaps, is a key to answering the question of how encounters with strangers shaped historical consciousness in the case of late seventeenth-century oriental travel.

125 Grafton, What was History?, pp. 118-122.

126 See, for example, Sheehan, Enlightenment Bible, p. 204. 


\title{
Dominik Collet
}

\section{Fremde Dinge}

\author{
Die Exotika früher Museen und das \\ europäische Geschichtsbewusstsein
}

»Auswärtige, Indianische und andere frembde Sachen $\aleph^{1}-$ so beschrieben frühneuzeitliche Sammler ihre exotischen Museumsstücke. Diese Assoziation von »fremd « mit »fremdländisch« hat auch die Forschung übernommen. Dass in den »Kunst- und Wunderkammern« neben exotischer auch historische Fremdheit konstruiert wurde, hat dagegen weniger Aufmerksamkeit gefunden. Dabei existierten räumliche und zeitliche Formen des »othering « nicht bloß parallel zueinander: Die Inszenierung exotischer Fremdheit inspirierte und strukturierte die Entdeckung der eigenen, europäischen Geschichtlichkeit.

Dass frühe Museen bisher vor allem als Orte interkultureller Begegnung untersucht worden sind, reflektiert den aktuellen Boom transnationaler Ansätze. In der Folge hat man das Museum als einen Kontaktraum ausgemacht, der möglicherweise vielschichtigere Formen von Begegnung zuließ als die von rigiden Essentialismen geprägten Reiseberichte. So vermutet Horst Bredekamp, dass die materiellen Zeugnisse früher Museen einen freieren Blick ermöglicht haben könnten, als dies die Lektüre von tendenziösen Texten zuließ. In frühen Sammlungsformen sei daher ein »offener, respektvoller Umgang « mit dem Fremden sowie ein »ehrendes Sammeln « praktiziert worden, das sich deutlich von der »kolonialistischen Beuteschau« späterer Museen unterschieden habe ${ }^{2}$. Die affirmative Bezugnahme auf die Wunderkammer als »Spielraum « zwischen Kunst und Wissenschaft sowie zwischen den Kulturen lässt sich als die Kehrseite der scharfen Kritik an modernen Museen verstehen. Während den heutigen Museen ihr kolonialer Blick und die gewaltsame Konstruktion von Alteritäten vorgeworfen werden ${ }^{3}$, erschei-

1 Inventarium der herzoglichen Kunstkammer, Schloss Friedenstein, 1656; Thüringisches Staatsarchiv Gotha, GA YY IIIa $2 / 9$.

2 Eckhardt FuHr, Das Humboldt-Forum als Museums-Revolution?, in: Welt-Online vom 09.07.2010 (URL: <http://www.welt.de/kultur/article4087176/Das-Humboldt-Forum-alsMuseums-Revolution.html> [17.10.2010]).

3 Vgl. Cordula Grewe, Die Schau des Fremden. Ausstellungskonzepte zwischen Kunst, Kommerz und Wissenschaft, Stuttgart 2006. 
nen die ehemals als Kuriositätenkabinette abqualifizierten Kunstkammern nun als »Theater des Wissens $\aleph^{4}$.

Ihren vorläufigen Höhepunkt erleben diese Überlegungen im Zusammenhang mit dem Humboldtforum des geplanten Berliner Stadtschlosses. Dessen Zentrum soll eine »Kunstkammer« als Raum des unschuldigen Staunens und Bewunderns bilden. Auf diese Weise soll zugleich die unrühmliche militaristische Tradition des preußischen Schlosses wie die problematische Geschichte der dorthin transferierten Berliner Kolonialmuseen aufgehoben und überschrieben werden ${ }^{5}$.

Diese politische und wissenschaftliche Inanspruchnahme droht zwei zentrale Bereiche zu verdecken: Erstens wurde auch der vermeintliche »Spielraum « des frühneuzeitlichen Museums durch die rigide Grenzziehung zwischen Christen und Heiden eingehegt und kodiert. Zweitens war es gerade dieser biblische Rahmen, der eine ganz andere Neuentdeckung beförderte: die der eigenen Vergangenheit. In dem Maße, in dem der Exot als Heide gekennzeichnet wurde, konnten auch die eigenen heidnischen Vorfahren zunehmend als fremd erscheinen und historisiert werden. Dieser Erkenntnisprozess lässt sich so als unintendierte Konsequenz religiöser Ausgrenzung verstehen.

Diese Entwicklungen werden im Folgenden beispielhaft anhand von zwei Akteuren vorgestellt: Das Schicksal des ersten illustriert die Grenzen der musealen Begegnung mit dem exotischen Fremden, das des zweiten veranschaulicht, wie exotische Objekte die Historisierung der eigenen Vergangenheit anregten. Ihr Umgang mit fernen und historisch Fremden verweist auf drei zentrale Felder: die Rolle materieller Zeugnisse für die Inszenierung von Fremdheit, die Bedeutung außereuropäischer Fremdheitserfahrungen für europäische Geschichtskonzeptionen sowie den zentralen Beitrag religiöser Vorstellungen zu diesem Prozess.

4 Vgl. Helmar Schramm u.a. (Hg.), Kunstkammer - Laboratorium - Bühne. Schauplätze des Wissens im 17. Jahrhundert, Berlin 2003.

5 FuHR, Humboldt-Forum. 


\section{Das exotische Fremde}

Caspar Schmalkalden ( 1617-1668) stammte aus der Umgebung von Gotha und hatte in seiner Jugend als Soldat und Landvermesser nahezu das gesamte niederländische Kolonialreich bereist. Als er 1653, nach über zehn Jahren, wieder zurückkehrte, fand er im mittlerweile zur Residenz aufgestiegenen Gotha das fast fertiggestellte Schloss Friedenstein vor. Rasch erfasste er die Möglichkeiten, die sich ihm hier boten. Er vermachte dem Herrscher der imposanten Residenz einige seiner exotischen Mitbringsel und wurde kurz darauf mit der Betreuung der im Aufbau befindlichen Kunstkammer betraut

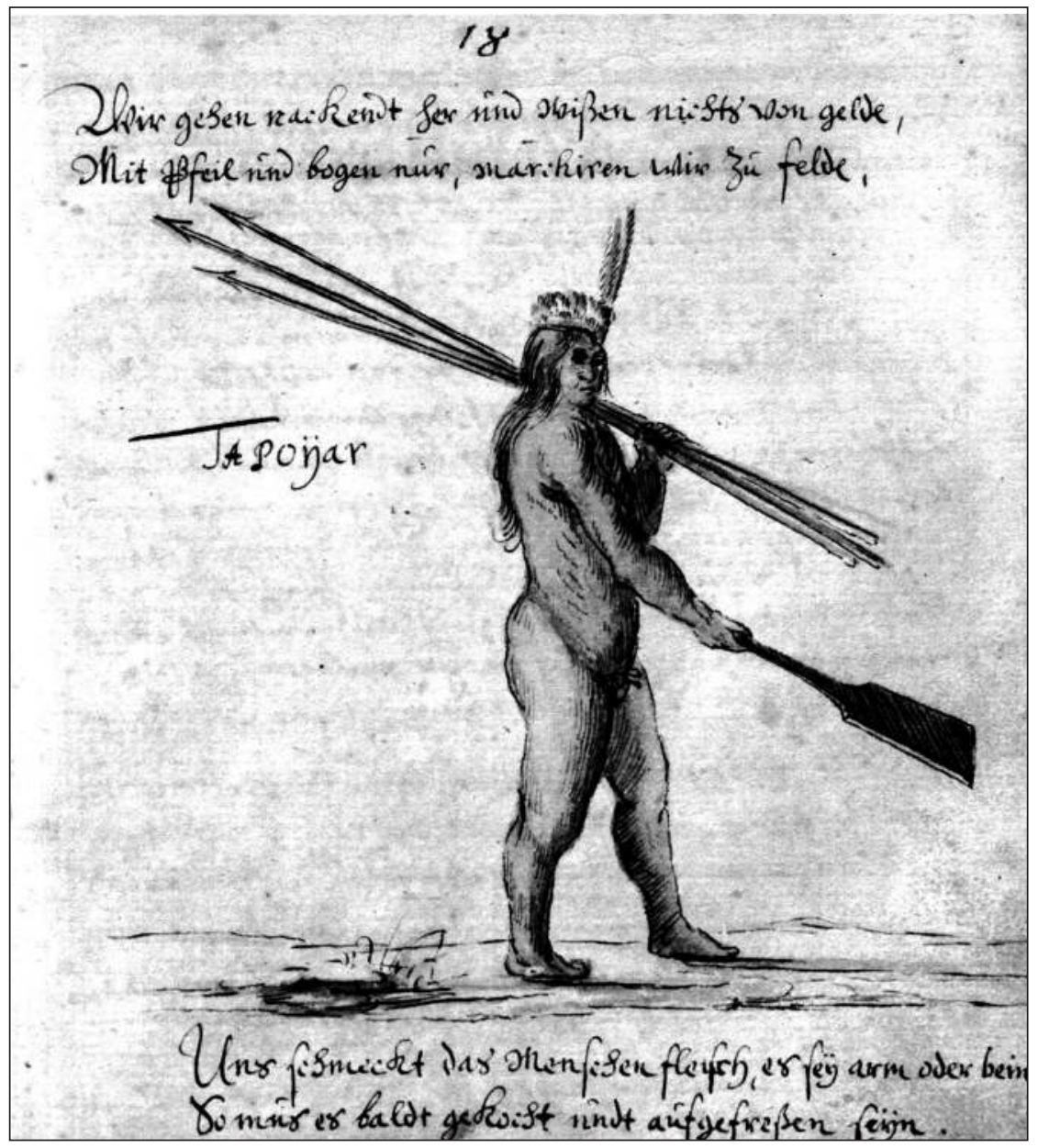

Abbildung 1: Caspar SchmalKaldEN, »Tapoyar«, UFB Gotha, Chart B 533, fol. 18r. 
- eine klassische Karriere für weitgereiste »Experten«, schließlich war die vermehrte Einfuhr exotischer Raritäten seit dem 16. Jahrhundert ein Hauptgrund für die Entstehung der ersten europäischen Museen ${ }^{6}$.

Am Hof war Schmalkalden bald für seine farbenfrohen Geschichten aus der weiten Welt berühmt. Wie ein Zeitgenosse notierte, pflegte Schmalkalden »öffters von gedachten seinen Reisen eins und anders zu erzehlen, auch die herrliche Landes $=$ Arth, die vielerley Nationen, kostbahre Wahren und Schätze Indiens zu rühmen und heraus zu streichen«?

Die neutralen Einträge in den Inventaren der Sammlung verraten kaum etwas über diese Geschichten. Allerdings fertigte Schmalkalden während seiner Gothaer Zeit mehrere Manuskripte an, in denen er nicht allein von seinen Reisen, sondern auch von den »Indianischen Raritäten« Bericht erstattete $^{8}$. Ein Vergleich dieser Aufzeichnungen mit den Rechnungen und den Inventaren der Sammlung belegt weitgehende Übereinstimmungen. Lässt man die Beschreibung von Schmalkaldens Reisen beiseite, entspricht der Aufbau seiner Manuskripte dem der populären Museumskataloge und naturhistorischen Enzyklopädien der Zeit. Zentrale Kapitel befassen sich mit den Indianern und zeigen jeweils Mann und Frau mit den wichtigsten Zeugnissen ihrer Kultur, die auch im Museum zu sehen waren (Abb. 1).

Schmalkaldens Erzählungen waren kein Beiwerk, sondern füllten im Museum die Lücken, die durch den Transport der Exponate aus ihrem ursprünglichen Umfeld entstanden waren'. Um diese Leerstellen zu schließen, benutzte Schmalkalden populäre Narrative: So dienten die Bastkörbe der Sammlung angeblich Kannibalinnen dazu, menschliches Fleisch zu transportieren, während die »indianischen « Pfeile und Bögen der Sammlung zugleich die Gewaltbereitschaft der »Wilden« sowie ihre technologische Unterlegenheit illustrierten ${ }^{10}$.

6 Zur Biographie Schmalkaldens vgl. Wolfgang Joost, Vorwort, in: Caspar SchmalKalden, Mit Kompass und Kanonen. Abenteuerliche Reisen nach Brasilien und Fernost 1642-1652, hg. v. Wolfgang Joost, Stuttgart 2002; zu seiner Karriere als Experte vgl. Dominik Collet, Die Welt in der Stube. Begegnungen mit Außereuropa in Kunstkammern der Frühen Neuzeit, Göttingen 2007, S. 94-132.

7 Johann Wilhelm Vogel, Gewesenen Fähndrichs und Bergmeisters, in Dienst der Edl. Niederl. Ost=Indischen Compagnie, anietzo F.G. Cammer=Meisters zu Altenburg, Zehen=Jährige, Jetzo auffs neue revidirt- und vermehrte Ost=Indianische Reise=Beschreibung, In Drey Theile abgetheilet. [...], Altenburg 1716, Vorrede, o.P.

8 Die drei erhaltenen Manuskripte befinden sich in der Forschungsbibliothek (FB) Gotha (Chart B 533), der Staats- und Universitätsbibliothek (SUB) Göttingen (HSD Ms. $8^{\circ}$ Histor. 833) sowie der Königlich Dänischen Bibliothek in Kopenhagen (Thott. $12954^{\circ}$ ).

9 Für eine typische Einkaufsliste exotischer Raritäten, deren rudimentäre Beschreibungen diese Dekontextualisierung illustrieren, vgl. Thüringisches Staatsarchiv Gotha, Kammerrechnungen $1658 / 59$, fol. 170.

10 FB Gotha, Chart B 533 (Caspar Schmalkalden, West- und Ostindianische Reisebeschreibung), fol. $10-23$. 
Auch äußerlich harmlose Naturalien wie die brasilianische Cashew-Nuss kontextualisierte Schmalkalden in diesem Sinne: So werde der aus der Frucht gewonnene berauschende Trank während der wilden Tänze der Indianer exzessiv konsumiert. Die Indianer machten sich

lustig und frölich, sie tantzen, singen und springen mit ihren bunden federn gezieret nacht und tag, so lang als etwas davon vorhanden ist [...] und welche das meiste sauffen, sich übergeben und wieder darauf sauffen können die werden für wackere Kerls geachtet $^{11}$.

Schmalkaldens Geschichten projizierten so Fragmente des europäischen imaginären Archivs in die entlegene Welt: den »danse sauvage«, den »Wilden Mann« oder die gewaltbereite »Amazone $\ll^{12}$.

Die Ordnung, Selektion und Präsentation der Gothaer Sammlung zeigt, dass sich die Inszenierungen des Museums eng an Schmalkaldens Vorgaben orientierten. Auf einem eigenen Tisch wurden nach ihrer visuellen Andersartigkeit ausgewählte Exotika ohne weitere regionale Differenzierung zur Schau gestellt. Wie in Schmalkaldens Beschreibungen präsentierte man die außereuropäische Welt so als separate, primitive, weitgehend homogene und statische Heimat von Heiden, die sich von der europäischen Welt grundsätzlich unterschied. Die sich dynamisch verändernden, hybriden Kolonialgesellschaften fanden im Museum dagegen keinen $\mathrm{Ort}^{13}$.

Dieser Befund erinnert daher weniger an das Wirken eines Augenzeugen und kolonialen Praktikers, als vielmehr an die Ergebnisse der Erforschung von Reiseberichten. Vergleicht man dementsprechend Schmalkaldens Aufzeichnungen mit der zeitgenössischen Reiseliteratur, zeigt sich, dass der Weltreisende seine Geschichten nahezu vollständig aus populären Büchern entlehnt hatte. Für Amerika griff er beispielsweise mit Kaspar von Baerle auf einen hochgeschätzten Autor zurück, der Europa aber - anders als Schmalkalden - nie verlassen hatte ${ }^{14}$. Besonders eindrücklich zeigt sich dieses Vorgehen in den Zeichnungen des Weltreisenden. Sie basierten nahezu vollständig auf Abbildungen aus bekannten Druckwerken. In keinem einzigen Fall griff Schmalkalden auf eigene Anschauung oder die realen Objekte der Kunstkammer zurück. Selbst dort, wo er authentische Vorlagen besaß, wie beim mehrfach in Gotha vorhandenen Adlerrochen, benutzte er lieber die

11 Ebd., fol. 14f.

12 Vgl. Peter Mason, Infelicities. Representations of the Exotic, Baltimore u.a. 1998.

13 Collet, Welt in der Stube, S. 110-113.

14 Caspar Barlaeus, Brasilianische Geschichte. Bey Achtjähriger in selbigen Landen geführeter Regierung seiner Fürstlichen Gnaden, Herrn Johann Moritz, Fürstens zu Nassau [...], Kleve 1659, S. 65-75 u. 692-717, entsprechen FB Gotha, Chart B 533, fol. 10-18 u. 18-23. 
etablierten europäischen Vor-Bilder. Sogar den von ihm persönlich aus Indonesien mitgebrachten Paradiesvogel illustrierte er mit einer Abbildung des berühmten Naturhistorikers Ole Worm ${ }^{15}$.

$\mathrm{Zu}$ den wenigen eigenständigen Aufzeichnungen Schmalkaldens gehören die Sinnsprüche, welche die Abbildungen der Indianer begleiten (Abb. 1). Sie illustrieren, dass der Augenzeuge sich die Aussagen seiner Vorbilder zu eigen machte und sogar noch bestärkte: So lautet der Sinnspruch des Tapoyars:

Wir gehen nackendt her, und wißen nichts vom gelde, Mit Pfeil und Bogen nur marschieren wir zu felde, Uns schmeckt das Menschenfleisch, es sey arm oder bein, so muss es baldt gekocht und aufgefreßen $\operatorname{sein}^{16}$.

Bei Schmalkaldens Auftraggeber, dem Gothaer Herzog Ernst I., fand diese alteritäre Interpretation Gefallen. Sie entsprach nicht nur den Inszenierungen berühmter Vorbildsammlungen, Schmalkaldens Bild der indianischen Heiden lieferte dem Herzog auch einen Anknüpfungspunkt für seinen Feldzug gegen die Unmoral seiner eigenen saufenden, ungezügelten Untertanen, der Ernst später den Beinamen »der Fromme« eingetragen hat ${ }^{17}$.

Dass Schmalkaldens Lebensweg eine ganz andere Entwicklung hätte nehmen können, wenn er die stereotypen Vorstellungen der Daheimgebliebenen aufgrund seiner Erfahrungen als Augenzeuge angezweifelt hätte, zeigt das Schicksal eines anderen Gothaers: Johann Michael Wansleben reiste 1663, zehn Jahre nach Schmalkaldens Rückkehr, im Auftrag des Herzogs nach Afrika. Anders als Schmalkalden entschied sich Wansleben aber nicht dafür, seine Berichte an den Erwartungshaltungen der Daheimgebliebenen auszurichten. Er unterließ es nicht nur, gegenweltliche Kuriositäten mitzubringen, Wansleben weigerte sich auch, die sicher geglaubten religiös-konfessionellen Grenzziehungen zu bestätigen. Die Christen Äthiopiens beschrieb er nicht wie erwartet als Erzfeinde der Türken, welche umgekehrt die europäischen Christen als ihre Brüder betrachteten. Auch mache die Akzeptanz der Priesterehe und die vehemente Ablehnung des Papstes aus den Äthiopiern noch keine »afrikanischen Lutheraner«. Dass Wansleben das dualistische Weltbild seiner Auftraggeber infrage stellte und die Kopten stattdessen als eigen-

15 Königlich Dänische Bibliothek Kopenhagen Thott. $12954^{\circ}$ (Caspar Schmalkalden, Beskrivelse over to Reiser), fol. 206r. entspricht Ole Worm, Museum Wormianum [...], Leiden 1655, S. 294. Eine ausführliche Analyse der Korrespondenzen bietet Collet, Welt in der Stube, S. $113-128$.

16 FB Gotha, Chart B 533, fol. 18r.

17 Vgl. Veronika Albrecht-Birkner, Reformation des Lebens. Die Reformen Herzog Ernsts des Frommen von Sachsen-Gotha und ihre Auswirkungen auf Frömmigkeit, Schule und Alltag im ländlichen Raum (1640-1675), Leipzig 2002. 
ständige, dritte Gruppe charakterisierte, kostete ihn seine Anstellung am Gothaer Hof. Erst als Wansleben daraufhin begann, doch die begehrten Götzen, Mumien und Monster nach Europa zu senden, erschloss sich ihm eine Karriere als Agent verschiedener Fürsten und Sammler bis hin zum französischen König ${ }^{18}$.

Ganz offenbar waren Akteure wie Schmalkalden nicht einfach in einem monolithischen Alteritätsdiskurs gefangen. Sie verfügten durchaus über ein differenziertes Bild der Fremden jenseits etablierter Dichotomien. Karriere machten jedoch diejenigen »Vermittler«, welche die Vorannahmen von Sammlern aufnahmen und bestätigten.

Die aus heutiger Perspektive defizitäre Darstellung der Fremden bot den zeitgenössischen Akteuren eine Reihe von Vorteilen: Den Besuchern der Museen eröffnete die stereotype Darstellung von Andersartigkeit eine sichere Gesprächsbasis in unbekannter Umgebung. Den Sammlern ermöglichte die Bezugnahme auf berühmte Autoritäten, ihre Teilhabe an der Gelehrtenwelt zu illustrieren. Den Augenzeugen bot die Bestätigung von Dichotomien Gelegenheit, ihren eigenen unsicheren Status als Experten abzusichern. Allen Beteiligten zusammen erlaubte es die Projektion von Andersartigkeit nach außen, den Sammlungsraum nach innen zu öffnen. Die Ausgrenzung der Barbaren, Heiden und Fremden bereitete die Öffnung für alle vor, die sich nun umgekehrt als Zivilisierte, als Christen und als Europäer imaginieren durften. Die Kunstkammern entwickelten sich in der Folge zu einem der seltenen Räume des Alten Reiches, in dem standes-, konfessions- und geschlechterübergreifende Soziabilität praktiziert werden konnte ${ }^{19}$.

\section{Das historische Fremde}

Während das museale Bild des exotischen Fremden durch Stillstand und Stereotype gekennzeichnet war, lassen sich bei den Vorstellungen zum historisch Fremden Veränderungen erkennen. Auch bei diesem Wandel beobachtet man aber keinen Bruch mit überkommenem Wissen als vielmehr einen Prozess der Emergenz. Er folgte Umwegen, basierte zuweilen auf Missverständnissen und stellt in mancherlei Hinsicht die unbeabsichtigte Kehrseite der exotistischen Verfremdung dar. Sein Verlauf lässt sich an einer weiteren Episode aus dem Umfeld der Gothaer Kunstkammer illustrieren.

18 Vgl. Dominik Collet, Dritte Räume im Konfessionalismus. Ernst der Fromme entdeckt Äthiopiens Christen, in: Susanne BöHm/Miriam Rieger (Hg.), »Hinaus ins Weite...«. Reisen Thüringer Protestanten, Erfurt 2010, S. 34-52.

19 Vgl. Stefan Siemer, Geselligkeit und Methode. Naturgeschichtliches Sammeln im 18. Jahrhundert, Mainz 2004. 
Im Dezember 1695 entdeckten einige Arbeiter in der Nähe von Gotha »etliche schrecklich große« Knochen. Noch an der Ausgrabungsstelle entspann sich unter den Schaulustigen ein heftiger Streit um die Natur der ungewöhnlichen Fundstücke. Daraufhin ließ der Herzog die Funde in die Kunstkammer bringen und trug den Kontrahenten auf, ihm Gutachten zur Entscheidung des Disputes vorzulegen ${ }^{20}$.

Die eine Gruppe um das »Collegium Medicum《 reichte ihr Urteil schon nach wenigen Tagen ein. Die Gothaer Ärzte hatten aus dem Studium etablierter medizinischer Bücher ermittelt, dass es sich bei den Funden um das Produkt einer »von Gott beseelten Natur« handeln müsse, welche die oberirdische Welt unter der Erde spielerisch nachahme. Da der Schädel eine Art "Horn" aufwies, schlossen sie, dass es sich in diesem Falle um das Abbild des biblischen Einhorns handeln müsse, und befürworteten daher den lange etablierten und profitablen Gebrauch der Knochen als Heilmittel ${ }^{21}$.

Wilhelm Ernst Tentzel, der Betreuer der Gothaer Kunstkammer, ließ sich für sein Gutachten mehr Zeit. Anstelle der Bücher nahm er sich die Objekte selbst vor und verglich die Funde sorgfältig mit anderen Knochen der Gothaer Sammlung und weiterer Kunstkammern. Erst danach veröffentlichte er seine Erkenntnisse. Dies geschah zudem nicht nur in einem Gutachten für den Herzog, sondern auch in Form eines »offenen Briefes« an die wichtigsten gelehrten Journale. In diesem Text identifizierte Tentzel die Funde nicht bloß als Elefanten-, statt als Einhorn-Knochen - er ging noch einen Schritt weiter: Die uralten Relikte seien nicht etwa ein bloßes »Abbild«, sondern die Überreste eines echten, historischen Tieres (Abb. 2) ${ }^{22}$.

In der Folge entwickelte sich eine heftige europaweite Auseinandersetzung, die von den Zeitgenossen als »Gothaer Federkrieg« bezeichnet wurde ${ }^{23}$. Zwar gelang es Tentzel, sich mit geschickten medialen Strategien, kluger Netzwerkbildung und der subtilen Bezugnahme auf den prestigeträchtigen dänischen »Elefantenorden «, in den sein Fürst Friedrich II. kurz zuvor aufgenommen worden war, den Streit für sich zu entscheiden. Sein Erfolg markierte aber erst den Beginn einer langen Reihe von komplizierten Fragen.

20 Georg Florschütz, Die erste Aufdeckung des Elephans antiquus in den Sandbrüchen bei Gräfentonna. Ein Beitrag zur Geschichte der Naturwissenschaften, in: Mitteilungen der Vereinigung für Gothaische Geschichte und Altertumsforschung 5 (1905), S. 43-57, hier S. 44.

21 Vgl. [Johann Christoph Schnetter], Kurtze doch ausführliche Beschreibung Des Unicornu Fossilis, oder gegrabenen Einhorns/Welches in der Herrschaft Tonna gefunden worden/Verfertiget von dem Collegio Medico, Gotha 1696, o.P.

22 Wilhelm Ernst Tentzel, Epistola de sceleto elephantino tonnae nuper effosso, ad Antonium Magliabechium, Gotha 1696.

23 Johann Georg KeyssLer, [...] Neüeste Reise durch Teütschland, Böhmen, Ungarn, die Schweitz, Italien, und Lothringen worinn der Zustand und das merckwürdigste dieser Länder beschrieben wird, Bd. 2, Hannover 1740-1742, S. 1142. 


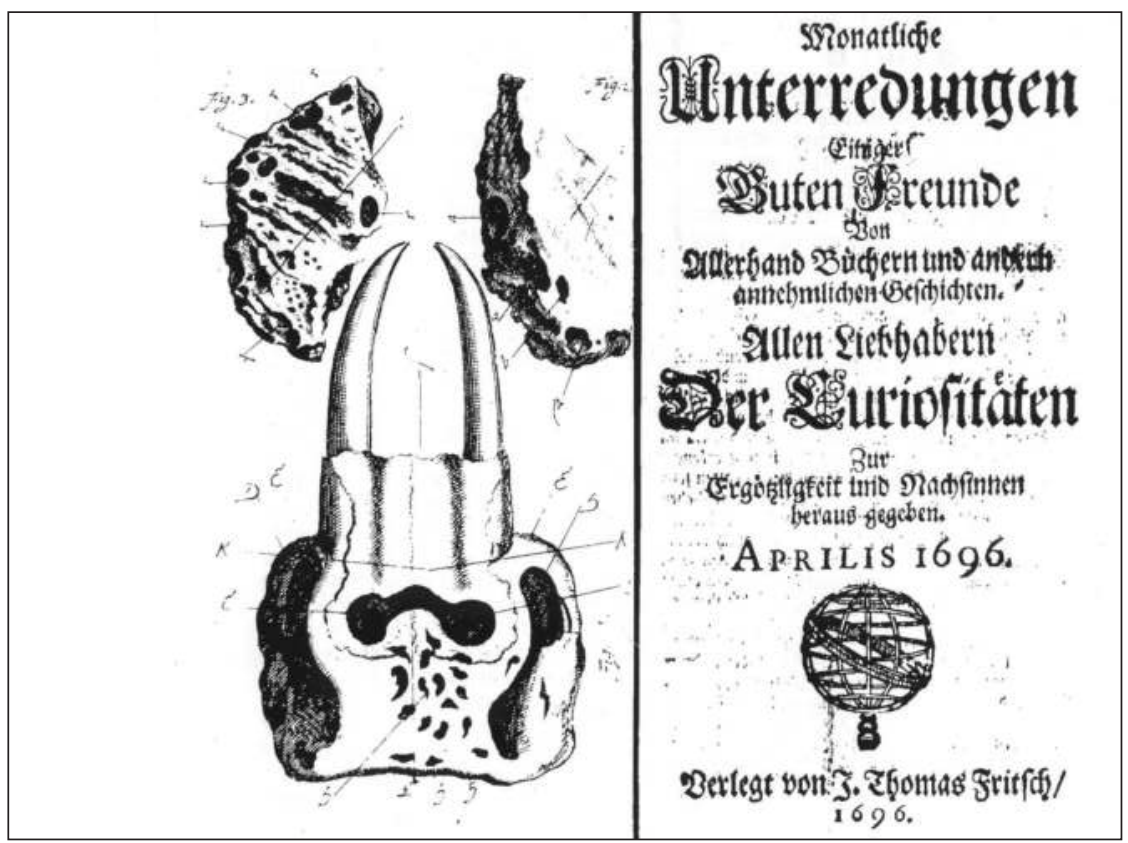

Abbildung 2: Wilhelm Ernst Tentzel, Monatliche Unterredungen, April 1996, Titelseite.

Wie war ein solches fremdländisches Tier überhaupt in die Gothaer Sandgrube gekommen - quer über die sonst so rigide gezogenen Grenzen zwischen Eigenem und Fremdem hinweg? Wie ließen sich diese Beobachtungen zudem mit der Bibel in Einklang bringen, die Elefanten klar als Geschöpfe Afrikas benannte?

Tentzel, der in Wittenberg ein Studium historicum absolviert hatte und sich im Historischen Reichskolleg engagierte, suchte zunächst in der Lokalgeschichte nach Erklärungen. Systematisch schloss er nacheinander aus, dass der Elefant - wie gemutmaßt wurde - mit einem Kaufmann des 16. Jahrhunderts, mit Karl dem Großen oder gar mit Attila dem Hunnenkönig nach Gotha gekommen sei. Gegen diese Interpretation sprach nicht zuletzt das Vorhandensein der wertvollen Stoßzähne. Als letzter und ältester historischer Fixpunkt schien ihm daher die »allgemeine Sündfluth « infrage zu kommen, welche »unsern Elephanten sowohl/als mehr seines gleichen und andere Thiere mit fortgeschleppet« habe ${ }^{24}$. In der fernen, biblischen Vergangenheit konnten

24 Wilhelm Ernst Tentzel, Inhalt Seines Lateinischen Schreibens an Den Welt=berühmten Herr Antonio Magliabechi, Rath und Bibliothecarium des Groß=Hertzogs zu Florenz/von dem 
sich die in der Gegenwart scheinbar so weit voneinander entfernten Extreme, der exotische Elefant und der heimische Fundort, begegnen ${ }^{25}$.

In der Folge eröffnete sich für Tentzel ein neuer Denkraum, den er in seiner Zeitschrift, den Monatlichen Unterredungen, ausbreitete. Dort begann er die Überlegungen zur Erdgeschichte von den Tieren auf die Vorgeschichte der Menschen zu übertragen. Begeistert berichtete er etwa von der Entdeckung des Sammlers Johan Daniel Major, dass es sich bei den beliebten »Donnerkeilen« nicht um Naturwunder, sondern um die Klingen prähistorischer Steinäxte handele. Auch in diesem Fall hatte der Vergleich mit exotischen Waffen die neue Interpretation inspiriert ${ }^{26}$. Bald debattierte Tentzel mit Gottfried Wilhelm Leibniz, dem Physikotheologen John Ray oder dem Amsterdamer Sammler Nicolas Witsen über den Vergleich von antiken europäischen mit kolonialen Fossilien und deren möglichen Beitrag zum Verständnis der Frühgeschichte ${ }^{27}$.

Mit der Übertragung des in der Philosophie lange etablierten Studiums von »Ähnlichkeiten « auf Objekte erschloss sich Tentzel in der Folge eine konservative, aber effektive Methode, mit der er die Alte Welt neu zu vermessen begann. Die Übereinstimmungen von Hausrat und Waffen der »alten Teutschen « und der »Indianer« erschienen ihm verblüffend groß. Bald mutmaßte Tentzel, dass auch die Thüringer aus exotischen Gegenden eingewandert sein könnten. Menschenopfer, Götzenfiguren und die Sprache machten für ihn eine heidnisch-asiatische Abstammung seiner Vorfahren plausibel ${ }^{28}$. Die offensichtlichen Parallelen führten Tentzel nicht dazu, die Indianer als weniger fremd zu empfinden, sie sorgten vielmehr dafür, dass nun auch die eigenen, einst so vertraut geglaubten Vorfahren immer fremder erschienen. Die

zu Tonna ausgegrabenen Elephanten=Cörper, Jena 1696. Die ausführlichen Aufzeichnungen seiner Nachforschungen finden sich in: FB Gotha, Chart B 209.

25 Bezeichnenderweise war es gerade der biblische Rahmen, der Tentzels Erkenntnisse inspirierte. Viele naturhistorisch besser ausgebildete Forscher glaubten, aufgrund der morphologischen Unterschiede zwischen den fossilen Funden und lebenden Spezies »Naturspiele« vor sich zu haben. Auch der Gothaer Fund, ein Paleoloxodon antiquus, unterschied sich physiognomisch deutlich von modernen Elefanten. Dennoch gelang Tentzel gerade aus der Überzeugung heraus, dass die Fossilien Teil einer universalen biblischen Geschichte mit einheitlichen und unveränderlichen Arten seien, die wegweisende Beobachtung, dass es sich um Relikte echter Pflanzen und Tiere handelte.

26 Vgl. Wilhelm Ernst Tentzel, Monatliche Unterredungen einiger guten Freunde von allerhand Büchern und andern annehmlichen Geschichten. Allen Liebhabern der Curiositäten zur Ergetzlichkeit und Nachsinnen herausgegeben, Leipzig 1689-1698, hier Oktober 1690, S. 896 sowie November 1695, S. 931-949 sowie seine Notizen zu Majors Text und Illustrationen in: FB Gotha, Chart B 216, fol. 344-369.

27 Vgl. FB Gotha, Chart B 209 (Wilhelm Ernst Tentzel, Acta Elephantina), bes. fol. 88, 131 u. 429. Eine gekürzte Edition der Korrespondenz mit Leibniz bietet: FlorschüTz, Aufdeckung, S. $50-57$.

28 Tentzel, Unterredungen, Februar 1691, S. 99 u. Juni 1694, S. 412-510. 
Gothaer erkannten im historischen Thüringen bald ein $»$ Teufels $=$ Nest $/$ voll allerley Heydnischen Abgötterey und Finsterniß « ${ }^{29}$.

\section{Museen entdecken die Vergangenheit}

Vergleichbare Überlegungen lassen sich nicht nur in Gotha, sondern in der gesamten europäischen Sammlerrepublik beobachten. Museen thematisierten Geschichtlichkeit und Chronologie keineswegs erst nach dem in der Museumsgeschichte kanonisierten Startpunkt: der ersten nach Epochen gegliederten Ausstellung, die Alexandre Lenoir 1795 im Pariser Musée des Monuments Français präsentierte ${ }^{30}$.

Die Debatte um »Fossilien « ${ }^{31}$ bot den frühen Museen eine hervorragende Gelegenheit ihre Relevanz für gelehrte Debatten zu inszenieren. Der Fokus auf dem visuellen Vergleich von leicht zu konservierendem und in den Kunstkammern reichlich vorhandenem Material kam den Möglichkeiten der Sammler entgegen. Anders als die Durchführung von Experimenten erforderte die Methode des Vergleichs keinen konfliktträchtigen Bruch mit etablierten Evidenzstrategien, der die konstitutive Geselligkeit des Sammlungsraumes bedroht hätte. Zudem vertrug sich die antiquarische Ausrichtung der Debatte hervorragend mit dem bewahrenden Impetus des Museums. Die Frühgeschichte avancierte daher zu einem der wenigen Felder, auf denen frühe Museen nicht bloß bereits vorhandenes Wissen illustrierten, sondern selbst breite Debatten inspirierten.

Zuvor hatte sich der Vergleich von außereuropäischen Völkern und europäischer Antike zumeist auf den religiösen Bereich konzentriert. Schon unmittelbar nach der Entdeckung der Neuen Welt durch die Europäer machten sich Theologen Gedanken über den heilsgeschichtlichen Platz der Indianer, die in der biblischen Überlieferung offensichtlich fehlten. Stammten sie von Völkern aus einer Zeit vor Adam ab, waren sie nach der Sintflut in die Neue Welt ausgewandert oder hatte Gott sie in einer Art »zweiter Schöpfung« geschaffen? Die Debatte wurde erst kanalisiert, als das tridentinische Konzil (1545-1563) unter dem Eindruck der Amerikafahrten entschied, dass die

29 Georg Michael Pfefferkorn, Merkwürdige und Auserlesene Geschichte von der berümten Landgrafschaft Thüringen. Darinnen Das Denkwürdigste von dieses Landes Chroniken, Lage, Fruchtbarkeit [...], Frankfurt 1684, S. 52.

$30 \mathrm{Vgl}$. Stephen BANN, »Views of the past«, reflections on the treatment of historical objects and museums of history (1750-1850), in: Gordon FyfE/John LAw (Hg.), Picturing Power, Visual Depiction and Social Relations, London 1988, S. 39-64.

31 Der zeitgenössische Begriff (von lat. fossilis = ausgegraben) bezeichnete bis ins 19. Jh. alle Gegenstände, die in der Erde gefunden wurden, unabhängig davon, ob es sich um Versteinerungen, echte Knochen oder von Menschen gemachte Relikte, wie Graburnen oder Antiken, handelte. 
Schöpfung ein einmaliger und universeller Vorgang gewesen sei. Neue Spezies oder gar Kontinente konnte es in dieser von allen geteilten Geschichte nicht geben.

In der Folge spekulierten Priester und Missionare wie Francisco López de Gómara, José de Acosta oder Isaac de la Peyrère über die Abstammung und mögliche Migrationswege der Indianer. Unabhängig davon, ob sie eine kastilische, eine asiatische oder eine unabhängige Abstammung der Indianer favorisierten, nutzten alle den Vergleich zwischen antiken und amerikanischen Kulturen als kognitives Raster ${ }^{32}$. Damit folgten sie nicht zuletzt dem Vorbild von Kolumbus, der sich die Fremde ebenfalls mit antiken Autoren erschlossen hatte und so - wie bereits Alexander von Humboldt feststellte neben seiner Raum-, auch eine Zeitreise unternahm ${ }^{33}$.

Der Universalismus der biblischen Heilsgeschichte bildete so zwar einen Rahmen für einen geographisch-historischen Vergleich. Zugleich beschränkte er die Debatte jedoch auf vorwiegend theologisch interessierte Gelehrte. Dies änderte sich, als man inspiriert vom blühenden Antiquarianismus dazu überging, konkreter über die Frühgeschichte der Erde nachzudenken. Nun waren es immer häufiger Sammler, Kunstkämmerer und Antiquare, die auf strukturelle Ähnlichkeiten zwischen Exotika und Altertümern hinwiesen, die im Sammlungsraum aufeinander trafen ${ }^{34}$. Im Königlich-Dänischen Museum präsentierte man die antiken Götzen im »Indianisk Saal«, in Aix-en-Provence ordnete man ägyptische Urnen zu den amerikanischen Utensilien und in Gottorf stellte der Kunstkämmerer mexikanische und ägyptische Mumien einander gegenüber (Abb. 3) ${ }^{35}$. Die Assoziation von

32 Werner Petermann, Die Geschichte der Ethnologie, Wuppertal 2004, S. 215-222 u. 242-244, sowie Alain Schnapp, Die Entdeckung der Vergangenheit. Ursprünge und Abenteuer der Archäologie, Stuttgart 2009, S. 240-247. Zumindest in La Peyrères Fall scheint die Idee für eine Nordisch-Grönländische Abstammung der amerikanischen »Prä-Adamiten« auch durch Museumsstücke inspiriert worden zu sein. Vgl. ebd., S. 248.

33 Humboldt bezeichnete Kolumbus' Unternehmen daher als »Eroberung durch Nachdenken«. Alexander von Humboldt, Kritische Untersuchungen über die Entwickelung der geographischen Kenntnisse von der Neuen Welt und die Fortschritte der nautischen Astronomie in dem 15ten und 16ten Jahrhundert, Bd. 2, Berlin 1836, S. 7.

34 Zur Bedeutung des Museums für den antiquarischen Diskurs vgl. Schnapp, Entdeckung, S. 183-196 u. 223-232. Zur Verflechtung von Museum und entstehender Anthropologie vgl. Margaret T. Hodgen, Early Anthropology in the Sixteenth and Seventeenth Centuries, Philadelphia 1964, S. 111-206.

35 Holger JaCOBAEUS, Museum Regium, seu Catalogus rerum tam naturalium, quam artificialium, quae in Basilica Bibliotheca augustissimi Daniae Norvegaeque Monarchae Christiani Quinti Hafniae asservantur, Kopenhagen 1696, S. 52; Paul Contant, Exagoga Mirabilivm naturae è Gazophylacio Pauli Contanti Pictauensis Pharmacopaei, in: Ders., Les Euvres des Iacqves et Pavl Contant pere et fils maistres apoticaires de la ville de Poictiers, Poitiers 1628, S. 7; Adam Olearius, Gottorfische Kunst=Kammer Worinnen Allerhand ungemeine Sachen So theils die Natur theils fürstliche Hände hervor gebracht und bereitet, Schleswig 1674, Tab. IV. 


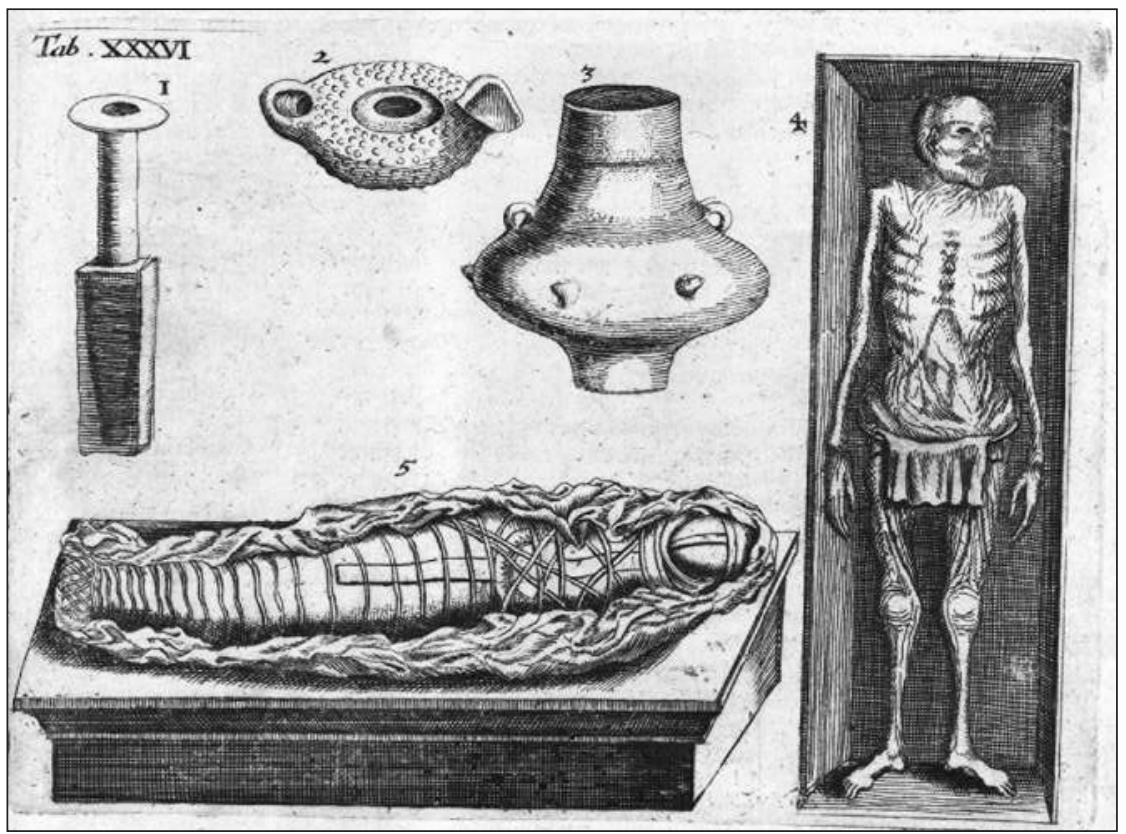

Abbildung 3: Adam Olearius, Gottorfische Kunst=Kammer [...], Schleswig 1674. Tafel 36 mit antiken Urnen sowie einer ägyptischen und einer peruanischen Mumie.

Altertümern und Exotika wurde auch in den museologischen Schriften der Zeit propagiert und war so verbreitet, dass sie bisweilen zu Verwechslungen führte ${ }^{36}$.

Die Sammler beließen es aber nicht bei bloßen Gegenüberstellungen. Bereits Montaigne inspirierten seine brasilianischen Sammlerstücke gegen Ende des 16. Jahrhunderts zu seinem kulturrelativistischen und -vergleichenden Essay über moderne, antike und exotische »Kannibalen « ${ }^{37}$. Wenig später stellte auch der Jesuit Athanasius Kircher anhand der Obelisken seines Museums Überlegungen über gemeinsame Wurzeln von Amerikanern und Ägyptern $a^{38}$. Im Katalog der Sammlung des Bologneser Edelmannes Cospi präsentierte man ägyptischen Sphinxen ähnelnde Dolchgriffe aus

36 Vgl. z.B. die exotischen Kleider der Antikenabteilung in: Johann Daniel MAJor, Unvorgreiffliches Bedencken von Kunst- und Naturalienkammern insgemein, Kiel 1674 sowie das als »indianisch« beschriebene Idol antiken Ursprungs in Werner FleischHaueR, Die Geschichte der Kunstkammer der Herzöge von Württemberg in Stuttgart, Stuttgart 1976, S. 51.

37 Michel Eyquem de Montaigne, Essais, Frankfurt a.M. 1998, Kap. 31 (zuerst Paris 1580). Zu seiner Sammlung vgl. Carlo Ginzburg, Montaigne, Cannibals and Grottoes, in: History and Anthropology 6 (1993), S. 125-155.

38 Athanasius Kircher, Oedipus Aegyptiacus, Bd. 1, Rom 1652. Vgl. auch Tentzel, Unterredungen, Januar 1689, S. 19f. 


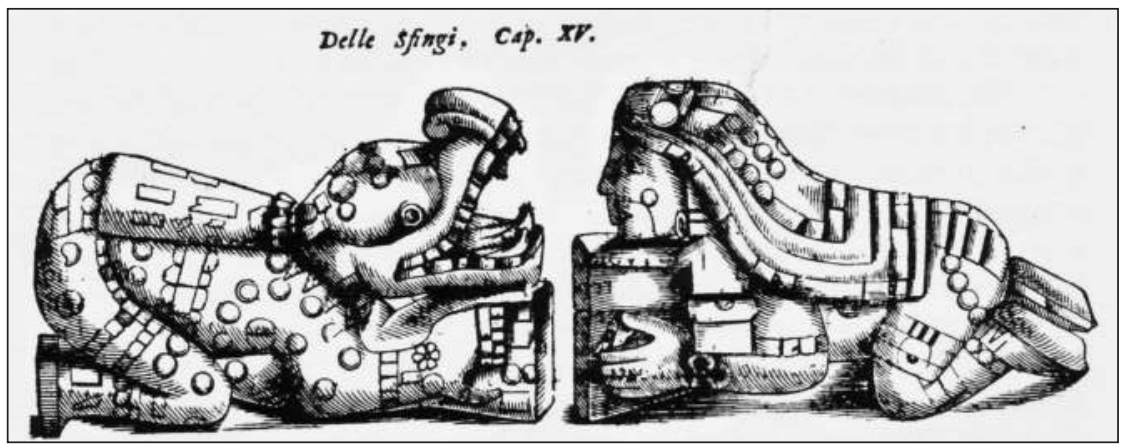

Abbildung 4: Lorenzo Legati, Museo Cospiano, Bologna 1677, S. 477. Mexikanische Messergriffe im Kapitel »Von den Sphinxen«.

Mexiko, verglich amerikanische mit ägyptischen Hieroglyphen und spekulierte über eventuelle prädiluviale Beziehungen zwischen beiden Zivilisationen (Abb. 4) ${ }^{39}$. In Amsterdam reflektierte der Sammler Jan de Laet anhand seiner Fossilien über die gängigen Abstammungsthesen ${ }^{40}$. In der Londoner Royal Society verglich man Proben von Tentzels Elefanten mit den Knochen des eigenen Museums und vermutete, dass Irland und Nordamerika in früheren Zeiten über eine Landbrücke verbunden gewesen sein könnten ${ }^{41}$.

Diese Überlegungen wurden auch außerhalb der Sammlerkreise begeistert aufgenommen. Bereits 1612 bat der italienische Gelehrte Lorenzo Pignoria seinen Freund Galileo, in den Florentiner Sammlungen nach den beliebten indianischen Götzen Ausschau zu halten. Seine Bitte war offenbar erfolgreich, denn in Pignarios Schrift Delle Imagini de gli Indiani von 1626 sind neben zwei Götzen aus der Münchener Kunstkammer auch zwei weitere aus der Florentiner Medici-Sammlung abgebildet, denen jeweils altägyptische Figurinen zur Seite gestellt wurden, um Vermutungen über deren gemeinsame Wurzeln anzustellen ${ }^{42}$. Ein Jahr nach Tentzels Fund war der Konnex zwischen Neuer Welt und europäischer Vergangenheit bereits so etabliert, dass der Londoner Fellow und begeisterte Sammler John Locke formulieren konnte: »In the beginning, all the world was America« ${ }^{43}$. Systema-

39 Lorenzo Legati, Museo Cospiano annesso a quello del famoso Ulisse Aldrovandi [...], Bologna 1677, S. 477f.

40 Jan DE Laet, Notae dissertationem Hugonis Grotii de origine gentium americanorum [...], Amsterdam 1643.

41 British Library, Ms. Sloane 3341 (Minutes of the Royal Society), fol. 45 sowie FB Gotha, Chart B 209, fol. 132f.

42 Vgl. David JAffé, The Barberini Circle. Some Exchanges between Peiresc, Rubens, and their Contemporaries, in: Journal of the History of Collections 1 (1989), S. 119-147, hier Anm. 34 sowie Detlef Heikamp / Ferdinand Anders, Mexikanische Altertümer aus süddeutschen Kunstkammern, in: Phanteon 28 (1970), S. 205-220, hier S. 210.

43 John Locke, Two Treatises of Government. The Second Treatise, London 1698, § 49. 
tisiert wurden diese Überlegungen zu einer gemeinsamen Geschichte einige Jahre nach Tentzels Entdeckung durch den Jesuiten und Missionar Joseph François Lafitau. Er legte mit den Sitten der amerikanischen Indianer im Vergleich mit den Sitten der Frühzeit ein programmatisches Werk vor, das den Vergleich des exotischen mit dem historischen Fremden zur Methode erhob (Abb. 5) ${ }^{44}$. In seinem Buch kombinierte Lafitau die frühgeschichtlichen Objekte europäischer Sammlungen mit seinen in Kanada gewonnenen Erfahrungen. Im Mittelpunkt des Werkes stand die mit prachtvollen Kupferstichen aufwändig visualisierte Gegenüberstellung indianischer und antiker »Monumente $\aleph^{45}$. Mit seinem Fokus auf »figures that speak» und der Pendelbewegung zwischen Schauen und Schreiben appropriierte er nicht nur die visuelle Autorität des Museums. Mit den Techniken der Sammlung, der Selektion und des Vergleichs imitierte er zugleich dessen Evidenzstrategien ${ }^{46}$.

Ziel seiner imaginären Sammlung war es nicht mehr, die Amerikaner in die Heilsgeschichte einzuschreiben, sondern anhand ihrer vermeintlich unverfälschten Gebräuche ein genaueres Bild über die eigene Vorgeschichte zu erlangen. Ähnlich wie Tentzels Umfeld gelangte auch der Jesuit Lafitau über die Logik des Vergleichs bald zu einer nicht ungefährlichen Neubewertung der Bibel als bloß lokale, partikulare und verfälschte Quelle, deren historische Reichweite zudem hinter den außereuropäischen Chronologien der Chinesen, Ägypter und Azteken zurückblieb ${ }^{47}$. Ernüchtert stellte er fest, dass auch die einst so verehrten Griechen primitive Barbaren gewesen seien ${ }^{48}$. Wie Michel de Certeau beobachtet hat, korrespondierte mit dieser radikalen Wende aber keine vergleichbare Neubewertung des exotischen Fremden. Auch bei Lafitau leiht der lebende Wilde dem antiken Barbaren lediglich seine Stimme, ohne selber zu sprechen ${ }^{49}$.

44 Joseph François LAFITAU, Mœurs des sauvages ameriquains comparées aux mœurs des premiers temps [...], 2 Bd., Paris 1724. Zu Vorläufern Lafitaus wie Fontenelle, Bayle oder Locke, vgl. Wiliam N. Fenton, Introduction, in: Ders. / Elizabeth L. Moore (Hg.), Joseph François Lafitau. Customs of the American Indians Compared with the Customs of the Primitive Times, Toronto 1974, S. XLII u. XCII.

45 Kaspar KäLIn, Indianer und Urvölker nach Jos. Fr. Lafitau (1681-1747), Fribourg 1943, S. 29; LAFitau, Mœurs, Tafeln.

46 Michel de Certeau, Writing vs. Time. History and Anthropology in the works of Lafitau, in: Yale French Studies 59 (1980), S. 37-64, hier S. 40-49.

47 Ebd., S. 53-57. Lafitaus Überzeugung zog Repressalien und Zensur nach sich, resultierte aber nicht mehr in Gefängnis oder Leibesstrafen wie bei La Peyrère oder Giordano Bruno. Vgl. dazu Petermann, Ethnologie, S. 217 sowie Schnapp, Entdeckung, S. 246 u. 251-253. Zu Tentzels vorsichtiger Relativierung der biblischen Überlieferung, vgl. Collet, Welt in der Stube, S. $200 f$.

48 Certeau, Writing vs. Time, S. 62; Fenton, Introduction, S. LV.

49 Certeau, Writing vs. Time, S. 61. 


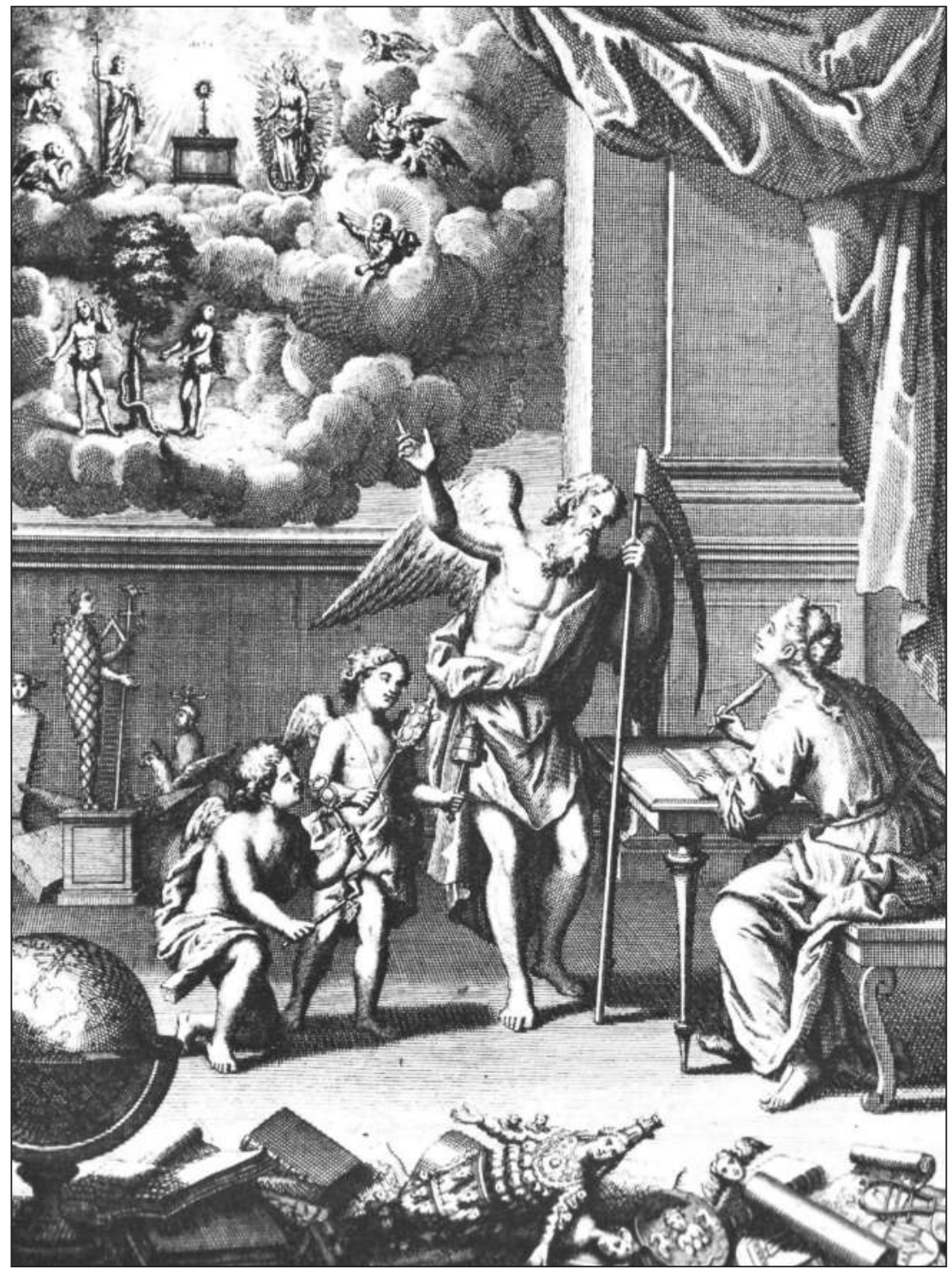

Abbildung 5: Joseph François LAfitau, Mœurs des sauvages ameriquains comparées aux mœurs des premiers temps [...], Paris 1724, Titelkupfer. »Une personne en attitude d'écrire " (vermutlich Kleio, die Muse der Geschichtsschreibung) schreibt inmitten von antiken und amerikanischen Objekten, die ihr zwei Genii zum Vergleich reichen. Die bärtige Figur der »Zeit« verweist dabei auf Anfang und Ende der Schöpfung, die beide Objektgruppen miteinander verbindet ${ }^{50}$.

50 Eine ausführliche Interpretation dieses Schlüsselbildes bietet MAsON, Infelicities, S. 98-103. 
Mit dieser Methode des geographisch-historischen Vergleichs gelangte man schon bald zu immer detaillierteren Chronologien der Frühgeschichte und löste mit der Mehrstufen-, Diffusions- und Degenerationstheorie die älteren unhistorischen Klimatheorien $a b^{51}$. Für Alexander von Humboldt und Georg Forster stellten Amerika bzw. Tahiti bereits Archive dar, deren »Monumente« als Präfigurationen eine als universell verstandene »Entwicklungsgeschichte« der Menschheit exemplifizierten. Politisch semantisiert dienten ihre materiellen Zeugnisse zugleich dazu, allgemeine Freiheitsrechte zu naturalisieren. Die Verbindung mit musealen Exponaten blieb daher bis zu Schlözer, Herder und Winckelmann so eng, dass Natur- und Menschheitsgeschichte thematisch und auch etymologisch lange miteinander verwoben blieben $^{52}$.

Die Überlegungen zu einer von Europäern und Exoten geteilten Geschichte gründeten daher in der christlichen Heilsgeschichte. Die absolute Trennung in »Andere« und in Europäer, wie sie in vielen Museen und Reiseberichten inszeniert wurde, fand in der Universalität der biblischen Überlieferung ihre Grenze. Mit ihrer Betonung einer einzigen linearen Geschichte beförderte die Bibel die Suche nach Gemeinsamkeiten und überall gültigen Gesetzen. Die christliche Weltsicht war damit Begrenzung und Anregung zugleich. Sie motivierte einerseits die unversöhnliche Trennung der Welt in Christen und Heiden und andererseits die Erforschung der (historischen) Gemeinsamkeiten. Im ersten Fall sorgte sie dafür, dass die exotischen Objekte als Stellvertreter einer heidnischen Gegenwelt verfremdet wurden. Im zweiten Fall ermöglichte sie es, über den Vergleich von Indianern und alten »Teutschen« die Fremdheit der eigenen Vergangenheit und der einst so vertraut geglaubten Antike neu zu konzeptualisieren.

\section{Exotika und das europäische Geschichtsbewusstsein}

Fremde Kulturen nicht über direkte Begegnungen, sondern allein anhand von Objekten zu erläutern, ist eine Herausforderung, die Museen auch heute noch vor große Probleme stellt. Bruno Latour hat auf die Bedeutung von stabilen Referenzketten verwiesen, damit »Aktanten« aus Objekt und Samm-

51 Petermann, Ethnologie, S. 215-253. Vgl. z.B. das wegweisende »Stein - Bronze - Eisen«Modell des Basler Sammlers und Gelehrten Isaac Iselin., in: Schnapp, Entdeckung, S. 291f.

52 Vgl. z.B. Thomas Nutz, »Varietäten des Menschengeschlechts«. Die Wissenschaften vom Menschen in der Zeit der Aufklärung, Köln u.a. 2009, S. 227-296 sowie zum Kontext: Lucas Marco Gisı, Einbildungskraft und Mythologie. Die Verschränkung von Anthropologie und Geschichte im 18. Jahrhundert, Berlin 2007, und Hendrik Frederik Vermeulen, Early History of Ethnography and Ethnology in the German Enlightenment. Anthropological Discourse in Europe and Asia, 1710-1808, Leiden 2008. 
ler erfolgreich als Vermittler entlegener Wissensbestände dienen können ${ }^{53}$. Im Fall der Kunstkammer-Exotika waren diese Beziehungen zwischen Repräsentant und Repräsentiertem vielfach gebrochen: Während das Objekt zumeist mit dem professionellen Exotikahandel nach Europa gelangte, reisten die zugehörigen Informationen entlang anderer, komplizierterer Routen und erreichten die Sammler meist erst nach einem Umweg über die europäischen Druckerpressen.

Die so entstandenen Leerstellen waren keineswegs unerwünscht. Sie ermöglichten den sammelnden Akteuren die bloß Anderen zu fundamental Fremden zu überhöhen und die Exponate entlang christlich-heidnischer Grenzziehungen zu rekontextualisieren. Europas »innere Andere « - Hexen, Bettler, Saufbrüder - wanderten auf diese Weise ebenso in die Neue (Gegen-) Welt wie Gewaltakte, Aberglauben, Zügellosigkeit und Prasserei. Diese »projektive Ethnographie« erlaubte es den Sammlern umgekehrt, ihren von konfessionellen, politischen und sozialen Spaltungen zerrissenen Kontinent als ein einheitliches, zivilisiertes und christliches »Europa« zu imaginieren. Die Leistungen der Kunstkammer lagen demnach weniger in der hierarchiefreien Begegnung der Kulturen als vielmehr in der Einladung zur Selbstvergewisserung.

Wenn sich in den Kunstkammern dennoch Veränderungen beobachten lassen, geschah dies nicht als gezielter Bruch mit älteren Evidenzstrategien oder als schillerndes Spiel in den Zwischenräumen etablierter Wissensordnungen. Der Wandel erscheint vielmehr als unintendierte Folge religiöser Grenzziehungen. Augenfällige Parallelen zwischen »indianischen « und europäischen Objekten oder die Präsenz von Fossilien diesseits und jenseits religiöser Grenzen liefen der Trennung in Eigenes und Fremdes zuwider. Über die Bewusstmachung der eigenen historischen Fremdheit gelang es, diese Grenzüberschreitung zu historisieren und einzuhegen. Mit dem Verweis auf die ferne Vergangenheit ließen sich die amerikanischen Völker ebenso in die Schöpfungsgeschichte integrieren wie der Gothaer Elefant.

Der christliche Universalismus erlaubte es den Akteuren, die räumliche Herausforderung der Neuen Welt in ein geschichtliches Kontinuum zu überführen. Er bot den Rahmen, in dem außereuropäische Exponate europäische Geschichtsvorstellungen anzuregen vermochten. Die »Entdeckung der Vergangenheit« (Alain Schnapp) lässt sich deshalb auch als biblisch codierte Reaktion auf die außereuropäische Welt verstehen.

Das Handeln der Akteure illustriert, wie sehr exotische und historische Fremdheit im Sammlungsraum ineinandergriffen und einander inspirierten. Es zeigt, wie Fremdsein sozial konstruiert und durch Objekte gleichsam

53 Bruno Latour, Pandora's Hope. Essays on the Reality of Science Studies, Cambridge 1999, S. 24-79. 
naturalisiert wurde. Nicht zuletzt verweisen die religiösen Wurzeln dieses Prozesses darauf, dass die Ablösung von geographischen durch historische Ordnungssysteme begann, lange bevor die Museen des 19. Jahrhunderts historische Periodisierungen auf vermeintlich säkularer Grundlage popularisierten. 



\section{Wolfgang Reinhard}

\section{Schlusskommentar}

Zusammenfassend zu kommentieren ist ein Himmelfahrtskommando. Soll man wiederholen, was die Referentinnen und Referenten schon viel besser gesagt haben? Das wäre nur langweilig! Soll man vortragen, was einem selbst dazu eingefallen ist? Das würde anmaßend wirken! Soll man höflich oder ehrlich sein? Ich probiere es mit einer Mischung aus allem und folge dem Kraftspruch des einst berühmten deutsch-jüdisch-englischen Historikers Sir Geoffrey Elton: »Wenn ich es schon nicht allen recht machen kann, dann hoffe ich wenigstens alle gleichmäßig zu verärgern!«

Und zwar möchte ich zunächst auf die spezifische Fragestellung des Bandes nach dem Geschichtsbewusstsein und seinem Wandel eingehen und dann etwas zu meiner Sicht der Begegnung mit Fremden sagen, die im Hintergrund steht.

\section{Geschichtsbewusstsein}

Um wessen Geschichtsbewusstsein sollte es sich handeln und hat es sich dann praktisch gehandelt? Es gibt drei Möglichkeiten:

1. Dasjenige bestimmter Individuen und Gruppen einer Kultur und Gesellschaft. Dabei können die Marginalen nicht ausgeschlossen werden. Dem haben die Veranstalterinnen teilweise gegen ihre einleitend erklärte Absicht bereits mit der Kategorie Fremd im eigenen Land Rechnung getragen. Außerdem wird die Einbeziehung der Marginalen selbstverständlich, sobald von Juden die Rede ist.

2. Das gemeinsame Geschichtsbewusstsein einer historischen Kultur und Gesellschaft. Doch - wer ist das? Die Eliten im Besitz der Deutungshoheit oder die Medien im Besitz ihrer Deutungshoheit oder die Massen der gewöhnlichen Menschen? Aber wie wäre an die letzteren heranzukommen? Heute vielleicht mit Schulbüchern, obwohl auch diese das Geschichtsbild der Inhaber der Deutungshoheit reproduzieren.

3. Unser eigenes Geschichtsbild, denn ich möchte behaupten, dass es bei der Untersuchung des Wandels historischer Geschichtsbilder unterschwellig 
um den (erwünschten) Wandel unseres eigenen Geschichtsbildes gehen sollte. Dies wird im Folgenden noch weiter ausgeführt.

Die auf der Tagung erzielten empirischen Ergebnisse bezogen sich nahezu ausschließlich auf Geschichtsbilder von Gruppen, nicht selten marginalen Gruppen, oder sogar bloßen Individuen, die Fremdheitserfahrungen machen mussten - entweder, weil sie selbst Fremde waren oder weil sie wirkungsvolle Begegnungen mit Fremden erlebt haben.

Einfluss auf das Geschichtsbild der jeweiligen Kultur und Gesellschaft blieb aus oder ist zumindest nicht nachzuweisen bzw. es wurde gar nicht danach gefragt. Die wenigen Ausnahmen bestätigen diese Regel.

Poma de Ayala lässt sich zwar in ein peruanisches historiographisches Spektrum einordnen, blieb aber ein »Einzelkämpfer« ohne Wirkung, sein Werk als Manuskript verschollen, bis es von der jüngeren Forschung wiederentdeckt wurde.

Sahagun, seine Mitbrüder und die Nahua, die mit ihnen zusammenarbeiteten, blieben ebenfalls ohne Wirkung, ihr Werk wurde als inopportun unterdrückt und ebenfalls erst neuerdings wieder entdeckt.

Umgekehrt konnten die chinesischen Historiker der Zwischenkriegszeit sich die Kontrolle über das nationale Geschichtsbild und das »Quellenmaterial« erst endgültig verschaffen, als sie die staatliche Macht auf ihrer Seite hatten. Dazu folgt unten noch mehr.

Ibibios haben offensichtlich ein positives Geschichtsbild von der Tätigkeit ihrer seinerzeitigen evangelischen Missionare, artikulieren es aber behutsam, weil es nicht der politisch korrekten Imperialismuskritik Nigerias entspricht.

Die Basler Mission hat ihr besonderes eschatologisches Geschichtsbild von zuhause mitgebracht und, was immer geschah oder nicht geschah, als dessen Bestätigung verstanden.

Joseph ha-Kohen schrieb seine Werke dezidiert im Dienst des Geschichtsbildes seiner Gruppe, der vertriebenen sephardischen Juden.

Der Wandel des deutsch-jüdischen Selbstverständnisses infolge der Begegnung mit dem Ostjudentum war und blieb eine binnenjüdische Angelegenheit.

Die dargestellte Hugenottenhistoriographie schrieb entweder im Gruppeninteresse dieser Minderheit oder zum Ruhme Brandenburg-Preußens. Wichtig ist hier, dass es durchaus ein abweichendes Mehrheitsgeschichtsbild gab, das sich aber angesichts der politischen Machtverhältnisse nicht artikulieren konnte.

Mit dem Übergang zur medial vermittelten Fremdheitserfahrung unter dem Stichwort »Rezeption von Erfahrungen mit Fremden« werden die Konstellationen komplexer, die Distanzen größer, Ungleichzeitigkeit spielt eine grö- 
ßere Rolle, aber am Gesamtbefund ändert sich dadurch kaum etwas. Die Beobachtungen der Kapläne der Levant Company verändern zwar die Bibeldeutung, aber nie revolutionär. Sie erzeugen keine »Aufklärung«, sondern sind nur auf der Basis vorhergehender »Aufklärung« möglich und können nur deshalb später ins allgemeine Geschichtsbild einsickern.

Das Beduinenbild der Orientreisenden, der Orientalistik und der Rezipienten von deren Vorstellungen bedient großenteils bereits vorhandenes Behagen oder Unbehagen an der eigenen Kultur und geht allenfalls auf diese Weise gefiltert, das heißt aber kaum innovativ ins allgemeine Geschichtsbewusstsein ein. Wie weit hat - nicht nur hier - Karl May als Vermittler Geschichtsbewusstsein erzeugt oder nur bestätigt?

Auch im höchst speziellen Fall der frühen Wahrnehmung afrikanischer Christen dominiert ungeachtet der Übernahme sachlich zutreffender Informationen das traditionelle Geschichtsbild des Sebastian Münster und nicht etwa das sehr viel behutsamere und sachlich zutreffendere des sogenannten Leo Africanus, das wahrscheinlich sowieso nur wegen seines dritten Ortes zwischen den Gruppen, zwischen Islam und Christentum, überhaupt möglich war.

Kunst- und Wunderkammern mögen langfristig neben »unschuldigem Staunen« Verunsicherung ausgelöst haben - doch selbst dann dienen sie ganz selbstverständlich einer neuartigen Bestätigung der eigenen Geschichte.

Weiter reichende Absichten von Protagonisten verlaufen wenig erfolgreich. Meine Überlegungen zu den Ursachen für diesen Befund treffen sich mit Feststellungen zum Fremden im Werk des Philosophen Hegel: Hegel theoretisiert allenfalls über Fremdheitserfahrung, diese selbst spielt für ihn aber keine Rolle, kontrafaktisch gesehen: Seine Philosophie wäre bei realer Fremdheitserfahrung auch nicht anders ausgefallen. Denn Fremdheitserfahrung ist für ihn allenfalls eine notwendige, nie aber die hinreichende Bedingung des Geschichtsverständnisses.

In unserer Sprache ausgedrückt heißt das: eine bloße Bestätigung dessen, was wir schon immer zu wissen meinten. Denn das herrschende Geschichtsbewusstsein, von dem sich die behandelten Anläufe zur Veränderung abheben mögen, dem sie aber unterliegen, herrscht, weil es Macht über uns hat. Zunächst die Macht, die soft power kultureller Selbstverständlichkeit, die mit Überlegenheitsbewusstsein einhergeht. Ihr entkommt man nur unter besonderen Umständen. Selbst abendländische Geistesriesen wie Leibniz oder Voltaire haben sich im Fremden, damals im Chinesen und Inder, nachweislich nur selbst wiedergefunden. Im weisen Konfuzianer oder Brahmanen bewunderte Europa sich selbst; sein Gegenüber blieb ein als Konfuzianer oder Brahmane maskierter Aufklärer! Es wäre also noch schärfer herauszuarbeiten, was die besonderen Bedingungen waren, die in den untersuchten 
Fällen zur teilweisen oder radikalen Infragestellung dieser Selbstverständlichkeiten geführt haben.

In jüngerer Zeit, deutlich zu fassen bei den chinesischen Historikern, aber auch schon bei der Hugenottenhistoriographie, spielt zusätzlich die konkrete Macht des modernen Staates, vor allem des Nationalstaates eine Rolle, vermutlich auch dann, wenn wir die unterlassene Frage nach unserem eigenen Geschichtsbild artikulieren würden. Denn, wie auch die Postkolonialisten immer wieder mit Recht betonen, unsere Geschichtswissenschaft steht von ihren Ursprüngen her im Dienst des modernen Nationalstaates westlichen Zuschnitts. Vergessen wir nicht, für die deutsche Tradition waren Volk und Staat primordiale Essenzen; Ranke erklärte sie zu Gedanken Gottes. Heute neigen wir stattdessen zu der Feststellung, die Geschichte sei immer die Hure der Mächtigen gewesen. Ob das junge Programm History goes global demgegenüber schon Erfolge zeigt, wird man trotz dieser eindrucksvollen Tagung und dem daraus resultierenden vorliegenden Sammelband mit der unterschwelligen Sehnsucht nach Wandel angesichts der üblichen Geschichts- und Stellenbesetzungspolitik in Deutschland und anderswo füglich bezweifeln dürfen.

\section{Begegnung mit Fremden}

Bereits am schon angesprochenen gescheiterten Ausschluss der binnengesellschaftlich Marginalen von unseren Untersuchungen hat sich gezeigt, dass Fremdheit und der Umgang mit ihr weitaus komplexer und vielschichtiger sind, als angenommen wurde.

In dieser Hinsicht wegweisend ist das Phänomen der Selbstverfremdung, wie wir sie bei Juden und Muslimen beobachten können. Symbole wie das Tragen der Kippa bzw. der verschiedenen Schleier muslimischer Frauen oder der Gebetsschnüre muslimischer Männer wollen nichts anderes signalisieren als: Wir sind anders, wir sind Fremde. Für Juden sind das Exil und damit die Fremdheit geradezu konstitutiv. Und bei den Moslems nimmt die Betonung der Fremdheit bezeichnenderweise deutlich zu, je mehr die Integrationsvorstellungen scheitern - wer immer dafür verantwortlich sein mag. Identität lebt von Alterität, daher dient die Betonung von Alterität zur Begründung oder Verstärkung der notwendigen Identität.

In anderer Weise kultivieren die bereits erwähnten Postcolonialists seit Edward Said ihre Fremdheit durch die Vorstellung, im überwiegend freiwillig gewählten Exil zu leben, und betonen die Kreativität ihres »dritten Ortes« in between. Bezeichnenderweise gibt es aber durchaus auch erfolgreiche im Ausland lebende Intellektuelle wie Salman Rushdie, die keinerlei Fremdheit empfinden (wollen) und diesen Kult des Exils ablehnen. 
Auf der anderen Seite wurde in unserer Diskussion einmal fast bedauernd festgestellt, dass frühneuzeitliche Reiseberichte sich häufig ausgesprochen schwer damit tun, den Anderen überhaupt als Fremden wahrzunehmen. Gewiss, sie oder er mag allerhand Merkwürdigkeiten aufzuweisen haben, aber deswegen ist er oder sie doch nichts anderes als unsereiner. Dieses Phänomen der Co-evalness hat bei uns immer wieder Anstoß erregt, weil der Andere doch gefälligst ein Fremder zu sein hat. »Fremd ist der Fremde nur in der Fremde « (Karl Valentin) - doch was wäre, wenn es gar keine Fremde im strengen Sinne gäbe, sondern nur komplementäre Varianten, die wir zu kontradiktorischen Gegensätzen empor steigern? Denn es besteht der begründete Verdacht, dass eine Alteritätsobsession zur Grundausstattung der Moderne gehört, ein Bedürfnis, Andere grundsätzlich als Fremde wahrzunehmen. Ich erkläre diese Besessenheit von Fremdheit mit dem gesteigerten Überlegenheitsbewusstsein des Westens gegenüber dem Rest der Welt seit seiner Übermacht (!) im 19. Jahrhundert, die seither infolge geänderter Machtverhältnisse zwar eine Inversion erlebt hat, aber in inverser Form weiter existiert!

Diese Überlegungen veranlassen mich zu der Folgerung, dass unsere unausgesprochene, weil selbstverständliche Prämisse, Kontakte mit respektvoll behandelten Fremden müssten produktiven Charakter haben und zur Beseitigung oder zumindest zur Reduzierung von Fremdheit führen, uns zwar ehrt, sich aber leider als unzutreffend erweist. Denn sie geht selbstverständlich von einer doppelten binären Opposition fremd - nicht-fremd gleich schlecht - gut aus und vereinfacht damit in irreführender Weise. Demgegenüber ist zweierlei festzuhalten:

1. Es gibt kaum eindeutige Alterität oder Identität, Fremdheit oder NichtFremdheit, sondern überwiegend multiple und graduelle Fremdheit, wie es multiple und graduelle Identität von Individuen und Gruppen gibt. Darüber hinaus können Individuen und Gruppen diese Identitäten und Alteritäten oft genug nach Bedarf ein- und ausschalten. Man kann als deutscher Mitbürger türkischer Abstammung vertraut und plötzlich als Türke, der in Deutschland lebt, fremd sein, als Arbeitskollege vertraut und plötzlich als Schwuler fremd, ja sogar als Ehepartner vertraut und plötzlich als Angehöriger einer anderen Konfession fremd - und das verschränkt mit weiteren Zugehörigkeiten, obendrein von Fall zu Fall wechselnd und mit unterschiedlicher Intensität.

2. Die Empirie lässt uns keine Wahl: Fremdenfeindlichkeit (Xenophobie) ist anthropologisch universal. Ungeachtet aller Co-evalness halten Gruppen fremde Gruppen grundsätzlich für minderwertig. Das ist grundlegend für ihre Identität. Auch Juden wissen sich den Gojim überlegen (oft genug sogar zu Recht!) und Türkenkinder in Deutschland wissen immerhin, dass sie keine »Schweinefleischfresser« sind. Nicht, wie wir unsere natürliche 
Xenophobie los werden, was nicht möglich ist, oder verleugnen, was nur schadet, ist das Problem, sondern wie wir damit umgehen, wie wir sie der Kontrolle unserer Humanität unterwerfen.

In diesem Sinn lässt sich die im ersten Beitrag angebotene Typologie der Fremdheiten sehr gut mit der im zweiten festgestellten Universalität der Xenophobie kombinieren (selbst wenn die beiden Autoren damit nicht einverstanden sein mögen): Nicht-wahr-haben-wollen von Fremdheit, Exklusion des Fremden, vor allem in nationalstaatlicher Verschärfung, Inklusion des Fremden, zum Beispiel durch universale Menschenrechte, aber auch durch indischen und neuerdings römisch-katholischen religiösen Universalismus, schließlich die Funktionalisierung des Fremden für eigene Zwecke, und sei es nur als Gastarbeiter (mit oder ohne green card), sind Formen von Xenophobie. Allerdings kann Inklusion und Funktionalisierung auch zu ihrer Entschärfung beitragen, manchmal sogar unbeabsichtigt. Ob infolge der globalen Individualisierung mit der Fremdheit auch die Xenophobie verschwinden wird, wissen wir nicht; wir können höchstens darauf hoffen.

Aristoteles hat die Minderwertigkeit der Anderen wissenschaftlich begründet. Denn unter den Barbaren, die von den Griechen ohnehin für minderwertig gehalten wurden, gab es für ihn solche, die durch ihre Minderwertigkeit von der Natur zur Knechtschaft bestimmt waren. Er bezog sich dabei aber noch nicht auf die Hautfarbe. Das sollte späteren Nutznießern der massenhaften Versklavung von Afrikanern vorbehalten bleiben, bis dann seit dem 18. Jahrhundert der biologische Rassismus die Theorie der menschlichen Minderwertigkeit auf ihren bisherigen Gipfel führte. Unglaubliche Exzesse von Xenophobie waren die Folge.

Allerdings bedarf es dazu keines Rassismus, wie Rwanda und Bosnien gezeigt haben. Simple Zugehörigkeit zur falschen, überwiegend ethnischen Gruppe kann genügen, wobei wie im Falle des Rassismus die Zugehörigkeitskriterien häufig mehr als dubios sind. Doch wenn von Re-Ethnisierung, von der Wiedergeburt der Stammesgesellschaft die Rede ist, so trifft nur das Re bzw. das Wieder nicht zu, denn die damit angesprochene Gruppenfeindschaft hat es immer gegeben. Höchstens ist sie im Zeitalter der Globalisierung auffälliger geworden, denn auch Globalisierung findet lokal statt, wird als sogenannte "Glokalisierung« buchstabiert und lässt genug Raum für Xenophobie. Verfeindete Familien waren und sind so selbstverständlich wie seit Jahrhunderten verfeindete Dörfer. Im Zeichen des deutschen Papstes erleben wir eine deutliche Re-Konfessionalisierung der Christen und im Zeichen der deutschen Einheit den latenten, aber durchaus wirkungsvollen Gegensatz von Ossis und Wessis, der viel unerfreulicher ist, als das neckische Vokabular nahe legen möchte. Flüchtlinge und Einheimische hielten lange Zeit nicht viel voneinander, bei Bayern und Preußen mag das immer 
noch der Fall sein. Wegen der Universalität des Phänomens sind der Beispiele Legion. Eine Teilerklärung für den Kleingruppenbereich hat übrigens die Biologie zu bieten. Denn die Zahl von seinesgleichen, mit denen ein Individuum engeren Kontakt pflegen kann, hängt von der Größe der Neocortex ab. Von wenigen Individuen beim Gibbon steigt sie auf ca. 150 Personen beim Menschen. Allerdings scheint die segmentierte Gesellschaft zu einer relativen Ausweitung darüber hinaus geführt zu haben. Während es sich in der Vormoderne um ein geschlossenes Umfeld multipler Kontakte gehandelt hat, gruppieren sich heute weitgehend verschiedene Personen als Berufskollegen, Sportskameraden, Parteifreunde, Kirchengemeinde und so fort. Doch jenseits ist immer noch Platz für Xenophobie.

Übrigens gelten bis zu einem gewissen Grad auch heute noch die beiden sachlich und zeitlich begrenzten Ausnahmen von der Xenophobie, der Händler und der Gast (Der Gast und die Fische - nach drei Tagen stinken sie [italienische Volksweisheit]). Der Händler, das ist heute die unverbindliche, international gleichförmige Gegenwart der unzähligen adrett und weitgehend gleich gekleideten Männchen und Frauchen mit Köfferchen und Computerchen, die mit überall gleichen Flugzeugen zu überall gleichen Büros reisen, in überall gleichen Hotels absteigen, überall dasselbe Essen bekommen und weltweit dieselben Geschäfte verrichten. Der Gast ist einerseits ebenfalls durch das Gastgewerbe entpersonalisiert und diese »Gastfreundschaft« in der Regel zeitlich begrenzt, andererseits spielt aber die Verweigerung der Gastfreundschaft mancherorts immer noch eine Rolle. Es ist oder war zum Beispiel für Fremde sehr schwierig, die Schwelle eines italienischen oder französischen Familienhaushalts zu überschreiten.

In Ermangelung eines fulminanten Schlusses mache ich aus dieser Not eine Tugend und benutze die Gelegenheit, weil ich ohnehin das Wort habe, als ältester Teilnehmer in Ihrer aller Namen den beiden Veranstalterinnen und ihrem Institut unser aller Dank für die lehrreiche Tagung, die umfassende Betreuung und Unterhaltung sowie die großzügige Versorgung auszusprechen! 



\section{Autorenverzeichnis}

Dr. Kerstin Armborst-Weihs, Leibniz-Institut für Europäische Geschichte, Alte Universitätsstraße 19, 55116 Mainz, Deutschland

Dr. Judith Becker, Leibniz-Institut für Europäische Geschichte, Alte Universitätsstraße 19, 55116 Mainz, Deutschland

PD Dr. Bettina Braun, Johannes Gutenberg-Universität Mainz, Historisches Seminar, Jakob-Welder-Weg 18, 55128 Mainz, Deutschland

Anja Bröchler M.A., Universität zu Köln, Historisches Seminar I, Abteilung für iberische und lateinamerikanische Geschichte, Albertus-Magnus-Platz, 50923 Köln, Deutschland

Dr. Dominik Collet, Georg-August-Universität Göttingen, Seminar für Mittlere und Neuere Geschichte, Platz der Göttinger Sieben 5, 37073 Göttingen, Deutschland

Dr. Eno Blankson Ikpe, Department of History and Strategic Studies, University of Lagos, Akoka, Lagos, Nigeria

Prof. Dr. Walter Jaeschke, Ruhr-Universität Bochum, Fakultät für Philosophie und Erziehungswissenschaft, Universitätsstraße 150, 44801 Bochum, Deutschland

Prof. Dr. Jeffrey Jaynes, Methodist Theological School Ohio, Mr. and Mrs. Francis A. Warner Chair of Church History, 3081 Columbus Pike, Delaware, Ohio, USA

Dr. Perry Johansson, Hong Kong Baptist University, David C. Lam Institute for East-West Studies, 55 Renfrew Road, Kowloon Tong, Kowloon, Hong Kong, SAR China

Dipl.-Kulturwiss. Maret Keller, Ruprecht-Karls-Universität Heidelberg, Transkulturelle Studien, Marstallstraße 6, 69117 Heidelberg, Deutschland

Dr. Simon Mills, University of Cambridge, Centre for Research in the Arts, Social Sciences and Humanities (CRASSH), Alison Richard Building, 7 West Road, Cambridge, CB3 9DT, Großbritannien 
Prof. Dr. em. Wolfgang Reinhard, Annaplatz 4 A, 79100 Freiburg, Deutschland

Dr. Viviane Rosen-Prest, 15 Rue Chaptal, 75009 Paris, Frankreich

Dr. Carsten Schliwski, Universität zu Köln, Digital Averroes Research Environment, Thomas-Institut, Universitätsstraße 22, 50923 Köln, Deutschland

Prof. Dr. Rudolf Stichweh, Universität Luzern, Soziologisches Seminar, Kasernenplatz 3, Postfach 7455, 6000 Luzern 7, Schweiz, ab 1. August 2012: Universität Bonn, Forum Internationale Wissenschaft Bonn, Heussallee 1824, 53113 Bonn, Deutschland

Prof. Dr. em. Theo Sundermeier, Kisselgasse 1, 69117 Heidelberg, Deutschland

Dr. Felix Wiedemann, Freie Universität Berlin, Exzellenzcluster »Topoi The Formation and Transformation of Space and Knowledge in Ancient Civilizations«, Hittorfstraße 18, 14195 Berlin, Deutschland 


\section{Register}

\section{Ortsregister}

Abendland 41, 226

Aberdeen 120, 125

Abessinien 233, 238

Abyssinia $\rightarrow$ Abessinien

Adrianopel 162

Africa $\rightarrow$ Afrika

Afrika 40, 78, 133, 200-202, 229-231,

233-241, 258, 272

Ägypten 50, 194, 233, 237, 240, 243f., 247, 250,258

Aimaraes 63

Aix-en-Provence 278

Akwa Ibom State 119

Aleppo 245-253, 258, 260f.

Alexandria 229, 237

America $\rightarrow$ Amerika

Amerika 62f., 69f., 79, 84, 137, 232, 234, 271, 280, 283

Amsterdam 276, 280

Anatolia $\rightarrow$ Anatolien

Anatolien 255

Andenraum 59, 61f., 64, 69

Ankara 247

Antalya (Sattalia) 249

Anua-Uyo 132

Anyang 113, $117 \mathrm{f}$.

Arabia $\rightarrow$ Arabien

Arabian peninsula $\rightarrow$ arabische Halbinsel

Arabien 207f., 213f., 218f., 223, 237, 244

Arabische Halbinsel 243

Armenia $\rightarrow$ Armenien

Armenien 237

Arochukwu 125, 130

Asia $\rightarrow$ Asien

Asien 47, 233, 237, 244, 246

Assyria $\rightarrow$ Assyrien
Assyrien 237

Äthiopien 233f., 238, 241, 272

Auerstedt 145

Avignon 157, 159

Azcapotzalco 98, 102

Aztlan 97

Baalbek 254

Baden 184

Bahluliah (Bellulca) 255

Basel 191, 203

Bayern 152, 292

Beer 259f.

Beijing 110, 113, 115, 117

Beirut 251

Bekka Valley 254

Belfast 120,125

Benin 129

Berlin 46, 51, 110f., 116, 137-140, 142, 144, $149-151,169,213,223$

Białystok 170, 173

Bombay 243

Bonn 116

Bonny 120

Bosnien 292

Brandenburg 137, 139f., 144f., 152

Brandenburg-Bayreuth 138

Brandenburg-Preußen 137f., 141, 144f., $148-150,288$

Braunschweig 152

Bukhara 247

Cabo Bianco 239

Cabo Rosso 239

Cairo $\rightarrow$ Kairo

Calabar 120, 124f., 129f. 
Cambridge 249, 263f.

Canaries $\rightarrow$ Kanarische Inseln

Canterbury 253

Cape Verde Islands $\rightarrow$ Kapverdische Inseln

Carthage $\rightarrow$ Karthago

Chalcedon 236

Chian 240f.

China $31,41,47,50,107-117$

Coatepec 101

Coatepetl 96, 99

Congo $\rightarrow$ Kongo

Constantinople $\rightarrow$ Konstantinopel

Copolco 94

Cross River State 119, 129

Cross River 129

Cuzco 63, 68, 74

Cyprus $\rightarrow$ Zypern

Cyrene $\rightarrow$ Kyrene

Cyrrhus 247

Dakar 239

Damascus $\rightarrow$ Damaskus

Damaskus 247, 254, 256f., 264

Damiata 237

Danzig 169

Dänemark 243

Denmark $\rightarrow$ Dänemark

Deutsches Reich 147, 237

Deutschland 27, 111, 137, 139, 141, 144149, 152f., 166, 168, 170, 184, 198, 210, $290 \mathrm{f}$.

Dunhuang 112

Eastern Europe $\rightarrow$ Osteuropa

Eastern Nigeria $\rightarrow$ Ost-Nigeria

Eastern Syria $\rightarrow$ Ost-Syrien

Egypt $\rightarrow$ Ägypten

Ekpene-Obom 132

Elsass 184

Emden 146

England 138, 148, 184, 243, 245f., 249, 263

Ephesus (modern Ayasoluğ) 255
Ethiopia $\rightarrow$ Äthiopien

Etinan 127,132

Euphrat 247

Euphrates $\rightarrow$ Euphrat

Europa 11, 21, 46, 61f., 71, 110, 115f., 137, 165f., 172, 177, 190, 193f., 200, 202, 212, 218, 220, 243, 252f., 264, 271, 273, 284, 289

Europe $\rightarrow$ Europa

Fernando Po 129

Ferner Osten 46

Ferrara 156

Fez 240

Frankfurt a.M. 31, 252

Frankreich 38, 46, 137f., 142f., 146, 151, $158-160$

Galiläa 263

Galilee $\rightarrow$ Galiläa

Galizien 180

Gambia 239

Gambia River 239

Gaoga 241

Genua 157,159

Georgien 198

German Reich $\rightarrow$ Deutsches Reich

Germany $\rightarrow$ Deutschland

Ghana 27

Goldküste 200

Golf von Mexiko 87

Gotha 269, 271, 274f., 277

Gottorf 278

Greater India 232, 234

Greece $\rightarrow$ Griechenland

Grenada 239

Griechenland 31, 47f., 52, $243 f$.

Halberstadt 169

Hama 255

Hannover 140, 152, 169

Heiliges Land 161, 164 
Heliopolis 254

Hessen 152

Hessen-Kassel 138, 145

Holland 146

Hongkong 30

Huamanga 64

Huánuco 64

Huete $157,160 f$.

Iberische Halbinsel $\quad$ 155, 159, 164

Ibibio Hinterland 125

Ibibioland 120-122, 124-128, 130-133

Ibiono 125

Ibuno 120,125

Igboland 126

Ikpa 120

India $\rightarrow$ Indien

Indien 47, 50, 233, 238, 247, 270

Indonesien 272

Innsbruck 232, 234

Iquita-Oron 132

Iran 38

Irland 280

Israel 31, 69, 155, 159f., 162, 188, 196, 252

Istanbul 245, 249f., 253, 255

Italien 156, 161, 164, 247

Italy $\rightarrow$ Italien

Itu $120,125,129 f$., 132

Izmir (Smyrna) 245-248, 250f., 253

Japan 30, 109, 116

Jeble $255 \mathrm{f}$.

Jemen 243,247

Jena 51,145

Jerusalem 156, 160, 235, 244, 246f., 249251, 255f., 258, 260, 263, $265 f$.

Jordan 263

Jordanien 207

Judäa $160,244,263$

Judea $\rightarrow$ Judäa

Kairo 194, 240
Kanada 281

Kanarische Inseln 239

Kane Leban 259-261

Kapverdische Inseln 239

Karthago 69, 237

Kaspisches Meer 191, 198

Kastoria 31

Kleve 138,150

Kongo 233

Königsberg 138, 150

Konstantinopel 231, 236

Korea 30

Kusadasi 254

Koşadası $\rightarrow$ Kusadasi

Kowno 170,172

Kura 198

Kyrene 237

Lagos 129

Lateinamerika 40,80

Lebanon $\rightarrow$ Libanon

Libanon 195, 251, 254

Liberia 192

Libyen 237

Libya $\rightarrow$ Libyen

Lippe 152

Litauen 173

London 110, 116, 125, 245f., 253, 258

Lothringen 139

Lucanas 65

Madrid 64,84

Magdeburg 150-152

Maghreb 239f.

Mainz 43, 243

Makassar 196

Malaysia 232

Mali 239

Marokko 239f., 251

Mauretanien 237

Mauritania $\rightarrow$ Mauretanien

Mecca $\rightarrow$ Mekka 
Mecklenburg 152

Media 237

Mekka 256

Menbij (Bambych) 247

Mesoamerika 81, 104

Mesopotamia $\rightarrow$ Mesopotamien

Mesopotamien 223, 243, 247

Metz 139

Mexico $\rightarrow$ Mexiko

Mexiko 79, 81f., 84, 158, 280

Mittelamerika 59

Mittelmeer 191, 207

Mittlerer Osten 208

Molukken 196, 203

Montferrato 157

Morocco $\rightarrow$ Marokko

Mosul 247

Nablus 251f.

Nanjing $112 \mathrm{f}$.

Neue Welt 41, 59, 79, 277, 280, 284

Neu-Spanien 85

Niederlande 138, 148

Niger Delta 130

Nigeria 119f., 129-133, 288

Nordafrika 208, 247

Nordamerika 280

Norddeutschland 184

Norditalien 157

Nordspanien 63

North Africa $\rightarrow$ Nordafrika

Novi 157

Nubia $\rightarrow$ Nubien

Nubien 233

Nueva España $\rightarrow$ Neu-Spanien

Numidia $\rightarrow$ Numidien

Numidien 237

Okoyong 125, 130

Okzident 212

Opobo 120
Orient 47, 50-55, 194f., 207, 211-213, 222, 224, $226 f$.

Osmanisches Reich 225

Osteuropa 111, 168, 170, 176, 178-180

Ostjordanland 207

Ost-Nigeria 119, 121, 133

Ostpreußen 147

Ost-Syrien 250

Oxford 247, 251, 262, 264

Pacsica 63

Padua 157

Palästina 237, 259

Palestine $\rightarrow$ Palästina

Palmyra 250, 262

Paris 110, 116, 277, 282

Pazifik 87

Pera 245

Persia $\rightarrow$ Persien

Persien 50, 198, 237

Persischer Golf 30, 191

Peru 59f., 63, 66, 76-78

Pfalz 152

Pichigua 63

Pocohuanca 63

Pohheice 180

Portugal 157

Preußen 138-140, 144f., 147, 149, 151, 292

Provence 157,159

Quauhxicalco 95

Rheinland 163

Rhone 159

Rom 231, 241, 253

Rome $\rightarrow$ Rom

Ruanda 292

Russländisches Reich 169

Rwanda $\rightarrow$ Ruanda

Sabbioneta 158

Salonika $\rightarrow$ Saloniki 
Saloniki 247

Samos 253

Schottland 120,125

Schweden 108

Schweiz 184, 198

Scotland $\rightarrow$ Schottland

Sechem 251

Senegal 233, 239

Sierra Leone 192, 201

Šitomir 170

South Eastern Nigeria $\rightarrow$ Süd-Ost-Nigeria

South Africa $\rightarrow$ Südafrika

Southern Nigeria $\rightarrow$ Süd-Nigeria

Spanien $63,77,82,84,157,159-161,164$

Stockholm 110, 113

Stuttgart 40

Südafrika 137, 233

Südamerika 62,197

Südfrankreich 151

Süd-Ost-Nigeria 130

Südmesopotamien 215

Süd-Nigeria 130

Sweden $\rightarrow$ Schweden

Syria $\rightarrow$ Syrien

Syrien 237, 245-247, 255, 258f., $261 \mathrm{f}$.

Tahiti 283

Tempelberg 256

Temple Mount $\rightarrow$ Tempelberg

Tenochtitlan 79, 82, 88f., 96-103, 105

Texcoco 98

Texcoco-See 97

Thailand 27,38

Thüringen 277

Thracia $\rightarrow$ Thrakien

Thrakien 237

Tlacopan 98
Tlatelolco $79,82 \mathrm{f} ., 89,97-105$

Tripoli $\rightarrow$ Tripolis

Tripolis 247, 254f., 261

Türkei 39f., 243, 245

Turkey $\rightarrow$ Türkei

Tyre 258f.

USA 21f., 115

Vereinigte Niederlande 46

Versailles 147

Voltaggio 157

Vorderasien $212 \mathrm{f}$.

Vorderer Orient 52, 207-209, 213-215, 218, 221, 226

Washington 110

Westafrika 27, 193, 200, 233

Western Africa $\rightarrow$ Westafrika

Western Russia $\rightarrow$ Westrussland

Western Syria $\rightarrow$ West-Syrien

Westpreußen 169

Westrussland 111

West-Syrien 251

Wien 11

Wittenberg 275

Wolhynien 170

Württemberg 152,184

Yanaca 63

Yemen $\rightarrow$ Jemen

Zarenreich 166,168

Zentralasien 215

Zentralmexiko 98

Zion 188, 193, 199, 201

Zypern 246, 250 


\section{Personenregister}

Abbot, George 253

Abraham 199

Acosta, José de 71, 278

Adam 277

Adams, Thomas 249

Ade-Ajayi, Jacob F. 133

Africanus, Leo 229f., 239-241, 289

Albornoz, Cristóbal de 65

al-Duwayhi, Estefan 250

Alexander der Große 207

Alvarado, Pedro de 88

Alvares, Paul 258

Alvarez, Francesco 238

al-Wazzan, al-hassan Ibn Muhammad 229f., 239-241

Ancillon, Charles $139 f$.

Anderson, Arthur 85

Andersson, Johan Gunnar 111, 113, 117

Aristoteles 69, 292

Aschheim, Steven E. 165

Attila 275

Augustinus, Aurelius 71

Axayacatl 98

Ayandele, A.E. 131

Baerle, Kaspar von 271

Baird, Ellen 86

Bär, Johann Jakob 196f., 203

Barnard, Edward 262

Barrett, William 245

Beecroft, John 129

Beheim-Schwarzbach, Max 147f.

Belon du Mans, Pierre 244

Bengel, Johann Albrecht 187f.

Bernard, Edward 262

Bezold, Carl 216, 222

Biddulph, William 258, 263, 266

Bill, Samuel Alexander 120,125

Bishop, Carl Whiting 113, 117

Bismarck, Otto von 149
Blumhardt, Christian Gottlieb 195

Böhm, Johannes 158

Boone, Elizabeth 86

Boyle, Robert 246

Brecht, Bertolt 34

Bredekamp, Horst 267

Brerewood, Edward 253

Breydenbach, Bernhard von 229, 235f., 238f., 241, 243

Brunn, Nikolaus von 193

Buber, Martin $167 \mathrm{f}$.

Burckhardt, Johann Ludwig 218f., 225

Cadamosto, Aloysius / Alvise 230,238-240

Caiaphas 263

Casparson, Wilhelm Johann 145

Castel, Edmund 263

Centzonhuitznahua 96

Certeau, Michel de 81, 281

Chaldun, Ibn 212

Chen Yinke 116f.

Chiang Kai-shek 113, 115

Chimalpahin 102

Chodowiecki, Daniel 143

Cigala, Hilarion 250

Coatlicue 96

Columbus $\rightarrow$ Kolumbus

Cortés, Hernando 81, 87-89, 100

Cospi, Ferdinando 279

Covel, John 245, 255, 262

Coyolxauhqui 96, 98

Cranmer, George 253

Cuitlahuac 89

Dädalus 140

Damiano, Juan 238

David 160f.

Davies, Ralph 248

Davis, Natalie 239

Delitzsch, Friedrich 216 
Denton, Henry 249, 253

Dias, Bartholomew 231

Díaz del Castillo, Bernal 81

Dibble, Charles 85

Diel, Laurie 80

Döblin, Alfred 171

Dohm, Christian Wilhelm von 145

Doyle, Elaine 126

Ekechi, Felix K. 126

Elisabeth I., Königin von England 245

Elton, Sir Geoffrey 287

Enríquez, Martín 84f.

Erman, Jean Pierre 141f., 144f., 147-149, 151

Ernst I., Herzog von Sachsen-Gotha 272

Escalona, Alonso de 84

Essien, Akaneren 122

Fakr al-Din 251

Fell, John 262

Finch, Heneage 250

Fischer, Joseph 232, 234

Florescano, Enrique 86

Forsskål, Peter 244

Forster, Georg 283

Foster, Tom 125

Foucault, Michel 118

Frampton, Robert 249f.

Franke, Otto 116

Freud, Sigmund 36

Friedrich I., König in Preußen $\rightarrow$ Friedrich III., Kurfürst

Friedrich II., König von Preußen 145, 274

Friedrich III., Kurfürst von Brandenburg $138 \mathrm{f}$.

Friedrich Wilhelm I., König in Preußen 138

Friedrich Wilhelm, Kurfürst von Brandenburg 137f., 142f., 150-152

Fromery, Pierre 143

Fu Sinian 109, 111-113, 115-117
Gadamer, Hans-Georg 35

Galilei, Galileo 280

Georgirenes, Joseph 253

Gilman, Sander 179

Goffman, Daniel 248, 255

Gronemann, Sammy 167, 169-181

Gruenwedel, Albert 110

Grumbkow, Friedrich Wilhelm von 143

Gruzinski, Serge 86

Guaman Poma de Ayala, Felipe 59, 61, 6478,288

Guiness, Grattan 125

Gu Jiegang 110f., 117

Gustav I. Wasa, König von Schweden 236

Haenisch, Eric 116

Hahn, Philipp Matthäus 189

ha-Kohen, Joseph 155, 157-164, 288

Halevi, Judah 155

Halifax, William 250, 262

Haskett, Robert 80

Hedin, Sven 110

Hegel, Georg Wilhelm Friedrich 40-55, $108,116,289$

Herder, Johann Gottfried 43, 47, 283

Herodot 42, 48, 52, 218

Holstein, Baron Stael 116

Huitzilopochtli 87f., 94, 96-100

Humboldt, Alexander von 50, 278, 283

Huntington, Robert 246, 249-252, 262, 264f.

Huntington, Samuel 30

Hu Shi 115

Husserl, Edmund 36

Hyde, Thomas 262

Ibn Daud, Abraham 156

Ibn Verga, Salomon 162

Ibrahim bin Adham at Jeble 256

Isaak 199

Itzquauhtzin $\quad 86,89-91,93-96,99-101$, 103 
Jacobs, Martin 159

Jakob 199

Jeffreys, M.W.D. 131

Jesus Christus 71, 129, 131, 235f., 257

Johannes (Apostel) 188

John, Prester 231-234, 236, 238, 241

Jonker, Gerdien 11

Josippon 160

Joseph $160 \mathrm{f}$.

Josua $160 f$.

Juda $160 f$.

Kant, Immanuel 24

Karl I., König von Spanien $\rightarrow$ Karl V.

Karl V., Kaiser 73, 82, 84, 95

Karl der Große 275

Karlbeck, Orvar 113

Karlgren, Bernhard 110f., 118

Kaufmann, Thomas 11

Kennicott, Benjamin 264-266

Kircher, Athanasius 279

Klaver, Ivo 244

Klempt, Adalbert 41f., 45f., 49

Kolumbus 79, 278

Laet, Jan de 280

Lafitau, Joseph François 281f.

Lascaris, Johannes 251

Las Casas, Bartolomé de 71, 84

Latour, Bruno 283

Lawrence, Thomas Edward 219f.

Le Coq, Albert von 110

Leeuws, van der 36

Legati, Lorenzo 280

Leibniz, Gottfried Wilhelm 276, 289

Lenoir, Alexandre 277

Leo X., Papst 239

Léon-Portilla, Miguel 81, 83

Lightfoot, John 263, 266

Li Ji 109, 113f., 117

Lisle, Samuel 249

Locke, John 246, 280
Lockhart, James 80, 85

López de Gómara, Francisco 158, 278

López de Velasco, Juan 84

Lowth, Robert 265

Lucaris, Cyril 253

Ludolf, Hiob 252, 265

Ludwig XIV., König von Frankreich $137 f$.

Luhmann, Niklas 16

Luke, John 246f., 249-251, 253-259, 261

Luther, Martin 257

Macdonald, Claude 130

Mach, Ernst 111

Maimon, Moses ben 155

Major, Johan Daniel 276

Marchand, Suzanne 215

Marina (Übersetzerin) 87f.

Marsh, Narcissus 262

Marshall, Thomas 251, 262

Martellus Germanus, Heinrich 231-233

Masters, Bruce $247 \mathrm{f}$.

Maundrell, Henry 246f., 250-261, 263, $265 f$.

May, Karl 219, 289

Megged, Amos 86

Meir 160f.

Meissner, Bruno 223

Melman, Billie 261

Mendoza, Antonio de 82

Menzel, Ulrich 31

Meyer, Eduard 215f.

Michaelis, Johann David 218, 221, 243f., 266

Mignolo, Walter 80

Miller, Perry 237

Mirabeau, Honoré Gabriel de Riqueti, Graf von 144

Mittelmann, Hanni 170

Moffat, Robert 202

Mohammed 256

Montaigne, Michel Eyquem de 279

Montalboddo, Fracanzano da 230, 239 
Moore, Henry 262

Moquihuix 98-101

Morgenstern, Christian 33

Mose 160f.

Moteucçoma 79, 86-92, 94f., 99f., 102-104

Mühlmann, W.E. 37

Müller, Friedrich W.K. 116

Müller, Klaus 35

Müller, Theodor 194f.

Münster, Sebastian 229, 236-239, 241, 289

Muhammad $\rightarrow$ Mohammed

Muret, Eduard 149

Murúa, Martin de 59-66, 68-70, 74-78

Musil, Alois 220f., 225

Newton, Isaak 246

Niebuhr, Carsten 218f., 221, 224, 243f., 246, 266

Noah $70,72,77$

Olearius, Adam 279

Oppenheim, Max Freiherr von 220

Osterhammel, Jürgen 210

Ovando, Juan de 84

Pandel, Hans-Jürgen 9f.

Parzival 37

Paşa, Mehmed 248

Paulus 188, 195

Pelliot, Paul 112, 116-118

Peyrère, Isaac de la 278

Philipp II., König von Spanien 73, 84, 104

Philipp III., König von Spanien 64f., 73

Pignoria, Lorenzo 280

Pococke, Edward 249, 251, 261f., 266

Polaschegg, Andrea 211

Pöllnitz, Karl Ludwig von 145

Pory, John 240

Pottere, Herren von 147

Ptolemäus, Claudius $229 \mathrm{f}$.

Ramusio, Giovanni 230, 239
Ranke, Leopold von 43f., 116, 290

Ratzel, Friedrich 212f., 224

Rauchenberger, Dietrich 240

Rauwolf, Leonard 244

Ray, John 276

Reclam, Pierre Chrétien Frédéric 141f., 144f., 147-149, 151

Renan, Ernest 217

Reuwich, Erhard 235

Rinder, David 20

Ritschl, Dietrich 35

Robinson, Edward 261

Roca, Cinche 71

Roth, Joseph 171

Rubiés, Joan-Pau 244

Rushdie, Salman 290

Russell, Alexander 248

Rycaut, Paul 253

Sahagún, Bernardino de $82-85,94 f ., 102$, 288

Said, Edward 211, 290

Saint-Exupéry, Antoine de 34

Salbach, Karl Ferdinand 200

Saltet, Johann Bernhard 198

Sandys, Edwin 252

Sandys, George 244, 252

Santa Maria Cipactzin, Luis de 102

Schaffter, Isaak 199

Schelling, Friedrich Wilhelm Joseph 55

Schlegel, Friedrich 55

Schleiermacher, Friedrich Daniel Ernst 35

Schlözer, August Ludwig von 283

Schmalkalden, Caspar 269-273

Schnapp, Alain 284

Schrader, Eberhard 214

Schütz, Alfred 8

Schwarzenegger, Arnold 30

Schweitzer, Albert 39

Seler, Eduard 85

Sepúlveda 71

Sequera, Rodrigo de 85 
Sessing, Jakob Friedrich 193

Shamgar 261

Sheehan, Jonathan 243, 261

Simmel, Georg 8

Sirén, Osvald 110, 113

Slessor, Mary Mitchel 120, 125, 130f.

Smith, Thomas 250, 262

Sombart, Werner 217, 226

Spengler, Oswald 226

Stallone, Sylvester 30

Stanhope, Hester 219

Stein, Aurel 110, 112f.

Stichweh, Rudolf 8, 153

Struck, Hermann 167, 170

Suarez, Carl Gottlieb 24

Temporal, Jean 240

Tentzel, Wilhelm Ernst 274-276, 280f.

Thatcher, Margaret 15

Theseus 140

Thesiger, Wilfred 208, 219, 225

Tlaloc 94, 96

Toland, John 140

Toledo, Francisco de 63, 69

Tollin, Henri 149-153

Townsend, Camilla 80

Tudela, Benjamin of 265

Udo, Edet Akpan 132

Udoma, Udo 127, 132

Usque, Samuel 162f.

Valentin, Karl 7f., 291
Valeriano, Antonio $102 \mathrm{f}$.

Valle, Pietro della 252, 265

Velasco, Luis de 82

Vitoria, Francisco de 71

Voltaire 289

Waddell, Hope Masterton 120, 124

Wahrmund, Adolf 217, 226

Waldseemüller, Martin 232-236, 241

Walton, Brian 263

Wang, Edward 118

Wansleben, Johann Michael 272f.

Weber, Otto 223

Wenz, Philipp Jakob 145-147

Wertheimer, Jürgen 34

Westgarth, J.W. 126, 128

Wieser, Franz Ritter von 232, 234

Wilhelm I., Kaiser 150

Winckelmann, Johann Joachim 283

Winckler, Hugo 213-215, $222 \mathrm{f}$.

Witkowsky, Gustav 180

Witsen, Nicolas 276

Wood, Stephanie 80

Worm, Ole 272

Yao Congwu 116

Yaranga, Abdón Valderrama 73

Yupanqui, Cusi 67

Zaremba, Felician 191

Zhao Yuanren 117

Zweig, Arnold 167, 171 


\section{Veröffentlichungen des Instituts für Europäische Geschichte Mainz, Beihefte}

Band 89: Irene Dingel /

Christiane Tietz (Hg.)

Kirche und Staat in Deutschland, Frankreich und den USA

Geschichte und Gegenwart einer spannungsreichen Beziehung

2012. Ca. 200 Seiten, gebunden

ISBN 978-3-525-10111-7

Band 87: Irene Dingel /

Christiane Tietz (Hg.)

Die politische Aufgabe

von Religion

Perspektiven der drei monotheistischen

Religionen

Mit einem Vorwort von Irene Dingel und

Christiane Tietz.

2011. 433 Seiten mit 4 Abb. und 1 Graphik, gebunden

ISBN 978-3-525-10113-1

Band 86: Heinz Duchhardt /

Martin Espenhorst (Hg.)

\section{August Ludwig (von) Schlözer in Europa}

2012. VIII, 272 Seiten, gebunden

ISBN 978-3-525-10103-2

Band 85: Heinz Duchhardt /

Małgorzata Morawiec (Hg.)

Die europäische Integration und die Kirchen

Akteure und Rezipienten

2010. VI, 127 Seiten, gebunden

ISBN 978-3-525-10099-8
Band 84: Irene Dingel /

Herman J. Selderhuis (Hg.)

Calvin und Calvinismus

Europäische Perspektiven

Unter Mitarbeit von Thomas Hahn-Bruckart. Mit einem Grußwort von Bischof Karl Kardinal Lehmann. 2011. XIV, 526 Seiten mit 43 Abb., gebunden. ISBN 978-3-525-10106-3

Band 83: Heinz Duchhardt (Hg.)

\section{Der Pyrenäenfriede 1659}

Vorgeschichte, Widerhall, Rezeptionsgeschichte

2010. VI, 103 Seiten, gebunden

ISBN 978-3-525-10098-1

Band 82: Irene Dingel /

Matthias Schnettger ( $\mathrm{Hg}$.)

\section{Auf dem Weg nach Europa}

Deutungen, Visionen, Wirklichkeiten

2010. VI, 274 Seiten mit 15 Abbildungen, gebunden. ISBN 978-3-525-10095-0

Band 81: Henning P. Jürgens /

Thomas Weller ( $\mathrm{Hg}$.)

\section{Religion und Mobilität}

Zum Verhältnis von raumbezogener Mobilität und religiöser Identitätsbildung im frühneuzeitlichen Europa

2010. VI, 419 Seiten mit 16 Abb., gebunden ISBN 978-3-525-10094-3

Band 80: Heinz Duchhardt (Hg.)

Russland, der Ferne Osten und die "Deutschen"

2009. VI, 123 Seiten mit 5 Abb., gebunden ISBN 978-3-525-10092-9

\section{Vandenhoeck \& Ruprecht}




\section{Veröffentlichungen des Instituts für Europäische Geschichte Mainz, Beihefte}

Band 79: Kerstin Armborst-Weihs / Judith Becker (Hg.)

\section{Toleranz und Identität}

Geschichtsschreibung und Geschichtsbewusstsein zwischen religiösem Anspruch und historischer Erfahrung

2010. VIII, 301 Seiten mit 2 Abbildungen, gebunden.

ISBN 978-3-525-10096-7

Band 78: Irene Dingel /

Christiane Tietz (Hg.)

\section{Das Friedenspotenzial von Religion}

2009. VIII, 124 Seiten mit 1 Abb., gebunden ISBN 978-3-525-10091-2

Band 77: Rolf Decot (Hg.)

Konfessionskonflikt, Kirchenstruktur, Kulturwandel

Die Jesuiten im Reich nach 1556

2007. IX, 222 Seiten, gebunden

ISBN 978-3-525-10088-2

Band 76: Christine Roll / Matthias Schnettger ( $\mathrm{Hg}$.)

\section{Epochenjahr 1806?}

Das Ende des Alten Reichs in zeitgenössischen Perspektiven und Deutungen

2008. V, 155 Seiten, gebunden

ISBN 978-3-525-10087-5
Band 75: Johannes Arndt /

Esther-Beate Körber (Hg.)

Das Mediensystem im Alten Reich der Frühen Neuzeit 1600-1750

2010. VI, 248 Seiten, gebunden ISBN 978-3-525-10093-6

Band 74: Wolf-Friedrich Schäufele / Irene Dingel ( $\mathrm{Hg}$.)

Kommunikation und Transfer im Christentum der Frühen Neuzeit

2007. IX, 325 Seiten, gebunden

ISBN 978-3-525-10086-8

Band 73: Horst Carl /

Martin Wrede (Hg.)

Zwischen Schande und Ehre.

Erinnerungsbrüche und die Kontinuität des Hauses

Legitimationsmuster und Traditionsverständnis des frühneuzeitlichen Adels in Umbruch und Krise

2007. VIII, 480 Seiten, gebunden ISBN 978-3-525-10085-1

Band 72: Matthieu Arnold / Rolf Decot (Hg.)

Christen und Juden im Reformationszeitalter 2006. XVI, 315 Seiten, gebunden ISBN 978-3-525-10084-4

Mehr Informationen zu den Bänden und zu weiteren Veröffentlichungen erhalten Sie auf unserer Homepage unter www.v-r.de

\section{Vandenhoeck \& Ruprecht}

